\title{
Impact of cable bacteria and changes in bottom water oxygen on coastal sediment biogeochemistry
}

\author{
Martijn Hermans
}


ISBN 978-90-6266-575-4

ISSN 2211-4335

Utrecht Studies in Earth Sciences (USES) No. 210

Thesis: Layout and design by Martijn Hermans

Cover: Sunset at the Baltic Sea. Photo by Martijn Hermans and design by Margot Stoete

Printed in Netherlands by Gildeprint

\section{Copyright (c) Martijn Hermans}

All rights reserved. No part of this publication may be copied or reproduced in any form, by print or photoprint, microfilm, or any other means without written permission from the author and publishers. 


\title{
Impact of cable bacteria and changes in bottom water oxygen on coastal sediment biogeochemistry
}

\author{
Impact van kabelbacteriën en veranderingen in bodemwater \\ zuurstofconcentraties op de biogeochemie van kustsediment \\ (met een samenvatting in het Nederlands)
}

\author{
Proefschrift
}

ter verkrijging van de graad van doctor aan de Universiteit Utrecht op gezag van de rector magnificus, prof. dr. H.R.B.M. Kummeling,

ingevolge het besluit van het college voor promoties in het openbaar te verdedigen op

woensdag 17 juni 2020 des middags te 2.30 uur

door

\section{Martijn Hermans}

geboren op 24 juli 1991

te Veghel 


\section{Promotor}

Prof. dr. Caroline P. Slomp

Members of the dissertation committee

Prof. dr. Robert C. Aller

Stony Brook University

Stony Brook, United States

Prof. dr. Jack J. Middelburg

Utrecht University

Utrecht, the Netherlands

Prof. dr. Lars Peter Nielsen

Aarhus University

Aarhus, Denmark

Prof. dr. Karline E. R. Soetaert

Royal Netherlands Institute for Sea Research

Yerseke, the Netherlands

Prof. dr. Bo Thamdrup

University of Southern Denmark

Odense, Denmark 
Don't count the days; make the days count.

- Muhammad Ali 


\section{Contents}

Abstract

Chapter 1 General Introduction and Outline 11

Chapter 2 Impact of Natural Re-oxygenation on the Sediment Dynamics of 21 Manganese, Iron and Phosphorus in a Euxinic Baltic Sea Basin

Martijn Hermans, Wytze K. Lenstra, Niels A.G.M. van Helmond, Thilo Behrends,

Matthias Egger, Marie J.M. Séguret, Erik Gustafsson, Bo G. Gustafsson and Caroline P. Slomp

Geochimica et Cosmochimica Acta (2019)

Chapter 3 Abundance and Biogeochemical Impact of Cable Bacteria in

Baltic Sea Sediments

Martijn Hermans, Wytze K. Lenstra, Silvia Hidalgo-Martinez, Niels A.G.M. van Helmond,

Rob Witbaard, Filip J.R. Meysman, Santiago Gonzalez and Caroline P. Slomp

Environmental Science and Technology (2019)

Chapter 4 Coupled Dynamics of Iron, Manganese and Phosphorus in

91

Brackish Coastal Sediments Populated by Cable Bacteria

Martijn Hermans, Marina Astudillo Pascual, Thilo Behrends, Wytze K. Lenstra,

Daniel J. Conley and Caroline P. Slomp (submitted)

Chapter 5 The Shelf-to-basin Iron Shuttle in the Black Sea Revisited

131

Wytze K. Lenstra, Martijn Hermans, Marie J.M. Séguret, Rob Witbaard, Thilo Behrends,

Nikki Dijkstra, Niels A.G.M. van Helmond, Peter Kraal, Patrick Laan, Micha J.A. Rijkenberg,

Silke Severmann, Adrian Teacă and Caroline P. Slomp

Chemical Geology (2019)

Chapter 6 Biogeochemical Impact of Cable Bacteria in Coastal Black Sea Sediment

Martijn Hermans, Nils Risgaard-Petersen, Filip J.R. Meysman and Caroline P. Slomp

(in preparation)

References

Nederlandse Samenvatting (Summary in Dutch)

Curriculum Vitae 



\section{Abstract}

Oxygen is essential for life in the sea. Marine waters are supplied with oxygen via air-sea gas exchange with the atmosphere, and photosynthesis by phytoplankton in the photic zone. When oxygen supply is outpaced by the demand of oxygen, this may ultimately result in hypoxia (oxygen $<63 \mu \mathrm{M}$ ) or even anoxia (oxygen $=0 \mu \mathrm{M}$ ). Depletion of bottom water oxygen in coastal areas is increasing worldwide. This is the compound result of eutrophication linked to increased riverine inputs of nitrogen and phosphorus by human activities and climate change. De-oxygenation in coastal areas can lead to the development of 'dead zones' characterized by mass mortality of marine life, either due to the lack of oxygen or the release of the highly toxic sulphide (euxinia).

Recently, a novel type of multicellular filamentous sulphur-oxidising bacteria was discovered. These so-called 'cable bacteria' can grow up to several centimetres long, and are a member of the Desulfobulbaceae family. Cable bacteria naturally occur in a broad range of marine environments with contrasting conditions. They are capable of spatially linking sulphide oxidation in deeper sediment layers to oxygen reduction near the sediment-water interface by conducting electrons over centimetre-scale distances. Activity of cable bacteria efficiently removes sulphide and can establish a suboxic zone up to a few centimetres wide. Their activity typically leads to a distinct $\mathrm{pH}$ profile, characterised by a relatively high $\mathrm{pH}(\sim 9)$ near the sediment-water interface and a low $\mathrm{pH}(\sim 6.5)$ in the suboxic zone. The strong pore water acidification in the suboxic zone promotes the dissolution of iron monosulphide and iron, manganese and calcium carbonates. When the iron and manganese ions liberated from the dissolution of the these minerals, diffuse upwards, they can precipitate as iron and manganese oxides near the sediment-water interface upon contact with oxygen. Iron and manganese oxides can buffer the benthic release of sulphide and phosphate when bottom water oxygen is low.

Since field observations are relatively scarce, it is currently unknown what environmental factors control the prevalence and activity of cable bacteria, and whether the role of cable bacteria in buffering the benthic release of sulphide and phosphate can be generalised to seasonally hypoxic systems. At present, it is largely unknown what impact cable bacteria might have on the permanent burial of phosphorus. This thesis shows that the prevalence of cable bacteria in sediments of the Baltic Sea is governed by three factors: 1) oxygen availability, 2) sulphide supply and 3) the rate of bioturbation. The results demonstrate that cable bacteria are of ecological relevance for seasonally hypoxic brackish coastal systems, through their formation of iron and manganese oxides, which can buffer the benthic release of sulphide and phosphate during peak hypoxia. Their activity does not affect permanent burial of iron, manganese and phosphorus, but rather amplifies their seasonal dynamics. The work further demonstrates that the oxygen demand arising from the accumulation of organic-rich sediments in deep basins of the Baltic Sea over several decades, 'the legacy of hypoxia', has significant implications for the biogeochemical response of euxinic basins to re-oxygenation. 


$$
1
$$




\section{Chapter 1:}

\section{General Introduction and Outline}

\subsection{Ocean De-oxygenation}

Oxygen $\left(\mathrm{O}_{2}\right)$ is a key component for life in the world's oceans, which cover $\sim 70 \%$ of our Earth's surface. In marine waters, $\mathrm{O}_{2}$ is taken up from the atmosphere and is also produced through photosynthesis in the photic zone (Anderson, 1995; Petsch, 2003). Photosynthesis is performed by plants, algae and bacteria capable of transforming carbon dioxide and water into organic matter and $\mathrm{O}_{2}$ using energy from sunlight (Falkowski and Raven, 2013). Dissolved $\mathrm{O}_{2}$ is a prerequisite for the presence of marine flora and fauna, since it is essential for their metabolism (Glud, 2008). In marine environments, $\mathrm{O}_{2}$ is consumed through aerobic respiration and the oxidation of products of anaerobic degradation of organic matter. When the $\mathrm{O}_{2}$ demand outpaces the supply of $\mathrm{O}_{2}$ in marine environments this may result in hypoxia $\left(\mathrm{O}_{2}<63 \mu \mathrm{M}\right)$ or even anoxia $\left(\mathrm{O}_{2}=0 \mu \mathrm{M}\right.$; Diaz and Rosenberg, 2008).

Hypoxia and anoxia can occur naturally in marine environments where water exchange and circulation are restricted (Rabalais et al., 2010). The Black Sea is a prime example of such a system, since the strong stratification of the water column restricts the ventilation of deeper waters (McQuatters-Gollop et al., 2008; Rabalais et al., 2010). The depletion of bottom water $\mathrm{O}_{2}$ can also be induced by human activities (Diaz and Rosenberg, 2008; Breitburg et al., 2018). In coastal areas, this is the compound result of excessive inputs of nitrogen $(\mathrm{N})$ and phosphorus $(\mathrm{P})$ from agricultural fertiliser and sewage and an increasing global temperature (Diaz and Rosenberg, 2008). Climate change induced warming decreases the solubility of $\mathrm{O}_{2}$ in surface waters, and reduces bottom water ventilation due to temperature-driven water column stratification (Schmidtko et al., 2017). However, in most coastal areas, eutrophication is currently the main cause of bottom water $\mathrm{O}_{2}$ depletion.

Higher marine organisms, such as fishes, crustaceans and bivalves are sensitive to $\mathrm{O}_{2}$ concentrations below a threshold of $<63 \mu \mathrm{M}$ (Vaquer-Sunyer and Duarte, 2008). As bottom waters become more $\mathrm{O}_{2}$ depleted, and more organic matter is deposited onto sediments due to eutrophication, this results in higher rates of sulphate $\left(\mathrm{SO}_{4}^{2-}\right)$ reduction in sediments (Howarth et al., 2011). The reduction of $\mathrm{SO}_{4}^{2-}$ is the most prevalent dissimilatory process responsible for organic matter breakdown in coastal marine sediments, ultimately resulting in high levels of dissolved sulphide $\left(\mathrm{\Sigma H}_{2} \mathrm{~S}=\mathrm{H}_{2} \mathrm{~S}+\mathrm{HS}^{-}+\mathrm{S}^{2-}\right)$ in pore waters (Jørgensen, 1977; Jørgensen, 1982; Howarth et al., 2011). This can lead to the benthic release of $\Sigma \mathrm{H}_{2} \mathrm{~S}$ and its subsequent accumulation in bottom waters, which is known as 'bottom water euxinia' (Diaz and Rosenberg, 2008).

In seasonally hypoxic coastal systems, the lack of $\mathrm{O}_{2}$ and/or the release of highly toxic $\Sigma \mathrm{H}_{2} \mathrm{~S}$ in bottom waters can lead to the development of so-called 'dead zones' (Figure 1.1). These dead zones are characterised by mass mortality of marine life (Diaz and Rosenberg, 2008). Bottom water 
$\mathrm{O}_{2}$ depletion can eventually lead to significant loss in biodiversity and can negatively impact the surviving organisms through numerous factors, such as reduced growth and reproduction and forced migration (Vaquer-Sunyer and Duarte, 2008). De-oxygenation of coastal areas can also lead to a decline in fisheries resources, such as fish, shrimps and crabs (Renaud, 1986; Rabalais et al., 2002). Besides these negative consequences of bottom water $\mathrm{O}_{2}$ depletion for marine life, low bottom water $\mathrm{O}_{2}$ also impacts the cycling of nutrients and this may contribute to a deterioration of water quality.

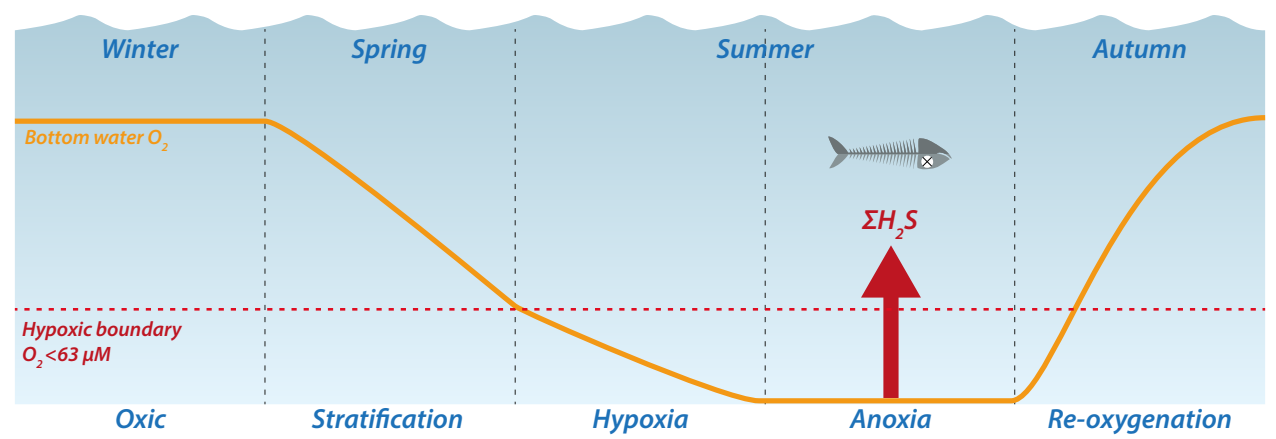

Figure 1.1 | Schematic of seasonal hypoxia in a coastal system: Bottom water $\mathrm{O}_{2}$ levels exhibit a strong seasonal pattern. The orange line represents the bottom water $\mathrm{O}_{2}$ concentration throughout the year, and the red line is the boundary between hypoxic $\left(\mathrm{O}_{2}<63 \mu \mathrm{M}\right)$ and oxic waters. In winter, bottom water $\mathrm{O}_{2}$ is high. In spring, bottom water $\mathrm{O}_{2}$ gradually decreases due to temperature-driven water column stratification. During peak anoxia in summer, highly toxic $\mathrm{SH}_{2} \mathrm{~S}$ may escape from sediments into the overlying water potentially contributing to loss of marine life. In autumn, water column stratification collapses, which allows re-oxygenation of bottom water.

\subsection{Impact of Low Oxygen on Sediments Biogeochemistry}

The biogeochemical cycling of elements, such as iron (Fe), manganese ( $\mathrm{Mn}), \mathrm{P}$ and $\mathrm{N}$ is strongly affected by the bottom water $\mathrm{O}_{2}$ concentrations in marine environments (Ingall and Jahnke, 1994; Vahtera et al., 2007; Howarth et al., 2011). Oxygen is energetically the most preferred electron acceptor for microbial respiration in marine sediments. When $\mathrm{O}_{2}$ is unavailable, a sequence of other electron acceptors can be utilised for anaerobic respiration. Alternative electron acceptors in order of energetic preference include: nitrate $\left(\mathrm{NO}_{3}{ }^{-}\right), \mathrm{Mn}(\mathrm{IV}), \mathrm{Fe}(\mathrm{III})$ and $\mathrm{SO}_{4}^{2-}$ (Froelich et al., 1979; Table 1.1). This cascade of reactions is reflected in the vertical distribution of those electron acceptors in the sediment. Hence, when an electron acceptor is depleted, the next most favourable one will be used, albeit vertical overlap of pathways does occur (Canfield and Thamdrup, 2009). In coastal sediments, anaerobic mineralisation through $\mathrm{SO}_{4}{ }^{2-}$ reduction is typically most prevalent, as a consequence of the high organic matter inputs (Jørgensen, 1982; Middelburg and Levin, 2009). This leads to production of $\mathrm{SH}_{2} \mathrm{~S}$ in sediments, and when $\mathrm{O}_{2}$ is absent, this may lead to benthic release and accumulation of $\sum \mathrm{H}_{2} \mathrm{~S}$ in the bottom water (Diaz and Rosenberg, 2008). 
Table 1.1 | Major oxidation reactions of sedimentary organic matter in marine sediments after Froelich et al. (1979).

\begin{tabular}{llll}
\hline Process & Chemical reaction & & \\
\hline Aerobic respiration & $\left(\mathrm{CH}_{2} \mathrm{O}\right)_{106}\left(\mathrm{NH}_{3}\right)_{16}\left(\mathrm{H}_{3} \mathrm{PO}_{4}\right)+138 \mathrm{O}_{2}$ & $\rightarrow$ & $106 \mathrm{CO}_{2}+16 \mathrm{HNO}_{3}+\mathrm{H}_{3} \mathrm{PO}_{4}+122 \mathrm{H}_{2} \mathrm{O}$ \\
Denitrification & $\left(\mathrm{CH}_{2} \mathrm{O}\right)_{106}\left(\mathrm{NH}_{3}\right)_{16}\left(\mathrm{H}_{3} \mathrm{PO}_{4}\right)+84.8 \mathrm{HNO}_{3}$ & $\rightarrow$ & $106 \mathrm{CO}_{2}+42.4 \mathrm{~N}_{2}+16 \mathrm{NH}_{3}+\mathrm{H}_{3} \mathrm{PO}_{4}+148.4 \mathrm{H}_{2} \mathrm{O}$ \\
Manganese reduction & $\left(\mathrm{CH}_{2} \mathrm{O}\right)_{106}\left(\mathrm{NH}_{3}\right)_{16}\left(\mathrm{H}_{3} \mathrm{PO}_{4}\right)+236 \mathrm{MnO}_{2}+472 \mathrm{H}^{+}$ & $\rightarrow$ & $236 \mathrm{Mn}^{2+}+106 \mathrm{CO}_{2}+8 \mathrm{~N}_{2}+\mathrm{H}_{3} \mathrm{PO}_{4}+366 \mathrm{H}_{2} \mathrm{O}$ \\
Iron reduction & $\left(\mathrm{CH}_{2} \mathrm{O}\right)_{106}\left(\mathrm{NH}_{3}\right)_{16}\left(\mathrm{H}_{3} \mathrm{PO}_{4}\right)+424{\mathrm{FeOOH}+848 \mathrm{H}^{+}}^{\text {Sulphate reduction }}$ & $\left(\mathrm{CH}_{2} \mathrm{O}\right)_{106}\left(\mathrm{NH}_{3}\right)_{16}\left(\mathrm{H}_{3} \mathrm{PO}_{4}\right)+53 \mathrm{SO}_{4}^{2-}$ & $424 \mathrm{Fe}^{2+}+106 \mathrm{CO}_{2}+16 \mathrm{NH}_{3}+\mathrm{H}_{3} \mathrm{PO}_{4}+742 \mathrm{H}_{2} \mathrm{O}$ \\
Methanogenesis & $\left(\mathrm{CH}_{2} \mathrm{O}\right)_{106}\left(\mathrm{NH}_{3}\right)_{16}\left(\mathrm{H}_{3} \mathrm{PO}_{4}\right)$ & $\rightarrow$ & $106 \mathrm{CO}_{2}+16 \mathrm{NH}_{3}+53 \mathrm{~S}^{2-}+\mathrm{H}_{3} \mathrm{PO}_{4}+106 \mathrm{H}_{2} \mathrm{O}$ \\
& & $\rightarrow$ & $53 \mathrm{CO}_{2}+53 \mathrm{CH}_{4}+16 \mathrm{NH}_{3}+\mathrm{H}_{3} \mathrm{PO}_{4}$ \\
\hline
\end{tabular}

Changes in bottom water $\mathrm{O}_{2}$ concentrations can have a significant impact on bacterial communities (Steenbergh et al., 2014; Noffke et al., 2016). Furthermore, the depletion of bottom water $\mathrm{O}_{2}$ can also have a detrimental impact on macrofaunal communities once concentrations are below the hypoxic threshold (Rosenberg, 1980). When there is sufficient $\mathrm{O}_{2}$ available, the activity of macrofauna can strongly alter sediment biogeochemistry through the physical displacement of particles and solutes through sediment reworking, so-called 'bioturbation' (Kristensen et al., 2012). Macrofaunal activity can also lead to the exchange of solutes between the sediment pore water and the overlying water through ventilation of macrofaunal burrows, which is called 'bioirrigation' (Kristensen et al., 2012). In the absence of bottom water $\mathrm{O}_{2}$ these two processes can no longer occur, and the geochemistry of the sediment is thus solely controlled by microbial and abiotic processes.

To summarise, the availability of $\mathrm{O}_{2}$ in the bottom water has a significant impact on the sediment biogeochemistry, since it plays a key role in the prevalent redox reactions, and the composition and activity of bacterial and macrofaunal communities.

\subsection{Sulphide Oxidation by Bacteria}

Sulphide production in sediments promotes the metabolic activity of S-oxidising bacteria, which can utilise $\mathrm{KH}_{2} \mathrm{~S}$ as an electron acceptor to fuel their growth (Jørgensen, 1982). S-oxidising bacteria constitute a wide variety of micro-organisms, ranging from single cells to multicellular bacteria. The large S-oxidising bacteria, known as Beggiatoaceae, typically form white microbial mats at the sediment surface (Sweerts et al., 1990). Beggiatoaceae are motile and can move between sediment zones with $\mathrm{O}_{2}$ and $\Sigma \mathrm{H}_{2} \mathrm{~S}$. They can efficiently oxidise $\Sigma \mathrm{H}_{2} \mathrm{~S}$ and thereby create a thin suboxic zone where both $\mathrm{O}_{2}$ and $\mathrm{\Sigma H}_{2} \mathrm{~S}$ are absent (Sayama et al., 2005; Preisler et al., 2007; Seitaj et al., 2015). Some members of the Beggiatoaceae family can store $\mathrm{NO}_{3}{ }^{-}$in their internal vacuoles, and subsequently use it to oxidise $\mathrm{\Sigma H}_{2} \mathrm{~S}$ (Schulz and Jørgensen, 2001; Jørgensen and Nelson, 2004).

Recently, a novel type of multicellular filamentous S-oxidising bacteria was discovered, which belongs to the clade of the Deltaproteobacteria within the Desulfobulbaceae family (Trojan et al., 2016). These so-called 'cable bacteria' can be up to several $\mathrm{cm}$ long (Pfeffer et al., 2012). Cable bacteria were initially discovered in laboratory incubations of marine sediments (Nielsen et al., 2010). However, more recent work showed that they naturally occur in a broad range of marine environments with contrasting conditions, including continental shelf sediments (Malkin et al., 2014), the seasonally hypoxic basin Lake Grevelingen (Seitaj et al., 2015), salt marshes (Larsen et al., 2015) and mangroves (Burdorf et al., 2016). A recent study demonstrated that cable bacteria can also be abundant around stable tubes in otherwise intensely bioturbated deposits (Aller et al., 2019). Cable bacteria have also been observed in freshwater systems, such as river banks (RisgaardPetersen et al., 2015) and in laboratory incubations of aquifer sediments (Müller et al., 2016; Müller 
et al., 2019). In natural environments, cable bacteria can form dense networks in the surface sediment containing up to hundreds of metres of filament per $\mathrm{cm}^{2}$ sediment (Burdorf et al., 2016; Malkin et al., 2017).

Filamentous cable bacteria, are capable of spatially linking the oxidation of free $\Sigma \mathrm{H}_{2} \mathrm{~S}$ in deeper sediment horizons to the reduction of $\mathrm{O}_{2}$, or in some cases $\mathrm{NO}_{3}^{-}$, by conducting electrons over cm-scale distances (Pfeffer et al., 2012; Marzocchi et al., 2014). This may give them a competitive advantage over other S-oxidising bacteria in aquatic environments (Meysman, 2018). The activity of cable bacteria typically leads to the formation of a suboxic zone of up to a few $\mathrm{cm}$ wide, and a distinct $\mathrm{pH}$ profile (Nielsen et al., 2010; Figure 1.2). This $\mathrm{pH}$ profile is defined by a relatively high $\mathrm{pH}(\sim 9)$ near the sediment-water interface and a low $\mathrm{pH}(\sim 6.5)$ in the suboxic zone (Pfeffer et al., 2012). The transport of electrons from cell to cell through cable bacterial filaments (Bjerg et al., 2016) also generates a distinct electric field of up to several $\mathrm{mV}$, that can be used as an indicator for their activity (Damgaard et al., 2014). Beggiatoaceae compete for the same ecological niche as cable bacteria (Seitaj et al., 2015; Sulu-Gambari et al., 2016b). However, Beggiatoaceae typically occur in sediments with lower bottom water $\mathrm{O}_{2}$ availability compared to cable bacteria (Møller et al., 1985; Burdorf et al., 2018).

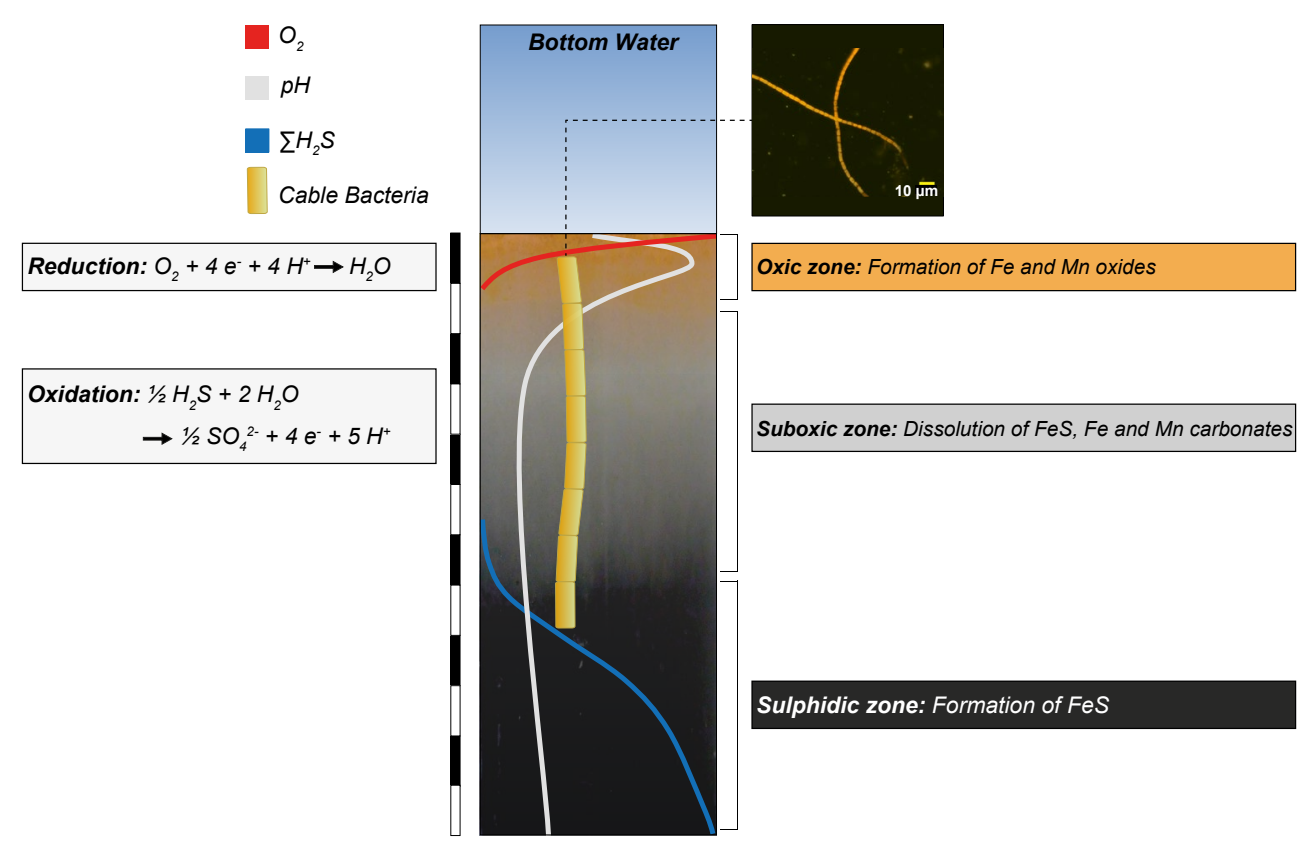

Figure 1.2 Impact of filamentous cable bacteria on sediment geochemistry (adapted from: Nielsen et al., 2010; Seitaj et al., 2015; Sulu-Gambari et al., 2016a). The vertical scale bar denotes a total distance of $6 \mathrm{~cm}$, with $0.5 \mathrm{~cm}$ depth intervals. The depth profiles in the sediment represent pore water constituents $\left(\mathrm{pH}=\right.$ white, dissolved $\mathrm{O}_{2}=$ red and $\sum \mathrm{H}_{2} \mathrm{~S}=$ blue). The yellow chain of rectangles represents cable bacteria, and the panel on the top right depicts a microscopic FISH image of two cable bacteria filaments. Cable bacteria activity typically leads to a distinct colour zonation in the surface sediment, characterised by (1) an oxic zone (orange colour) where Fe and Mn oxides form, (2) a suboxic zone (grey colour) in which FeS, Fe and Mn carbonates dissolve and (3) a sulphidic zone (black colour) where formation of FeS takes place. 


\subsection{Cable Bacteria as Ecosystem Engineers}

The metabolic activity of cable bacteria exerts a strong impact on sediment geochemistry (Figure 1.2), since their activity removes dissolved $\mathrm{SH}_{2} \mathrm{~S}$ and promotes the formation of Fe and Mn oxides in surface sediments (Seitaj et al., 2015; Sulu-Gambari et al., 2016a; Sulu-Gambari et al., 2016b). The strong pore water acidification in the suboxic zone promotes the dissolution of iron monosulphide (FeS; Risgaard-Petersen et al., 2012; Seitaj et al., 2015) and Fe, Mn and calcium (Ca) carbonates (Rao et al., 2016; Sulu-Gambari et al., 2016a). When the $\mathrm{Fe}^{2+}$ and $\mathrm{Mn}^{2+}$ ions liberated from the dissolution of these minerals, diffuse upwards, they can precipitate as Fe and Mn oxides near the sediment-water interface upon contact with $\mathrm{O}_{2}$ (Risgaard-Petersen et al., 2012; Sulu-Gambari et al., 2016a). In some cases, $\mathrm{Fe}$ oxides can also form via oxidation of $\mathrm{Fe}^{2+}$ with $\mathrm{Mn}$ oxides (Sulu-Gambari et al., 2016a; Sulu-Gambari et al., 2016b).

Beggiatoaceae may also contribute to the preservation of $\mathrm{Fe}$ and $\mathrm{Mn}$ oxides in the surface sediment by forming a suboxic zone (Sulu-Gambari et al., 2016b). Beggiatoaceae are not capable of dissolving FeS, implying that their only source of $\Sigma \mathrm{H}_{2} \mathrm{~S}$ is from $\mathrm{SO}_{4}^{2-}$ reduction (Seitaj et al., 2015). Overall, cable bacteria have a stronger impact on the sediment geochemistry than Beggiatoaceae.

The formation of $\mathrm{Fe}$ and $\mathrm{Mn}$ oxides near the sediment-water interfaces can prevent the benthic release of $\mathrm{SH}_{2} \mathrm{~S}$ (Kristiansen et al., 2002; Kristensen et al., 2003). Manganese oxides have a stronger tendency for reductive dissolution in the presence of $\Sigma \mathrm{H}_{2} \mathrm{~S}$ compared to Fe oxides and are thus reduced first (Burdige et al., 1992; Burdige, 1993). Iron and Mn oxides in the surface sediment can both efficiently sequester P (Mort et al., 2010; Slomp et al., 2013). Iron oxides can sequester P up to 20 times more efficiently compared to Mn oxides (Gunnars et al., 2002; Turnewitsch and Pohl, 2010).

By stimulating Fe and Mn oxide formation, cable bacteria act as 'ecosystem engineers' and are of ecological relevance for seasonally hypoxic marine systems. The Fe and $\mathrm{Mn}$ oxides can buffer the release of toxic $\mathrm{LH}_{2} \mathrm{~S}$ and the nutrient $\mathrm{HPO}_{4}{ }^{2-}$ from the sediment to the bottom water during peak hypoxia, as has been shown for seasonally hypoxic marine Lake Grevelingen (Seitaj et al., 2015; Nielsen, 2016; Sulu-Gambari et al., 2016b). Since field observations are relatively scarce, it is currently unknown whether the role of cable bacteria in buffering the benthic release of $\Sigma \mathrm{H}_{2} \mathrm{~S}$ and phosphate $\left(\mathrm{HPO}_{4}{ }^{2-}\right)$ can be generalised to other marine systems that are subject to seasonal hypoxia, such as the brackish coastal Baltic Sea. At present, it is also largely unknown in which mineral forms $\mathrm{P}$ is sequestered as a consequence of cable bacteria activity.

\subsection{Scope and Framework}

The main impetus of this work is to improve the understanding of the impact of cable bacteria on the coupled sedimentary dynamics of $\mathrm{Fe}, \mathrm{Mn}, \mathrm{P}$ and $\mathrm{S}$ in coastal areas subject to variations in bottom water $\mathrm{O}_{2}$. To resolve and analyse the complex interactions of these elements, a range of sampling techniques was used during field campaigns in the Baltic Sea and Black Sea. These include (1) water column sampling, (2) suspended matter collection through in-situ pumping, (3) in-situ benthic lander incubations for the determination of solute fluxes across the sedimentwater interface and (4) multi-coring for the collection of sediments for pore water and solid phase analyses. The sediment samples were subjected to a range of analytical methods, such as sequential extractions for Fe, $\mathrm{P}$ and $\mathrm{S}$ combined with high-resolution microscopic and spectroscopic techniques, such as micro X-ray fluorescence and X-ray spectroscopy to identify the mineralogical composition and quantity of $\mathrm{Fe}, \mathrm{Mn}, \mathrm{P}$ and $\mathrm{S}$ in these samples. 
Three chapters investigate the impact of changes in bottom water $\mathrm{O}_{2}$ and the presence and activity of cable bacteria on the biogeochemistry of Baltic Sea sediments. Samples were retrieved during an expedition with R/V Pelagia in May/June 2016. The brackish Baltic Sea (Figure 1.3A) has been adversely affected by enhanced anthropogenic nutrient inputs and is now the world's largest humaninduced $\mathrm{O}_{2}$-depleted water body (Carstensen et al., 2014a), with the Gulf of Finland being its most eutrophic basin (Pitkänen et al., 2007). The extent of hypoxia in the Baltic Sea has expanded drastically in the last century. Hypoxia was restricted to a surface area of $<10,000 \mathrm{~km}^{2}$ before 1950 and rapidly expanded to more than $50,000 \mathrm{~km}^{2}$ around 1970 (Carstensen et al., 2014b). The Baltic Sea is naturally sensitive to hypoxia since its submarine sills restrict horizontal water exchange and pronounced vertical stratification in the water column further inhibits the supply of $\mathrm{O}_{2}$ to deeper waters (Mohrholz et al., 2015). Natural bottom water ventilation in the Baltic Sea relies on largescale episodic inflow events from the adjacent North Sea. Such inflow events are coined major Baltic inflows, and are caused by wind and air pressure driven sea level variations (Gustafsson and Andersson, 2001). Typically, a major Baltic inflow results in substantial inputs of saline and $\mathrm{O}_{2}$-rich water to the deeper waters of the Baltic Sea. In the short-term, these inflows re-oxygenate the deeper waters. However, on longer time scales of years to decades, the introduction of saline water enhances stratification, resulting in reduced vertical mixing of $\mathrm{O}_{2}$ across the halocline and thereby a further increase in hypoxia (Conley et al., 2002). Recently, two major Baltic inflows re-oxygenated the deeper basins (Mohrholz et al., 2015; Mohrholz et al., 2016).

Chapter 2 investigates the impact of these two major Baltic inflows on the biogeochemistry of the water column and sediment in the Gotland Deep, a euxinic Baltic Sea basin. The ventilation of the bottom waters induced the activity of the S-oxidising bacteria Beggiatoaceae. Their activity led to the removal of $\mathrm{\Sigma H}_{2} \mathrm{~S}$ and the development of a suboxic zone in the sediment. Cable bacteria were also present but the biogeochemical fingerprint for their activity, based on $\mathrm{pH}, \mathrm{O}_{2}$ and $\Sigma \mathrm{H}_{2} \mathrm{~S}$ profiles in the pore water, was not observed and their limited relative abundance indicates that they likely did not affect the sediment geochemistry. Synchrotron-based X-ray spectroscopy revealed the abundant presence of rhodochrosite and $\mathrm{Mn}(\mathrm{II})$ phosphates in the sediment. Sedimentary $\mathrm{P}$ sequestration associated with Fe oxides was limited. These results suggest that artificial ventilation projects that intend to remove water column $\mathrm{HPO}_{4}{ }^{2-}$ by increasing the sedimentary pool of $\mathrm{Fe}$ oxide bound $\mathrm{P}$, and thereby improve water quality in the Baltic Sea, will likely not have the desired effect. This chapter further highlights that, the $\mathrm{O}_{2}$ demand arising from the accumulation of organicrich sediments over several decades, 'the legacy of hypoxia', has significant implications for the biogeochemical response of euxinic basins to re-oxygenation.

Chapter 3 explores the prevalence, activity and biogeochemical impact of cable bacteria in sediments at twelve sites with contrasting depositional environments and bottom water redox conditions in the Baltic Sea. The findings indicate that three factors are key in determining the abundance of cable bacteria: (1) the availability of bottom water $\mathrm{O}_{2}$, (2) the supply of $2 \mathrm{H}_{2} \mathrm{~S}$ and (3) the rate of bioturbation. The geochemical data suggest that cable bacteria promote the conversion of FeS to Fe oxides in the Gulf of Finland in spring, likely explaining why bottom waters in this extremely eutrophic area rarely become euxinic during peak hypoxia in summer.

Chapter 4 focuses on the impact of cable bacteria activity on the coupled dynamics of Fe, $\mathrm{P}$ and $\mathrm{Mn}$ in sediments of the Gulf of Finland. The findings indicate that cable bacteria may induce the formation of poorly crystalline Fe oxides, the formation of $\mathrm{Mn}$ (II) phosphates and the preservation of Mn oxides in the surface sediment. While the poorly crystalline Fe oxides and Mn(II) phosphates 
are suggested to be of diagenetic origin, most of the Mn oxides were likely deposited from the water column as part of a cycle of repeated deposition and remobilisation, so-called 'refluxing'. While cable bacteria have little impact on permanent burial of Fe, Mn and P in Gulf of Finland sediments, the results indicate that their activity amplifies the seasonality of the sedimentary Fe, Mn and $\mathrm{P}$ cycles.

\section{The Black Sea}

The last two chapters focus on the Black Sea. Samples were collected during a research expedition with R/V Pelagia in September 2015 on the Western Black Sea shelf (Figure 1.3B). The Black Sea is a restricted basin, since its only connection to the rest of the world's oceans is through the Bosporus Strait, the Sea of Marmara and sequentially through the straits of the Dardanelles to the Aegean Sea (Arthur and Dean, 1998). The Bosporus sill located at $35 \mathrm{~m}$ water depth strongly restricts the inflow of relatively warm and saline Mediterranean surface waters to the Black Sea (Gunnerson and Ozturgut, 1974). The water column of the Black Sea is stratified as a consequence of a gradient in salinity, and the oxic surface waters are separated from the eunixic deep basin by a suboxic chemocline located at $\sim 150$ m water depth (Arthur and Dean, 1998; Coolen et al., 2009). As a consequence, the Black Sea is the world's largest naturally formed euxinic basin (Arthur and Dean, 1998). In the deeper waters, below the redoxcline, $\mathrm{KH}_{2} \mathrm{~S}$ reaches concentrations up to $\sim 370$ $\mu \mathrm{M}$ (Neretin et al., 2001).

Chapter 5 explores the mechanisms that regulate the release and lateral transport of Fe over the north-western Black Sea shelf, so-called 'shuttling' This chapter highlights that Fe is released from organic-rich bioirrigated sediments overlain by oxic bottom waters, and subsequently is shuttled towards the deep basin as ferrihydrite and Fe associated with clay. The results highlight the critical role of organic matter input, associated biological activity and riverine Fe input as drivers of Fe shuttling on continental shelves. This chapter also shows that physical transport controls the ultimate fate of shuttled $\mathrm{Fe}$ in continental shelf areas that receive low inputs of organic matter.

Chapter 6 investigates the potential impact of cable bacteria on the biogeochemistry of $\mathrm{Fe}$, $\mathrm{S}, \mathrm{Mn}$ and $\mathrm{P}$ using laboratory incubations of FeS-poor coastal Black Sea sediments. The results show that dissolution of siderite induced by cable bacteria activity, can also lead to the release of a significant amount of pore water $\mathrm{Fe}^{2+}$ and the formation of a layer highly enriched in $\mathrm{Fe}$ oxides upon contact of $\mathrm{Fe}^{2+}$ with $\mathrm{O}_{2}$. Using X-ray fluorescence, we show that the enrichments in $\mathrm{Fe}$ oxides induced by cable bacteria are situated within a thin subsurface layer of a few $\mathrm{mm}$. We further show that the formation of this subsurface layer highly enriched in $\mathrm{Fe}$ is also observed at field sites where cable bacteria were recently active and where relatively little bioturbation occurs. This suggests that this $\mathrm{Fe}$ oxide layer is a consistent feature in sediments populated by cable bacteria and that this could potentially be a marker for their present or recent activity. 

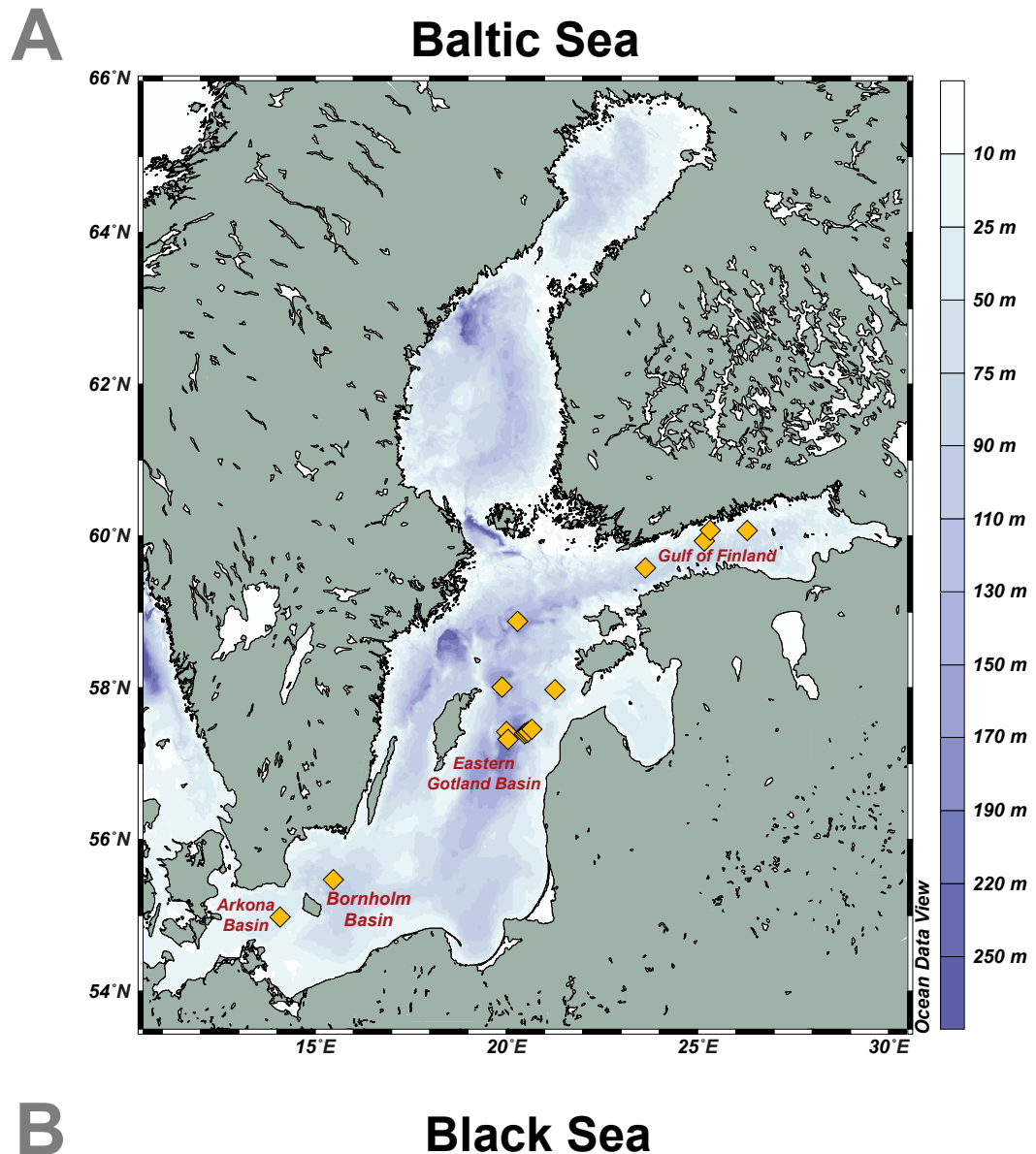

Black Sea

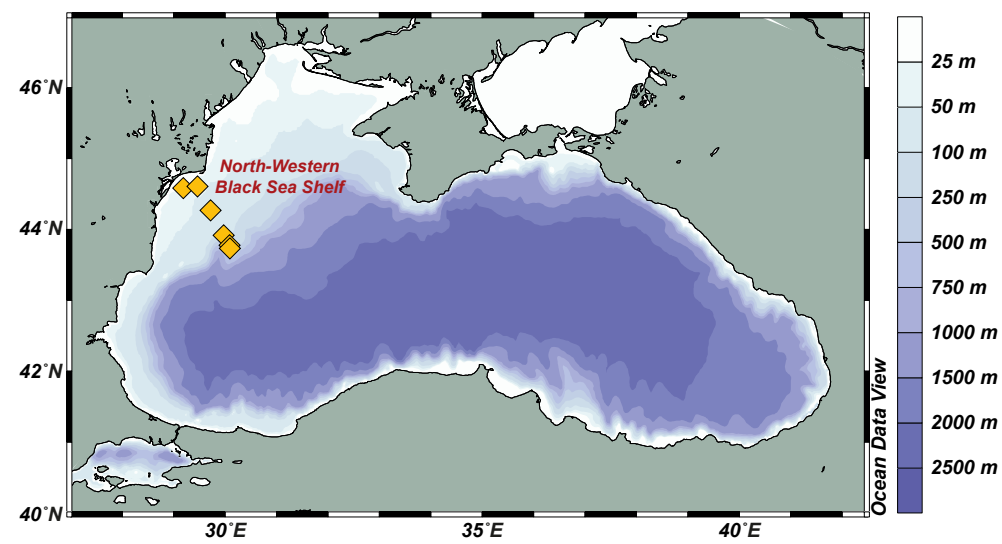

Figure 1.3 Study sites in the Baltic Sea and Black Sea (Ocean Data View 4; Schlitzer, 2015). 


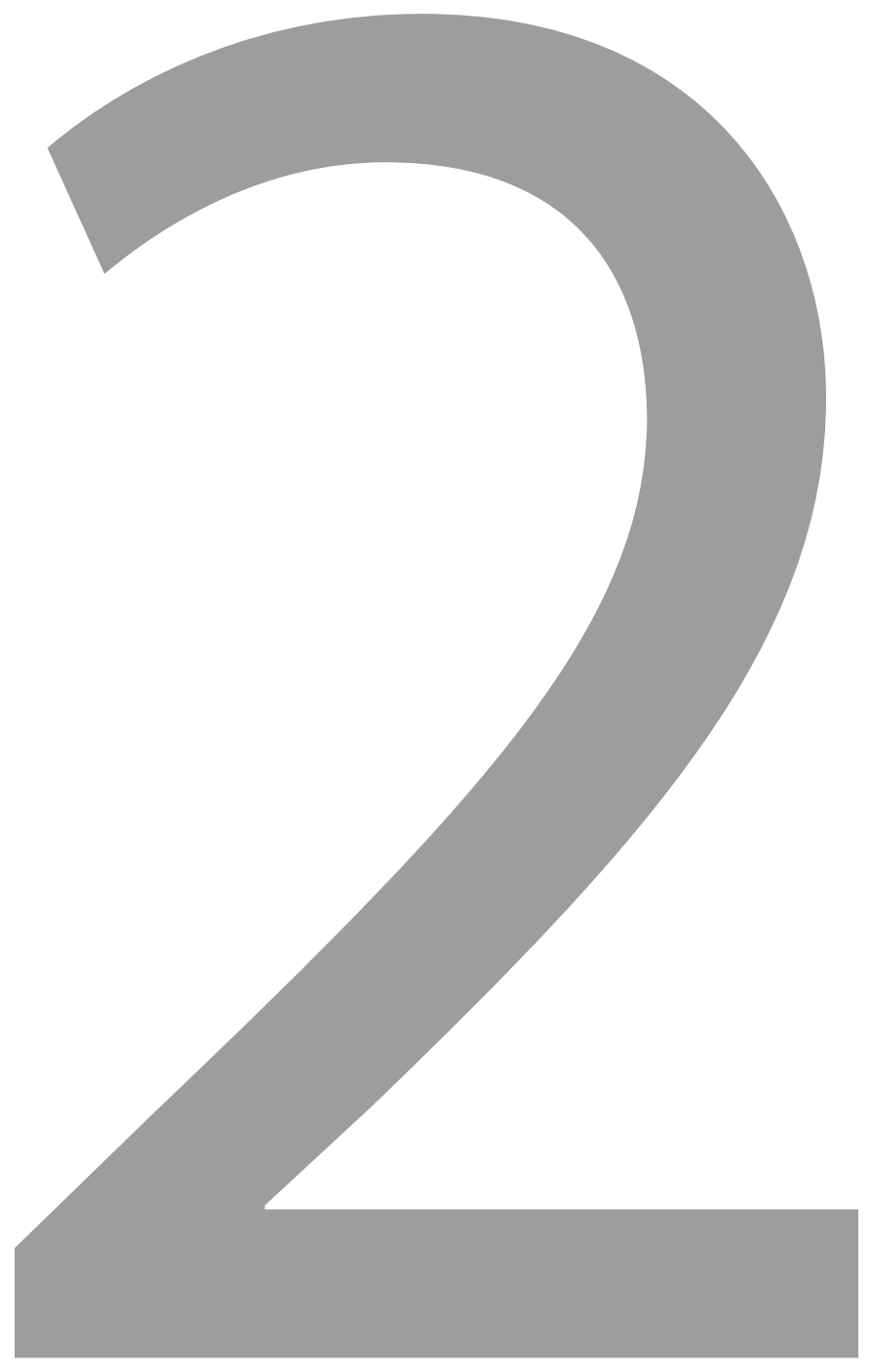




\title{
Chapter 2:
}

\section{Impact of Natural Re-oxygenation on the Sediment Dynamics of Manganese, Iron and Phosphorus in a Euxinic Baltic Sea Basin}

\author{
Martijn Hermans, Wytze K. Lenstra, Niels A.G.M. van Helmond, Thilo Behrends, Matthias Egger, \\ Marie J.M. Séguret, Erik Gustafsson, Bo G. Gustafsson and Caroline P. Slomp
}

Geochimica et Cosmochimica Acta, 246, pp. 174-196

\begin{abstract}
The Baltic Sea is characterized by the largest area of hypoxic (oxygen $\left(\mathrm{O}_{2}\right)<2 \mathrm{mg} \mathrm{L}^{-1}$ ) bottom waters in the world's ocean induced by human activities. Natural ventilation of these $\mathrm{O}_{2}$-depleted waters largely depends on episodic Major Baltic Inflows from the adjacent North Sea. In 2014 and 2015 , two such inflows led to a strong rise in $\mathrm{O}_{2}$ and decline in phosphate $\left(\mathrm{HPO}_{4}^{2-}\right)$ in waters below $125 \mathrm{~m}$ depth in the Eastern Gotland Basin. This provided the opportunity to assess the impact of such re-oxygenation events on the cycles of manganese $(\mathrm{Mn})$, iron $(\mathrm{Fe})$ and phosphorus $(\mathrm{P})$ in the sediment for the first time. We demonstrate that the re-oxygenation induced the activity of sulphur (S)-oxidising bacteria, known as Beggiatoaceae in the surface sediment where a thin oxic and suboxic layer developed. At the two deepest sites, strong enrichments of total $\mathrm{Mn}$ and to a lesser extent Fe oxides and $\mathrm{P}$ were observed in this surface layer. A combination of sequential sediment extractions and synchrotron-based X-ray spectroscopy revealed evidence for the abundant presence of P-bearing rhodochrosite and $\mathrm{Mn}$ (II) phosphates. In contrast to what is typically assumed, the formation of $\mathrm{Fe}$ oxides in the surface sediment was limited. We attribute this lack of Fe oxide formation to the high flux of reductants, such as sulphide, from deeper sediments which allows $\mathrm{Fe}(\mathrm{II})$ in the form of $\mathrm{FeS}$ to be preserved and restricts the penetration of $\mathrm{O}_{2}$ into the sediment. We estimate that enhanced $\mathrm{P}$ sequestration in surface sediments accounts for only $\sim 5 \%$ of water column $\mathrm{HPO}_{4}{ }^{2-}$ removal in the Eastern Gotland Basin linked to the recent inflows. The remaining $\mathrm{HPO}_{4}{ }^{2-}$ was transported to adjacent areas in the Baltic Sea. Our results highlight that the benthic $\mathrm{O}_{2}$ demand arising from the accumulation of organic-rich sediments over several decades, the legacy of hypoxia, has major implications for the biogeochemical response of euxinic basins to re-oxygenation. In particular, $\mathrm{P}$ sequestration in the sediment in association with Fe oxides is limited. This implies that artificial ventilation projects that aim at removing water column $\mathrm{HPO}_{4}^{2-}$ and thereby improving water quality in the Baltic Sea will likely not have the desired effect.
\end{abstract}




\subsection{Introduction}

Oxygen $\left(\mathrm{O}_{2}\right)$ depletion in marine environments is increasing worldwide (Diaz and Rosenberg, 2008; Altieri et al. 2017; Schmidtko et al., 2017). In coastal systems, bottom water hypoxia $\left(\mathrm{O}_{2}<2 \mathrm{mg}\right.$ $\left.\mathrm{L}^{-1} ;<63 \mu \mathrm{M}\right)$ and anoxia $\left(\mathrm{O}_{2}=0 \mathrm{mg} \mathrm{L}^{-1}\right)$ can result in areas known as 'dead zones', characterized by mass mortality of marine life due to the lack of $\mathrm{O}_{2}$ and, in some cases, by the presence of highly toxic hydrogen sulphide $\left(\mathrm{H}_{2} \mathrm{~S}\right)$ (euxinia; Diaz and Rosenberg, 2008). The spatial extent of these dead zones has increased drastically in coastal marine waters since the 1960s (Diaz and Rosenberg, 2008). Furthermore, hypoxia and anoxia have greatly altered the sedimentary cycles of key nutrients, such as manganese $(\mathrm{Mn})$, iron $(\mathrm{Fe})$, phosphorus $(\mathrm{P})$ and nitrogen $(\mathrm{N})$ in many coastal systems (Ingall and Jahnke, 1994; Vahtera et al., 2007; Howarth et al., 2011; Lenz et al., 2015).

The semi-enclosed brackish Baltic Sea is the world's largest human-induced hypoxic/anoxic water mass (Carstensen et al., 2014a). While hypoxia/anoxia was restricted to a surface area of $\sim 10,000 \mathrm{~km}^{2}$ before 1950 , the $\mathrm{O}_{2}$-depleted areas expanded to more than $60,000 \mathrm{~km}^{2}$ in recent years due to eutrophication and global warming (e.g. Carstensen et al., 2014b). The Baltic Sea is naturally susceptible to hypoxia because submarine sills limit horizontal water exchange, also with the adjacent North Sea, and pronounced vertical stratification in the water column prevents the supply of $\mathrm{O}_{2}$ to waters below the permanent halocline, which is located at $60-80 \mathrm{~m}$ water depth in the Central Baltic (Mohrholz et al., 2015).

Natural ventilation of deeper waters in the Baltic Sea depends on large-scale episodic inflow events of oxygenated waters from the North Sea. Such episodic events, so-called Major Baltic Inflows (MBIs) are regulated by wind and air pressure related variations in sea level (Gustafsson and Andersson, 2001). During MBIs substantial amounts of saline and $\mathrm{O}_{2}$-rich water enter the Baltic Sea through the Danish Straits and subsequently ventilate the deeper basins. However, the inflow of saline water enhances stratification, ultimately resulting in reduced vertical mixing of $\mathrm{O}_{2}$ across the halocline, thereby contributing to the expansion of hypoxia (Conley et al., 2002). Considering the fact that natural ventilation occurs rarely and episodically, there have been calls to artificially ventilate the deep basins in order to increase $\mathrm{O}_{2}$ levels in the deeper water layers (Stigebrandt and Gustafsson, 2007; De Brabandere et al., 2015; Stigebrandt et al., 2015).

Re-oxygenation of the bottom water following an MBI alters the water column and sediment biogeochemistry. Sedimentary rhodochrosite $\left(\mathrm{MnCO}_{3}\right)$ is typically formed after an MBI when Mn oxides precipitate in the water column (Turnewitsch and Pohl, 2010) and are deposited onto the sediment where they undergo subsequent conversion to $\mathrm{MnCO}_{3}$ (Huckriede and Meischner, 1996; Lenz et al., 2014). Ventilation of the bottom water also is thought to result in the formation of Fe(oxyhydr)oxides (henceforth termed Fe oxides) in the water column (Turnewitsch and Pohl, 2010) and in the surface sediments (Mort et al., 2010). The cycling of $P$ is particularly sensitive to changes in bottom water $\mathrm{O}_{2}$ concentrations, since Fe oxides, $\mathrm{Mn}$ oxides and $\mathrm{MnCO}_{3}$ can all bind dissolved phosphate ( $\mathrm{HPO}_{4}^{2-}$; Mort et al., 2010; Jilbert and Slomp, 2013). Sediment molybdenum (Mo) is an indicator for the presence of $\mathrm{H}_{2} \mathrm{~S}$ near the sediment-water interface and hence serves as an excellent proxy for the oxidation state of the sediment (Helz et al., 1996; Scott and Lyons, 2012).

Changes in bottom water $\mathrm{O}_{2}$ concentrations also have an impact on bacterial communities in the Baltic Sea (Steenbergh et al., 2014; Noffke et al., 2016). In particular, bottom water re-oxygenation enhances the activity of sulphur (S)-oxidising bacteria belonging to the family Beggiatoaceae (Noffke et al., 2016). These bacteria are chemotrophic species using sulphide as an electron donor and $\mathrm{O}_{2}$ as an electron acceptor (Teske and Nelson, 2006). Their activity can lead to the development of a suboxic zone, which may contribute to the preservation of $\mathrm{Mn}$ oxides and 
Fe oxides in the surface sediment (Sulu-Gambari et al., 2016b). These bacteria can incorporate $\mathrm{P}$ in their cells by taking up pore water $\mathrm{HPO}_{4}{ }^{2-}$, subsequently storing it as polyphosphate in their

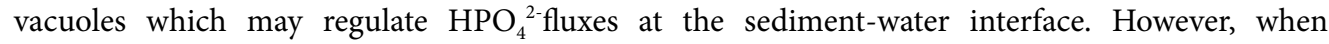
dissolved $\mathrm{O}_{2}$ reaches low levels $(<10 \mu \mathrm{M})$, Beggiatoaceae may release $\mathrm{HPO}_{4}{ }^{2-}$ into the pore water (Goldhammer et al., 2010; Brock and Schulz-Vogt, 2011; Dale et al., 2013).

Recently, the third largest MBI since 1880 was observed. From December 2014 to January 2015 a total estimated water volume of $320 \mathrm{~km}^{3}$ entered the Baltic Sea (Mohrholz et al., 2015), followed by a second smaller MBI in November 2015 (Mohrholz et al., 2016). These events re-oxygenated the bottom waters in the Central Baltic Sea (Holtermann et al., 2017; Neumann et al., 2017), which had been euxinic since 2005. The changes in bottom water $\mathrm{O}_{2}$ concentrations had a direct impact on the nutrient dynamics in the Baltic Sea. Thus, for example, the exposure of the sediments in the deep basin to $\mathrm{O}_{2}$ rich water was suggested to lead to a 5-33\% reduction in the release of $\mathrm{P}$ from sediments in the Baltic Proper based on in-situ measured benthic fluxes and water column profiles (Hall et al., 2017; Sommer et al., 2017). In July 2015, an orange surface layer was observed in sediments from the deep basin in the Central Baltic Sea (Rosenberg et al., 2016; Stigebrandt et al., 2017). Based on the visual observations, this layer was suggested to be enriched in Mn oxides and Fe oxides that were formed as a result of the re-oxygenation (Rosenberg et al., 2016). In April 2016, this layer had become thinner, which was suggested to be related to the reductive dissolution of Mn oxides and $\mathrm{Fe}$ oxides following a decline in bottom water $\mathrm{O}_{2}$ concentrations (Stigebrandt et al., 2017). As described above, the details of the sedimentary cycles of $\mathrm{Mn}$, Fe and P following an inflow have so far been deduced from water column sampling, benthic flux measurements, visual observations of the sediment and from chemical sediment data after the re-establishment of euxinic bottom water conditions. As a consequence, the chemical and mineralogical nature of the $\mathrm{Mn}-$, Fe- and P-bearing deposits in the surface sediments formed directly after re-oxygenation remains unknown. The impact of bottom water re-oxygenation on the forms of Mn, Fe and P in Baltic Sea sediments and their dynamics has not yet been assessed.

In this study, we present pore water and solid phase data for sediment cores retrieved from six sites and water column data along a water depth gradient in the Eastern Gotland Basin. Our samples were collected in June 2016. Additional samples taken in June 2009 prior to the recent inflows were used for comparison. The objective of this study is to assess the impact of the recent MBIs on the cycling of $\mathrm{Mn}, \mathrm{Fe}$ and $\mathrm{P}$ in surface sediments of the Eastern Gotland Basin, using bulk geochemical analyses, synchrotron-based micro X-ray fluorescence $(\mu \mathrm{XRF})$ and X-ray absorption spectroscopy (XAS). We show that the recent MBIs led to the development of a surface sediment layer enriched in P-bearing rhodochrosite (Mn-carbonate) and $\mathrm{Mn}$ (II) phosphates in the deepest parts of the Eastern Gotland Basin, with only a relatively minor role for Fe oxide bound P. We estimate that only 5\% of the water column $\mathrm{HPO}_{4}{ }^{2-}$ removed from the Eastern Gotland basin as a result of re-oxygenation was sequestered in the sediment. 


\subsection{Material and Methods}

\subsubsection{Study Area and Sampling}

The Eastern Gotland Basin is located in the Central Baltic Sea (Figure 2.1A). In June 2016, six sites located along a water depth gradient in the Eastern Gotland Basin were sampled during a research expedition with R/V Pelagia (Figure 2.1A; Table 2.1). Sediment cores were retrieved with a multicorer (Oktopus $\mathrm{GmbH}$, Germany) at each site. Duplicate bottom water samples were taken directly from the overlying water using $20 \mathrm{~mL}$ syringes. At each site, one core was sectioned in a nitrogen purged glovebox for sediment and pore water collection $(0.5 \mathrm{~cm}$ resolution for the first $2 \mathrm{~cm} ; 1 \mathrm{~cm}$ resolution for $2-5 \mathrm{~cm}$ ). For each depth interval a sediment sub-sample was placed in a pre-weighed glass vial for porosity and solid-phase analysis. The glass vials were transferred into nitrogen purged aluminium bags and stored at $20^{\circ} \mathrm{C}$. The remaining sediment for each depth interval was placed in a $50 \mathrm{~mL}$ centrifuge tube and subsequently centrifuged at $4500 \mathrm{rpm}$ for $25 \mathrm{~min}$ to collect pore water. A second core was subjected to high resolution depth profiling of dissolved $\mathrm{O}_{2}, \mathrm{H}_{2} \mathrm{~S}$ and $\mathrm{pH}$. At site $\mathrm{BY} 15$, located in the deepest part of the basin, a third core was taken for sediment micro analysis ( $\mu$ XRF and XAS).
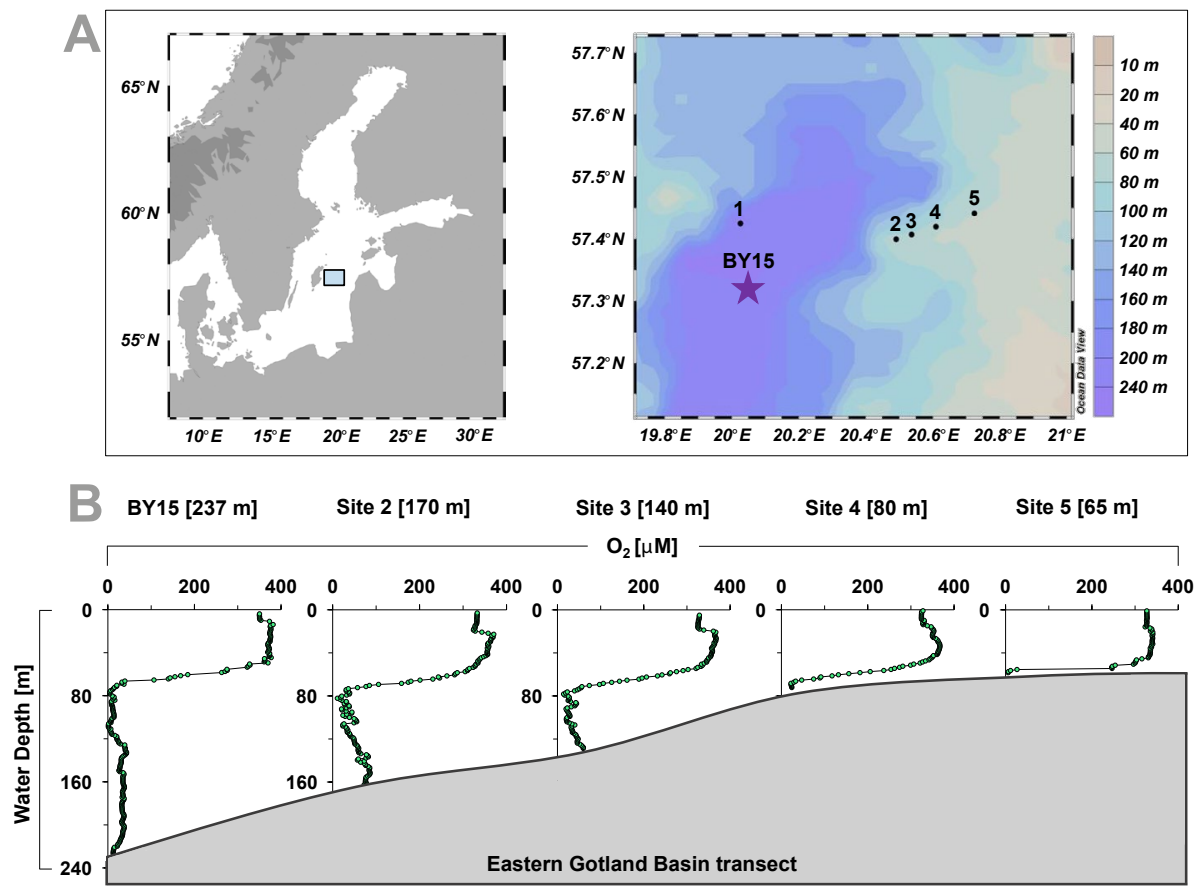

Figure 2.1 | (A) Map of the Baltic Sea (left) and bathymetric map of the Eastern Gotland Basin showing the locations of the sites presented in this study (right), adapted from Ocean Data View 4 (Schlitzer, 2015). The purple star indicates the location of site BY15. Site characteristics are given in Table 5.1. (B) The green-dotted lines represent water column profiles of dissolved $\mathrm{O}_{2}$ concentrations for the Eastern Gotland Basin transect. Note that there are no water column data available for site 1 (200 $\mathrm{m}$ water depth). 
Table 2.1 | Characteristics of the sites sampled in June 2016.

\begin{tabular}{llllllll}
\hline Site & Water depth $[\mathrm{m}]$ & Coordinates $[\mathrm{N}]$ & Coordinates $[\mathrm{E}]$ & $\begin{array}{l}\text { Bottom water } \\
\mathrm{O}_{2}[\mu \mathrm{M}]\end{array}$ & $\begin{array}{l}\mathrm{O}_{2} \text { penetration } \\
\text { depth }[\mathrm{mm}]\end{array}$ & $\begin{array}{l}\Sigma \mathrm{H}_{2} \mathrm{~S} \text { appearance S-oxidising bacteria } \\
\text { depth }[\mathrm{mm}]\end{array}$ \\
present
\end{tabular}

Water column depth profiles of dissolved $\mathrm{O}_{2}$ were obtained at five sites (Figure 2.1A), using an $\mathrm{O}_{2}$ sensor (Sea-Bird) attached to a CTD-Rosette. At site BY15, water column samples were collected using an ultra-clean CTD system with 24 ultra-trace metal clean PVDF samplers of 24 $\mathrm{L}$ in two rows of 12 samplers mounted onto a rectangular titanium frame (developed and built by the Royal Netherlands Institute for Sea Research (NIOZ), Texel), which was deployed with a Kevlar hydrowire (De Baar et al., 2008; Rijkenberg et al., 2015). All water column samples were retrieved by applying nitrogen pressure at the top of the sampler. Samples for $\mathrm{H}_{2} \mathrm{~S}$ and $\mathrm{HPO}_{4}^{2-}$ were collected with $20 \mathrm{~mL}$ syringes and filtered $\left(0.45 \mu \mathrm{m}\right.$ Teflon). To avoid loss of $\mathrm{H}_{2} \mathrm{~S}$, the aliquot for $\mathrm{H}_{2} \mathrm{~S}$ analysis was transferred into a $\mathrm{N}_{2}$ purged $8 \mathrm{mM} \mathrm{NaOH}$ solution immediately after filtration. Acid-washed LDPE bottles (Nalgene ${ }^{\mathrm{TM}}$ ) were rinsed three times with the sample collected using acid-washed LDPE tubing connected to the top of the sampler. For the determination of dissolved $\mathrm{Mn}$ and Fe, seawater was filtered through a $0.2 \mu \mathrm{m}$ Sartobran 300 cartridge with a cellulose acetate membrane (Sartorius), pre-rinsed with $0.5 \mathrm{~L}$ of seawater. Unfiltered samples for total dissolvable $\mathrm{Mn}$ and $\mathrm{Fe}$ (henceforth termed total $\mathrm{Mn}$ and total $\mathrm{Fe}$ ) were also collected. Samples for $\mathrm{Mn}$ and Fe analyses were acidified to $\mathrm{pH} 1.8$ with distilled $\mathrm{HCl}$ and stored at $4{ }^{\circ} \mathrm{C}$ until analysis.

Suspended matter samples from the water column at site BY15 were collected through in-situ pumping for $1-4 \mathrm{~h}$ at four water depths $(85,175,200$ and $220 \mathrm{~m})$ using four McLane pumps $(3 \times$ WTS-LV; $1 \times$ WTS-LV dual Filter). The water on the filters was removed directly upon retrieval by vacuum pumping and the filters were placed in petridishes, sealed in plastic bags and stored at $20{ }^{\circ} \mathrm{C}$ until analysis.

Monthly time-series data for dissolved $\mathrm{O}_{2}, \mathrm{H}_{2} \mathrm{~S}$ and $\mathrm{HPO}_{4}{ }^{2-}$ in the water column at BY15 for January 2002 to September 2018 were obtained from the Swedish Ocean Archive (SHARK) database at the Swedish Meteorological and Hydrological Institute (SMHI; http://sharkweb.smhi.se). Sediment and pore water from a sediment core collected at site BY15 during an expedition with R/V Aranda in June 2009 (Jilbert et al., 2011) were analysed for their Mn and P composition, and are assumed to be representative for pre-inflow conditions.

\subsubsection{Water Column Analyses}

Water column samples were analysed colourimetrically for $\mathrm{H}_{2} \mathrm{~S}$ and $\mathrm{HPO}_{4}{ }^{2-}$ based on methylene and molybdate blue complexes, respectively, using QuAAtro (Bran+Luebbe) gas-segmented continuous flow analysers on board ship (Murphy and Riley, 1962; Grasshoff and Ehrhardt, 1983). Water column Mn concentrations were determined using Inductively Coupled Plasma Mass Spectrometry (ICP-MS; Nexion, Perkin Elmer), after sample preparation using a SC-DX SeaFAST S2 (Elemental Scientific). Acidified samples $(\mathrm{pH} \sim 2)$ were pre-concentrated on the SeaFAST system and eluted 
directly into the ICP-MS and measured online (Lagerström et al., 2013). The blank was $1.012 \pm 0.155$ nM Mn. Three reference materials were used (NASS-6, SLRS and SLEW) and the overall recovery was $102.4 \pm 10.6 \%(\mathrm{n}=24)$. Water column Fe concentrations were determined by flow injection using a mixture of luminol and triethylenetetramine with preconcentration on an iminodiacetic acid resin (Obata et al., 1993; Klunder et al., 2011; Rijkenberg et al., 2014). All Fe in the samples was oxidized to $\mathrm{Fe}^{3+}$ by adding $0.1 \%$ hydrogen peroxide more than $12 \mathrm{~h}$ prior to analysis. The blank of acidified ultrapure water $(\mathrm{pH}=1.8)$ was $25 \mathrm{pM} \pm 1 \mathrm{pM}(\mathrm{n}=30)$. To ensure the accuracy of the analyses, the system was checked daily using a GEOTRACES standard or an in-house reference material (acidified seawater at $\mathrm{pH}$ 1.8). For GEOTRACES SAFe D1, we measured an average value of $0.69 \pm 0.26 \mathrm{nM}(\mathrm{n}=37)$ consistent with the community consensus value of $0.67 \pm 0.04 \mathrm{nM}$ (Johnson et al., 2007; www.geotraces.org (2013). Forms of Fe in suspended matter were determined on a quarter of every filter using a 5-step sequential extraction procedure targeting the following phases: (1) ferrihydrite, (2) labile Fe (III) oxides and Fe(II) (iron monosulphide (FeS) + siderite $\mathrm{FeCO}_{3}$ ), (3) crystalline Fe oxide minerals, (4) magnetite and (5) pyrite (Table 2.2). Concentrations of Fe were analysed spectrophotometrically (Shimadzu, UV-1800) using the 1-10, phenanthroline method (Cleceri et al., 1998). All extracts, except nitric acid extracts, were passed through a $0.45 \mu \mathrm{m}$ nylon filter prior to analysis. Concentrations of Mn were measured colourimetrically using a mixed ammonia/formaldoxime reagent, as described in Brewer and Spencer (1971). The sum of all Mn phases extracted in the five Fe extraction steps was assumed to represent reactive $\mathrm{Mn}$ (Mn oxides and Mn carbonates; Sulu-Gambari et al., 2016a).

\subsubsection{Pore Water Collection and Analyses}

Bottom water and supernatant from each centrifuged sample were filtered through nylon filters $(0.45 \mu \mathrm{m})$ in a nitrogen purged glovebox for analysis of dissolved pore water constituents. Immediately after retrieval of the pore water, samples for sulphide analyses $(0.5 \mathrm{~mL})$ were placed in glass vials filled with a nitrogen purged $8 \mathrm{M} \mathrm{NaOH}$ solution $(1.5 \mathrm{~mL})$. Samples for $\mathrm{HPO}_{4}{ }^{2-}$ were acidified with $4 \mu \mathrm{L}$ of $5 \mathrm{M} \mathrm{HCl}$ per mL. Concentrations of both $\mathrm{H}_{2} \mathrm{~S}$ and $\mathrm{HPO}_{4}{ }^{2-}$ were analysed as described for the water column samples. Samples for metals were acidified with $10 \mu \mathrm{L}$ Suprapur ${ }^{\circ}$ $\mathrm{HCl}(35 \%)$ per $\mathrm{mL}$ and analysed for $\mathrm{Mn}$ and Fe by Inductively Coupled Plasma-Optical Emission Spectroscopy (ICP-OES; Spectro Arcos). Pore water data for Mn and Fe, are assumed to represent $\mathrm{Mn}^{2+}$ and $\mathrm{Fe}^{2+}$, although some $\mathrm{Mn}^{3+}$ (Madison et al., 2013) or colloidal and nanoparticulate $\mathrm{Mn}$ or Fe (Boyd and Ellwood, 2010; Raiswell and Canfield, 2012) might also be present. Concentrations of Mo were determined by ICP-MS (XSeries II, Thermo Fisher Scientific). Samples for $\mathrm{NH}_{4}{ }^{+}$were analysed on board with a QuAAtro (Bran + Luebbe) gas-segmented continuous flow analyser following the phenol-hypochlorite method (Koroleff, 1969). Pore water $\mathrm{Mn}^{2+}$ and $\mathrm{HPO}_{4}^{2-}$ in the 2009 samples were determined by ICP-OES as described previously by Jilbert et al. (2011). 
Table 2.2 | Sequential P, S and Fe extractions for suspended matter and sediment samples. The ferrihydrite extraction step from the sequential Fe extraction was only applied to the suspended matter. Unless stated otherwise, all extracts from the sequential extractions were passed through a $0.45 \mu \mathrm{m}$ nylon filter. The three sequential extraction procedures for $\mathrm{P}, \mathrm{Fe}$ and $\mathrm{S}$ fractionation were performed under strictly anoxic conditions.

\begin{tabular}{|c|c|c|}
\hline Targeted mineral phase & Solvent & Time \\
\hline \multicolumn{3}{|l|}{ SEQUENTIAL PHOSPHORUS EXTRACTION ${ }^{1}$} \\
\hline 1. Exchangeable $P$ & $1 \mathrm{M} \mathrm{MgCl}_{2}$ & $0.5 \mathrm{~h}$ \\
\hline \multirow[t]{2}{*}{ 2. Easily reducible or reactive ferric Fe-bound $P(C D B-P)$} & Citrate-bicarbonate-CDB buffered to $\mathrm{pH} 7.5$ with Na citrate/Na bicarbonate & $8 \mathrm{~h}$ \\
\hline & $1 \mathrm{M} \mathrm{MgCl}_{2}$ (wash step) & $0.5 \mathrm{~h}$ \\
\hline \multirow[t]{2}{*}{ 3. Authigenic $P$} & $1 \mathrm{M} \mathrm{Na}$-acetate buffered to $\mathrm{pH} 4$ with acetic acid & $6 \mathrm{~h}$ \\
\hline & $1 \mathrm{M} \mathrm{MgCl}_{2}$ (wash step) & $0.5 \mathrm{~h}$ \\
\hline 4. Detrital P & $1 \mathrm{M} \mathrm{HCl}$ & $24 \mathrm{~h}$ \\
\hline 5. Organic $P$ & $1 \mathrm{M} \mathrm{HCl}$, after ashing at $550^{\circ} \mathrm{C}$ & $24 \mathrm{~h}$ \\
\hline \multicolumn{3}{|l|}{ SEQUENTIAL IRON EXTRACTION ${ }^{2,3,4}$} \\
\hline 1. Ferrihydrite ${ }^{2}$ & $0.057 \mathrm{M}$ ascorbic acid/0.17 M sodium citrate/0.6 M sodium bicarbonate & $24 \mathrm{~h}$ \\
\hline $\begin{array}{l}\text { 2. Labile } \mathrm{Fe}(\mathrm{III}) \text { oxides and } \mathrm{Fe}(\mathrm{II}) \\
\left.\text { (iron monosulphide }(\mathrm{FeS})+\text { siderite } \mathrm{FeCO}_{3}\right)^{3}\end{array}$ & $1 \mathrm{M} \mathrm{HCl}$ & \\
\hline \multirow[t]{2}{*}{ 3. Crystalline Fe oxides (goethite, hematite) ${ }^{3}$} & $0.35 \mathrm{M}$ acetic acid/0.2 M sodium-citrate with & $4 \mathrm{~h}$ \\
\hline & $50 \mathrm{~g} / \mathrm{L}$ sodium dithionite, $\mathrm{pH} 4.8$ & \\
\hline 4. Magnetite ${ }^{4}$ & $0.2 \mathrm{M}\left(\mathrm{NH}_{4}\right)_{2} \mathrm{C}_{2} \mathrm{O}_{4} / 0.17 \mathrm{M} \mathrm{C}_{2} \mathrm{H}_{2} \mathrm{O}_{4}$ & $6 \mathrm{~h}$ \\
\hline 5. Pyrite ${ }^{3}$ & $\mathrm{HNO}_{3}(65-70 \%)$ & $2 \mathrm{~h}$ \\
\hline \multicolumn{3}{|l|}{ SEQUENTIAL SULPHUR EXTRACTION ${ }^{5,6}$} \\
\hline 1. Acid-volatile sulphide (AVS) & $6 \mathrm{M} \mathrm{HCl}$ & $24 \mathrm{~h}$ \\
\hline 2. Elemental sulphur & Methanol (99.8\%) & $16 \mathrm{~h}$ \\
\hline Acetone (wash step) & & $20 \mathrm{~min}$ \\
\hline 3. Chromium reducible sulphur (CRS) & $500 \mathrm{~g} / \mathrm{L} \mathrm{Cr}(\mathrm{II}) \mathrm{Cl}_{2}$ in $32 \% \mathrm{HCl}$ & $48 \mathrm{~h}$ \\
\hline
\end{tabular}

${ }^{1}$ Ruttenberg (1992) as modified by Slomp et al. (1996).

${ }^{2}$ Raiswell et al. (2010).

${ }^{3}$ Claff et al. (2010).

${ }^{4}$ Poulton and Canfield (2005).

${ }^{5}$ Burton et al. (2006).

${ }^{6}$ Burton et al. (2008).

\subsubsection{High-resolution Depth Profiling}

High-resolution depth profiles of pore water $\mathrm{O}_{2}(50-\mu \mathrm{m}), \mathrm{pH}(100-\mu \mathrm{m})$ and total $\mathrm{H}_{2} \mathrm{~S}(50-\mu \mathrm{m})$ were retrieved using microelectrodes and a $2 \mathrm{D}$ micromanipulator (Unisense A.S., Denmark) with a step size of 50 to $100 \mu \mathrm{m}$. For the $\mathrm{O}_{2}$ sensor, a 2-point calibration was performed $\left(100 \% \mathrm{O}_{2}\right.$ saturated and $\mathrm{N}_{2}$ purged artificial seawater) using a calibration chamber (Unisense A.S., Denmark, CAL300). For the calibration of the $\mathrm{pH}$ sensor, 3 NBS standards ( $\mathrm{pH} \mathrm{4,} 7$ and 10) were used. A TRIS buffer was used to correct for salinity effects (Dickson, 1990; Dickson et al., 2007). The $\mathrm{pH}$ is reported on a total scale. For the $\mathrm{H}_{2} \mathrm{~S}$ sensor calibration, a 5-point calibration was performed with $\mathrm{NaS}_{2}$ standards. Total $\mathrm{H}_{2} \mathrm{~S}\left(\mathrm{LH}_{2} \mathrm{~S}=\mathrm{H}_{2} \mathrm{~S}+\mathrm{HS}+\mathrm{S}_{2}\right)$ was calculated from the observed $\mathrm{H}_{2} \mathrm{~S}, \mathrm{pH}$, temperature in Kelvin (T) and salinity (S) (Millero et al., 1988; Jeroschewski et al., 1996).

$$
\left[\Sigma H_{2} S\right]=\left[H_{2} S\right] \cdot\left(1+\frac{10^{-p K_{1}}}{\left[H_{3} O^{+}\right]}\right)
$$


$p K_{1}=\frac{-98.080+5765.4}{T+15.0455 \ln (T)}+\left(-0.157 \cdot\left(S^{0.5}\right)\right)+0.0135 \cdot S$

\subsubsection{Diffusive Fluxes}

Diffusive fluxes of $\mathrm{O}_{2}, \mathrm{HPO}_{4}{ }^{2-}, \mathrm{\Sigma H}_{2} \mathrm{~S}, \mathrm{NH}_{4}{ }^{+}$and $\mathrm{Mn}^{2+}$ across the sediment-water interface and upward fluxes of $\mathrm{\Sigma}_{2} \mathrm{~S}$ into the suboxic zone were calculated using Fick's first law (Berner, 1980):

$J=-\phi D_{s} \cdot \frac{d C}{d z}$

where $\mathrm{J}$ represents the diffusive flux $\left[\mathrm{mmol} \mathrm{m}^{-2} \mathrm{yr}^{-1}\right], \varphi$ expresses the sediment porosity, Ds represents the sediment diffusion coefficient $\left[\mathrm{m}^{2} \mathrm{yr}^{-1}\right], \mathrm{C}$ is the concentration of $\mathrm{O}_{2}, \mathrm{HPO}_{4}^{2-}, \Sigma \mathrm{H}_{2} \mathrm{~S}$, $\mathrm{NH}_{4}^{+}$or $\mathrm{Mn}^{2+}[\mathrm{mM}]$ and $\mathrm{z}$ stands for the sediment depth [m]. The diffusion coefficient for the ambient tortuosity, temperature, pressure and salinity at each station was calculated using the $\mathrm{R}$ package marelac (Soetaert et al., 2010), which implements the constitutive relations listed in Boudreau (1997). For sectioned cores, the concentration gradient at the sediment-water interface was calculated from the difference in concentration in the bottom water and that of in the first sediment depth interval $(0-0.5 \mathrm{~cm})$. For micro-electrode profiles, the linear gradient immediately below the sediment-water interface was taken (Malkin et al., 2014). Upward diffusive fluxes of $\Sigma \mathrm{H}_{2} \mathrm{~S}$ into the suboxic zone were calculated in a similar manner.

\subsubsection{Solid-phase Analysis}

Surface sediments were analysed on board directly after core collection using a stereomicroscope to assess which S-oxidising bacteria were present at the different sites in the Eastern Gotland Basin. Sediment samples from core slicing were freeze-dried, homogenised and ground to a fine powder with an agate mortar and pestle in an argon purged glovebox. Depth profiles for porosity were derived from the weight loss after freeze-drying, assuming a sediment dry density of $2.65 \mathrm{~g} \mathrm{~cm}^{-3}$ (see Supplementary Information, section S.2.1). Sediment weights were corrected for salt content. The amount of salt was calculated from the gravimetric water content and salinity. The freeze-dried samples were stored in air tight jars which were kept in an argon atmosphere at all times to prevent oxidation artefacts (Kraal et al., 2009; Kraal and Slomp, 2014).

\subsubsection{Organic Carbon Content}

Aliquots of $\sim 300 \mathrm{mg}$ of freeze-dried sediment were decalcified with 2 wash steps of $1 \mathrm{M} \mathrm{HCl}$ as described in Van Santvoort et al. (2002). The samples were subsequently dried at $60{ }^{\circ} \mathrm{C}$, powdered and analysed for carbon using a Fisons Instruments NA 1500 NCS analyser. The organic carbon content was calculated after correction for the weight loss during decalcification. The measurements were normalized to in-house standards, acetanilide, atropine and nicotinamide. Average analytical uncertainty based on duplicate analyses of sediment samples was $0.01 \mathrm{wt}$ \% for organic carbon. 


\subsubsection{Total Manganese, Phosphorus and Molybdenum Contents}

For the analysis of the total $\mathrm{Mn}, \mathrm{P}$ and Mo contents $\sim 100 \mathrm{mg}$ freeze-dried sediment was digested overnight at $90{ }^{\circ} \mathrm{C}$ in closed PTFE vessels, using a mixture of $\mathrm{HF}(40 \%)$ and $2.5 \mathrm{~mL} \mathrm{HClO}_{4}-\mathrm{HNO}_{3}$ (ratio 3:2). Subsequently, the acid solution was evaporated at $140{ }^{\circ} \mathrm{C}$ until a gel was formed. The gel was then dissolved overnight with $1 \mathrm{M} \mathrm{HNO}_{3}$ at $90^{\circ} \mathrm{C}$. Finally, the $\mathrm{Mn}, \mathrm{P}$ and Mo concentrations in the $1 \mathrm{M} \mathrm{HNO}_{3}$ solutions were measured by ICP-OES. To assess the accuracy and precision of the measurements, we used ISE-921 as reference material. The accuracy varied between 97 and 104\%, and the relative errors were $<4 \%$ for all measured elements. The average analytical uncertainty of duplicate samples was $1 \%$ for $\mathrm{Mn}, 1.5 \%$ for $\mathrm{P}$ and $0.15 \%$ for Mo.

\subsubsection{Sequential P Fractionation}

The SEDEX sequential extraction procedure (Ruttenberg, 1992, as modified by Slomp et al., 1996) was applied to determine the sedimentary $\mathrm{P}$ phases using $\sim 100 \mathrm{mg}$ of freeze dried sediment. Solidphase $\mathrm{P}$ was fractionated into the following phases (Table 2.2): (1) exchangeable-P (Ex-P), (2) CDB-P (citrate-bicarbonate buffer), (3) authigenic P (carbonate fluorapatite (CFAP) + biogenic hydroxyapatite + calcium carbonate), (4) detrital $\mathrm{P}$ and (5) organic P. Dissolved $\mathrm{HPO}_{4}{ }^{2-}$ in all extracts, except CDB extracts, was analysed colourimetrically on a spectrophotometer (Shimadzu, UV-1800) applying the ammonium heptamolybdate-ascorbic acid method (Strickland and Parsons, 1972). Phosphorus concentrations in the CDB extracts were determined by ICP-OES.

\subsubsection{Sequential Fe Fractionation}

Aliquots of $\sim 80 \mathrm{mg}$ of freeze-dried sediment were used for the Fe solid-phase fractionation using a combination of two extraction methods (Poulton and Canfield, 2005; Claff et al., 2010) as described by Kraal et al. (2017). Solid-phase Fe was fractionated into the following phases (Table 2.2; step 2-5): (1) labile $\mathrm{Fe}(\mathrm{III})$-oxides and $\mathrm{Fe}(\mathrm{II})$ (iron monosulphide (FeS)+ siderite $\mathrm{FeCO}_{3}$ ), (2) crystalline Fe minerals, (3) magnetite and (4) pyrite $\left(\mathrm{FeS}_{2}\right)$. Concentrations of Fe were analysed spectrophotometrically (Shimadzu, UV-1800) using the 1-10, phenanthroline method (Cleceri et al., 1998), except for the Fe in CDB extracts which were analysed by ICP-OES. All extracts were passed through a $0.45 \mu \mathrm{m}$ nylon filter except for nitric acid extracts.

\subsubsection{Sequential S Fractionation}

Aliquots of $\sim 300 \mathrm{mg}$ freeze-dried sediment were used to determine (1) FeS (Acid Volatile Sulphur, AVS, (2) elemental sulphur and (3) $\mathrm{FeS}_{2}$ (chromium reducible sulphur, CRS) (Table 2.2; Burton et al., 2006; Burton et al., 2008). The $\mathrm{ZnS}$ concentration formed in the $\mathrm{Zn}$ acetate traps was determined by iodometric titration (Cleceri et al., 1998). Elemental sulphur was determined using the cyanide-ferric chloride colorimetric method (Bartlett and Skoog, 1954) and was measured spectrophotometrically (Shimadzu, UV-1800). 
A vertically intact sub-core from the upper $7 \mathrm{~cm}$ of the sediment was taken from a sediment core at site BY15 and embedded with epoxy resin under an argon purged atmosphere for high-resolution elemental mapping (Jilbert et al., 2008; Jilbert and Slomp, 2013; Egger et al., 2015). Subsequently, the epoxy-embedded sub-core was split vertically with a rock saw and polished with alumina powder $(0.3 \mu \mathrm{m})$. A navigation grid was drilled in the surface of the sub-core, with a micro drill. Exposure time to $\mathrm{O}_{2}$ was limited to prevent oxidation artefacts (Kraal et al., 2009; Kraal and Slomp, 2014). High-resolution $(30 \mathrm{~mm}$ ) elemental maps for $\mathrm{Mn}, \mathrm{Fe}, \mathrm{Ca}$ and $\mathrm{P}$ were retrieved using a Desktop EDAX Orbis $\mu$ XRF analyser (Rh tube set at $30 \mathrm{kV}, 500 \mu \mathrm{A}, 300 \mathrm{~ms}$ dwell-time, equipped with a poly-capillary lens providing a $30 \mu \mathrm{m}$ spot size).

\subsubsection{XAS and Synchrotron-based $\mu X R F$ Mapping}

Suspended matter samples from the water column and epoxy embedded sediments were examined for their Mn and Fe mineralogy at the European Synchrotron Radation Facility (ESRF) in Grenoble, France, using X-ray Absorption Spectroscopy (XAS). The filters with suspended matter samples were analysed at the Dutch-Belgium beamline (DUBBLE, BM26; Borsboom et al., 1998; Nikitenko et al., 2008). The sediments were analysed at the ID21 beamline (Salomé et al., 2013). At BM26, X-ray Absorption Near Edge Structure (XANES) and Extended X-ray Absorption Fine Structure (EXAFS) spectra were collected on samples in Kapton ${ }^{\circledR}$ tape with an unfocused beam in fluorescence mode using a 9 element Ge detector, and four spectra per sample were merged. Samples were measured within the energy range of 6.50-6.90 keV for Mn and 7.00-7.65 keV for $\mathrm{Fe}$. Levels of $\mathrm{Fe}$ in suspended matter were too low to obtain Fe-XANES and Fe-EXAFS spectra of sufficient quality. Therefore, only those for $\mathrm{Mn}$ are presented.

At ID21, high-resolution elemental maps of $\mathrm{Mn}, \mathrm{P}, \mathrm{Ca}$ and $\mathrm{Fe}$ for epoxy embedded sediment from site BY15 were made. Focusing of the X-ray beam $(0.35 \times 0.80 \mu \mathrm{m})$ was performed by a Kirkpatrick-Baez mirrors system. Identified hotspots of $\mathrm{Mn}$ and $\mathrm{Fe}$ from the synchrotron-based $\mu \mathrm{XRF}$ maps were further analysed with XANES to determine the mineralogy of $\mathrm{Mn}$ and $\mathrm{Fe}$. The XANES spectra were collected within the corresponding energy range, 6.50-6.90 keV for Mn and 7.00-7.65 keV for Fe, respectively. For both measurements, the calibration of the monochromator energy was based on the maximum intensity of the first derivative of $\mathrm{Mn}$ foil at $6.53862 \mathrm{keV}$ for $\mathrm{Mn}$ and Fe foil at $7.11198 \mathrm{keV}$ for Fe. High-resolution elemental maps were processed using the PyMca X-ray Fluorescence Toolkit (Solé et al., 2007). Subsequently, the ATHENA software package was used to subtract the background and normalise XANES spectra (Ravel and Newville, 2005). Reference standards for hureaulite $\left(\mathrm{Mn}_{5}^{2+}{ }_{5}\left[\mathrm{PO}_{3} \mathrm{OH}\right]_{2}\left[\mathrm{PO}_{4}\right]_{2} \cdot 4 \mathrm{H}_{2} \mathrm{O}\right)$ and $\mathrm{Mn}(\mathrm{III}) \mathrm{PO}_{4}$ were obtained from Manceau et al. (2012). Collection of EXAFS spectra at ID21, using a continuously moving monochromator, did not result in spectra of sufficient quality, because of a high noise ratio in the spectra. Therefore, only XANES spectra are presented. 


\subsection{Results}

\subsubsection{Water Column Geochemistry}

Depth profiles of dissolved $\mathrm{O}_{2}$ in the water column of the Eastern Gotland Basin, retrieved in June 2016, show saturated levels of $\mathrm{O}_{2}(340-380 \mu \mathrm{M})$ in the upper $50 \mathrm{~m}$ of the water column (Figure 2.1B). From $50 \mathrm{~m}$ down to $80 \mathrm{~m}$ water depth, the $\mathrm{O}_{2}$ levels decrease rapidly, reaching a minimum of $\sim 10 \mu \mathrm{M}$ (Figure 2.1B). Below $80 \mathrm{~m}$ water depth the concentrations of dissolved $\mathrm{O}_{2}$ increase, reaching levels up to $50-80 \mu \mathrm{M}$, as a result of the deep water renewal (Figure 2.1B).

Monthly time-series of dissolved $\mathrm{O}_{2}$ depth profiles for the time period January 2002 until September 2018 show that the upper $80 \mathrm{~m}$ of the water column at site BY15 always contained saturated concentrations of $\mathrm{O}_{2}$ (Figure 2.2A). However, below $80 \mathrm{~m}$ water depth, sulphide was generally present, except for two time periods, namely after the MBI that occurred in 2003 and the recent MBIs that took place in December 2014/January 2015 and November 2015. These MBIs consequently led to a removal of all free sulphide in the water column (Figure 2.2B) and a two-fold lowering of water column $\mathrm{HPO}_{4}{ }^{2-}$ (Figure 2.2C).
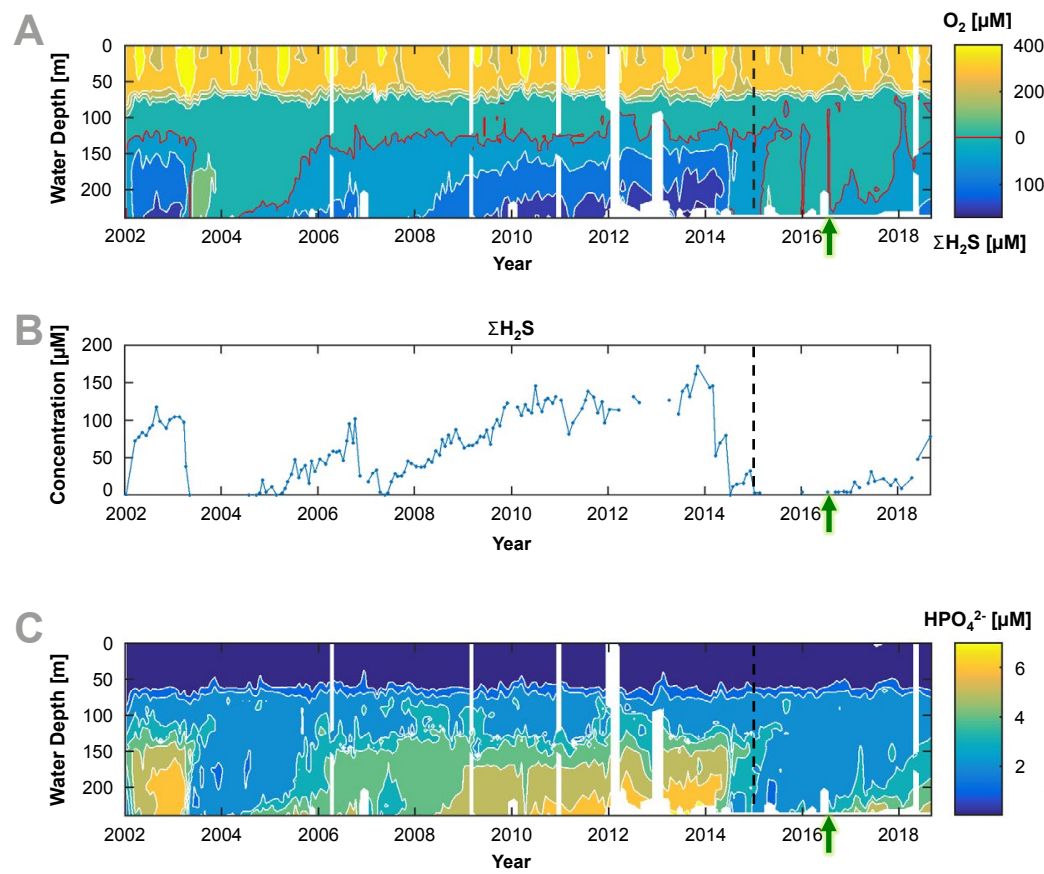

Figure 2.2 | (A) Time-series of monthly water column depth profiles of dissolved $\mathrm{O}_{2}$ and $\Sigma \mathrm{H}_{2} \mathrm{~S}$ at site BY15 for January 2002 - September 2018. The red line indicates the boundary between $\mathrm{O}_{2}$ and $\Sigma \mathrm{H}_{2} \mathrm{~S}$ (B) Time-series of monthly bottom water $\mathrm{SH}_{2} \mathrm{~S}$ concentrations at $225 \mathrm{~m}$ water depth for January 2002 - September 2018. (C) Monthly time-series (January 2002 - September 2018) of dissolved $\mathrm{HPO}_{4}{ }^{2-}$ in the water column at site BY15. The data presented in panel A, B and $\mathrm{C}$ were derived from the Swedish Ocean Archive (SHARK) database at the Swedish Meteorological and Hydrological Institute (SMHI; http://sharkweb.smhi.se). The dotted black line in panels A, B and C indicates the time point at which the recent MBIs occurred. The green arrow indicates the time of sampling. 
The impact of the MBIs on the water column chemistry is further illustrated by the contrasting depth profiles of $\mathrm{O}_{2}$ and $\Sigma \mathrm{H}_{2} \mathrm{~S}$ at BY15 in December 2014 and June 2016 (Figure 2.3). While in December 2014, $\mathrm{O}_{2}$ was only present in the upper part of the water column, in June 2016, $\mathrm{O}_{2}$ was found below $80 \mathrm{~m}$ water depth and reached levels up to $\sim 40 \mu \mathrm{M}$ (Figure 2.3A). At this time, free $\Sigma \mathrm{H}_{2} \mathrm{~S}$ was no longer present in the deeper part of the water column (Figure 2.3B). The deep water renewal led to a two-fold decrease in water column $\mathrm{HPO}_{4}{ }^{2-}$ (from $\sim 4.6 \mu \mathrm{M}$ to $\sim 2.5 \mu \mathrm{M}$ ) below 125 $\mathrm{m}$ water depth (Figure 2.3C).
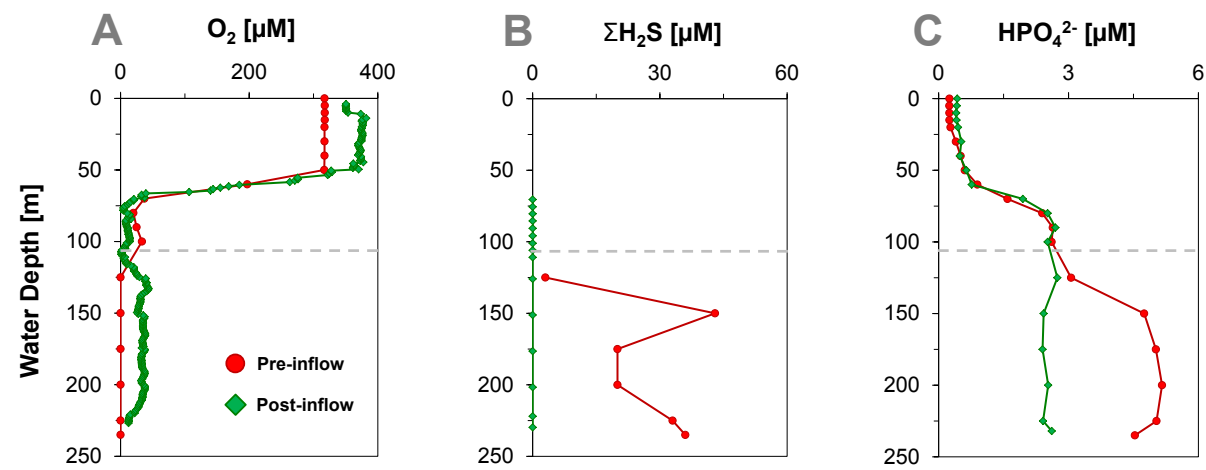

Figure 2.3 | (A) Comparison of water column $\mathrm{O}_{2}$ for December 2014 and June 2016. (B) Comparison of water column $\mathrm{\Sigma H}_{2} \mathrm{~S}$ for December 2014 (from SHARK database) and June 2016. (C) Comparison of water column $\mathrm{HPO}_{4}{ }^{2-}$ for preinflow conditions (averaged over a two year time period covering 2013-2014) and post-inflow (averaged over a 5 month time period covering February 2016 - June 2016). These depth profiles of $\mathrm{HPO}_{4}^{2-}$ were averaged to smooth the trend. The deeper water layer affected by the inflow is below the grey line.

Concentrations of total $\mathrm{Mn}$ in suspended matter in the water column at BY15 increased with water depth from $80 \mathrm{nM}$ ( $85 \mathrm{~m}$ below sea surface; mbss) to $650 \mathrm{nM}(220 \mathrm{mbss}$; Figure 2.4A). The concentration of total $\mathrm{Fe}$ in suspended matter in the water column showed the opposite pattern, with the highest Fe at $85 \mathrm{~m}$ water depth ( $25 \mathrm{nM}$; Figure 2.4B). Further down in the water column, at $175 \mathrm{~m}$ water depth, the concentration of Fe in suspended matter was only $1 \mathrm{nM}$ and below this depth $\mathrm{Fe}$ in suspended matter was below the detection limit. Concentrations of total and dissolved $\mathrm{Mn}$ were low in surface waters and increased with water depth up to $350 \mathrm{nM}$ and $1840 \mathrm{nM}$, respectively (Figure 2.4C). Total and dissolved Fe concentrations were low in surface waters, reached a maximum between 70 and $85 \mathrm{~m}$, and were low again below $85 \mathrm{~m}$ (Figure 2.4D). The normalized Mn-XANES and Mn-EXAFS spectra of the suspended matter from the water column collected at site BY15 (85, 175, 200 and $220 \mathrm{~m}$ water depth) are very similar with respect to the positioning of the peaks and post-edge oscillations (Figure 2.5). Both the Mn-XANES and Mn-EXAFS spectra of the suspended matter show great similarity with those of birnessite (Figure 2.5). The increase in quality of the spectra with water depth reflects the amount of $\mathrm{Mn}$ on the filters. In summary, the Mn-XANES and Mn-EXAFS spectra of the water column samples indicate that birnessite is the dominant $\mathrm{Mn}$ phase in suspended matter in the water column at site BY15. 


\section{Water column manganese and iron}
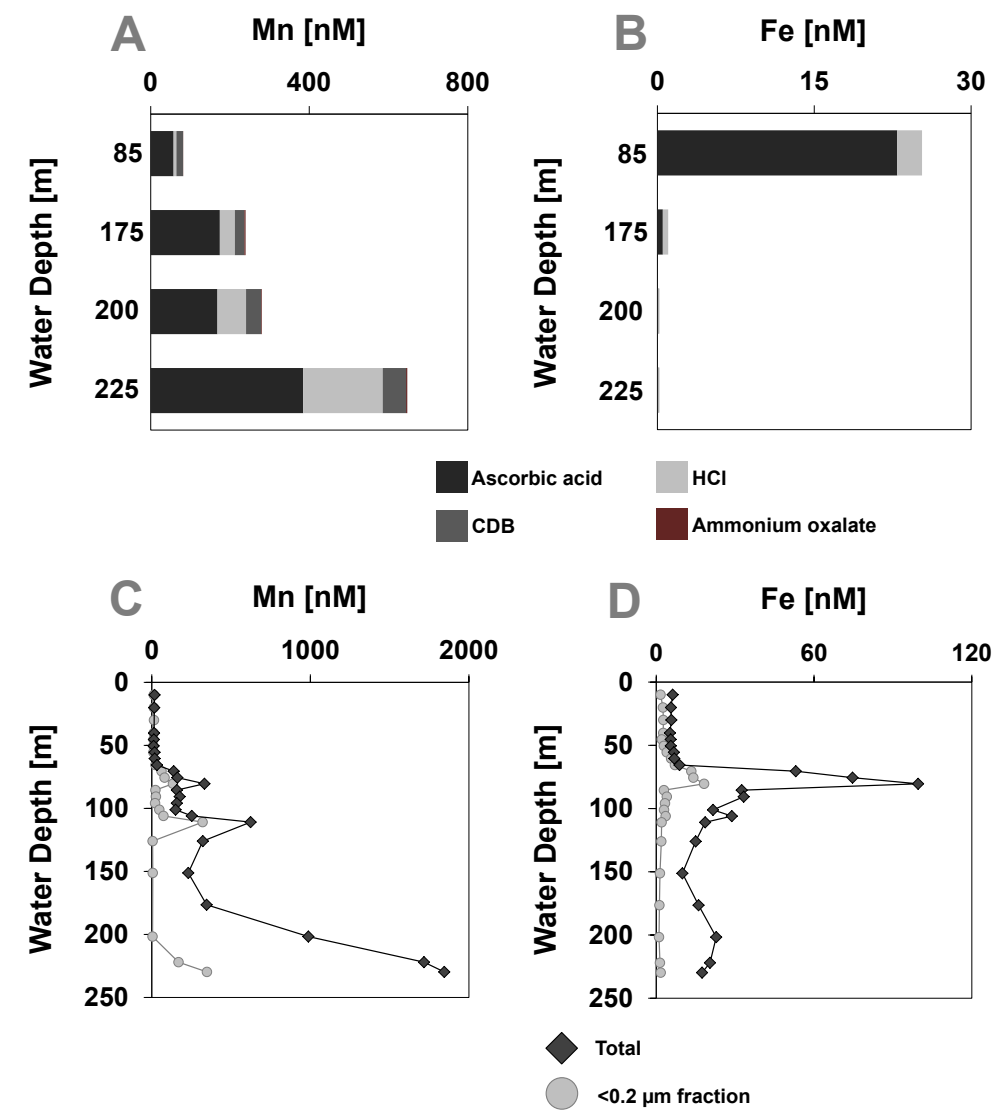

Figure 2.4 Water column depth profiles of total Mn (A) and Fe (B) in suspended matter at site BY15 from four water depths in June 2016. Levels of Fe in the CDB and ammonium oxalate step were below the detection limit. Water column depth profiles of total Mn, the $\mathrm{Mn}<0.2 \mu \mathrm{m}$ fraction (C), total Fe and the $\mathrm{Fe}<0.2 \mu \mathrm{m}$ fraction (D) at site BY15 in June 2016. The difference between the Mn and Fe contents in panels A and C, and B and D is likely related to the difference in detection limit of the methods used.

\subsubsection{Microscopy and High-resolution Depth Profiles of $\mathrm{pH}, \mathrm{O}_{2}$ and $\mathrm{H}_{2} \mathrm{~S}$}

Microscopic observations of the surface sediments revealed that Beggiatoaceae were present at all sites (Table 2.1; Figure S.2.1). Another type of S-oxidising bacteria, more commonly known as cable bacteria, belonging to the family Desulfobulbaceae, was visually observed at site 1 (Figure S.2.1). Oxygen was present in the bottom water at all sites with concentrations varying from 5 to $50 \mu \mathrm{M}$ (Figure 2.6; Table 2.1). Bottom water $\mathrm{O}_{2}$ concentrations were highest at site $2(30 \mu \mathrm{M})$ and $3(50 \mu \mathrm{M})$. The oxygen penetration depth at site 1, 2, 3 and 4 varied from 1 to $3 \mathrm{~mm}$ (Figure 2.6; Table 2.1). At BY15 and site 5, $\mathrm{O}_{2}$ did not penetrate into the sediment (Figure 2.6). High resolution depth profiles show an increase of $\Sigma \mathrm{H}_{2} \mathrm{~S}$ in the pore water with depth in the sediment at all sites 
(Figure 2.6). Sulphide was present near the sediment water interface at site BY15. Site 1 and 2 are characterised by a suboxic zone $(\sim 4 \mathrm{~mm})$ that lacks both dissolved $\mathrm{O}_{2}$ and $\Sigma \mathrm{H}_{2} \mathrm{~S}$. At sites $\mathrm{BY} 15,1$ and 2 , a $\mathrm{pH}$ maximum was observed in the surface sediment, followed by a $\mathrm{pH}$ decline with depth in the surface sediment. The strongest $\mathrm{pH}$ excursion was found at site 1 where the $\mathrm{pH}$ increased by 0.7 units (from $\mathrm{pH} 8$ to 8.7 ) near the sediment water interface and decreased by 1.2 units (from 8.7 to 7.5 ) in the upper $5 \mathrm{~cm}$ of the sediment. At sites 3,4 and 5 the $\mathrm{pH}$ remained rather constant with depth (Figure 2.6). The combination of the $\mathrm{pH}, \mathrm{O}_{2}$ and $\mathrm{H}_{2} \mathrm{~S}$ profiles at sites BY15, 1 and 2 is typical for an active Beggiatoaceae community in surface sediments (Figure S.2.2).

\subsubsection{Pore Water Profiles}
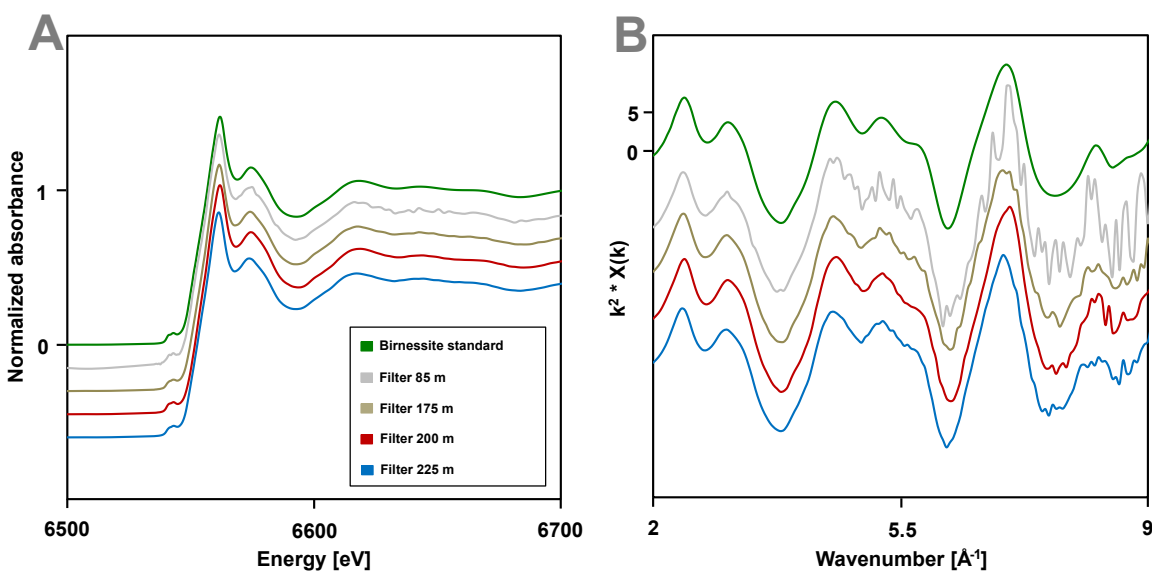

Figure 2.5 | (A) Normalized manganese XANES spectra of birnessite and suspended matter in the water column collected at 85, 175, 200 and $225 \mathrm{~m}$ water depth at site BY15. (B) Manganese $k^{2}$ weighed EXAFS spectra of birnessite and suspended matter in the water column at the same water depths.
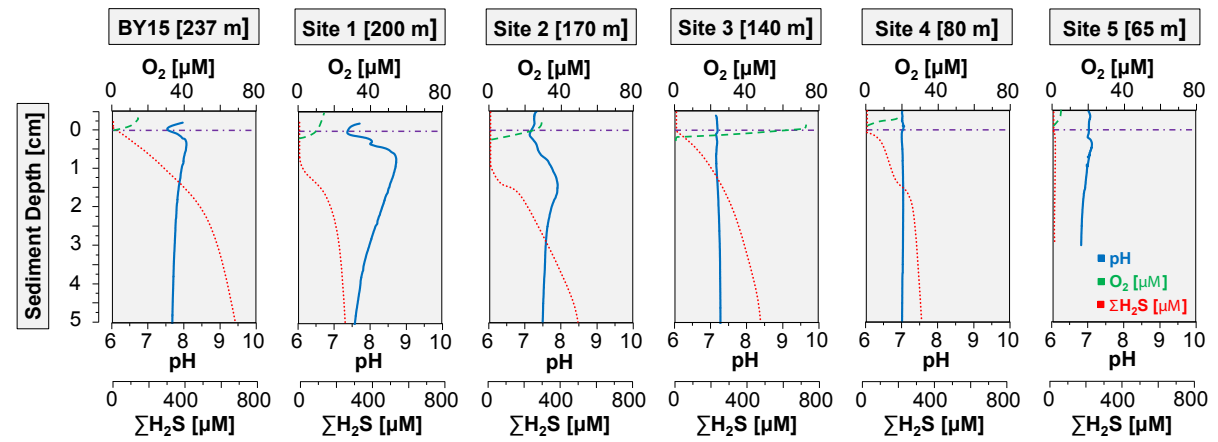

Figure 2.6 | High resolution pore water depth profiles of dissolved $\mathrm{O}_{2}$ (green-dashed line), $\Sigma \mathrm{H}_{2} \mathrm{~S}$ (red-dotted line) and $\mathrm{pH}$ (blue line) for six sites along the Eastern Gotland Basin depth transect (June 2016). The pH is reported on a total scale and corrected for salinity effects. The dashed dotted purple line represents the sediment water interface. The oxygen penetration depth and sulphide appearance depth are reported in Table 2.1. 
Dissolved $\mathrm{Mn}^{2+}$ in the pore water was highest at sites BY15 and 1, reaching values up to $450 \mu \mathrm{M}$, while much lower concentrations of $35-80 \mu \mathrm{M}$ were found at sites 2 and 3 respectively (Figure 2.7). At sites 4 and 5, dissolved $\mathrm{Mn}^{2+}$ in the pore water was below the detection limit. Dissolved $\mathrm{Fe}^{2+}$ was only present in the pore water at site 5 where it reached concentrations up to $\sim 150 \mu \mathrm{M}$. Dissolved $\mathrm{HPO}_{4}{ }^{2-}$ generally increased with depth in the sediment at all sites. Only at site BY15, very little $\mathrm{HPO}_{4}{ }^{2-}$ was present in the upper $1.5 \mathrm{~cm}$ of the sediment. Dissolved sulphide appeared at $\sim 2$ $\mathrm{cm}$ depth at sites BY15, 1 and 2 reaching concentrations up to $\sim 360 \mu \mathrm{M}$. These three sites are thus characterized by a sub-oxic zone. Sites 3 and 4 contained sulphide throughout the entire depth of the sediment. The shallowest site 5 had low background concentrations of $\Sigma \mathrm{H}_{2} \mathrm{~S}(<9 \mu \mathrm{M})$. Dissolved $\mathrm{NH}_{4}{ }^{+}$levels increased with depth in the sediment at all sites reaching concentrations up to $\sim 150 \mu \mathrm{M}$. Our results are indicative of the release of Mo into the pore water at BY15 and site 1.

A comparison of pore water profiles of $\mathrm{Mn}^{2+}$ and $\mathrm{HPO}_{4}{ }^{2-}$ for 2009 and 2016 (pre- and postinflow, respectively) at site BY15, suggests that the oxygenation of the bottom water led to an increase in dissolved $\mathrm{Mn}^{2+}$ and a decrease in $\mathrm{HPO}_{4}{ }^{2-}$ in the upper $5 \mathrm{~cm}$ of the sediment (Figure 2.8).

\subsubsection{Diffusive Fluxes}

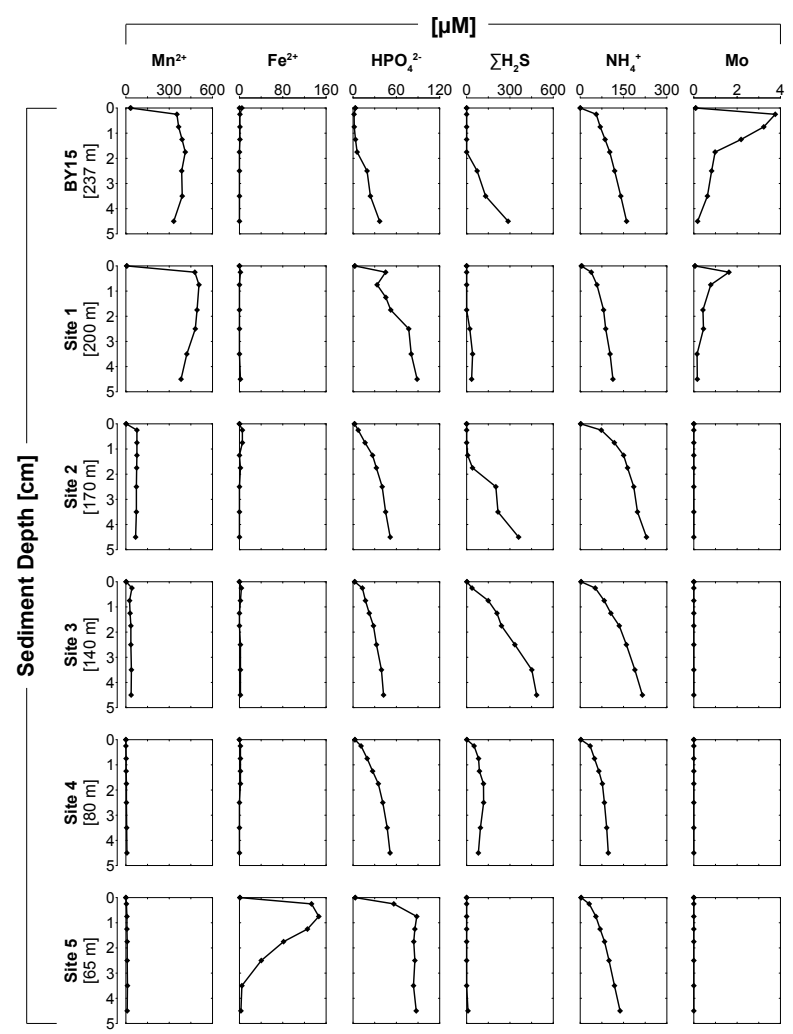

Figure 2.7 | Pore water depth profiles of dissolved $\mathrm{Mn}^{2+}, \mathrm{Fe}^{2+}, \mathrm{HPO}_{4}^{2-}, \mathrm{LH}_{2} \mathrm{~S}, \mathrm{NH}_{4}{ }^{+}$and Mo for the upper $5 \mathrm{~cm}$ of the sediment at sites BY15 and 1 to 5 (June 2016). 
The estimated uptake of $\mathrm{O}_{2}$ by the sediment ranged from 0.11 to $4.90 \mathrm{mmol} \mathrm{m}^{-2} \mathrm{~d}^{-1}$ (Table 2.3 ). The estimated benthic release of $\mathrm{H}_{2} \mathrm{~S}$ ranged from 1.13 to $4.17 \mathrm{mmol} \mathrm{m}^{-2} \mathrm{~d}^{-1}$. Upward diffusive fluxes of $\mathrm{H}_{2} \mathrm{~S}$ into the suboxic zone ranged from 0.12 to $2.02 \mathrm{mmol} \mathrm{m}^{-2} \mathrm{~d}^{-1}$. The higher $\mathrm{H}_{2} \mathrm{~S}$ fluxes derived from the micro electrodes in comparison to the $\mathrm{H}_{2} \mathrm{~S}$ fluxes calculated from pore water concentrations from core sectioning can be explained by sulphide loss during core slicing. Benthic release of $\mathrm{HPO}_{4}^{2-}$ ranged from 0.01 to $0.27 \mathrm{mmol} \mathrm{m}^{-2} \mathrm{~d}^{-1}$, whereas benthic $\mathrm{NH}_{4}^{+}$fluxes ranged from 0.89 to $2.76 \mathrm{mmol} \mathrm{m}^{-2} \mathrm{~d}^{-1}$. Benthic fluxes of $\mathrm{Mn}^{2+}$ were highest at site BY15, 1 and 2 and decreased with water depth, ranging from $6.5 \mathrm{mmol} \mathrm{m}^{-2} \mathrm{~d}^{-1}$ at site 1 down to $0 \mathrm{mmol} \mathrm{m}^{-2} \mathrm{~d}^{-1}$ at site 5 . A comparison of the sediment-water exchange rates of $\mathrm{HPO}_{4}{ }^{2-}, \mathrm{NH}_{4}{ }^{+}$and $\mathrm{Mn}^{2+}$ for 2009 and 2016 at site BY15 (pre- and post-inflow, respectively), suggest a decline in the benthic release of $\mathrm{HPO}_{4}{ }^{2-}$ (from 0.04 to $0.01 \mathrm{mmol} \mathrm{m}^{-2} \mathrm{~d}^{-1}$ ) but an increase in that of $\mathrm{NH}_{4}^{+}$(from 0.5 to $2.2 \mathrm{mmol} \mathrm{m}^{-2} \mathrm{~d}^{-1}$ ) and $\mathrm{Mn}^{2+}$ (from 0.1 to $4.4 \mathrm{mmol} \mathrm{m}^{-2} \mathrm{~d}^{-1}$ ) due to the re-oxygenation.

$\mathrm{Mn}^{2+}[\mu \mathrm{M}]$

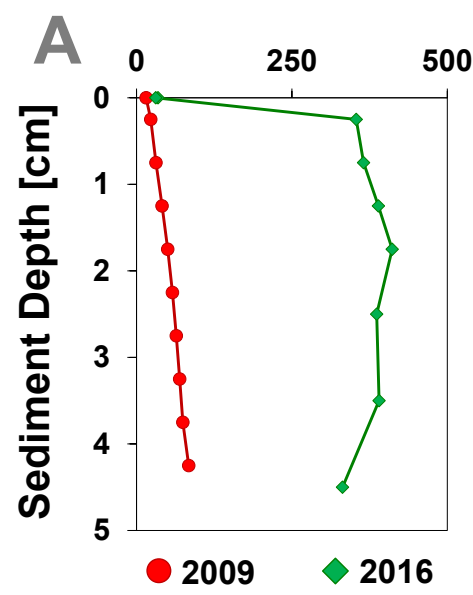

$\mathrm{HPO}_{4}^{2-}[\mu \mathrm{M}]$

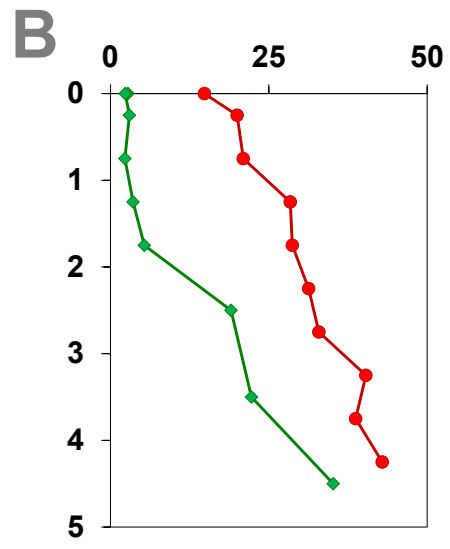

Figure 2.8 | Comparison of pore water $\mathrm{Mn}^{2+}(\mathrm{A})$ and $\mathrm{HPO}_{4}{ }^{2-}(\mathrm{B})$ at site BY15 for 2009 and 2016 (pre-inflow and postinflow, respectively). 
Table 2.3 | Calculated diffusive fluxes of $\mathrm{O}_{2}, \Sigma \mathrm{H}_{2} \mathrm{~S}, \mathrm{HPO}_{4}{ }^{2-}, \mathrm{NH}_{4}{ }^{+}$and $\mathrm{Mn}^{2+}$ at the sediment-water interface (unless indicated otherwise) for pre-inflow (2009; BY15 only) and post-inflow (2016) conditions. Note, that only the sites below $80 \mathrm{~m}$ water depth were subjected to bottom water re-oxygenation. The $\mathrm{O}_{2}$ fluxes and the $\mathrm{\Sigma H}_{2} \mathrm{~S}$ fluxes highlighted with a black rectangle were calculated based on high resolution depth profiles obtained with micro electrodes, whereas all the other fluxes were calculated based on pore water profiles from core sectioning. Upward diffusive fluxes of $\Sigma \mathrm{H}_{2} \mathrm{~S}$ into the suboxic zone are highlighted in bold and underlined. N/A: not available. Negative and positive values indicate a downward and upward flux, respectively. ${ }^{\star}$ Data from Jilbert et al. (2011).

\begin{tabular}{|c|c|c|c|c|c|c|c|}
\hline Site & Water depth [m] & $\begin{array}{l}\mathrm{O}_{2} \\
{\left[\mathrm{mmol} \mathrm{m}^{-2} \mathrm{~d}^{-1}\right]}\end{array}$ & $\begin{array}{l}\sum \mathrm{H}_{2} \mathrm{~S} \\
{\left[\mathrm{mmol} \mathrm{m}^{-2} \mathrm{~d}^{-1}\right]^{\mathrm{a}}}\end{array}$ & $\begin{array}{l}\Sigma \mathrm{H}_{2} \mathrm{~S} \\
{\left[\mathrm{mmol} \mathrm{m}^{-2} \mathrm{~d}^{-1}\right]^{\mathrm{b}}}\end{array}$ & $\begin{array}{l}\mathrm{HPO}_{4}{ }^{2-} \\
{\left[\mathrm{mmol} \mathrm{m}^{-2} \mathrm{~d}^{-1}\right]}\end{array}$ & $\begin{array}{l}\mathrm{NH}_{4}^{+} \\
{\left[\mathrm{mmol} \mathrm{m}^{-2} \mathrm{~d}^{-1}\right]}\end{array}$ & $\begin{array}{l}\mathrm{Mn}^{2+} \\
{\left[\mathrm{mmol} \mathrm{m}^{-2} \mathrm{~d}^{-1}\right]}\end{array}$ \\
\hline BY15 (pre-inflow) & 237 & - & $\mathrm{N} / \mathrm{A}$ & $\mathrm{N} / \mathrm{A}$ & 0.04 & 0.54 & 0.10 \\
\hline BY15 & 237 & -1.01 & 4.17 & 0.93 & 0.01 & 2.22 & 4.44 \\
\hline Site 1 & 200 & -0.54 & $\underline{1.38}$ & 0.21 & 0.5 & 1.35 & 6.52 \\
\hline Site 2 & 170 & -1.12 & $\underline{2.02}$ & 0.57 & 0.06 & 2.76 & 1.00 \\
\hline Site 3 & 140 & -4.90 & 2.00 & 1.13 & 0.11 & 1.79 & 0.50 \\
\hline Site 4 & 80 & -0.71 & 3.21 & 1.47 & 0.08 & 1.07 & 0.00 \\
\hline Site 5 & 65 & -0.11 & $\underline{0.12}$ & 0.07 & 0.27 & 0.89 & 0.02 \\
\hline
\end{tabular}

${ }^{\mathrm{a} M i c r o p r o f i l e s .}$

${ }^{\mathrm{b}}$ Core sectioning.

\subsubsection{Solid-phase Profiles}

Strong enrichments in total Mn were observed near the sediment-water interface at sites BY15 $\left(\sim 1000 \mu \mathrm{mol} \mathrm{g}^{-1}\right)$ and site $1\left(\sim 2500 \mu \mathrm{mol} \mathrm{g}^{-1}\right)$, but very little Mn was present in the sediment at depth at these sites and throughout the profiles at the other four sites (Figure 2.9). Sites BY15 and 1 are also characterized by enrichments in labile Fe(III) oxides near the sediment-water interface ( 45 and $\sim 115 \mu \mathrm{mol} \mathrm{g}{ }^{-1}$, respectively; Figure 2.9). In contrast, sites 2, 3, 4 and 5 do not show such an enrichment and are largely devoid of labile Fe(III) oxides. Concentrations of iron monosulphide were low at site BY15, 1 and 4, highest at site 2 and 3 and below the detection limit at site 5 (Figure 2.9). Pyrite concentrations mostly increased with depth in the sediment (Figure 2.9). Sediments at site 4 and 5 were relatively low in pyrite $\left(\sim 70 \mu \mathrm{mol} \mathrm{g}{ }^{-1}\right)$. Sediment molybdenum was highest $(\sim 3$ $\left.\mu \mathrm{mol} \mathrm{g} \mathrm{g}^{-1}\right)$ at the deepest site (BY15) and decreased with decreasing water depth along the transect (Figure 2.9).

We observed substantial enrichments in Ex-P and CDB-P at the deepest sites in the Eastern Gotland Basin (BY15; $\sim 50 \mu \mathrm{mol} \mathrm{g}^{-1}$, site $1 ; \sim 120 \mu \mathrm{mol} \mathrm{g}^{-1}$; Figure 2.10). Levels of authigenic and detrital $\mathrm{P}$ in the surface sediments remained relatively constant with depth at all sites. Organic-P decreased with decreasing water depth along the transect (Figure 2.10). Bottom water re-oxygenation led to an increase in total Mn, Ex-P+CDB-P and total $\mathrm{P}$ in the upper $2 \mathrm{~cm}$ of the sediment at site BY15 as revealed by the change in concentration between 2009 (pre-inflow) and 2016 (postinflow) (Figure 2.11; Table 2.4). The increase in total $\mathrm{P}$ following the inflow led to a decrease in the Corg/total P ratio in the surface sediment (Figure 2.11D). 


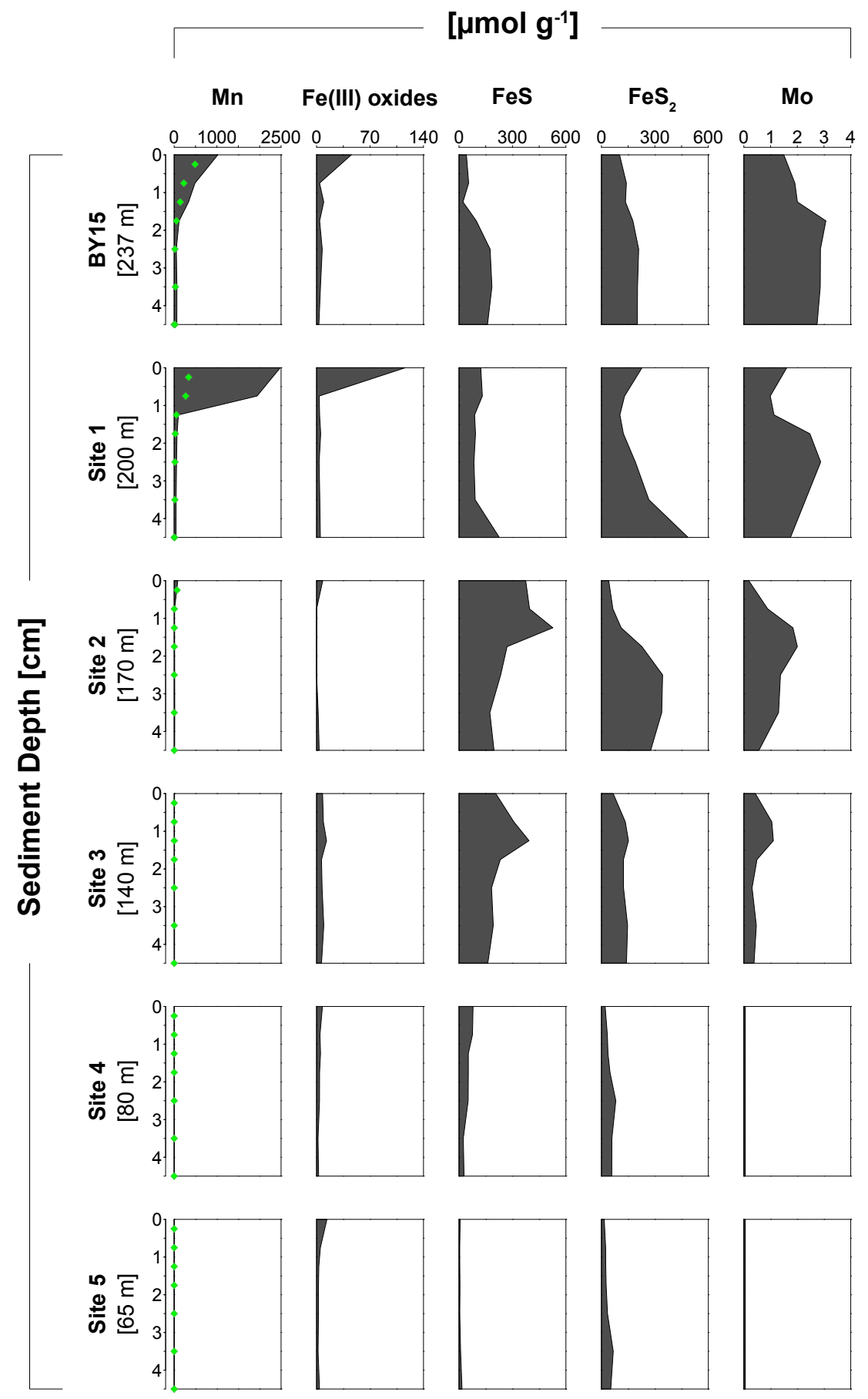

Figure 2.9 | Depth profiles of sediment $\mathrm{Mn}$, labile $\mathrm{Fe}(\mathrm{III})$ oxides, $\mathrm{Fe}$ monosulphide (FeS), pyrite $\left(\mathrm{FeS}_{2}\right)$ and molybdenum (Mo). The green diamonds represent the Mn extracted in the CDB step of the SEDEX procedure. 


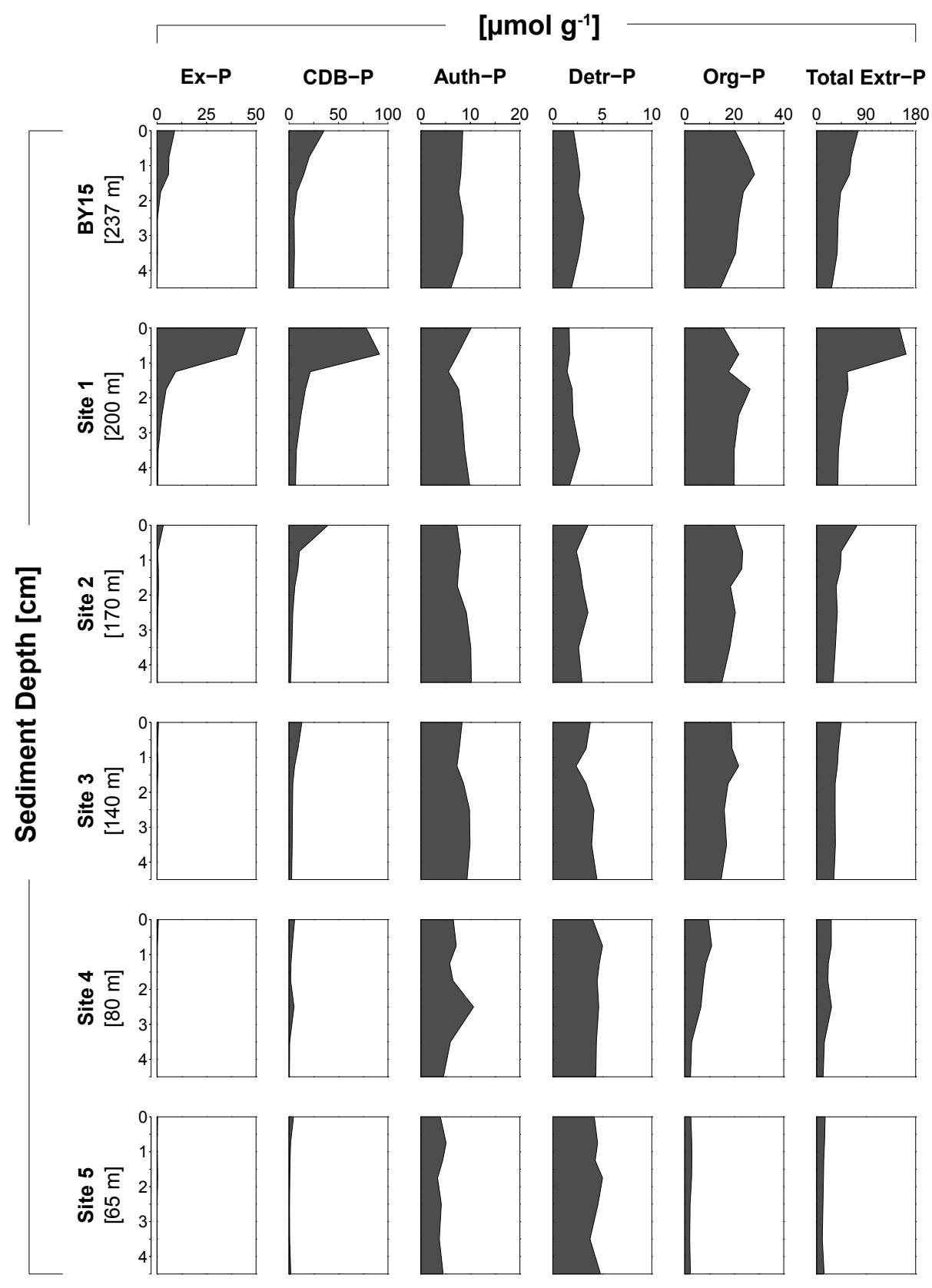

Figure 2.10 | Sedimentary phosphorus speciation (Ex-P, CDB-P, Auth-P, Detr-P, Org-P and Total Extr-P) for the upper $5 \mathrm{~cm}$ of the sediment at sites BY15 and 1 to 5 (June, 2016). 

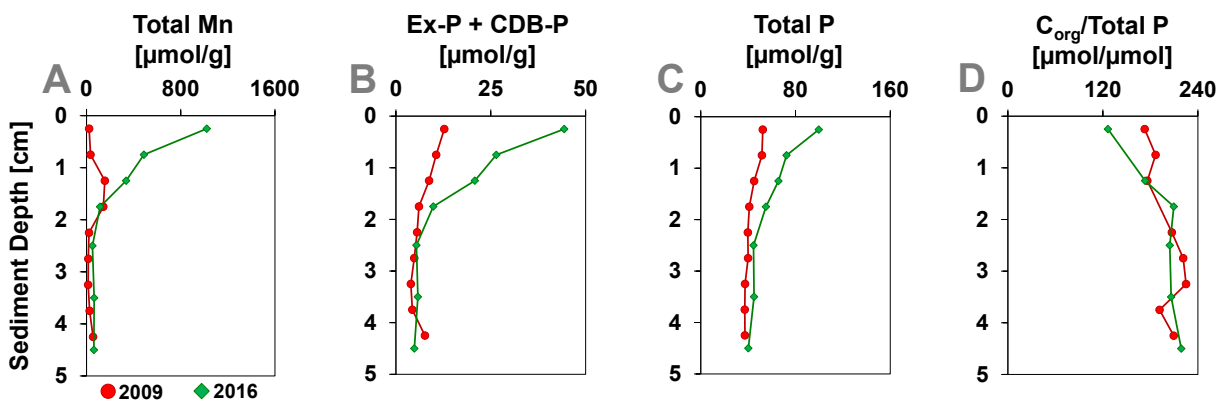

Figure 2.11 | Depth profiles of (A) total Mn, (B) Ex-P + CDB-P, (C) total P and (D) $\mathrm{C}_{\text {org }} /$ total $\mathrm{P}$ ratio at site BY15 in 2009 (red; pre-inflow) and 2016 (green; post-inflow).

Table 2.4 | Comparison of sediment P speciation at site BY15 for pre-inflow (2009) and post-inflow conditions (2016).

\begin{tabular}{|c|c|c|c|c|c|c|c|}
\hline & Sediment depth & $\begin{array}{l}\text { Ex-P } \\
{[\mu \mathrm{mol} / \mathrm{g}]}\end{array}$ & $\begin{array}{l}\text { CDB-P } \\
{[\mu \mathrm{mol} / \mathrm{g}]}\end{array}$ & $\begin{array}{l}\text { Ca-P } \\
{[\mu \mathrm{mol} / \mathrm{g}]}\end{array}$ & $\begin{array}{l}\text { Detr-P } \\
{[\mu \mathrm{mol} / \mathrm{g}]}\end{array}$ & $\begin{array}{l}\text { Org-P } \\
{[\mu \mathrm{mol} / \mathrm{g}]}\end{array}$ & $\begin{array}{l}\text { Total } \\
{[\mu \mathrm{mol} / \mathrm{g}]}\end{array}$ \\
\hline BY15 & (2016) & & & & & & \\
\hline $0-0.5$ & $\mathrm{~cm}$ & 8.89 & 35.46 & 8.46 & 2.10 & 20.40 & 99.66 \\
\hline $0.5-1$ & $\mathrm{~cm}$ & 6.02 & 20.44 & 8.25 & 2.51 & 25.66 & 72.42 \\
\hline $1-1.5$ & $\mathrm{~cm}$ & 5.80 & 15.00 & 8.06 & 2.74 & 28.18 & 65.51 \\
\hline $1.5-2$ & $\mathrm{~cm}$ & 1.83 & 8.02 & 7.64 & 2.56 & 23.68 & 55.04 \\
\hline $2-3$ & $\mathrm{~cm}$ & 0.22 & 5.18 & 8.56 & 3.15 & 21.89 & 44.55 \\
\hline $3-4$ & $\mathrm{~cm}$ & 0.26 & 5.53 & 8.37 & 2.69 & 20.56 & 44.99 \\
\hline $4-5$ & $\mathrm{~cm}$ & 0.06 & 4.79 & 6.07 & 1.88 & 14.43 & 40.19 \\
\hline BY15 & (2009) & & & & & & \\
\hline $0-0.5$ & $\mathrm{~cm}$ & 1.97 & 10.78 & 4.47 & 0.81 & 13.35 & 52.37 \\
\hline $0.5-1$ & $\mathrm{~cm}$ & 1.94 & 8.68 & 5.28 & 0.75 & 13.51 & 51.64 \\
\hline $1-1.5$ & $\mathrm{~cm}$ & 1.14 & 7.60 & 6.36 & 1.01 & 12.75 & 45.09 \\
\hline $1.5-2$ & $\mathrm{~cm}$ & 0.06 & 6.01 & 6.89 & 1.13 & 14.54 & 41.00 \\
\hline $2-2.5$ & $\mathrm{~cm}$ & 0.16 & 5.42 & 7.06 & 1.08 & 15.52 & 39.76 \\
\hline $2.5-3$ & $\mathrm{~cm}$ & 0.41 & 4.42 & 6.30 & 0.84 & 12.92 & 39.98 \\
\hline $3-3.5$ & $\mathrm{~cm}$ & 0.42 & 3.52 & 7.31 & 1.14 & 15.27 & 37.40 \\
\hline $3.5-4$ & $\mathrm{~cm}$ & 0.12 & 4.20 & 6.48 & 1.15 & $\mathrm{~N} / \mathrm{A}$ & 37.17 \\
\hline $4-4.5$ & $\mathrm{~cm}$ & 0.19 & 7.46 & 5.64 & 1.08 & 13.06 & 37.30 \\
\hline
\end{tabular}

\subsubsection{XANES, EXAFS and High-resolution Elemental Mapping of Surface Sediment}

Desktop $\mu$ XRF mapping of Mn, P, Ca and Fe using epoxy embedded surface sediment (upper 10 $\mathrm{mm}$ ), revealed that the spatial distribution of Mn at BY15 closely resembled that of $\mathrm{P}$ and $\mathrm{Ca}$ (Figure 2.12). A well-defined layer strongly enriched in $\mathrm{Mn}, \mathrm{P}$ and $\mathrm{Ca}$ was observed in the upper $1.5 \mathrm{~mm}$ of the surface sediment of BY15, whereas a background in sedimentary Fe was found below $1.5 \mathrm{~mm}$. A secondary layer concentrated in $\mathrm{Mn}, \mathrm{P}$ and $\mathrm{Ca}$ was observed at $3 \mathrm{~mm}$ depth. 
The normalized Mn XANES spectra collected at Mn-rich spots 1 to 5, in the upper $0.6 \mathrm{~mm}$ of the surface sediment, were very similar to the spectrum of rhodochrosite (Figures $2.13 \mathrm{~A}$ and 2.14A). The Mn-XANES spectra in the interval between 4.6 and $4.8 \mathrm{~mm}$ were distinctly different from those collected in the upper $0.6 \mathrm{~mm}$ of the sediment. Spectra collected in Mn-rich spots 7-11 resemble those of hureaulite, a $\mathrm{Mn}$ (II) phosphate (Figures 2.13B and 2.14A). The spectrum collected at spot 6 (Figure 2.13B) is a hybrid signal that can be reproduced by linear combination fitting of the XANES spectra of rhodochrosite and hureaulite (Figures 2.14A and S.2.4). In this part of the sediment $\mathrm{Mn}, \mathrm{P}$ and Ca are strongly correlated (Figure S.3A and B).

Deeper in the sediment in the interval from 7.5 to $7.9 \mathrm{~mm}$, the enrichment of $\mathrm{Mn}$ was less pronounced (Figure 2.13C). Relative enrichments in $\mathrm{Mn}$ in this depth interval coincided with high $\mathrm{Fe}$ and $\mathrm{S}$ contents. The Fe and $\mathrm{S}$ in these enrichments showed a strong correlation with $\mathrm{Mn}$ (Figure S.2.3C). The shape of the Mn XANES spectra resembled that of Fe in pyrite, which has been collected at the Fe $\mathrm{K}$ edge, suggesting that in this part of the sediment $\mathrm{Mn}$ is associated with pyrite (Figure 2.14B). A comparison of the available part of the Mn EXAFS spectrum to that of Fe in pyrite supports this interpretation (Figure S.2.5). Other Mn XANES spectra collected at spots which did not show significant enrichments in $\mathrm{Mn}, \mathrm{Fe}, \mathrm{P}$ or S represented a fourth type of Mn in the surface sediment (Figure 2.14B). The position of the edge and the shape of the XANES spectrum was similar to the spectrum interpreted as background Si-bound Mn in Lenz et al. (2014).
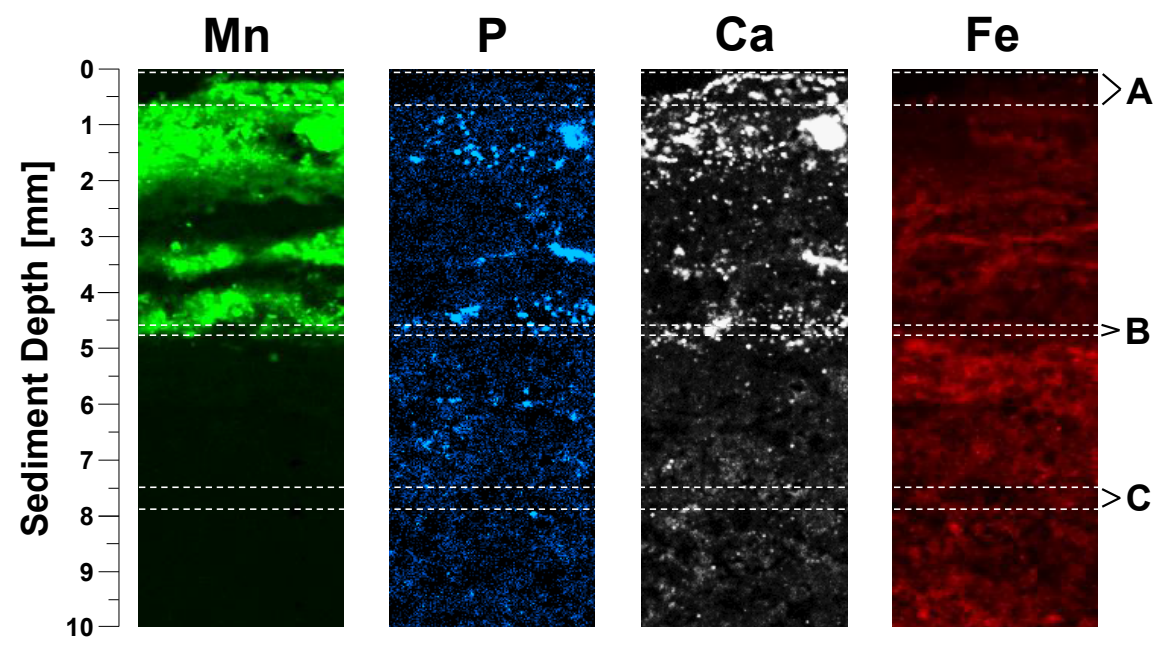

Figure 2.12 | Desktop $\mu$ XRF maps of Mn (green), P (blue), Ca (grey) and Fe (red) in the top $10 \mathrm{~mm}$ of epoxyembedded sediment at BY15. These maps are shown in true vertical orientation and the brightness was adjusted to emphasize the features in the sediment. Zone A $(0-0.6 \mathrm{~mm}), \mathrm{B}(4.6-4.8 \mathrm{~mm})$ and $\mathrm{C}(7.5-7.9 \mathrm{~mm})$ represent the sediment depth intervals that were mapped at ID21 at the ESRF in Grenoble (Figure 2.13). 


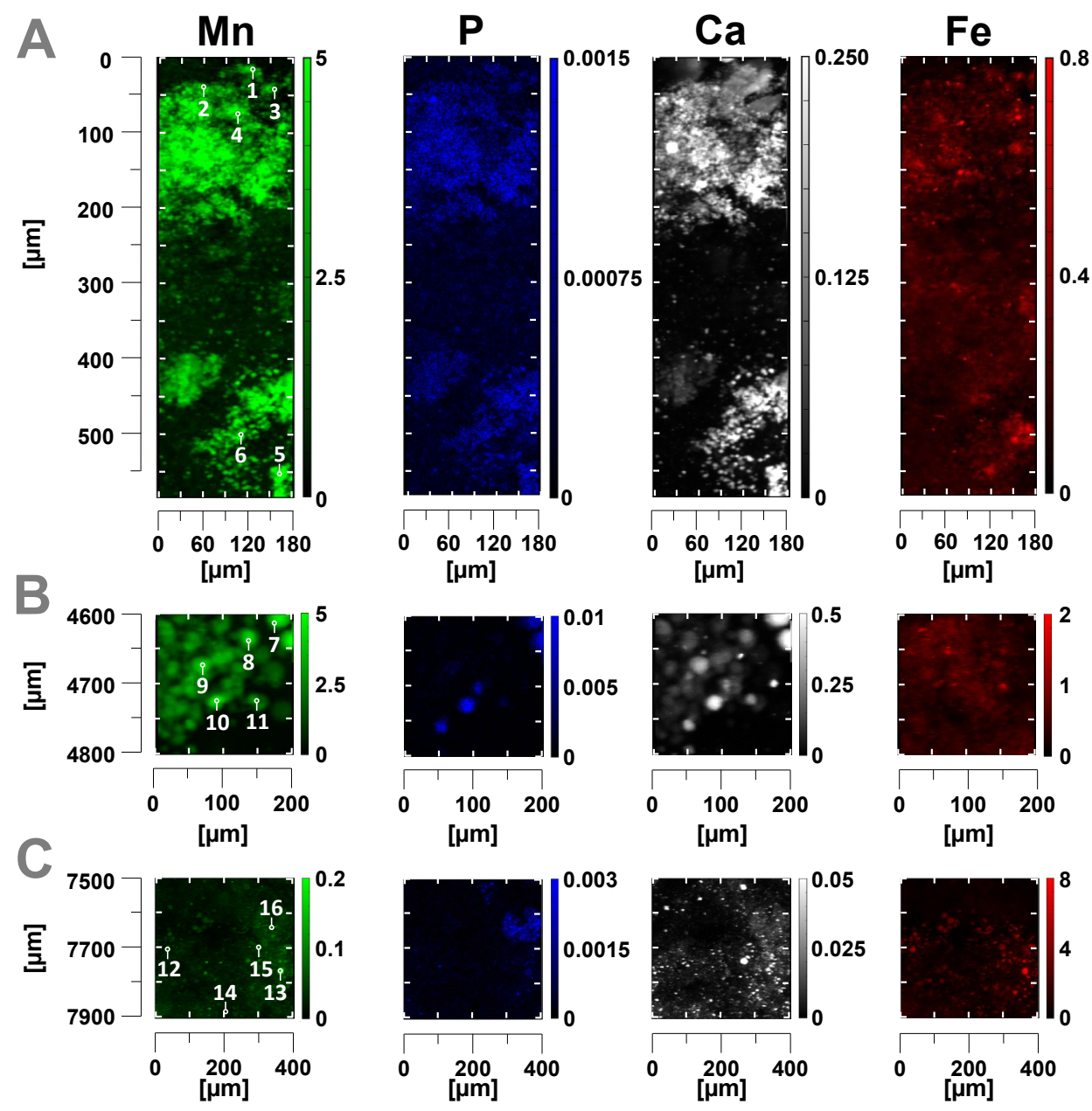

Figure 2.13 | Synchrotron-based high-resolution $(1 \mu \mathrm{m}) \mu$ XRF maps of Mn (green), P (blue), Ca (white) and Fe (red) for the top $8 \mathrm{~mm}$ of epoxyembedded sediment at BY15. These maps are shown in true vertical orientation The colours accentuate relative count intensities that are adjusted for brightness and contrast to emphasise the features in the sediment. These maps were created using the PyMca X-ray Fluorescence Toolkit (Solé et al., 2007). The white labels with corresponding numbers indicate the spots for which Mn XANES spectra were collected (Fig. 14). (A) Elemental $\mu$ XRF maps of the 0-0.6 mm sediment depth interval. (B) Elemental $\mu$ XRF maps of the 4.6-4.8 mm sediment depth interval. (C) Elemental $\mu \mathrm{XRF}$ maps of the 7.5-7.9 mm sediment depth interval. 

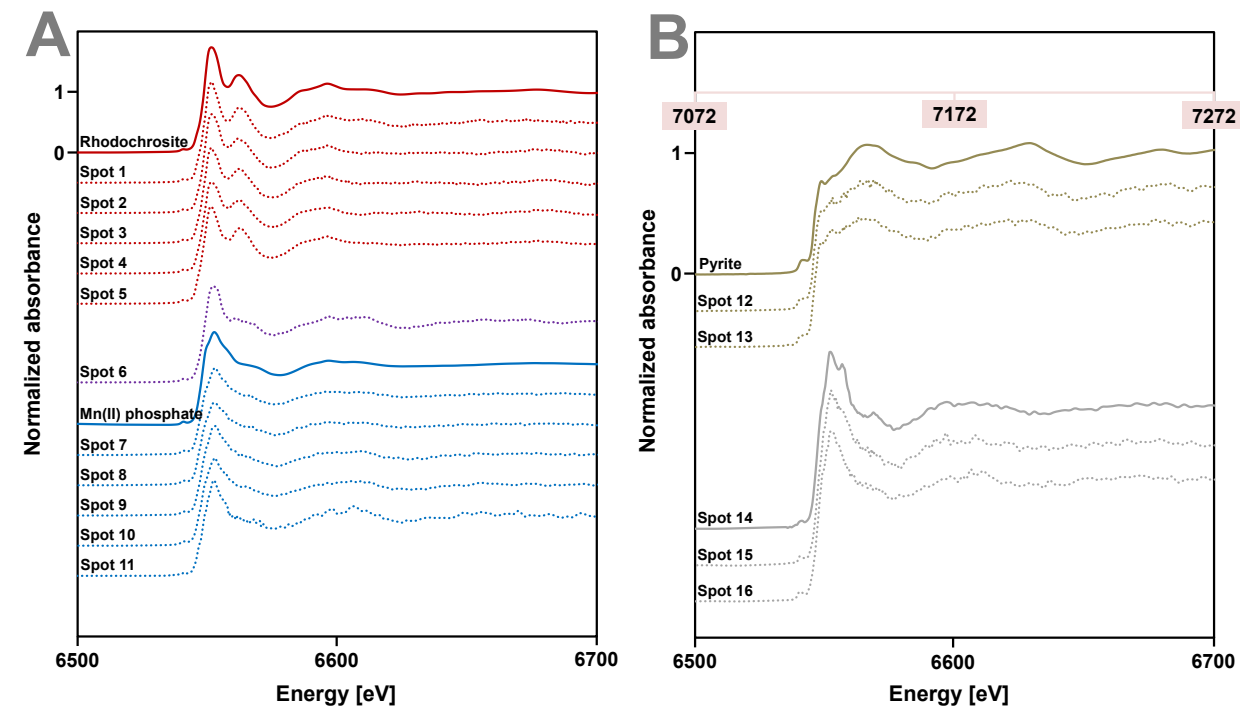

Figure 2.14 (A) Normalised Mn XANES spectra of the surface sediment at site BY15. XANES spectra from spots 1 to 5 (red) resemble the spectrum of rhodochrosite. XANES spectra from spot 7 to 11 (blue) are similar to the spectrum of Mn(II) phosphate. The spectrum from spot 6 contains features of the XANES spectra of both, rhodochrosite and Mn(II) phosphate. (B) Normalised Mn XANES spectra of the subsurface sediment at site BY15. The Mn spectra from spots 12 and 13 (gold) have a similar shape as the XANES spectrum of Fe in pyrite. XANES spectra from spots 14 to 16 (grey) show features that are similar to the XANES spectrum that was interpreted as background Si-bound Mn in Lenz et al. (2014).

\subsection{Discussion}

\subsubsection{Impact of Re-oxygenation on Water Column Chemistry}

During MBIs, saline and oxygenated North Sea water mixes with and partly replaces the euxinic deep waters in the Eastern Gotland Basin (Schneider, 2011). As a consequence, nutrient and $\mathrm{H}_{2} \mathrm{~S}$ rich waters from the deep basin are pushed upward in the water column and transferred laterally to the north and east while becoming distributed over a larger surface area (Reissmann et al., 2009; Eilola et al., 2014). Changes in water column chemistry are thus the compound result of re-oxygenation and replacement of the deep water.

Our results highlight that the deep water renewal in 2014 and 2015 indeed led to an increase in $\mathrm{O}_{2}$ and complete removal of $\mathrm{\Sigma H}_{2} \mathrm{~S}$ below $125 \mathrm{~m}$ water depth (Figure 2.2). Research on previous MBIs has shown that increased $\mathrm{O}_{2}$ concentrations in the water column always led to major changes in its $\mathrm{Mn}, \mathrm{Fe}$ and $\mathrm{P}$ chemistry (Turnewitsch and Pohl, 2010). Prior to these MBIs, concentrations of dissolved $\mathrm{Mn}^{2+}$ and $\mathrm{Fe}^{2+}$ typically ranged from 5 to $15 \mu \mathrm{M}$ and 1 to $1.5 \mu \mathrm{M}$ (Dellwig et al., 2010; Turnewitsch and Pohl, 2010; Dellwig et al., 2018), while particulate Mn and Fe concentrations generally were at least an order of magnitude lower (Turnewitsch and Pohl, 2010). Previous MBIs led to the removal of most of the dissolved $\mathrm{Mn}^{2+}$ and $\mathrm{Fe}^{2+}$ and formation of $\mathrm{Mn}$ oxides and $\mathrm{Fe}$ oxides in the water column (Huckriede and Meischner, 1996; Turnewitsch and Pohl, 2010; Yakushev et al., 2011; Pohl and Fernández-Otero, 2012). 
In June 2016, approximately 7 months after the 2015 inflow, particulate Mn, which we show was in the form of the Mn oxide birnessite (Figure 2.5), was still present in the lower part of the water column at concentrations ranging up to $\sim 1800 \mathrm{nM}$ (Figure 2.4). Almost no $\mathrm{Fe}^{2+}$ was present in the water column. The concentrations of Fe oxides and total Fe in the suspended matter in the water column $(<70 \mathrm{nM})$ (Figures $2.4 \mathrm{~B}$ and $\mathrm{D})$ were much lower than those for $\mathrm{Mn}$. The contrasting behaviour of $\mathrm{Mn}$ and $\mathrm{Fe}$ in the water column is the direct result of the less efficient sequestration of $\mathrm{Mn}$ in mineral form in the sediment under permanently anoxic conditions and the slower oxidation kinetics of $\mathrm{Mn}^{2+}$ with $\mathrm{O}_{2}$ when compared to $\mathrm{Fe}^{2+}$ (Burdige, 1993). Furthermore, FeS formation upon contact of $\mathrm{Fe}^{2+}$ with sulphide prevents escape of $\mathrm{Fe}^{2+}$ from the sediment into the water column. As a consequence, an order of magnitude higher $\mathrm{Mn}^{2+}$ concentrations than those of $\mathrm{Fe}^{2+}$ build-up in the anoxic water column between MBIs, allowing more Mn oxides to be formed following an inflow. The relatively high abundance of Mn oxide in the lower water column at site BY15 (Figure 2.4A and C) is likely due to 'Mn-refluxing', i.e. remobilization of $\mathrm{Mn}^{2+}$ from sediment pore water (Figure 2.7), formation of Mn oxides in the water column and redeposition of the Mn oxides (Adelson et al., 2001; Sulu-Gambari et al., 2017). To our knowledge, this is the first time that pore water and sediment depth profiles are combined with water column records for the Baltic Sea to show evidence for such Mn-refluxing after an inflow.

We observed a strong decrease in water column $\mathrm{HPO}_{4}^{2-}$ following the most recent MBIs (Figures $2.2 \mathrm{C}$ and 2.3C). Based on analysis of water column profiles, various authors have concluded that most of the decrease in water column $\mathrm{HPO}_{4}{ }^{2-}$ below $125 \mathrm{~m}$ water depth following MBIs is due to replacement of the $\mathrm{HPO}_{4}^{2-}$ rich, anoxic water by $\mathrm{HPO}_{4}^{2-}$ poor, oxic water originating from the North Sea (Schneider, 2011; Eilola et al., 2014; Almroth-Rosell et al., 2015). Both Mn oxides and Fe oxides are known to act as a carrier of $P$ to the sediment (Dellwig et al., 2010). This implies that re-oxygenation could lead to an enhanced depositional flux of Mn oxides and Fe oxide associated $\mathrm{P}$ to the sediment, thus potentially contributing to part of the observed removal of water column $\mathrm{HPO}_{4}{ }^{2-}$. The role of the depositional flux of metal oxides in removing $\mathrm{P}$ from the water column is best assessed by analyzing the oxygenation state (Section 2.4.2) and chemical composition (Section 2.4.3) of the sediments.

\subsubsection{Impact of Re-oxygenation on $\mathrm{O}_{2}$ Penetration in the Sediment and the Role of S-oxidising Bacteria}

The exposure of surface sediments to $\mathrm{O}_{2}$ rich water, as a result of bottom water ventilation, led to an $\mathrm{O}_{2}$ penetration into the sediment of up to $3 \mathrm{~mm}$ (Figure 2.6; Table 2.1). The presence of $\mathrm{O}_{2}$ also induced the activity of S-oxidising bacteria belonging to the family Beggiatoaceae (Table 2.1). The activity of Beggiatoaceae is characterized by a distinct biogeochemical signature (Figure S.2.2) with a low $\mathrm{pH}$ near the sediment surface due to proton formation and a high $\mathrm{pH}$ in the deeper sediment due to proton consumption by sulphide oxidation (Seitaj et al., 2015). The $\mathrm{pH}$ gradients in the pore waters of sites BY15, 1 and 2, are indicative of a highly active Beggiatoaceae community. Prior to the 2014/2015 MBIs, these Beggiatoaceae were only observed in the hypoxic transition zone at 80-120 m water depth (Noffke et al., 2016). In our study, we found active Beggiatoaceae mats down to a water depth of $237 \mathrm{~m}$, which is the result of the availability of $\mathrm{O}_{2}$ in the bottom waters (Table 2.1; Figure S.2.1A). Another recent study also observed that the activity of Beggiatoaceae extended to the deepest part of the Eastern Gotland Basin, as a consequence of bottom water renewal (Sommer et al., 2017). 
Microbial mats of Beggiatoaceae contribute to the benthic filter for sulphide in the Baltic Sea by linking the oxidation of dissolved $\mathrm{H}_{2} \mathrm{~S}$ to the reduction of $\mathrm{O}_{2}$. This is complemented by chemical oxidation of $\mathrm{H}_{2} \mathrm{~S}$ by $\mathrm{Fe}$ oxides and $\mathrm{Mn}$ oxides, where they are present in the surface sediment. The resulting suboxic zone (Figure S.2.2) prevents the direct release of sulphide from sediments to the water column (Seitaj et al., 2015; Yücel et al., 2017). We found that the suboxic zone only developed in the surface sediments at site BY15, 1 and 2 (Figures 2.6 and 2.7). The observed differences between the depth profiles of $\Sigma \mathrm{H}_{2} \mathrm{~S}$ obtained with micro-electrodes and after pore water sectioning at BY15 are attributed to spatial variability and could be due to spatial differences in the abundance and activity of Beggiatoaceae.

Besides their role in oxidation of dissolved $\mathrm{H}_{2} \mathrm{~S}$, Beggiatoaceae are also capable of taking up pore water $\mathrm{HPO}_{4}{ }^{2-}$ and subsequently storing it as polyphosphate in their vacuoles (Goldhammer et al., 2010; Brock and Schulz-Vogt, 2011; Dale et al., 2013). This mechanism might explain part of the removal of pore water $\mathrm{HPO}_{4}{ }^{2-}$ in the surface sediment at the deepest sites (Figures 2.7 and 2.8B).

\subsubsection{Impact of Re-oxygenation on the Sediment Geochemistry}

Sediment records for the Gotland Deep show that deep water re-oxygenation events can lead to the formation of layers of Ca-rhodochrosite from Mn oxides (Heiser et al., 2001; Lenz et al., 2015). We show that the deposition of Mn oxides related to the MBIs indeed resulted in enrichments in $\mathrm{Mn}$ in the surface sediment at site BY15 $\left(\sim 1000 \mu \mathrm{mol} \mathrm{g}{ }^{-1}\right)$ and site $1\left(\sim 2500 \mu \mathrm{mol} \mathrm{g}^{-1}\right)$, as revealed by the change in Mn concentration between 2009 (pre-inflow) and 2016 (post-inflow; Figure 2.11A). The water depth dependence of the Mn enrichment is likely the combined effect of a greater overlying Mn-bearing water mass at deeper sites and a larger role for gravitational focussing of suspended material (Sulu-Gambari et al., 2017).

We found no evidence for the presence of birnessite in the surface sediment in the resinembedded core at site BY15, despite the fact that birnessite is the dominant Mn phase in suspended matter in the water column. The absence of birnessite is likely due to its rapid dissolution upon contact with $\mathrm{H}_{2} \mathrm{~S}$ in the pore water (Burdige and Nealson, 1986; Lenz et al., 2015). Given the strong spatial variability in $\mathrm{H}_{2} \mathrm{~S}$ concentrations near the sediment surface at site BY15 (Figures 2.6 and 2.7), which is likely linked to the patchy occurrence of Beggiatoaceae, we expect that the distribution of birnessite was equally patchy. Thus, birnessite may have been present in the core used to determine the bulk geochemistry and likely was present in the surface sediments of the Eastern Gotland Basin.

The penetration of $\mathrm{O}_{2}$ into the sediment led to major changes in its $\mathrm{Mo}, \mathrm{Fe}$ and $\mathrm{P}$ geochemistry. Sediment Mo provides an excellent indicator for the oxidation state of the sediment (Scott and Lyons, 2012). Molybdenum occurs as molybdate $\left(\mathrm{MoO}_{4}^{2-}\right)$ in the water column, but when $\mathrm{H}_{2} \mathrm{~S}$ concentrations exceed $\sim 11 \mu \mathrm{M}$, complete conversion to tetrathiomolybdate $\left(\mathrm{MoS}_{4}^{2-}\right)$ and subsequent sequestration in the sediment is thought to occur (Helz et al., 1996; Erickson and Helz, 2000). Exposure of Mo-bearing sediments to $\mathrm{O}_{2}$ rich bottom water results in the release of Mo to the pore water (Crusius et al., 1996). Our results indeed show such a release of Mo from the sediment into the pore water at site BY15 and site 1 as a consequence of bottom water re-oxygenation (Figure 2.7). Our results further show that sedimentary Mo is highest at site BY15 and decreases along the transect with a decrease in water depth, becoming undetectable at the two shallowest sites 4 and 5 (Figure 2.9). The comparatively high solid-phase Mo observed at the four deepest sites can be attributed to the euxinic conditions that prevailed in the deep bottom waters of the Eastern Gotland Basin prior to the recent MBIs (Figure 2.2A). 
The re-oxygenation led to distinct surface enrichments in labile Fe(III) oxides in the sediment at site BY15 and 1 (Figure 2.9). These Fe oxide enrichments were $\sim 20$-fold smaller than those in total Mn (Figure 2.9). This difference can be partly explained by the 10- to 15-fold lower concentrations of $\mathrm{Fe}^{2+}$ in the water column prior to the re-oxygenation, when compared to $\mathrm{Mn}^{2+}$ (Section 2.4.1). As a consequence less Fe oxides than Mn oxides were formed upon re-oxygenation, leading to a smaller Fe oxide flux from the water column to the sediment. In addition, formation of Fe oxides from dissolved $\mathrm{Fe}^{2+}$ in the pore water was restricted by the high sulphide flux from the deeper sediment. We note that some Fe sulphides in the upper centimetre of the sediment may have been converted to Fe oxides. Importantly, we find little evidence for major downward oxidation of the sediment, as observed in other marine systems upon a bottom water redox change (Van Santvoort et al., 1996). We attribute this difference to the high upward fluxes of $\mathrm{H}_{2} \mathrm{~S}$ and $\mathrm{NH}_{4}^{+}$to the surface sediment and the corresponding high $\mathrm{O}_{2}$ demand of the sediment (Table 2.3). When taking into account that two moles of $\mathrm{O}_{2}$ are required to oxidize one mole of $\mathrm{NH}_{4}{ }^{+}$or $\mathrm{H}_{2} \mathrm{~S}$ (Reed et al., 2011), it is evident that the $\mathrm{O}_{2}$ flux into the sediment $\left(0.5-4.9 \mathrm{mmol} \mathrm{m}^{-2} \mathrm{~d}^{-1}\right.$; Table 2.3$)$ is currently insufficient to oxidize the upward flux of reductants at all sites (1.4-4.2 and 1.4-2.8 $\mathrm{mmol} \mathrm{m}^{-2} \mathrm{~d}^{-1}$ for $\mathrm{H}_{2} \mathrm{~S}$ and $\mathrm{NH}_{4}^{+}$, respectively; Table 2.3). This implies that $\mathrm{H}_{2} \mathrm{~S}$ and $\mathrm{NH}_{4}^{+}$will escape to the overlying water.

The oxidation of the surface sediments at site BY15, 1 and 2 led to enhanced P sequestration, as inferred from the surface enrichments in Ex-P + CDB-P (Figures 2.10 and 2.11B). The sequential Ex-P step targets loosely sorbed $\mathrm{P}$ while the CDB-P targets Fe-oxide bound P. However, the observed P levels in the Ex-P + CDB-P extraction phases cannot solely be linked to Fe oxides. This is because the ratio of Fe oxides to Ex-P + CDB-P is $\sim 1$ (Figures 2.9 and 2.10) whereas the lowest stoichiometric ratio that has been observed in marine environments for Fe oxides: $\mathrm{P}$ is $\sim 2$ (Gunnars et al., 2002). This implies that other minerals were co-extracted during the Ex-P + CDB-P steps in the SEDEX procedure. Phosphorus associated with $\mathrm{CaCO}_{3}$ may be co-extracted during the SEDEX CDB-step (Kraal et al., 2017). However, $\mathrm{CaCO}_{3}$ represents a minor pool ( 2.5 wt\%) in the sediments of the Eastern Gotland Basin, implying that $\mathrm{P}$ sequestration by $\mathrm{CaCO}_{3}$ at our study sites is unlikely to be important. Previous studies of Baltic Sea sediments suggested that $\mathrm{P}$ associated with $\mathrm{MnCO}_{3}$ minerals are also extracted in the SEDEX CDB step (Suess, 1979; Manheim, 1982; Jilbert and Slomp, 2013).

We indeed find that $\mathrm{Mn}$ enrichments in our sediments are strongly associated with $\mathrm{P}$ and $\mathrm{Ca}$ and not with Fe (Figures 2.12, 2.13 and S.2.3). This coupling between $\mathrm{Mn}, \mathrm{P}$ and $\mathrm{Ca}$ is further supported by the XANES spectra, which reveal the presence of $\mathrm{MnCO}_{3}$ and $\mathrm{Mn}$ (II) phosphate minerals in these $\mathrm{Mn}-$, $\mathrm{Ca}$ - and P-rich areas (Figure 2.14). The Mn enrichments in the upper $0-0.6 \mathrm{~mm}$ of the surface sediment mainly consist of $\mathrm{MnCO}_{3}$ minerals associated with $\mathrm{P}$ (Figures 2.14A and S.2.3A). Based on the Mn spectra (Figure 2.14), we observed a gradual transition from $\mathrm{MnCO}_{3}-\mathrm{P}$ into $\mathrm{Mn}(\mathrm{II})$ phosphates $\left(\mathrm{Mn}_{3}\left[\mathrm{PO}_{4}\right]_{2}\right)$ within the upper $(0.5-4.8 \mathrm{~mm})$ of the surface sediment (Figures 2.13 and S.2.3B). The presence of $\mathrm{Mn}(\mathrm{II})$ phosphates in coastal sediments was previously documented for the Bothian Sea (Egger et al., 2015). Manganese(II) phosphates have a high capacity to bind $\mathrm{P}$ and their resistance to reductive dissolution in the presence of $\mathrm{H}_{2} \mathrm{~S}$ will determine their contribution to the sequestration of $\mathrm{P}$ in the Baltic Sea. Below $7.5 \mathrm{~mm}$ depth in the surface sediment, the $\mu \mathrm{XRF}$ and XANES results indicate that Mn is primarily bound to pyrite and present in Mn-silicates (Figures 2.13C and 2.14B). In summary, our results suggest a strong correlation between $\mathrm{Mn}, \mathrm{Ca}$ and $\mathrm{P}$ in the surface sediment at site BY15 and a role for rhodochrosite and $\mathrm{Mn}$ (II) phosphates formation in P sequestration in the Eastern Gotland Basin.

The $\mathrm{P}$ sequestration associated with mineral formation in response to re-oxygenation was estimated from the change in solid-phase Ex-P + CDB-P (averaged over $2 \mathrm{~cm}$ sediment depth) 
between 2009 and 2016 (Figure 2.11B). The details of the calculations are provided in the Supplementary Material, section 2.1.2. Here, we summarize the procedure. We first calculated the change in water column $\mathrm{HPO}_{4}^{2-}(\sim 2.07 \mu \mathrm{M})$ upon re-oxygenation in the deeper water layer located below $125 \mathrm{~m}$ water depth based on the water column $\mathrm{HPO}_{4}{ }^{2-}$ profiles (Figure 2.3C). The deeper water layer below $125 \mathrm{~m}$ water depth contains 112,000 L per $\mathrm{m}^{2}$ of sediment. Assuming that the $\sim 2.07 \mu \mathrm{M}$ change in $\mathrm{HPO}_{4}^{2-}$ in the deep water following the inflow was sequestered in the sediment, we calculate a total input of $232 \mathrm{mmol}$ of $\mathrm{P} \mathrm{\textrm {m } ^ { 2 }}$ sediment. Applying the porosity (0.986) and sediment density $\left(2.65 \mathrm{~g} \mathrm{~cm}^{-1}\right)$ this gives an average increase in concentration of Ex-P + CDB-P of $313 \mu \mathrm{mol} \mathrm{P} \mathrm{g}{ }^{-1}$ over $2 \mathrm{~cm}$ per $\mathrm{m}^{2}$. However, the actual average increase in the Ex-P + CDB-P phase over the upper $2 \mathrm{~cm}$ per $\mathrm{m}^{2}$ of the sediment as a result of re-oxygenation was only $16 \mu \mathrm{mol}$ $\mathrm{P} \mathrm{g}^{-1}$ (or $12 \mathrm{mmol} \mathrm{P} \mathrm{m}{ }^{-2}$ ) which is equal to $\sim 5 \%$ of the observed decline in water column $\mathrm{HPO}_{4}{ }^{2-}$. Re-oxygenation of the water column thus had a limited impact on the removal of $\mathrm{HPO}_{4}^{2-}$ in the deeper waters of the Eastern Gotland Basin.

Similar calculations were made for $\mathrm{Mn}$ and Fe, as described in the Supplementary Material, section 2.1.3. Briefly, we used water column records for dissolved Mn for site BY15 from Dellwig et al. (2018) to estimate the loss of $\mathrm{Mn}$ from the water column following the re-oxygenation. For Fe, we used water column records from Pohl and Fernández-Otero (2012) to estimate the change in dissolved Fe. The surface enrichment in total $\mathrm{Mn}$ and Fe oxides at BY15 was assumed to be deposited from the water column. Based on these numbers, we estimate that at most $60 \%$ of the water column $\mathrm{Mn}$ and $11 \%$ of the water column Fe was sequestered in the sediment, as a consequence of the re-oxygenation (Table 2.5). Importantly, these metal oxides were not effective as scavengers of $\mathrm{HPO}_{4}^{2-}$ from the water column, since at most $5 \%$ of water column $\mathrm{HPO}_{4}{ }^{2-}$ was sequestered in the sediment.

Table 2.5 | Proportion of water column P, Mn and Fe that was observed in the sediment.

\begin{tabular}{|c|c|c|c|}
\hline & Phosphorus & Manganese & Iron \\
\hline $\begin{array}{l}\text { Calculated loss from the water } \\
\text { column based on water column data }\end{array}$ & $\sim 232 \mathrm{mmol} \mathrm{m}^{-2}$ & $\sim 493 \mathrm{mmol} \mathrm{m}^{-2}$ & $\sim 103 \mathrm{mmol} \mathrm{m}^{-2}$ \\
\hline $\begin{array}{l}\text { Observed deposition onto the } \\
\text { sediment based on sediment analysis }\end{array}$ & $\sim 12 \mathrm{mmol} \mathrm{m}^{-2}$ & $\sim 298 \mathrm{mmol} \mathrm{m}^{-2}$ & $\sim 11.5 \mathrm{mmol} \mathrm{m}^{-2}$ \\
\hline $\begin{array}{l}\text { Contribution of the sediment to total } \\
\text { removal }\end{array}$ & $5 \%$ & $60 \%$ & $11 \%$ \\
\hline
\end{tabular}

\subsubsection{Implications}

Previous work has shown that the increased accumulation of organic matter and Fe sulphides in sediments linked to hypoxia enhances the benthic $\mathrm{O}_{2}$ demand (Turner et al., 2008; Reed et al., 2011). This 'legacy of hypoxia' may hinder return of a system to its previous state, i.e. the longer and more intense a period of hypoxia is, the more difficult recovery from hypoxia becomes because of the higher sediment $\mathrm{O}_{2}$ demand (Turner et al., 2008). Our results show evidence for an upward flux of $\mathrm{H}_{2} \mathrm{~S}$ and $\mathrm{NH}_{4}^{+}$in the sediment that at the time of sampling outpaced benthic $\mathrm{O}_{2}$ supply, thereby confirming such a 'legacy of hypoxia'. 
Surface enrichments of Mn oxides and Fe oxides can act as a buffer for $\mathrm{H}_{2} \mathrm{~S}$, restricting its release into the overlying water (Kristiansen et al., 2002; Kristensen et al., 2003). Based on the inventory of total Mn and Fe oxides in the surface sediment, we estimated that at site BY15, this amount of metal oxides could, buffer the $\mathrm{H}_{2} \mathrm{~S}$ for approximately two months (71 days for Mn oxides, 3 days for Fe oxides; Supplementary Material, section 2.1.4). The duration of the buffering by Mn oxides was likely shorter, since a significant proportion of the Mn consisted of $\mathrm{Mn}$ (II) minerals. The first sampling of the Eastern Gotland Basin by SMHI took place 7 weeks after our sampling campaign and revealed the reoccurrence of euxinia (Figure 2.2). This is in accordance with a time scale of buffering by metal oxides of days to weeks. We suggest that, as a consequence of the high flux of reductants, the natural ventilation events in the Eastern Gotland Basin only had a minor effect on the oxidation state of the sediment, allowing only a thin suboxic zone enriched in $\mathrm{Fe}$ oxides, Mn carbonates and $\mathrm{Mn}$ (II) phosphates to develop. Thus, the highly reducing conditions in sediments of the Eastern Gotland Basin currently limit the extent to which $\mathrm{Mn}, \mathrm{Fe}$ and $\mathrm{P}$ are sequestered in mineral form in the sediment following re-oxygenation. While for $\mathrm{Mn}$, this was previously recognized (Lenz et al., 2015; Häusler et al., 2018), the impact of the 'legacy of hypoxia' on Fe and $\mathrm{P}$ recycling upon re-oxygenation has so far not been well-described. We show here, for the first time, that the high flux of reductants from deeper sediment layers plays a role in restricting the penetration of $\mathrm{O}_{2}$ into the sediment and thereby the formation of Fe oxides and associated $\mathrm{P}$ sequestration.

Our findings are of particular relevance to marine systems where a high P recycling contributes to a high productivity, as is the case in the present-day Baltic Sea (e.g. Gustafsson et al., 2012). Here, both the high $\mathrm{O}_{2}$ demand and the limited $\mathrm{P}$ sequestration in the sediment act to minimize the biogeochemical impact of re-oxygenation events.

There have been calls to artificially ventilate the deep bottom waters in the Baltic Sea to reduce eutrophication (Stigebrandt and Gustafsson, 2007). Several pilot studies have been carried out in an anoxic fjord to stimulate the formation of $\mathrm{Mn}$ oxides and Fe oxides for the purpose of P sequestration (Viktorsson et al., 2013; De Brabandere et al., 2015; Stigebrandt et al., 2015). A critical assumption in such artificial ventilation attempts is that oxygenation always enhances $\mathrm{P}$ sequestration significantly. Thus, for example, Gustafsson and Stigebrandt (2007) estimated that the seafloor below $150 \mathrm{~m}$ water depth in the Baltic Sea may bind $\sim 93 \mathrm{mmol} \mathrm{P} \mathrm{m}^{-2}$ upon re-oxygenation. Here, we show that only $\sim 12 \mathrm{mmol} \mathrm{P} \mathrm{m}^{-2}$ is sequestered at site BY15 (Table 2.5), which we attribute to the highly reducing nature of the sediment and possibly the gradual decline in bottom water $\mathrm{O}_{2}$ since the onset of re-oxygenation (Figure 2.2). Since this 'legacy of hypoxia' currently strongly limits the formation of $\mathrm{Mn}$ - and Fe minerals in sediments and their capacity to sequester $\mathrm{P}$, these artificial re-oxygenation projects that aim at removing water column $\mathrm{HPO}_{4}^{2-}$ and thereby improving water quality in the Baltic Sea will likely not have the desired outcome. Several modelling studies have shown that reducing $\mathrm{P}$ inputs to the Baltic Sea will eventually lead to a decline in water column $\mathrm{HPO}_{4}^{2-}$ and a decrease in the hypoxic area (Conley, 2012). Further reductions in $\mathrm{P}$ inputs from land thus are recommended over artificial re-oxygenation when aiming for an improvement of the water quality in the Baltic Sea. 


\subsection{Conclusions}

The recent Major Baltic inflows in 2014 and 2015 mixed and partly replaced the deeper euxinic waters in the Eastern Gotland Basin with saline and oxygen-rich water from the North Sea. These natural ventilation events led to a rise in oxygen $\left(\mathrm{O}_{2}\right)$ and complete removal of sulphide $\left(\mathrm{H}_{2} \mathrm{~S}\right)$ in deeper waters. We show that re-oxygenation led to formation of the manganese $(\mathrm{Mn})$ oxide birnessite and Fe oxides in the water column and their deposition on the sediment. Only a relatively small proportion of the water column $\mathrm{Mn}(60 \%)$ and $\mathrm{Fe}(11 \%)$ was estimated to be sequestered in the sediment.

The exposure of the surface sediments to $\mathrm{O}_{2}$-rich water induced the activity of sulphuroxidizing bacteria belonging to the family Beggiatoaceae and an oxic and suboxic zone developed in the sediment at sites in the deeper part of the basin. In this thin surface layer, Fe oxides, Mn carbonates (and associated P), Mn(II) phosphates and possibly some Mn oxides accumulated.

Strikingly, our results indicate that the $\mathrm{P}$ sequestration linked to the recent inflows accounted for only $\sim 5 \%$ of water column $\mathrm{HPO}_{4}{ }^{2-}$ removal in the Eastern Gotland Basin, with most $\mathrm{HPO}_{4}{ }^{2-}$ being displaced and transported to other parts of the basin. We attribute the limited sequestration of $\mathrm{P}$ to the highly reducing conditions in the sediment, which inhibited the formation of Fe oxides.

Our work shows that, the limited sequestration of $\mathrm{P}$ in the sediments of the Eastern Gotland Basin upon re-oxygenation forms an essential part of its 'legacy of hypoxia'. This finding is likely of relevance to many other euxinic basins subject to re-oxygenation. Finally, our research indicates that reducing nutrient inputs to the Baltic Sea is a better strategy when attempting to reduce the area of hypoxia/anoxia than artificial re-oxygenation.

\section{Acknowledgments}

We express our gratitude to the captain and crew of R/V Pelagia for their support during the expedition to the Baltic Sea in June 2016 (64PE411). We are grateful to S. Hidalgo-Martinez for assistance with the onboard microscopic analyses. This research was funded by the Netherlands Organisation for Scientific Research, Netherlands, Vici grant 865.13.005. Seventh Framework Programme, EU (European Union) and Formas (Sweden), BONUS COCOA grant 21129321. B. Gustafsson and E. Gustafsson were funded by the Swedish Agency for Marine and Water Management, Sweden, 1.11 Measure for Marine and Water environment. We thank T. Jilbert, H. de Waard, J.J Mulder and S. Ossebaar for analytical support. We are grateful to the European Synchrotron Radiation Facility (ESRF) for providing beam time at the Dutch-Belgium beamline (DUBBLE BM 26) in November 2016 and at the ID21 beamline (experiment ES-591) in May 2017. We thank the beamline scientists D. Banerjee, W. de Nolf and A.E. Pradas del Real for their assistance. 


\section{S.2. Supplementary Information}

Beggiatoaceae

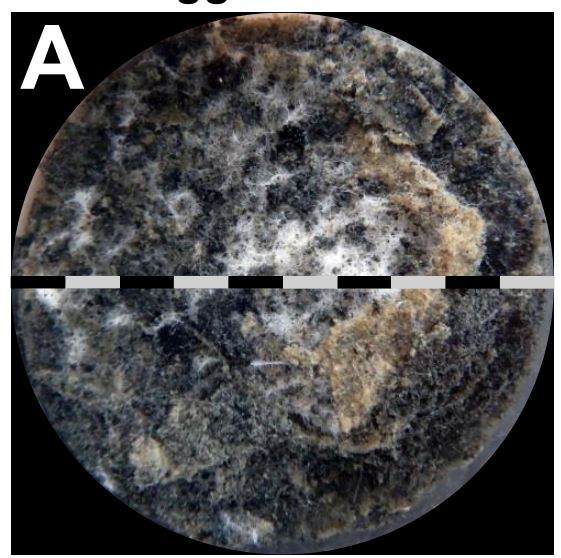

Cable Bacteria

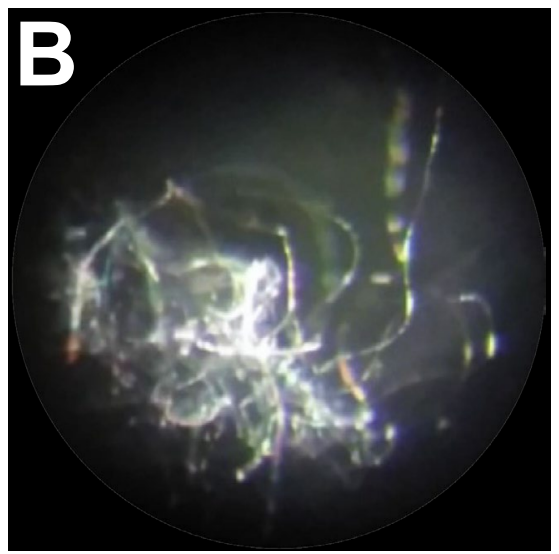

Figure S.2.1 | Sulphur oxidising bacteria (A) Microbial mat of S-oxidising bacteria belonging to the family Beggiatoaceae observed at site 2. The scale bar denotes a total distance of $10 \mathrm{~cm}$, with $1 \mathrm{~cm}$ intervals. (B) Cluster of cable bacteria filaments observed in the surface sediment of site 1. Sulphur-oxidising bacteria belonging to the family Desulfobulbaceae (cable bacteria) were visually observed by microscopy at site 1 . The activity of cable bacteria results in a distinct biogeochemical fingerprint for $\mathrm{pH}, \mathrm{O}_{2}$ and $\mathrm{\Sigma H}_{2} \mathrm{~S}$, as described in Nielsen et al. (2010) and Pfeffer et al. (2012). However, high resolution depth profiles retrieved from site 1 strongly resembled the biogeochemical fingerprint for Beggiatoaceae activity (Seitaj et al., 2015) and not the fingerprint for active cable bacteria.

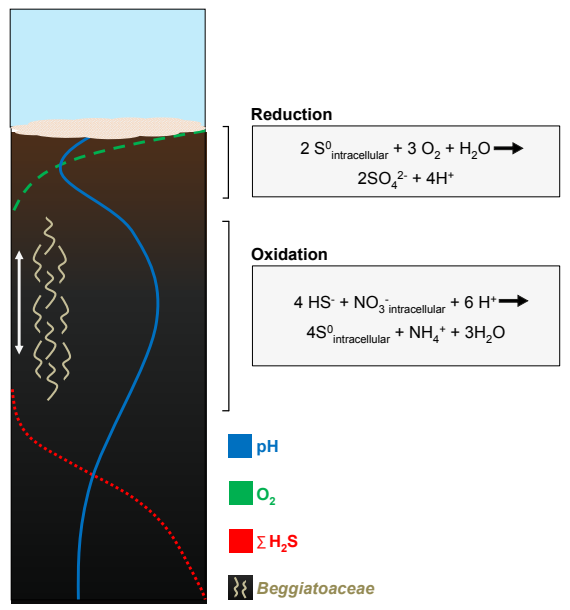

Figure S.2.2 | Biogeochemical signature of Beggiatoaceae activity. These S-oxidising bacteria are capable of spatially separating redox reactions, by creating a suboxic zone that is devoid of dissolved $\mathrm{O}_{2}$ and $\Sigma \mathrm{H}_{2} \mathrm{~S}$ (Seitaj et al. 2015). 


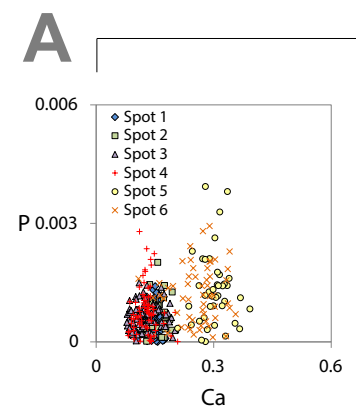

Rhodochrosite
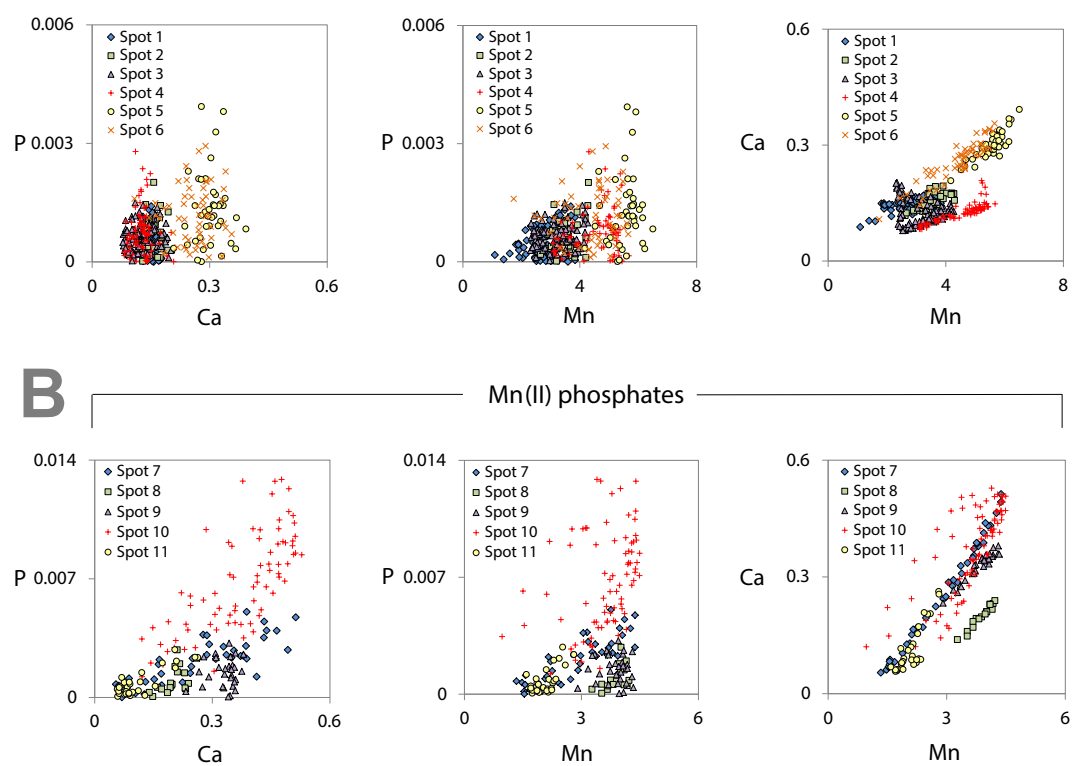

$\mathrm{Mn}(\mathrm{II})$ phosphates
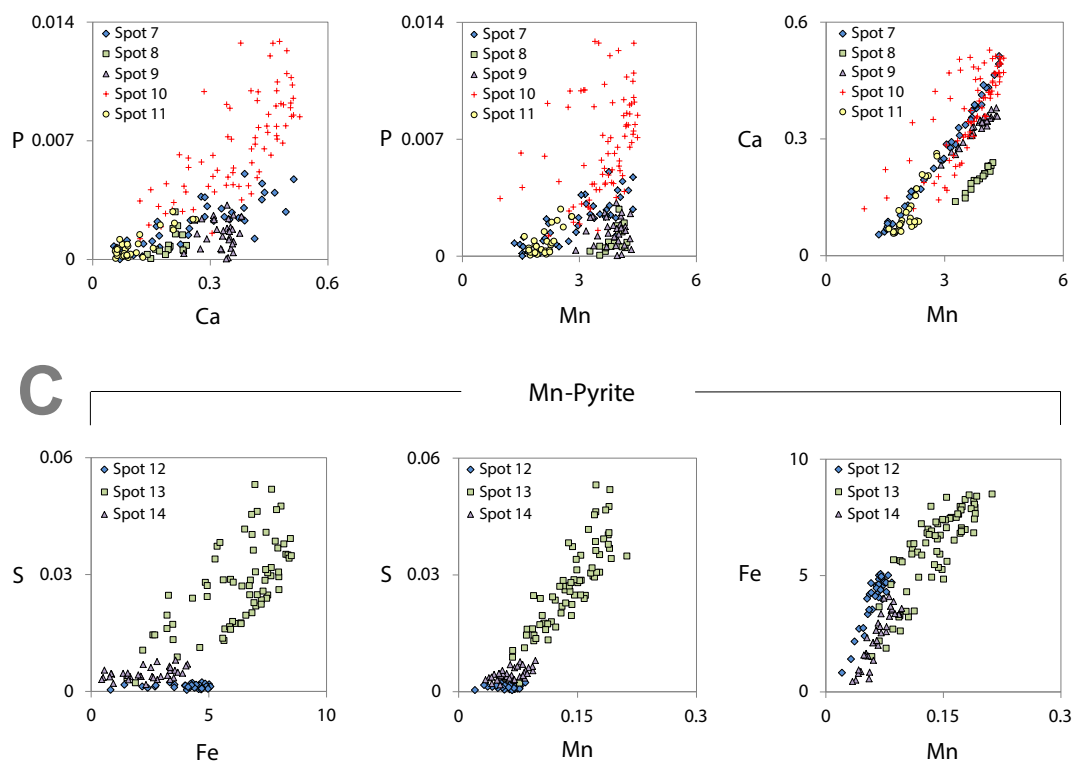

Mn-Pyrite
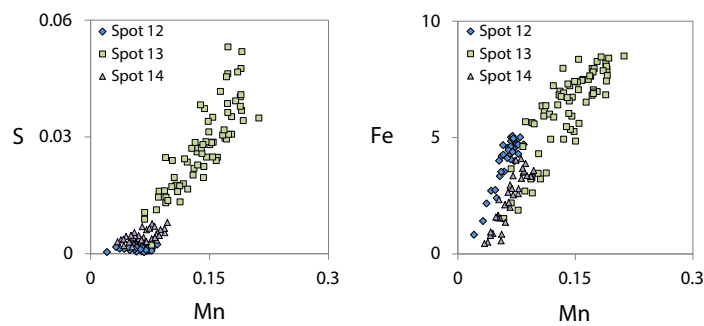

Figure S.2.3 | Elemental correlations, obtained from the areas around the selected spots of the high resolution $\mu \mathrm{XRF}$ maps in the surface sediment of BY15. At spots containing (A) rhodochrosite or (B) Mn(II) phosphates, Ca and $\mathrm{Mn}$ are correlated with each other. (C) At spots of Mn associated with pyrite, the distribution of Mn shows a strong correlation with the allocation of $\mathrm{S}$ and $\mathrm{Fe}$. 


\section{Linear Combination Fit of Spot 6}

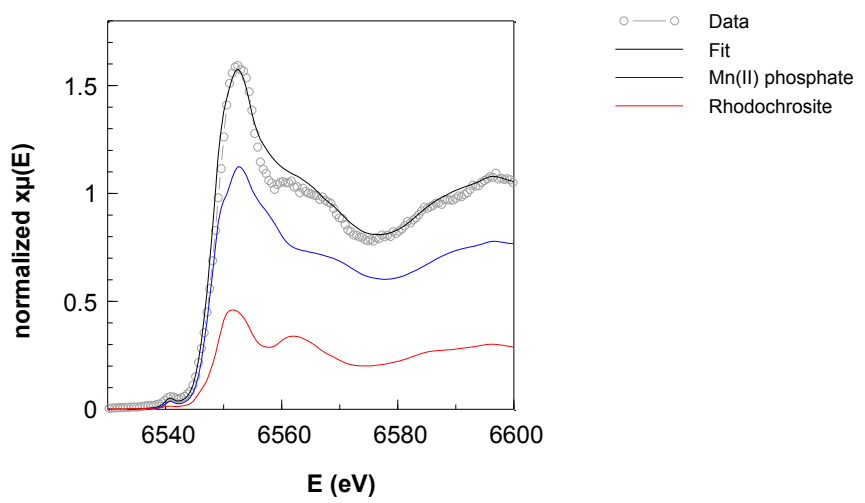

Figure S.2.4 Results from linear combination fitting of spot 6 using the XANES spectra of Mn(II) phosphate and rhodochrosite in the energy range 6520 to $6600 \mathrm{eV}$. The grey-dotted line represents the data from the measurements obtained at spot 6 (Figures 2.13A and 2.14). The blue line represents the spectrum of the Mn(II) phosphate standard, whereas the red line is the spectrum of a rhodochrosite standard. The spectrum of spot 6 can be reproduced by linear combination fitting using the spectra of those two standards, as represented by the black line. The corresponding contributions of $\mathrm{Mn}(\mathrm{II})$ phosphate and rhodochrosite were $74 \pm 4 \%$ and $27 \pm 4 \%$, respectively.

\section{Comparison of $\mathbf{k}^{2}$ weighted Mn EXAFS spectrum of spot 13 with the EXAFS spectrum of Fe in pyrite}

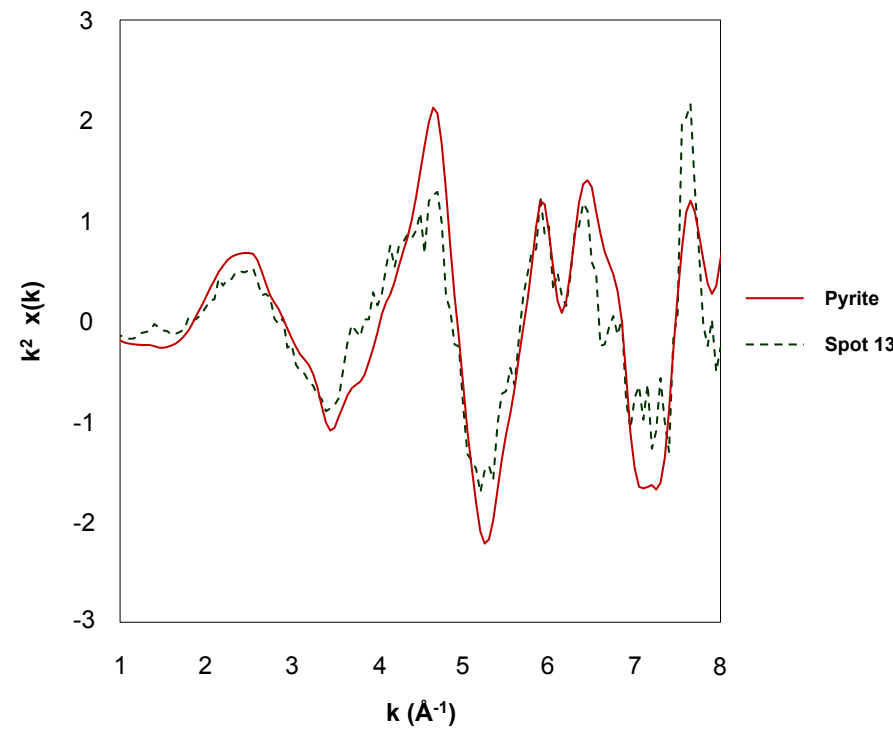

Figure S.2.5 | Comparison of $\mathrm{k}^{2}$ weighted Mn EXAFS spectrum of spot 13 with the EXAFS spectrum of Fe in pyrite. 


\section{S.2.1. Calculation of $\mathrm{P}, \mathrm{Mn}$ and Fe Deposition from the Water Column}

We estimated what proportion of water column $\mathrm{P}, \mathrm{Mn}$ and Fe was deposited onto the sediment, as a result of the re-oxygenation events, based on (1) the change in the concentrations of $\mathrm{P}, \mathrm{Mn}$ and Fe in the water column and (2) the change in solid-phase Ex-P + CDB-P, total Mn and Fe oxides. We explain our calculations in detail below.

\section{S2.I.I. Sediment Porosity}

The sediment porosity $(\varphi)$ is a very sensitive parameter in our mass balance calculations. We corrected the sediment porosity for pore water salinity, using the following equation from Burdige (2006):

$\phi=\frac{m_{w} / p_{w}}{m_{w} / p_{w}+\left(m_{d}-\left(S \cdot m_{w}\right)\right) / p_{s}}$

where $m_{w}$ is the mass of the water; $p_{w}$ is the pore water density; $m_{d}$ is the mass of the dried sediment plus salt; $S$ is the salinity; $p_{s}$ represents the sediment dry density, which is $2.65 \mathrm{~g} \mathrm{~cm}^{-3}$. This equation gives an average porosity of 0.986 for the first $2 \mathrm{~cm}$ at site BY 15 .

\section{S.2.I.2. Deposition of Water Column P onto the Sediment}

We first calculated the change in water column $\mathrm{HPO}_{4}{ }^{2-}$, by comparing the water column depth profiles before and after the recent inflows (Figure S.2.6A). Only the $\mathrm{HPO}_{4}^{2-}$ levels below $125 \mathrm{~m}$ water depth were affected by the recent inflows (Figure S.2.6A). This deeper water layer (from 125 to $237 \mathrm{~m}$ water depth) spans a distance of $112 \mathrm{~m}$. This means that the deeper water layer contains $112,000 \mathrm{~L}$ per $\mathrm{m}^{2}$ of sediment. The average change in water column $\mathrm{HPO}_{4}{ }^{2-}$, calculated from the 'blue' surface area (Figure S.2.6A), was $\sim 2.07 \mu \mathrm{M}$. Assuming that the $\sim 2.07 \mu \mathrm{M}$ change in the water column was entirely caused by deposition onto the sediment, gives a total input of $\sim 232 \mathrm{mmol}$ of $\mathrm{P}$ per $\mathrm{m}^{2}$ sediment (calculated by multiplying the change in concentration of $\sim 2.07 \mu \mathrm{M}$ in water column $\mathrm{HPO}_{4}{ }^{2-}$ with the volume of the deeper water layer 112,000 L).

Re-oxygenation of the Eastern Gotland Basin led to an increase in the top $2 \mathrm{~cm}$ of the Ex-P and CDB-P pools (Figure S.2.6B). Assuming a total input of $\sim 232 \mathrm{mmol}$ of $\mathrm{P}$ per $\mathrm{m}^{2}$ sediment, and applying a porosity of $0.986 \mathrm{~cm}^{3} \mathrm{~cm}^{-3}$ and sediment density of $2.65 \mathrm{~g} \mathrm{~cm}^{-3}$ this would lead to an average increase in concentration of Ex-P $+\mathrm{CDB}-\mathrm{P}$ of $313 \mu \mathrm{mol} \mathrm{g}{ }^{-1}$ over $2 \mathrm{~cm}$ :

$$
\begin{aligned}
& 2.65 \mathrm{~g} \mathrm{~cm}^{-3} \cdot(1-0.986) \cdot 20,000 \mathrm{~cm}^{3} \mathrm{~m}^{-2}=742{\mathrm{~g} \text { sediment } \mathrm{m}^{-2}}^{-2}{\mathrm{mmol} \mathrm{P} \mathrm{m}^{-2}}=313 \mu \mathrm{mol} \mathrm{P} \mathrm{g}^{-1}
\end{aligned}
$$

However, the actual average increase in the sum of Ex-P + CDB-P in the top $2 \mathrm{~cm}$ of the sediment due to re-oxygenation was $16 \mu \mathrm{mol} \mathrm{g}^{-1}$ (calculated from the 'blue' surface area; Figure S.2.6B) or $12 \mathrm{mmol} \mathrm{P} \mathrm{m}^{-2}$. The proportion of the change in water column $\mathrm{HPO}_{4}{ }^{2-}$ that is sequestered in the sediments is thus only $5 \%$. 

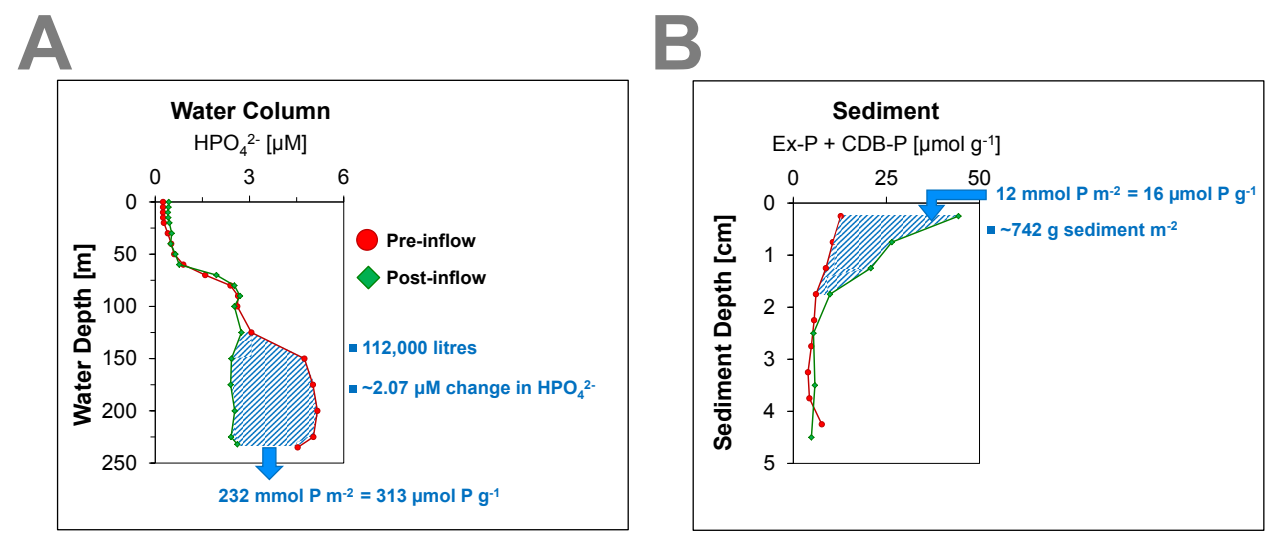

Figure S.2.6 | Calculation of the phosphorus deposition; the blue surface areas indicate the change in (A) water column $\mathrm{HPO}_{4}{ }^{2-}$ and (B) the Ex-P + CDB-P pool as a result of the re-oxygenation event.

\section{S.2.1.3. Deposition of Water Column Mn and Fe onto the Sediment}

Similar calculations were made for Mn and Fe. We used water column records of dissolved Mn for February 2015 (before the first recent inflow reached the Eastern Gotland Basin) from Dellwig et al. (2018) to estimate the loss of Mn from the water column following the re-oxygenation (using their site BY15). Dellwig et al. (2018) showed that in April 2015 all dissolved Mn was removed from waters below $129 \mathrm{~m}$ depth. The average change in dissolved $\mathrm{Mn}$ for this period in the water column was $4.4 \mu \mathrm{M}$, which gives a total input of $\sim 493 \mathrm{mmol} \mathrm{Mn} \mathrm{m}^{-2}$ sediment ( $\sim 664 \mu \mathrm{mol} \mathrm{Mn} \mathrm{g} \mathrm{g}^{-1}$ sediment$)$. Our total $\mathrm{Mn}$ records indicate that the increase in $\mathrm{Mn}$ was $\sim 298 \mathrm{mmol} \mathrm{Mn} \mathrm{m}^{-2}$ sediment $(\sim 401$ $\mu \mathrm{mol} \mathrm{Mn} \mathrm{g}{ }^{-1}$ sediment). This implies that $60 \%$ of the change in water column Mn may be lost to the sediment. For Fe, we used water column records from Pohl and Fernández-Otero (2012) to estimate the change in dissolved Fe. We assumed that all dissolved Fe was removed from the water column following re-oxygenation, which gives a change of $921 \mathrm{nM}$. The calculated total input was 103 mmol Fe $\mathrm{m}^{-2}$ sediment $\left(\sim 139 \mu \mathrm{mol} \mathrm{Fe} \mathrm{g}^{-1}\right.$ sediment $)$, whereas the actual increase in the sediment was only $\sim 11.5 \mathrm{mmol} \mathrm{Fe} \mathrm{m}^{-2}\left(\sim 16 \mu \mathrm{mol} \mathrm{Fe} \mathrm{g}{ }^{-1}\right.$ sediment). According to our calculations only $11 \%$ of the water column Fe was removed by the sediment, following re-oxygenation. We summarized the results of our calculations in Table 2.5. 
We estimated the duration of $\Sigma \mathrm{H}_{2} \mathrm{~S}$ buffering by Mn oxides and Fe oxides based on the amount of total $\mathrm{Mn}$ and $\mathrm{Fe}$ oxides that was available within the upper $2 \mathrm{~cm}$ of the sediment at site BY15 in June 2016 and the upward sulphide flux (Table 2.3). Note, that in our estimation we assume that the total $\mathrm{Mn}$ in the sediment consisted entirely of Mn oxides. The actual amount of Mn oxides is likely lower since a significant proportion of the solid phase Mn consisted of $\mathrm{Mn}$ (II) minerals (e.g. rhodochrosite and $\mathrm{Mn}$ (II) phosphates). The amount of total $\mathrm{Mn}$ and Fe oxides over the upper 2 $\mathrm{cm}$ of the sediment at site BY15 was $\sim 298 \mathrm{mmol} \mathrm{m}^{-2}$ and $\sim 11.5 \mathrm{mmol} \mathrm{m}^{-2}$ respectively. Using the sulphide flux of $4.17 \mathrm{mmol} \mathrm{m}^{-2} \mathrm{~d}^{-1}$ for BY15 (Table 2.3), assuming a 1:1 ratio for $\Sigma \mathrm{H}_{2} \mathrm{~S}$ to $\mathrm{Mn}$ or Fe (Reed et al. 2011), respectively, gives a duration of buffering of $\sim 71$ days for Mn oxides and $\sim 3$ days for Fe oxides. 


$$
3
$$




\title{
Chapter 3:
}

\section{Abundance and Biogeochemical Impact of Cable Bacteria in Baltic Sea Sediments}

\author{
Martijn Hermans, Wytze K. Lenstra, Silvia Hidalgo-Martinez, Niels A.G.M. van Helmond, \\ Rob Witbaard, Filip J.R. Meysman, Santiago Gonzalez and Caroline P. Slomp \\ Environmental Science and Technology, 53, pp. 7494-7503
}

\begin{abstract}
Oxygen depletion in coastal waters may lead to release of toxic sulfide from sediments. Cable bacteria can limit sulfide release by promoting iron oxide formation in sediments. Currently, it is unknown how widespread this phenomenon is. Here, we assess the abundance, activity, and biogeochemical impact of cable bacteria at 12 Baltic Sea sites. Cable bacteria were mostly absent in sediments overlain by anoxic and sulfidic bottom waters, emphasizing their dependence on oxygen or nitrate as electron acceptors. At sites that were temporarily reoxygenated, cable bacterial densities were low. At seasonally hypoxic sites, cable bacterial densities correlated linearly with the supply of sulfide. The highest densities were observed at Gulf of Finland sites with high rates of sulfate reduction. Microelectrode profiles of sulfide, oxygen, and $\mathrm{pH}$ indicated low or no in-situ cable bacteria activity at all sites. Reactivation occurred within 5 days upon incubation of an intact sediment core from the Gulf of Finland with aerated overlying water. We found no relationship between cable bacterial densities and macrofaunal abundances, salinity, or sediment organic carbon. Our geochemical data suggest that cable bacteria promote conversion of iron monosulfides to iron oxides in the Gulf of Finland in spring, possibly explaining why bottom waters in this highly eutrophic region rarely contain sulfide in summer.
\end{abstract}




\subsection{Introduction}

Coastal areas with low oxygen $\left(\mathrm{O}_{2}\right)$ in bottom waters are expanding worldwide because of human activities (Diaz and Rosenberg, 2008; Breitburg et al., 2018).Hypoxia $\left(\mathrm{O}_{2}<63 \mu \mathrm{M}\right)$, anoxia $\left(\mathrm{O}_{2}\right.$ $=0 \mu \mathrm{M})$, and the presence of toxic hydrogen sulfide $\left(\mathrm{H}_{2} \mathrm{~S}\right)$, termed euxinia, can lead to loss of marine life and the development of "dead zones" (Diaz and Rosenberg, 2008). Iron (Fe) oxides and manganese $(\mathrm{Mn})$ oxides in surface sediments can delay the development of bottom water euxinia, preventing the release of $\mathrm{H}_{2} \mathrm{~S}$ from the sediment (Kristiansen et al., 2002; Kristensen et al., 2003).

Recently, a group of multicellular filamentous bacteria was discovered (Pfeffer et al., 2012), which can promote the formation of Fe oxides and $\mathrm{Mn}$ oxides and can efficiently remove $\mathrm{H}_{2} \mathrm{~S}$ from surface sediments (Risgaard-Petersen et al., 2012; Seitaj et al., 2015; Sulu-Gambari et al., 2016a). These so-called cable bacteria belong to the Desulfobulbaceae family and link the oxidation of free $\mathrm{H}_{2} \mathrm{~S}$ in deeper sediment horizons to the reduction of $\mathrm{O}_{2}$ or nitrate $\left(\mathrm{NO}_{3}\right)$ by conducting electrons over centimeter scale distances (Pfeffer et al., 2012; Marzocchi et al., 2014). The metabolic activity of cable bacteria results in the development of a suboxic zone (i.e., where $\mathrm{O}_{2}$ and $\mathrm{H}_{2} \mathrm{~S}$ are absent) and a unique $\mathrm{pH}$ profile, 10 characterized by a rise in $\mathrm{pH}$ near the sediment-water interface and a strong acidification in the suboxic zone (of up to $\sim 2 \mathrm{pH}$ units; Pfeffer et al., 2012; Malkin et al., 2014). This so-called "fingerprint for cable bacteria" can be used as an indicator for their activity (Pfeffer et al., 2012; Malkin et al., 2014; Meysman et al., 2015). The strong acidification of the pore water can lead to the dissolution of iron monosulfide (FeS; Risgaard-Petersen et al., 2012; Seitaj et al., 2015) and calcium (Ca), Fe and Mn carbonates (Sulu-Gambari et al., 2016a). When the $\mathrm{Fe}^{2+}$ and $\mathrm{Mn}^{2+}$ released from these minerals diffuse upward to the oxic zone, Fe oxides and Mn oxides may form (Risgaard-Petersen et al., 2012; Sulu-Gambari et al., 2016a). Cable bacteria can fundamentally alter the biogeochemistry of coastal systems, as shown in a recent study for a seasonally hypoxic coastal marine basin where the Fe oxides formed through their activity in spring prevented the release of $\mathrm{H}_{2} \mathrm{~S}$ from the sediment during peak hypoxia in summer (Seitaj et al., 2015; Sulu-Gambari et al., 2016b). At present, it is unknown whether this role of cable bacteria as "ecosystem engineers" can be generalized to other coastal zones experiencing seasonal hypoxia.

Cable bacteria are tolerant to a wide range of salinities and temperatures, have been observed in a variety of sediments, can occur in bioturbated systems, and may be widespread in the seafloor (Malkin et al., 2014; Burdorf et al., 2017). Their ecological niche has been suggested to be primarily determined by the availability of $\mathrm{H}_{2} \mathrm{~S}$ as an electron donor, either as FeS or dissolved $\mathrm{H}_{2} \mathrm{~S}$, and $\mathrm{O}_{2}$ or $\mathrm{NO}_{3}$ as an electron acceptor (Risgaard-Petersen et al., 2012; Burdorf et al., 2017) However, other factors must also be at play because cable bacteria do not always establish when these conditions are met. Cable bacteria can co-occur with other sulfur oxidizing bacteria, such as Beggiatoaceae, suggesting competition for the same ecological niche (Seitaj et al., 2015; Sulu-Gambari et al., 2016b). Unlike cable bacteria, Beggiatoaceae are not capable of dissolving FeS, implying that their only source of $\mathrm{H}_{2} \mathrm{~S}$ is from sulfate reduction. However, Beggiatoaceae are likely better adapted to low bottom water $\mathrm{O}_{2}$ than cable bacteria (Møller et al., 1985; Burdorf et al., 2018).

Since field investigations of cable bacteria are relatively scarce it remains unclear how widespread their occurrence and how prevalent their role in delaying bottom water euxinia is. Here, we present field data on the abundance of cable bacteria and the geochemical characteristics of 12 sites from contrasting depositional environments in the Baltic Sea, as sampled in May and June 2016. We found that cable bacteria are most abundant in sediments of seasonally hypoxic sites with high rates of sulfate reduction. We infer that cable bacteria activity may prevent the development of bottom water euxinia in the highly eutrophic Gulf of Finland in summer. 


\subsection{Materials and Methods}

\subsubsection{Study Area}

The brackish Baltic Sea is naturally susceptible to bottom water hypoxia and anoxia due to vertical stratification and limited horizontal water exchange with the adjacent North Sea (Mohrholz et al., 2015). Extensive nutrient loading due to human activities and global warming has led to a massive expansion of the areal extent of $\mathrm{O}_{2}$-depleted bottom water, from $\sim 10000 \mathrm{~km}^{2}$ before 1950 to more than $60000 \mathrm{~km}^{2}$ in recent years (Carstensen et al., 2014a; Carstensen et al., 2014b).

This study focuses on 12 sites in the Baltic Sea, with varying bottom water redox conditions (Figure 3.1). These sites are divided into four categories based on their bottom water $\mathrm{O}_{2}$ characteristics (Table 3.1): (1) oxic, (2) seasonally hypoxic, (3) anoxic, and (4) reoxygenated. The classification and bottom water $\mathrm{O}_{2}$ ranges were determined based on HELCOM monitoring data for the period January 2014 to December 2016 (Supporting Information 3.1; Table S.3.1). Three of our sites (Bornholm, BY15, and BY15A) were subject to bottom water reoxygenation during our sampling campaign (Table 3.1), as a result of two major Baltic inflows that occurred in 2014 and 2015 (Mohrholz et al., 2015; Mohrholz et al., 2016; Hermans et al., 2019). During such major Baltic inflows, large amounts of saline $\mathrm{O}_{2}$-rich North Sea water enter the Baltic Sea and subsequently ventilate the deeper basins (Mohrholz et al., 2015).

Table 3.1 | Characteristics of the Sites Sampled in May and June 2016.

\begin{tabular}{|c|c|c|c|c|c|c|c|c|c|c|}
\hline Site & $\begin{array}{l}\text { Bottom water } \\
\text { conditions }\end{array}$ & $\begin{array}{c}\text { Water } \\
\text { depth }[\mathrm{m}]\end{array}$ & $\begin{array}{l}\text { Latitude and } \\
\text { longitude }\end{array}$ & $\begin{array}{c}\text { Bottom } \\
\text { water }[\mu \mathrm{M}]\end{array}$ & $\begin{array}{c}\mathrm{O}_{2} \\
\text { penetration } \\
\text { depth }[\mathrm{mm}]\end{array}$ & $\begin{array}{c}\qquad \mathrm{H}_{2} \mathrm{~S} \\
\text { appearance } \\
\text { depth }[\mathrm{mm}]\end{array}$ & $\begin{array}{l}\text { Suboxic zone } \\
\text { width }[\mathrm{mm}]\end{array}$ & $\begin{array}{l}\text { Avg. } C_{\text {org }} \text { in } \\
\text { upper } 2 \mathrm{~cm} \\
\text { (wt } \%)\end{array}$ & $\begin{array}{c}\text { Cable } \\
\text { bacteria }\end{array}$ & Beggiatoaceae \\
\hline GOF3 & oxic & 55 & $\begin{array}{c}60^{\circ} 4.43^{\prime} \\
25^{\circ} 19.42^{\prime}\end{array}$ & 80 & 2 & 27 & 25 & 5.8 & - & + \\
\hline Arkona & seasonally hypoxic & 47 & $\begin{array}{l}54^{\circ} 58.50^{\prime} \\
14^{\circ} 05.94^{\prime}\end{array}$ & 135 & 3 & $95^{\mathrm{a}}$ & 92 & 5.9 & - & + \\
\hline LF1 & seasonally hypoxic & 67 & $\begin{array}{l}57^{\circ} 58.95^{\prime} \\
21^{\circ} 16.84^{\prime}\end{array}$ & 48 & 1 & 11 & 10 & 2.9 & - & + \\
\hline 311 & seasonally hypoxic & 65 & $\begin{array}{l}57^{\circ} 26.49^{\prime} \\
20^{\circ} 43.49^{\prime}\end{array}$ & 5 & 0 & 2 & 2 & 1.0 & - & + \\
\hline GOF5 & seasonally hypoxic & 65 & $\begin{array}{l}59^{\circ} 57.10^{\prime} \\
25^{\circ} 11.02^{\prime}\end{array}$ & 10 & 1 & 9 & 8 & 8.0 & + & + \\
\hline LL3A & seasonally hypoxic & 60 & $\begin{array}{l}60^{\circ} 4.43^{\prime} \\
26.18 .30^{\prime}\end{array}$ & 5 & 0 & 6 & 6 & 8.0 & + & + \\
\hline JML & seasonally hypoxic & 80 & $\begin{array}{l}59^{\circ} 34.92^{\prime} \\
23^{\circ} 37.50^{\prime}\end{array}$ & 0 & 0 & 0 & 0 & 5.9 & - & + \\
\hline LL19 & anoxic & 173 & $\begin{array}{l}58^{\circ} 52.84^{\prime} \\
20^{\circ} 18.65^{\prime}\end{array}$ & 0 & 0 & 4 & 4 & 9.0 & - & + \\
\hline F80 & anoxic & 194 & $\begin{array}{l}58^{\circ} 00.00^{\prime} \\
19^{\circ} 53.80^{\prime}\end{array}$ & 0 & 0 & 0 & 0 & 13.2 & - & + \\
\hline Bornholm & reoxygenated & 87 & $\begin{array}{l}55^{\circ} 28.09^{\prime} \\
15^{\circ} 28.63^{\prime}\end{array}$ & 27 & 2 & 31 & 29 & 5.4 & + & + \\
\hline BY15 & reoxygenated & 237 & $\begin{array}{c}57^{\circ} 19.20^{\prime} \\
20^{\circ} 3.00^{\prime}\end{array}$ & 10 & 0 & 0 & 0 & 11.5 & - & + \\
\hline BY15A & reoxygenated & 200 & $\begin{array}{c}57^{\circ} 25.51^{\prime} \\
20^{\circ} 1.53^{\prime}\end{array}$ & 15 & 2 & 6 & 4 & $\mathrm{~N} / \mathrm{A}$ & + & + \\
\hline
\end{tabular}

${ }^{a}$ Deduced from the pore water profile of the sectioned core; N/A, not available. 


\subsubsection{Sediment and Pore Water Sampling}

Sediment cores (inner diameter $10 \mathrm{~cm}$ ) were retrieved at 12 sites in the Baltic Sea (Figure 3.1) using a multicorer (Oktopus $\mathrm{GmbH}$, Germany) during an expedition with R/V Pelagia in May and June 2016 (Table 3.1). From one core per site, two bottom water samples were retrieved from the overlying water. Subsequently, one core was sectioned under nitrogen for sediment and pore water collection $(0.5 \mathrm{~cm}$ depth resolution for the first $2 \mathrm{~cm}, 1 \mathrm{~cm}$ resolution for $2-10 \mathrm{~cm})$. For each sediment slice interval, a split was made: a subsample was placed in a preweighed glass vial for porosity determination, and another subsample was transferred to $50 \mathrm{~mL}$ centrifuge tubes.

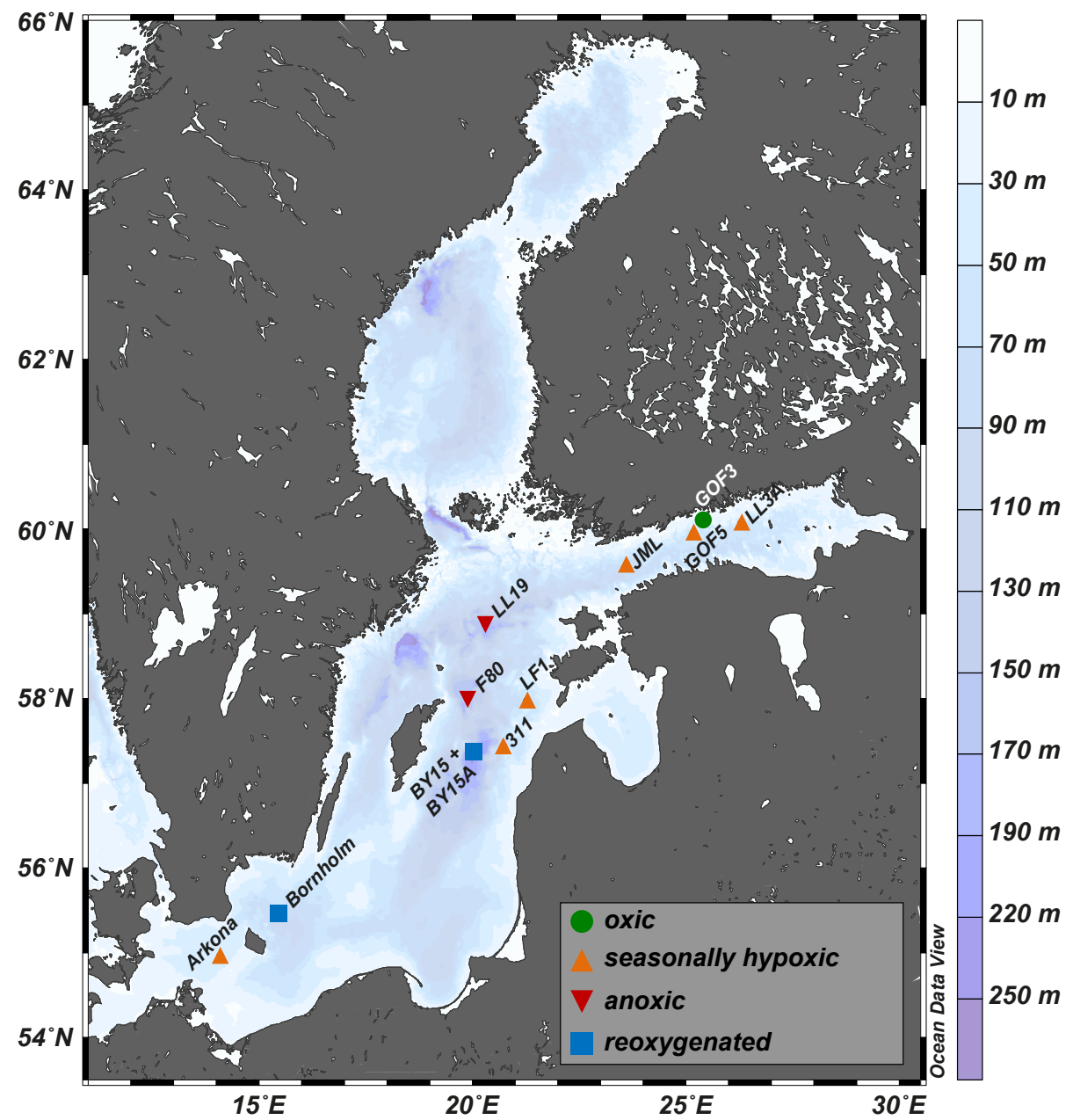

Figure 3.1 | Map of the Baltic Sea showing the locations of the 12 sites. Our sites are classified based on the typical bottom water redox conditions between 2014 and 2016, which are indicated as follows: oxic (green); seasonally hypoxic (orange); anoxic (red); reoxygenated (blue). 
Subsequently, pore water was extracted by centrifugation (15 min at $4500 \mathrm{rpm}$ ), filtered through $0.45 \mu \mathrm{m}$ nylon filters, and subsampled under nitrogen. Directly after centrifugation, samples for sulfide analysis $(0.5 \mathrm{~mL})$ were transferred into glass vials filled with a nitrogen-purged $8 \mathrm{M}$ $\mathrm{NaOH}$ solution $(1.5 \mathrm{~mL})$. Both $\mathrm{H}_{2} \mathrm{~S}$ and ammonium $\left(\mathrm{NH}_{4}^{+}\right)$concentrations were determined using a QuAAtro (Bran+Luebbe) gas segmented continuous flow analyzer onboard ship (Koroleff, 1969; Grasshoff and Ehrhardt, 1983). Pore water sulfate $\left(\mathrm{SO}_{4}{ }^{2-}\right)$ was determined using ion chromatography (IC).

High-resolution depth profiles of $\mathrm{pH}, \mathrm{O}_{2}$, and $\mathrm{H}_{2} \mathrm{~S}$ were retrieved from intact sediment cores within $2 \mathrm{~h}$ of retrieval using microelectrodes (50 or $100 \mu \mathrm{m}$ tip diameter) operated with a motorized micromanipulator (Unisense A.S., Denmark). Calibrations of $\mathrm{pH}, \mathrm{O}_{2}$, and $\mathrm{H}_{2} \mathrm{~S}$ electrodes were performed as described in Sulu-Gambari et al. (2016b) Total $\mathrm{H}_{2} \mathrm{~S}\left(\sum \mathrm{H}_{2} \mathrm{~S}=\mathrm{H}_{2} \mathrm{~S}+\mathrm{HS}^{-}+\mathrm{S}^{2-}\right)$ was calculated based on Jeroschewski et al. (1996).

Sulfate reduction rates (SRR) were measured, at all sites except BY15A, by extracting $5 \mathrm{~mL}$ of wet sediment sample from predrilled and taped cores directly upon retrieval using cut off syringes following Egger et al. (2016). Within $4 \mathrm{~h}$ of core retrieval, $20 \mu \mathrm{L}$ of carrier free ${ }^{35} \mathrm{SO}_{4}{ }^{2-}(74-91$ $\mathrm{kBq}$ ) was injected in these syringes. The sediment was incubated for $20-24 \mathrm{~h}$ in the dark under a nitrogen atmosphere, after which it was transferred to $50 \mathrm{~mL}$ centrifuge tubes containing 20 $\mathrm{mL}$ of deoxygenated $20 \%$ zinc acetate to precipitate dissolved $\Sigma \mathrm{H}_{2} \mathrm{~S}$ and inhibit biological activity (Fossing and Jørgensen, 1989; Kallmeyer et al., 2004). Upon analysis, samples were rinsed twice using deoxygenated bottom water $(10 \mathrm{~mL})$ and centrifuged for removal of unreacted ${ }^{35} \mathrm{SO}_{4}{ }^{2-}$ (Egger et al., 2016). The reduced $S$ was extracted with an acidic chrome chloride solution ( $48 \mathrm{~h}$ ) via the passive diffusion method (Burton et al., 2008). SRR integrated over the entire depth of the core were calculated by comparing the activity (decays per minute) of the radiolabeled total reduced inorganic sulfur (aTRIS) to the total $\mathrm{SO}_{4}^{2-}$ (aTOT) radiotracer as described in Kallmeyer et al. (2004):

$$
S R R=\left[{S O_{4}}^{2-}\right] \cdot \phi \cdot \frac{a_{T R I S}}{a_{T O T}} \cdot \frac{1}{t} \cdot 1.06
$$

where $\varphi$ represents the porosity; $t$ is the incubation time (days), and the correction factor 1.06 represents the expected isotopic fractionation (Jørgensen and Fenchel, 1974; Kallmeyer et al., 2004).

\subsubsection{Diffusive Fluxes}

Diffusive fluxes of $\Sigma \mathrm{H}_{2} \mathrm{~S}$ and $\mathrm{NH}_{4}^{+}$across the sediment-water interface, upward fluxes of $\Sigma \mathrm{H}_{2} \mathrm{~S}$ into the suboxic zone, and downward fluxes of $\mathrm{SO}_{4}{ }^{2-}$ in the upper part of the sediment were determined based on the linear pore water gradient using Fick's first law (Berner, 1980):

$J=-\phi D_{s} \cdot \frac{d C}{d z}$

where $\mathrm{J}$ is the diffusive flux $\left(\mathrm{mmol} \mathrm{m} \mathrm{m}^{-2} \mathrm{day}^{-1}\right) ; \phi$ represents the sediment porosity; Ds stands for the sediment diffusion coefficient; $\mathrm{C}$ is the concentration of $\Sigma \mathrm{H}_{2} \mathrm{~S}, \mathrm{NH}_{4}^{+}$, or $\mathrm{SO}_{4}{ }^{2-}(\mathrm{mM})$; and $\mathrm{z}$ represents the sediment depth $(\mathrm{m})$. The diffusion coefficient was calculated as a function of pressure, salinity, and temperature using the R package marelac (Soetaert et al., 2010) and corrected for the ambient tortuosity (Boudreau, 1997). 


\subsubsection{Macrofaunal Density}

A benthic lander system equipped with three chambers, with a surface area of $144 \mathrm{~cm}^{2}$ per chamber, was utilized to collect sediment samples for the determination of macrofauna (Witbaard et al., 2000). The first $\sim 12 \mathrm{~cm}$ of the sediment was collected by the chambers, which was subsequently sieved $(0.5 \mathrm{~mm}$ mesh size). Macrofauna were retrieved and stored in $4 \%$ formaldehyde in plastic jars until determination of the species and their abundance (Eleftheriou, 2013). At site GOF3, no macrofauna samples were collected. For the determination of ash free dry mass (AFDM), macrofaunal specimens were first dried, weighed, and then ashed. The AFDM was calculated based on the difference of the dry weight and the weight of the remaining ash.

\subsubsection{Identification of Sulfur Oxidizing Bacteria and Cable Bacteria Quantification}

To identify which sulfur oxidizing bacteria were present (provisionally determined based on thickness and length of filaments), surface sediments were analyzed onboard using a stereomicroscope. Beggiatoaceae filaments were distinguished from cable bacteria filaments based on their greater thickness and prominent sulfur inclusions. The abundance of Beggiatoaceae was not enumerated. For the quantification of cable bacteria, sediment cores were sectioned at all sites $(0.5 \mathrm{~cm}$ depth resolution for the first $2.5 \mathrm{~cm})$. Each sediment slice was homogenized, and then 0.5 $\mathrm{mL}$ of sediment was mixed with $0.5 \mathrm{~mL}$ of $99 \%$ ethanol and stored at $-20{ }^{\circ} \mathrm{C}$. Fluorescence in-situ hybridization (FISH) was used for microscopic identification and quantification of cable bacteria filaments, as described in Seitaj et al. (2015). Aliquots of $100 \mu \mathrm{L}$ were transferred in a 1:1 mixture of PBS/ethanol $(500 \mu \mathrm{L})$. Subsequently, $10 \mu \mathrm{L}$ of this mixture was filtered through a polycarbonate membrane (type GTTP, pore size $0.2 \mu \mathrm{m}$, Millipore, USA). Cable bacteria filaments were detected with a Desulfobulbaceae-specific oligonucleotide probe (DSB706; 5'-ACC CGT ATT CCT CCC GAT-3') after counter staining with DAPI $(1 \mu \mathrm{g} / \mathrm{mL})$ under an epifluorescence microscope (Zeiss Axioplan, Germany) at $100 \times$ magnification. The abundance of cable bacteria was determined by determining the length and diameter of all observed cable bacteria in a field $(105 \times 141 \mu \mathrm{m})$ on the filter at $100 \times$ magnification (200 fields per sample). The cable bacteria abundances are reported either as filament length per volumetric unit $\left(\mathrm{m} \mathrm{cm}^{-3}\right)$ or integrated over depth expressed per unit area of sediment surface $\left(\mathrm{m} \mathrm{cm}^{-2}\right)$.

\subsubsection{Incubation Experiment}

The overlying water in two intact sediment cores from site GOF5 and BY15A was continuously aerated onboard to see whether a high concentration of $\mathrm{O}_{2}$ in the bottom water would induce the metabolic activity of cable bacteria. After $\sim 5$ days the two cores were subjected to high-resolution depth profiling.

\subsubsection{Solid-Phase Analysis}

Sediment samples from core sectioning were freeze-dried and subsequently ground in an argonpurged glovebox. Solid-phase Fe was fractioned into (1) labile $\mathrm{Fe}$ (III) oxides and $\mathrm{Fe}(\mathrm{II})$ (FeS + $\left.\mathrm{FeCO}_{3}\right)$, (2) crystalline Fe minerals, (3) magnetite, and (4) pyrite $\left(\mathrm{FeS}_{2}\right)$, using a combination of two extraction methods (Poulton and Canfield 2005; Claff et al. 2010) as described by Hermans et al. (2019). Solid-phase S was separated into (1) acid volatile sulfur (AVS; FeS) and (2) chromium 
reducible sulfur (CRS; $\mathrm{FeS}_{2}$ ), using the method after Burton et al. (2008) as modified by Kraal et al. (2013). FeS and $\mathrm{FeS}_{2}$ were quantified by iodometric titrations (APHA, 1989). Total solid-phase Mn was determined by ICP-OES, after dissolution using a mixture of $\mathrm{HF}$ and $\mathrm{HNO}_{3}$. Sediment porosity and a sediment density of $2.65 \mathrm{~g} \mathrm{~cm}^{-3}$ were used to convert Fe oxide and FeS contents in $\mathrm{mol} \mathrm{g}^{-1}$ to mol m${ }^{-2}$ (Burdige, 2006).

\subsection{Results and Discussion}

\subsubsection{Classification of Sites Based on Bottom Water Oxygen.}

The range in bottom water $\mathrm{O}_{2}$ for 2014-2016 varied greatly among the 12 sites (Figure 3.2A; Table S.3.1). Bottom waters at GOF3 were characterized by high concentrations of $\mathrm{O}_{2}(>150 \mu \mathrm{M})$ and were never hypoxic $(<63 \mu \mathrm{M})$. Five of the seasonally hypoxic sites - Arkona, LF1, 311, GOF5, and LL3A - in contrast, showed a distinct seasonal cycle with high bottom water $\mathrm{O}_{2}$ most of the year and relatively low $\mathrm{O}_{2}$ in summer ( $<63 \mu \mathrm{M}$ for $\sim 60-90$ days). Site JML was hypoxic most of the time and only briefly became oxic (in June 2015). Bottom waters at sites LL19 and F80 were always anoxic. At the reoxygenated sites, the bottom water $\mathrm{O}_{2}$ varied between 0 and $150 \mu \mathrm{M}$. At the time of sampling, bottom water $\mathrm{O}_{2}$ was low or absent at all of the seasonally hypoxic sites and the reoxygenated sites, except Arkona and LF1 (Figure 3.2B).

\subsubsection{Abundance of Cable Bacteria in Baltic Sea Sediments}

Visual observations of the surface sediment onboard ship by light microscopy revealed the presence of filaments that were likely cable bacteria. These filaments were observed at the seasonally hypoxic sites GOF5 and LL3A and at the reoxygenated sites Bornholm and BY15A, while Beggiatoaceae were found at all sites (Table 3.1). Thick microbial mats of Beggiatoaceae were observed only at the reoxygenated sites BY15 and BY15A in the Eastern Gotland basin (Figure S.3.1). A more detailed examination of the surface sediments using FISH revealed that cable bacteria were present at all sites except for LL19 (Figure S.3.2). Cable bacterial abundances, however, varied greatly between sites and also with sediment depth (Figures S.3.2 and S.3.3).

At the oxic site GOF3, the areal density of cable bacteria was low $\left(12 \mathrm{~m} \mathrm{~cm}^{-2}\right.$; Figure $\left.3.2 \mathrm{C}\right)$. At four of the seasonally hypoxic sites - Arkona, LF1, 311, and JML - the areal density was 5 times higher $\left(\sim 60 \mathrm{~m} \mathrm{~cm}^{-2}\right)$. The seasonally hypoxic sites GOF5 and LL3A, both located in the Gulf of Finland, had the highest abundance of cable bacteria (121 and $150 \mathrm{~m} \mathrm{~cm}^{-2}$, respectively). Such densities are comparable with sediments with active cable bacteria communities as found, for example, in seasonally hypoxic Lake Grevelingen (Burdorf et al., 2016; Malkin et al., 2017). The two anoxic sites LL19 and F80 had the lowest abundance of cable bacteria $\left(0\right.$ and $\left.4 \mathrm{~m} \mathrm{~cm}^{-2}\right)$, while at the reoxygenated sites - Bornholm, BY15, and BY15A - abundances varied $\left(12\right.$ and $\left.55 \mathrm{~m} \mathrm{~cm}^{-2}\right)$. The low amounts of cable bacteria at discontinuous depths at the reoxygenated sites are likely inactive remnant cells that have not yet decayed (Figure S.3.2). At sites BY15 and BY15A, the abundances of cable bacteria were similar to those observed in reoxygenated Baltic Sea sediments in a recent study (Marzocchi et al., 2018).

Evidence for cable bacteria activity was visible in high-resolution depth profiles of $\mathrm{pH}, \mathrm{O}_{2}$, and $\mathrm{\Sigma H}_{2} \mathrm{~S}$, at sites GOF5 and LL3A (Figure S.3.4). Sediments at these sites were characterized by the presence of a suboxic zone (Table 3.1) and a distinct $\mathrm{pH}$ peak near the subsurface. However, with a minimum $\mathrm{pH}$ of $\sim 7$, only moderate acidification of the pore water in the suboxic zone was observed 


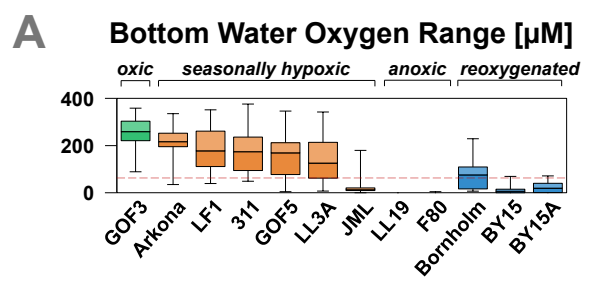

C Areal Density of Cable Bacteria $\left[\mathrm{m} \mathrm{cm}^{-2}\right]$ $\begin{array}{r}160 \\ 80- \\ 0\end{array}-\square \square \square \square$
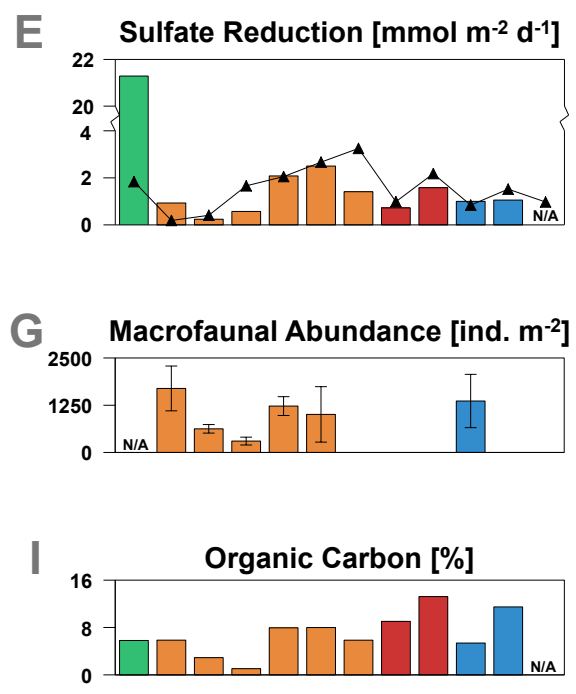
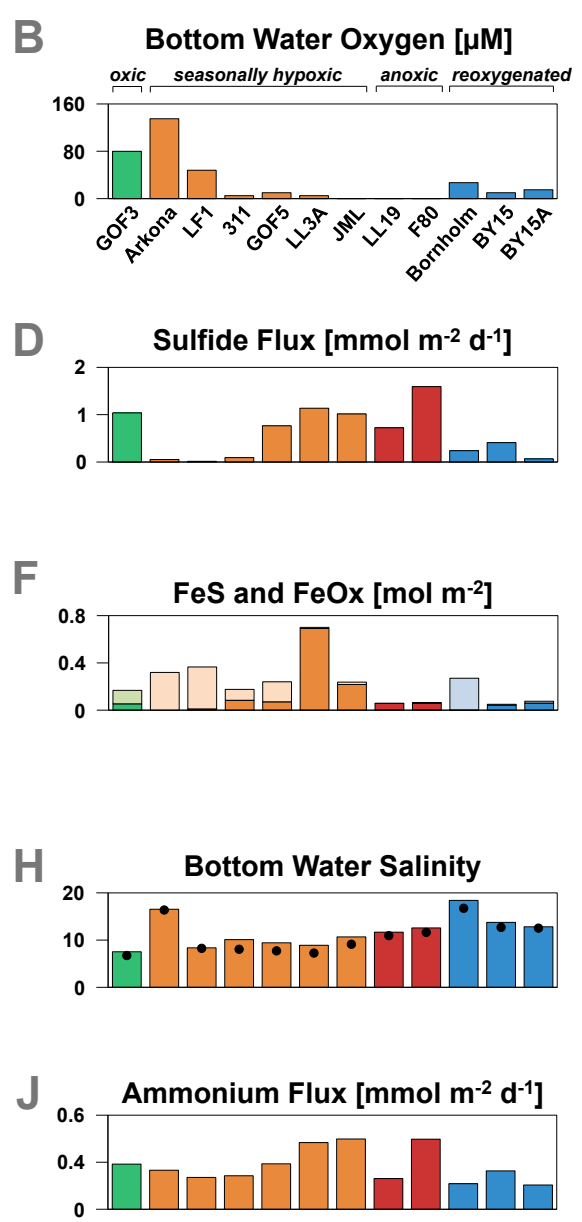

Figure 3.2 | (A) Range in bottom water $\mathrm{O}_{2}(\mu \mathrm{M})$ for 2014-2016 based on the HELCOM database where available. The red dashed line (located at $63 \mu \mathrm{M}$ ) indicates the hypoxic boundary. The solid line between the boxes is the median, whereas the boxes represent the lower and upper quartiles. The error bars indicate the minimum and maximum $\mathrm{O}_{2}$ levels. (B) Bottom water $\mathrm{O}_{2}$ concentrations $(\mu \mathrm{M})$ in May/June 2016 derived from microelectrode profiles near the sediment-water interface. (C) Areal density of cable bacteria $\left(\mathrm{m} \mathrm{cm}^{-2}\right)$. (D) Upward flux of sulfide toward the sediment-water interface/suboxic zone $\left(\mathrm{mmol} \mathrm{m}^{-2}\right.$ day $\left.^{-1}\right)$. (E) Sulfate reduction rates $\left(\mathrm{mmol} \mathrm{m}^{-2}\right.$ day $^{-1}$; black triangles represent the downward flux of sulfate in $\mathrm{mmol} \mathrm{m}^{-2}$ day ${ }^{-1}$ ). (F) Sedimentary FeS (AVS) and labile Fe(III) oxides ( $\mathrm{mol} \mathrm{m}^{-2}$; integrated over top $2 \mathrm{~cm}$; the dark and light colors represent $\mathrm{FeS}$ and labile $\mathrm{Fe}$ (III) oxides respectively). (G) Macrofaunal abundance (ind. $\mathrm{m}^{-2}$ ). The error bars represent the standard deviation. (H) Bottom water salinity. The black dots represent the bottom water salinity prior to the major Baltic inflows. (I) Sediment organic carbon (\%; averaged over top $2 \mathrm{~cm}$ ). (J) Upward flux of ammonium $\left(\mathrm{mmol} \mathrm{m}^{-2} \mathrm{day}^{-1}\right)$ toward the sediment-water interface. The study sites are classified based on bottom water redox conditions as described in Figure 3.1. 
when compared to the $\mathrm{pH}$ of $\sim 6.5$, which is typical for cable bacteria activity (Pfeffer et al., 2012; Malkin et al., 2014). At the time of sampling, bottom water $\mathrm{O}_{2}$ levels were extremely low at these sites (Table $3.1 ; 5-10 \mu \mathrm{M}$ saturation). Limited availability of $\mathrm{O}_{2}$ typically results in the collapse of the metabolic activity of cable bacteria (Burdorf et al., 2018). The observed pH profiles at site GOF5 and LL3A thus may reflect a residue signal of cable bacteria activity shortly after such a collapse. The depth profiles of $\mathrm{pH}, \mathrm{O}_{2}$, and $\mathrm{\Sigma H}_{2} \mathrm{~S}$ at sites BY15 and BY15A, in contrast, resembled the typical $\mathrm{pH}$ profiles for activity of Beggiatoaceae (Seitaj et al., 2015). This $\mathrm{pH}$ signature is characterized by a low $\mathrm{pH}$ near the sediment surface as a result of proton formation and a high $\mathrm{pH}$ in the deeper sediment horizon caused by proton consumption by $\Sigma \mathrm{H}_{2} \mathrm{~S}$ oxidation (Seitaj et al., 2015).

In summary, the highest abundances of cable bacteria were found at the seasonally hypoxic sites, in particular those located in the Gulf of Finland. Furthermore, we found that the presence of cable bacteria does not imply that the characteristic fingerprint for cable bacteria activity is observed in the pore water. However, the $\mathrm{pH}, \mathrm{O}_{2}$, and $\Sigma \mathrm{H}_{2} \mathrm{~S}$ fingerprints, for sites with the highest cable bacteria density (GOF5 and LL3A), did show a strong similarity with the typical fingerprint for cable bacteria activity.

\subsubsection{Controls on the Abundance and Activity of Cable Bacteria}

Metabolic activity of cable bacteria requires bottom water $\mathrm{O}_{2}$ and availability of $\Sigma \mathrm{H}_{2} \mathrm{~S}$ (RisgaardPetersen et al., 2012). While bottom water $\mathrm{O}_{2}$ was typically available at the oxic, seasonally hypoxic, and reoxygenated sites (Figure 3.2A), only the seasonally hypoxic sites had a high abundance of cable bacteria (Figure 3.2C). Here we assess the relationship between the abundance of cable bacteria at our 12 Baltic Sea sites with $\mathrm{\Sigma}_{2} \mathrm{~S}$ supply from sulfate reduction and dissolution of FeS, macrofaunal abundance, salinity, sediment organic matter, the rate of organic matter degradation, and potential competition of cable bacteria with Beggiatoaceae.

Any free $\Sigma \mathrm{H}_{2} \mathrm{~S}$ that was not removed chemically or microbially may have diffused into the zone were cable bacteria were active (Figure S.3.4). Diffusive $\Sigma \mathrm{H}_{2} \mathrm{~S}$ fluxes into the suboxic or oxic zone (Figures 3.2D, S.3.5, and S.3.6) varied greatly between sites with highest fluxes at the oxic site (GOF3; $1 \mathrm{mmol} \mathrm{m}^{-2} \mathrm{day}^{-1}$ ), the three seasonally hypoxic sites in the Gulf of Finland (JML, GOF5, LL3A; 0.8-1.1 mmol m${ }^{-2} \mathrm{day}^{-1}$ ), and the two anoxic sites (LL19, F80; 0.7-1.6 $\mathrm{mmol} \mathrm{m}^{-2} \mathrm{day}^{-1}$ ). Sulfide fluxes were much lower at the other seasonally hypoxic sites (Arkona, LF1, 311; 0.01-0.09 $\mathrm{mmol} \mathrm{m}{ }^{-2} \mathrm{day}^{-1}$ ) and the reoxygenated sites (Bornholm, BY15, BY15 A; 0.07-0.4 mmol m${ }^{-2} \mathrm{day}^{-1}$ ). Strikingly, the abundance of cable bacteria depends linearly on the diffusive supply of $\Sigma \mathrm{H}_{2} \mathrm{~S}$, at all seasonally hypoxic sites, except JML (Figure 3.3A). Data for sediments populated by cable bacteria, in other systems, such as Lake Grevelingen (March 2012; Seitaj et al., 2015), Wadden Sea (Mussel Reef; June 2013; Malkin et al., 2017), and a mangrove (Burdorf et al., 2016), follow the same general trend (Figure 3.3A). In contrast, our anoxic and reoxygenated sites and the seasonally hypoxic site JML do not show such a correlation, likely because $\mathrm{O}_{2}$ was limiting during most of the year. We conclude that, when sufficient bottom water $\mathrm{O}_{2}$ is available during a large part of the year, the supply of $\Sigma \mathrm{H}_{2} \mathrm{~S}$ acts as the main control on the abundance of cable bacteria.

Sulfate reduction can provide a key supply of sulfide to cable bacteria (Malkin et al., 2017). We found a large variation in rates at our 12 sites (Figures 3.2E, S.3.5, and S.3.7), with the highest rate observed at the oxic site GOF3 $\left(21.4 \mathrm{mmol} \mathrm{m}^{-2}\right.$ day $\left.^{-1}\right)$. Of the other sites, the seasonally hypoxic sites GOF5 and LL3A had the highest sulfate reduction rates $\left(2.1\right.$ and $2.5 \mathrm{mmol} \mathrm{m}^{-2}$ day $^{-1}$, respectively). Comparison of the sulfate reduction rates and diffusive fluxes for GOF5 and LL3A shows that a significant proportion of the $\mathrm{\Sigma H}_{2} \mathrm{~S}$ that was produced diffused to the suboxic or oxic zone. When 
we plot the areal density of cable bacteria against the sulfate reduction rates, no direct relation can be found. However, three groups can be identified (Figure 3.3B) which consist of (1) sites with a high areal density of cable bacteria in concert with high sulfate reduction rates and seasonal bottom water $\mathrm{O}_{2}$ availability; (2) sites with sufficient bottom water $\mathrm{O}_{2}$ during a large part of the year, but relatively low sulfate reduction rates and $\mathrm{\Sigma H}_{2} \mathrm{~S}$ availability; and (3) sites with a low areal density of cable bacteria and low bottom water $\mathrm{O}_{2}$ availability during the year. At the two seasonally hypoxic sites GOF5 and LL3A in group 1, sulfate reduction rates were high $\left(2.1\right.$ and $2.5 \mathrm{mmol} \mathrm{m}^{-2}$ day $^{-1}$, respectively) close to the sediment surface (Figure S.3.5). Such conditions likely allow cable bacteria to access electrons released from $\Sigma \mathrm{H}_{2} \mathrm{~S}$ by sulfate reduction close to the oxic zone, stimulating a rapid and dense growth (Malkin et al., 2017).
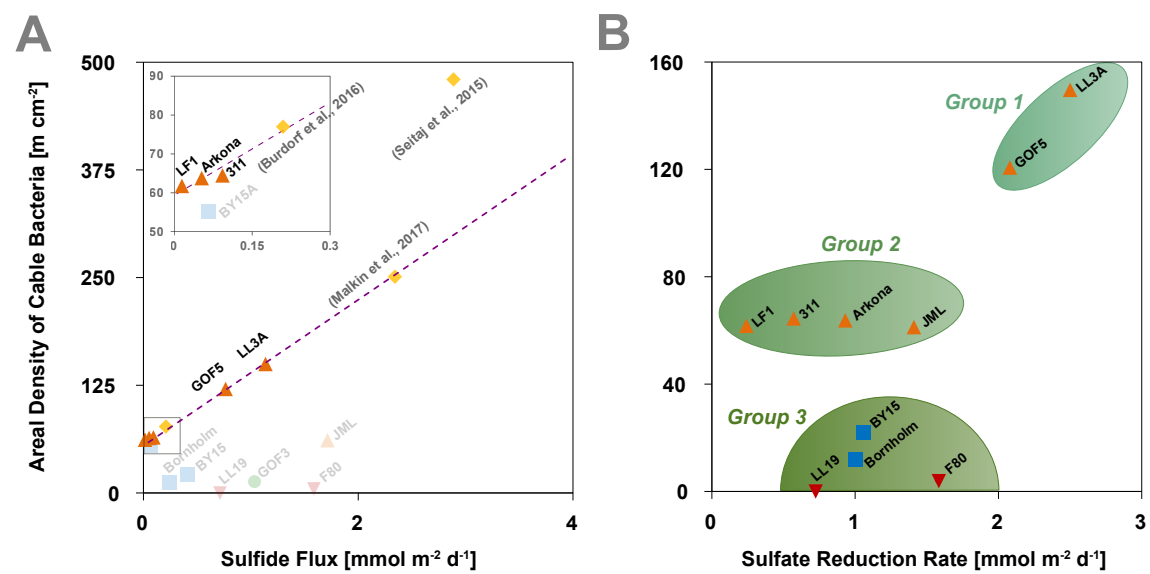

Figure 3.3 | (A) Linear correlation between diffusive supply of $\Sigma \mathrm{H}_{2} \mathrm{~S}\left(\mathrm{mmol} \mathrm{m}^{-2}\right.$ day $\left.^{-1}\right)$ and areal density of cable bacteria $\left(\mathrm{m} \mathrm{cm}^{-2}\right)$. The toned down sites in the background are omitted from the linear correlation, because other factors, such as insufficient bottom water $\mathrm{O}_{2}$, controlled the abundance of cable bacteria. (B) Relationship between measured sulfate reduction rates $\left(\mathrm{mmol} \mathrm{m}^{-2} \mathrm{day}^{-1}\right)$ and areal density of cable bacteria $\left(\mathrm{m} \mathrm{cm}^{-2}\right)$. GOF3 is omitted from the plot, because of the exceptionally high sulfate reduction rate. The sulfate reduction rate at BY15A is not available The sample sites are classified based on the bottom water redox conditions as described in Figure 3.1.

Iron monosulfide can also serves as a source of $\Sigma \mathrm{H}_{2} \mathrm{~S}$ for cable bacteria, with cable bacteria inducing the dissolution of $\mathrm{FeS}$ by pore water acidification. The $\mathrm{Fe}^{2+}$ released by dissolution can subsequently be oxidized upon contact with $\mathrm{O}_{2}$ to form Fe oxides (Risgaard-Petersen et al., 2012; Meysman et al., 2015). When bottom water $\mathrm{O}_{2}$ levels are low again, the Fe oxides are converted back to FeS upon contact with $\mathrm{\Sigma H}_{2} \mathrm{~S}$ (Sulu-Gambari et al., 2016b). Because of this "pool switching" mechanism and the fact that the sediment FeS concentrations observed in June 2016 represented one time point at the beginning of summer, we consider the sum of the FeS and Fe oxides as a more representative term for the total pool of potentially available FeS for cable bacteria (hereafter FeS + $\mathrm{FeOx})$ at the end of summer. The lowest $\mathrm{FeS}+\mathrm{FeOx}$ pools were found at both anoxic sites and the two reoxygenated sites BY15 and BY15A $\left(0.05\right.$ and $0.08 \mathrm{~mol} \mathrm{~m}^{-2}$; Figure 3.2F). The highest FeS + FeOx was found at site LL3A $\left(0.7 \mathrm{~mol} \mathrm{~m}^{-2}\right)$. Most of the FeS + FeOx $(\sim 71 \%)$ at site GOF5 consisted of Fe oxides, likely as a result of cable bacteria activity prior to our sampling campaign (Figure 3.2F). In contrast, at site LL3A, 99\% of the FeS + FeOx consisted of FeS, likely because Fe oxides formed by cable bacteria already underwent conversion to FeS because of the low bottom water 
$\mathrm{O}_{2}$ concentrations at the time of sampling. This pool of FeS, if dissolved in spring, for example, in 100 days, is equivalent to a $\Sigma \mathrm{H}_{2} \mathrm{~S}$ supply of $7 \mathrm{mmol}^{-2}$ day ${ }^{-1}$. Given the sulfate reduction rate of 2.5 mmol m${ }^{-2}$ day $^{-1}$ at LL3A, this indicates that sediment FeS could be a major source of $\Sigma \mathrm{H}_{2} \mathrm{~S}$ for cable bacteria in this region. In summary, the sites with the highest abundance of cable bacteria were characterized by a large $\mathrm{FeS}+\mathrm{FeOx}$ pool, relatively high rates of sulfate reduction and upward fluxes of $\Sigma \mathrm{H}_{2} \mathrm{~S}$, and large seasonal variations in bottom water $\mathrm{O}_{2}$ with high concentrations in winter and spring (Figures 3.2 and 3.3). We conclude that both sulfate reduction and the dissolution of FeS act as a source of $\Sigma \mathrm{H}_{2} \mathrm{~S}$ for cable bacteria in the Gulf of Finland.

Bioturbation can inhibit the development of cable bacteria by damaging the bacterial filaments, causing a disruption of the electrochemical signal (Malkin et al., 2014). Previously, high numbers of polychaetes belonging to the genus Marenzelleria were observed at the oxic site GOF3 (Josefson et al., 2012). Visual observations during slicing of the cores for pore water collection also suggest disturbance by macrofauna at this site. Polychaetes also dominated the macrofaunal community at Arkona, GOF5, LL3A, and Bornholm, whereas bivalves were most abundant at LF1 and 311 (Table 3.2 and Figures S.3.9-S.3.11). The genera of polychaetes (ind. $\mathrm{m}^{-2}$ ) differed among these four sites (Figure S.3.10A). The three major polychaetes observed at Arkona were Scoloplos, Bylgides, and Terebellides. At sites GOF5 and LL3A, Marenzelleria dominated, whereas Scoloplos were the most prevalent polychaetes at Bornholm. In terms of macrofaunal biomass (AFDM), site GOF5 and LL3A had the highest biomass of polychaetes (1.8 and $2.2 \mathrm{~g} \mathrm{~m}^{-2}$, respectively; Figure S.3.10B). The biomass of polychaetes at Arkona was comparatively low $\left(0.2 \mathrm{~g} \mathrm{~m}^{-2}\right)$, even though the absolute number of polychaetes at Arkona was similar to that of GOF5 and LL3A (Table 3.2). Macrofauna were absent at JML, LL19, and F80 (Figure 3.2G). In general, macrofaunal abundances at our 12 sites were relatively low ( $<1700$ ind. $\mathrm{m}^{-2}$; Figure $\left.3.2 \mathrm{G}\right)$ when compared to other temperate coastal systems, such as, for example the Western Black Sea shelf (6 000-10 000 ind. $\mathrm{m}^{-2}$; Friedrich et al., 2002; Lenstra et al., 2019) and the North Sea (2 400-21 000 ind. $\mathrm{m}^{-2}$; Dauwe et al., 1998). The relatively impoverished macrofaunal community in the Baltic Sea is a consequence of its natural constraints by brackish conditions that limit macrofaunal abundance and diversity and the recent human-induced increased prevalence of hypoxia (Conley et al., 2009). We did not find a relationship between macrofaunal abundances (expressed as ind. $\mathrm{m}^{-2}$ and AFDM g m $\mathrm{m}^{-2}$ ) and cable bacterial abundances (Figure S.3.12A and B), suggesting that at most sites the impoverished macrofaunal communities did not significantly hamper growth of cable bacteria. Interestingly, the areal density of cable bacteria and biomass (AFDM) of polychaetes was highest at sites GOF5 and LL3A (Figure S.3.12C). This further indicates that the polychaetes did not disturb the growth of cable bacteria. However, at our oxic site GOF3, which was characterized by high bottom water $\mathrm{O}_{2}$ and a high diffusive supply of $\Sigma \mathrm{H}_{2} \mathrm{~S}$, the low areal density of cable bacteria was likely due to intense bioturbation by Marenzelleria. A similar low areal density of cable bacteria was observed in a recent study at a permanently oxic site in the Eastern Gotland Basin and was also attributed to the presence of Marenzelleria (Marzocchi et al., 2018) .

Cable bacteria can tolerate a wide range of salinities, because they occur in marine, brackish, and fresh water environments (Risgaard-Petersen et al., 2015). Bottom water salinity varied widely among our 12 sites, from 7.5 to 18.5 , but showed no relationship with the abundance of cable bacteria (Figures $3.2 \mathrm{H}$ and S.3.12D). Bottom water salinities at our study sites were slightly higher than under normal circumstances because of recent inflows of saline water from the North Sea (Figure 3.2H). Organic carbon in the upper $2 \mathrm{~cm}$ of the surface sediment varied from 1 to $13 \mathrm{wt}$ $\%$ (Table 3.1), and again, there was no relationship with the abundance of cable bacteria (Figures 3.2I and S.3.12E). The rate of anaerobic degradation of organic matter, here approximated by the 
ammonium flux toward the sediment-water interface (Figures 3.2J and S.3.8) showed the same linear trend with cable bacterial abundances as $\mathrm{\Sigma}_{2} \mathrm{~S}$ at most seasonally hypoxic sites (Figure S.3.12F).

Table 3.2 | Macrofaunal Individuals per Square Meter for Six Taxonomic Classes in May and June 2016.

\begin{tabular}{|c|c|c|c|c|c|c|c|}
\hline Site & Polychaeta & Sipunculida & Oligochaeta & Bivalvia & Malacostraca & Insecta & Total \\
\hline GOF3 & $\mathrm{N} / \mathrm{A}$ & $\mathrm{N} / \mathrm{A}$ & $\mathrm{N} / \mathrm{A}$ & $\mathrm{N} / \mathrm{A}$ & $\mathrm{N} / \mathrm{A}$ & $\mathrm{N} / \mathrm{A}$ & $\mathrm{N} / \mathrm{A}$ \\
\hline Arkona & $1111 \pm 393$ & 0 & $69 \pm 62$ & $306 \pm 243$ & $139 \pm 124$ & $69 \pm 76$ & $1694 \pm 593$ \\
\hline LF1 & $23 \pm 33$ & $139 \pm 57$ & 0 & $463 \pm 87$ & 0 & 0 & $625 \pm 113$ \\
\hline 311 & $23 \pm 33$ & $81 \pm 48$ & 0 & $185 \pm 65$ & 0 & $12 \pm 26$ & $301 \pm 104$ \\
\hline GOF5 & $1100 \pm 225$ & $12 \pm 26$ & 0 & $58 \pm 129$ & $12 \pm 26$ & $46 \pm 33$ & $1227 \pm 249$ \\
\hline LL3A & $995 \pm 741$ & 0 & 0 & 0 & 0 & $12 \pm 26$ & $1007 \pm 734$ \\
\hline JML & 0 & 0 & 0 & 0 & 0 & 0 & 0 \\
\hline LL19 & 0 & 0 & 0 & 0 & 0 & 0 & 0 \\
\hline $\mathrm{F} 80$ & 0 & 0 & 0 & 0 & 0 & 0 & 0 \\
\hline Bornholm & $1278 \pm 717$ & 0 & 0 & 0 & 0 & $83 \pm 28$ & $1361 \pm 705$ \\
\hline BY15 & 0 & 0 & 0 & 0 & 0 & 0 & 0 \\
\hline BY15A & 0 & 0 & 0 & 0 & 0 & 0 & 0 \\
\hline
\end{tabular}

The absence of a correlation between the abundance of cable bacteria, macrofaunal abundances, salinity, and sediment organic carbon (Figures 3.2 and S.3.12) highlights that in sediments with no to moderate disturbance by bioturbation, the availability of $\mathrm{O}_{2}$ and $\Sigma \mathrm{H}_{2} \mathrm{~S}$ are the key controls that determine the abundance of cable bacteria. While at the oxic site GOF3 both $\mathrm{O}_{2}$ and $\Sigma \mathrm{H}_{2} \mathrm{~S}$ were abundantly present, cable bacteria were likely inhibited by high macrofaunal activity. At the anoxic sites LL19 and F80, there was insufficient $\mathrm{O}_{2}$. At the reoxygenated sites Bornholm, BY15, and BY15A, $\mathrm{O}_{2}$ concentrations likely remained too low for cable bacteria. Beggiatoaceae were abundantly present as thick mats, and because they are better adapted to such low bottom $\mathrm{O}_{2}$ conditions, they likely outcompeted the cable bacteria. This is supported by our observation that reoxygenation of the overlying water for sediment from site BY15A in the laboratory did not result in cable bacteria activity (Figure S.3.13A).

The seasonally hypoxic sites provided the best conditions for cable bacteria, with the variation in abundance between sites explained by the diffusive supply of $\mathrm{\Sigma H}_{2} \mathrm{~S}$ (Figure 3.3A). These sites had a high $\mathrm{O}_{2}$ availability during a major part of the year in concert with a high diffusive supply of $\Sigma \mathrm{H}_{2} \mathrm{~S}$ and a large $\mathrm{FeS}+\mathrm{FeOx}$ pool (Figure 3.2F). Because the bottom water $\mathrm{O}_{2}$ levels at both sites were extremely low at the time of sampling $(\sim 5-10 \mu \mathrm{M}$; Table 3.1$)$, cable bacteria were not very active. Strikingly, the activity of cable bacteria in a sediment core retrieved from GOF5 could be stimulated rapidly (within $\sim 5$ days) upon reoxygenation of the overlying bottom water (Figure S.3.13B).

In summary, this indicates three requirements for a high abundance of cable bacteria: (1) high bottom water $\mathrm{O}_{2}$ availability during a major part of the year; (2) availability of $\Sigma \mathrm{H}_{2} \mathrm{~S}$; (3) no to moderate disturbance by macrofaunal bioturbation. Such conditions are found at our study sites in the Gulf of Finland. Other factors, such as the availability and degradation of organic matter and bottom water salinity (within the salinity range at our sites, i.e. 7.5-18.5) are of less importance. The strong dependence of cable bacteria on the availability of $\Sigma \mathrm{H}_{2} \mathrm{~S}$ is typical for chemoautotrophic sulfuroxidizing bacteria (e.g., Nelson and Jannasch, 1983). However, recent work on cable bacteria indicates that they are likely heterotrophs (Vasquez-Cardenas et al., 2015). Apparently, the requirements of cable bacteria for organic carbon are relatively easily met, allowing the availability of $\Sigma \mathrm{H}_{2} \mathrm{~S}$ to become a key control. 


\subsubsection{Biogeochemical Impact of Cable Bacteria}

Cable bacteria activity can strongly impact sedimentary Fe and S cycling (Seitaj et al., 2015; SuluGambari et al., 2016a; Sulu-Gambari et al., 2016b), because the acidification of the pore water ( $\mathrm{pH}$ 6.5; Figure S.3.13B; Pfeffer et al., 2012; Malkin et al., 2014) can facilitate the dissolution of FeS and promote the formation of Fe oxides(Risgaard-Petersen et al., 2012; Meysman et al., 2015). The FeS $+\mathrm{FeOx}$ pool in the upper part of the sediment (Figure 3.2F) provides insight into the maximum amount of Fe oxides that can be formed on a seasonal basis. This amount of Fe oxides ultimately controls how much $\Sigma \mathrm{H}_{2} \mathrm{~S}$ can be sequestered before free $\Sigma \mathrm{H}_{2} \mathrm{~S}$ is released into the water column during bottom water anoxia.

In the Gulf of Finland at site GOF5, the metabolic activity of cable bacteria and associated pore water acidification in spring likely contributed to the formation of the Fe oxides $\left(0.17 \mathrm{~mol} \mathrm{~m}^{-2}\right)$ observed in the surface sediment in June 2016 (Figures 3.2F and 3.4A). The estimated depletion of $\mathrm{FeS}$ at GOF5 over the first $2.5 \mathrm{~cm}$ is $0.17 \mathrm{~mol} \mathrm{~m}^{-2}$ (Figure 3.4B). Assuming that all $\mathrm{Fe}^{2+}$ released upon dissolution of $\mathrm{FeS}$ would precipitate as $\mathrm{Fe}$ oxides upon contact with $\mathrm{O}_{2}$, this would give an increase in $\mathrm{Fe}$ oxides of $0.17 \mathrm{~mol} \mathrm{~m}^{-2}$, which is in line with our observations. The abundant presence of Fe oxides in surface sediments has previously been shown to delay euxinia in seasonally hypoxic Lake Grevelingen (Seitaj et al., 2015). At our site GOF5, the sulfate reduction rate was $2 \mathrm{mmol} \mathrm{m}^{-2} \mathrm{day}^{-1}$. This would imply that if the activity of the cable bacteria ceases because of the onset of hypoxia, the Fe oxide layer can temporarily delay the escape of $\Sigma \mathrm{H}_{2} \mathrm{~S}$ from the sediment for a period of $\sim 85$ days.

An alternative mechanism for the development of an Fe oxide layer could be bioirrigation by Marenzelleria. These Marenzellaria are capable of pumping $\mathrm{O}_{2}$ into pore waters, thereby enhancing the oxidation of reduced Fe (Norkko et al., 2012). However, the number of Marenzellaria that wa
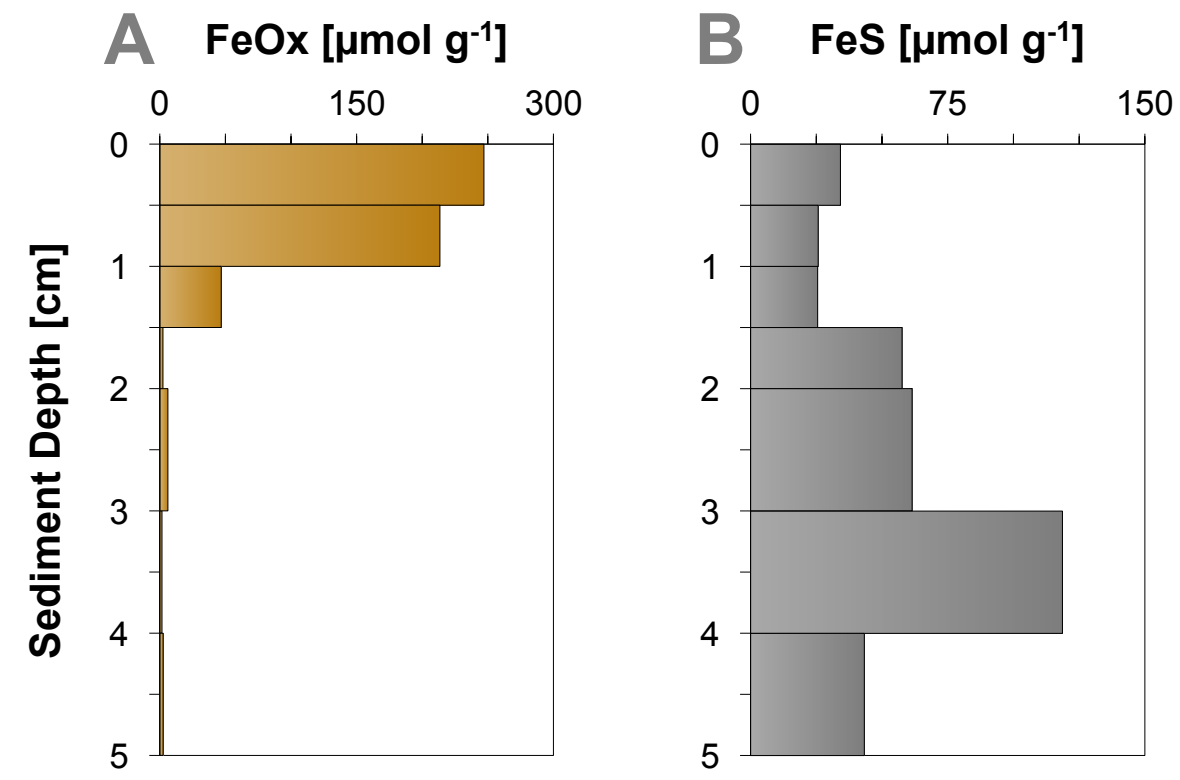

Figure 3.4 | Solid-phase profiles of (A) labile Fe(III) oxides (FeOx) and (B) FeS (AVS) for GOF5 in June 2016. 
observed at GOF5 was relatively moderate (1100 \pm 225 ind. $\mathrm{m}^{-2}$; Table 3.2), and results of a reactive transport model for a similar site suggest that much higher population densities $>3000$ ind. $\mathrm{m}^{-2}$ are required to have a significant effect on the formation of Fe oxides (Norkko et al., 2012). Bioirrigation by Marenzelleria also typically leads to oxidation of the sediment down to a depth of several centimeters (Norkko et al., 2012). Because we observed Fe oxides only within the top $1 \mathrm{~cm}$ of the surface sediment at site GOF5, this confirms that the role of Marenzelleria with respect to oxidation of the sediment by bioirrigation was likely negligible. The insignificant impact of Marenzelleria on biorrigation is further supported by bromide incubations performed on intact sediment cores retrieved from site LF1 and Arkona (Supporting Information 3.10; Figure S.3.14). These incubations indicate very low rates of bioirrigation at site LF1 and Arkona, despite the presence of polychaetes (Table 3.2).

Water column monitoring data indicate that the bottom waters in the Gulf of Finland are rarely euxinic (Figure 3.2A). We suggest that cable bacteria are responsible for the absence of $\Sigma \mathrm{H}_{2} \mathrm{~S}$ in the bottom water of the Gulf of Finland in summer, by inducing the formation of strong surface enrichments of Fe oxides in winter and/or spring (Figure 3.5). The Gulf of Finland is only the second system for which this Fe oxide buffer mechanism has been suggested, after Lake Grevelingen, and the first with a relatively low bottom water salinity $(\sim 9-11$ versus $\sim 32$; Hagens et al., 2015). The Fe oxide buffer mechanism induced by cable bacteria is likely of importance in many other eutrophic, brackish coastal areas characterized by moderate of disturbance by bioturbation, high bottom water $\mathrm{O}_{2}$ and a high sediment supply of $\Sigma \mathrm{H}_{2} \mathrm{~S}$.

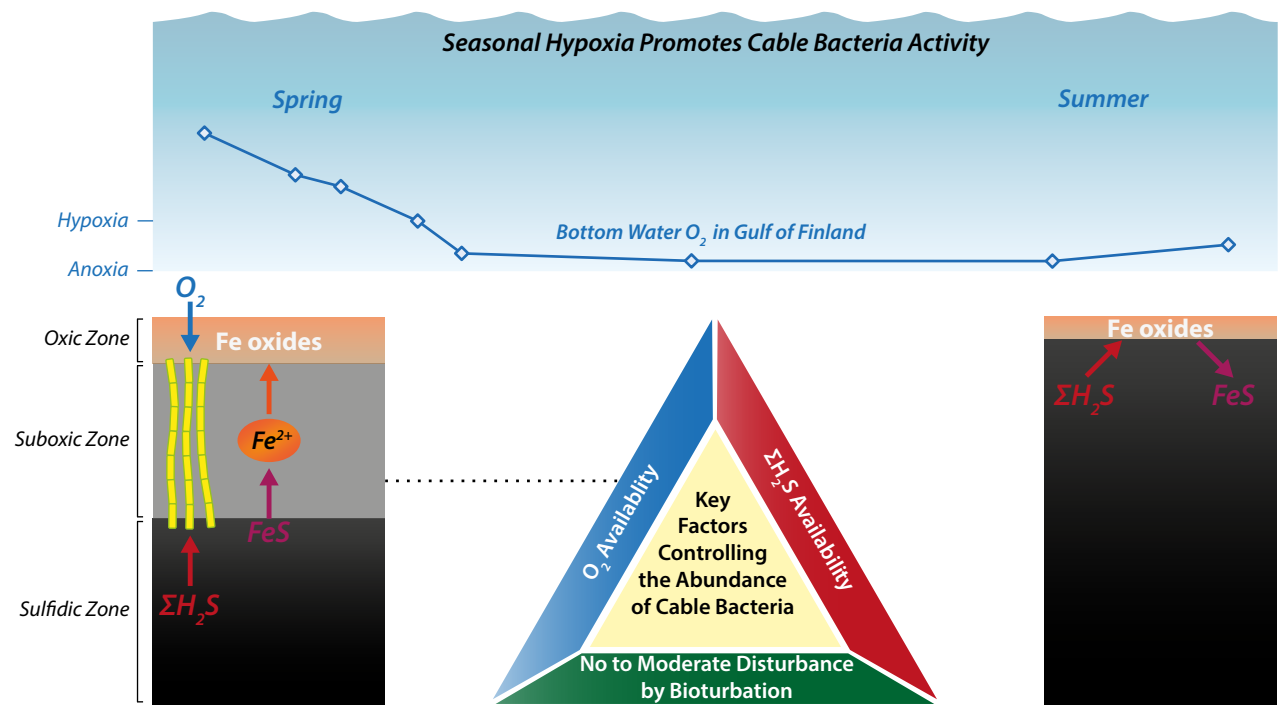

Figure 3.5 Impact of cable bacteria on the bottom water in the Gulf of Finland. Conversion of FeS to Fe oxides by cable bacteria in spring, prevents release of sulfide in summer. The three requirements for metabolic activity of cable bacteria are: (1) bottom $\mathrm{O}_{2}$ availability, (2) supply of $\Sigma \mathrm{H}_{2} \mathrm{~S}$ and (3) low to no bioturbation. 


\section{Acknowledgments}

We are grateful to the crew of the R/V Pelagia and scientists for their assistance during the sampling campaigns. We are also grateful to M. Astudillo Pascual, R. van Zummeren, R. K. Groeneveld, H. de Waard, J. J. Mulder, and A. E. van Dijk for analytical support. This research was funded by The Netherlands Organization for Scientific (NWO) Research Vici Grant 865.13.005 to C.P.S. Further support was provided by NWO Vici Grant 016.VICI.170.072 to F.J.R.M. and Research Foundation Flanders FWO Grant G031416N to F.J.R.M. and The Netherlands Earth System Science Center (NESSC), financially supported by the Ministry of Education, Culture and Science (OCW). 


\section{S.3. Supplementary Information}

\section{S.3.1 Bottom Water $\mathrm{O}_{2}$ Ranges}

Table S.3.1 | Bottom water $\mathrm{O}_{2}$ ranges based on HELCOM monitoring data for January 2014 - December 2016 (Figure 3.2A). Our study sites are divided into four categories based on their bottom water $\mathrm{O}_{2}$ conditions. Oxic sites are defined by bottom water $\mathrm{O}_{2}$ levels that are higher than $63 \mu \mathrm{M}$ (hypoxic boundary) throughout the year. Seasonally hypoxic sites are characterized by a large range in bottom water $\mathrm{O}_{2}$ and bottom waters are temporarily $<63 \mu \mathrm{M}$ during the year. Bottom waters at anoxic sites contain very little $(0-5 \mu \mathrm{M}) \mathrm{O}_{2}$ throughout the year. Reoxygenated sites are anoxic under normal conditions, however, due to the recent Major Baltic Inflows, bottom water $\mathrm{O}_{2}$ was elevated in the time period 2014-2016. Note that, bottom water $\mathrm{O}_{2}$ measurements on a high temporal resolution (1-3 months) were not available for all sites. Where this was the case, we used $\mathrm{O}_{2}$ monitoring data from nearby sites. These sites are highlighted in blue.

\begin{tabular}{|c|c|c|c|c|c|c|c|c|}
\hline Site & $\begin{array}{l}\text { Bottom water } \\
\text { conditions }\end{array}$ & HELCOM site & $\begin{array}{l}\text { Water depths } \\
\text { used [m] }\end{array}$ & $\begin{array}{c}\text { Median } \mathrm{O}_{2} \\
{[\mu \mathrm{M}]}\end{array}$ & $\begin{array}{l}\text { Lower quartile } \\
\qquad \mathrm{O}_{2}[\mu \mathrm{M}]\end{array}$ & $\begin{array}{l}\text { Upper quartile } \\
\qquad \mathrm{O}_{2}[\mu \mathrm{M}]\end{array}$ & $\begin{array}{c}\text { Minimum } \\
\mathrm{O}_{2}[\mu \mathrm{M}]\end{array}$ & $\begin{array}{c}\text { Maximum } \\
\mathrm{O}_{2}[\mu \mathrm{M}]\end{array}$ \\
\hline GOF3 & oxic & UU-10A & $46-53$ & 258.8 & 220.5 & 303.2 & 88.8 & 358.3 \\
\hline Arkona & seasonally hypoxic & Arkona (BY2) & $46-47$ & 216.1 & 195.1 & 252.2 & 34.6 & 335.1 \\
\hline LF1 & seasonally hypoxic & F80 & $61-71$ & 177.2 & 110.9 & 261.0 & 38.9 & 351.3 \\
\hline 311 & seasonally hypoxic & BY15 & $65-71$ & 173.7 & 94.1 & 235.8 & 48.6 & 375.8 \\
\hline GOF5 & seasonally hypoxic & LL7 & $61-78$ & 168.7 & 77.0 & 211.9 & 4.4 & 346.1 \\
\hline LL3A & seasonally hypoxic & LL3A & $57-60$ & 125.1 & 61.7 & 213.5 & 7.0 & 342.1 \\
\hline JML & seasonally hypoxic & $\mathrm{JML}$ & $73-81$ & 12.3 & 9.2 & 20.4 & 0.0 & 179.4 \\
\hline LL19 & anoxic* & - & - & - & - & - & - & - \\
\hline F80 & anoxic & $\mathrm{F} 80$ & $187-194$ & 0.0 & 0.0 & 0.0 & 0.0 & 4.4 \\
\hline Bornholm & reoxygenated & $\begin{array}{l}\text { W Bornholm Basin } \\
\text { Off Shore }\end{array}$ & $84-90$ & 75.0 & 16.2 & 109.2 & 6.6 & 228.8 \\
\hline BY15 & reoxygenated & BY15 & $227-237$ & 5.9 & 0.0 & 14.9 & 0.0 & 69.1 \\
\hline BY15A & reoxygenated & BY15 & $200-202$ & 18.8 & 0.7 & 39.9 & 0.0 & 71.3 \\
\hline
\end{tabular}

*Classification for LL19 based on Jilbert and Slomp (2013). 


\section{S.3.2 Visual Observation of Beggiatoaceae}

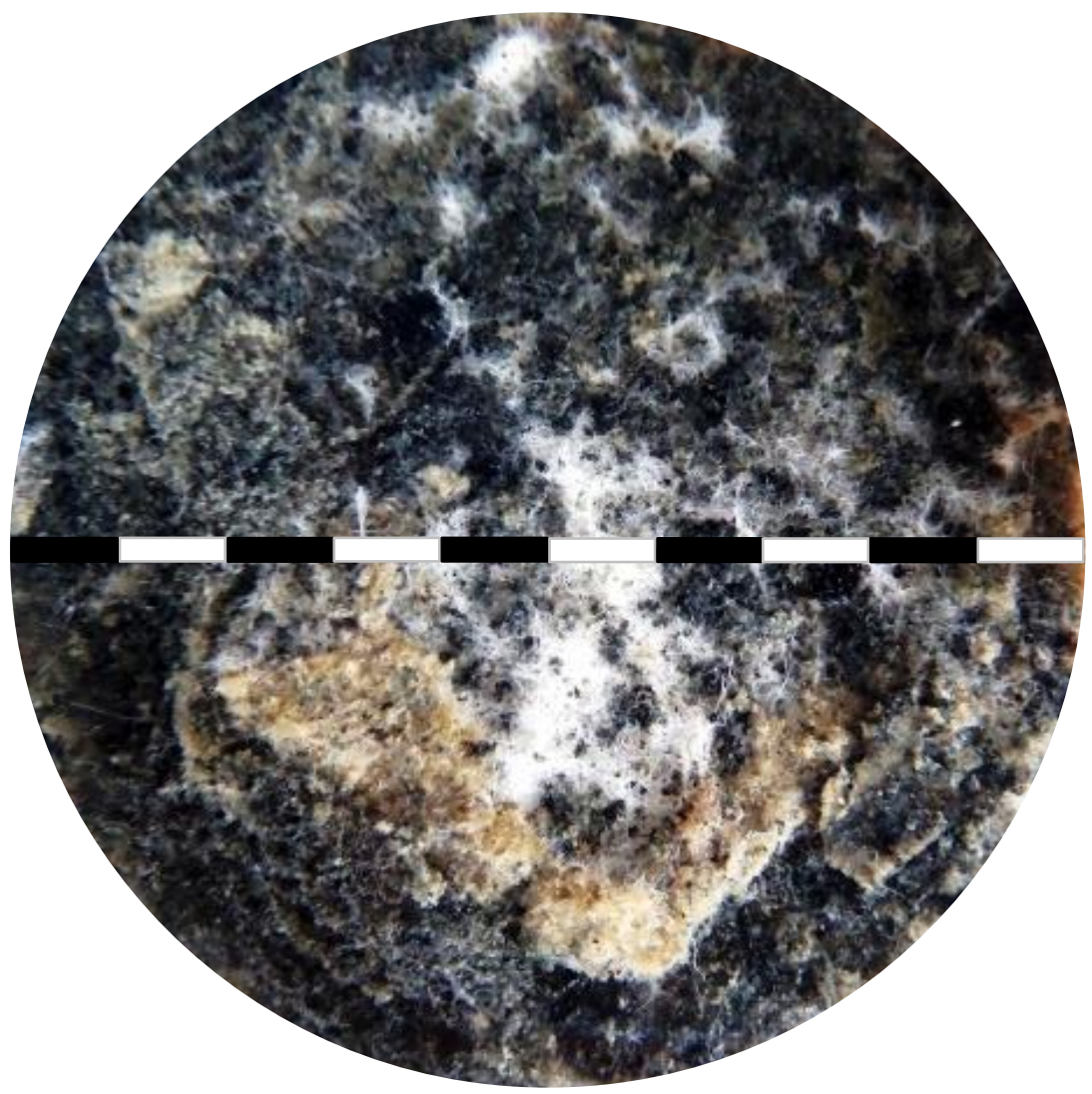

Figure S.3.1 | The brown and white patches represent a microbial mat of sulfur oxidizing bacteria belonging to the family Beggiatoaceae. This photo shows the surface sediment from a sediment core retrieved at site BY15A. The scale bar covers a distance of $10 \mathrm{~cm}$, with $1 \mathrm{~cm}$ intervals. Adapted from Hermans et al. (2019). 


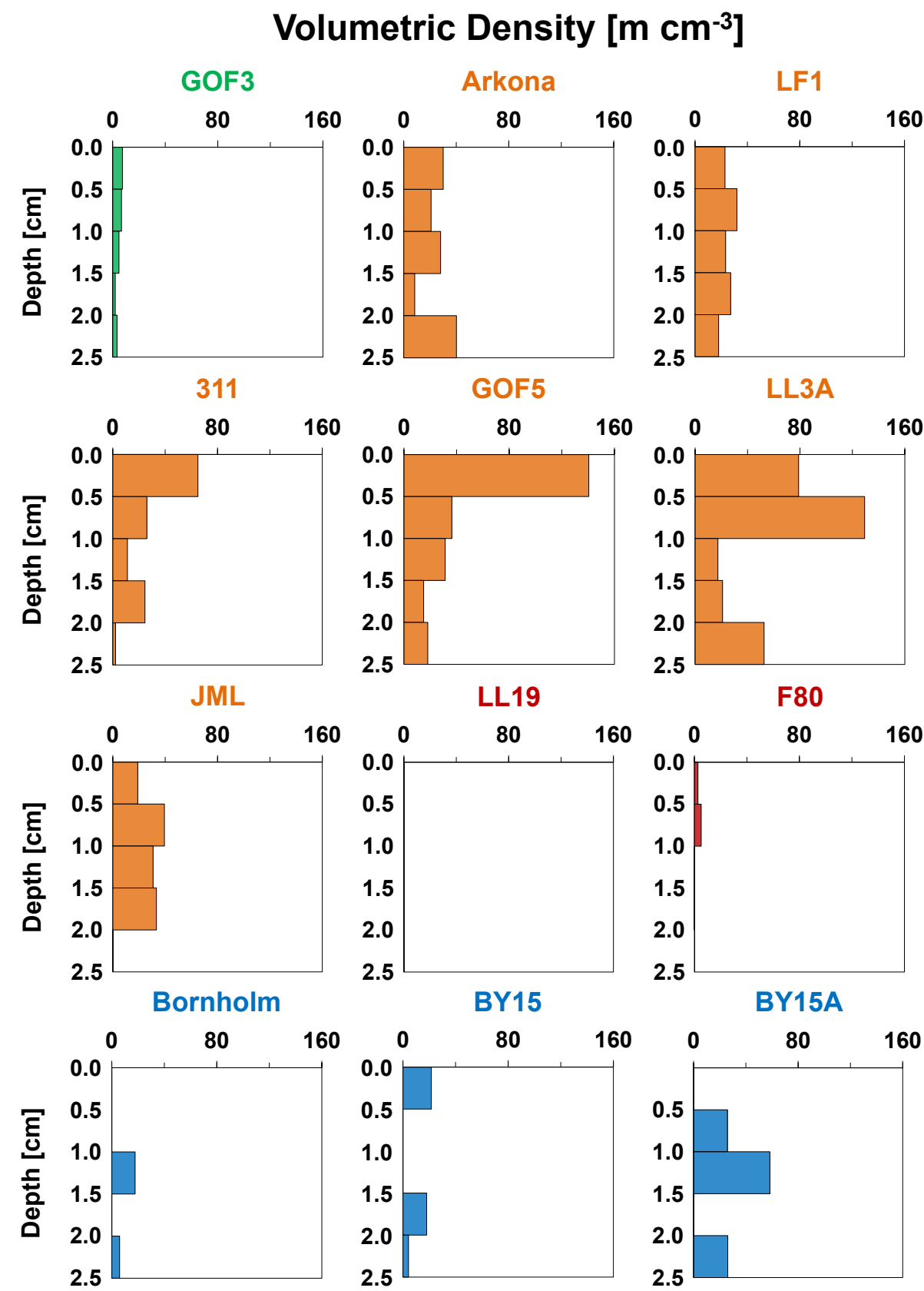

Figure S.3.2 | Volumetric Density $\left[\mathrm{m} \mathrm{cm}^{-3}\right]$ of cable bacteria in the top $2.5 \mathrm{~cm}$ of the sediment. The sample sites are classified based on bottom water redox conditions, as described in Figure 3.1. 


\section{FISH analysis}

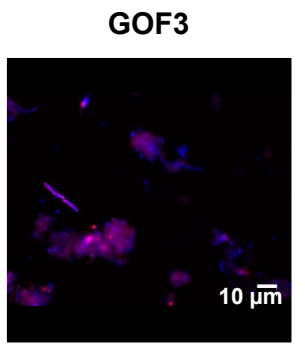

311

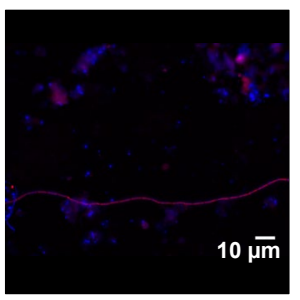

JML

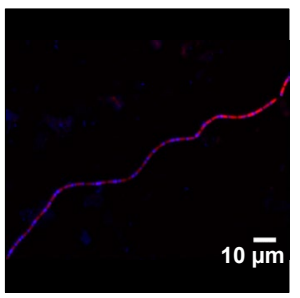

Bornholm

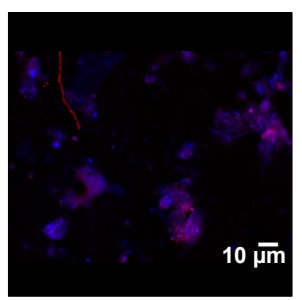

Arkona

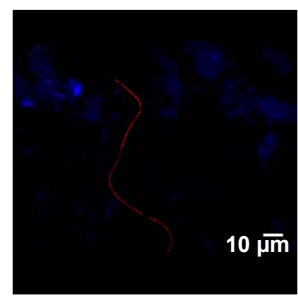

GOF5

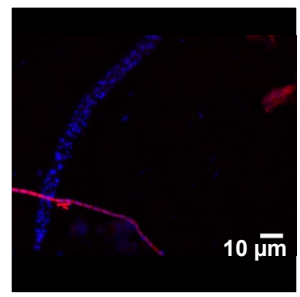

LL19

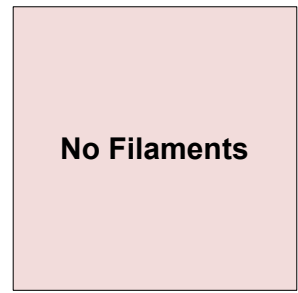

BY15

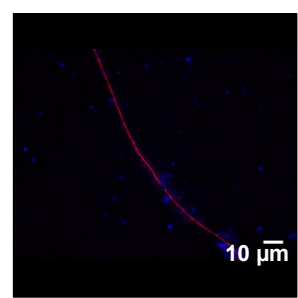

LF1

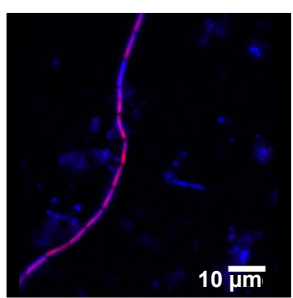

LL3A

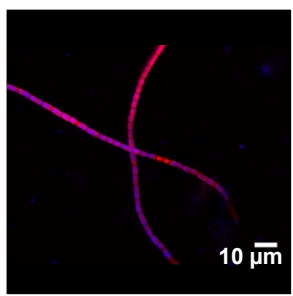

F80

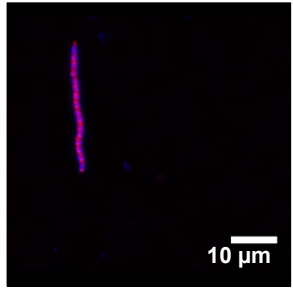

BY15A

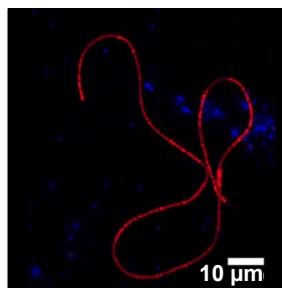

Figure S.3.3 | FISH analysis of cable bacteria filaments in the surface sediment at the twelve Baltic Sea sites (May/June 2016). 

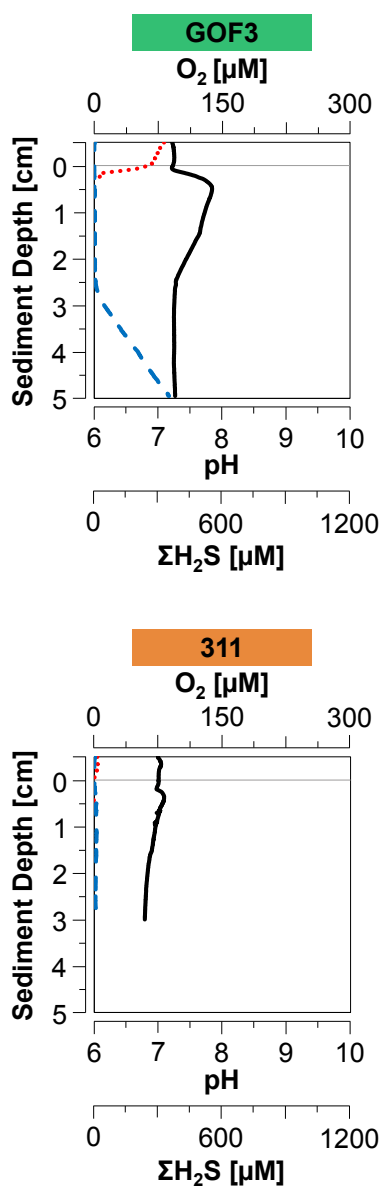
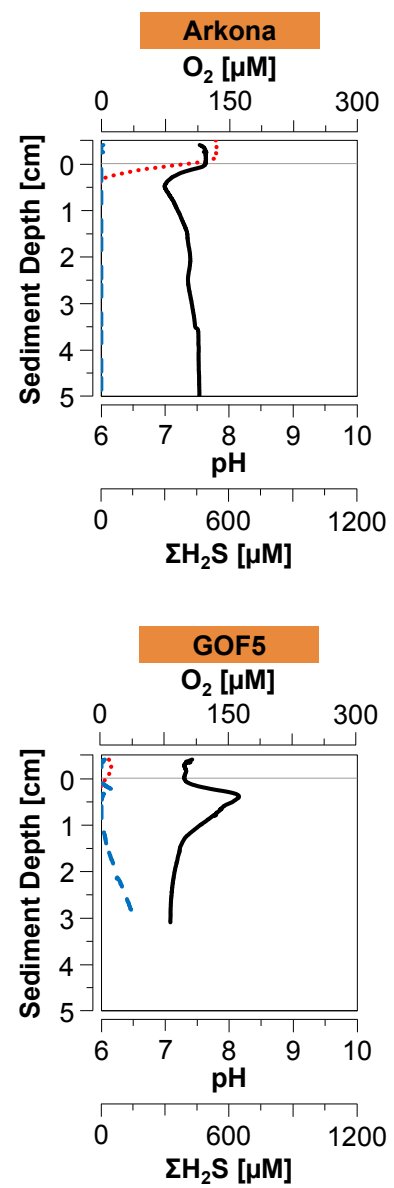
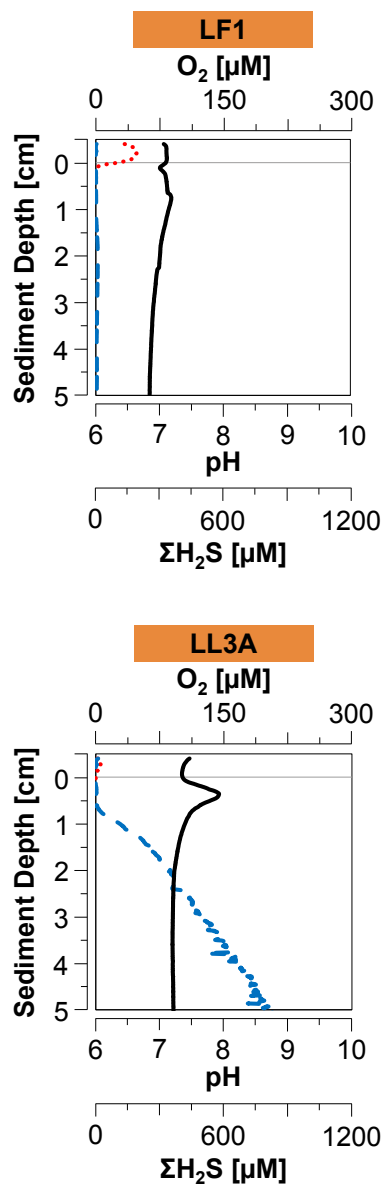

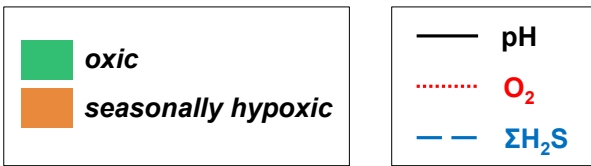

Figure S.3.4 | High resolution depth profiles of $\mathrm{pH}$ (black), $\mathrm{O}_{2}$ (red) and $\Sigma \mathrm{H}_{2} \mathrm{~S}$ (blue). Duplicate measurements of $\mathrm{pH}$ were similar. 

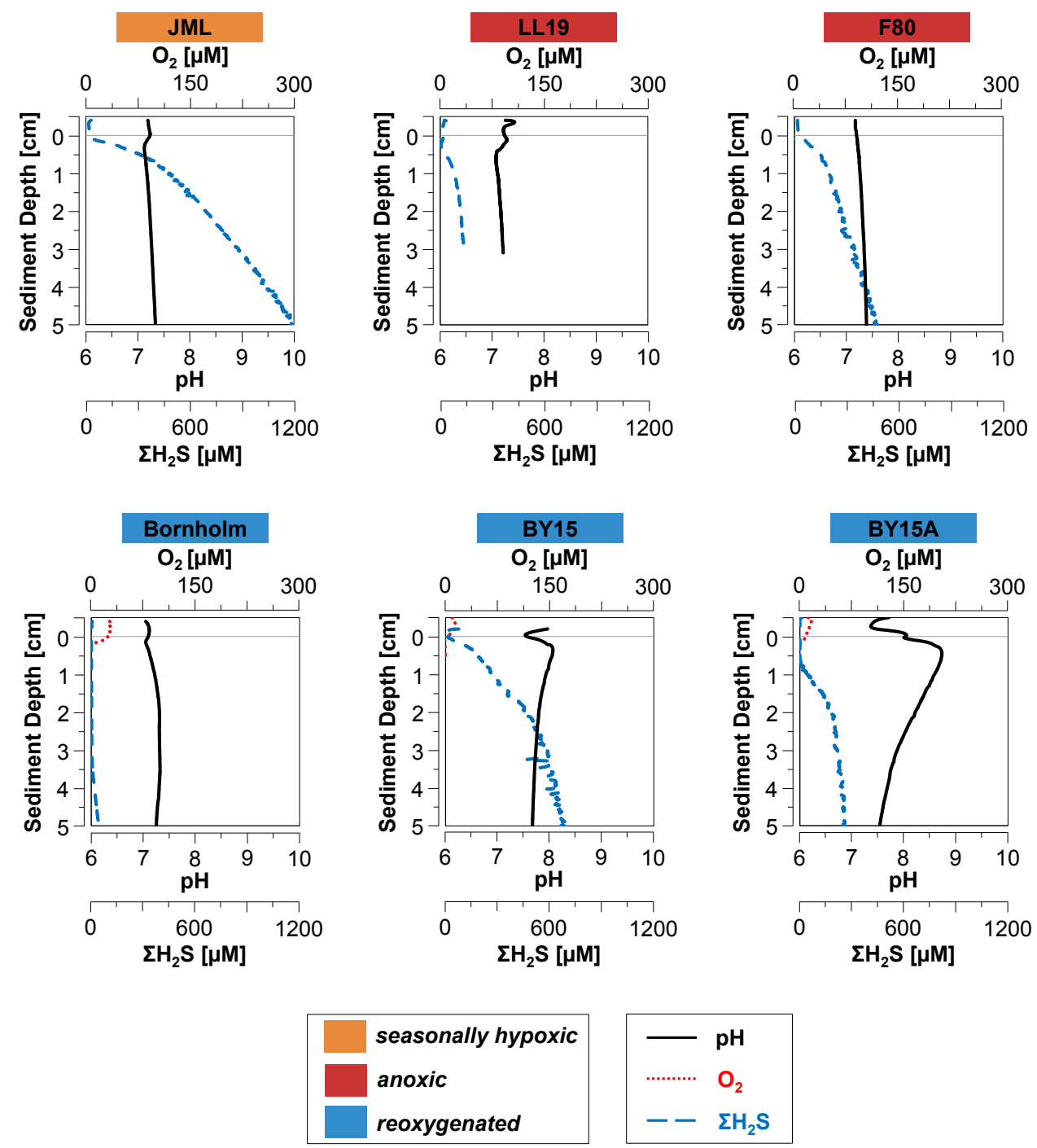

Figure S.3.4 (continued) | High resolution depth profiles of $\mathrm{pH}$ (black), $\mathrm{O}_{2}$ (red) and $\Sigma \mathrm{H}_{2} \mathrm{~S}$ (blue). Duplicate measurements of $\mathrm{pH}$ were similar. 
S.3.5. Depth Profiles of Sulfate Reduction Rates and Pore Water $\mathrm{SO}_{4}^{2-}, \Sigma \mathrm{H}_{2} \mathrm{~S}$ and $\mathrm{NH}_{4}^{+}$

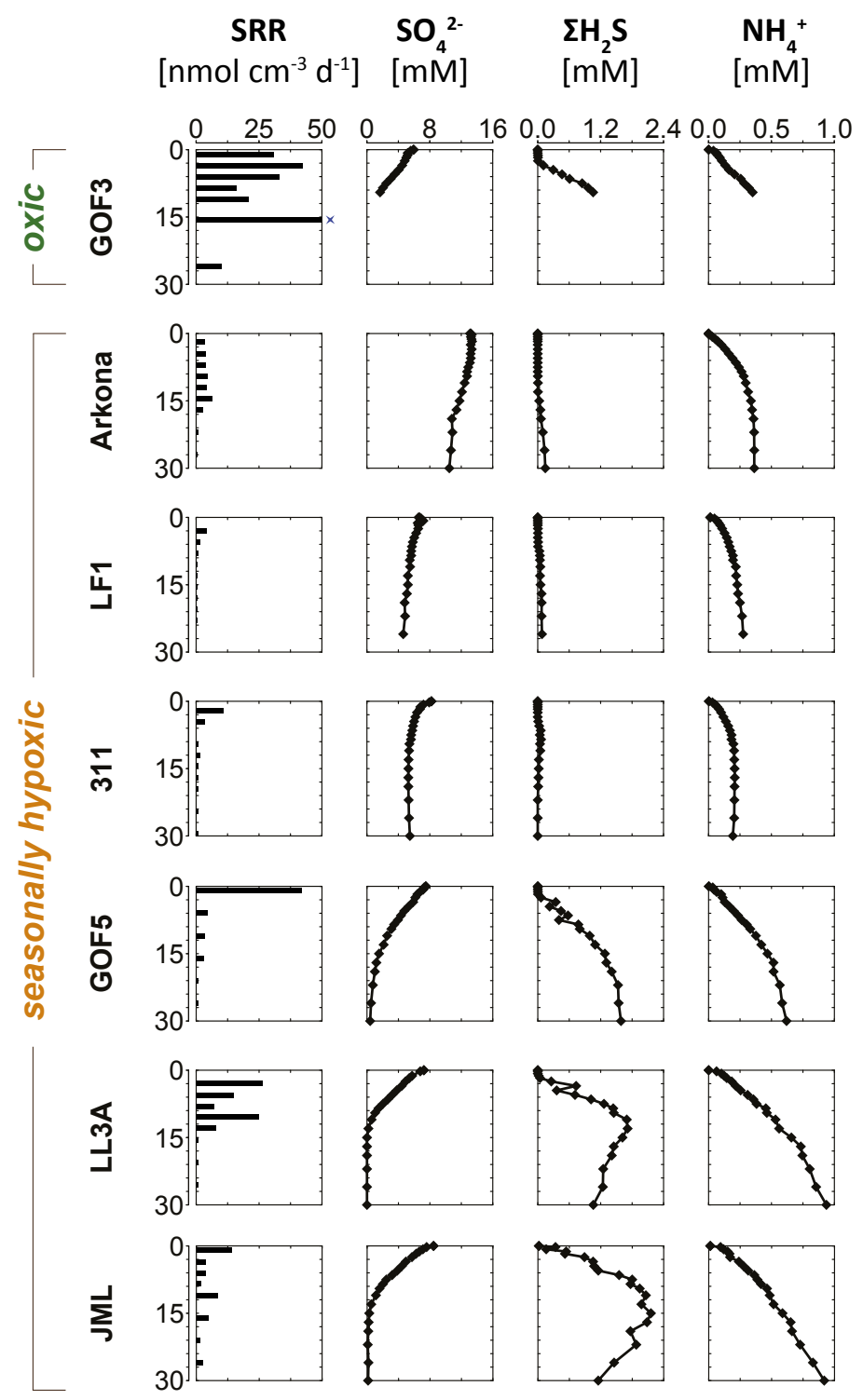

Figure S.3.5 | Depth profiles of sulfate reduction rates (SRR) and pore water $\mathrm{SO}_{4}{ }^{2-}, \mathrm{\Sigma H}_{2} \mathrm{~S}_{\text {and }} \mathrm{NH}_{4}{ }^{+}$at the oxic and seasonally hypoxic sites (May/June 2016). The blue star indicates an extremely high sulfate reduction rate at site GOF3 $\left(279 \mathrm{nmol} \mathrm{cm}^{-3} \mathrm{~d}^{-1}\right)$. 


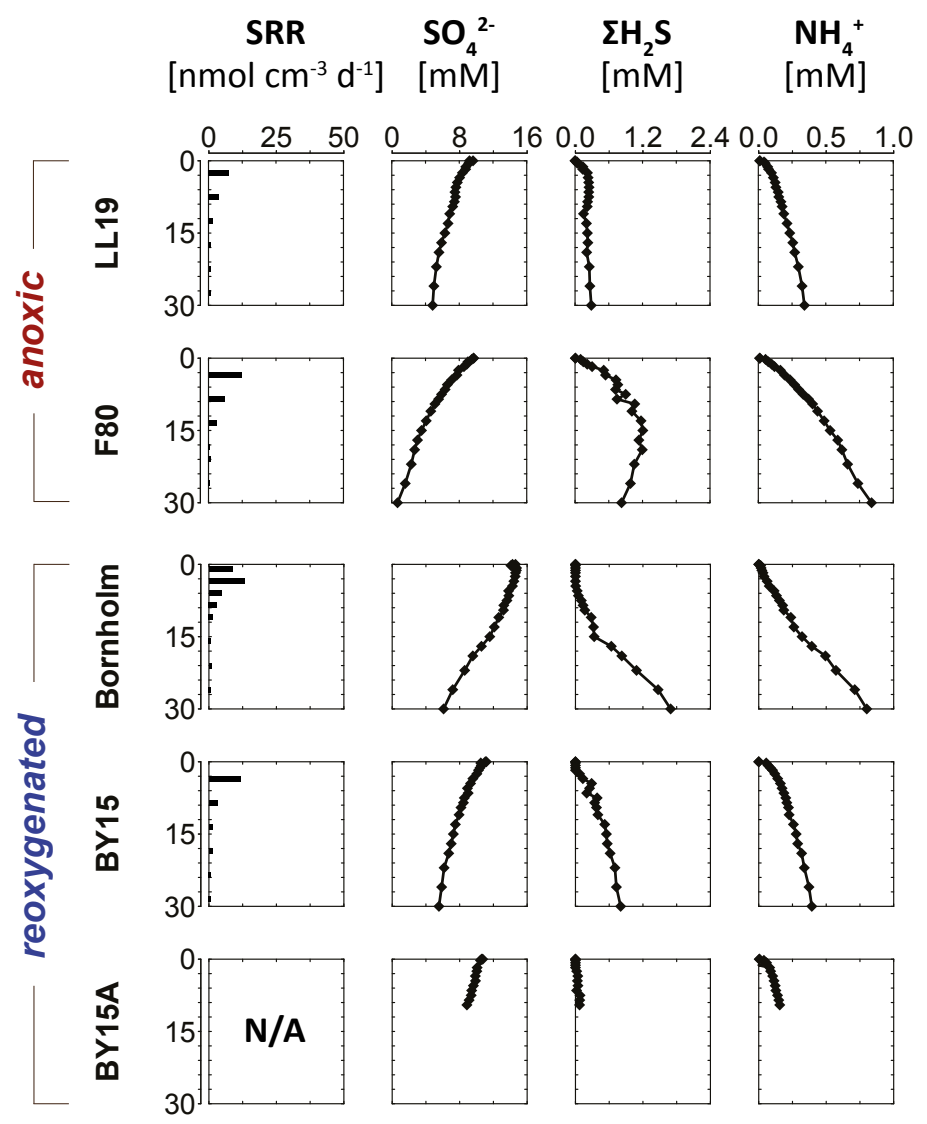

Figure S.3.5 (continued) | Depth profiles of sulfate reduction rates (SRR) and pore water $\mathrm{SO}_{4}^{2-}, \Sigma \mathrm{H}_{2} \mathrm{~S}$ and $\mathrm{NH}_{4}^{+}$at the oxic and seasonally hypoxic sites (May/June 2016). 


\section{S.3.6. Linear Pore Water Gradients of $\mathrm{\Sigma H}_{2} \mathrm{~S}, \mathrm{SO}_{4}{ }^{2-}$ and $\mathrm{NH}_{4}{ }^{+}$used for Diffusive Fluxes}
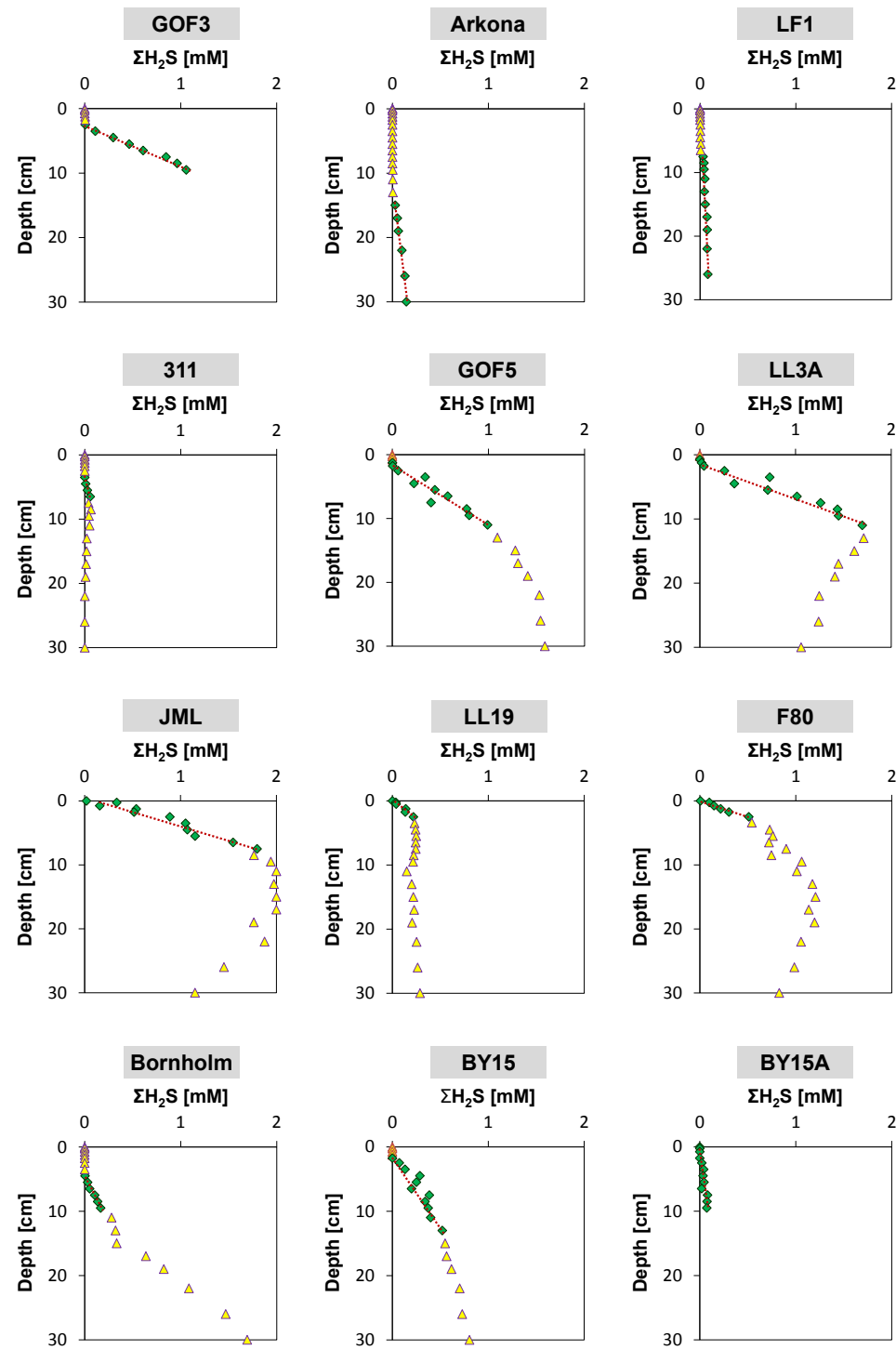

Data points used for flux $\triangle$ Other data points

Figure S.3.6 | Pore water depth profiles of $\mathrm{\Sigma H}_{2} \mathrm{~S}$ (May/June 2016). The linear gradient in the green diamonds represents data points that were used for the calculation of the upward $\mathrm{\Sigma H}_{2} \mathrm{~S}$ flux, whereas the yellow triangles are data points that were not used for this calculation. 

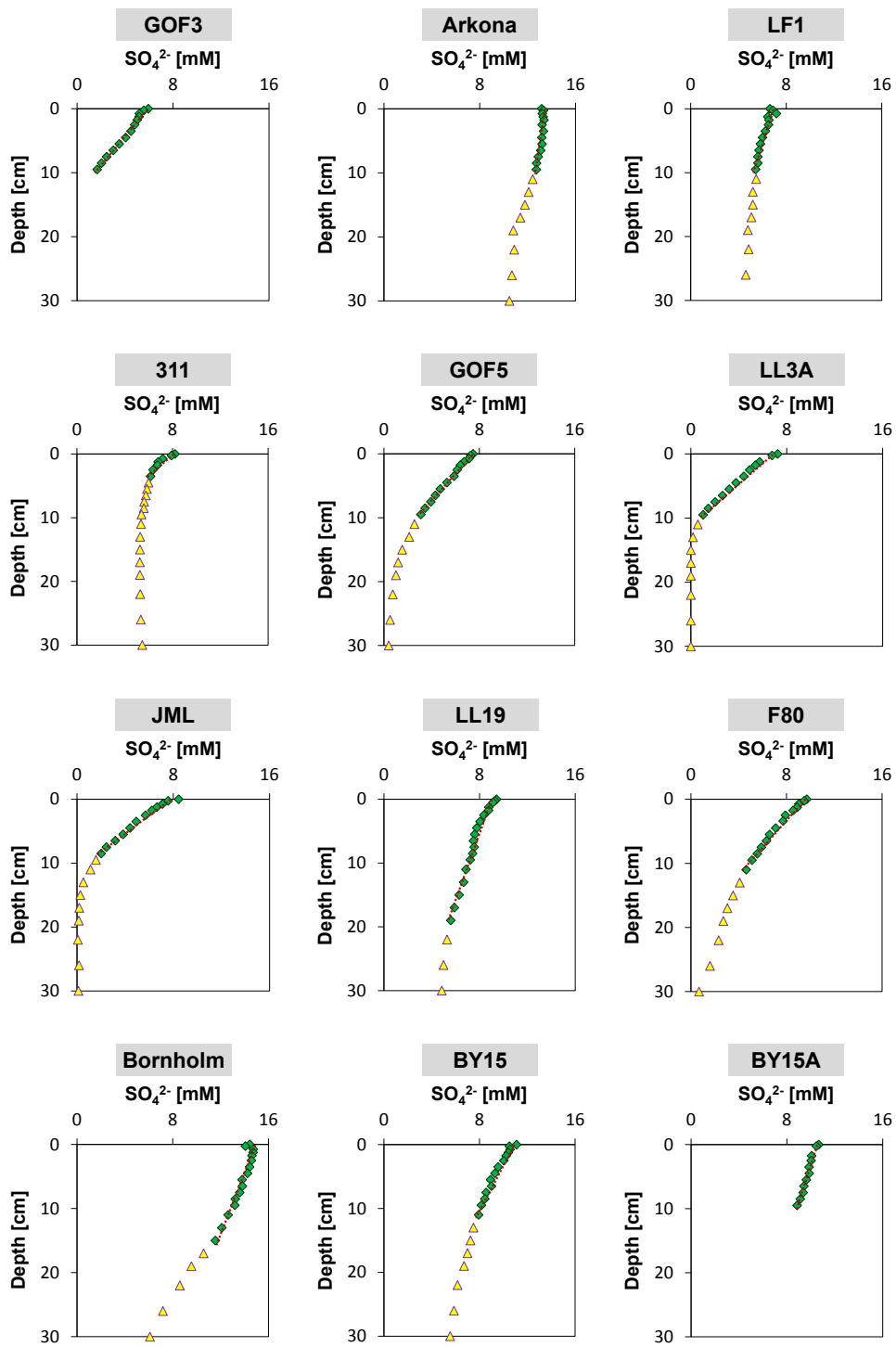

Data points used for flux $\triangle$ Other data points

Figure S.3.7 | Pore water depth profiles of $\mathrm{SO}_{4}^{2-}$ (May/June 2016). The linear gradient in the green diamonds represents data points that were used for the calculation of the upward $\mathrm{SO}_{4}^{2-}$ flux, whereas the yellow triangles are data points that were not used for this calculation. 

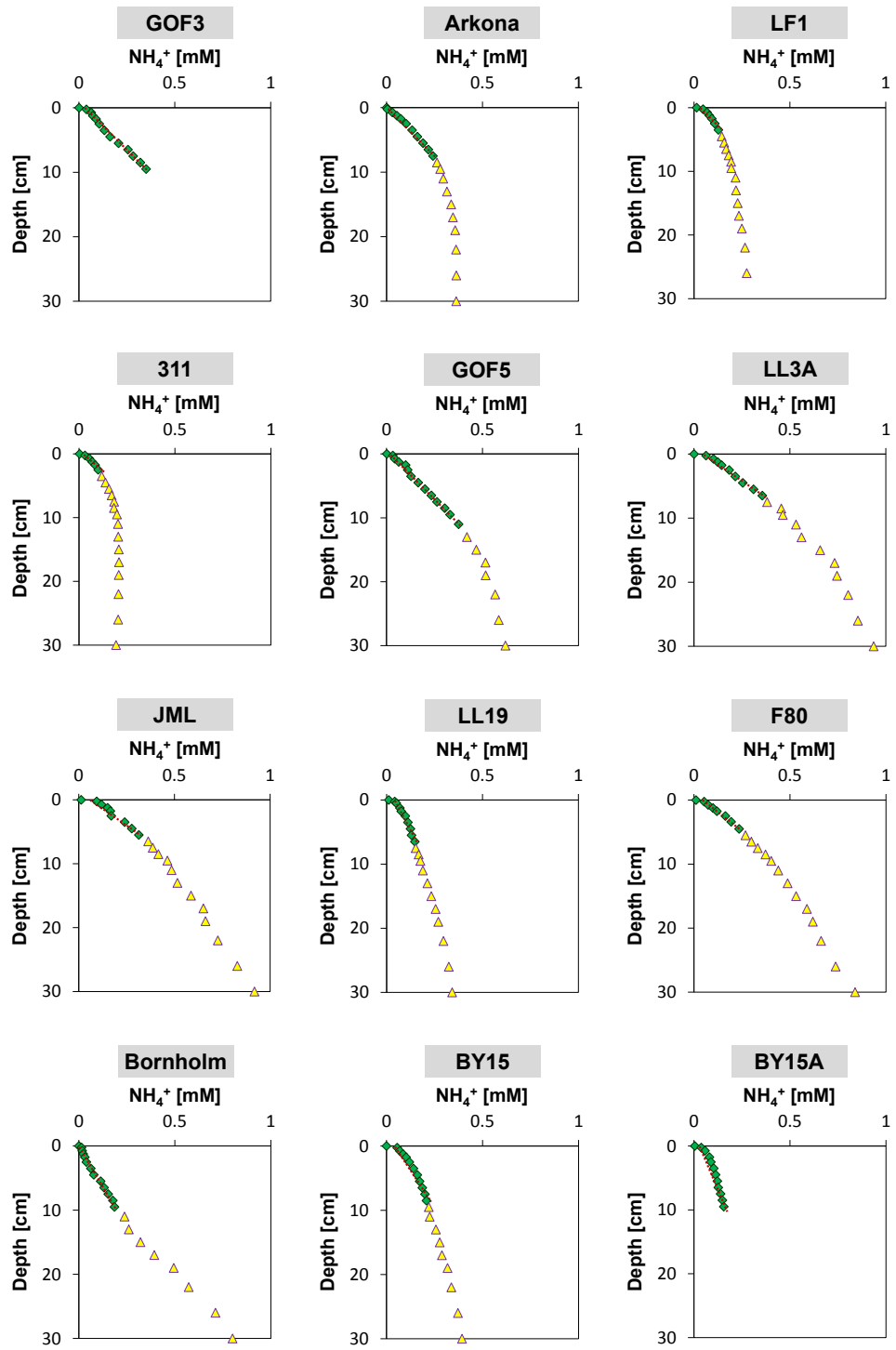

Data points used for flux $\triangle$ Other data points

Figure S.3.8 | Pore water depth profiles of $\mathrm{NH}_{4}^{+}$(May/June 2016). The linear gradient in the green diamonds represents data points that were used for the calculation of the upward $\mathrm{NH}_{4}^{+}$flux, whereas the yellow triangles are data points that were not used for this calculation. 


\section{S.3.7. Macrofauna}

\section{A Macrofaunal Abundance [ind. $\mathrm{m}^{-2}$ ]}

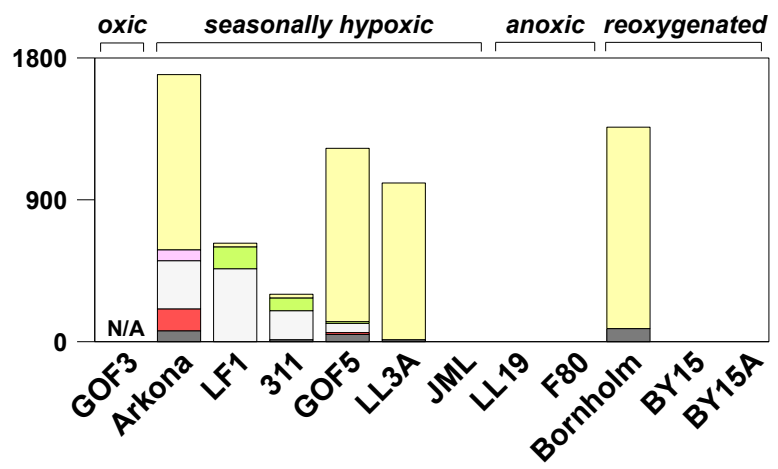

B

\section{Ash Free Dry Mass (AFDM) [ $\left.\mathrm{g} \mathrm{m}^{-2}\right]$}

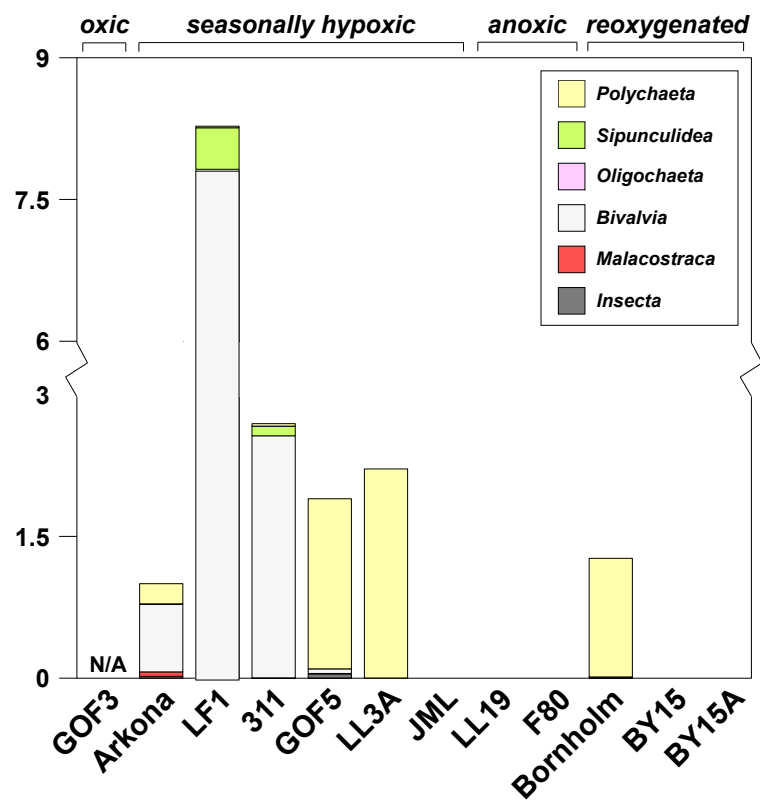

Figure S.3.9 | (A) Macrofaunal Abundance [ind. $\left.\mathrm{m}^{-2}\right]$ and (B) Ash Free Dry Mass (AFDM) $\left[\mathrm{g} \mathrm{m}^{-2}\right]$ of six taxonomic classes: Polychaeta (yellow), Sipunculidea (green), Oligochaeta (pink), Bivalvia (light gray), Malacostraca (red) and Insecta (dark gray). 


\section{Polychaetes [ind. $\mathbf{m}^{-2}$ ]}

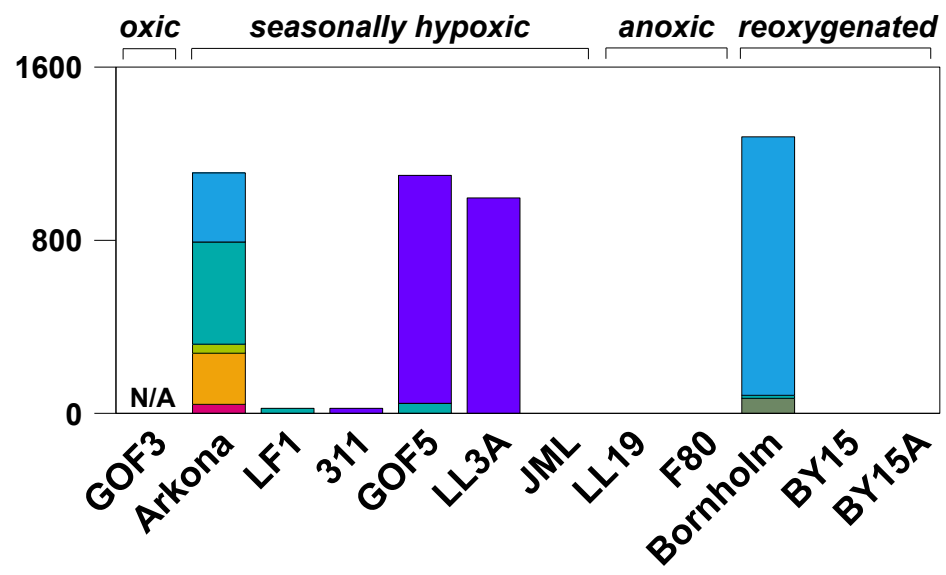

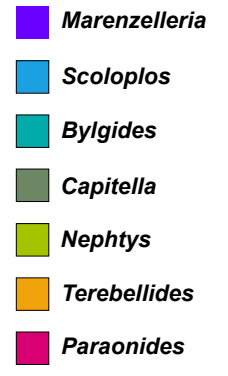

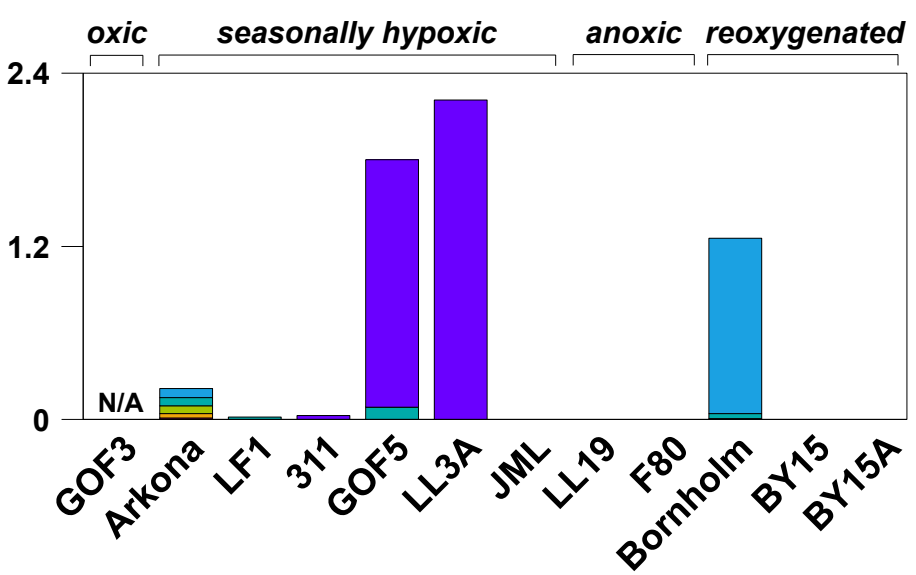

Figure S.3.10 | (A) Abundance of Polychaetes [ind. $\mathrm{m}^{-2}$ ] and (B)Ash Free Dry Mass (AFDM) in $\mathrm{g} \mathrm{m}^{-2}$ of Polychaetes, divived into different genera: Marenzelleria, Scoloplos, Bylgides, Capitella, Nepthys, Terebellides and Paraonides. 


\section{Size of Bivalves [mm]}

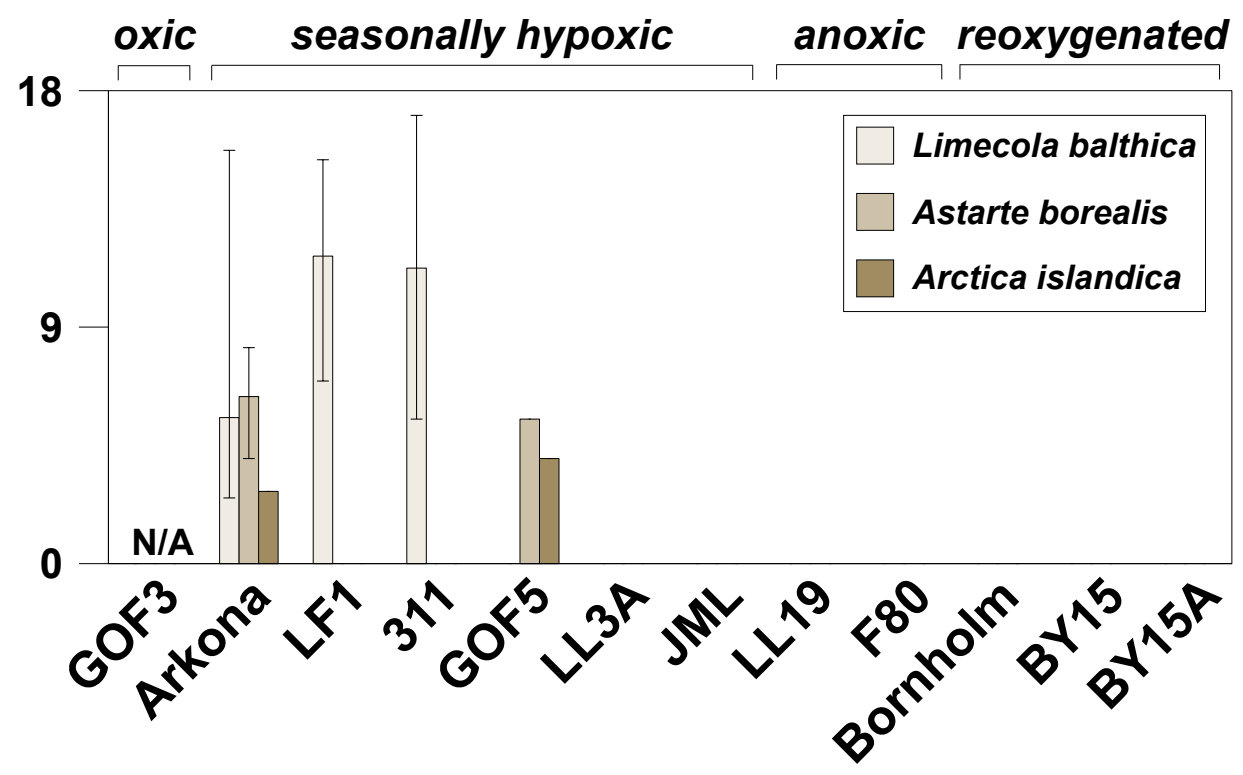

Figure S.3.11 | Size of Bivalves [mm] for three species: Limecola balthica, Astarte borealis and Arctica islandica. The error bars represent the minimum and maximum sizes. 

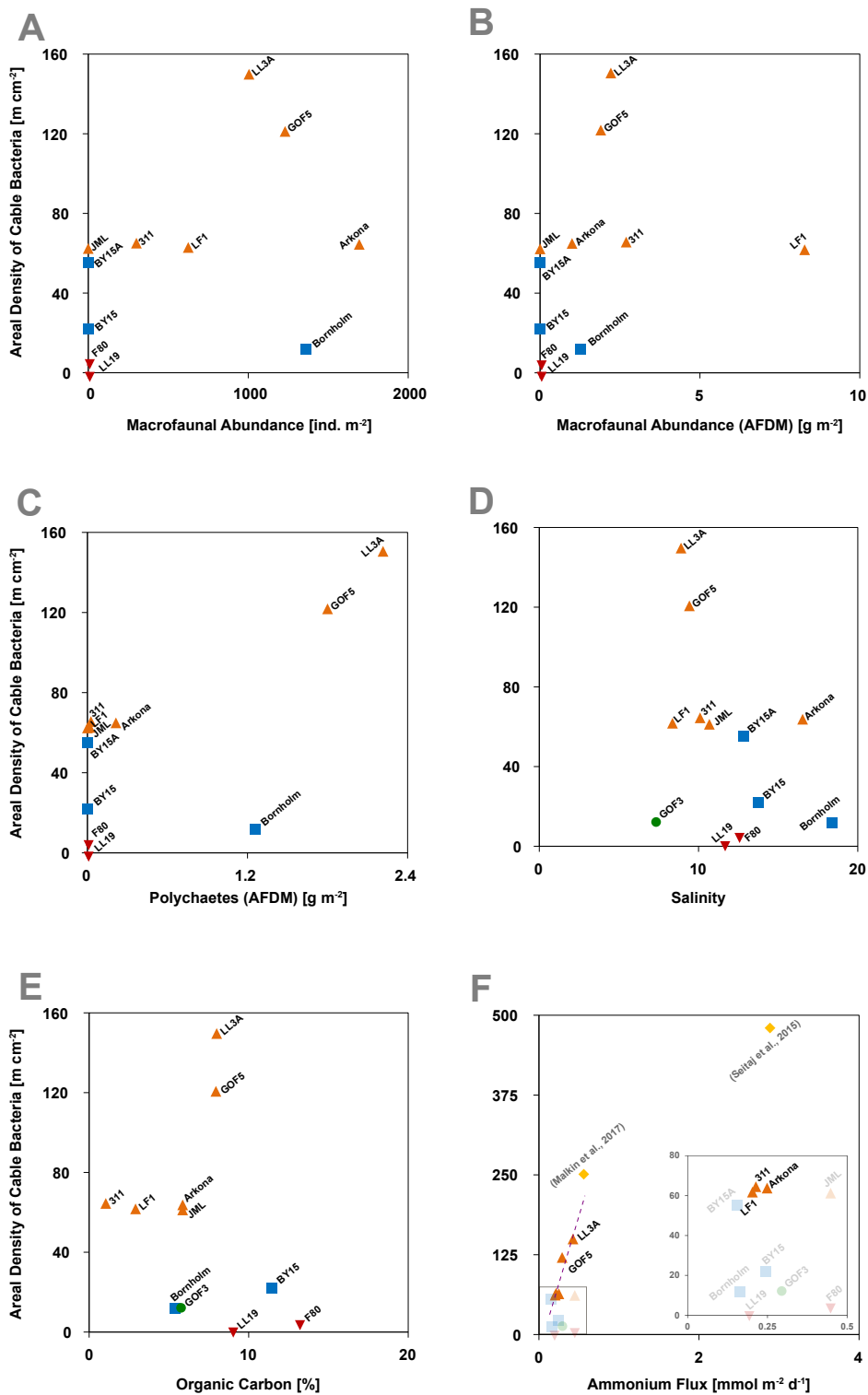

Figure S.3.12 | Relationship between the areal density of cable bacteria, (A) macrofaunal abundance [ind. $\mathrm{m}^{-2}$ ], (B) macrofaunal abundance (AFDM) $\left[\mathrm{g} \mathrm{m}^{-2}\right],(\mathrm{C})$ polychaetes (AFDM) $\left[\mathrm{g} \mathrm{m}^{-2}\right]$, (D) salinity, (E) sediment organic carbon and (F) ammonium flux $\left[\mathrm{mmol} \mathrm{m} \mathrm{d}^{-1}\right]$. 


\section{S.3.9. Laboratory Induced Activity of Cable Bacteria}

Here we assess whether reoxygenation of bottom water of intact sediment cores reactivates the metabolic activity of cable bacteria. We selected a core from site GOF5, since the high resolution depth profiles of $\mathrm{pH}, \mathrm{O}_{2}$ and $\mathrm{\Sigma}_{2} \mathrm{~S}$ resembled the characteristic fingerprint of cable bacteria after a period of their activity. Furthermore, the surface sediment of GOF5 was characterized by an orange oxidized layer near the top (oxic zone) followed by a gray layer (suboxic zone) and a black layer (sulfidic zone), which is typical for sediments that have been impacted by cable bacteria activity. A core from site BY15A was selected, to assess whether cable bacteria would outcompete Beggiatoaceae (Figure S.3.1) upon reoxygenation.

Onboard laboratory induced bottom water reoxygenation of an intact sediment core retrieved from GOF5 induced a high activity of cable bacteria ( $<5$ days; Figure S.3.13B), as indicated by the characteristic geochemical pH signature (Nielsen, et al. 2010; Meysman, et al. 2015). This suggests that the metabolic activity of cable bacteria in the Gulf of Finland can be reactivated rapidly upon bottom water reoxygenation. In our experiment, the $\mathrm{pH}$ minimum decreased from $\sim 7$ (Figure S.3.4) to $\sim 6.5$ within 5 days (Figure S.3.13B). A similar experiment performed on an intact sediment core retrieved from BY15A did not lead to an active cable bacteria community after 5 days (Figure S.3.13A). The $\mathrm{pH}$ signal resembles the $\mathrm{pH}$ signal generated by Beggiatoaceae (Seitaj, et al. 2015).
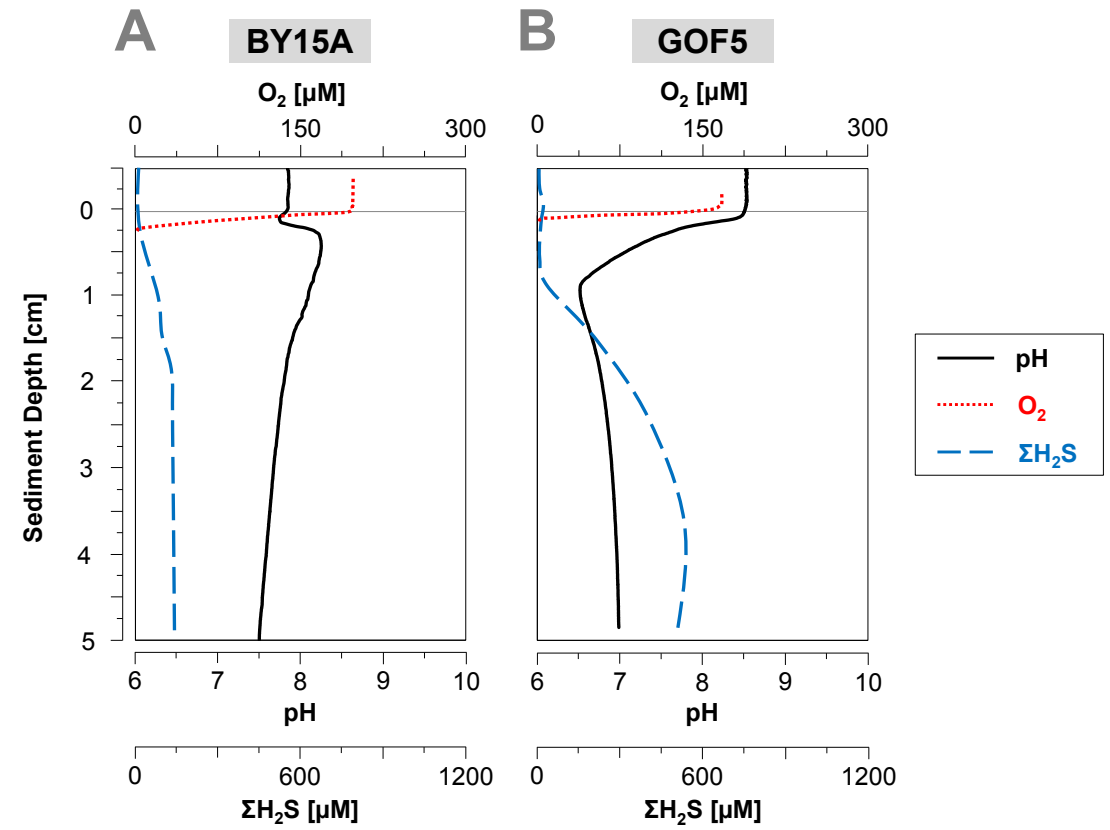

Figure S.3.13 | Onboard incubations: High resolution pore water profiles of pH (black), $\mathrm{O}_{2}$ (red) and $\Sigma \mathrm{H}_{2} \mathrm{~S}$ (blue) for site BY15A and GOF5 after $\sim 5$ days of incubation with oxygenated overlying water. 


\section{S.3.10. Bioirrigation}

To assess rate constants for bioirrigation, sediment cores retrieved from site LF1 and Arkona were incubated with an inert bromide tracer following Martin and Banta (1992). Directly, after core retrieval the overlying water was adjusted to a volume of $550 \mathrm{~mL}$ to which a concentrated bromide solution was added until a concentration of $\sim 2.5 \mathrm{mM}$ was reached. During a two-day incubation at in-situ temperature, the overlying water was continuously aerated and homogenized by pumping in air. Prior to and after bromide incubations, the sediment cores were sectioned into intervals of 0.5 to $4 \mathrm{~cm}$. Sediment from each depth interval was transferred into $50 \mathrm{~mL}$ centrifuge tubes. Subsequently, pore water was extracted using centrifugation (15 min at $4500 \mathrm{rpm}$ ). Finally, pore water bromide was determined using Ion Chromatography. Pore water bromide and rate constants for bioirrigation were determined using a 1-D nonlocal exchange function (Emerson et al., 1984; Boudreau, 1984).

$\frac{\delta(\varphi \cdot c)}{\delta t}=\frac{\delta}{\delta z}\left(\delta D_{s} \cdot \frac{\delta c}{\delta z}\right)-\alpha\left(c-c_{0}\right)$

where $\varphi$ represents the depth dependent porosity, $\mathrm{z}$ is the sediment depth in $\mathrm{cm}$ and $D$ s represents the diffusion coefficient. This diffusion coefficient was corrected for tortuosity (Boudreau, 1996) and ambient pressure, salinity and temperature, using the R package CRAN marelac (Soetaert et al., 2010), which uses the relations listed in Boudreau et al. (1997) $\alpha$ represents the rate constant for bioirrigation for bromide, which is assumed to be time-invariant. $c$ represents the concentration of pore water bromide, whereas $c_{0}$ represents bromide levels in the overlying water. Rate constants for bioirrigation $(\alpha)$ were determined by fitting the pore water bromide depth profiles after incubation. Rate constants for bioirrigation were low at both sites $\left(<0.06 \mathrm{~d}^{-1}\right.$; Figure S.3.14), despite the presence of polychaetes (Table 3.2). Also, the rate constant of biorrigation for Arkona was similar to that of LF1 even though the number of polychaetes was four times higher (Table 3.2).

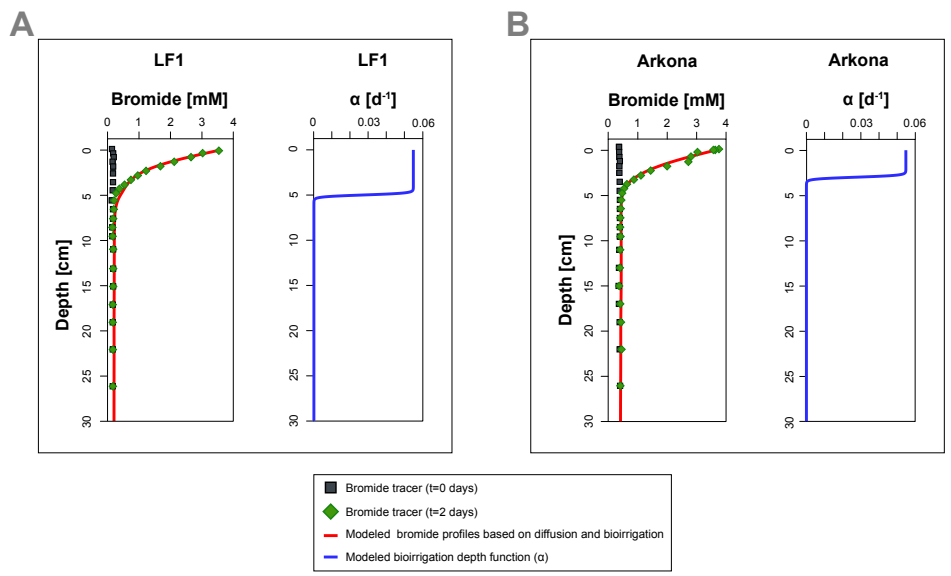

Figure S.3.14 | Pore water bromide depth profiles and rate constants for bioirrigation for site LF1 and Arkona. Gray rectangles represent pore water bromide levels prior to incubation, whereas green diamonds represent pore water bromide after incubation. The red line is the modeled bromide profile based on both diffusion and bioirrigation, whereas the blue line represents the modeled bioirigation depth function $(\alpha)$. 


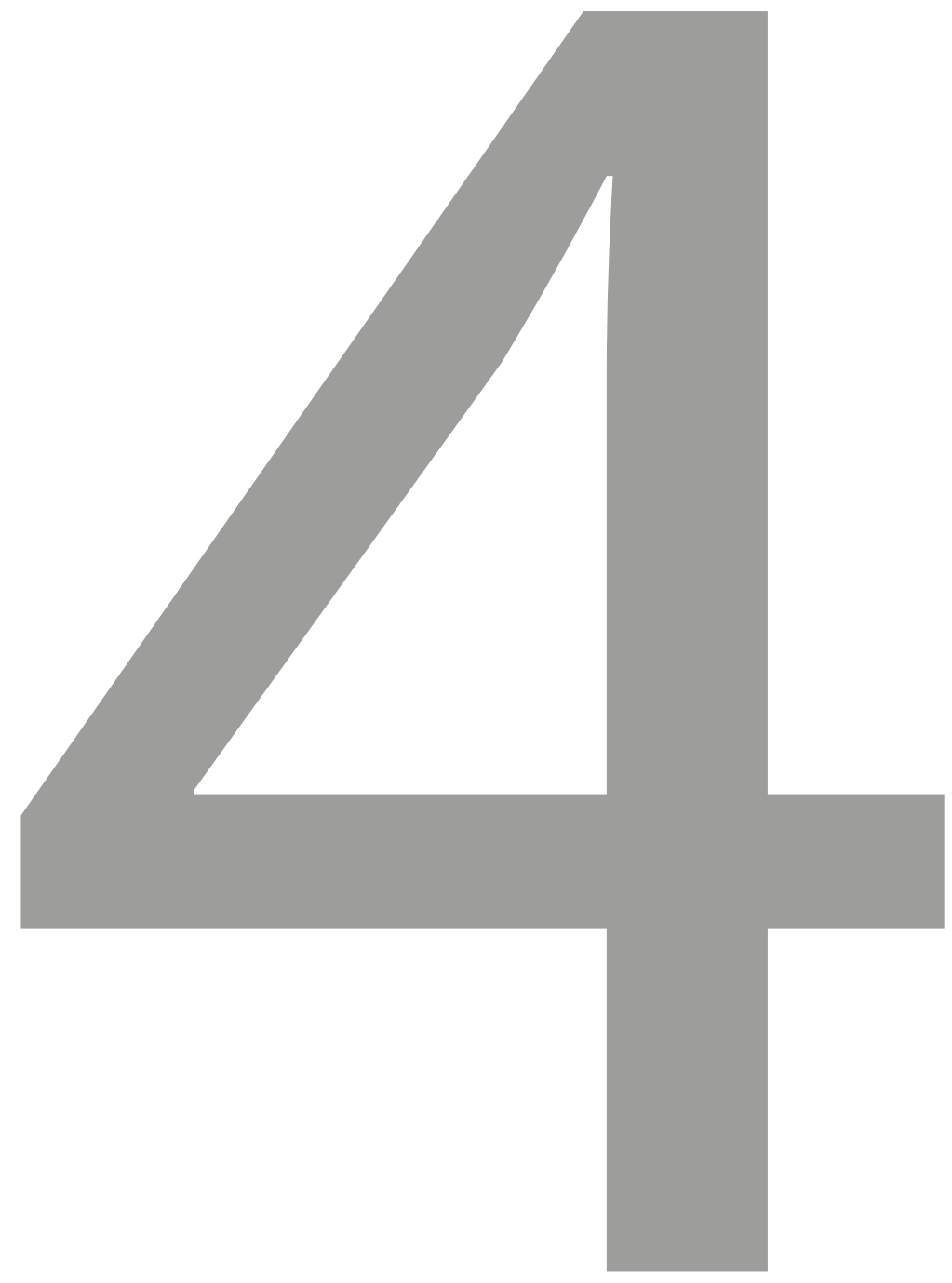




\title{
Chapter 4:
}

\section{Coupled Dynamics of Iron, Manganese and Phosphorus in Brackish Coastal Sediments Populated by Cable Bacteria}

\author{
Martijn Hermans, Marina Astudillo Pascual, Thilo Behrends, \\ Wytze K. Lenstra, Daniel J. Conley and and Caroline P. Slomp
}

\begin{abstract}
Coastal waters worldwide suffer from increased eutrophication and seasonal bottom water hypoxia. Here, we assess the dynamics of iron $(\mathrm{Fe})$, manganese $(\mathrm{Mn})$ and phosphorus $(\mathrm{P})$ in sediments of the eutrophic, brackish Gulf of Finland populated by cable bacteria. At sites where bottom waters are oxic in spring, surface enrichments of $\mathrm{Fe}$ and $\mathrm{Mn}$ oxides and high abundances of cable bacteria were observed in sediments upon sampling in early summer. We argue that cable bacteria activity led to pore water acidification and dissolution of $\mathrm{Fe}$ monosulfides and carbonates in the preceding months. At one of the sites, part of the Fe was retained in a thin layer $(\sim 3 \mathrm{~mm})$ just below the sediment-water interface that additionally was enriched in P. Using Fe and Mn XANES and $\mu$ XRF analyses we show that two-thirds of this $\mathrm{P}$ was associated with poorly crystalline Fe oxides, with an additional contribution of $\mathrm{Mn}$ (II) phosphates. The Fe enriched layer was directly overlain by a Mn oxide-rich surface layer $(\sim 2 \mathrm{~mm})$. While the Fe oxide layer is of diagenetic origin, most of the Mn oxides were likely deposited from the water column as part of a cycle of repeated deposition and remobilization. Our results highlight how cable bacteria activity can promote the formation of distinct layers of $\mathrm{Fe}, \mathrm{Mn}$ and $\mathrm{P}$ minerals in sediments of seasonally hypoxic brackish coastal systems. While cable bacteria activity has little impact on permanent $\mathrm{Fe}, \mathrm{Mn}$ and $\mathrm{P}$ burial in Gulf of Finland sediments, it amplifies the seasonal dynamics of these elemental cycles.
\end{abstract}




\subsection{Introduction}

Oxygen $\left(\mathrm{O}_{2}\right)$ depletion in bottom waters in coastal areas is expanding worldwide, as a result of excessive nutrient inputs by human activities and climate change (Diaz and Rosenberg 2008; Breitburg et al. 2018). Bottom water hypoxia $\left(\mathrm{O}_{2}<63 \mu \mathrm{M}\right)$ and anoxia $\left(\mathrm{O}_{2}=0 \mu \mathrm{M}\right)$ have negative consequences for coastal systems. Low bottom water $\mathrm{O}_{2}$ can lead to the release of toxic hydrogen sulfide $\left(\mathrm{H}_{2} \mathrm{~S}\right)$ from sediments into the water column. The lack of $\mathrm{O}_{2}$ and the presence of $\mathrm{H}_{2} \mathrm{~S}$ in bottom waters can lead to the formation of 'dead zones', which are defined by mass mortality of marine species (Rabalais et al. 2002; Diaz and Rosenberg 2008).

Seasonal hypoxia and anoxia greatly impact the biogeochemical cycles of iron (Fe), manganese $(\mathrm{Mn})$ and phosphorus (P) in coastal systems (Ingall and Jahnke 1994; Rabalais et al. 2014; Lenz et al. 2015). When bottom waters are oxic, sedimentary Fe and Mn minerals can form that can sequester dissolved phosphate $\left(\mathrm{PO}_{4}\right.$; Conley et al. 2009; Turnewitsch and Pohl 2010; Rydin et al. 2011). During periods of hypoxia/anoxia, these Fe and Mn minerals, which mostly consist of oxides or (oxy)hydroxides (collectively referred to as oxides) can reductively dissolve, leading to release of dissolved $\mathrm{Fe}, \mathrm{Mn}$ and $\mathrm{PO}_{4}$ from sediments to the overlying water (Sundby et al. 1986; Burdige 1993). The recycling of $\mathrm{PO}_{4}$ from the sediment can contribute to a high primary productivity in surface waters and thereby to high rates of organic matter supply to the sediment. This ultimately may sustain bottom water hypoxia even when riverine inputs of $\mathrm{P}$ are reduced (Conley et al. 2002; Turner et al. 2008; Sharpley et al. 2013).

Recently, a novel type of multicellular filamentous bacteria, belonging to the Desulfobulbaceae family was discovered (Nielsen et al. 2010; Pfeffer et al. 2012). These so-called 'cable bacteria' can strongly enhance the formation of $\mathrm{Fe}$ and $\mathrm{Mn}$ oxides in surface sediments (Risgaard-Petersen et al. 2012; Seitaj et al. 2015; Rao et al. 2016; Sulu-Gambari et al. 2016a), and thereby impact the sedimentary P cycle (Sulu-Gambari et al. 2016b). Cable bacteria couple the oxidation of dissolved $\mathrm{H}_{2} \mathrm{~S}$ in deeper sediment layers to the reduction of $\mathrm{O}_{2}$ or nitrate $\left(\mathrm{NO}_{3}{ }^{-}\right)$near the sediment surface by transporting electrons along their filaments over $\mathrm{cm}$-scale distances (Pfeffer et al. 2012; Marzocchi et al. 2014). Their metabolic activity leads to the formation of a suboxic zone (i.e. where $\mathrm{O}_{2}$ and $\mathrm{H}_{2} \mathrm{~S}$ are both absent) and a unique $\mathrm{pH}$ profile (Nielsen et al. 2010), defined by a $\mathrm{pH}$ increase ( 9) near the sediment-water interface and a relatively low $\mathrm{pH}(<6.5)$ in the suboxic zone (Pfeffer et al. 2012). The strong acidification leads to dissolution of iron monosulfide (FeS; Risgaard-Petersen et al. 2012; Seitaj et al. 2015) and Fe, Mn and calcium (Ca) carbonates (Sulu-Gambari et al. 2016a). When the dissolved $\mathrm{Fe}$ and $\mathrm{Mn}$ released from mineral dissolution diffuse upward, $\mathrm{Fe}$ and $\mathrm{Mn}$ oxides can form upon contact with $\mathrm{O}_{2}$ (Risgaard-Petersen et al. 2012; Sulu-Gambari et al. 2016a), or, for dissolved $\mathrm{Fe}$, upon contact with Mn oxides (Postma 1985; Wang and Van Cappellen 1996; Sulu-Gambari et al. 2016a; Sulu-Gambari et al. 2016b). Hence, the metabolic activity of cable bacteria can lead to a pronounced redistribution of reactive $\mathrm{Fe}$ and $\mathrm{Mn}$ in aquatic sediments.

The formation of $\mathrm{Fe}$ and $\mathrm{Mn}$ oxides can have major biogeochemical impacts at the system scale, as shown in a study for a seasonally hypoxic marine basin, Lake Grevelingen, where the metal oxides formed through metabolic activity of cable bacteria in spring buffered the release of $\mathrm{H}_{2} \mathrm{~S}$ and $\mathrm{PO}_{4}$ from the sediment during hypoxia in summer (Seitaj et al. 2015; Sulu-Gambari et al. 2016b). Recently, the same buffer mechanism for $\mathrm{H}_{2} \mathrm{~S}$, was suggested to be active in sediments of the eutrophic, brackish Gulf of Finland, in an area subject to seasonal hypoxia (Hermans et al. 2019a). Here, the activity of cable bacteria may explain why bottom waters seldom become anoxic and sulfidic ('euxinic') during peak hypoxia in summer (Hermans et al. 2019a). Whether cable bacteria also impact the dynamics of $\mathrm{P}$ in the Gulf of Finland is not known. Besides their impact 
on sedimentary Fe and Mn cycling, cable bacteria may also affect water column dynamics of Fe and $\mathrm{Mn}$ by promoting repeated cycles of mobilization of $\mathrm{Fe}$ and $\mathrm{Mn}$ in dissolved from in the sediment pore water, release to the overlying water, oxidation upon contact with $\mathrm{O}_{2}$ followed by deposition of Fe and Mn oxides, which is referred to as 'refluxing' (Adelson et al. 2001; Sulu-Gambari et al. 2017).

Here, we assess the coupled dynamics of $\mathrm{Fe}, \mathrm{Mn}$ and $\mathrm{P}$ in the water column and sediment at three sites in the Gulf of Finland with contrasting bottom water redox conditions. Using a combination of geochemical pore water and sediment analyses, including X-ray spectroscopy, we address whether sedimentary Fe and Mn minerals at these sites contribute to $\mathrm{P}$ sequestration and the role of cable bacteria therein. Water column data and in-situ measured benthic fluxes of Fe, Mn and $\mathrm{P}$ are used to assess the potential impact of cable bacteria on the water column chemistry at our study sites. We find a strong effect of cable bacteria on Fe, Mn and P dynamics near the sedimentwater interface, whereas permanent burial of these elements is not affected.

\subsection{Methods}

\subsubsection{Study Area}

The Baltic Sea has received excessive riverine inputs of $\mathrm{P}$ and nitrogen $(\mathrm{N})$ over the last century resulting in enhanced primary production and an increase in the spatial extent of bottom water $\mathrm{O}_{2}$ depletion (Savchuk et al. 2008; Gustafsson et al. 2012). The Baltic Sea is now considered the world's largest human-induced hypoxic/anoxic water body (Carstensen et al. 2014).

The Gulf of Finland is the most eutrophic basin of the Baltic Sea (Figure 4.1A; Pitkänen et al. 2007; HELCOM. 2009; Carstensen et al. 2014). The absence of a sill between the Baltic Proper and Gulf of Finland allows exchange of large water volumes between the two basins (Lehtoranta et al. 2017) resulting in a maximum residence time of water in the Gulf of Finland of $~ 2$ years (Andrejev et al. 2004). Strong westerly and south-westerly winds push surface water from the main basin into coastal areas of the Gulf of Finland, with a compensating outflow of deeper saline water. As a consequence, stratification frequently decreases or completely collapses during winter (Liblik et al. 2013; Elken et al. 2014).

Our three study sites (JML, GOF5 and LL3A) are located along a water depth gradient in the Gulf of Finland (Figure 4.1B; Table 4.1) and differ in terms of bottom water $\mathrm{O}_{2}$ conditions. From 2014 to 2016, site JML was mostly hypoxic and only briefly became oxic in June 2015 (Figure 4.1C; Hermans et al. 2019a). In contrast, sites GOF5 and LL3A, were characterized by a seasonal cycle with high bottom water $\mathrm{O}_{2}$ most of the year and low bottom water $\mathrm{O}_{2}$ in summer (Figure 4.1C; Hermans et al. 2019a). The sediments were populated by cable bacteria at sites GOF5 and LL3A in June 2016 (Figure 4.1D; Hermans et al. 2019a). Site JML had a much lower abundance of cable bacteria $\left(61 \mathrm{~m} \mathrm{~cm}^{-2}\right)$ than GOF5 and LL3A (121 and $150 \mathrm{~m} \mathrm{~cm}^{-2}$, respectively) as a consequence of the lower $\mathrm{O}_{2}$ availability (Hermans et al. 2019a). Macrofauna were absent at site JML, whereas relatively low macrofaunal abundances were observed at site GOF5 and LL3A. At these latter sites, the polychaete Marenzelleria dominated (Figure 4.1E; Hermans et al. 2019a). 


\section{A}

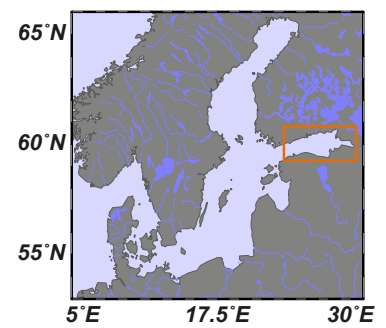

C

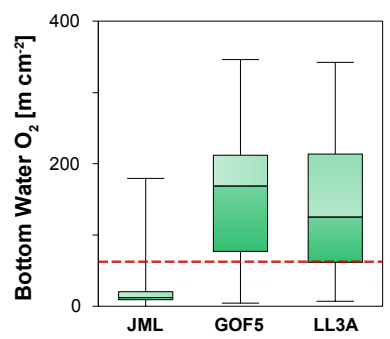

B

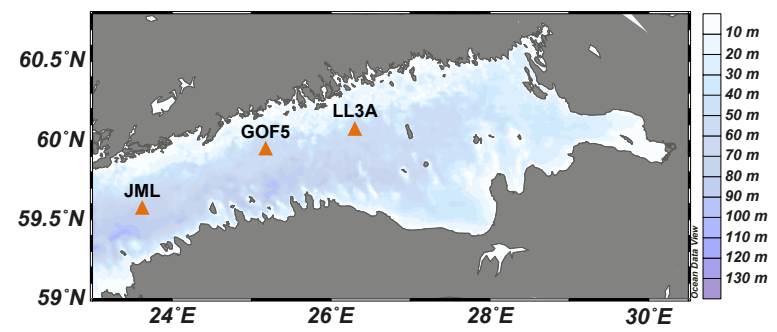

D

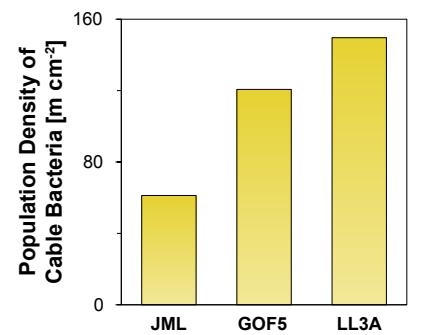

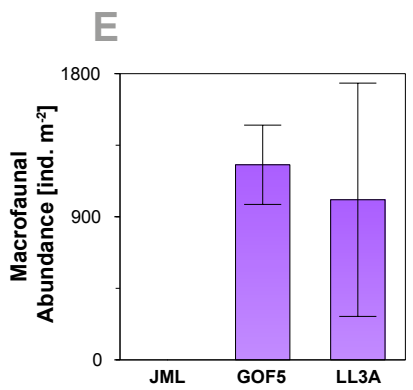

Figure 4.1 Study area: (A) Map of the Baltic Sea, the orange rectangle highlights our study area. (B) Bathymetric map of the Gulf of Finland indicating the location of the three stations. (C) Range in bottom water $\mathrm{O}_{2}$ for 2014-2016 derived from the HELCOM database. The red dashed line represents the hypoxic boundary $(63 \mu \mathrm{M})$. The solid line between the boxes represents the median, whereas the boxes are the lower and upper quartile, respectively. The error bars indicate the minimum and maximum $\mathrm{O}_{2}$ levels. (D) Population density of cable bacteria $\left[\mathrm{m} \mathrm{cm}^{-2}\right]$ integrated over the top $2.5 \mathrm{~cm}$ of the surface sediment collected in June 2016 (Hermans et al. 2019a). (E) Macrofaunal abundance [ind. $\mathrm{m}^{-2}$ ] in June 2016 integrated over a sediment depth of $\sim 12 \mathrm{~cm}$ (Hermans et al. 2019a). The error bars indicate the standard deviation.

Table 4.1 | Site characteristics in June 2016.

\begin{tabular}{|c|c|c|c|c|c|c|c|c|}
\hline Sites & $\begin{array}{l}\text { Water Depth } \\
{[\mathrm{m}]}\end{array}$ & $\begin{array}{l}\text { Coordinates }[N] \\
\text { Coordinates }[E]\end{array}$ & $\begin{array}{l}\text { Sedimentation } \\
\text { Rate } \\
{\left[\mathrm{cm} \mathrm{yr}{ }^{-1}\right]}\end{array}$ & $\begin{array}{l}\text { Total P Burial } \\
\text { Rate } \\
{\left[\mathrm{mmol} \mathrm{m}{ }^{-2} \mathrm{yr}^{-1}\right]}\end{array}$ & 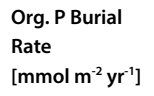 & Salinity & $\begin{array}{l}\text { Bottom Water } \mathrm{O}_{2} \\
{[\mu \mathrm{M}]}\end{array}$ & $\begin{array}{l}\text { Areal Density of } \\
\text { Cable Bacteria } \\
{\left[\mathrm{m} \mathrm{cm}^{-3}\right]^{*}}\end{array}$ \\
\hline JML & 80 & $\begin{array}{l}59^{\circ} 34.92^{\prime} \\
23^{\circ} 37.50^{\prime}\end{array}$ & 0.4 & 43 & 12 & 10.7 & 0 & 61 \\
\hline GOF5 & 65 & $\begin{array}{l}59^{\circ} 57.10^{\prime} \\
25^{\circ} 11.02^{\prime}\end{array}$ & 0.7 & 89 & 29 & 9.4 & 10 & 121 \\
\hline LL3A & 60 & $\begin{array}{l}60^{\circ} 4.43^{\prime} \\
26^{\circ} 18.30^{\prime}\end{array}$ & 1.5 & 147 & 55 & 8.9 & 5 & 150 \\
\hline
\end{tabular}

*Adapted from Hermans et al. (2019a). 


\subsubsection{Water Column Sampling and Analyses}

In June 2016, sites JML, GOF5 and LL3A were sampled during a research expedition with R/V Pelagia. Water column depth profiles of dissolved $\mathrm{O}_{2}$, were obtained with a Sea-Bird $\mathrm{O}_{2}$ sensor attached to an ultraclean CTD-system. Water column samples were collected using 24 ultratrace metal clean PVDF samplers of $24 \mathrm{~L}$ each, placed in two rows of 12 samplers mounted onto a rectangular titanium frame (De Baar et al. 2008; Rijkenberg et al. 2015). The CTD system was deployed with a Kevlar hydrowire and nitrogen pressure was applied at the top of the sampler during sample collection.

Samples for dissolved $\mathrm{PO}_{4}$ and $\mathrm{H}_{2} \mathrm{~S}$ were obtained using $20 \mathrm{~mL}$ syringes and passed through 0.45 $\mu \mathrm{m}$ nylon filters. Aliquots for $\mathrm{H}_{2} \mathrm{~S}$ analysis were transferred into $\mathrm{N}_{2}$ purged $8 \mathrm{mM} \mathrm{NaOH}$ solutions immediately after filtration to prevent loss of $\mathrm{H}_{2} \mathrm{~S}$. Subsequently, the $\mathrm{PO}_{4}$ and $\mathrm{H}_{2} \mathrm{~S}$ concentrations were determined via the methylene and molybdate blue complex methods, respectively (Murphy and Riley 1962; Grasshoff et al. 2009), using QuAAtro (Bran+Luebbe) gas-segmented continuous flow analyzers on board ship.

Acid-washed LDPE bottles (NalgeneTM) were rinsed three times with sample prior to sample collection. Unfiltered samples for total dissolvable $\mathrm{Fe}$ and total dissolvable $\mathrm{Mn}$ were acidified to $\mathrm{pH} 1.8$ using distilled $\mathrm{HCl}$ and stored at $4{ }^{\circ} \mathrm{C}$. This acidification can potentially lead to an underestimation of total dissolvable $\mathrm{Fe}$ and $\mathrm{Mn}$ as a consequence of precipitation of humic substances upon acidification (Oldham et al. 2017). Total dissolvable Fe concentrations were determined by flow injection using a mixture of luminol and triethylenetetramine with preconcentration on an iminodiacetic acid resin (Klunder et al. 2011; Rijkenberg et al. 2014). . Total dissolvable Mn concentrations were determined by Inductively Coupled Plasma Mass Spectrometry (ICP-MS; Nexion Pelkin Elmer), after online sample pre-treatment using a SC-DX SeaFAST S2 (Elemental Scientific) as described in Lagerström et al. (2013). The detection limit and standard deviation of the measurements for total dissolvable Fe and Mn are given in Hermans et al. (2019b). At sites GOF5 and LL3A, suspended matter samples from the water column were retrieved from the PVDF samplers using $0.2 \mu \mathrm{m}$ Supor membrane filters at 60 and $58 \mathrm{~m}$ water depth, respectively.

Monthly time-series data for bottom water $\mathrm{O}_{2}$ and $\mathrm{PO}_{4}$ for 2002-2017 were obtained from the Swedish Ocean Archive (SHARK) database at the Swedish Meteorological and Hydrological Institute (SMHI; http://sharkweb.smhi.se).

\subsubsection{Sediment and Pore Water Collection}

Sediment cores $(\varnothing 10 \mathrm{~cm}$ ) were collected using a multi corer (Oktopus $\mathrm{GmbH}$, Germany). Duplicate bottom water samples were retrieved directly from the overlying water. At each site, one sediment core was sectioned in a glovebox under a $\mathrm{N}_{2}$ atmosphere ( 0.5 to $4 \mathrm{~cm}$ resolution). Slices for each depth interval were split into vials for porosity and solid-phase analysis and tubes that were centrifuged at $3500 \mathrm{rpm}$ for 20 minutes for pore water retrieval. The sediment was stored under a $\mathrm{N}_{2}$ atmosphere at $-20{ }^{\circ} \mathrm{C}$. Additional cores were used for high resolution depth profiling of pore water $\mathrm{pH}, \mathrm{O}_{2}$ and $\mathrm{H}_{2} \mathrm{~S}$, sediment micro X-Ray Fluorescence ( $\mu \mathrm{XRF}$ ) and X-Ray Absorption Spectroscopy (XAS; sites JML and GOF5 only) and the determination of sedimentation rates using ${ }^{210} \mathrm{~Pb}$ dating.

Bottom water samples and the supernatant from the centrifuge tubes were passed through 0.45 $\mu \mathrm{m}$ nylon filters under anoxic conditions. Directly after filtration, sub-samples of $0.5 \mathrm{~mL}$ for $\mathrm{H}_{2} \mathrm{~S}$ analysis were trapped in an $8 \mathrm{mM} \mathrm{NaOH}$ solution $(1.5 \mathrm{~mL})$. Concentrations of $\mathrm{H}_{2} \mathrm{~S}$ and $\mathrm{PO}_{4}$ were determined as described for the water column samples. Ammonium $\left(\mathrm{NH}_{4}{ }^{+}\right)$concentrations were 
determined onboard ship using a QuAAtro (Bran+Luebbe) gas segmented continuous flow analyzer using the phenol-hypochlorite method (Koroleff 1969). Samples for metals were acidified on-board with $10 \mu \mathrm{L}$ Suprapur ${ }^{\circledast} \mathrm{HCl}(35 \%)$ per $\mathrm{mL}$ sample and analyzed for dissolved $\mathrm{Fe}$ and $\mathrm{Mn}$ onshore using Inductively Coupled Plasma-Optical Emission Spectroscopy (ICP-OES, Spectro Arcos). Sulfate $\left(\mathrm{SO}_{4}{ }^{2-}\right)$ concentrations were determined using ion chromatography (IC).

\subsubsection{High-resolution Depth Profiling of $\mathrm{O}_{2}, \mathrm{pH}$ and $\Sigma \mathrm{H}_{2} \mathrm{~S}$}

High-resolution depth profiles of dissolved $\mathrm{O}_{2}, \mathrm{pH}$ and $\Sigma \mathrm{H}_{2} \mathrm{~S}\left(\mathrm{H}_{2} \mathrm{~S}+\mathrm{HS}^{-}+\mathrm{S}^{2-}\right)$ were obtained using commercial microelectrodes $(50-\mu \mathrm{m}$ or $100-\mu \mathrm{m}$ tip-size; Unisense A.S., Denmark). Calibration, profiling and calculation procedures were performed as described in Hermans et al. (2019b).

\subsubsection{Benthic and Diffusive Fluxes}

Fluxes of dissolved $\mathrm{NH}_{4}^{+}, \mathrm{PO}_{4}$, $\mathrm{Fe}$ and $\mathrm{Mn}$ across the sediment-water interface were determined in-situ, using two benthic landers, equipped with three chambers each (surface area: $144 \mathrm{~cm}^{2}$; with overlying water with a volume ranging from 0.9 to $2 \mathrm{~L}$ ) as described in Lenstra et al. (2019). Fluxes of dissolved $\mathrm{NH}_{4}^{+}, \mathrm{PO}_{4}, \mathrm{Fe}$ and $\mathrm{Mn}$ derived from the lander's incubation chambers were averaged.

Diffusive fluxes of dissolved $\mathrm{NH}_{4}^{+}, \mathrm{PO}_{4}, \mathrm{Fe}$ and $\mathrm{Mn}$ across the sediment-water interface were determined using Fick's first law (Supplementary Information 4.1.1) as described in Berner (1980). In this calculation, dissolved $\mathrm{Fe}$ and $\mathrm{Mn}$ were assumed to be $\mathrm{Fe}^{2+}$ and $\mathrm{Mn}^{2+}$, although $\mathrm{Mn}^{3+}$ (Madison et al. 2013) or colloidal and nanoparticulate Fe and Mn might also have been present (Boyd and Ellwood 2010; Raiswell and Canfield 2012; Oldham et al. 2017).

\subsubsection{Sediment Analyses}

Sediments were freeze-dried, ground and stored under anoxic conditions to prevent oxidation artefacts (Kraal et al. 2009; Kraal and Slomp 2014). Porosity was determined from the weight loss upon freeze-drying, using a sediment density of $2.65 \mathrm{~g} \mathrm{~cm}^{-3}$ (Burdige 2006). Salt corrections were applied to all solid phase data, using the gravimetric water content and salinity to determine the amount of salt after freeze-drying.

For the analysis of total $\mathrm{Fe}, \mathrm{Mn}$ and $\mathrm{P}$ contents, aliquots of $\sim 125 \mathrm{mg}$ freeze-sediment were digested in a mixture of strong acids as described in van Helmond et al. (2018). The residual gel was dissolved in $1 \mathrm{M} \mathrm{HNO}_{3}$ and the $\mathrm{Fe}, \mathrm{Mn}$ and $\mathrm{P}$ contents were determined by ICP-OES.

Aliquots of $\sim 300 \mathrm{mg}$ of freeze-dried sediment were decalcified using $1 \mathrm{M} \mathrm{HCl}$ as described in van Helmond et al. (2018). After drying and re-powdering, the decalcified samples were analyzed for their carbon contents using a Fisons Instruments NA 1500 NCS analyzer. Organic carbon $\left(\mathrm{C}_{\text {org }}\right)$ contents were corrected for the weight loss during decalcification.

Iron phases were fractionated using aliquots of $\sim 80 \mathrm{mg}$ freeze dried sediment. A combination of 2 operational sequential extraction methods after Poulton and Canfield (2005) and Claff et al. (2010) as described by Kraal et al. (2017) was applied to fractionate the Fe phases into: [I] labile ferrous $\mathrm{Fe}$ (siderite $\left(\mathrm{FeCO}_{3}\right)$ and $\mathrm{FeS}$ ) and ferric $\mathrm{Fe}$ minerals using $1 \mathrm{M} \mathrm{HCl}$ for $4 \mathrm{~h}$. [II] crystalline Fe minerals using CDB for $4 \mathrm{~h}$, [III] magnetite $\left(\mathrm{Fe}_{3} \mathrm{O}_{4}\right)$ using $0.2 \mathrm{M}\left(\mathrm{NH}_{4}\right)_{2} \mathrm{C}_{2} \mathrm{O}_{4} / 0.17 \mathrm{M} \mathrm{C}_{2} \mathrm{H}_{2} \mathrm{O}_{4}$ for $6 \mathrm{~h}$ and [IV] pyrite $\left(\mathrm{FeS}_{2}\right)$ extracted by concentrated $\mathrm{HNO}_{3}$ for $2 \mathrm{~h}$. The sum of these four fractions is defined as total extractable Fe. 
For sedimentary P speciation, the sequential extraction procedure after Ruttenberg (1992) as modified by Slomp et al. (1996) was applied using aliquots of $\sim 150 \mathrm{mg}$ freeze dried sediment. Sediment $\mathrm{P}$ was fractionated into: [I] exchangeable-P (1 M MgCl$\left.{ }_{2} ; 0.5 \mathrm{~h}\right)$, [II] CDB-P (citrate-

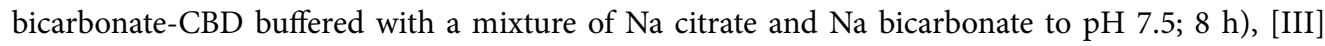
authigenic-P associated with calcium carbonate $\left(\mathrm{CaCO}_{3}\right)+$ carbonate fluorapatite (CFAP) + biogenic hydroxyapatite (1 M Na-acetate buffered with acetic acid to $\mathrm{pH} 4,6 \mathrm{~h}$ ), [IV] detrital-P (1M $\mathrm{HCl}, 24 \mathrm{~h}$ ) and $[\mathrm{V}]$ organic-P (ashed at $550{ }^{\circ} \mathrm{C}$ for $2 \mathrm{~h}$ following extraction with $1 \mathrm{M} \mathrm{HCl}$ for $24 \mathrm{~h}$ ).

Sulfide was fractionated using aliquots of $\sim 300 \mathrm{mg}$ freeze-dried sediment following the sequential extraction procedure after Burton et al. $(2006 ; 2008)$ as modified by Kraal et al. (2013). [I] FeS (Acid Volatile Sulfur (AVS, representing FeS; $6 \mathrm{M} \mathrm{HCl} ; 24$ h, [II] elemental sulfur (S0; methanol; $16 \mathrm{~h}$ ) and [III] chromium reducible sulfur (CRS, representing $\mathrm{FeS}_{2} ; 500 \mathrm{~g} \mathrm{~L}^{-1}$ chromium(II) chloride in $32 \% \mathrm{HCl} ; 48 \mathrm{~h}$ ).

\subsubsection{Sediment Accumulation and $P$ Burial Rates}

Freeze-dried sediment samples were analyzed for ${ }^{210} \mathrm{~Pb}$ by direct gamma counting at $46.5 \mathrm{keV}$ with a high purity germanium detector (Ortec GEM-FX8530P4-RB). Self-absorption was measured directly and the detector efficiency was verified with a National Institute of Standards and Technology standard. Excess ${ }^{210} \mathrm{~Pb}$ was derived from the difference between the measured total

${ }^{210} \mathrm{~Pb}$ and the estimate of the supported ${ }^{210} \mathrm{~Pb}$ activity as given by ${ }^{214} \mathrm{~Pb}\left({ }^{210} \mathrm{~Pb}_{\text {exc }}={ }^{210} \mathrm{~Pb}_{\text {total }}-{ }^{214} \mathrm{~Pb}\right)$. Sedimentation rates were estimated by fitting a reactive transport model (Soetaert and Herman 2008) to the ${ }^{210} \mathrm{~Pb}$ depth profiles taking the depth dependent changes in porosity into account. Total $\mathrm{P}$ burial was calculated as a function of the sedimentation rate, total $\mathrm{P}$ at depth in the sediment and the porosity (Supplementary Information 4.1.2).

\subsubsection{Epoxy Embedding and Desktop $\mu$ XRF Mapping}

At sites JML and GOF5, sub-cores (first $7 \mathrm{~cm}$ of surface sediment) were embedded with epoxy resin for high-resolution elemental mapping (Jilbert et al. 2008; Jilbert and Slomp 2013). After curing the epoxy-embedded core was split vertically using a rock saw. The embedded core was polished by applying a $0.3 \mu \mathrm{m}$ layer of alumina powder. High-resolution elemental maps of $\mathrm{Fe}, \mathrm{Mn}, \mathrm{P}, \mathrm{Ca}$ and $\mathrm{S}$ (30 $\mu \mathrm{m}$ spot size) were obtained using a Desktop EDAX Orbis $\mu$ XRF analyzer (Rh tube set at $30 \mathrm{kV}$, $500 \mu \mathrm{A}, 300 \mathrm{~ms}$ dwell-time, equipped with a poly-capillary lens).

\subsubsection{Synchrotron-based XAS and $\mu$ XRF Mapping}

Suspended matter samples from the water column (Supplementary Information 4.1.3) and epoxy embedded sediment retrieved from site GOF5 were further investigated for their Fe and $\mathrm{Mn}$ mineralogy at the ID21 beamline (Salomé et al. 2013) at the European Synchrotron Radiation Facility (ESRF) in Grenoble, France, combining X-ray fluorescence and X-ray Absorption Spectroscopy (XAS). High-resolution $\mu \mathrm{XRF}$ maps of Fe and Mn were processed using the PyMca X-ray Fluorescence Toolkit (Solé et al. 2007). Calibration of the monochromator energy was performed using the maximum intensity of the first derivative of Fe foil at 7.11198 for $\mathrm{Fe}$ and $\mathrm{Mn}$ foil at $6.53862 \mathrm{keV}$ for $\mathrm{Mn}$. The size of the X-ray beam $(0.35 \times 0.80 \mu \mathrm{m})$ was controlled by a Kirkpatrick-Baez mirrors system. Although the cross section of the beam was very narrow, the analyzed volume in the sediment sample was relatively large. The absorption length at $7 \mathrm{keV}$ in a 
silica matrix is $\sim 90 \mu \mathrm{m}$. This implies that X-ray fluorescence of Fe and Mn atoms $\sim 90 \mu \mathrm{m}$ below the sample surface was approximately $10 \%$ of what it would be when the atoms would be located at the surface.

Hotspots of Fe and Mn selected from the synchrotron-based maps were further subjected to XAS analysis to determine the Fe and Mn mineralogy at these spots/areas. Spectra to investigate the X-ray Absorption Near Edge Structure (XANES) were collected within the energy range, 7.00$7.65 \mathrm{keV}$ for Fe and 6.50-6.90 keV for Mn. The XANES spectra were corrected for the background signal and normalized using the ATHENA software package (Ravel and Newville 2005). The ATHENA software package was also used for Linear Combination Fitting (LCF) of the spectra. The normalized Fe and Mn spectra were subjected to Iterative Transformation Factor Analysis (ITFA) using the ITFA software package as described in Rossberg et al. (2003) for principal component analysis of the spectra.

The Fe content in the suspended matter samples was too low to obtain XAS data of sufficient quality, therefore only those of Mn are presented. XAS spectra were collected with a continuously moving monochromator, implying that acquisition time and energy resolution were not adjusted depending on energy range. The latter is typically used to improve the signal to noise ratio for analyzing the Extended X-ray Absorption Fine Structure (EXAFS) of spectra. For this reason, the quality of Mn spectra was insufficient for EXAFS analysis and the energy range of Fe EXAFS spectra was limited. Nevertheless, Fe EXAFS spectra were used for epoxy embedded sediments in order to better constrain the LCF.

\subsection{Results}

\subsubsection{Water Column Geochemistry}

At all sites, $\mathrm{O}_{2}$ was near-saturated in the upper $\sim 50 \mathrm{~m}$ of the water column. Below $50 \mathrm{~m}, \mathrm{O}_{2}$ decreased strongly from $\sim 350$ to $\sim 0 \mu \mathrm{M}$ with increasing water depth (Figure $4.2 \mathrm{~A}$ ). Sulfide was only observed in the bottom water at site JML, reaching concentrations up to $18 \mu \mathrm{M}$. At all sites, $\mathrm{PO}_{4}$ increased with water depth from 0.02 up to $\sim 5 \mu \mathrm{M}$ (Figure $4.2 \mathrm{~B}$ ). Total dissolvable Fe and $\mathrm{Mn}$ concentrations were relatively low in the upper $\sim 50 \mathrm{~m}$ of the water column, and highest near the seafloor, reaching values up to $\sim 1700$ and $\sim 14.000 \mathrm{nM}$, respectively (Figure $4.2 \mathrm{C}$ and D). Concentrations of total dissolvable Fe were generally 4 to 37 fold lower compared to those of $\mathrm{Mn}$.

For satisfactory reproduction of the Mn XANES spectra for the suspended matter samples from the water column at sites GOF5 and LL3A the combination of at least three reference spectra was required. When using the combinatorics option in LCF using ATHENA, the best result was obtained when using the Mn oxides, birnessite and hausmannite, and $\mathrm{Mn}$ (II) phosphate standards (Figures 4.3A and S.4.1). The position of the absorption maximum of our spectra was close to that of $\mathrm{Mn}$ in birnessite and hence indicates the predominant presence of $\mathrm{Mn}(\mathrm{IV})$. However, the spectra differ with respect to the shape and position of the edge, which is shifted to lower energies when compared to birnessite, which points towards the presence of $\mathrm{Mn}$ with a lower oxidation state. Based on LCF, we estimated that Mn in suspended matter was predominantly present in the form of $\mathrm{Mn}(\mathrm{IV})$ (57-67\%), with $\mathrm{Mn}$ (III) and Mn(II) contributing the remainder of the Mn (33-43\%; Figure $4.3 \mathrm{~B})$. The results from LCF further suggested that the Mn(IV) occurs in the form of phyllo- or tectomanganates with predominantly edge sharing Mn octahedra, such as birnessite or todorkite (and not pyrolusite). This implies that most $\mathrm{Mn}$ in the suspended matter was present in the form of $\mathrm{Mn}(\mathrm{IV})$ accompanied with $\mathrm{Mn}(\mathrm{II})$ and possibly some minor amounts of $\mathrm{Mn}$ (III). 

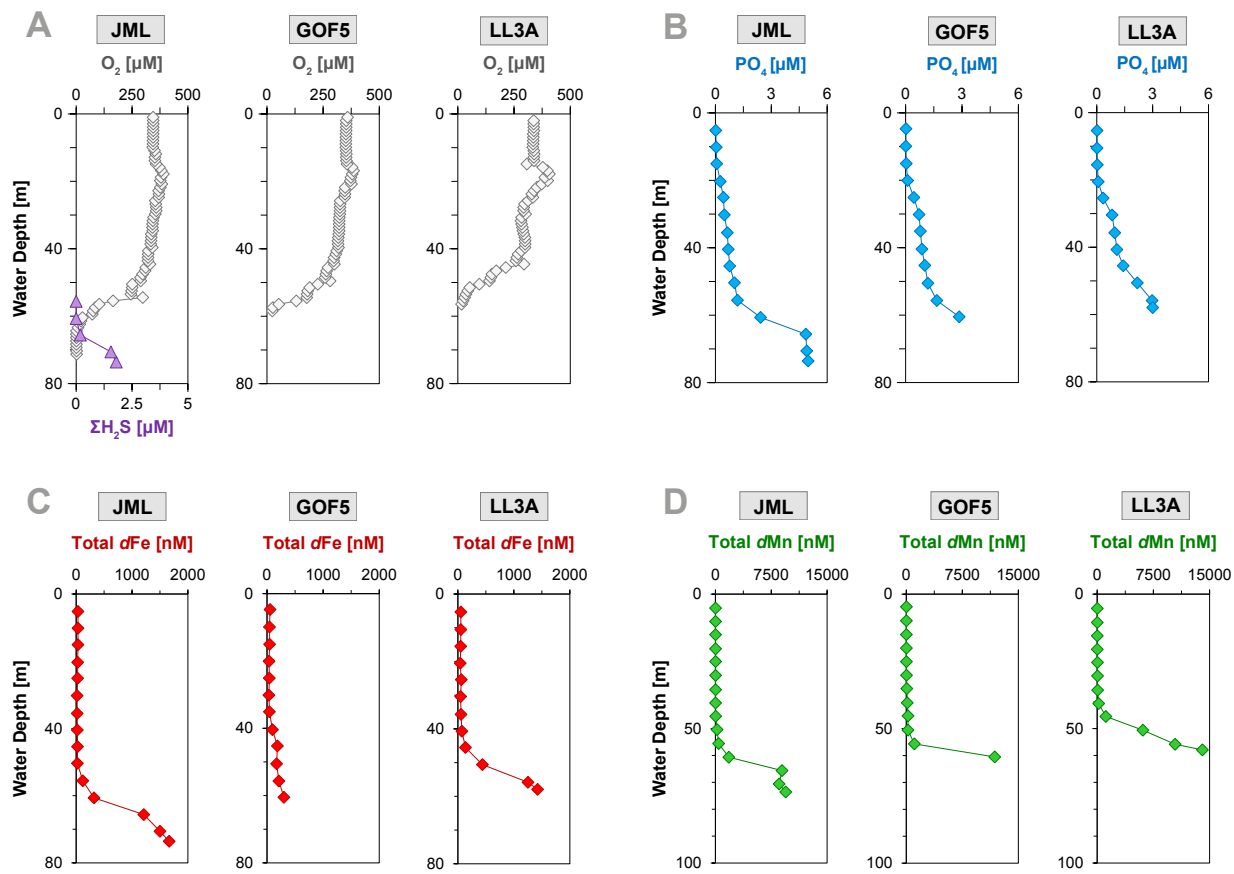

Figure 4.2 $\mid$ Water column depth profiles of (A) dissolved $\mathrm{O}_{2}$ (gray) and $\Sigma \mathrm{H}_{2} \mathrm{~S}$ (purple), (B) dissolved $\mathrm{PO}_{4}$ (blue), (C) total dissolvable (d) Fe (red), (D) total dissolvable (d) Mn (green) at sites JML, GOF5 and LL3A in June 2016.
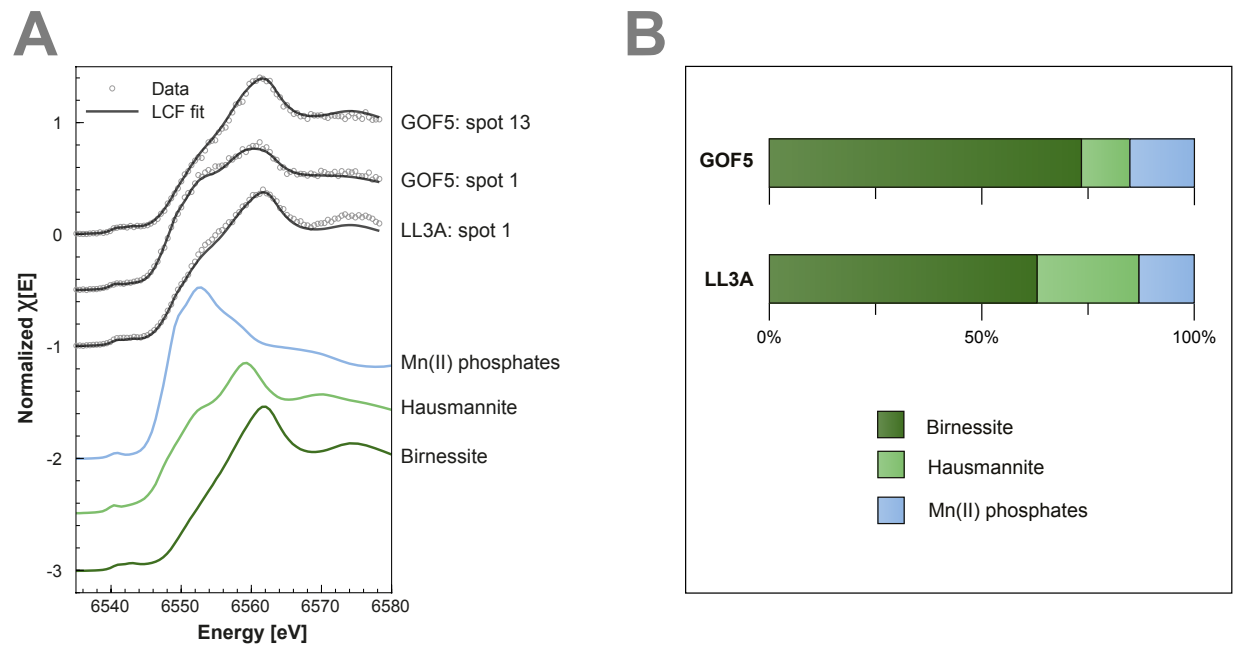

Figure 4.3 | Synchrotron-based Mn analysis for suspended matter in the water column at sites GOF5 and LL3A. (A) Mn XANES spectra from three spots selected from the water column filters (Figure S.4.1). The selected spectra represent the most diverting spectra based on component analysis. The gray circles represent the actual XANES measurements, whereas the black line was obtained through linear combination fitting using the spectra of the three reference materials: birnessite (Mn(IV), hausmannite (Mn(II/III) and Mn(II) phosphates (B) Relative proportion of Mn phases in the suspended matter. 


\subsubsection{Pore Water Profiles}

At all sites, $\mathrm{NH}_{4}^{+}$and $\mathrm{PO}_{4}$ in the pore water increased with depth reaching concentrations of up to $\sim 900 \mu \mathrm{M}$ and $\sim 250 \mu \mathrm{M}$, respectively (Figure 4.4). Phosphate was removed within the top $\sim 1 \mathrm{~cm}$ of the sediment at sites GOF5 and LL3A. Dissolved Fe and Mn were low at site JML, whereas sites GOF5 and LL3A were characterized by subsurface peaks of dissolved Fe and Mn with maximum concentrations of up to 44 and $350 \mu \mathrm{M}$, respectively. Sites GOF5 and LL3A were both characterized by a suboxic zone of $\sim 7 \mathrm{~mm}$ (Figure S.4.2). Sulfide increased within the first $15 \mathrm{~cm}$ of the sediment at all sites with maximum concentrations of up to $2100 \mu \mathrm{M}$. Sulfide decreased again below $15 \mathrm{~cm}$ depth at sites JML and LL3A. At all sites, most $\mathrm{SO}_{4}{ }^{2-}$ was removed within the top $15 \mathrm{~cm}$ of the sediment.

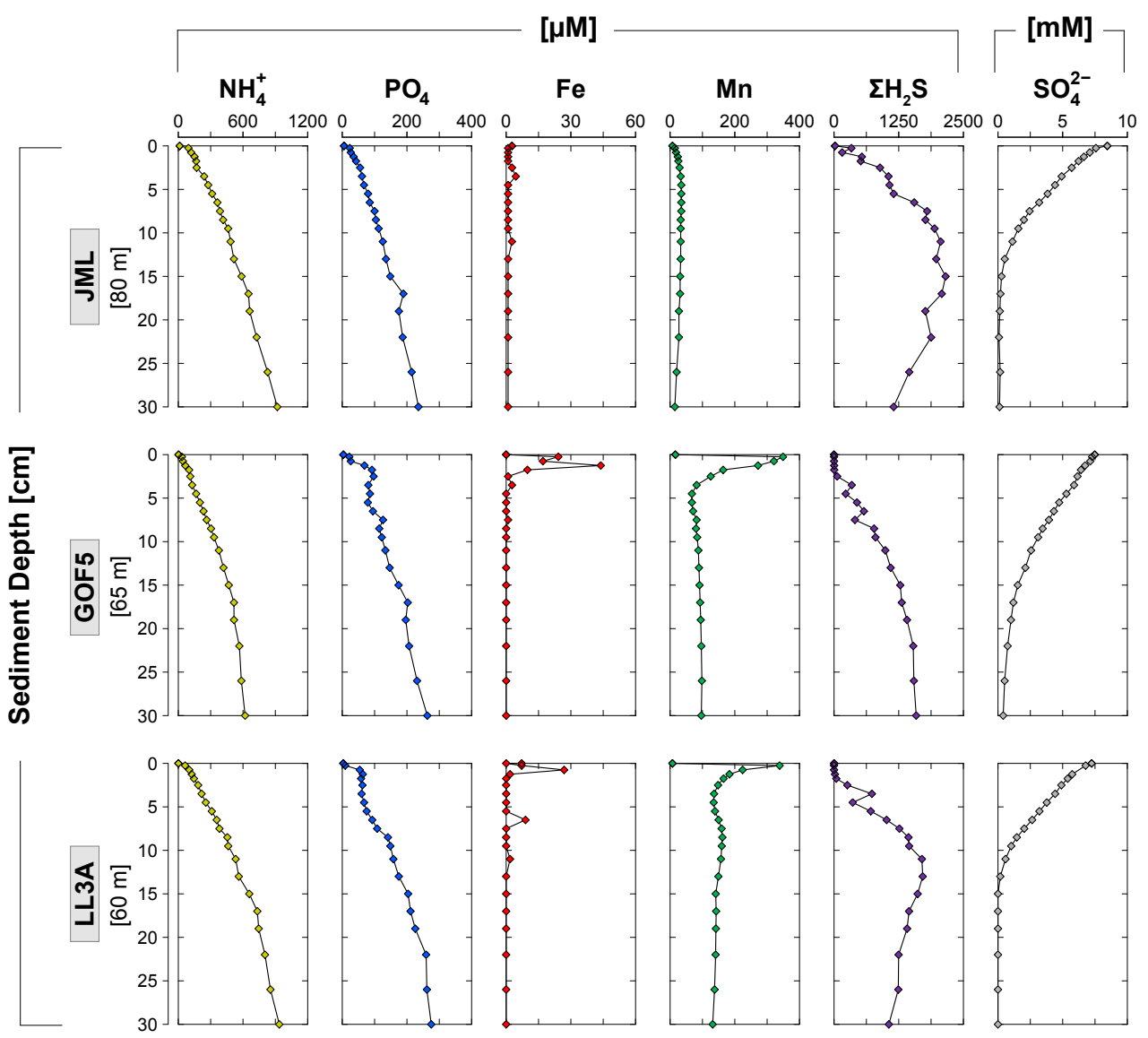

Figure 4.4 | Pore water profiles of dissolved $\mathrm{NH}_{4}{ }^{+}, \mathrm{PO}_{4}, \mathrm{Fe}, \mathrm{Mn}, \Sigma \mathrm{H}_{2} \mathrm{~S}$ and $\mathrm{SO}_{4}{ }^{2-}$ for the upper $30 \mathrm{~cm}$ of the sediment at sites JML, GOF5 and LL3A in June 2016. 


\subsubsection{Benthic Fluxes}

In-situ benthic fluxes of dissolved $\mathrm{NH}_{4}^{+}, \mathrm{PO}_{4}$ and $\mathrm{Fe}$ were typically higher at site LL3A when compared to GOF5, with average fluxes at the former site of $1.6,1.0$ and $1.0 \mathrm{mmol} \mathrm{m}^{-2} \mathrm{~d}^{-1}$, respectively (Figures 4.5A, B, C, S.4.3 and S.4.4). Manganese in-situ fluxes at sites GOF5 and LL3A were much higher than in-situ fluxes of Fe (with values for Mn of 6.6 and $3.7 \mathrm{mmol} \mathrm{m}^{-2} \mathrm{~d}^{-1}$, respectively; Figure 4.5D). While in-situ benthic fluxes for $\mathrm{NH}_{4}{ }^{+}$and dissolved $\mathrm{Mn}$ were similar to calculated diffusive fluxes (Figure 4.5A and D; Table S.4.2), this was not the case for $\mathrm{PO}_{4}$ and $\mathrm{Fe}$ (Figure $4.5 \mathrm{~B}$ and $\mathrm{C}$ ).
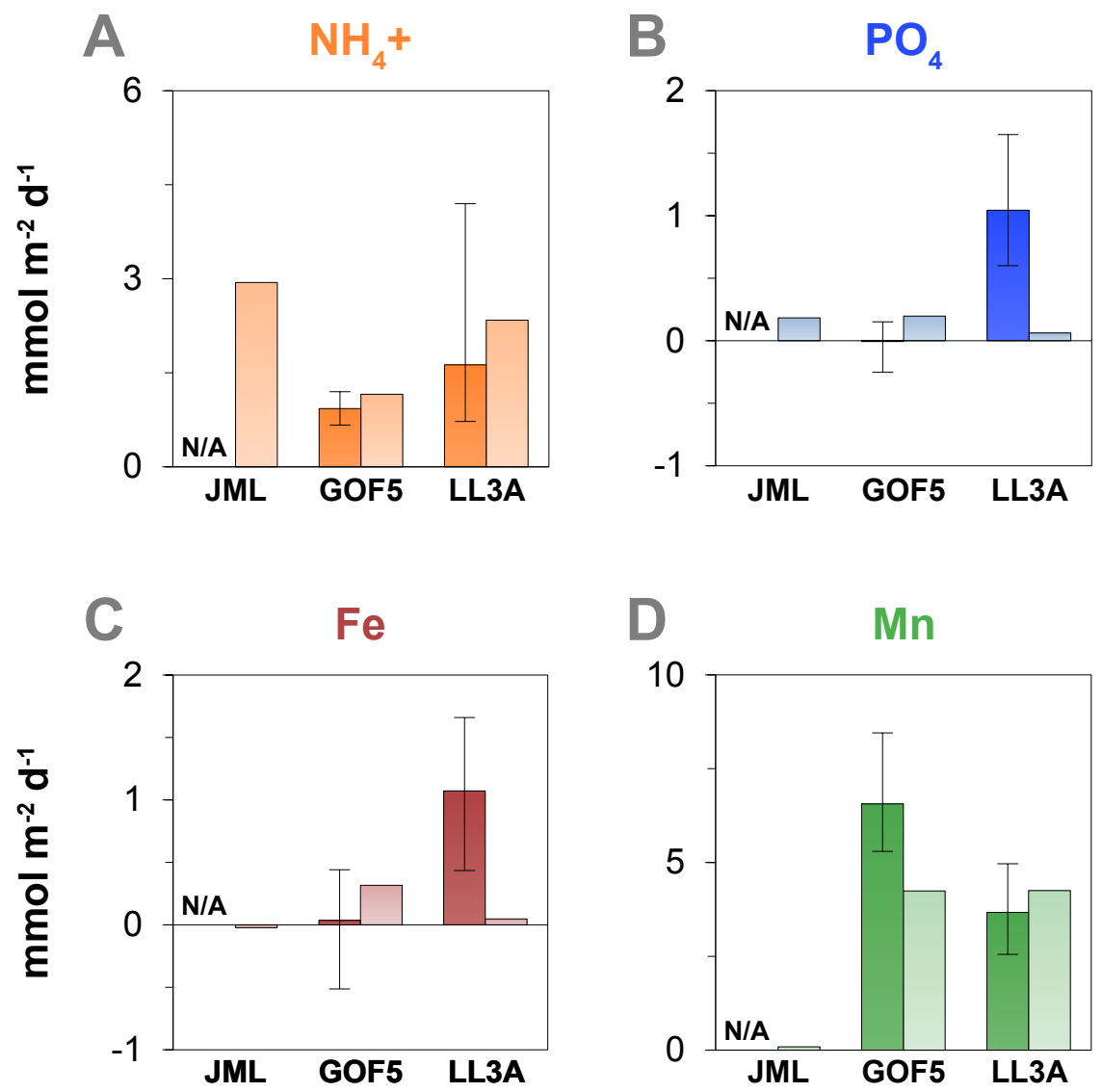

Figure 4.5 | Benthic fluxes of key solutes in $\mathrm{mmol}^{-2} \mathrm{~d}^{-1}$ : (A) $\mathrm{NH}_{4}^{+}$, (B) $\mathrm{PO}_{4}$, (C) Fe and (D) Mn. Darker colors with minimum and maximum bars represent $i n$-situ fluxes that were obtained using the benthic lander, whereas the lighter colors represent diffusive fluxes that were calculated from pore water profiles. N/A = not available. 


\subsubsection{Sediment Geochemistry}

Sediment accumulation rates ranged from 0.4 to $1.5 \mathrm{~cm} \mathrm{yr}^{-1}$ (Table 4.1; Figures S.4.5 and S.4.6). Sediment $\mathrm{C}_{\text {org }}$, was highest at the top and decreased with sediment depth at all sites (Figure 4.6). Small surface enrichments of Fe oxides were observed at sites JML and LL3A (18 and $36 \mu \mathrm{mol} \mathrm{g}{ }^{-1}$, respectively), whereas site GOF5 was characterized by a strong surface enrichment of $\mathrm{Fe}$ oxides $\left(250 \mu \mathrm{mol} \mathrm{g}^{-1}\right)$. Relatively high surface FeS levels were found at sites JML and LL3A (90 and 175 $\mu \mathrm{mol} \mathrm{g} \mathrm{g}^{-1}$, respectively), whereas FeS was depleted in the surface sediment at site GOF5 $\left(34 \mu \mathrm{mol} \mathrm{g}^{-1}\right)$. At GOF5, FeS increased with depth within the first $15 \mathrm{~cm}$ of the sediment followed by a decrease, which coincided with a strong increase in sedimentary pyrite. Siderite exhibited strong surface enrichments at sites GOF5 and LL3A $\left(\sim 300 \mu \mathrm{mol} \mathrm{g}{ }^{-1}\right)$. Crystalline Fe oxides and magnetite showed no trend with sediment depth at all sites. Total extractable Fe represented $\sim 40-70 \%$ of the total Fe pool. Total Mn was low at site JML, whereas surface enrichments in total Mn were observed at sites GOF5 and LL3A (85 and $96 \mu \mathrm{mol} \mathrm{g}^{-1}$, respectively).

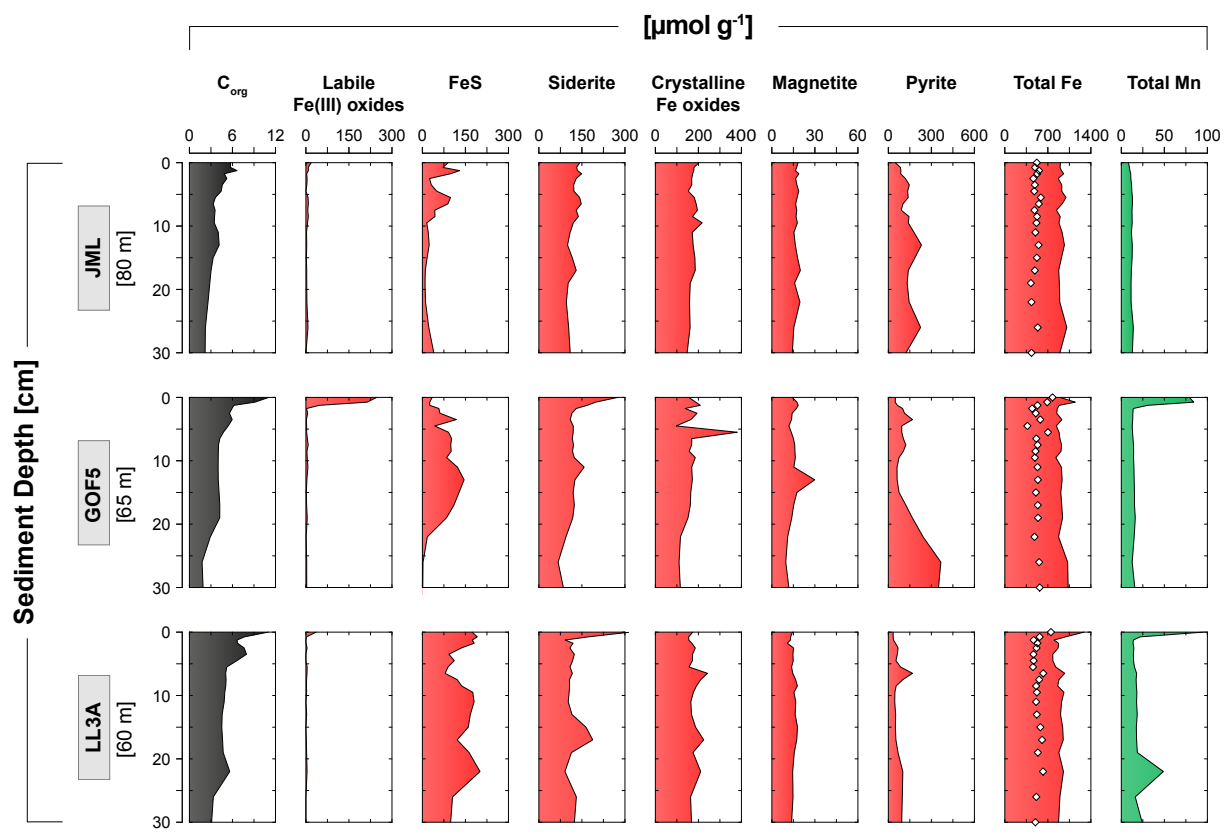

Figure 4.6 | Solid-phase depth profiles of organic carbon $\mathrm{C}_{\text {org }}$ (black), labile Fe(III) oxides, FeS, siderite, crystalline Fe oxides, magnetite, pyrite, total Fe (red) and total Mn (green) at site JML, GOF5 and LL3A in June 2016. The white diamonds represent the total amount Fe extracted in the sequential procedure.

Exchangeable-P and CDB-P, hereafter referred to as metal bound P, were low at site JML, whereas sites GOF5 and LL3A exhibited strong surface enrichments of $\sim 200$ and $\sim 100 \mu \mathrm{mol} \mathrm{g}^{-1}$ respectively (Figure 4.7). Authigenic-P and detrital-P showed no clear trend with depth in the sediment at all sites. Organic-P was highest near the surface, and decreased with sediment depth at all sites. Total $\mathrm{P}$ burial rates ranged from 43 to $147 \mathrm{mmol} \mathrm{m}^{-2} \mathrm{yr}^{-1}$ (Table 4.1). The organic-P fraction accounted for 27 to $37 \%$ of total P burial. 


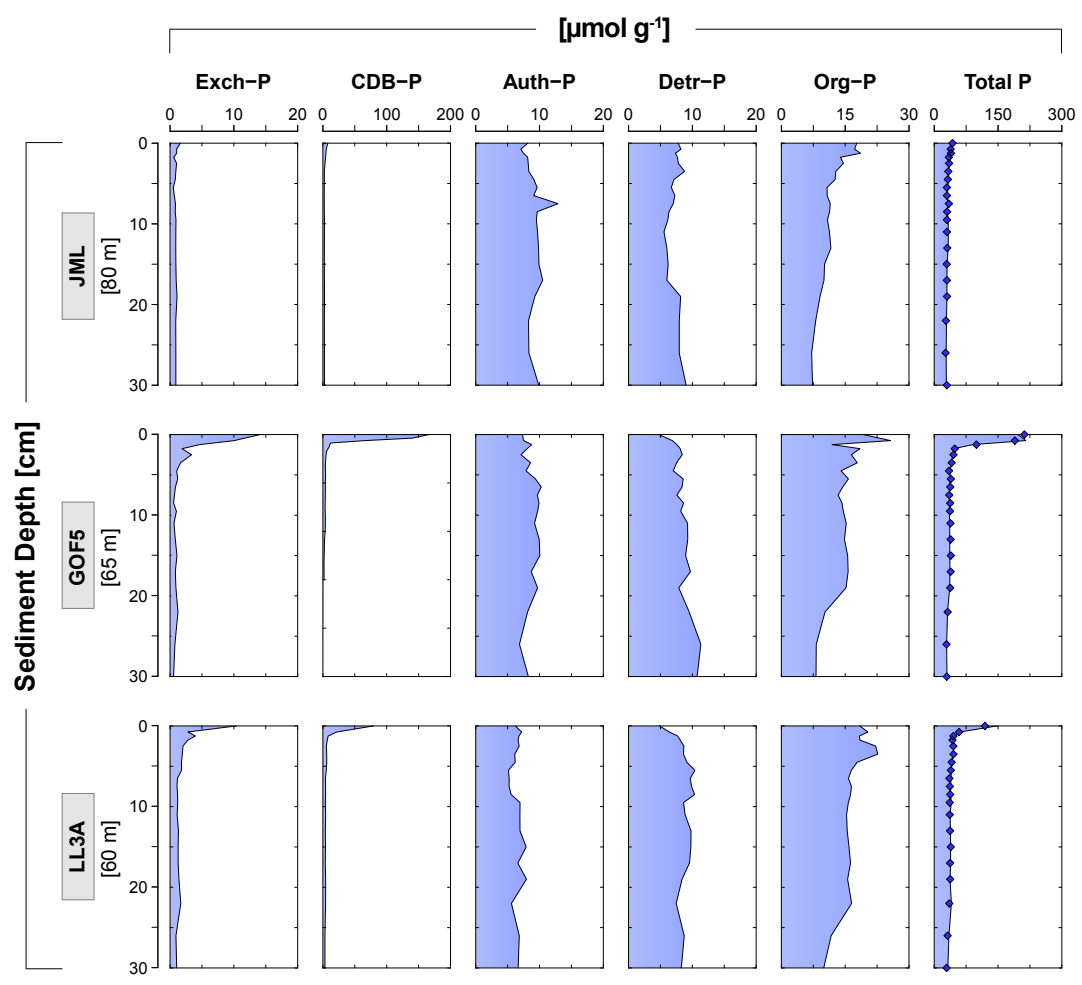

Figure 4.7 | Solid-phase depth profiles of exchangeable-P, CDB-P, authigenic-P, detrital-P, organic- $\mathrm{P}$ and total $\mathrm{P}$ site JML, GOF5 and LL3A in June 2016. The dark blue diamonds represent the total amount of P extracted in the sequential procedure.

\subsubsection{High-resolution Elemental Mapping of Surface Sediment}

High-resolution desktop $\mu$ XRF mapping of $\mathrm{Fe}, \mathrm{Mn}, \mathrm{P}, \mathrm{Ca}$ and $\mathrm{S}$, revealed a surface sediment layer highly enriched in Mn (Zone A; 0-2 mm; Figure 4.8A). Below this layer, a well-defined layer highly enriched in $\mathrm{Fe}$ was observed, in which the spatial distribution of Fe and $\mathrm{Mn}$ closely resembled the distribution of P (Zone B; 2-6 mm; Figure 4.8A). Counts of Fe and P in Zone A and Zone B were linearly correlated, although the Fe:P ratios differed (290:1 and 75:1, respectively; Table S.4.3 and Figure 4.8B). Counts of $\mathrm{Mn}$ and $\mathrm{P}$ were also linearly correlated, and were characterized by even larger differences in Mn:P ratios between Zone A and Zone B (315:1 and 5:1, respectively; Table S.4.3 and Figure 4.8B). This implies that relatively more $\mathrm{P}$ was associated with Fe and $\mathrm{Mn}$ in Zone B compared to Zone A. Deeper in the sediment (Zone C; 18-20 mm) total S increased and further down (Zone D; 20-22 mm), the enrichment in $S$ coincided with an enrichment in Fe (Figure 4.8A). 

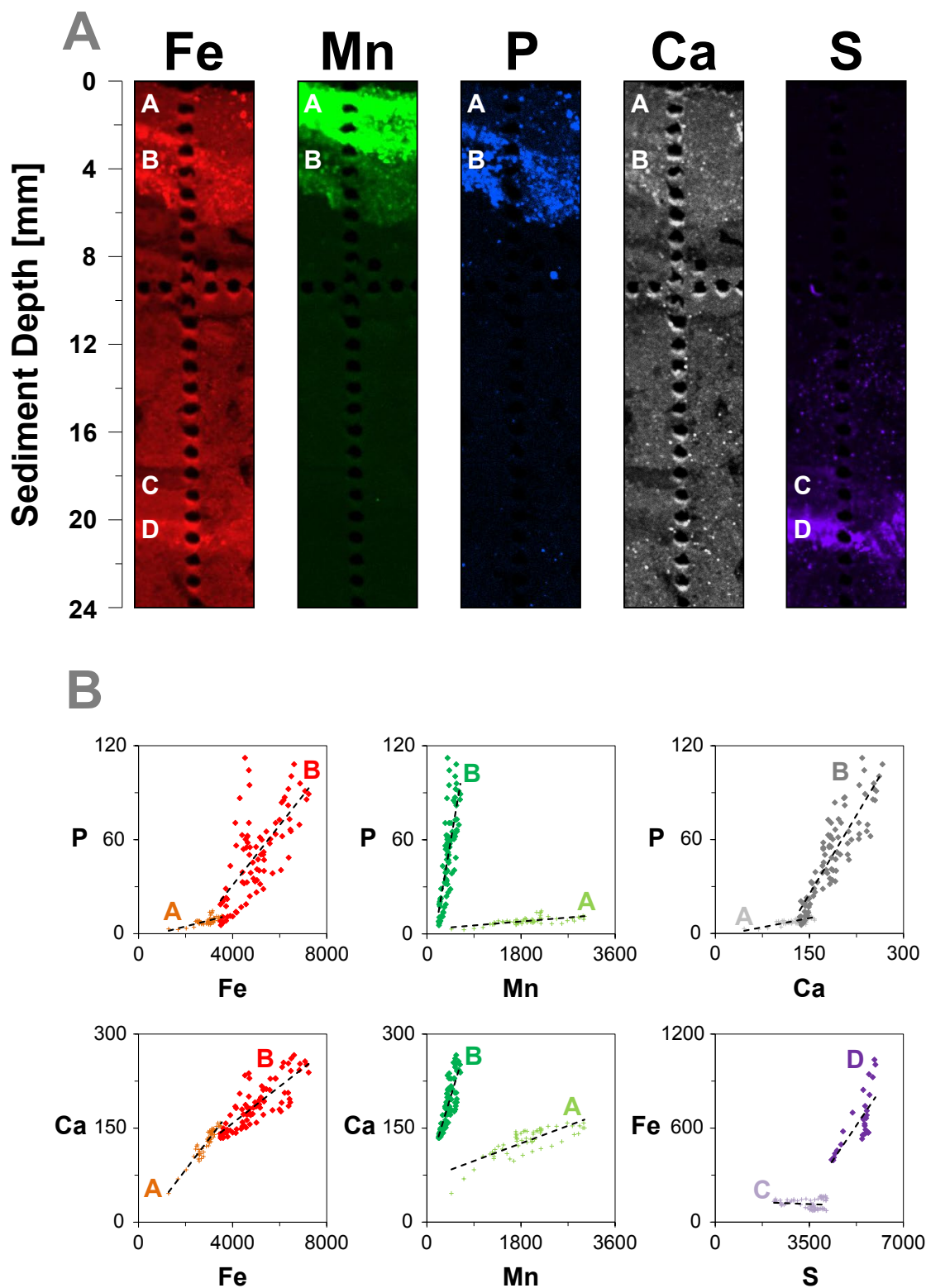

Figure 4.8 | (A) Desktop $\mu$ XRF maps of Fe (red), Mn (green), P (blue), Ca (gray) and S (purple) of the top $24 \mathrm{~mm}$ of the (epoxy embedded) surface sediment at site GOF5. Zone A, B, C and D represent the sediment depth intervals that were investigated for elemental correlations. (B) Correlations between $\mathrm{P}$ and $\mathrm{Fe}, \mathrm{P}$ and $\mathrm{Mn}$, and $\mathrm{P}$ and $\mathrm{Ca}$, and between $\mathrm{Ca}$ and $\mathrm{Fe}, \mathrm{Ca}$ and $\mathrm{Mn}$ and $\mathrm{Fe}$ and $\mathrm{S}$ in relevant zones. 


\subsubsection{Synchrotron-based Fe Analysis of the Sediment}

The Fe XANES and EXAFS spectra collected from the Fe enriched spots in Zone A and Zone B (Figure 4.9A and B) were similar to each other (Figure 4.9C). However, the spectra showed subtle differences related to the relative Fe enrichment. For XANES spectra, increased Fe contents led to a shift of the edge position towards the right at a higher energy and a broadening of the maximum absorption peak. For EXAFS spectra, increased Fe contents led to major oscillations within the range of 3 to $7 \AA^{-1}$ shifted towards higher $k$ values. The similarity in the spectra can be attributed to the relatively large analyzed volume due to the 'infinite thickness' of the sample and a penetration depth beyond $100 \mu \mathrm{m}$ at the used X-ray energy. Even large zones of Fe enrichments are smaller in size (Figure 4.9C) implying that the obtained spectra include a signal from $\mathrm{Fe}$ in particles outside the enrichments, which is assumed to be detrital Fe. An average Fe XANES spectra retrieved from spots in the sediment containing very little Fe (hereafter referred to as background Fe and assumed to reflect detrital Fe), could be best reproduced by LCF of XANES spectra from biotite and illite (Supplementary Information 4.1.11; Figure S.4.7).
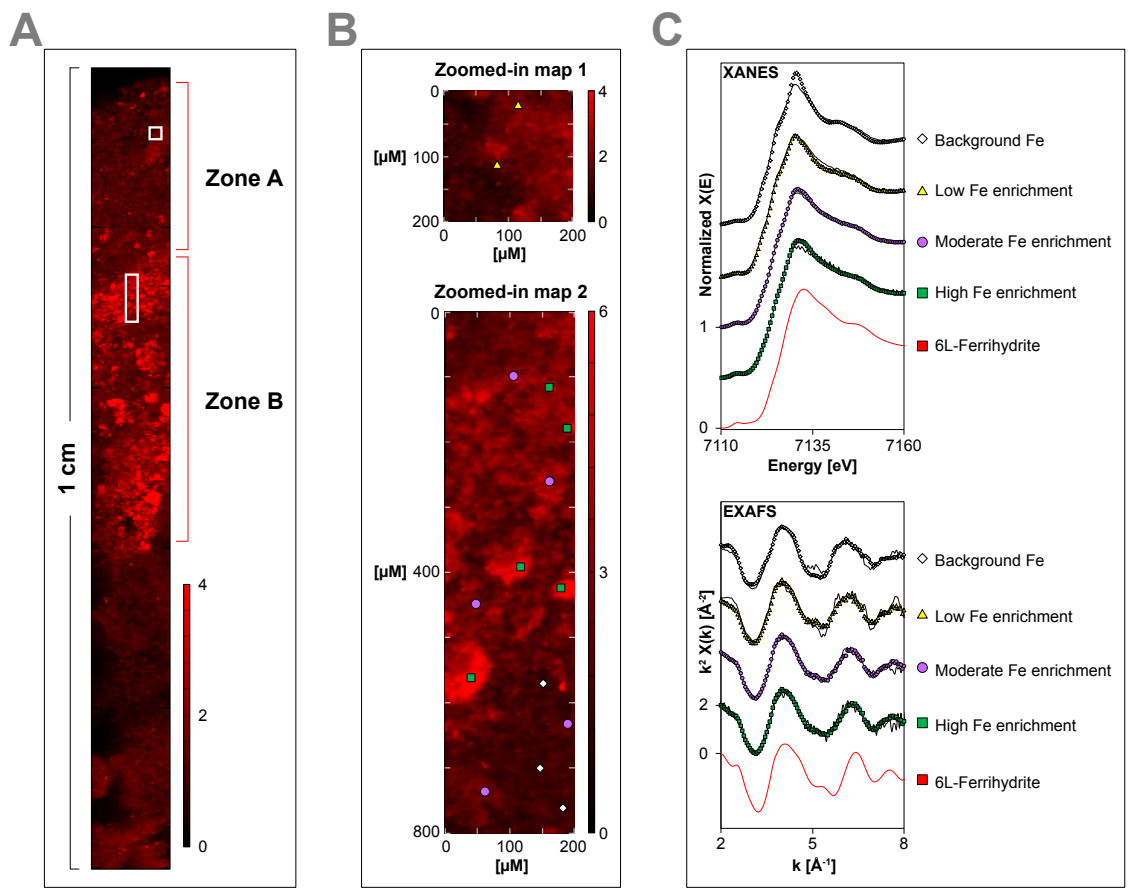

Figure 4.9 Synchrotron-based Fe analyses for epoxy embedded surface sediment at site GOF5: (A) High resolution $\mu \mathrm{XRF}$ map of the first $10 \mathrm{~mm}$ of the surface sediment. The white square and rectangle represent areas that were analyzed in further detail (B). These maps are shown in true vertical orientation, and the colors accentuate the relative counts adjusted for brightness and contrast to highlight the Fe enrichments in the sediment. The labels indicate the spots that were further subjected to XANES and EXAFS analysis: gray triangles = background Fe; yellow triangles = low Fe enrichment; purple circles = moderate Fe enrichment; green squares = high Fe enrichment. (C) Normalized XANES and $k^{2}$ weighted EXAFS spectra of Fe. The points are measured data, the lines reflect the results from LCF (Supplementary Information 4.11). 
In order to reveal information on the Fe enrichments, the spectra collected at all spots were subjected to LCF by combining the spectrum from background Fe with that of other reactive Fe phases (Figure S.4.7). Only when combining the spectra of background Fe with that of $6 \mathrm{~L}$-ferrihydrite, consistent results were obtained when applied to XANES (energy range 7103$7183 \mathrm{eV}$ ) and $k^{2}$ weighted EXAFS spectra (k-range 2-8 $\AA^{-1}$ ). The fitting results indicate an increased contribution of $6 \mathrm{~L}$-ferrihydrite with an increase in the Fe content (Table 4.2).

Table 4.2 Composition of Fe minerals at site GOF5

\begin{tabular}{lllll}
\hline Spectrum & Fe XANES & & Fe EXAFS \\
\hline & Background Fe [\%] & 6 -ferrihydrite [\%] & Background Fe [\%] & \\
\hline Low Fe enrichment & $97 \pm 1$ & $3 \pm 1$ & $84 \pm 4$ & \\
Moderate Fe enrichment & $65 \pm 1$ & $35 \pm 1$ & $64 \pm 3$ & \\
& & & & \\
High Fe enrichment & $53 \pm 2$ & $47 \pm 2$ & $52 \pm 3$ \\
\hline
\end{tabular}

\subsubsection{Synchrotron-based Mn Analysis of the Sediment}

Principal component analysis of all collected Mn XANES spectra in combination with LCF suggested that LCF fitting using the spectra of six reference Mn minerals, birnessite, hausmannite, bixbyite, manganite, $\mathrm{Mn}$ (II) phosphate (hureaulite) and rhodochrosite, was the most consistent approach to reproduce all the spectra (Supplementary Information 4.1.12). The Mn XANES spectra retrieved from the Mn-rich areas in the upper part of the surface sediment (Area \#1-3; Figure 4.10) systematically deviated from those in the Fe-enriched zone (Area \#4) whose edge position and white line was located at lower energies than in the spectra above. LCF of the XANES spectra allowed to reproduce the edge position and the adsorption maxima at the various spots which, both, reflect the oxidation state of Mn. For detailed analysis of the Mn mineralogy EXAFS spectra would be required. Hence, the interpretation of the LCF results was limited to distinguish Mn oxides with various oxidation states from $\mathrm{Mn}$ (II) carbonates and phosphates. According to the LCF of the Mn XANES spectra, Mn oxides (Area \# 1-3) accounted for $~ 74-87 \%$ of total Mn, with Mn(II) phosphates and carbonates accounting for the remaining $~ 5-26 \%$ (Table 4.3). The XANES spectra for Area \#4 closely resemble that of Mn(II) phosphates and LCF suggests that Mn (II) phosphates account for about $\sim 97 \%$ of total Mn) while Mn(II) carbonate was absent (Table 4.3). 

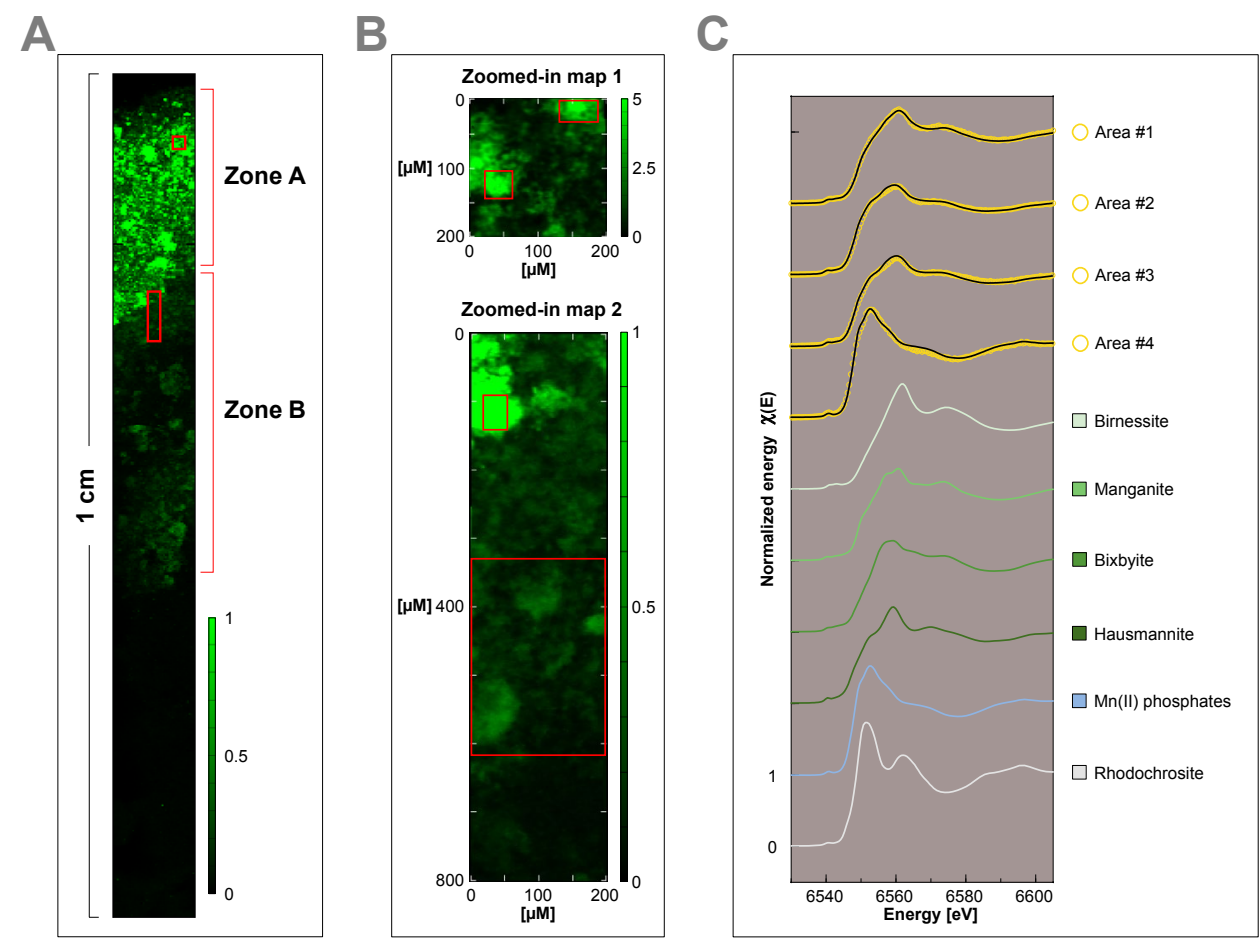

Figure 4.10 | Synchrotron-based Mn analyses for epoxy embedded surface sediment at site GOF5: (A) High resolution $\mu \mathrm{XRF}$ map of the first $10 \mathrm{~mm}$ of the surface sediment. The red rectangles represent areas that were analyzed in further detail (B). These maps are shown in true vertical orientation, and the colors accentuate the relative counts adjusted for brightness and contrast to highlight the Fe enrichments in the sediment. The red rectangles indicate the areas that were further subjected to XANES analysis. (C) Normalized Mn XANES spectra.

Table 4.3 | Composition of Mn minerals at site GOF5

\begin{tabular}{llll}
\hline Spectra & Mn oxides [\%] & Mn(II) phosphates [\%] & Rhodochrosite [\%] \\
\hline Area \#1 & $87 \pm 14$ & $5 \pm 3$ & $8 \pm 8$ \\
Area \#2 & $73 \pm 12$ & $24 \pm 2$ & $3 \pm 7$ \\
Area \#3 & $74 \pm 14$ & $26 \pm 3$ & \\
Area \#4 & $3 \pm 0$ & $97 \pm 3$ & \\
\hline
\end{tabular}

No values $=$ contribution $<1 \%$ 


\section{Discussion}

\subsubsection{Benthic Release of $\mathrm{Fe}, \mathrm{Mn}$ and $\mathrm{P}$ in the Gulf of Finland}

Eutrophication of the Baltic Sea has led to the expansion of areas with bottom waters that are low in $\mathrm{O}_{2}$ (Diaz and Rosenberg 2008). The lack of $\mathrm{O}_{2}$ has led to high concentrations of dissolved $\mathrm{PO}_{4}$ and dissolved and/or particulate Fe and $\mathrm{Mn}$ in the water column of the deep basins (Gotland and Landsort Deep) due to less efficient sequestration in the sediment (Turnewitsch and Pohl 2010; Pohl and Fernández-Otero 2012). Here, we report high concentrations of total dissolvable Fe and Mn and dissolved $\mathrm{PO}_{4}$ in the bottom waters of the Gulf of Finland (Figure 4.2). Combined with high benthic fluxes of dissolved Fe, Mn and $\mathrm{PO}_{4}$ at sites GOF5 and LL3A (Figure 4.5; Table S.4.2), this implies that release from the sediment contributes to the enrichment of these solutes in the bottom water at seasonally hypoxic sites (Figures 4.11, S.4.8A and S.4.9A).

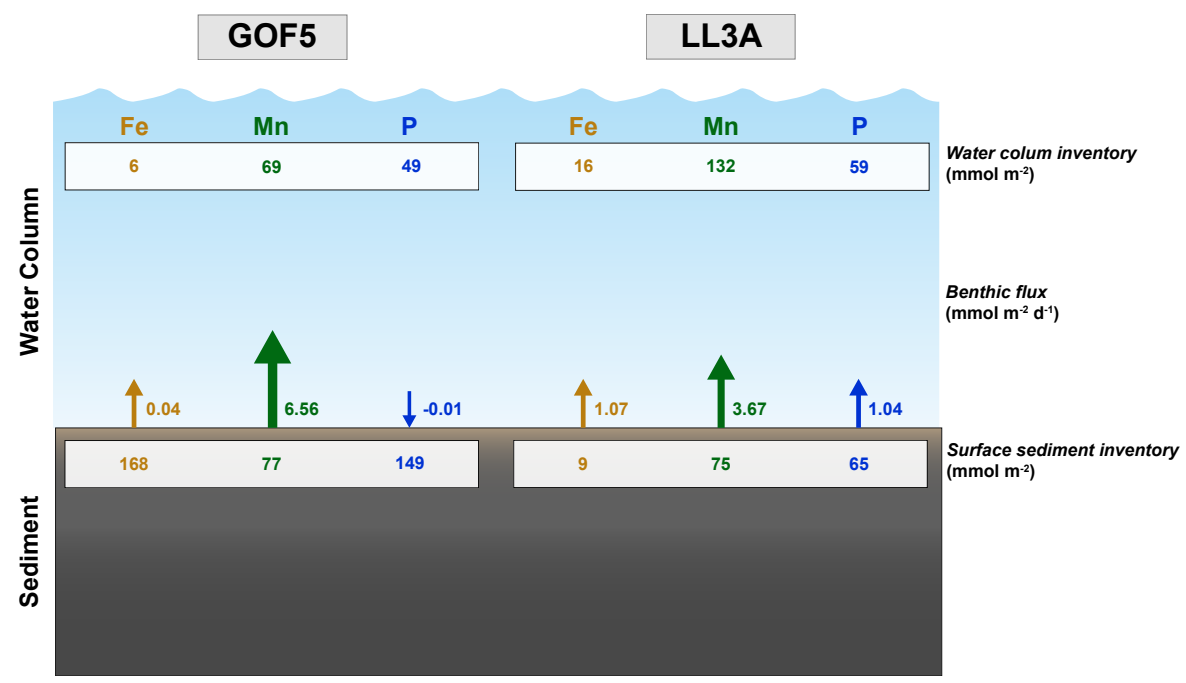

Figure 4.11 Inventories in the water column and surface sediment and benthic release fluxes for Fe, Mn and P at sites GOF5 and LL3A.

The form of the Fe and $\mathrm{Mn}$ in the bottom water at our study sites depends on its redox state as shown in a parallel study on Fe and Mn dynamics in the Baltic Sea (Lenstra et al. Submitted). At site JML, where bottom waters were sulfidic, Fe was likely mainly present as FeS, whereas Mn was present in dissolved form only. At sites GOF5 and LL3A, where waters were low in $\mathrm{O}_{2}$ but not sulfidic, Fe was mainly present in particulate form as poorly crystalline Fe oxides, whereas dissolved Mn dominated the total dissolvable Mn pool. Nevertheless, there was still a substantial amount of particulate $\mathrm{Mn}$ in the bottom water ( 1600-3100 nM; Lenstra et al. Submitted) and we show here that at these latter sites, this particulate $\mathrm{Mn}$ is predominantly present in the form of $\mathrm{Mn}$ oxides (Figure 4.3).

The geochemistry of the surface sediment at sites GOF5 and LL3A differed distinctly from that of site JML, with only the former being characterized by enrichments in Fe and Mn oxides and associated P (Figure 4.6 and 4.7) and sharp peaks in pore water Fe and Mn near the sediment- 
water interface (Figure 4.4). Sedimentary P in the surface sediment at sites GOF5 and LL3A was predominantly bound to Fe and Mn minerals (Figure S.4.10A). At site JML, most of the P in the surface sediment $(0-2 \mathrm{~cm})$ was associated with organic matter.

The above suggests there is potential for a continuous cycle of release of dissolved Fe and/or $\mathrm{Mn}$ from the sediment, formation of oxides above the thin hypoxic layer in the water column and subsequent deposition of metal oxides, as described for $\mathrm{Mn}$ for other seasonally hypoxic coastal systems (Adelson et al. 2001; Sulu-Gambari et al. 2017). At site GOF5, the high benthic flux of Mn $\left(6.6 \mathrm{mmol} \mathrm{m}^{-2} \mathrm{~d}^{-1}\right)$ and nearly equal amounts of $\mathrm{Mn}$ in the water column and surface sediment (69 and $77 \mathrm{mmol} \mathrm{m}^{-2}$; Figure 4.11 and S.4.8) point towards strong refluxing.

The higher water column concentrations and benthic fluxes of Mn compared to those of $\mathrm{Fe}$ at sites GOF5 and LL3A can be explained by their contrasting geochemical dynamics. When bottom water $\mathrm{O}_{2}$ is low, dissolved $\mathrm{Mn}$ can more easily escape to the overlying water than dissolved $\mathrm{Fe}$ (Burdige 1993). Contributing factors include the slower oxidation kinetics of dissolved Mn with $\mathrm{O}_{2}$, which is mainly a microbially-mediated process, and the less efficient sequestration of $\mathrm{Mn}$ in mineral form when compared to Fe (Burdige 1993; Luther 2010; Learman et al. 2011; McManus et al. 2012). This difference in sequestration is also apparent from the sediment Fe and Mn contents below the surface sediment at all sites: while Fe sulfides account for a significant fraction of reactive Fe (Figure 4.6), sediment Mn contents are very low and the $\mathrm{Mn}$ is likely mostly associated with clays and/or carbonates (Suess 1979; Lenz et al. 2014). In the following sections, we will focus on the potential role of cable bacteria activity in determining the formation of $\mathrm{Fe}$ and $\mathrm{Mn}$ oxides and $\mathrm{P}$ sequestration in Gulf of Finland sediments.

\subsubsection{Diagenetic Fe and Mn Mineral Formation Induced by Cable Bacteria}

Bottom water $\mathrm{O}_{2}$ availability acts as a key control on cable bacteria activity and likely induced the removal of $\mathrm{\Sigma H}_{2} \mathrm{~S}$ and formation of Fe oxides and preservation of Mn oxides in the surface sediment at sites GOF5 and LL3A in spring (Figures 4.4, 4.6 and S.4.2; Hermans et al. 2019a). The impact of Marenzelleria on the formation of these Fe oxides was likely limited, since much higher population densities than observed at these sites (>3000 ind. $\mathrm{m}^{-2}$ versus 1200 ind. $\mathrm{m}^{-2}$; Hermans et al. 2019a) are necessary to significantly promote the formation of Fe oxides (Norkko et al. 2012). At site JML, the lack of $\mathrm{O}_{2}$ hindered cable bacteria activity and the presence of $\Sigma \mathrm{H}_{2} \mathrm{~S}$ in the bottom water during part of the year prevented the formation and preservation of Fe and $\mathrm{Mn}$ oxides.

The geochemical impact of cable bacteria on the pore water and surface sediment was most pronounced at site GOF5 (Figures 4.6 and 4.7). This is further supported by visual observations of the surface sediment at the time of sampling, which revealed an orange Fe oxide layer (oxic zone), overlying a gray FeS depleted layer (suboxic zone) and a black layer (sulfidic zone; Figure S.4.11). These features are typical for sediments that have been geochemically altered by cable bacteria (Nielsen and Risgaard-Petersen 2015; Sulu-Gambari et al. 2016a). Sites LL3A and JML (Figures 4.6 and S.4.12) did not exhibit these characteristic features, therefore only the samples for site GOF5 were studied in detail for their mineralogy.

The Fe oxides formed by the activity of cable bacteria in spring at site GOF5 were focused within a thin layer near the sediment-water interface (Zone B; $2-5 \mathrm{~mm}$ depth; Figure 4.8A). The reactive $\mathrm{Fe}$ in this layer predominantly consisted of poorly crystalline Fe (III) oxides (Figure 4.9; Table 4.2). As shown previously by Hermans et al. (2019a), the size of the deficit in FeS in the upper $2 \mathrm{~cm}$ of the sediment is equal to that of the enrichment in Fe oxides (both $0.17 \mathrm{~mol} \mathrm{~m}^{-2}$ ), suggesting a full conversion of $\mathrm{FeS}$ to $\mathrm{Fe}$ oxides as a consequence of pore water acidification by cable bacteria in 
spring, (Figures 4.6 and S.4.8B). For comparison, the amount of Fe in the water column at the time of sampling was $0.006 \mathrm{~mol} \mathrm{~m}^{-2}$ (Figures 4.11 and S.4.8A).

Directly above the Fe-rich layer and below the sediment-water interface (Zone A; 0-2 mm depth), the sediment was highly enriched in Mn oxides (Figure 4.8A and 4.10; Table 4.3). Some of these Mn oxides may have formed diagenetically in spring from upward diffusing dissolved Mn. Given the position of the redox cline in the water column, Mn oxides likely did not form in the sediment at the time of sampling (Figure 4.1), and deposition of suspended matter from the water column was likely the main source of $\mathrm{Mn}$ in the surface sediment.

Underneath the Mn oxide rich layer, thus in the same zone as the Fe oxide enriched layer (Zone B; 2-5 mm depth; Figure 4.8A), a moderate enrichment in Mn was observed, mainly consisting of $\mathrm{Mn}(\mathrm{II})$ phosphates (Figure 4.10; Table 4.3). The formation of $\mathrm{Mn}$ (II) phosphates is likely favored by high concentrations of dissolved $\mathrm{Mn}$ and $\mathrm{PO}_{4}$ and low levels of $\Sigma \mathrm{H}_{2} \mathrm{~S}$. Such conditions were present in the surface sediment at site GOF5 (Figure 4.4 and S.4.2). Cable bacteria likely contributed to the development of the geochemical niche for formation of $\mathrm{Mn}$ (II) phosphates by removing $\Sigma \mathrm{H}_{2} \mathrm{~S}$.

The relative contributions of the Fe and Mn oxides and $\mathrm{Mn}$ (II) phosphates in sequestering $\mathrm{P}$ in the surface sediment at site GOF5 was estimated (Table 4.4) by combining the sequential extraction and $\mu$ XRF data. The total amount of metal bound P (Ex-P + CDB-P) in the top $5 \mathrm{~mm}$ of the surface sediment was $0.048 \mathrm{~mol} \mathrm{~m}^{-2}$ (Figure 4.7$)$ of which $10 \%\left(0.005 \mathrm{~mol} \mathrm{~m}^{-2}\right)$ was located in Zone A and $90 \%\left(0.043 \mathrm{~mol} \mathrm{~m}^{-2}\right)$ in Zone B (Figure S.4.13). The total amount of Fe integrated over the top 5 $\mathrm{mm}$ of the surface sediment at site GOF5 amounted to $0.24 \mathrm{~mol} \mathrm{~m}^{-2}$ (Figure 4.6). Approximately, $29 \%\left(0.07 \mathrm{~mol} \mathrm{~m}^{-2}\right)$ of total Fe was located in Zone A $(0-2 \mathrm{~mm})$ and $71 \%\left(0.17 \mathrm{~mol} \mathrm{~m}^{-2}\right)$ in Zone B (2-5 mm; Figure S.4.13). The relative contribution of Fe to P sequestration in Zone A was likely negligible, since illite and biotite are both relatively not as efficient in sequestering $\mathrm{P}$ compared to Fe oxides (Edzwald et al. 1976; Gunnars et al. 2002). In contrast, the Fe minerals in Zone B, likely did contribute to $\mathrm{P}$ sequestration. Approximately $38 \%$ of the total Fe in Zone B consisted of poorly crystalline Fe oxides (Table 4.2). Assuming a 2 to 1 ratio of Fe to P (Gunnars et al. 2002; Table 4.4), these Fe oxides $\left(0.066 \mathrm{~mol} \mathrm{~m}^{-2}\right)$ could potentially sequester $0.033 \mathrm{~mol} \mathrm{P} \mathrm{m}^{-2}$.

The total amount of $\mathrm{Mn}$ in the top $5 \mathrm{~mm}$ of the surface sediment amounted to $0.021 \mathrm{~mol} \mathrm{~m}^{-2}$. Approximately, $73 \%\left(0.015 \mathrm{~mol} \mathrm{~m}^{-2}\right)$ of total $\mathrm{Mn}$ was located in Zone A (0-2 mm) and about 27\% $\left(0.006 \mathrm{~mol} \mathrm{~m}^{-2}\right)$ in Zone B $(2-5 \mathrm{~mm}$; Figure S.4.14). Because Fe oxides were not present in Zone A, the relative contribution of $\mathrm{Mn}$ oxides in this zone with respect to $\mathrm{P}$ sequestration was $\sim 10 \%$. The $\mathrm{Mn}(\mathrm{II})$ phosphates in Zone B accounted for the remaining $22 \%\left(0.010 \mathrm{~mol} \mathrm{~m}^{-2}\right)$ of P sequestration.

To summarize, $\mathrm{P}$ sequestration in the surface sediment of GOF5 occurred in a very narrow zone of the sediment and was predominately associated with Fe oxides (68\%), whereas Mn oxides and $\mathrm{Mn}(\mathrm{II})$ phosphates both played a smaller role (32\%; Table 4.4). Pore water acidification and associated FeS dissolution as a consequence of cable bacteria activity in spring acted as the main source for the Fe oxides in the surface sediment at site GOF5, whereas deposition of suspended matter from the water column acted as the main source for sedimentary Mn oxides.

Table 4.4 | Relative contribution of Fe and Minerals to P sequestration in the surface sediment at site GOF5.

\begin{tabular}{|c|c|c|c|}
\hline Layer & Fe oxides [\%] & Mn oxides [\%] & Mn(II) phosphates [\%] \\
\hline 0-2 mm (Zone A) & 0 & 10 & 0 \\
\hline$\underline{2-5 \mathrm{~mm} \text { (Zone B) }}$ & 68 & 0 & 22 \\
\hline Layer & Fe oxides $\left[\mathrm{mmol} \mathrm{m}^{-2}\right]$ & Mn oxides $\left[\mathrm{mmol} \mathrm{m}^{-2}\right]$ & Mn(II) phosphates $\left[\mathrm{mmol} \mathrm{m}^{-2}\right]$ \\
\hline 0-2 mm (Zone A) & 0 & 4.9 & 0 \\
\hline 2-5 mm (Zone B) & 32.9 & 0 & 10.3 \\
\hline
\end{tabular}




\subsubsection{Implications for Water Quality in Seasonally Hypoxic Systems}

In the Gulf of Finland, release of $\mathrm{PO}_{4}$ from metal oxides and organic matter during periods with low bottom water $\mathrm{O}_{2}$ have been suggested to control the highly varying concentrations of $\mathrm{PO}_{4}$ in the bottom water (Pitkänen et al. 2001). Water column monitoring data (SMHI) reveals that bottom water $\mathrm{O}_{2}$ is typically inversely correlated with $\mathrm{PO}_{4}$ (Figure S.4.14; Viktorsson et al. 2012). At the time of sampling bottom water $\mathrm{O}_{2}$ was low, whereas benthic fluxes of $\mathrm{PO}_{4}$ were relatively high, ranging up to $1.65 \mathrm{mmol} \mathrm{m}^{-2} \mathrm{~d}^{-1}$ (Table 4.1; Figure 4.5B). Similar high fluxes of $\mathrm{PO}_{4}$ were observed previously at other sites in the Gulf of Finland upon reductive dissolution of metal oxides in the sediment (Pitkänen et al. 2001; Lehtoranta 2003; Viktorsson et al. 2012). The Fe and Mn minerals formed and preserved by cable bacteria in spring may temporarily buffer the release of $\mathrm{PO}_{4}$ in summer. Recycled Fe and Mn oxides depositing from the water column potentially could also contribute to this buffer. We find that this refluxing process is most pronounced for Mn. Cable bacteria likely amplify the refluxing, since their activity typically removes $\Sigma \mathrm{H}_{2} \mathrm{~S}$ in the surface sediment. This allows dissolved $\mathrm{Fe}$ and $\mathrm{Mn}$ to escape more easily from the sediment into the water column where they can precipitate as $\mathrm{Fe}$ and $\mathrm{Mn}$ oxides upon contact with $\mathrm{O}_{2}$, and return to the sediment through deposition.

At site GOF5, bottom water records indicate that the layer of poorly crystalline Fe oxides in the surface sediment likely was not completely removed during hypoxia (Figure S.4.14). Complete reductive dissolution of this Fe oxide layer would give an expected increase of $7.4 \mu \mathrm{M}$ $\mathrm{PO}_{4}$, whereas the maximum observed increase in bottom water $\mathrm{PO}_{4}$ was only $5 \mu \mathrm{M}$ during peak bottom water anoxia (Figure S.4.14). At site LL3A, most of the poorly crystalline Fe oxides and associated $\mathrm{P}$ formed in spring likely already underwent reductive dissolution at the time of sampling, leading to a relatively low content of these Fe oxides and relatively high FeS content in the surface sediment (Figure 4.6). The relatively higher $\mathrm{SO}_{4}{ }^{2-}$ reduction rate observed at site LL3A $\left(2.7 \mathrm{mmol} \mathrm{m}^{-2} \mathrm{~d}^{-1}\right)$ compared to that of site GOF5 $\left(2 \mathrm{mmol} \mathrm{m} \mathrm{d}^{-1}\right.$; Hermans et al. 2019a) could explain this observation. As a consequence of spatial variability in bottom water $\mathrm{O}_{2}$ availability and $\mathrm{SO}_{4}{ }^{2-}$ reduction rates in the seafloor, the role of cable bacteria acting as a buffer for $\mathrm{PO}_{4}$ during low bottom $\mathrm{O}_{2}$ cannot be generalized for the entire Gulf of Finland (Figure 4.11).

Although, cable bacteria can enhance the sequestration of $\mathrm{P}$ in the surface sediment, their role in permanent $\mathrm{P}$ burial in the Gulf of Finland is likely limited. Despite a stark contrast in bottom water redox conditions and surface sediment geochemistry, all sites exhibit a strong similarity in pore water and solid-phase geochemistry below $2 \mathrm{~cm}$ sediment depth (Figures 4.4, 4.6, 4.7 and S.4.7). At all sites, total $\mathrm{P}$ decreases strongly with sediment depth as a compound result of the reduction of $\mathrm{Fe}$ and $\mathrm{Mn}$ minerals to which $\mathrm{PO}_{4}$ is bound and breakdown of organic $\mathrm{P}$. As a consequence, permanent burial of $\mathrm{P}$ is mostly in the form of organic $\mathrm{P}$, detrital $\mathrm{P}$ and authigenic $\mathrm{P}$, with only a minor fraction (6-9\%) bound to Fe and Mn minerals (Figure S.4.10). This distribution in sedimentary $\mathrm{P}$ burial pools is in line with previous observations for Gulf of Finland sediments (Lukkari et al. 2009a; Lukkari et al. 2009b). Rates of P burial in our study (43 to $147 \mathrm{mmol} \mathrm{m}^{-2} \mathrm{yr}^{-1}$; Table 4.1; Figure S.4.5) are also in line with previous estimates for Gulf of Finland sediments (42 to $139 \mathrm{mmol} \mathrm{m}^{-2} \mathrm{yr}^{-1}$; Pitkänen 1994; Lukkari et al. 2008; Asmala et al. 2017).

To summarize, the availability of bottom water $\mathrm{O}_{2}$ and associated cable bacteria activity exerts a strong impact on the geochemistry of the surface sediment, and likely amplifies the recycling of $\mathrm{Fe}, \mathrm{Mn}$ and $\mathrm{P}$ to the water column at sites where they are active in the Gulf of Finland. However, the bottom water $\mathrm{O}_{2}$ availability and associated cable bacteria activity do not significantly impact P burial. These results support previous observations by Sulu-Gambari et al. (2016a; 2016b) for 
sediments in a seasonally hypoxic marine lake. We demonstrate that the same mechanism can also be active in sediments of seasonally hypoxic brackish coastal systems. Our results highlight that only a very narrow zone of the sediment is involved in the recycling of $\mathrm{Fe}, \mathrm{Mn}$ and $\mathrm{P}$.

\subsection{Conclusions}

In the Gulf of Finland, the activity of cable bacteria likely exerts a strong impact on the surface sediment geochemistry and benthic exchange of $\mathrm{Fe}, \mathrm{Mn}$ and $\mathrm{P}$. Our results suggest that cable bacteria activity leads to removal of $\mathrm{\Sigma}_{2} \mathrm{~S}$ and the formation of poorly crystalline Fe oxides and $\mathrm{Mn}$ (II) phosphates and preservation of Mn oxides near the sediment-water interface in the Gulf of Finland. At one site, the Fe oxides formed by the activity of cable bacteria in spring, focused within a thin layer $(3 \mathrm{~mm})$, were responsible for $\sim 68 \%$ of the $\mathrm{P}$ sequestration in the surface sediment. Hence, formation of $\mathrm{Fe}$ oxides formed in spring may temporarily delay the benthic release of $\mathrm{PO}_{4}$ in summer. We show that cable bacteria activity likely promotes recycling of $\mathrm{Mn}$ between the sediment and water column. Manganese minerals are estimated to account for $\sim 32 \%$ of $\mathrm{P}$ sequestration in the surface sediment. The buffer mechanism for $\mathrm{PO}_{4}$ involving poorly crystalline $\mathrm{Fe}$ oxides may be active in other brackish seasonally hypoxic systems where rates of $\mathrm{SO}_{4}^{2-}$ reduction near the surface sediment are sufficient to sustain cable bacteria. Despite the large impact of cable bacteria activity on temporal sequestration of $\mathrm{P}$, their activity does not affect the permanent burial of $\mathrm{Fe}, \mathrm{Mn}$ and $\mathrm{P}$ in Gulf of Finland sediments.

\section{Acknowledgements}

We thank the captain and crew of R/V Pelagia for their assistance during the Baltic Sea expedition in June 2016 (64PE411). This research was funded by a Vici grant (865.13.005) from the Netherlands Organization for Scientific Research (NWO) and by an ERC Starting Grant (278364) from the European Research Council under the European Community's Seventh Framework Program. This research was also supported by the BONUS COCOA Project (2112932-1), funded jointly by the EU and FORMAS, and by the Swedish Agency for Marine and Water Management (Havs-och vattenmyndigheten, 1960-2018). We thank K. Wunsch, H. de Waard, J.J Mulder, J. van Ooijen and S. Ossebaar for their analytical support. We are grateful to the European Synchrotron Radiation Facility (ESRF) for beam time at the ID21 beamline (experiment ES-591) in May 2017. We thank the beamline scientists W. de Nolf and A.E. Pradas del Real for their support at the ESRF. 


\section{S.4. Supplementary Information}

\section{S.4.1. Diffusive Flux Calculations}

The diffusive fluxes of dissolved $\mathrm{NH}_{4}^{+}, \mathrm{PO}_{4}, \mathrm{Fe}$ and $\mathrm{Mn}$ were calculated using Fick's first law as described in Berner (1980):

$J=-\phi D_{s} \cdot \frac{d C}{d z}$

where $J$ is the diffusive flux [ $\mathrm{mmol} \mathrm{m} \mathrm{yr}^{-1}$ ], $\phi$ represents the sediment porosity, $D_{s}$ is the diffusion coefficient $\left[\mathrm{m}^{2} \mathrm{yr}^{-1}\right], C$ is the concentration and $z$ represents the sediment depth $[\mathrm{m}]$. The diffusion coefficient was calculated as a function of ambient tortuosity, pressure, salinity and temperature using the $\mathrm{R}$ package marelac (Soetaert et al. 2010), which implements the constitutive relations described in Boudreau (1997). The concentration gradient between the bottom water and the first sediment depth interval was used for the calculations.

\section{S.4.2. Phosphorus Burial Calculations}

The total $\mathrm{P}$ burial rates in $\mathrm{mmol} \mathrm{m} \mathrm{mr}^{-2}$ were calculated as a function of the sedimentation rate, total $\mathrm{P}$ in the deeper sediment and the porosity using the following equation:

$P_{\text {burial }}=P_{\text {total }} \cdot S R \cdot \rho \cdot(1-\phi) \cdot 10^{4}$

where $P_{\text {total }}$ represents the average concentration of total $\mathrm{P}\left(\mathrm{mol} \mathrm{g}^{-1}\right)$ in the 20 to $30 \mathrm{~cm}$ sediment depth interval, $S R$ is the sedimentation rate $\left(\mathrm{cm} \mathrm{yr}^{-1}\right), \phi$ is the porosity within the same depth interval and $\rho$ represents the density of dry sediment $2.65 \mathrm{~g} \mathrm{~cm}^{-3}$ (Burdige 2006).

\section{S.4.3. Manganese XAS Analysis of Suspended Matter Samples}

Suspended matter samples from the water column from sites GOF5 and LL3A, were analyzed for their Mn content and mineralogy. High-resolution $\mu$ XRF maps $\left(1.6-2.5 \mathrm{~mm}^{2}\right)$ were analyzed using a horizontal and vertical step size of 0.5 to $0.75 \mu \mathrm{m}$, respectively. Mn XANES spectra were retrieved at 12 to 14 spots that were enriched in Mn. At each spot only one Mn XANES spectrum was collected to avoid photo-induced reduction of Mn during X-ray analyses. Mn XANES spectra, were subjected to component analysis using the Iterative Transformation Factor Analysis (ITFA) software package (Rossberg et al. 2003).

The indicator function from the component analysis revealed that three components are the optimal number for reproducing the Mn XANES spectra of suspended material at the three locations. Spectra from three spots were identified based on the Varimax analysis, each having a high loading on one of the components and only a minor loading on the others. None of the three Mn XANES spectra showed a close resemblance with one of the spectra from reference materials including several Mn oxides, carbonate, phosphate and sulphide. The position of the absorption maximum of all spectra was close to that of $\mathrm{Mn}$ in birnessite. The spectra differ, in particular, regarding the shape and position of the edge which is shifted to lower energies compared to birnessite. This indicates that the fraction of Mn with a lower oxidation state than IV (e.g. Mn(II) or $\mathrm{Mn}(\mathrm{III})$ ) at the analyzed spots is higher than that of $\mathrm{Mn}$ in birnessite. Birnessite contains 
predominately $\mathrm{Mn}(\mathrm{IV})$ but can also contain $\mathrm{Mn}$ (III) which leads to an excess negative charge in the layers which is compensated by accommodating cations in the interlayer.

Based on the results from the component analysis, the maximum number of spectra for LCF was constrained to three. For LCF, the normalized Mn XANES spectra in the range 6530 to $6580 \mathrm{eV}$ was used. When searching the best combination of three Mn XANES spectra out of a set of spectra from various materials for reproducing the three spectra by LCF, consistently birnessite was selected in combination with hausmannite $\left(\mathrm{Mn}_{3} \mathrm{O}_{4}\right), \mathrm{Mn}(\mathrm{II})$ phosphates or dissolved $\mathrm{Mn}^{2+}$. The contribution of aqueous $\mathrm{Mn}^{2+}$ to one of the spectra was only very minor. Hence, the Mn XANES spectra can be well reproduced when combining the spectra of birnessite, hausmannite and $\mathrm{Mn}(\mathrm{II})$ phosphate. The R-factor ( $\operatorname{sum}\left((\text { fit-data })^{2}\right) / \operatorname{sum}\left(\right.$ data $\left.\left.^{2}\right)\right)$ was on average 0.00167 and always below 0.005 .

The quality of the spectra was insufficient for investigating their extended X-ray absorption fine structure (EXAFS). Hence, confirmation of the results from LCF of XANES spectra by investigating the EXAFS was not possible. Furthermore, due to the relatively short energy range, the results of LCF are strongly influenced by the position and shape of the edge. Consequently, the assigned fractions of hausmannite and $\mathrm{Mn}$ (II) phosphate might not necessarily reflect the concentrations of these two phases but, instead, account for the presence of $\mathrm{Mn}$ (II) and $\mathrm{Mn}$ (III) including, for example, also adsorbed $\mathrm{Mn}$ (II) or birnessite with a higher $\mathrm{Mn}$ (III) content compared to the reference material in the LCF.

\section{S.4.4. Iron Enrichment Classification}

Spots in the synchotron-based $\mu \mathrm{XRF}$ map were classified into three categories based on their total Fe content as reflected in the relative count intensities. (Table S.4.1).

Table S.4.1 | Classification of Fe based on relatively count intensity bandwiths.

\begin{tabular}{ll}
\hline Classification & Counts \\
\hline Low & $2-3$ \\
Moderate & $3-6$ \\
High & $6-8$ \\
\hline
\end{tabular}




\section{S.4.5. High-resolution Maps of Mn in Suspended Matter in the Water Column}

At sites GOF5 and LL3A, Mn XANES spectra of suspended matter in the water column were collected from 14 and 12 spots, respectively (Figure S.4.1).
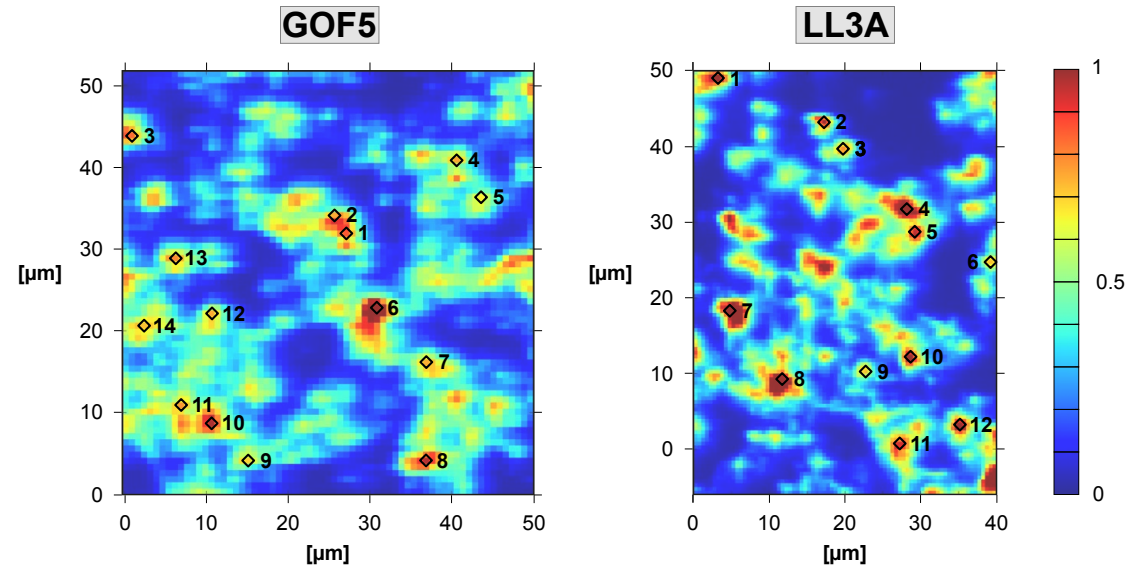

Figure S.4.1 | High-resolution synchrotron-based $\mu$ XRF maps of suspended matter in the water column at sites GOF5 (60 $\mathrm{m}$ water depth) and LL3A (58 $\mathrm{m}$ water depth). The colors accentuate the relative count intensities adjusted for brightness and contrast to highlight the Mn enrichments. The open black diamonds indicate the Mn enrichments that were further subjected to Mn XANES analysis to identify their mineralogical composition. 


\section{S.4.6. High-resolution Depth Profiles of $\mathrm{pH}, \mathrm{O}_{2}$ and $\mathrm{\Sigma H}_{2} \mathrm{~S}$}

Pore water $\mathrm{pH}$ at site JML increased slightly with sediment depth from 7.1 to 7.4 following an initial small decrease at the sediment-water interface (Figure S.4.2). Sites GOF5 and LL3A had a distinct $\mathrm{pH}$ profile, characterized by a $\mathrm{pH}$ peak of $0.6-0.8 \mathrm{pH}$ units near the sediment-water interface. The combination of the pore water $\mathrm{pH}, \mathrm{O}_{2}$ and $\mathrm{\Sigma H}_{2} \mathrm{~S}$ profiles observed at sites GOF5 and LL3A, resemble the typical signature of cable bacteria after a period of their activity (Hermans et al., 2019). At site GOF5, the activity of cable bacteria could be reactivated within 5 days upon bottom water re-oxygenation of an intact sediment core (Hermans et al., 2019).
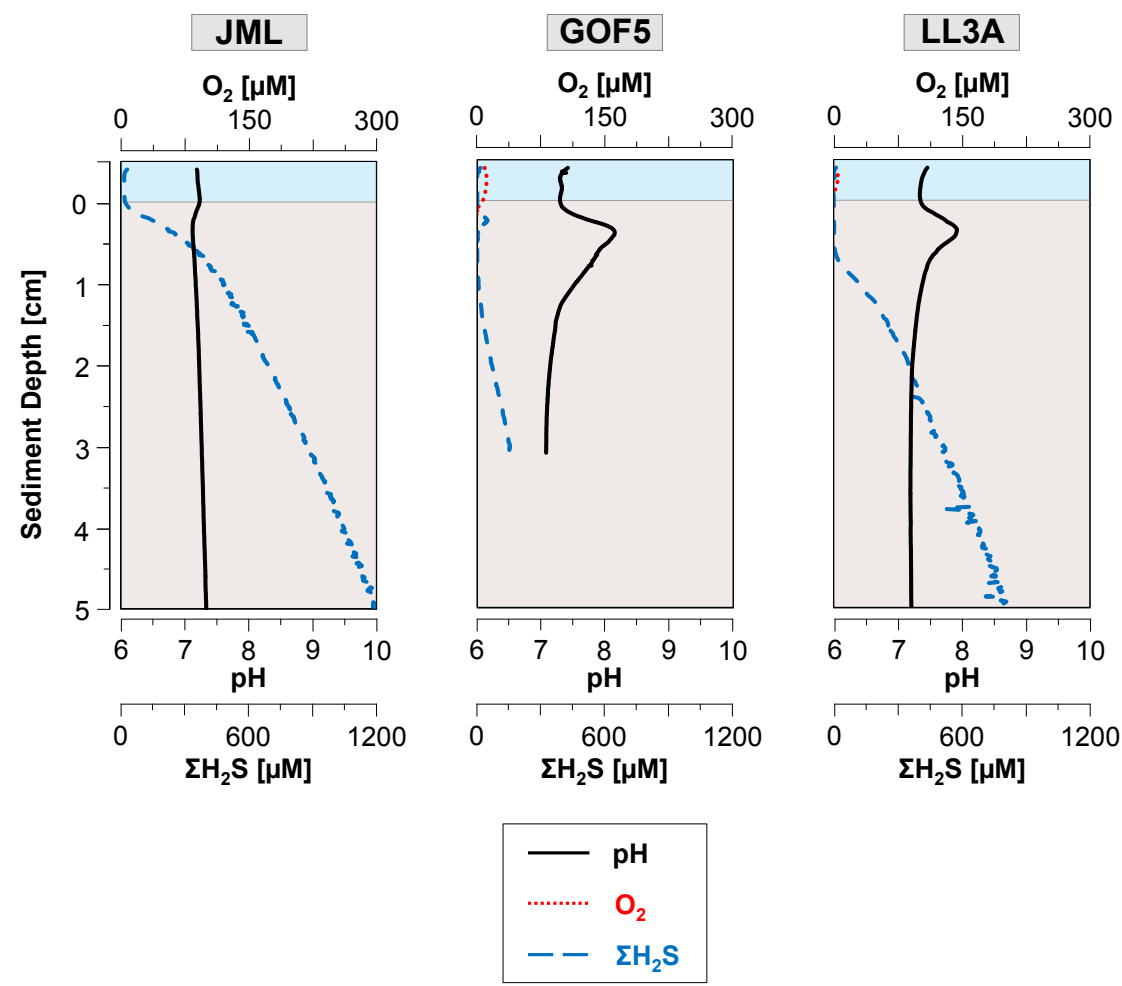

Figure S.4.2 | High-resolution depth profiles of pH (black), $\mathrm{O}_{2}$ (red) and $\Sigma \mathrm{H}_{2} \mathrm{~S}$ (blue). Duplicate measurements of the $\mathrm{pH}$ depth profiles were similar. 


\section{S.4.7. Benthic Fluxes of Dissolved $\mathrm{NH}_{4}{ }^{+}, \mathrm{PO}_{4^{\prime}} \mathrm{Fe}$ and $\mathrm{Mn}$}

\section{GOF5}
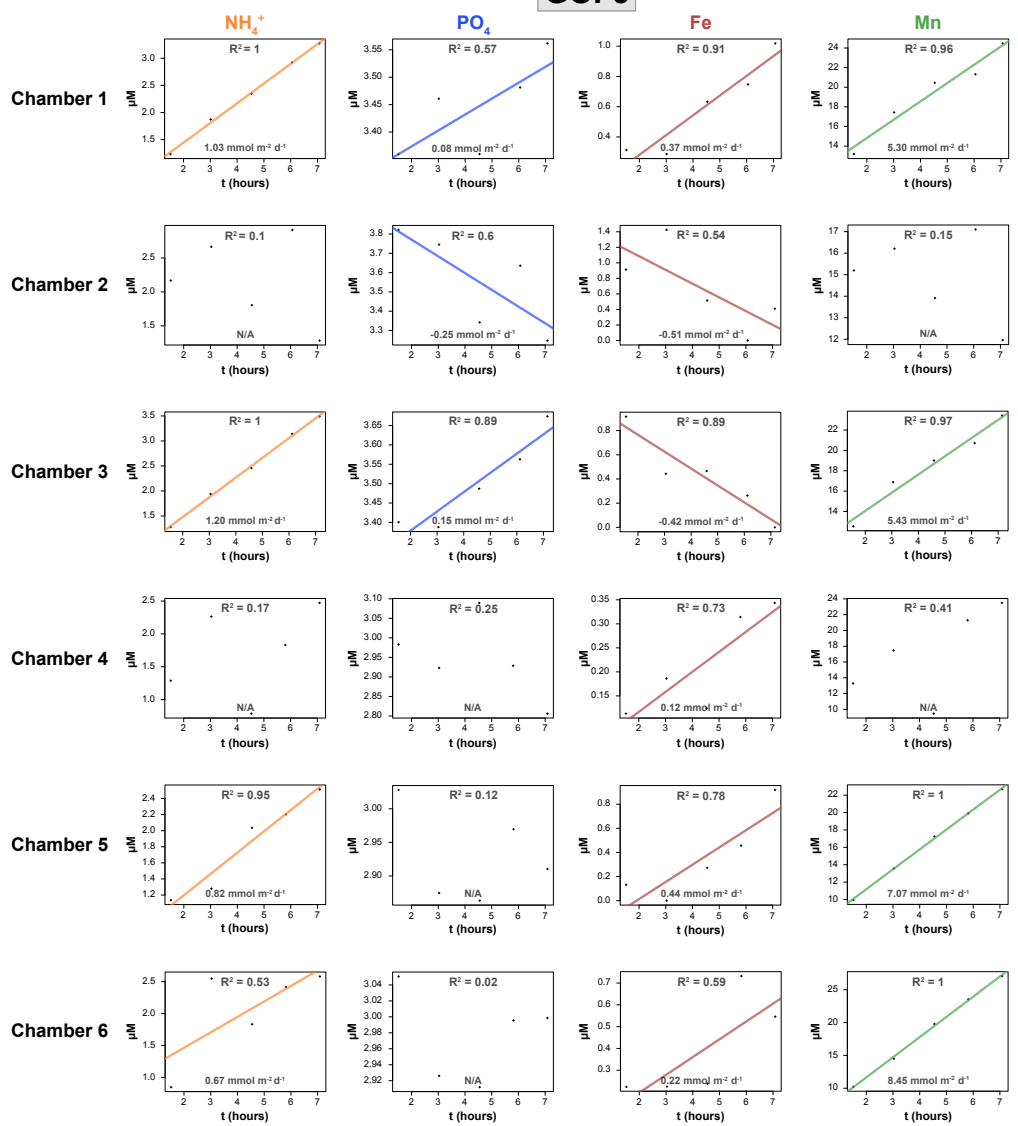

Figure S.4.3 | Concentrations of dissolved $\mathrm{NH}_{4}{ }^{+}, \mathrm{PO}_{4}, \mathrm{Fe}$ and $\mathrm{Mn}$ derived from six chambers of a benthic lander incubation at site GOF5 in June 2016. The benthic fluxes were determined from the linear correlation and are expressed in mmol m $\mathrm{d}^{-2}$. Only linear gradients with an $\mathrm{R}^{2}>0.5$ were used for the calculation of the benthic fluxes. $\mathrm{N} / \mathrm{A}=$ not available $\left(\mathrm{R}^{2}<0.5\right)$. 

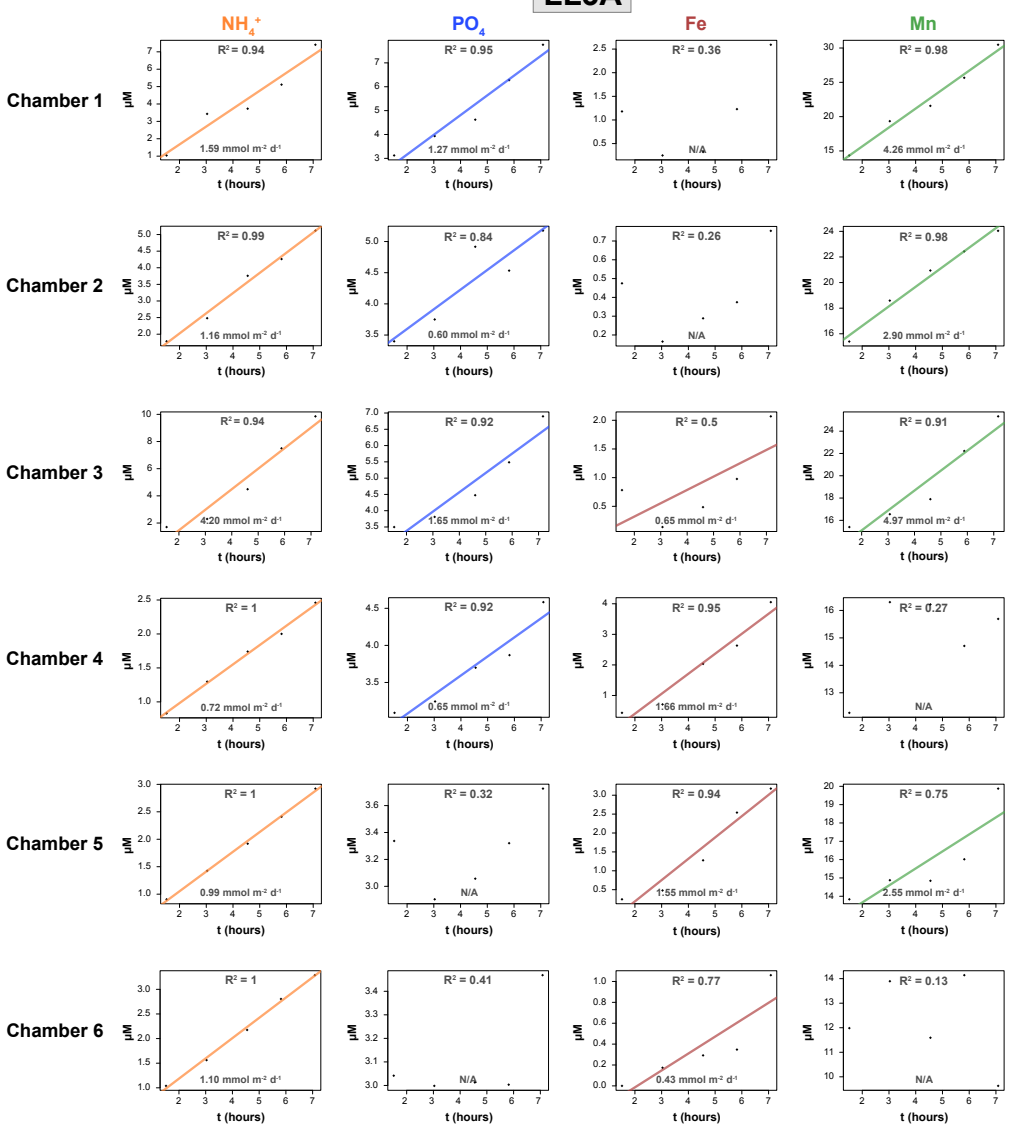

Figure S.4.4 | Concentrations of dissolved $\mathrm{NH}_{4}{ }^{+}, \mathrm{PO}_{4}, \mathrm{Fe}$ and $\mathrm{Mn}$ derived from six chambers of a benthic lander incubation at site LL3A in June 2016. The benthic fluxes were determined from the linear correlation and are expressed in $\mathrm{mmol} \mathrm{m}^{-2} \mathrm{~d}^{-1}$. Only linear gradients with an $\mathrm{R}^{2}>0.5$ were used for the calculation of the benthic fluxes. N/A = not available $\left(\mathrm{R}^{2}<0.5\right)$.

Table S.4.2 | Benthic fluxes of dissolved $\mathrm{NH}_{4}{ }^{+}, \mathrm{PO}_{4}$, $\mathrm{Fe}$ and $\mathrm{Mn}$ in $\mathrm{mmol} \mathrm{m}{ }^{-2} \mathrm{~d}^{-1}$ determined from the pore water concentrations near the sediment-water interface (PW) and the benthic lander incubations (Lander).

\begin{tabular}{|c|c|c|c|c|c|c|c|c|}
\hline Site & $\begin{array}{l}\mathrm{NH}_{4}^{+} \\
{\left[\mathrm{mmol} \mathrm{m}^{-2} \mathrm{~d}^{-1}\right]} \\
(\mathrm{PW})\end{array}$ & $\begin{array}{l}\mathrm{NH}_{4}^{+} \\
{\left[\mathrm{mmol} \mathrm{m}^{-2} \mathrm{~d}^{-1}\right]} \\
\text { (Lander) }\end{array}$ & $\begin{array}{l}\mathrm{PO}_{4} \\
{\left[\mathrm{mmol} \mathrm{m}^{-2} \mathrm{~d}^{-1}\right]} \\
(\mathrm{PW})\end{array}$ & $\begin{array}{l}\mathrm{PO}_{4} \\
{\left[\mathrm{mmol} \mathrm{m}^{-2} \mathrm{~d}^{-1}\right]} \\
\text { (Lander) }\end{array}$ & 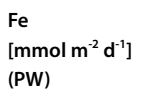 & 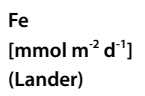 & $\begin{array}{l}\mathrm{Mn} \\
{\left[\mathrm{mmol} \mathrm{m}^{-2} \mathrm{~d}^{-1}\right]} \\
(\mathrm{PW})\end{array}$ & $\begin{array}{l}\text { Mn } \\
{\left[\mathrm{mmol} \mathrm{m}^{-2} \mathrm{~d}^{-1}\right]} \\
\text { (Lander) }\end{array}$ \\
\hline JML & 2.94 & $\mathrm{~N} / \mathrm{A}$ & 0.18 & N/A & -0.02 & N/A & 0.09 & $\mathrm{~N} / \mathrm{A}$ \\
\hline GOF5 & 1.16 & 0.93 & 0.20 & -0.01 & 0.32 & 0.04 & 4.24 & 6.56 \\
\hline LL3A & 2.34 & 1.63 & 0.06 & 1.04 & 0.05 & 1.07 & 4.25 & 3.67 \\
\hline
\end{tabular}




\section{S.4.8. Sedimentation Rates}

Sedimentation rates were estimated by fitting a reactive transport model (Soetaert and Herman, 2008) to the ${ }^{210} \mathrm{~Pb}$ depth profiles (Figure S.4.5) taking the depth dependent changes in porosity into account (Figure S.4.6).
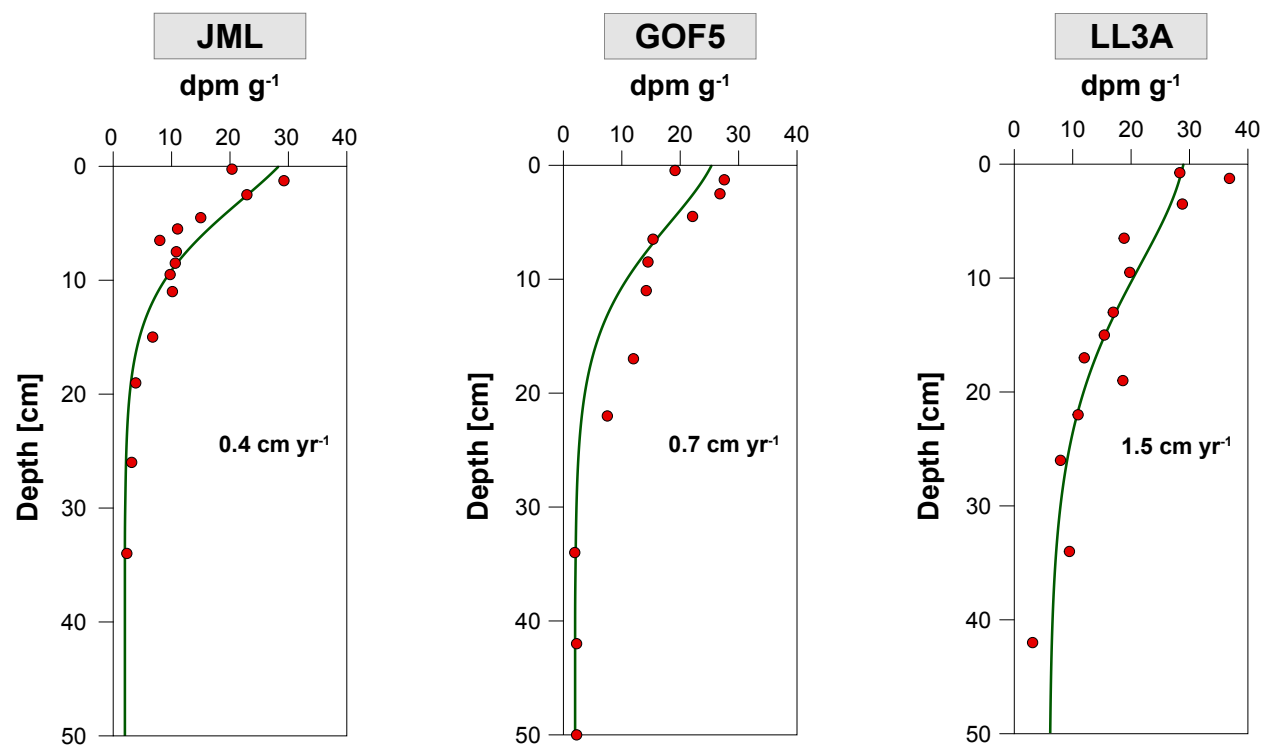

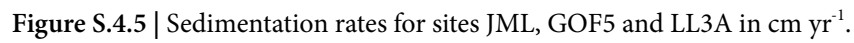




\section{S.4.9. Porosity}

The porosity (Figure S.4.6) was calculated from the water loss upon freeze-drying and sediment density following Burdige (2006).
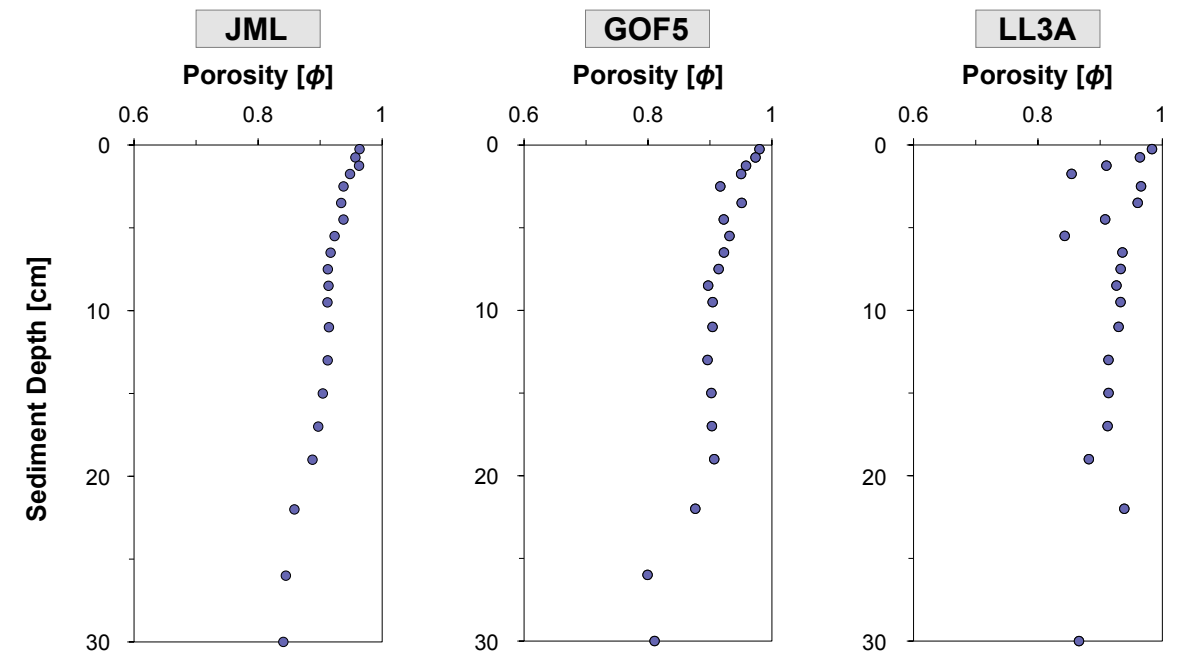

Figure S.4.6 | Porosity depth profiles in vol $\mathrm{vol}^{-1}$. 


\section{S.4.10. Elemental Ratios in the Surface Sediment of Site GOF5}

Table S.4.3 | Elemental ratios of Fe, Mn, P, Ca and S in the surface sediment of site GOF5.

\begin{tabular}{llll}
\hline Elements & Layer & Correlation $\left[\mathbf{R}^{2}\right]$ & Ratio [counts/counts] \\
\hline $\mathrm{Fe}: \mathrm{P}$ & Zone A & 0.45 & $290: 1$ \\
$\mathrm{Fe}: \mathrm{P}$ & Zone B & 0.49 & $75: 1$ \\
$\mathrm{Mn}: \mathrm{P}$ & Zone A & 0.42 & $315: 1$ \\
$\mathrm{Mn}: \mathrm{P}$ & Zone B & 0.61 & $5: 1$ \\
$\mathrm{Ca}: \mathrm{P}$ & Zone A & 0.51 & $13: 1$ \\
$\mathrm{Ca}: \mathrm{P}$ & Zone B & 0.78 & $3: 2$ \\
$\mathrm{Fe}: \mathrm{Ca}$ & Zone A & 0.89 & $21: 2$ \\
$\mathrm{Fe}: \mathrm{Ca}$ & Zone B & 0.67 & $29: 1$ \\
$\mathrm{Mn}: \mathrm{Ca}$ & Zone A & 0.63 & $25: 1$ \\
$\mathrm{Mn}: \mathrm{Ca}$ & Zone B & 0.68 & $7: 2$ \\
$\mathrm{~S}: \mathrm{Fe}$ & Zone C & 0.02 & $\mathrm{~N} / \mathrm{A}$ \\
$\mathrm{S}: \mathrm{Fe}$ & Zone D & 0.55 & $3: 8$ \\
\hline
\end{tabular}

$\mathrm{N} / \mathrm{A}=$ not available

\section{S.4.11. Fe XANES Spectra of Resin-embedded Sediment from Site GOF5}

In contrast to $\mathrm{Mn}$, the ratio between the reactive and unreactive fraction of Fe (i.e. Fe oxide and $\mathrm{Fe}$ sulfide versus clay $\mathrm{Fe}$ ) was generally low in the sediments, even in enriched layers. As the size of the Fe enrichments was also smaller than the depth of the volume probed by XAS, the obtained Fe spectra also entail a contribution from non-reactive, silicate-bound Fe. In order to investigate the nature of $\mathrm{Fe}$ enrichments an attempt was made to isolate the contribution from non-reactive Fe. Based on the relative count intensities derived from synchrotron-based mapping of Fe in the surface sediment at site GOF5, spots containing very little Fe were selected, which are assumed to represent 'background Fe' (Figure 4.9B and C). Subsequently, the XANES spectra of background Fe were averaged and compared with the XANES spectra of various Fe mineral reference materials (Figure S.4.7). Our findings indicate that background Fe did not resemble the XANES spectra of Fe oxides, Fe carbonates, Fe phosphates and Fe sulfides. However, the XANES and EXAFS spectrum of background Fe could be best reproduced by combining the XANES spectra of biotite (an Fe phyllosilicate mineral) and illite (Fe associated with clay) which supports the interpretation that the spectrum reflects silicate-bound Fe (Figure S.4.7). The isolated XANES spectrum from 'background Fe' was then used in combination with spectra of reactive Fe phases in the LCF to reproduce the XANES and EXAFS spectra collected at the various spots. For the XANES spectra the energy range between about 7110 to $7190 \mathrm{eV}$ was used and for the $k^{2}$ weighted EXAFS spectra the k-range between 2 and $8 \AA^{-1}$ was used in the LCF. Within the set of spectra of reference materials, the combination with the spectra of $6 \mathrm{~L}$-ferrihydrite gave the best and consistent results when applied to the XANES and EXAFS spectra. 


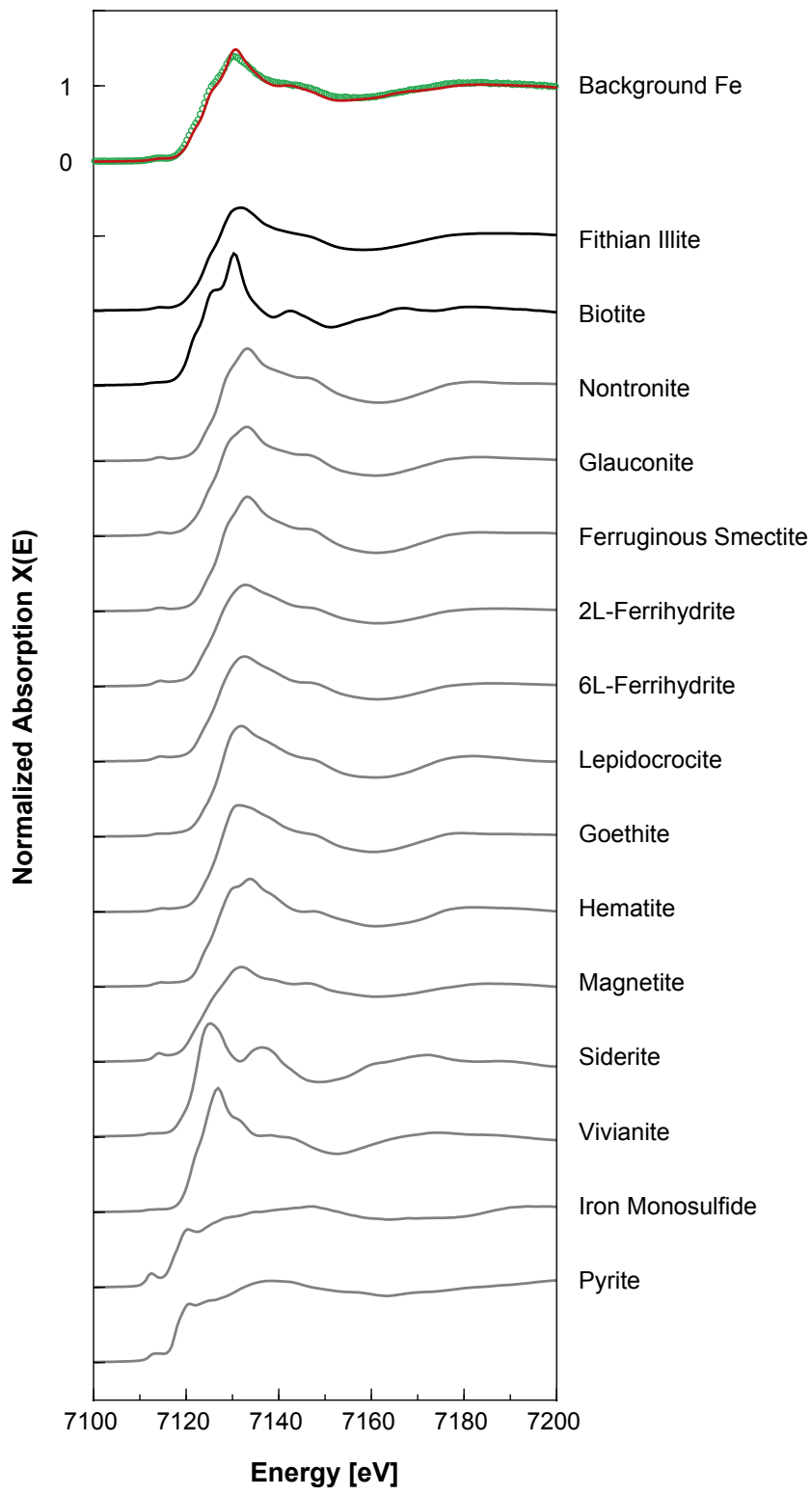

Figure S.4.7 | Normalized Fe XANES spectra of the 'background Fe' and reference materials. The grey circles are the measured spectrum and the line is the result from linear combination fitting using Fithian illite and biotite. The other spectra are from reference materials taken into account for the linear combination fitting. 


\section{S.4.12. Mn XANES Spectra of Resin-embedded Sediment from Site GOF5}

In general, the approach for analyzing the Mn XANES spectra from sediments was similar to that used for suspended matter. In total $32 \mathrm{Mn}$ XANES spectra collected from resin-embedded sediments of site GOF5 were used for the component analysis. The indicator function had a minimum at four components suggesting that the optimum number of endmember spectra for the reproduction of the sample spectra is four. Subsequently, the data set was extended by adding XANES spectra from reference materials to explore the effect on the indicator function and varimax rotation. All attempts to find a set of four spectra of reference materials without the need to increase the number of eigenvectors for maintaining the quality of reproductions did not succeed. This suggests that endmember spectra, which could be assigned to the components., might contain signals from more than one Mn phase. Another possibility is that one or more Mn phases that were present in the sediment are not included in the set of reference materials.

Based on these results, an approach was taken to include more than four spectra from reference materials in the LCF, in particular several spectra of solids containing $\mathrm{Mn}(\mathrm{II})$ and $\mathrm{Mn}(\mathrm{III})$. After testing several combinations, a good reproduction of all XANES spectra with a R-factor of 0.001 was achieved by using the spectra of the six reference materials: birnessite, manganite, bixbyite, hausmannite, $\mathrm{Mn}$ (II) phosphate, and rhodochrosite). However, due to the limitation of unambiguous identification of Mn phases based on Mn XANES spectra only, the results of the LCF were solely used to constrain the fractions of $\mathrm{Mn}$ (II) containing phosphates and carbonates, from Mn-containing oxides. 


\section{S.4.13. Fe, Mn and Metal-bound P Pools at Site GOF5}
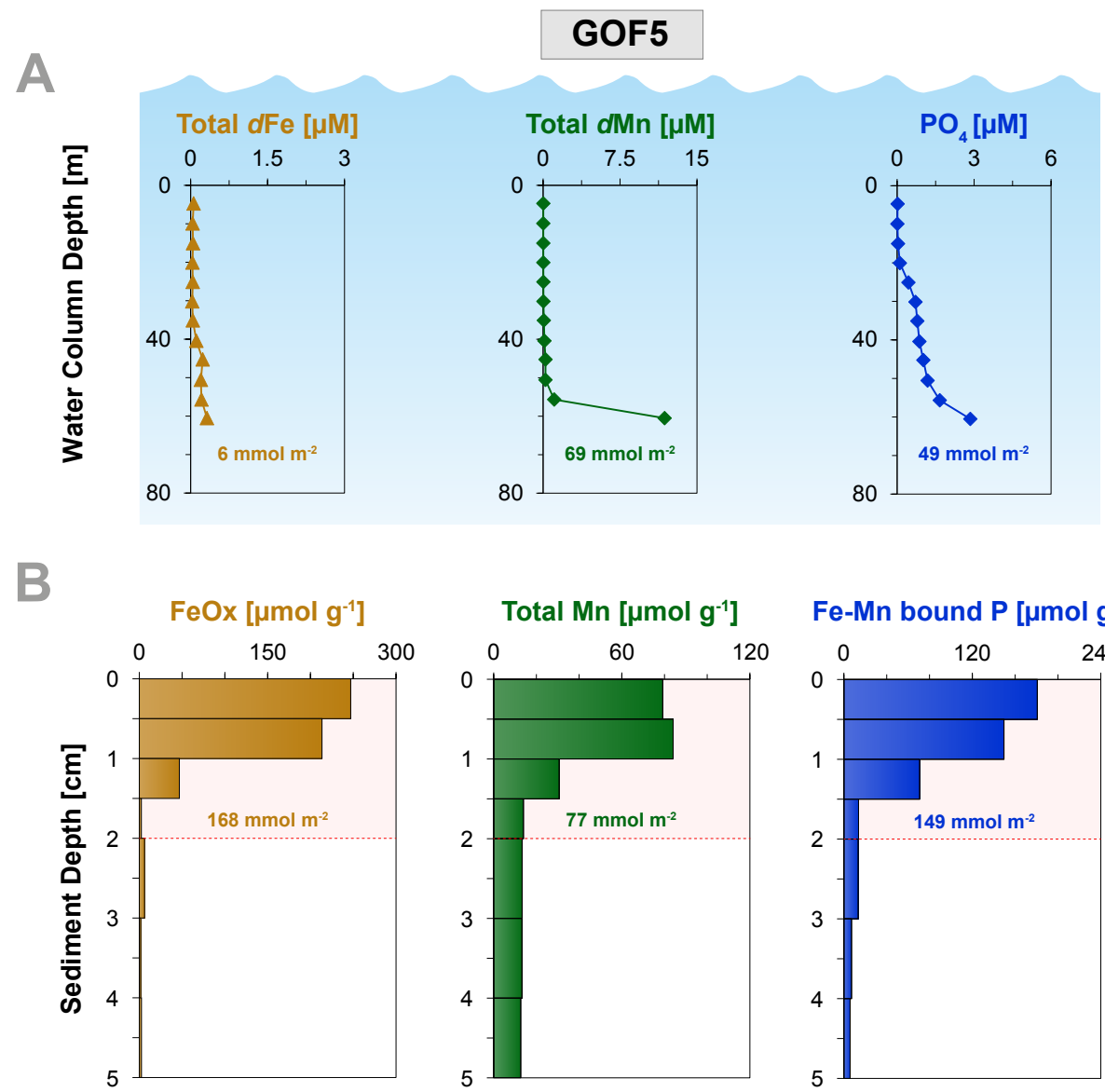

\section{Fe-Mn bound $\mathrm{P}\left[\mu \mathrm{mol} \mathrm{g} \mathrm{g}^{-1}\right]$}

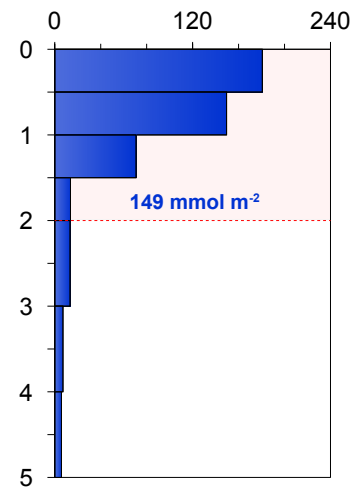

Figure S.4.8 | Fe, Mn, and P in the water column and seafloor at site GOF5 (A) Water column depth profiles of total dissolvable $\mathrm{Fe}$, total dissolvable $\mathrm{Mn}$ and dissolved $\mathrm{PO}_{4}$. The values reported in $\mathrm{mmol} \mathrm{m}{ }^{-2}$ indicate the total amount available in the water column by integrating the concentrations with water depth. (B) Solid-phase surface layer depth profiles of $\mathrm{Fe}$ oxides $(\mathrm{FeOx})$, total $\mathrm{Mn}$ and $\mathrm{Fe}-\mathrm{Mn}$ bound $\mathrm{P}$. The values reported in $\mathrm{mmol} \mathrm{m}^{-2}$ represent the total available pool of those species within the top $2 \mathrm{~cm}$ of the surface sediment. 


\section{S.4.14. Fe, Mn and Metal-bound P Pools at Site LL3A}
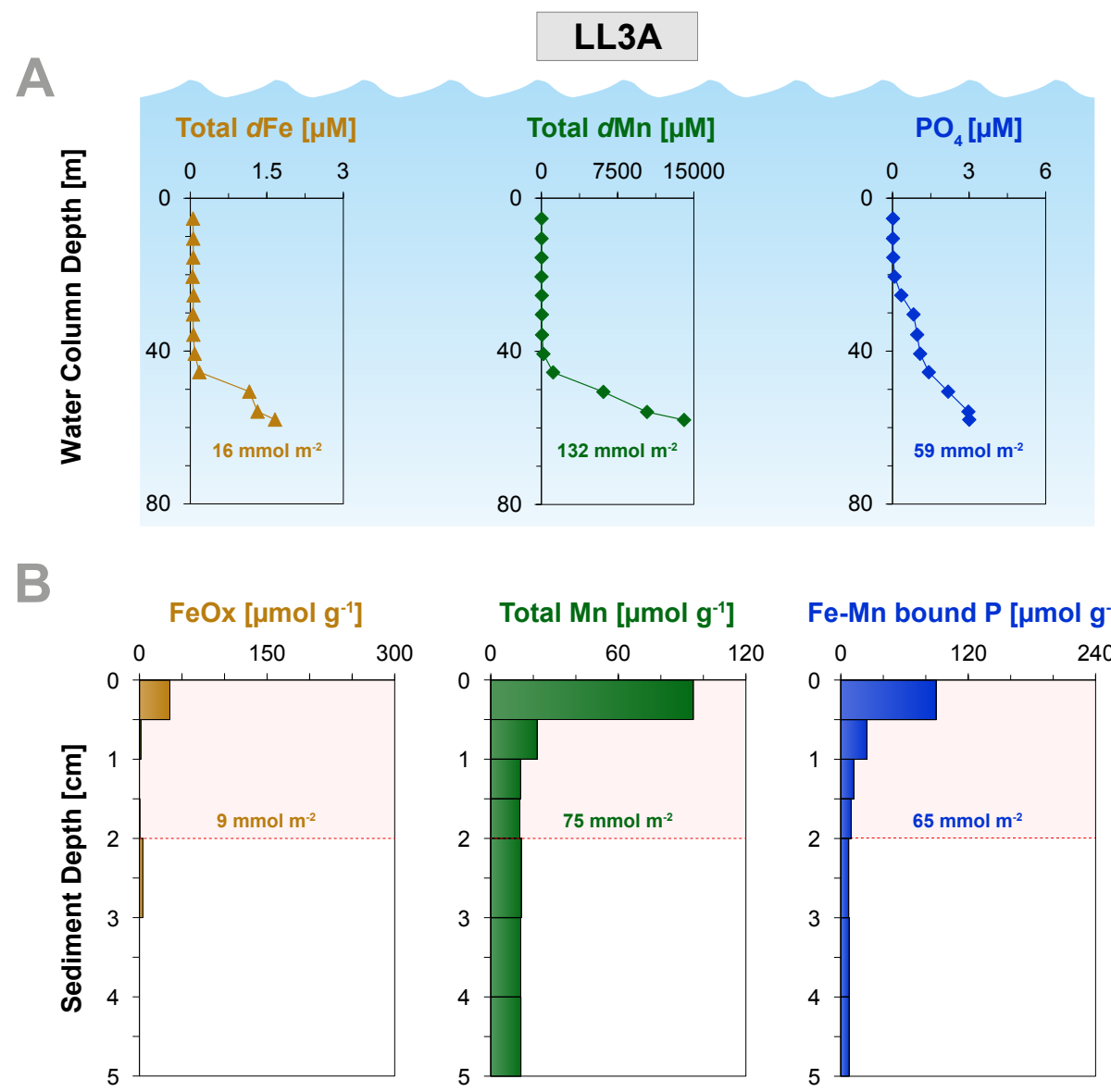

Fe-Mn bound $P$ [ $\left.\mu \mathrm{mol} \mathrm{g}^{-1}\right]$

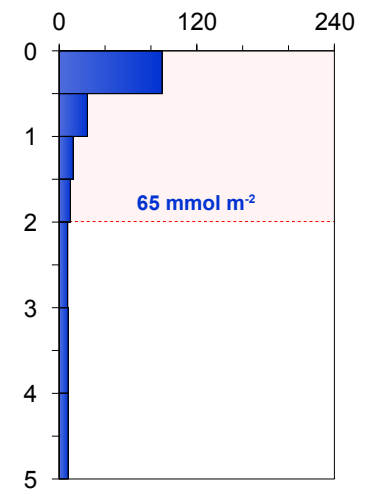

Figure S.4.9 | Fe, Mn, and P in the water column and seafloor at site LL3A (A) Water column depth profiles of total dissolvable $\mathrm{Fe}$, total dissolvable $\mathrm{Mn}$ and dissolved $\mathrm{PO}_{4}$. The values reported in $\mathrm{mmol} \mathrm{m}{ }^{-2}$ indicate the total amount available in the water column by integrating the concentrations with water depth. (B) Solid-phase surface layer depth profiles of Fe oxides (FeOx), total $\mathrm{Mn}$ and Fe-Mn bound P. The values reported in $\mathrm{mmol} \mathrm{m}^{-2}$ represent the total available pool of those species within the top $2 \mathrm{~cm}$ of the surface sediment. 


\section{S.4.15. Phosphorus Burial in the Gulf of Finland Sediment}
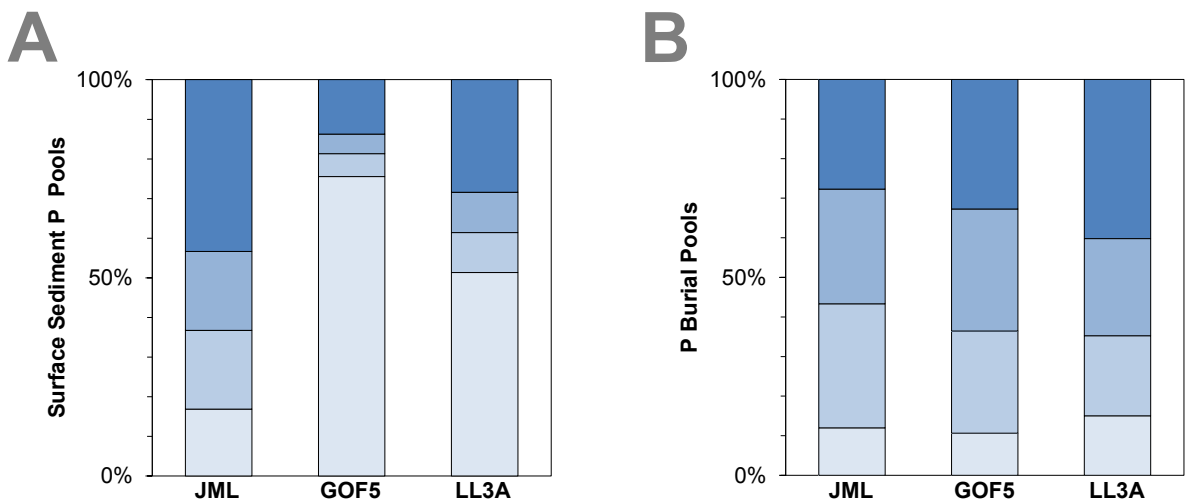

\begin{tabular}{|l}
$\square$ Organic P \\
$\square$ Detrital P \\
$\square$ Authigenic P \\
$\square$ Fe-Mn bound P
\end{tabular}

Figure S.4.10 | Phosphorus burial in the Gulf of Finland; (A) Sedimentary P pools in the upper $2 \mathrm{~cm}$ of the surface sediment. (B) Phosphorus burial pools in the deeper sediment $(20-30 \mathrm{~cm})$.

\section{S.4.16. Characteristic Sediment Features at Site GOF5}

\section{GOF5}

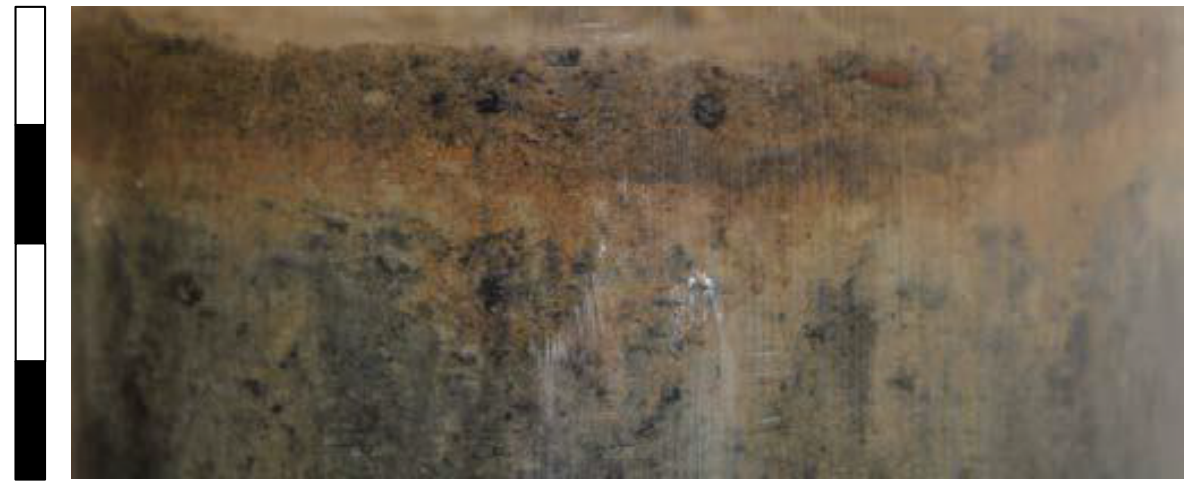

Figure S.4.11 | Photograph of the surface sediment at site GOF5, which is characterized by a distinct color zonation. The scale bar denotes a total distance of $2 \mathrm{~cm}$, with $0.5 \mathrm{~cm}$ intervals. 


\section{S.4.17. Desktop $\mu X R F$ Elemental Maps of Fe, Mn, P and S for Site JML}

In contrast to sites GOF5 and LL3A, the surface sediment at site JML was not characterized by an enrichment of total $\mathrm{Fe}$ and $\mathrm{Mn}$ near the sediment-water interface (Figure S4.12). However, total Fe, $\mathrm{Mn}, \mathrm{P}$ and $\mathrm{S}$ do exibit vertical laminations, which is likely a consequence of the contrasting bottom water redox conditions over time.

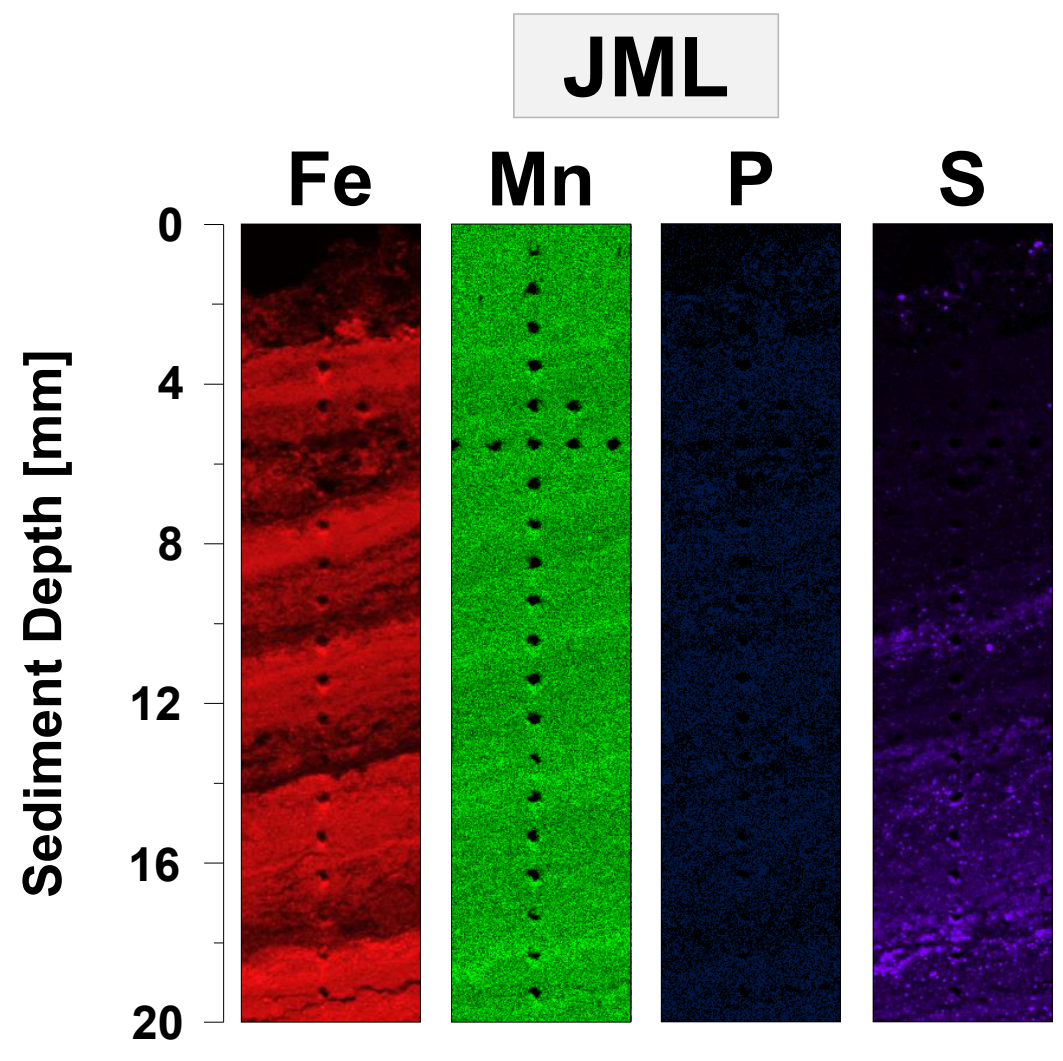

Figure S.4.12 | Desktop $\mu$ XRF elemental maps of Fe, Mn, P and S for site JML in June 2016. 


\section{S.4.18. Distribution Fe, Mn and P in Surface Layer of Site GOF5}

\section{GOF5}
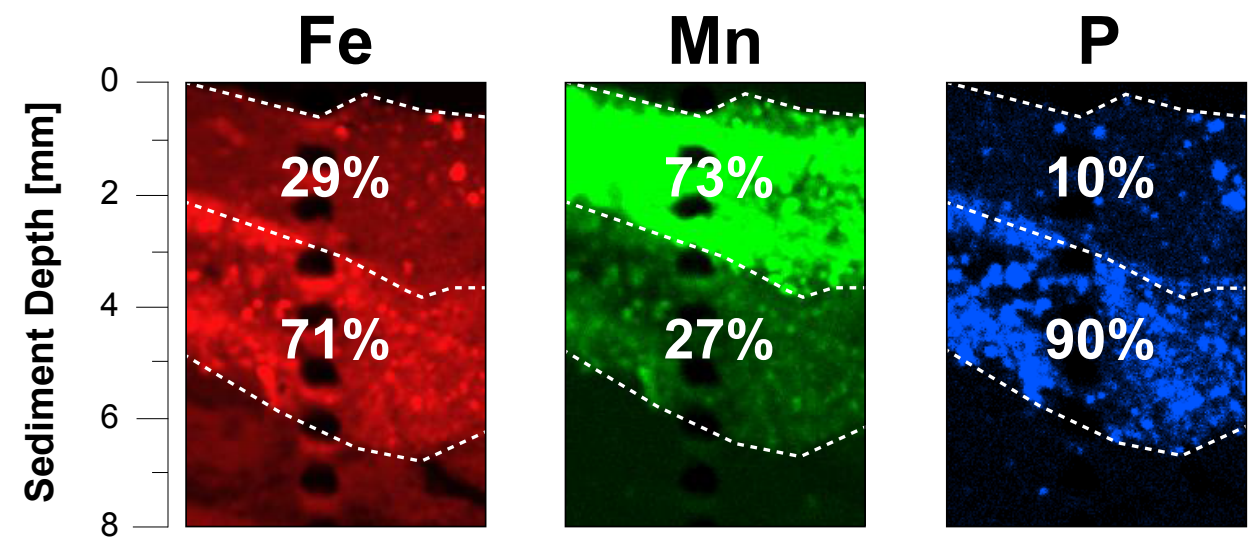

Figure S.4.13 | Desktop $\mu$ XRF elemental maps, indicating the relative distribution of $\mathrm{Fe}, \mathrm{Mn}$ and $\mathrm{P}$ in the top surface layer $(0-2 \mathrm{~mm})$ and the subsurface layer $(2-5 \mathrm{~mm})$. This distribution was determined from the relative count intensity of pixels.

\section{S.4.19. Bottom Water $\mathrm{O}_{2}$ versus $\mathrm{PO}_{4}$}

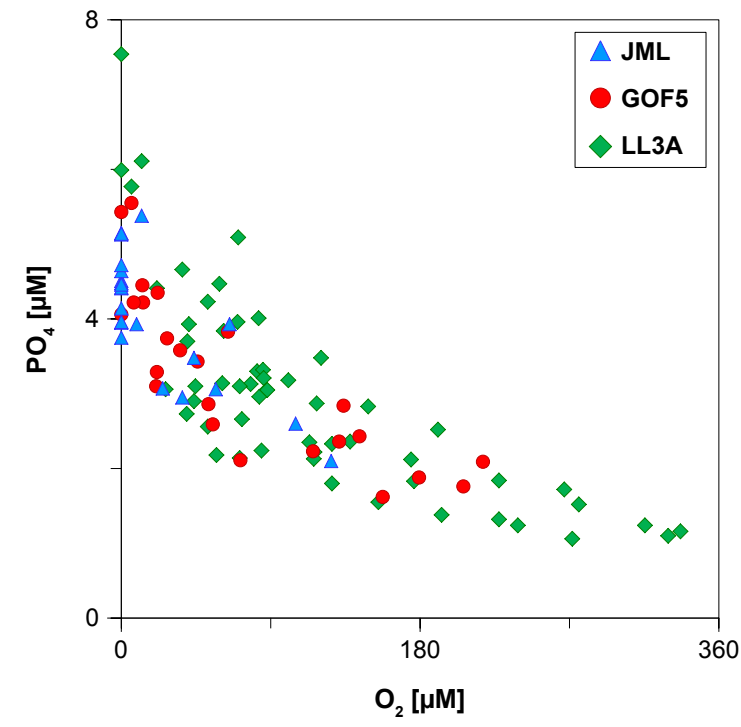

Figure S.4.14 | Relationship between bottom water $\mathrm{O}_{2}$ levels and $\mathrm{PO}_{4}$. Monthly time-series data for 2002-2017, obtained from the Swedish Ocean Archive (SHARK) database at the Swedish Meteorological and Hydrological Institute (SMHI; http://sharkweb.smhi.se). 


$$
5
$$




\title{
Chapter 5:
}

\section{The Shelf-to-basin Iron Shuttle in the Black Sea Revisited}

\author{
Wytze K. Lenstra, Martijn Hermans, Marie J.M. Séguret, Rob Witbaard, Thilo Behrends, Nikki \\ Dijkstra, Niels A.G.M. van Helmond, Peter Kraal, Patrick Laan, Micha J.A. Rijkenberg, S. \\ Severmann, A. Teacă and Caroline P. Slomp
}

Chemical Geology, 20I9, 5II, pp. 3I4-34I

\begin{abstract}
Continental shelf sediments are a major source of iron (Fe) for phytoplankton in surface waters. In this study, we investigate the mechanisms that control release of Fe from shelf sediments and its lateral transport ("shuttling") in oxic and hypoxic waters on the northwestern Black Sea shelf. We find that at two coastal stations near the outflow of the Danube river high input of organic matter drives strong reductive dissolution of $\mathrm{Fe}$ (oxyhydr)oxides (henceforth termed Fe oxides) in surface sediments, supporting high rates of Fe release to oxygenated bottom waters $\left(\sim 0.36 \mathrm{mmol} \mathrm{m}^{-2} \mathrm{~d}^{-1}\right)$. We suggest that bioirrigation plays a key role in the release of Fe from these sediments. At four stations further offshore organic matter deposition is lower resulting in limited mobilization of $\mathrm{Fe}^{2+}$ in the sediment and low benthic fluxes of $\mathrm{Fe}\left(<0.07 \mathrm{mmol} \mathrm{m}^{-2} \mathrm{~d}^{-1}\right)$. Lateral transport of Fe from the coastal zone towards the deep basin mostly takes place in colloidal and/or particulate form ( $>$ $0.2 \mu \mathrm{m}$ ) in the lower part of the water column, likely through repeated deposition and resuspension of Fe oxides from surface sediments. Using synchrotron-based X-ray spectroscopy and sequential chemical extractions, we demonstrate that the suspended matter and surface sediments are enriched in easily reducible $\mathrm{Fe}$ oxides (mostly ferrihydrite) and $\mathrm{Fe}$ associated with clay. The mobilization of $\mathrm{Fe}$ in the coastal zone and subsequent lateral transport of these Fe-bearing particles results in higher ratios of $\mathrm{Fe} / \mathrm{Al}$ in surface sediments at outer shelf stations (ca. 1.2 to $2 \mathrm{wt} . \% \mathrm{wt} . \%^{-1}$ ) than at coastal stations (ca. 0.5 to 0.9 wt. $\%$ wt. $\%^{-1}$ ). However, below the sediment surface layer Fe/Al ratios are similar at all stations indicating limited burial of the laterally transported Fe. Our results highlight the critical role of organic matter input, associated biological activity and riverine Fe input as drivers of Fe shuttling on continental shelves. We also show that in shelf areas where sediments receive low inputs of organic matter, physical transport controls the ultimate fate of the shuttled Fe.
\end{abstract}




\subsection{Introduction}

Iron $(\mathrm{Fe})$ is an essential micronutrient that can limit the growth of phytoplankton in the ocean (Martin and Fitzwater, 1988; Moore et al., 2013; Tagliabue et al., 2017). Release of Fe from continental shelf sediments is a key source of both dissolved and particulate Fe in offshore areas (Canfield et al., 1996; Wijsman et al., 2001a; Raiswell and Canfield, 2012). This release and lateral transport of Fe, which is termed "Fe shuttling", is a complex function of a range of factors, such as organic matter input, bottom water oxygen $\left(\mathrm{O}_{2}\right)$ and biological and physical transport processes (Elrod et al., 2004; Dale et al., 2015). Temporal variations in Fe shuttling can be recorded in deep basin sediments overlain by anoxic and sulfidic (euxinic) waters adjacent to continental shelves (Lyons and Severmann, 2006). Mechanistic insight in Fe shuttling on continental shelves is critical for our understanding of variations in Fe availability in the ocean due to natural and humaninduced eutrophication and de-oxygenation (Diaz and Rosenberg, 2008; Scholz et al., 2014a).

Mobilization of ferrous iron $\left(\mathrm{Fe}^{2+}\right)$ in shelf sediments is highly dependent on the input of organic matter (Elrod et al., 2004). Degradation of organic matter drives the reductive dissolution of ferric ( $\mathrm{Fe}(\mathrm{III})$ )(oxyhydr)oxides (henceforth termed $\mathrm{Fe}$ oxides) and subsequent release of $\mathrm{Fe}^{2+}$ into pore waters (Lovley and Phillips, 1987; Canfield, 1989). Part of this $\mathrm{Fe}^{2+}$ can diffuse upwards where it may re-oxidize and form Fe oxides by reaction with $\mathrm{O}_{2}$, nitrate, nitrite and/or manganese oxides near the sediment-water interface (Postma, 1985; Kappler et al., 2005; Scholz et al., 2016; Robertson et al., 2016). In sediments where sulfide is abundant, $\mathrm{Fe}^{2+}$ can precipitate as $\mathrm{Fe}$ sulfide (Berner, 1970, 1984). Escape of $\mathrm{Fe}^{2+}$ to the overlying water through diffusion is most pronounced under $\mathrm{O}_{2}$-depleted but non-sulfidic bottom water conditions (Slomp et al., 1997; Homoky et al., 2011). Evidence for such a "redox window" in which release of Fe from shelf sediments is enhanced is available from both direct measurements of benthic fluxes (Pakhomova et al., 2007; Severmann et al., 2010; Noffke et al., 2012) and the geological record (i.e. Scholz et al., 2014a; Lenz et al., 2015).

The presence of macrofauna can enhance the release of Fe from sediments through bioturbation and bioirrigation (Berelson et al., 2003; Elrod et al., 2004; Severmann et al., 2010). Bioturbation is a key driver of downward transport of Fe oxides and organic matter, and thereby stimulates Fe mobilization in sediments (Canfield et al., 1993; Aller, 1994). Bioirrigation, the ventilation of burrows by macrofauna, increases the exchange of solutes between pore water and the overlying water and can enhance $\mathrm{Fe}^{2+}$ release from sediments. However, given that bioirrigation also enhances the input of $\mathrm{O}_{2}$ into the sediment (Aller, 1982; Aller and Aller, 1998) and that the oxidation kinetics of $\mathrm{Fe}^{2+}$ are fast at circumneutral $\mathrm{pH}$ (Millero et al., 1987; Nealson, 1997), bioirrigation can also lead to oxidation of $\mathrm{Fe}^{2+}$ inside burrows and formation of colloidal or nanoparticulate ferric iron particles that can remain in suspension (particle size mostly between 0.02 and $0.2 \mu \mathrm{m}$, Raiswell and Canfield, 2012). Upon flushing of burrows, some of this colloidal and nanoparticulate Fe might be released to the overlying water.

Dissolved $\mathrm{Fe}^{2+}$ that escapes from the sediment can precipitate as Fe oxides or, if it is complexed with organic ligands, can remain in solution at nanomolar levels (Gledhill and van den Berg, 1994; Rue and Bruland, 1995; Klar et al., 2017). While larger Fe oxide particles will typically sink directly and settle at the sediment-water interface, a significant proportion of the dissolved, colloidal and nanoparticulate Fe may be transported laterally through currents (Cullen et al., 2009; Noble et al., 2012). On continental shelves, repeated deposition and remobilization or resuspension of part of this Fe may occur during this lateral transfer. The characteristic mineralogy and isotope composition from shelf-derived Fe has been used to trace it over hundreds of kilometers offshore 
(Lam et al., 2012; Conway and John, 2014). In some cases, Fe may also be retained on the shelf (e.g. Hong and Kester, 1986; Scholz et al., 2014b), likely due to settling of Fe-bearing particulate matter.

In the Black Sea, the transfer of Fe from the continental shelf to offshore regions is recorded in the adjacent deep basin sediments. This is the result of efficient trapping of incoming $\mathrm{Fe}$ as $\mathrm{Fe}$ sulfides in the anoxic and sulfidic (euxinic) water column that is characteristic for the off shelf waters in the Black Sea below 150 m (e.g. Wijsman et al., 2001a; Raiswell and Canfield, 2012). Records of $\mathrm{Fe} / \mathrm{Al}$ for the Holocene show major variations in Fe input to the deep basin on time scales of millennia, that have been attributed to variations in the efficiency of the shelf to basin Fe shuttle linked to the position of the chemocline (Eckert et al., 2013). In this scenario, release of Fe from slope or shelf sediments overlain by suboxic waters in the chemocline controls the efficiency of the Fe shuttle. The sediment area underlying the present-day chemocline is relatively small, however, and the Fe supply to the deep basin can only be maintained if replenished by Fe input from the wider shelf (Anderson and Raiswell, 2004; Lyons and Severmann, 2006) or from rivers. Given that the waters overlying the Black Sea shelf are currently mostly oxygenated, this implies a need for significant transport of Fe through an oxic water column ("oxic shuttling of Fe"; Raiswell and Canfield, 2012). While coastal sediments have been suggested to act as the major source of Fe to the deep basin based on sediment Fe analyses (Wijsman et al., 2001a), it is not well understood where and how Fe is released from Black Sea shelf sediments, whether oxic shuttling involves recycling of Fe from sediments over the whole shelf, and in what form the Fe is transported.

In this study, we assess the dynamics of Fe in the sediment and water column at seven stations along a water depth transect in the northwestern Black Sea. By combining in-situ benthic flux measurements and a range of pore water, sediment and water column analyses, we were able to identify the areas of the shelf where Fe is released from the sediment and in which form Fe is transported across the shelf. We also explore the role of bioirrigation in sedimentary Fe release by assessing the macrofaunal abundance and activity. We find that organic-rich, bioirrigated coastal sediments are a key source of Fe in oxic waters overlying the northwestern shelf of the Black Sea and that transport of Fe on the shelf is dominated by physical transport of a mixture of Fe oxides and Fe associated with clay (clay-Fe).

\subsection{Methods}

\subsubsection{Study Area and Sampling}

Our study sites are located along a transect on the northwestern Black Sea shelf, with water depths ranging from 27 to $180 \mathrm{~m}$ (Figure 5.1; Table 5.1). Water column and sediment samples were collected at seven stations during a cruise with R/V Pelagia in September 2015. Two stations were near the mouth of the Danube river, two stations were on the open shelf and three were on the shelf edge (Table 5.1). The northwestern Black Sea shelf covers an area of 70,000 $\mathrm{km}^{2}$ (Wijsman et al., 1999). In the Black Sea, oxic surface waters are separated from the euxinic deep basin by a suboxic chemocline at $\sim 150$ m water depth (Arthur and Dean, 1998; Coolen et al., 2009). Depth profiles of conductivity, temperature, density and dissolved $\mathrm{O}_{2}$ were obtained with a CTD profiler equipped with an $\mathrm{O}_{2}$ sensor (SBE43) on a titanium frame. Water samples were collected using ultra-trace metal clean PVDF samplers attached to the same frame (Rijkenberg et al., 2015), deployed with a Kevlar hydrowire (De Baar et al., 2008; Rijkenberg et al., 2014). Sediment cores were collected with an Oktopus multicorer (inner diameter: $10 \mathrm{~cm}$ ) using polycarbonate tubes of $60 \mathrm{~cm}$ length. Only sediments with a minimum of $20 \mathrm{~cm}$ overlying water and an intact sediment surface were 
processed further. At all stations, two bottom water samples were taken directly after core retrieval. In-situ benthic flux measurements were carried out with an Albex lander (Witbaard et al., 2000) at all stations except station 5 .

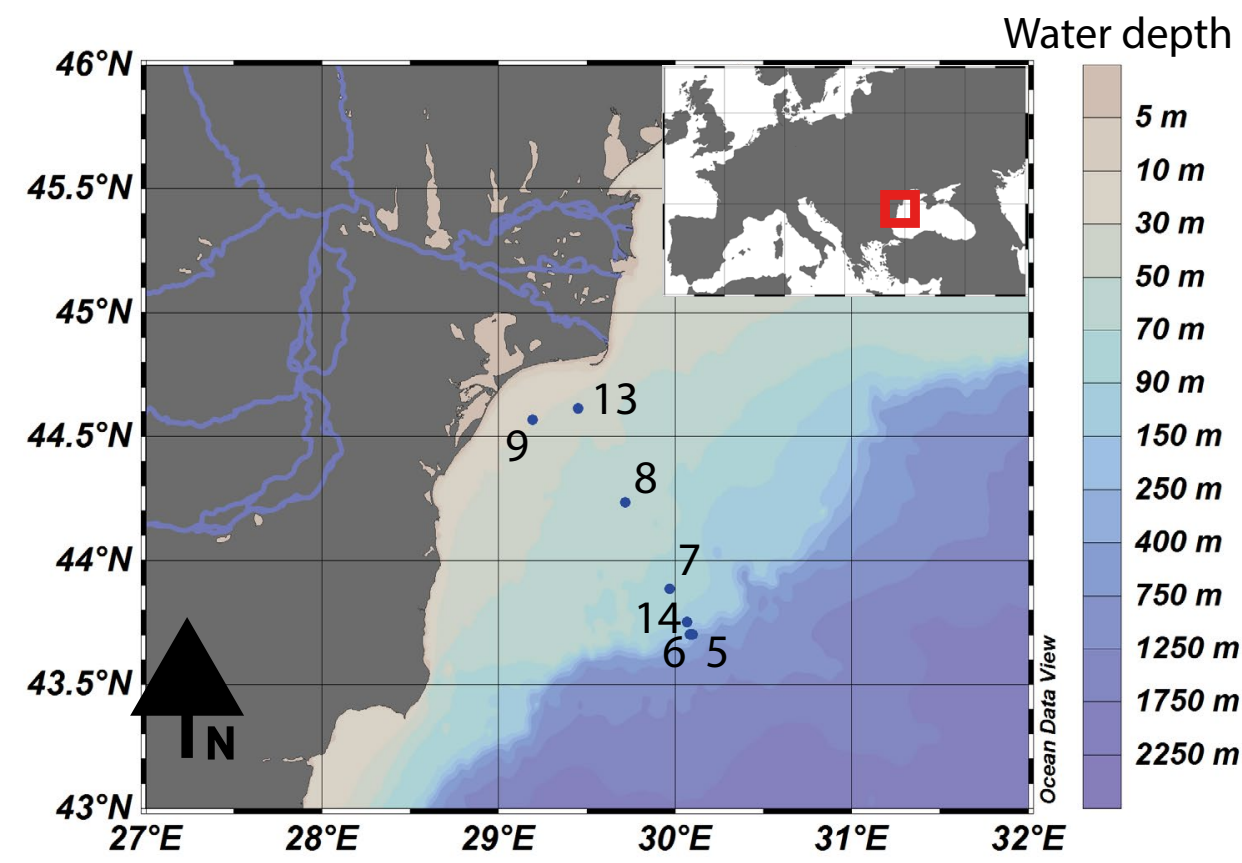

Figure 5.1 | Locations of the 7 stations sampled on the northwestern Black Sea shelf in September 2015. This figure was drawn using Ocean Data View (Schlitzer, 2015).

Table 5.1 | Coordinates, water depth, bottom water temperature and salinity at the 7 stations sampled on the northwestern Black Sea shelf. Unit mbss is meters below sea surface.

\begin{tabular}{llllll}
\hline Station & $\begin{array}{l}\text { Latitude } \\
\mathbf{N}\end{array}$ & $\begin{array}{l}\text { Longitude } \\
\mathbf{E}\end{array}$ & $\begin{array}{l}\text { Depth } \\
\text { mbss }\end{array}$ & $\begin{array}{l}\text { Temperature } \\
{ }^{\circ} \mathrm{C}\end{array}$ & Salinity \\
\hline 9 (coast) & $44^{\circ} 34.9^{\prime}$ & $29^{\circ} 11.4^{\prime}$ & 27 & 13.3 & 17.9 \\
13 (coast) & $44^{\circ} 36.4^{\prime}$ & $29^{\circ} 27.4^{\prime}$ & 44 & 9.2 & 18.1 \\
8 (open shelf) & $44^{\circ} 14.7^{\prime}$ & $29^{\circ} 43.4^{\prime}$ & 65 & 8.2 & 18.2 \\
7 (open shelf) & $43^{\circ} 53.8^{\prime}$ & $29^{\circ} 58.6^{\prime}$ & 78 & 8.5 & 18.7 \\
14 (shelf edge) & $43^{\circ} 45.9^{\prime}$ & $29^{\circ} 11.4^{\prime}$ & 114 & 8.4 & 20.0 \\
6 (shelf edge) & $43^{\circ} 42.8^{\prime}$ & $30^{\circ} 05.1^{\prime}$ & 130 & 8.5 & 21.2 \\
5 (shelf edge) & $43^{\circ} 42.6^{\prime}$ & $30^{\circ} 06.1^{\prime}$ & 180 & 8.6 & \\
\hline
\end{tabular}




\subsubsection{Water Column Analyses}

Unfiltered samples for total dissolvable Fe (henceforth termed "total Fe") were taken from the PVDF samplers using acid-washed LDPE tubing. Samples for dissolved Fe were obtained using a $0.2 \mu \mathrm{m}$ Sartobran 300 cartridge (Sartorius), which was pre-filtered with $0.5 \mathrm{~L}$ of ambient seawater. In both cases, nitrogen pressure was applied at the top of the sampler and the samples were collected in acid-washed $60 \mathrm{~mL}$ LDPE bottles (Nalgene), filled to the shoulder of the bottle. Samples were acidified to $\mathrm{pH} 1.8$ by adding $120 \mu \mathrm{L}$ of distilled $10 \mathrm{M} \mathrm{HCl}$ to $60 \mathrm{~mL}$ of sample. Samples were stored at $4^{\circ} \mathrm{C}$ until analysis.

The concentration of $\mathrm{Fe}$ was determined by flow injection chemiluminescence with preconcentration detection at Utrecht University (Klunder et al., 2011; Rijkenberg et al., 2014). All samples per station were analyzed in triplicate in the same run. We ensured that all the Fe was in the $\mathrm{Fe}^{3+}$ form by adding $0.1 \%$ hydrogen peroxide more than $12 \mathrm{~h}$ before analysis. Each sample was loaded on a chelating iminodiacetic acid (IDA), Toyopearl, AFChelate column for $25 \mathrm{~s}$ (high concentration; i.e. 2-25 nM) or $90 \mathrm{~s}$ (low concentration; i.e. $0-2 \mathrm{nM}$ ), followed by a rinse of $60 \mathrm{~s}$ with ultrapure de-ionized water $(<18.2 \mathrm{M} \Omega$ ) and elution for $110 \mathrm{~s}$ with $0.4 \mathrm{M}$ suprapur $\mathrm{HCl}$. All reagents were prepared with suprapur grade chemicals and ultrapure deionized water. The blank of acidified ultrapure water $(\mathrm{pH}=1.8)$ was $20 \pm 17 \mathrm{pM}(\mathrm{n}=512)$. The average limit of detection, calculated as the standard deviation of the blanks, multiplied by 3 , was $24 \pm 18$ pM. The accuracy of the system was checked daily using GEOTRACES reference seawater. For SAFe (D1), we measured an average value of $0.69 \pm 0.03 \mathrm{nM}$, consistent with the community consensus value of $0.67 \pm 0.04 \mathrm{nM}$ (Johnson et al., 2007 and www.geotraces.org (2013)).

Suspended matter was collected through in-situ pumping for 1-4 h at 2 to 4 water depths per station (Table S.5.1) using four McLane pumps (3x WTS-LV, 1x WTS-LV Dual Filter). After retrieval of the pumps, water around filters (Supor, $0.8 \mu \mathrm{m}, 142 \mathrm{~mm}$ diameter) was removed by vacuum pumping and the filters were placed in petri-dishes, sealed in plastic bags and stored at $-20^{\circ} \mathrm{C}$. The forms of $\mathrm{Fe}$ in the suspended matter were determined on a quarter of every filter in a 4-step sequential extraction procedure targeting the following phases (Table 5.2): (1) ferrihydrite, (2) easily reducible $\mathrm{Fe}(\mathrm{III})$ and $\mathrm{Fe}(\mathrm{II})$ minerals, (3) reducible (crystalline) Fe oxides and (4) magnetite. Step (1) was taken from Raiswell et al. (2010). Steps (2)-(4) are based on Poulton and Canfield (2005) and Claff et al. (2010) as described by Kraal et al. (2017). Total Fe in the extraction solutions was determined colorimetrically using the 1,10-phenanthroline method (APHA, 2005) after reduction of $\mathrm{Fe}(\mathrm{III})$ to $\mathrm{Fe}(\mathrm{II})$ by $0.4 \mathrm{M}$ hydroxylamine hydrochloride. In the $1 \mathrm{M} \mathrm{HCl}$ solutions (step 2), both $\mathrm{Fe}(\mathrm{II})$ and total Fe were measured and Fe(III) was calculated by extracting the $\mathrm{Fe}$ (II) pool from total Fe. 
Table 5.2 | Sequential extraction procedure for Fe as performed on suspended matter (steps 1 to 4 ) and sediment samples (steps 2 to 4) based on Poulton and Canfield (2005) and Claff et al. (2010). A separate extraction was carried out to extract $\mathrm{FeS}_{2}$ after removal of $\mathrm{FeS}$ with $6 \mathrm{M} \mathrm{HCl}$ for $24 \mathrm{~h}$ and elemental sulfur with methanol for $16 \mathrm{~h}$, followed by an acetone rinse for $20 \mathrm{~min}$ according to Burton et al. $(2006,2008)$. The sum of extracted Fe in the different steps is defined as highly reactive Fe.

\begin{tabular}{|c|c|c|c|c|}
\hline Step & Extractant & Time (hours) & Target phase & Term \\
\hline 1 & $\begin{array}{l}0.17 \mathrm{M} \text { sodium citrate, } 0.6 \mathrm{M} \text { sodium bicarbonate and } \\
0.057 \mathrm{M} \text { ascorbic acid ( } \mathrm{pH} \text { 7.5) }\end{array}$ & 24 & Ferrihydrite & Ferrihydrite \\
\hline 2 & $1 \mathrm{M} \mathrm{HCl}$ & 4 & $\begin{array}{l}\text { Easily reducible Fe oxides, } \\
\text { Fe carbonates and FeS }\end{array}$ & $\mathrm{Fe}_{\mathrm{ox} 1}, \mathrm{Fe}(\mathrm{II})$ \\
\hline 3 & $\begin{array}{l}50 \mathrm{~g} \mathrm{~L}^{-1} \text { sodium dithionite solution buffered to } \mathrm{pH} 4.8 \\
\text { with } 0.35 \mathrm{M} \text { acetic acid/0.2 } \mathrm{M} \text { sodium citrate }\end{array}$ & 4 & $\begin{array}{l}\text { Reducible (crystalline) Fe } \\
\text { oxides }\end{array}$ & $\mathrm{Fe}_{\mathrm{ox2}}$ \\
\hline 4 & $0.2 \mathrm{M}$ ammonium oxalate/0.17 M oxalic acid ( $\mathrm{pH} 3.2)$ & 6 & Magnetite & $\mathrm{Fe}_{\text {mag }}$ \\
\hline & $500 \mathrm{~g} \mathrm{~L}^{-1}$ chromous chloride in $10 \mathrm{M} \mathrm{HCl}$ & 48 & $\mathrm{FeS}_{2}$ & $\mathrm{FeS}_{2}$ \\
\hline
\end{tabular}

* Magnetite may also be extracted in this step (Henkel et al., 2016).

\subsubsection{Pore Water Analyses}

At each station, one sediment core was sliced into intervals of 0.5 to $3 \mathrm{~cm}$ under a nitrogen atmosphere at bottom water temperature (Table 5.1). Each slice was divided over a pre-weighed glass vial and a $50 \mathrm{~mL}$ centrifuge tube. The glass vials were stored under a nitrogen atmosphere at $-20^{\circ} \mathrm{C}$ for solid-phase analyses onshore. The $50 \mathrm{~mL}$ centrifuge tubes were centrifuged on-board at $4500 \mathrm{rpm}$ for $20 \mathrm{~min}$ to extract pore water. Pore water was filtered under a nitrogen atmosphere through $0.45 \mu \mathrm{m}$ pore size filters to determine total dissolved Fe. At station 9, pore water was also filtered through 0.2 and $0.02 \mu \mathrm{m}$ pore size filters to differentiate between colloidal/nanoparticulate $(0.02-0.2 \mu \mathrm{m})$ and aqueous (< $0.02 \mu \mathrm{m}$; (Boyd and Ellwood, 2010; Homoky et al., 2011; Raiswell and Canfield, 2012)) Fe. All samples were acidified with $10 \mu \mathrm{L} 10 \mathrm{M}$ suprapur $\mathrm{HCl}$ per $\mathrm{mL}$ of sample and stored at $4^{\circ} \mathrm{C}$ prior to analysis. Total dissolved $\mathrm{Fe}$ at all stations was analyzed by inductively coupled plasma optical emission spectroscopy (ICP-OES; Spectro Arcos). The samples for the $<0.02,<0.2$ and $<0.45 \mu \mathrm{m}$ filter fractions for station 9 were measured colorimetrically using the 1,10-phenanthroline method (APHA, 2005). The ICP-OES and colorimetric results for total dissolved $\mathrm{Fe}$ fraction $(<0.45 \mu \mathrm{m})$ at station 9 were similar (Figure S.5.1). Concentrations of ammonium $\left(\mathrm{NH}_{4}^{+}\right)$, sulphate $\left(\mathrm{SO}_{4}{ }^{2-}\right)$ and sulfide $\left(\mathrm{H}_{2} \mathrm{~S}\right)$ were determined as described in Kraal et al. (2017)).

At stations 9 and 13, high-resolution depth profiles of dissolved $\mathrm{O}_{2}$ were obtained in a separate sediment core directly after retrieval using microelectrodes (50 $\mu \mathrm{m}$ resolution) and a 2D-micromanipulator using a 2-point calibration with $100 \% \mathrm{O}_{2}$ saturated and nitrogen purged artificial seawater (Unisense A.S., Denmark). Diffusive fluxes of $\mathrm{O}_{2}$ and $\mathrm{Fe}^{2+}\left(\mathrm{J}\right.$ in $\mathrm{mmol} \mathrm{m}^{-2} \mathrm{~d}^{-1}$ ) across the sediment-water interface were calculated using Fick's first law of diffusion (Eq. (5.1)):

$J=-\phi D_{s} \cdot \frac{d C}{d z}$

where $\varphi$ is porosity, $D_{s}$ is the molecular diffusion coefficient for $\mathrm{Fe}^{2+}$, corrected for tortuosity in the porous medium (Boudreau, 1996), and $d C / d z$ is the concentration gradient between the top layer of the sediment and the bottom water concentration. The molecular diffusion coefficient $D_{s}$ for 
the ambient salinity, pressure and temperature at each station was calculated using the $\mathrm{R}$ package CRAN: marelac (Soetaert et al., 2010), which implements the constitutive relations listed in Boudreau (1997).

\subsubsection{Solid-phase Analyses}

All sediments were freeze-dried and the porosity was determined from the weight loss upon freezedrying. Freeze-dried sediments were ground in an agate mortar inside an argon filled glovebox and separated into various subsamples. To determine the total elemental concentrations, ca. $125 \mathrm{mg}$ of sediment was digested in $2.5 \mathrm{~mL}$ mixed acid $\left(\mathrm{HNO}_{3}: \mathrm{HClO}_{4} ; 2: 3\right)$ and $2.5 \mathrm{~mL} 40 \% \mathrm{HF}$ at $90^{\circ} \mathrm{C}$. After fuming off the acids, the residue was redissolved in $1 \mathrm{M} \mathrm{HNO}_{3}$. The solutions were subsequently analyzed for total $\mathrm{Fe}, \mathrm{S}$ and aluminum (Al) on an ICP-OES. The analytical uncertainty based on duplicates was $5 \%$ for $\mathrm{Fe}, 7 \%$ for $\mathrm{S}$ and $5 \%$ for Al. A second subsample of circa $300 \mathrm{mg}$ was decalcified with 2 wash steps of $1 \mathrm{M} \mathrm{HCl}$ (Van Santvoort et al., 2002) and subsequently dried, powdered and analyzed for carbon (C) using an elemental analyzer (Fisons Instruments model NA 1500 NCS). Organic C contents were determined after correction for the weight loss following decalcification. A third subsample of circa $50 \mathrm{mg}$ was subjected to steps (2)-(4) of the sequential extraction procedure for $\mathrm{Fe}$ (Table 5.2). Pyrite was determined in a separate extraction as chromium reducible sulfur (CRS) from which FeS and elemental sulfur first were removed (only at stations 9, 13, 8; Table 5.2; Burton et al., 2006, 2008). The analytical uncertainty based on duplicates was 3\%, and $3.5 \%$ for steps (2) to (4), respectively, and $8 \%$ for CRS.

\subsubsection{X-ray Spectroscopy: Fe k-edge XANES and EXAFS}

Freeze-dried and finely-ground sediment samples from stations 9, 13, 8, 7, 14, 6 and 5 and suspended matter samples (collected through in-situ pumping) from the same stations were analyzed by X-ray absorption spectroscopy (XAS) analysis at the Dutch-Belgian beamline (DUBBLE, BM26) at the European Synchrotron Radiation Facility (ESRF) in Grenoble (France). A description of the set-up and the optics of the beamline is provided by Borsboom et al. (1998) and Nikitenko et al. (2008).

The powdered sediment samples were compressed to a pellet and measured in transmission mode at room temperature. The amount of sediment sample per pellet was optimized in view of minimizing total adsorption and maximizing the step height of the Fe edge. Suspended material was measured in fluorescence mode using a 9 element Ge detector. The energy was calibrated using $\mathrm{Fe}(0)$ foil by assigning the energy of $7112 \mathrm{eV}$ to the maximum slope of the absorption edge. The software ATHENA (Ravel and Newville, 2005) was used for averaging spectra, normalization, background subtraction as well as for linear combination fitting. For X-ray absorption near edge structure (XANES) spectra, the energy range between 7100 and $7180 \mathrm{eV}$, and for the $k^{2}$ weighted extended $\mathrm{x}$-ray absorption fine structure (EXAFS) spectra the k-range between 1 and $9 \AA^{-1}$ was used in the linear combination fitting.

XANES and EXAFS spectra collected from the powdered sediments were compared to those of a variety of reference materials. The library of reference materials used for this comparison consists of a wide range of $\mathrm{Fe}$ containing minerals and includes various Fe oxides, siderite, vivianite, FeS, pyrite, and several silicates, such as clay minerals and biotite (Figure S.5.2). Based on this pre-screening, three reference materials were identified of which the combination of XANES and EXAFS spectra gave the best reproduction of spectra from the bulk sediment samples. These were 
Fithian illite, which was treated with dithionite to remove Fe oxides, 6-line ferrihydrite and pyrite (Schwertmann and Cornell, 2007). Based on electrochemical analysis, about $20 \%$ of the structurally bound $\mathrm{Fe}$ in the illite is in the form of Fe(II) (Hoving et al., 2017).

For the sediment samples, only spectra collected in transmission mode with a step height larger than 0.1 were included in the analysis. As a consequence, the spectra for station 7 were excluded. The bulk XAS measurements of suspended material only yielded spectra with sufficient quality at stations 9 and 13.

The suspended matter from stations 9 and 13 was analyzed at the X-ray microscopy beamline ID21 (Salomé et al., 2013) at the ESRF. The dimensions of the beam were about $400 \mathrm{~nm}$ vertically and $800 \mathrm{~nm}$ horizontally. $\mu$ XRF mapping was performed at an energy of $7200 \mathrm{eV}$. The spatial distribution of the elements Fe and potassium (K) was determined and Fe-XANES spectra were collected at various spots on the sample.

\subsubsection{In-situ Benthic Flux of Fe and $\mathrm{O}_{2}$ and Macrofaunal Density}

Benthic $\mathrm{O}_{2}$ uptake and fluxes of total Fe across the sediment-water interface were determined in-situ with a benthic lander, equipped with three chambers made of the inert plastic delrin, each with a surface area of $144 \mathrm{~cm}^{2}$ and volume between 1.3 and $1.8 \mathrm{~L}$ of water (Witbaard et al., 2000). Two or three of the chambers were equipped with dissolved $\mathrm{O}_{2}$ optodes (JFE Advantech; Figure S.5.3). During the incubation, water samples were taken simultaneously with $30 \mathrm{~mL}$ plastic syringes connected to inlet ports inside and outside the incubation chamber after 2, 4, 7, 10 and $13 \mathrm{~h}$. Each time a water sample was taken from the chamber, an equivalent volume of surrounding bottom water was allowed to enter the chamber. At the end of the deployment, the chambers were closed at the bottom allowing the upper $\sim 12 \mathrm{~cm}$ of sediment to be collected upon retrieval of the lander. The sediment from each chamber was sieved over a $0.5 \mathrm{~mm}$ mesh size. Macrofauna was collected and stored in $4 \%$ formaldehyde in plastic jars (Eleftheriou and McIntyre, 2007) until determination of the species and number of macrofauna. At station 5, only samples for macrofauna were collected because the incubation chambers were inserted too deep into the soft sediment and the volume of water in the chambers was not sufficient were directly transferred to a temperature controlled laboratory maintained at in-situ temperature, acidified with $10 \mu \mathrm{L} 10 \mathrm{M}$ suprapur $\mathrm{HCl}$ per $\mathrm{mL}$ of sample and stored at $4^{\circ} \mathrm{C}$. Total $\mathrm{Fe}$ in the syringe samples was determined through flow injection chemiluminescence as described above. Fluxes of $\mathrm{Fe}$ across the sediment-water interface were determined by fitting a linear regression to the concentration time series from each chamber (after correction for the dilution with the bottom water at each sampling interval). Only regressions with $\mathrm{R}^{2}>0.3$ were considered, following Friedrich et al. (2002) (Figure S.5.4). Calculated Fe fluxes for the different incubation chambers were averaged for each station. Oxygen uptake was determined by fitting a linear regression line through all data points at all stations except for station 9 where only data collected in the first two hours were used due to a change in slope. To assess the potential consequences for Fe release, the benthic Fe release based on the first three time points was also determined (Table 5.5). 


\subsubsection{Bioirrigation Rates}

At stations 9 and 13, a sediment core was incubated with the inert tracer bromide to determine bioirrigation rates (Martin and Banta, 1992). Directly after core retrieval, the volume of the overlying water was adjusted to $550 \mathrm{~mL}$ and a concentrated bromide solution was added to the overlying water to achieve a concentration of ca. $2.5 \mathrm{mM}$. During a two-day incubation at in-situ temperature, the overlying water was kept saturated with $\mathrm{O}_{2}$ and well-mixed by bubbling with air. After incubation, the sediment was sliced into intervals of 0.5 to $4 \mathrm{~cm}$ and centrifuged for $20 \mathrm{~min}$ at $4500 \mathrm{rpm}$. After centrifugation, the supernatant was filtered $(0.45 \mu \mathrm{m})$ and stored at $4^{\circ} \mathrm{C}$. Bromide concentrations were determined with ion chromatography. Rates of bioirrigation were calculated assuming a 1-D, nonlocal exchange function (Supplementary Information S.5.1; Emerson et al., 1984; Boudreau, 1984).

\subsection{Results}

\subsubsection{General Station Characteristics}

Bottom water temperature and salinity at the 7 stations ranged from 8.2 to $13.3^{\circ} \mathrm{C}$ and 17.9 to 21.2 , respectively (Table 5.1). Bottom water $\mathrm{O}_{2}$ was the highest at the coastal station 13 at $209 \mu \mathrm{mol} \mathrm{L}^{-1} \mathrm{O}_{2}$ and decreased to $5 \mu \mathrm{mol} \mathrm{L} \mathrm{L}^{-1}$ at station 5 at the shelf edge (Table 5.3; Figure 5.2A). The coastal station 9 had a relatively low $\mathrm{O}_{2}$ concentration of $92 \mu \mathrm{mol} \mathrm{L} \mathrm{L}^{-1}$. In-situ measured $\mathrm{O}_{2}$ uptake was the highest at coastal stations 9 and 13, at values of 25.8 and $17.8 \mathrm{mmol} \mathrm{m}^{-2} \mathrm{~d}^{-1}$, respectively, and decreased offshore (Figure 5.2B). Oxygen penetration depths in the sediment at stations 9 and 13 were 2.25 and $1.65 \mathrm{~mm}$, respectively (Table 5.3; Figure S.5.5). Calculated diffusive fluxes of $\mathrm{O}_{2}$ were a factor 2 lower than measured $\mathrm{O}_{2}$ fluxes (Table 5.3). Organic carbon contents in the surface sediments (0-0.5 $\mathrm{cm}$ ) at the coastal stations 9 and 13 ranged from 1.8 to nearly 2.9 wt. \% and were distinctly higher than those in offshore areas, where values ranged from 0.5 to 1.3 wt. \% (Table 5.3). Similarly $\mathrm{NH}_{4}^{+}$ concentrations were higher and there was less of a decline in pore water $\mathrm{SO}_{4}{ }^{2-}$ with depth at the coastal sites than at the shelf and shelf edge stations. Concentrations of $\mathrm{H}_{2} \mathrm{~S}$ were very low in the upper $5 \mathrm{~cm}$ of the sediment at all sites except station 5 (Figure S.5.6).

Table 5.3 | Key station characteristics: organic carbon contents in the surface sediment $(0-0.5 \mathrm{~cm}), \mathrm{O}_{2}$ concentrations in the bottom water as determined with an $\mathrm{O}_{2}$ sensor (SBE43) attached to the CTD frame, in-situ $\mathrm{O}_{2}$ uptake as determined with chamber incubations, $\mathrm{O}_{2}$ penetration depth in the sediment $(\mathrm{mm})$ from microprofiles (Figure S.5.5), calculated diffusive flux of $\mathrm{O}_{2}$, and macrofaunal abundance (individuals $\mathrm{m}^{-2}$ ). N/A: not available.

\begin{tabular}{|c|c|c|c|c|c|}
\hline Station & $\begin{array}{l}\text { Organic C } \\
\text { wt.\% }\end{array}$ & $\begin{array}{l}\mathrm{O}_{2} \text { Bottom water } \\
\mu \mathrm{mol} \mathrm{L}{ }^{-1}\end{array}$ & $\begin{array}{l}\mathrm{O}_{2} \text { uptake } \\
\mathrm{mmolm}^{-2} \mathrm{~d}^{-1}\end{array}$ & $\begin{array}{l}\mathrm{O}_{2} \text { penetration depth } \\
\mathrm{mm}\end{array}$ & $\begin{array}{l}\mathrm{O}_{2} \text { diffusive flux } \\
\mathrm{mmol} \mathrm{m}^{-2} \mathrm{~d}^{-1}\end{array}$ \\
\hline 9 (coast) & 1.8 & 92 & $25.8 \pm 1.77$ & 2.25 & 13.0 \\
\hline 13 (coast) & 2.9 & 209 & $17.8 \pm 2.8$ & 1.65 & 9.4 \\
\hline 8 (open shelf) & 0.78 & 197 & $8.1 \pm 3.4$ & $\mathrm{~N} / \mathrm{A}$ & $\mathrm{N} / \mathrm{A}$ \\
\hline 7 (open shelf) & 0.54 & 155 & $3.7 \pm 1.4$ & $\mathrm{~N} / \mathrm{A}$ & $\mathrm{N} / \mathrm{A}$ \\
\hline 14 (shelf edge) & 1.25 & 93 & $1.6 \pm 0.1$ & $\mathrm{~N} / \mathrm{A}$ & $\mathrm{N} / \mathrm{A}$ \\
\hline 6 (shelf edge) & 0.91 & 27 & $0.4 \pm 0.02$ & $\mathrm{~N} / \mathrm{A}$ & $\mathrm{N} / \mathrm{A}$ \\
\hline 5 (shelf edge) & $\mathrm{N} / \mathrm{A}$ & 5 & $\mathrm{~N} / \mathrm{A}$ & $\mathrm{N} / \mathrm{A}$ & $\mathrm{N} / \mathrm{A}$ \\
\hline
\end{tabular}



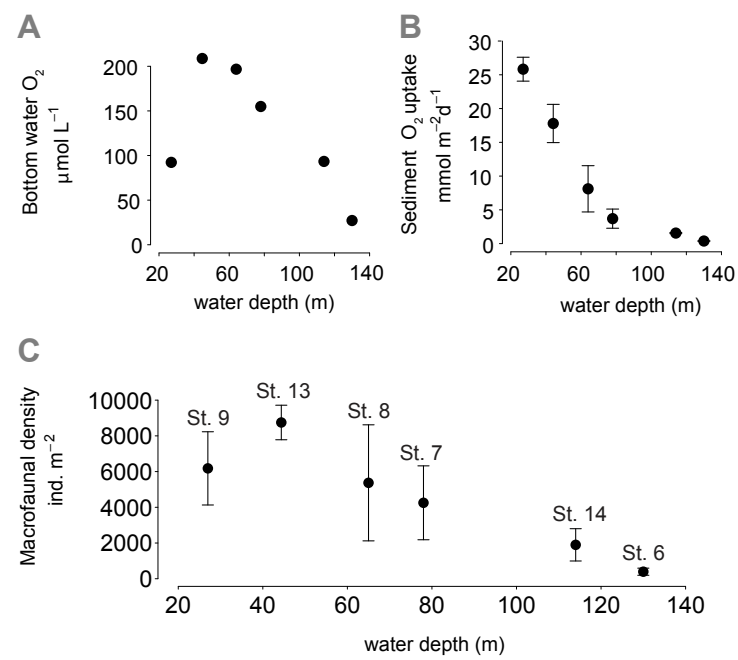

Figure 5.2 (A) Bottom water $\mathrm{O}_{2}$ (in $\mu \mathrm{mol} \mathrm{L-1}$ ), (B) Sediment $\mathrm{O}_{2}$ uptake (in $\mathrm{mmolm}^{-2} \mathrm{~d}^{-1}$; average for 2 or 3 incubation chambers) and (C) Macrofaunal density (individuals per $\mathrm{m}^{2}$, average and standard deviation for 3 incubation chambers) in the sediment at 6 stations on the northwestern Black Sea shelf (i.e. all stations except 5).

\subsubsection{Macrofaunal Density and Activity}

The macrofaunal density was the highest at the coastal stations, where on average ca. 6000 to 9000 individuals per $\mathrm{m}^{2}$ were observed (Table 5.4; Figure 5.2C). The macrofaunal density decreased towards the shelf edge. At station 9 bivalves were the most abundant macrofaunal species while at station 13 worms were the most abundant (Table 5.4). No living macrofauna were found at station 5 . Results of bromide incubations suggest bioirrigation activity down to a depth of 17 and $8 \mathrm{~cm}$ depth at stations 9 and 13, respectively (Figure S.5.7). Results of 1D-modeling of the bromide profiles suggest a depth-averaged non-local transport coefficient $(\alpha)$ in this bioirrigated layer of $0.41 \mathrm{~d}^{-1}$ at station 9 and $0.21 \mathrm{~d}^{-1}$ at station 13 .

Table 5.4 | Abundance of macrofauna present in benthic lander incubation chambers (ind. $\mathrm{m}^{-2}$ ). Macrofaunal species are divided over three main groups: worms, mollusca and arthropoda. At station 5 no living macrofauna was found.

\begin{tabular}{|c|c|c|c|c|c|c|c|c|c|c|c|c|c|c|c|c|c|c|}
\hline & \multicolumn{3}{|c|}{ Station 9} & \multicolumn{3}{|c|}{ Station 13} & \multicolumn{3}{|c|}{ Station 8} & \multicolumn{3}{|c|}{ Station 7} & \multicolumn{3}{|c|}{ Station 14} & \multicolumn{3}{|c|}{ Station 6} \\
\hline $\begin{array}{l}\text { Lander } \\
\text { chamber }\end{array}$ & 1 & 2 & 3 & 1 & 2 & 3 & 1 & 2 & 3 & 1 & 2 & 3 & 1 & 2 & 3 & 1 & 2 & 3 \\
\hline Worms & 417 & 1736 & 1597 & 6041 & 5208 & 8055 & 833 & 3472 & 1805 & 3056 & 2083 & 1389 & 1042 & 139 & 486 & 625 & 417 & 139 \\
\hline $\begin{array}{l}\text { Fraction of } \\
\text { polychaetes }\end{array}$ & 1 & 0.96 & 0.65 & 0.78 & 0.7 & 0.67 & 0.5 & 0.82 & 0.8 & 1 & 0.93 & 0.9 & 1 & 1 & 1 & 0 & 0 & 0 \\
\hline Mollusca & 3333 & 4097 & 7152 & 2083 & 2361 & 1944 & 0 & 2778 & 1458 & 3389 & 694 & 139 & 1389 & 417 & 2083 & 0 & 0 & 0 \\
\hline Arthropoda & 69 & 69 & 69 & 278 & 208 & 69 & 347 & 2847 & 2569 & 486 & 486 & 833 & 0 & 69 & 69 & 0 & 0 & 0 \\
\hline Total & 3819 & 5902 & 8818 & 8402 & 7777 & 10068 & 1180 & 9097 & 5832 & 7431 & 3263 & 2361 & 2431 & 625 & 2638 & 625 & 417 & 139 \\
\hline
\end{tabular}




\subsubsection{Water Column Fe Profiles}

Surface waters were slightly enriched in total Fe at stations 8, 14, 6 and 5 (Figure 5.3). At all stations, concentrations of dissolved and total Fe were elevated in the lower part of the water column. Dissolved and total Fe concentrations in the deeper water column decrease from the coast to the shelf edge (up to $1850 \mathrm{nM}$ total Fe at station 9 versus ca. $20 \mathrm{nM}$ total Fe at station 6). A similar offshore trend in total $\mathrm{Fe}$ is seen in bottom water taken during lander incubation (average of 2050 $\mathrm{nM}$ at station 9 to $290 \mathrm{nM}$ at station 6 (Tables S.5.9-S.5.14). At station 5, dissolved and total Fe increased rapidly below $150 \mathrm{~m}$ depth because of sampling of the chemocline in the deep basin (e.g. Kraal et al., 2017). At this station, particulate Fe additionally shows a maximum between 100 and $120 \mathrm{~m}$ water depth.

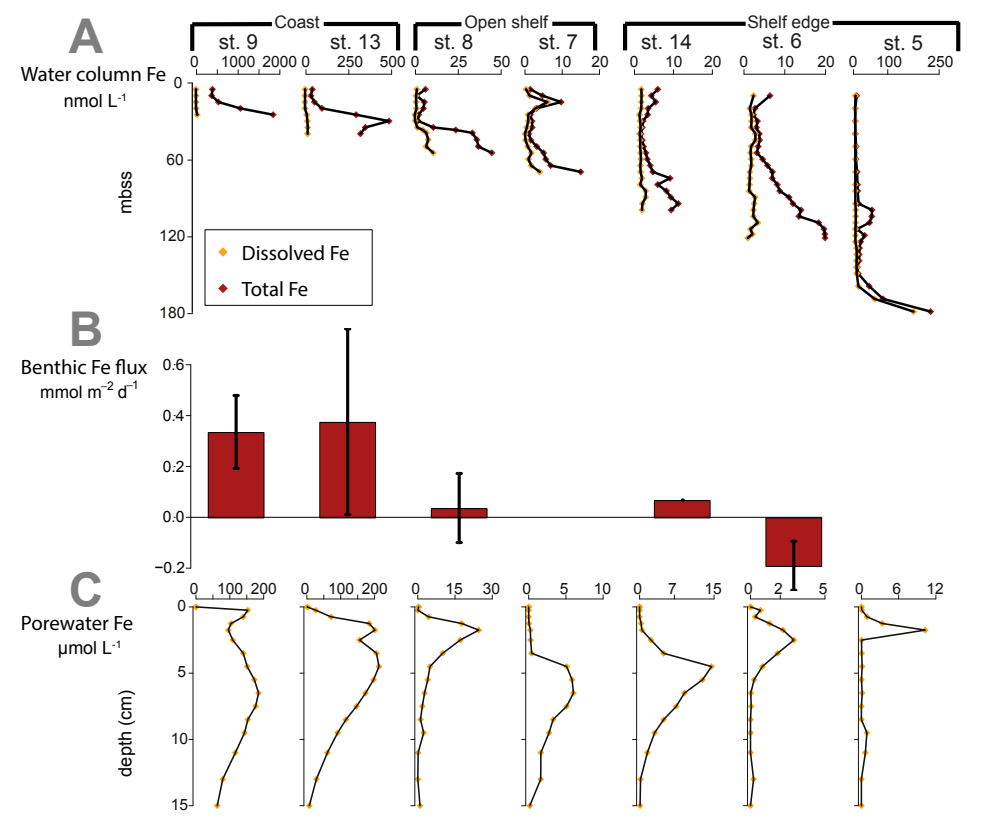

Figure 5.3 | (A) Water column profiles of total and dissolved Fe (in nM), (B) Benthic Fe fluxes ( $\mathrm{mmol} \mathrm{m}^{-2} \mathrm{~d}^{-1}$ ) and (C) Pore water profiles of $\mathrm{Fe}\left(\mu \mathrm{mol} \mathrm{L}{ }^{-1}\right)$ at our 7 stations on the northwestern Black Sea shelf. Note that no benthic flux measurements are available for station 5 and that a zero flux was observed at station 7 .

\subsubsection{Benthic Exchange and Pore Water Profiles of Fe}

In-situ measured benthic fluxes of total Fe towards the overlying water were the highest near the coast, with average values of 0.34 and $0.38 \mathrm{mmol} \mathrm{m}^{-2} \mathrm{~d}^{-1}$ at stations 9 and 13, respectively (Figure 5.3B; Table 5.5; mean $\mathrm{R}^{2}$ for all chambers: 0.84 ). At the open shelf and shelf edge stations, in contrast, average Fe fluxes were below $0.07 \mathrm{mmol} \mathrm{m}^{-2} \mathrm{~d}^{-1}$ and at station 6 an Fe flux into the sediment of $\sim 0.2 \mathrm{mmol} \mathrm{m}^{-2} \mathrm{~d}^{-1}$ was observed. At station 7 no flux of Fe was detected. Pore water Fe profiles show a distinct subsurface maximum at all stations, which is indicative of release of $\mathrm{Fe}$ to the pore water (Figure 5.3C). Dissolved Fe concentrations were an order of magnitude higher at the coastal stations 9 and 13 than at the open shelf and shelf edge stations. Accumulation of dissolved Fe was the strongest and occurred closest to the sediment-water interface at these coastal stations. At 
station 9 , on average $70 \%$ of the dissolved Fe in the pore water $(<0.45 \mu \mathrm{m})$ was present in aqueous form $(<0.02 \mu \mathrm{m})$ and colloidal/nanoparticulate Fe $(0.02 \mu \mathrm{m}-0.2 \mu \mathrm{m})$ on average accounted for less than $13 \%$ of the total Fe (Figure 5.4).

Table 5.5 | In-situ measured and calculated diffusive benthic Fe fluxes. In-situ fluxes are averages for three incubation chambers. N/A.: not available. At station 7 a zero flux was determined; no measurement was carried out at station 5 .

\begin{tabular}{lll}
\hline Station & Measured in-situ flux mmol $\mathrm{m}^{-2} \mathrm{~d}^{-1}$ & Calculated diffusive flux $\mathrm{mmol} \mathrm{m}^{-2} \mathrm{~d}^{-1}$ \\
\hline 9 & $0.34 \pm 0.12^{*}(0.11 \pm 0.012)$ & 2.23 \\
13 & $0.38 \pm 0.3$ & 0.36 \\
8 & $0.037 \pm 0.01$ & -0.04 \\
7 & 0 & 0 \\
14 & 0.068 & 0 \\
6 & $-0.19 \pm 0.07$ & 0.01 \\
5 & $\mathrm{~N} / \mathrm{A}$ & 0.001 \\
\hline
\end{tabular}

"Benthic Fe release based on first three points in time (Figure S.5.4). Although we did not see a clear change in Fe release at station 9 in response to the decline in oxygen (Figure S.5.3) in two chambers, measured fluxes based on the first three data points were lower than for the full incubation period. Whether we use the full data set or not does not affect the conclusions of this study.

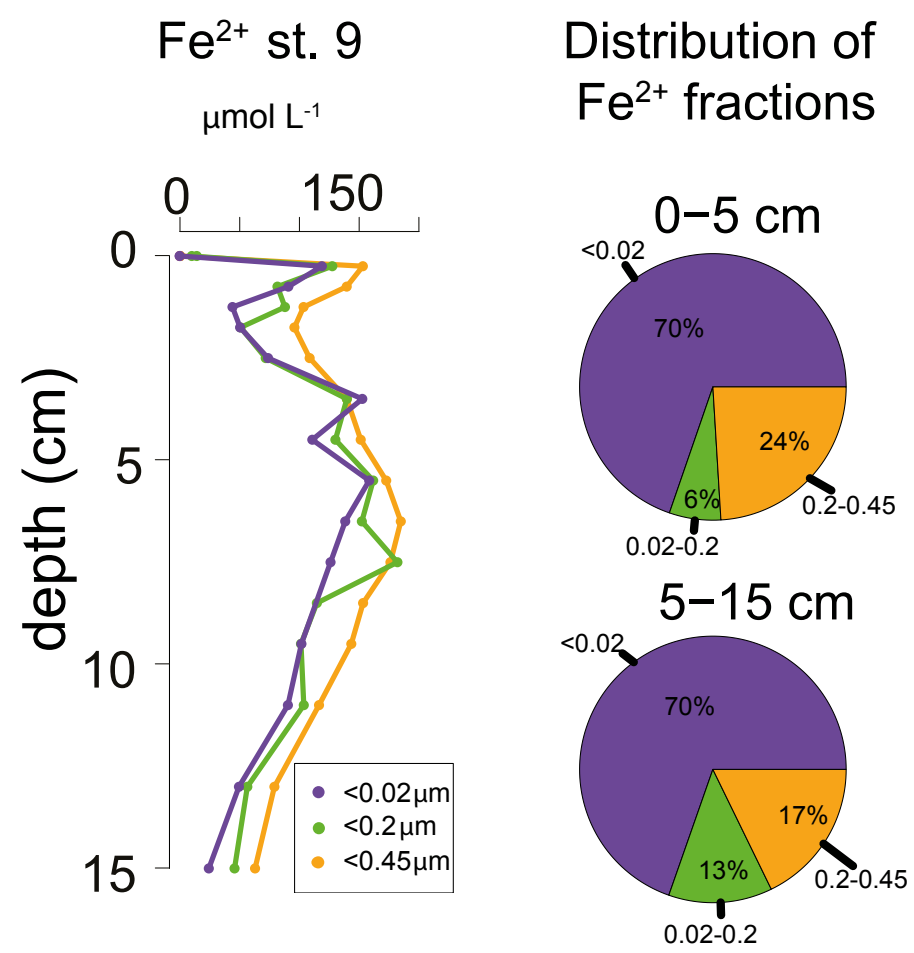

Figure 5.4 Pore water depth profiles of filtered fractions of $\mathrm{Fe}(<0.02,<0.2$ and $<0.45 \mu \mathrm{m})$ at station 9 and average percentages of the different fractions for the depth intervals from $0-5 \mathrm{~cm}$ to $5-15 \mathrm{~cm}$. 


\subsubsection{Suspended Matter and Sediment Fe Composition}

The particulate $\mathrm{Fe}$ in the suspended matter at six stations as determined with the sequential chemical extraction (Table 5.2) decreases significantly from the coast to the shelf edge (Figure 5.5A, Table S.5.1). Generally, samples from the lower part of the water column were enriched in Fe when compared to samples taken closer to the water surface. Ferrihydrite and reducible (crystalline) Fe oxides were the dominant reactive $\mathrm{Fe}$ phases in the suspended matter at all stations. In general, suspended matter from the lower part of the water column was enriched in ferrihydrite when compared to samples from shallower depths.

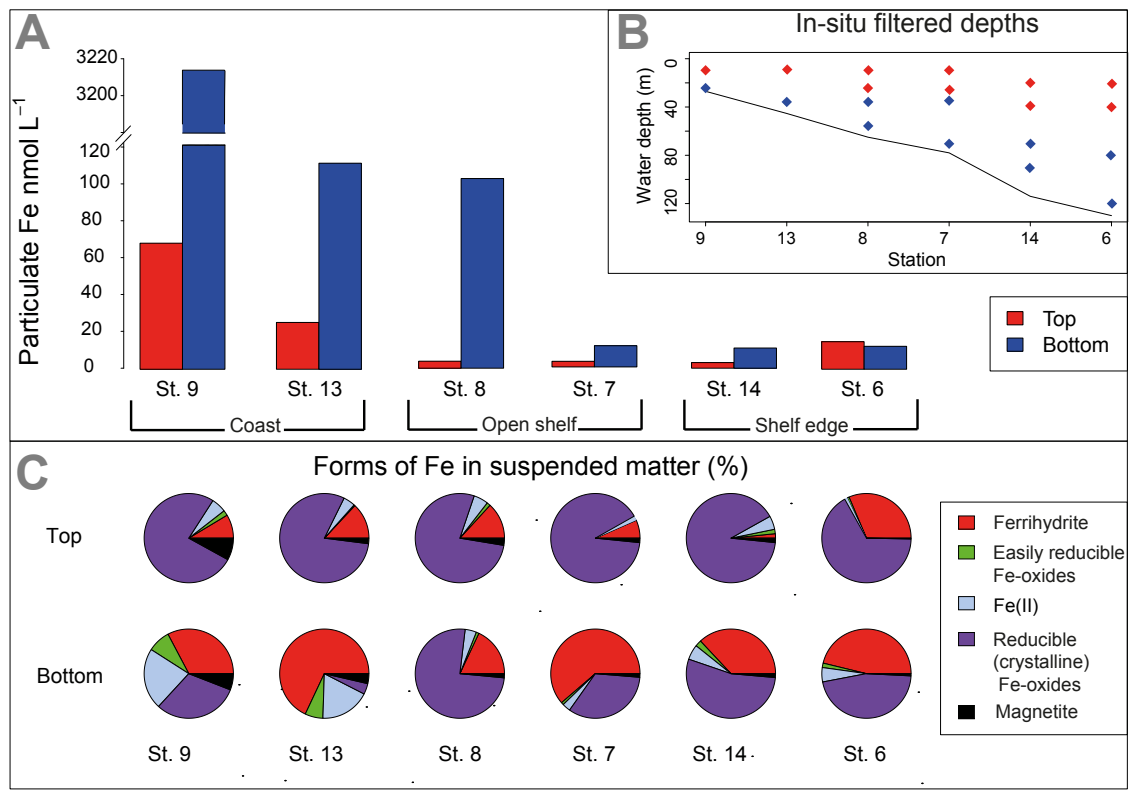

Figure 5.5 | Fe in suspended matter at 6 stations on the northwestern Black Sea shelf; (A) Particulate Fe refers to the sum of all Fe fractions upon sequential Fe extraction as calculated for the upper (top) and lower (bottom) part of the water column; (B) Water depths at which samples were collected; colors indicate separation into top and bottom. The black line indicates the sediment water interface; (C) Forms of Fe in suspended matter (in \%). Data for individual filters are given in Table S.5.1.

The surface sediments at all stations were enriched in easily reducible Fe oxides $\left(\mathrm{Fe}_{\mathrm{ox} 1}\right)$ which includes ferrihydrite (Figure 5.6). Fe(II) phases and reducible (crystalline) Fe oxides, with the former mostly consisting of FeS and Fe carbonate, contributed a variable fraction. Magnetite was a minor phase in the sediment. The coastal stations 9 and 13 were characterized by the highest total Fe contents, which range up to ca. $1200 \mu \mathrm{mol} \mathrm{g}^{-1}$. At all stations, the top sediment layer of 1 to $3 \mathrm{~cm}$ was strongly enriched in $\mathrm{Fe}_{\text {ox } 1}$ and $\mathrm{Fe}_{\mathrm{ox} 2}$ and total Fe relative to $\mathrm{Al}$, except for station 9 (Figure S.5.8). The Fe/Al ratio increases with distance from the shore, with values of ca. 0.5 to 0.8 wt. $\%$ wt. $\%^{-1}$ at coastal stations and 1.2 to $2 \mathrm{wt} . \% \mathrm{wt} . \%^{-1}$ at the outer shelf stations. Total S increases with sediment depth at all stations, with maximum values increasing from the coastal zone towards the shelf edge. Pyrite contents at stations 9,13 and 8 range from 20 to $\sim 110 \mu \mathrm{mol} \mathrm{g}^{-1}$ and generally increase with depth (Figure S.5.9). 

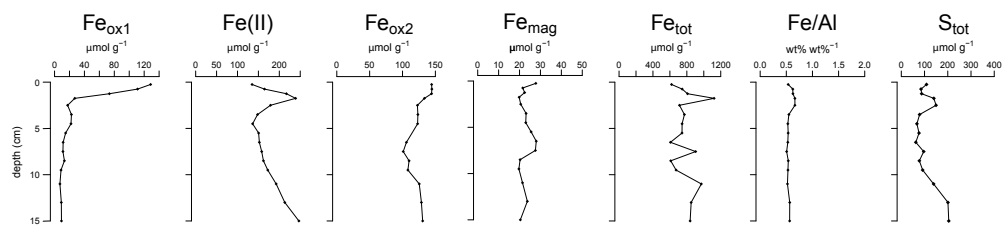

St. 9
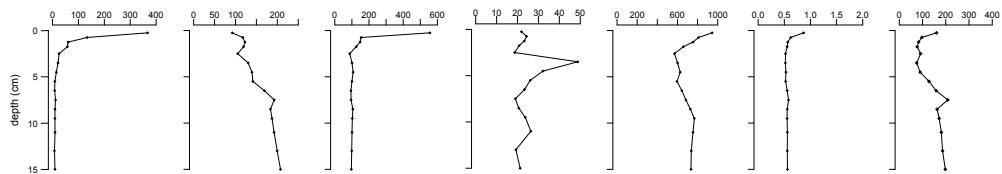

St. 13
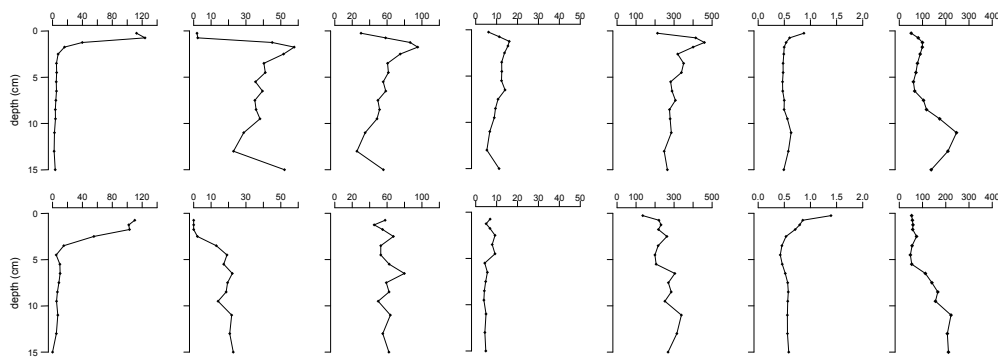

St. 8
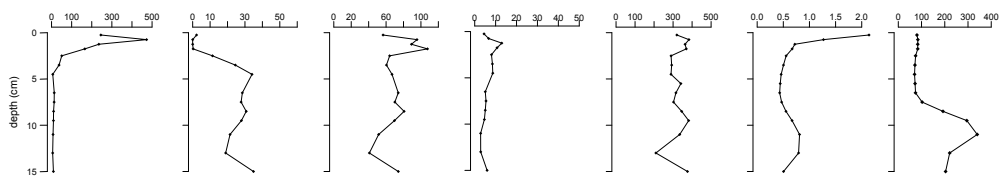

St. 7
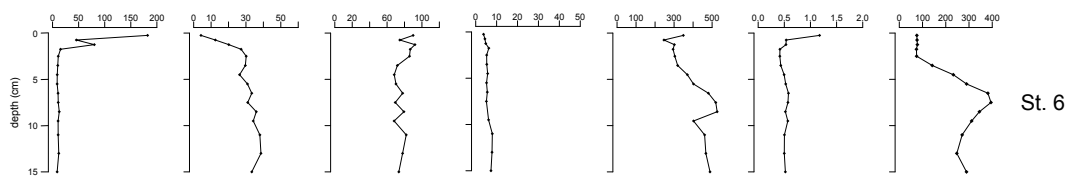

Figure 5.6 | Solid-phase depth profiles of easily reducible Fe oxides $\left(\mathrm{Fe}_{\mathrm{ox}}\right)$, Fe carbonates and $\mathrm{FeS}$ ( $\mathrm{Fe}(\mathrm{II})$ ), reducible (crystalline) $\mathrm{Fe}$ oxides $\left(\mathrm{Fe}_{\mathrm{ox} 2}\right)$, magnetite $\left(\mathrm{Fe}_{\mathrm{mag}}\right)$, total $\mathrm{Fe}\left(\mathrm{Fe}_{\mathrm{tot}}\right), \mathrm{Fe} / \mathrm{Al}$ and total $\mathrm{S}\left(\mathrm{S}_{\mathrm{tot}}\right)$ at six stations on the northwestern Black Sea shelf. Depth profiles of $\mathrm{Fe}_{\mathrm{ox} 1}, \mathrm{Fe}(\mathrm{II}), \mathrm{Fe}_{\mathrm{ox} 2}$ and $\mathrm{Femag}$ normalized against $\mathrm{Al}$ are plotted in Figure S.5.8.

\subsubsection{X-ray Spectroscopy of Suspended Matter and Sediment}

The Fe K-edge XANES and EXAFS spectra for surface sediment and suspended matter show systematic changes that are best explained by variations in the relative content of illite, ferrihydrite and pyrite (Figure 5.7A and B). There are especially distinct contrasts between spectra for the coastal station 9, shelf edge station 14 and station 5 in the chemocline. For station 9, a good match between the spectrum for the sediment and illite was found, while for station 14, the spectrum was very similar to that for ferrihydrite. The XANES spectrum for station 5 exhibited a step with a maximum slope around $7118 \mathrm{eV}$ which is characteristic for pyrite and was absent in the spectra of all other stations. The EXAFS spectra support the XANES results. Distinct contrasts between the spectra for stations 9 and 13, for example, can be explained by differences in the abundance of illite and ferrihydrite. The characteristic signatures of crystalline Fe oxides were not observed in the EXAFS spectra. Adding crystalline Fe oxides to the set of endmembers in the linear combination fitting did not lead to significant improvements and illite, ferrihydrite, and pyrite were consistently 
selected when looking for the best combination of two or three reference spectra. This implies that the content of crystalline Fe oxides in the samples was not large. At both stations, bulk XAS measurements of the suspended material and surface sediment, were similar indicating a similar Fe mineralogy.
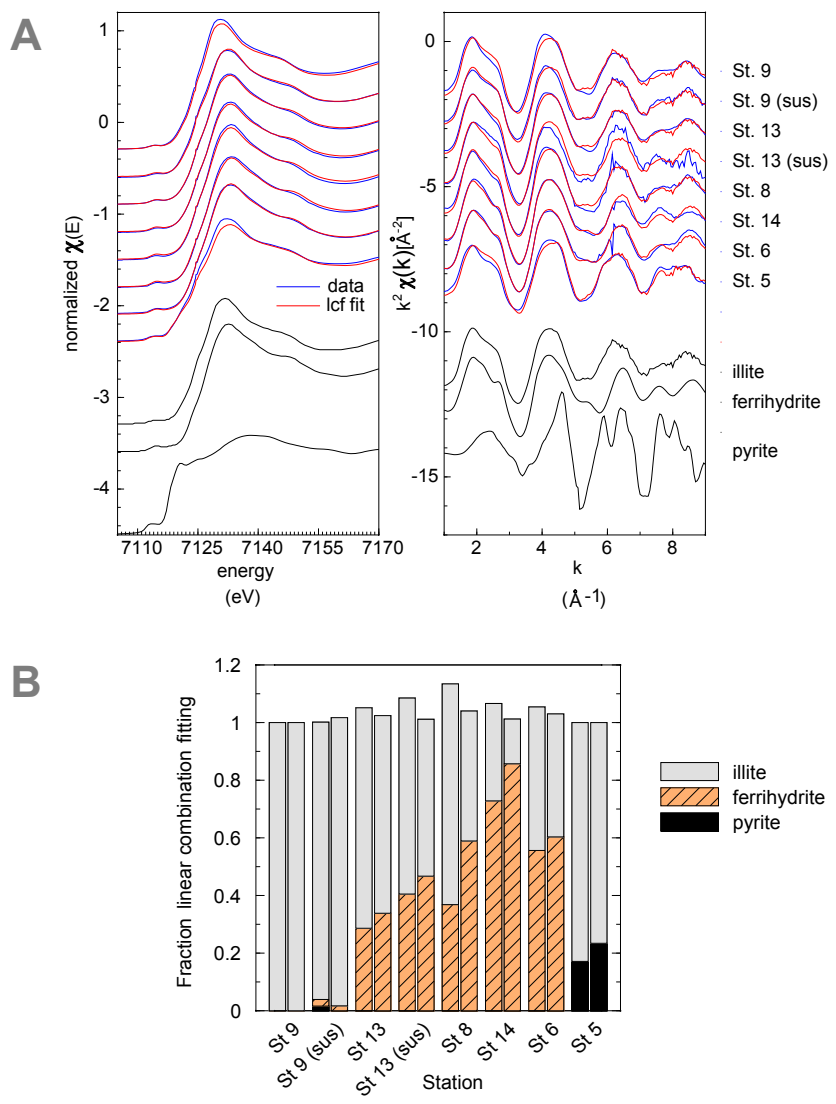

Figure 5.7 | (A) Fe-XANES and EXAFS of powdered surface sediment samples and suspended matter samples from a range of stations compared to the reference materials illite, ferrihydrite and pyrite. (B) Relative contribution of the spectra of the reference materials to the EXAFS (left bar) and XANES (right bar) spectra based on linear combination fitting. The uncertainty of the optimized relative contributions varied between 0.03 and 0.08 . The sum of the contributions was forced to be 1.0 within in the range of uncertainty. A sum above 1.0 can be, therefore, explained by the cumulative error of the individual contributions and the deviation from 1.0 is not significant.

$\mu$-XRF mapping of Fe and $\mathrm{K}$ in suspended matter and Fe-XANES spectra at selected spots confirm the presence of clay-Fe at station 9 and both clay-Fe and ferrihydrite at station 13 (Figure 5.8 A-C). The ratios of Fe to $\mathrm{K}$ fluorescence (expressed in counts, not calibrated) exhibit a lower limit for all investigated areas of the filter from station 13 and area 3 on the filter from station 9 (Figure 5.8B). The corresponding baselines are interpreted as the relative intensities of $\mathrm{Fe}$ and $\mathrm{K}$ fluorescence originating from clay minerals. For station 13, baseline ratios of $\mathrm{Fe} / \mathrm{K}$ differ between the sub-areas and are roughly around 8,2, 9 for areas 1, 2 and 3, respectively. Fluorescence 
intensities of Fe above the baseline are interpreted to indicate the presence of non-silicate $\mathrm{Fe}$. The Fe-XANES spectra (Figure 5.8C) collected on various spots at station 13 support the interpretation of the elemental correlations. All spectra at station 13 can be reproduced by linear combination of XANES spectra of illite and ferrihydrite where the contribution of ferrihydrite contributes up to ca. 50\% (Figure 5.8C). The contribution of ferrihydrite follows the trend in Fe/ K ratios: spots that have a $\mathrm{Fe} / \mathrm{K}$ ratio above the baseline ratio also show higher fractions of ferrihydrite in the linear combination fitting. In contrast, spectra of spots with $\mathrm{Fe} / \mathrm{K}$ ratios close to the corresponding baseline ratio resemble the spectrum of illite. At station 9, two distinct hotspots for Fe were observed in the $\mu$-XRF map (Area 1 and 2, Figure 5.8A). The Fe-XANES spectrum for the spot in area 1 was disturbed and could not be used, but Mn-XANES at the same location pointed towards the presence of spessarite, a Mn-rich garnet (not shown). The Fe-XANES spectra for area 2 show the same features and edge position as biotite (Figure 5.8C). The spectra for the background and area 3 resemble those for illite in accordance with the Fe-XANES of the bulk samples (Figure 5.7). Overall, our data indicate a lateral gradient in the forms of Fe in the surface sediment, with the coastal zone stations being dominated by clays, while sediments at the open and outer shelf stations are mostly enriched in ferrihydrite.

\subsection{Discussion}

\subsubsection{Organic Matter Supply Drives Fe Mobilization in Shelf Sediments}

The Danube river is a major source of terrestrial organic carbon, nutrients and lithogenic particles, including reactive Fe, to the northwestern Black Sea shelf (Popa, 1993; Panin and Jipa, 2002; Poulton and Raiswell, 2002). In the coastal sediments directly in front of the Danube delta, rates of organic matter production, sediment accumulation and benthic mineralization are high, decreasing with distance from the coast (Wijsman et al., 1999). This is confirmed by the offshore decline in $\mathrm{NH}_{4}{ }^{+}$ concentrations in the pore water (Figure S.5.6). The offshore decline in sediment organic carbon content, $\mathrm{O}_{2}$ uptake and macrofaunal density observed in our study (Table 5.3; Figure 5.2) is in accordance with these previous observations.

The distinct contrast in depositional conditions near the coast and on the remainder of the shelf has a major impact on pore water Fe concentrations. While pore water Fe reaches values close to $200 \mu \mathrm{mol} \mathrm{L}{ }^{-1}$ in the surface sediments at the coastal stations 9 and 13 (Figure 5.3), Fe concentrations were below $30 \mu \mathrm{mol} \mathrm{L}{ }^{-1}$ at the open shelf and shelf edge stations. This implies that only sediments receiving relatively high inputs of organic matter show strong mobilization of $\mathrm{Fe}$ in the pore water. At the coastal stations, the abundant presence of organic matter supports a macrofaunal population that transports organic matter and Fe oxides downward into the sediment through mixing. This enhances the reductive dissolution of the Fe oxides by promoting dissimilatory Fe reduction and/ or sulfate reduction and sulfide-driven Fe reduction (Aller, 1994). At the open shelf and shelf edge stations, in contrast, the organic matter flux is very low and the sediment surface is covered with shells of Modiolula phaseolina and Mytilus galloprovincialis (Table 5.4, Wijsman et al., 1999), that do not mix the sediment. In this area, Fe mobilization to the pore water is limited due to relatively low rates of organic matter degradation (Figure 5.2; Wijsman et al., 1999).

That bottom water $\mathrm{O}_{2}$ is not the key control of Fe release is evident from the lack of reductive release of $\mathrm{Fe}$ in the pore water at station 6 (Figure 5.3). Here, bottom waters are hypoxic $(27 \mu \mathrm{mol}$ $\left.\mathrm{L}^{-1}\right)$ but pore water Fe concentrations remain low $\left(<3 \mu \mathrm{mol} \mathrm{L}{ }^{-1}\right.$; Figure 5.3C) despite the abundant presence of easily reducible Fe oxides in the surface sediment (ca. $200 \mu \mathrm{mol} \mathrm{g}{ }^{-1}$; Figure 5.6). 
Station 9

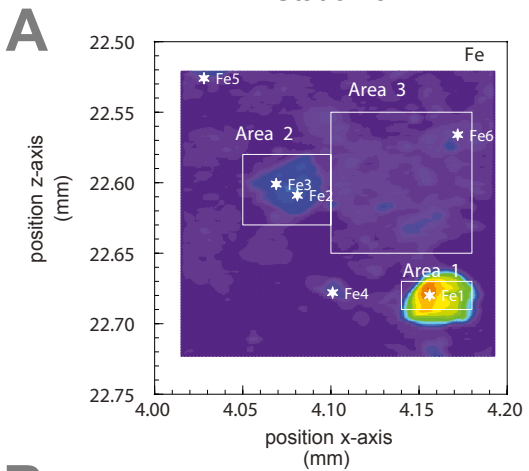

B
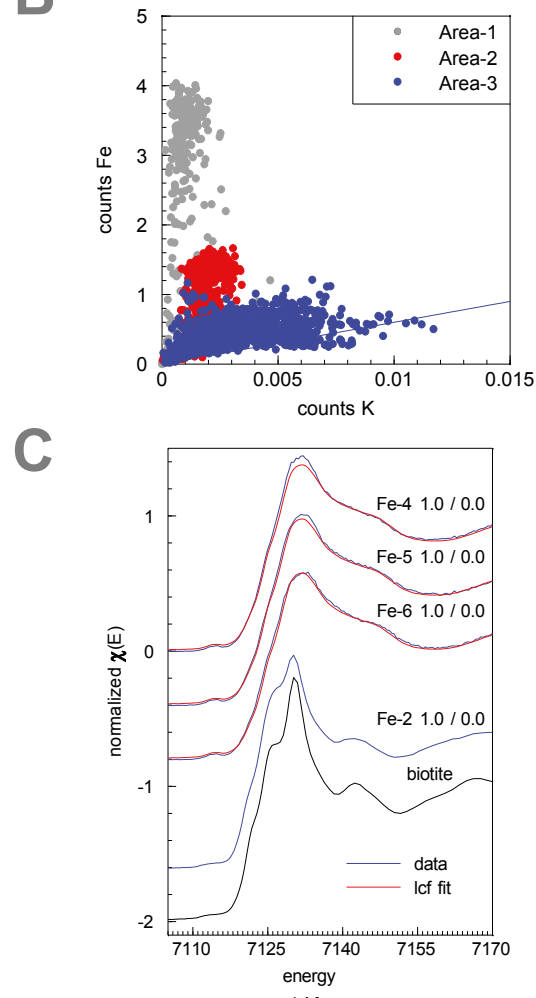

$(\mathrm{eV})$
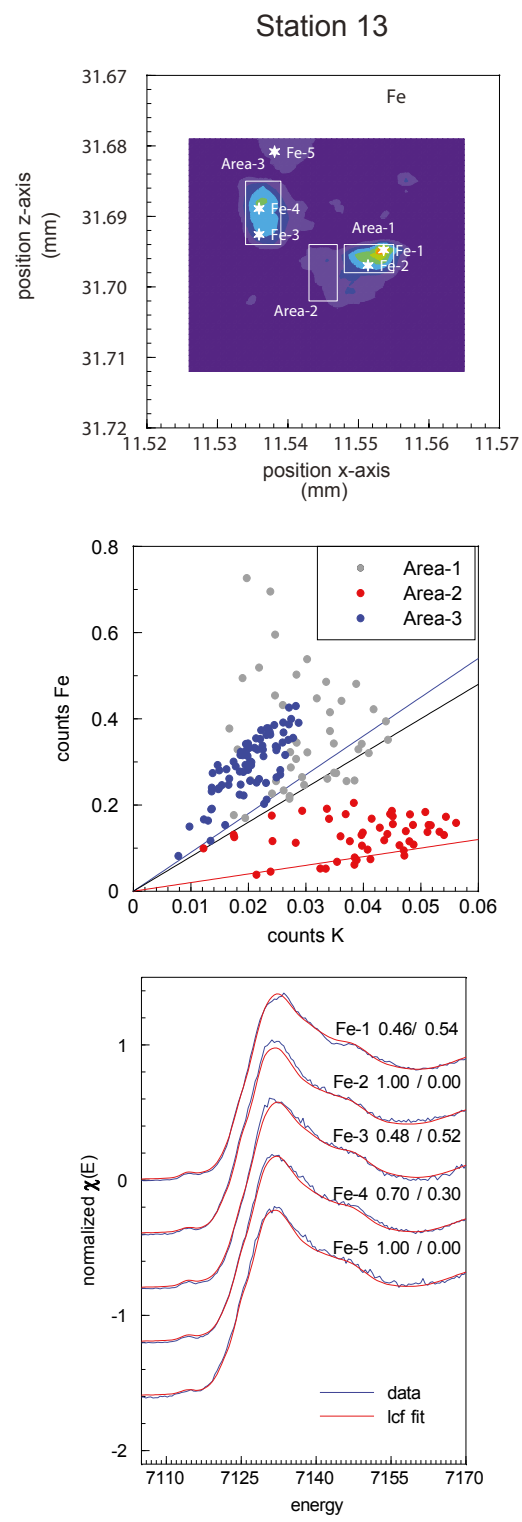

(eV)

Figure 5.8 $\mid \mu \mathrm{XRF}$ and Fe-XANES analyses of suspended matter at stations 9 and 13. (A) $\mu$ XRF map of Fe. (B) Fe and $\mathrm{K}$ in $\mu \mathrm{XRF}$ maps (fluorescence intensity, counts, not calibrated) in three areas of the sample for each station. The lines are baselines and show the lower limit of the ratio of Fe counts to $\mathrm{K}$ counts in the various areas. These baselines reflect the intensity ratio of $\mathrm{Fe}$ and $\mathrm{K}$ fluorescence of clay minerals in the corresponding area. Higher Fe/K ratios are indicative of enrichments in nonsilicate Fe. (C) Fe-XANES spectra collected on various spots on the samples; for each spot measurement the fraction of clay-Fe and ferrihydrite in the sample based on linear combination fitting is given. The spectrum for spot Fe-1 is not shown because it was disturbed. The spectrum for spot Fe-3 is not shown because it was similar to that of spot $\mathrm{Fe}-2$. 
This emphasizes that mobilization of $\mathrm{Fe}^{2+}$ in the sediment and a corresponding benthic $\mathrm{Fe}$ flux in hypoxic settings requires a sufficient supply of organic matter. At open shelf and shelf edge regions of the Black Sea, the required organic matter is not consistently present resulting in a limited benthic Fe flux despite a low bottom water $\mathrm{O}_{2}$ concentration.

At station 9, 70\% of the pore water Fe was found to be truly dissolved $(<0.02 \mu \mathrm{m})$ with colloidal and/or nanoparticulate Fe accounting for ca. 30\%. An important role for truly dissolved Fe was also observed recently for pore waters of shelf sediment in the Celtic Sea (Klar et al., 2017). We hypothesize that the colloidal and/or nanoparticulate Fe at station 9 is formed in sediment burrows.

\subsubsection{Sediment Release of Fe: Role of Diffusion and Bioirrigation}

The elevated pore water Fe concentrations at the coastal stations 9 and 13 drive the high benthic release of Fe from the sediment to the overlying water (up to on average $0.38 \mathrm{mmol} \mathrm{m}^{-2} \mathrm{~d}^{-1}$; Figure 5.3). Much lower to negligible Fe fluxes are observed at the open shelf and shelf edge stations where pore water Fe concentrations are low. The range in Fe fluxes is of the same order of magnitude as those measured previously in this region with benthic landers (with maxima in dissolved Fe fluxes up to 0.44 and $0.53 \mathrm{mmol} \mathrm{m}^{-2} \mathrm{~d}^{-1}$ Friedl et al., 1998; Friedrich et al., 2002). However, in contrast to Friedrich et al. (2002) we did not find an enhanced benthic flux of Fe near the shelf edge.

Benthic fluxes measured at the coastal stations are, however, rather high when compared to typical fluxes of dissolved $\mathrm{Fe}$ reported in sediments overlain by well-oxygenated bottom waters (mostly $<0.05 \mathrm{mmol} \mathrm{Fe} \mathrm{m}^{-2} \mathrm{~d}^{-1}$; Dale et al., 2015). Our values are close to the range of dissolved Fe fluxes reported for river-dominated coastal stations with similar carbon oxidation rates on the Californian continental shelf (up to $\sim 0.3 \mathrm{mmol} \mathrm{Fe} \mathrm{m}^{-2} \mathrm{~d}^{-1}$; Severmann et al., 2010). Bioirrigation was suggested to play an important role in controlling the benthic flux of Fe in these systems.

Quantifying the relative contribution of both diffusion and bioirrigation processes is difficult because of the strong vertical and horizontal variability in pore water chemistry of bioirrigated sediments (Aller, 1980; Aller and Aller, 1998), that is not captured with our sampling methods (e.g. Slomp et al., 1997; Wijsman et al., 2001a; Raiswell and Canfield, 2012; Dale et al., 2015). At the coastal stations, calculated diffusive fluxes are high (i.e. $0.36-2.23 \mathrm{mmol} \mathrm{m}^{-2} \mathrm{~d}^{-1}$; Table 5.5). However, we are likely greatly overestimating the diffusive fluxes at these coastal sites in our calculations because we use a concentration gradient based on the average dissolved $\mathrm{Fe}$ concentration in the upper $5 \mathrm{~mm}$ of the sediment. We know that the actual gradient will be smaller because of rapid oxidation of $\mathrm{Fe}^{2+}$ with $\mathrm{O}_{2}$ present in the oxic layer (Figure S.5.5; Dale et al., 2015). Actual diffusive fluxes are thus expected to be negligible.

With bioirrigation rate determinations, we estimated the potential enhancement of pore water transport by macrofaunal activity with the inert tracer bromide. The corresponding nonlocal transport coefficients of 0.21 to $0.41 \mathrm{~d}^{-1}$ at the coastal stations fall within the high end of the range typically observed in coastal surface sediments (Martin and Banta, 1992; Boudreau, 1998; Schlüter et al., 2000). The potential maximum enhancement of Fe release through bioirrigation can be calculated from these coefficients and the pore water Fe profile, by integrating the following bioirrigation rate (R) term with depth (Eq. (5.2)),

$R=\int_{0}^{b} \alpha(x) \cdot([F e](x)-[F e](0)$ 
where $\alpha(\mathrm{x})$ stands for the non-local transport coefficient as a function of depth in the sediment, [Fe] $(\mathrm{x})$ is the pore water concentration of dissolved $\mathrm{Fe}$ as a function of depth, $[\mathrm{Fe}](0)$ is the dissolved $\mathrm{Fe}$ concentration in the overlying water and $\mathrm{b}$ is the maximum depth where bioirrigation takes place (Figure S.5.7). At stations 9 and 13, the maximum bioirrigative flux of Fe calculated from this equation is 3.8 and $2.4 \mathrm{mmol} \mathrm{m}^{-2} \mathrm{~d}^{-1}$, respectively. These potential bioirrigative fluxes of Fe are one order of magnitude higher than the in-situ measured Fe fluxes. This suggest that a major proportion of the $\mathrm{Fe}$ is retained in the sediment through formation of Fe oxides in oxygenated burrows (Meile et al., 2005). However, we find that Fe still escapes to the overlying water and suggests that bioirrigation mainly controls this flux of $\mathrm{Fe}^{2+}$

and colloidal or nanoparticulate Fe out of macrofaunal burrows.

\subsubsection{Fe Shuttling over the Black Sea Shelf and into the Deep Basin}

Most $\mathrm{Fe}$ in the water column along our water depth transect is present as particulate $\mathrm{Fe}(>0.2$ $\mu \mathrm{m}$ ) (Figure 5.3) with concentrations decreasing with increasing distance from the shore. Similar general trends in dissolved and particulate Fe were reported for a range of stations in a nearby area in the summer of 1995 (Tankéré et al., 2001), suggesting that this is a consistent feature of the northwestern Black Sea shelf.

High Fe release from the coastal stations led to elevated concentrations of dissolved Fe in the water column near the sediment water interface at stations 9, 13 and 8 (Figures 5.3A and S.5.10). Given the instability of $\mathrm{Fe}^{2+}$ in an oxygenated environment at circumneutral $\mathrm{pH}$, the dissolved $\mathrm{Fe}$ in the water column was likely in the form of $\mathrm{Fe}^{3+}$ complexed with organic ligands (Wu et al., 2001; Gerringa et al., 2016). The plume of dissolved Fe does not extend beyond station 8 because of limited benthic release of $\mathrm{Fe}$ at the open shelf and shelf edge stations. Particulate Fe is enriched in the lower part of the water column at all stations on the shelf, but particularly in the coastal zone (Figures 5.3A and S.5.10), suggesting that benthic Fe release is a key source of Fe to the water column. The results of our sequential extractions suggest that $\mathrm{Fe}$ in suspended matter and the surface sediment is present as ferrihydrite and reducible (crystalline) Fe oxides (Figures 5.5 and 5.6). However, while the XAS results confirm a role for ferrihydrite in both the suspended matter and surface sediment (Figure 5.7), there is little evidence for a major contribution of reducible (crystalline) Fe oxides. Instead, there is a strong contribution of clay-Fe. We have two possible explanations. First, we may extract Fe from clays in the dithionite solution used in step 3 of our extraction procedure $\left(\mathrm{Fe}_{\mathrm{ox} 2}\right.$; Table 5.2), which could lead to an overestimation of the $\mathrm{Fe}_{\mathrm{ox} 2}$. Second, we may not be accurately separating ferrihydrite and clay-Fe in the XAS analysis if the clay-Fe in the Black Sea differs from our illite standard, which could lead to an uncertainty in the illite fraction. Regardless of the absolute contribution of each phase, both sequential extraction and XAS results suggest the highest concentrations of easily reducible Fe oxides in the surface sediments at the shelf edge.

At the coastal stations, both the pore water and water column profiles suggest that Fe oxides are actively precipitating in the surface sediment and water column (Figure 5.3), with the suspended matter at station 13 being particularly enriched in easily reducible $\mathrm{Fe}$ oxides (Figures 5.5C and 5.7). The presence of clay-Fe suggests that there is also riverine input of Fe-bearing material, possibly as resuspended surface sediment. At the open shelf and shelf edge stations lateral transfer through repeated deposition and resuspension controls the composition of the particulate Fe in the water column since there is practically no release of Fe from the sediment in this area (Figure 5.3B). 
Further insight into the dynamics of Fe on the shelf and its ultimate fate can be obtained by combining our data with those of Kraal et al. (2017) to create a water depth transect that extends into the deep basin (Table S.5.2, Figure S.5.11). We focus on four indicators that provide insight into the degree to which $\mathrm{Fe}$ is associated with sulfur and the degree to which $\mathrm{Fe}$ is authigenically enriched in the surface sediment $(0-2 \mathrm{~cm})$ and at depth $(2-15 \mathrm{~cm})$ in four regions, namely the coastal zone, open shelf, shelf edge and euxinic basin (Figure 5.9).
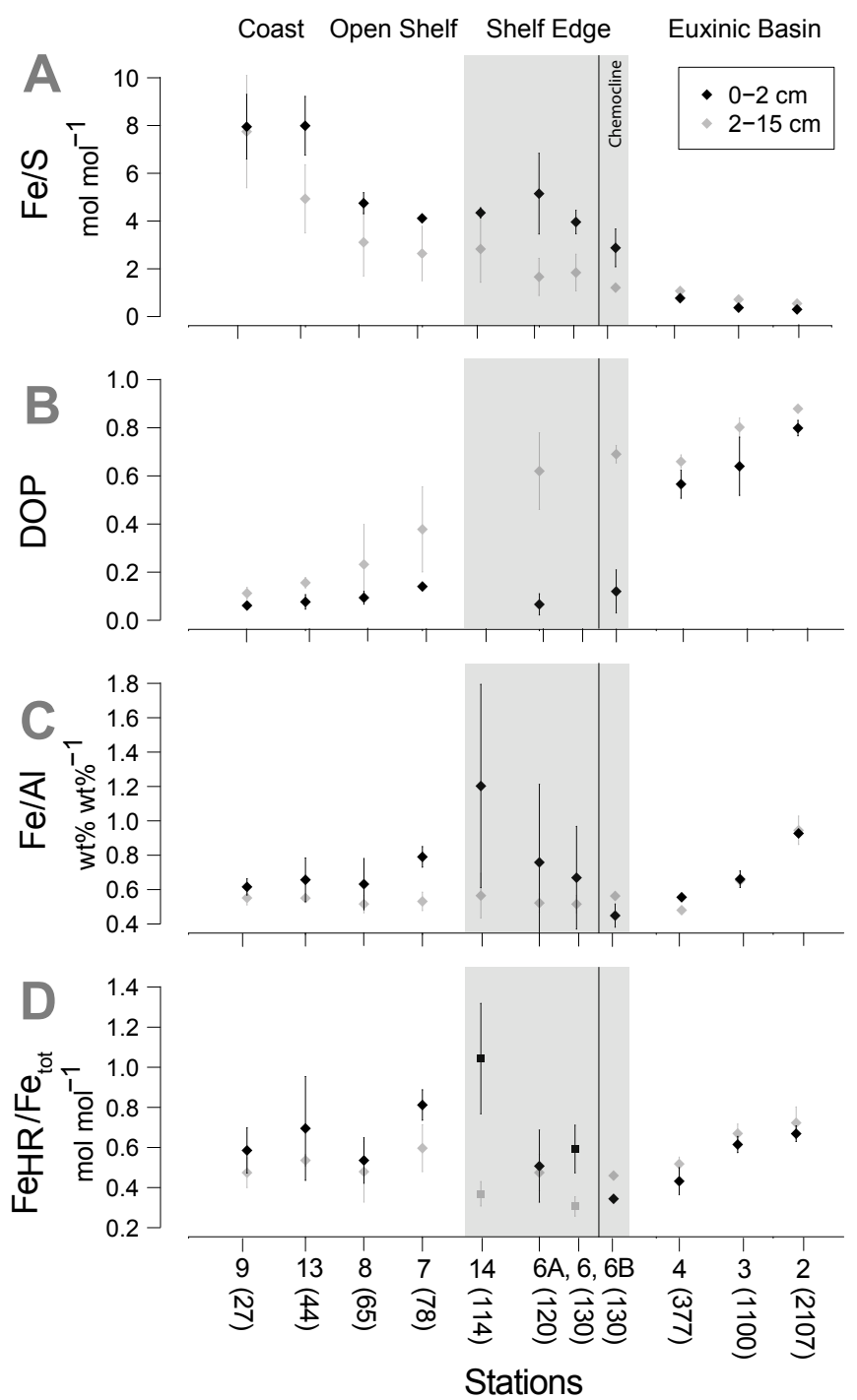

Figure 5.9 Indicators for the degree of sulfidization (A, B) and authigenic enrichment of Fe (C, D) in the surface sediment $(0-2 \mathrm{~cm})$ and at greater depth $(2-15 \mathrm{~cm})$ at 6 of our shelf stations and 5 stations from Kraal et al. (2017) (Table 5.6). (A) $\mathrm{Fe}_{\mathrm{tot}} / \mathrm{S}_{\text {tot }}$; (B) degree of pyritization (DOP); (C) $\mathrm{Fe}_{\mathrm{tot}} / \mathrm{Al}_{\mathrm{tot}}$ and (D) Highly reactive Fe/Fetot. Given that at stations 14 and 6, no $\mathrm{FeS}_{2}$ data are available, FeHR is based on fractions (2) to (4) from Table 5.2 only (indicated as a square instead of a diamond in panel D). 
The first two indicators are the total Fe/S ratio and the degree of pyritization (DOP), with the latter being defined as the fraction of highly reactive Fe (FeHR) that is bound in pyrite (Berner, 1970; Raiswell et al., 1988). FeHR, in turn, is defined as the sum of pyrite and all forms of Fe extracted in our sequential extraction procedure for sediments (Table 5.2). The trends in the Fe/S and DOP reflect increased sulfidization of Fe from the coastal zone to the euxinic basin and with depth in the sediment, (Figure 5.9A and B; Table 5.6), as reported previously Canfield et al. (1996), Wijsman et al. (2001a), Lyons and Severmann (2006). Importantly, the coastal sediments, which act as a source of Fe to the shelf, are characterized by the lowest degree of pyritization $(\mathrm{DOP}<0.2)$ and high $\mathrm{Fe} / \mathrm{S}$. Such a low degree of pyritization is typical for rapidly accumulating coastal sediments with high macrofaunal activity where sulfide that is produced is reoxidized and not bound to Fe (Jørgensen, 1977). This provides conditions where Fe can accumulate in the pore water and escape to the overlying water. At the open shelf and shelf edge stations, in contrast, a larger proportion of the Fe is sulfidized ( $\mathrm{DOP}>0.2$ ), particularly at depth, through long-term exposure of the slowly accumulating sediment to sulfide produced through sulfate reduction (Weber et al., 2001; Slomp et al., 2013). In the euxinic deep basin, DOP values increase towards 1, typical for iron-limited pyrite formation in sulfidic waters where pyritization of FeHR is nearly complete (Berner, 1984; Raiswell and Berner, 1985).

Table 5.6 | Average values of sediment indicators for degree of sulfidization (Fe/S and DOP) and authigenic enrichments of $\mathrm{Fe}\left(\mathrm{Fe} / \mathrm{Al}\right.$ and $\left.\mathrm{FeHR} / \mathrm{Fe}_{\mathrm{tot}}\right)$ for 4 different areas for depth intervals $0-2$ and $2-15 \mathrm{~cm}$ in the sediment.

\begin{tabular}{llllll}
\hline & Area & $\begin{array}{l}\mathrm{Fe} / \mathrm{S} \\
\mathrm{mol} \mathrm{mol}\end{array}$ & DOP & $\begin{array}{l}\mathrm{Fe} / \mathrm{Al} \\
\text { wt.\% wt.\% }\end{array}$ & $\begin{array}{l}\mathrm{Fe}_{\mathrm{HR}} / \mathrm{Fe}_{\text {tot }} \\
\mathrm{mol}^{-1}\end{array}$ \\
\hline $0-2 \mathrm{~cm}$ & Coast & 7.95 & 0.07 & 0.63 & 0.64 \\
& Open shelf & 4.41 & 0.12 & 0.71 & 0.67 \\
& Shelf edge & 4.06 & 0.09 & 0.77 & 0.62 \\
& Euxinic basin & 0.46 & 0.67 & 0.71 & 0.57 \\
& Coast & 6.32 & 0.13 & 0.55 & 0.50 \\
& Open shelf & 2.85 & 0.30 & 0.52 & 0.54 \\
& Shelf edge & 1.86 & 0.65 & 0.54 & 0.40 \\
& Euxinic basin & 0.76 & 0.78 & 0.69 & 0.63 \\
\hline
\end{tabular}

The second two indicators are associated with the degree to which Fe is authigenically enriched, are the ratio of $\mathrm{Fe} / \mathrm{Al}$ and $\mathrm{FeHR} / \mathrm{Fe}_{\text {tot }}$. Both ratios have been used previously to assess the sources and sinks of $\mathrm{Fe}$ in sediments of the Black Sea and other basins and are thought to carry the same information although exact definitions of FeHR vary (Wijsman et al., 2001a; Anderson and Raiswell, 2004; Lyons and Severmann, 2006). Trends in both ratios generally are similar along our water depth transect (Figure 5.9C and D). However, there is a striking contrast between the $\mathrm{Fe} / \mathrm{Al}$ and FeHR/Fetot ratios in the upper $2 \mathrm{~cm}$ of the sediment and deeper sediment layers. The high ratios in the $0-2 \mathrm{~cm}$ layer on the shelf edge $(>1)$ are in accordance with the abundant presence of ferrihydrite. This strong enrichment of $\mathrm{Fe}$ at the sediment-water interface at the shelf edge is likely mainly due to lateral transport of Fe from the coastal zone and open shelf. Upward diffusing $\mathrm{Fe}^{2+}$ could also contribute to the surface enrichment of total Fe at the shelf edge. However, given the low upward diffusive $\mathrm{Fe}^{2+}$ flux at stations 14 and 6, its contribution is expected to be small (Table S.5.3). Additionally, transport of Fe from the chemocline to the shelf edge might contribute to the surface enrichment at station 6 (Figures 5.3A and S.5.10). Physical transport of the ferrihydrite likely acts 
as a key source of Fe for the deep basin in the absence of benthic Fe release at the shelf edge. The classical signature of relatively low $\mathrm{Fe} / \mathrm{Al}$ (and $\mathrm{FeHR} / \mathrm{Fe}_{\mathrm{tot}}$ ) ratios on the oxic shelf $(<0.6)$ relative to the deep basin (>0.6) (Lyons and Severmann, 2006) is visible only in the deeper sediment layers (2-15 cm depth; Table 5.6). Our results emphasize that the ultimate fate of most of the ferrihydrite in the surface sediment on the shelf is burial in the deep basin.

From our findings, a picture emerges in which diagenetic recycling of $\mathrm{Fe}$ in organic-rich, bioturbated and bioirrigated sediments in the coastal zone drives the shuttling of ferrihydrite over the continental shelf (Figure 5.10). Input of reactive Fe from the Danube river likely contributes to the high availability of $\mathrm{Fe}$ in the sediment at our coastal stations and the corresponding high $\mathrm{Fe} / \mathrm{S}$ and DOP values. Our results highlight that sediments receiving high inputs of organic matter and reactive $\mathrm{Fe}$ that are overlain by oxic bottom waters can act as a major source of Fe to the water column. This contrasts with conclusions drawn from a diagenetic modeling study for the Black Sea shelf where high rates of organic matter degradation and sulfate reduction were suggested to prevent the release of Fe to pore waters and the overlying water (Wijsman et al., 2001b). However, this is in agreement with the sensitivity analyses presented in Dale et al. (2015) where Fe release could strongly be enhanced at high rates of input of Fe. The lateral transport of Fe in the water column of the open shelf and shelf edge areas is largely controlled by physical transport of particles. At the time of sampling in our study, the waters on the shelf were strongly stratified and the reactive $\mathrm{Fe}$ oxides remained in the lower part of the water column. The small enrichment in particulate Fe in the surface water is likely due to atmospheric input of Fe via dust. Winter mixing of the water column might lead to upward transport of particulate Fe to surface waters, as observed in other areas (Vink, 2001; Pollard et al., 2009; Klunder et al., 2011). Our results highlight, however, that oxic shuttling of Fe dominates shelf transport of particulate Fe in the northwestern Black Sea.

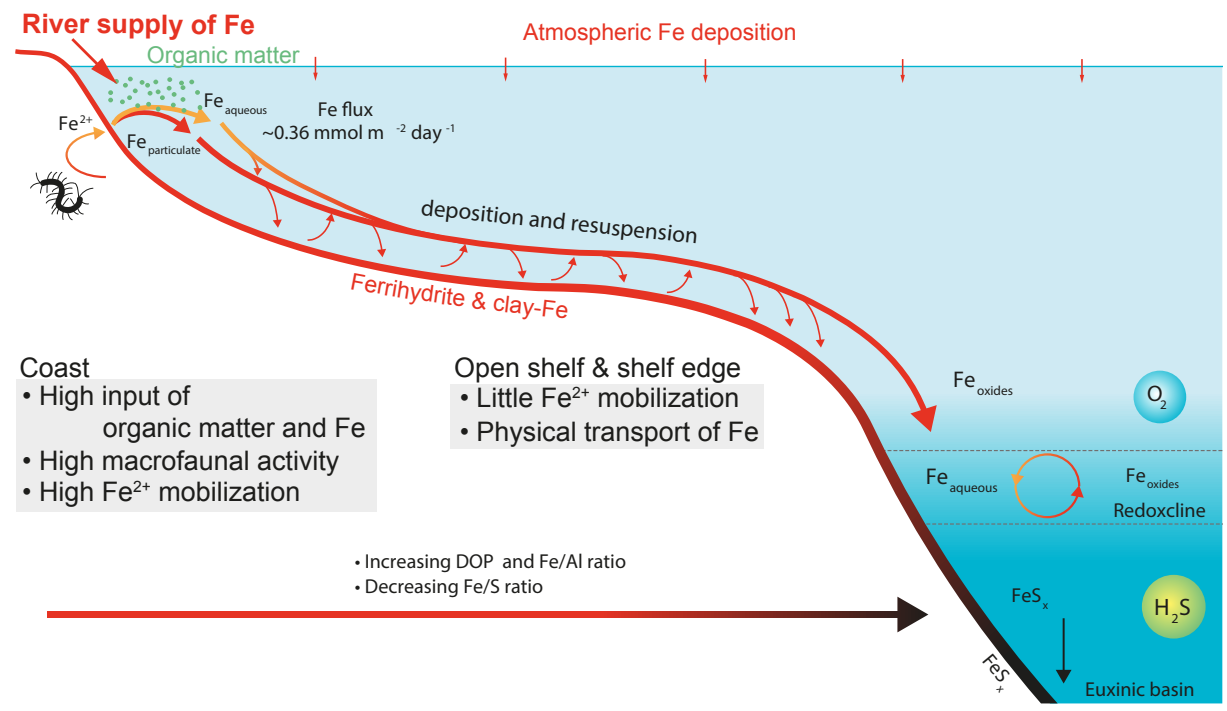

Figure 5.10 | Schematic overview of Fe-shuttling on the northwestern Black Sea shelf. Red lines and arrows indicate colloidal and particulate $\mathrm{Fe}(>0.2 \mu \mathrm{m})$, orange arrows indicate dissolved $\mathrm{Fe}(<0.2 \mu \mathrm{m})$. 


\subsubsection{Implications}

The coastal zone of the Black Sea is sensitive to human-induced eutrophication and bottom water hypoxia (Bodeanu et al., 1998; Capet et al., 2013). Because biological activity drives the release of Fe from coastal sediments, the immediate effect of a decrease in bioturbation and bioirrigation linked to an expansion of coastal hypoxia (Diaz and Rosenberg, 1995; Levin et al., 2009) could be a lower flux of Fe from the sediment to the overlying water. However, given that the oxidative removal of $\mathrm{Fe}^{2+}$ in the surface sediment would also decrease, the net effect would likely be an enhanced efflux of $\mathrm{Fe}^{2+}$ from the sediment. Whether this benthic Fe release would be maintained would depend on the balance between the availability of Fe oxides and the production of sulfide in the sediment. This latter response to hypoxia is in accordance with the concept of a redox window for Fe release upon increased hypoxia (Scholz et al., 2014a; Lenz et al., 2015).

Bottom water redox conditions on the open shelf and shelf edge are very sensitive to changes in the position of the Black Sea chemocline. Fluctuations in its position can occur on time scales from seasons to millennia (e.g. Murray et al., 1989; Sinninghe Damsté et al., 1993; Capet et al., 2016) and have been invoked to explain long-term variations in Fe burial in the deep basin (Eckert et al., 2013). During our sampling campaigns in 2013 and 2015, the depth of the chemocline was located at 130 and 150m depth respectively, which is typical for this region (Arthur and Dean, 1998; Coolen et al., 2009). While the sediments in the redoxcline are depleted in Fe oxides (Stations 6B; Figure 5.9C and D), sediments above this water depth zone are highly enriched in Fe oxides (e.g. station 14 and 6; Figure 5.6). Changes in the position of the redoxcline could thus lead to mobilization of $\mathrm{Fe}$, if sufficient organic matter is available. Evidence for release of $\mathrm{Fe}$ is provided by the low $\mathrm{Fe} / \mathrm{Al}$ and especially the low $\mathrm{FeHR} / \mathrm{Fe}_{\text {tot }}$ ratios in the redoxcline (Figure 5.9C and D; Table 5.6). Given the limited input of organic matter in this area and low rates of sulfate reduction (Weber et al., 2001), the release of Fe upon a change in the position of the redoxcline is not necessarily immediate.

Our data suggest that variations in Fe input to the coastal zone could also act as a key control on Fe shuttling on continental shelves. In our study, the sediments with the highest benthic release of Fe are very enriched in Fe relative to S (Figure 5.9A and B). While this may be partly explained by efficient reoxidation of sulfide from sulfate reduction linked to bioturbation and bioirrigation (e.g. Jørgensen, 1977), the riverine input of Fe oxides likely also plays a role. A similar explanation was invoked to explain high benthic Fe fluxes in the Eel river area on the California margin (Severmann et al., 2010). These findings suggest that changes in river fluxes of Fe could modulate the strength of the oxic Fe shuttle on continental shelves, by altering the extent of Fe mobilization in the coastal zone. Current functions to predict benthic Fe fluxes based on organic matter inputs and/or bottom water $\mathrm{O}_{2}$ concentrations alone (Elrod et al., 2004; Dale et al., 2015) thus need to be expanded to include Fe input (as also recognized by Dale et al., 2015) and to include bioirrigation when describing benthic Fe fluxes from bioirrigated continental shelf sediments in river-dominated areas. Further insight in the release and lateral transport of Fe from such systems is needed for a truly quantitative understanding of Fe transport from continental shelves to the ocean. 


\subsection{Conclusions}

Our study reveals large benthic fluxes of $\mathrm{Fe}\left(\sim 0.36 \mathrm{mmol} \mathrm{m}^{-2} \mathrm{~d}^{-1}\right)$ from organic-rich, coastal sediments overlain by oxic bottom waters on the northwestern Black Sea. We suggest that high rates of bioirrigation drive this benthic release of Fe to the water column. Despite the abundant presence of Fe oxides in surface sediments on the open shelf and at the shelf edge, reductive dissolution of Fe oxides and benthic Fe release is low in these areas because of a limited input of organic matter. This lack of benthic release of $\mathrm{Fe}$ is also observed at shelf edge sites where bottom waters are hypoxic. The benthic Fe release in the coastal zone is suggested to act as the key source of the particulate Fe observed in the lower part of the water column over the shelf. We show that this particulate Fe consists of a mixture of both easily reducible Fe oxides (ferrihydrite) and iron associated with clay. The similarity in the composition of the suspended matter and the surface sediment suggests that transport of $\mathrm{Fe}$ towards the shelf edge mainly takes place through deposition and resuspension of particles. We find no evidence for repeated oxidation and reduction of Fe during this lateral transport, emphasizing the role of physical transport processes for Fe shuttling. Coastal sediments are characterized by relatively low $\mathrm{Fe} / \mathrm{Al}$ ratios compared to those for the open shelf and shelf edge supporting the role of the coastal zone as a source of Fe. Besides variations in coastal hypoxia and the position of the chemocline on the shelf and slope, changes in the availability of organic matter and reactive $\mathrm{Fe}$ linked to river input at coastal sites likely contribute to temporal variations in $\mathrm{Fe}$ shuttling on the Black Sea shelf.

\section{Acknowledgments}

We thank the captain, crew and technicians and Amy Kuzminov aboard R/V Pelagia in September 2015 for their assistance and D. van de Meent, T. Claessen, T. Zalm, A. van Dijk and R.K. Groeneveld for their analytical assistance in Utrecht. This research was funded by NWO-Vici grant 865.13.005 (to CPS). PK acknowledges support from NWO-Veni grant 863.14.014. We further thank the staff of the DUBBLE beamline (BM 26) at the European Synchrotron Radiation Facility (ESRF) and of beamline ID21 and local contacts D. Banerjee, W. de Nolf and A.E. Pradas del Real. Funding at the DUBBLE beamline was granted by the Netherlands Organisation for Scientific Research (NWO experiment 26-01-1094) and by the ESRF (ES 591 (ID-21)). 


\section{S.5. Supplementary Information}

\section{S.5.1. Biorrigation Model}

Pore water bromide is modeled using a 1-D, nonlocal exchange function (Emerson et al., 1984; Boudreau, 1984). Here, dissolved bromide is described as (Eq. (S.5.1)):

$\frac{\delta(\phi \cdot c)}{\delta t}=\frac{\delta}{\delta z}\left(\varphi \cdot D_{s} \cdot \frac{\delta c}{\delta z}\right)-\varphi \cdot \alpha\left(c-c_{0}\right)$

where $\varphi$ is the depth dependent sediment porosity (Figure S.5.12), $z$ is depth in the sediment $(\mathrm{cm})$ and $D_{s}$ is the sediment diffusion coefficient for bromide. The molecular diffusion coefficients Ds at stations 9 and 13 were corrected for tortuosity in the porous medium (Boudreau, 1996) and for the ambient salinity $S$, temperature $T$ (Table 5.3) and P, 2.73 and 3.94 bar respectively, using the R package CRAN: marelac (Soetaert et al., 2010), which implements the constitutive relations listed in (Boudreau, 1997). $\alpha$ is the nonlocal bioirrigation function for bromide, which is assumed to be time-invariant. $\mathrm{c}$ is the concentration of bromide in the pore water and $c_{0}$ is the bromide concentration of the overlying water.

In the model, porosity is interpolated linearly for every depth layer in the model (1 layer every $\mathrm{mm}$ ) between measured points. The bioirrigation function $(\alpha)$ was determined by fitting pore water bromide depth profiles after incubation to Eq. (S.5.1).

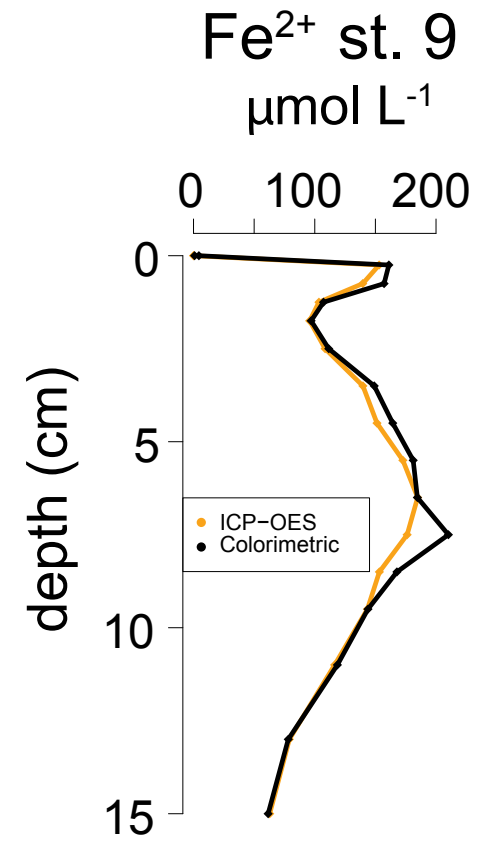

Figure S.5.1 | Pore water depth profiles of $\mathrm{Fe}^{2+}$ filtered through $0.45 \mu \mathrm{m}$ at station 9, determined by ICP-OES and colorimetrically. 

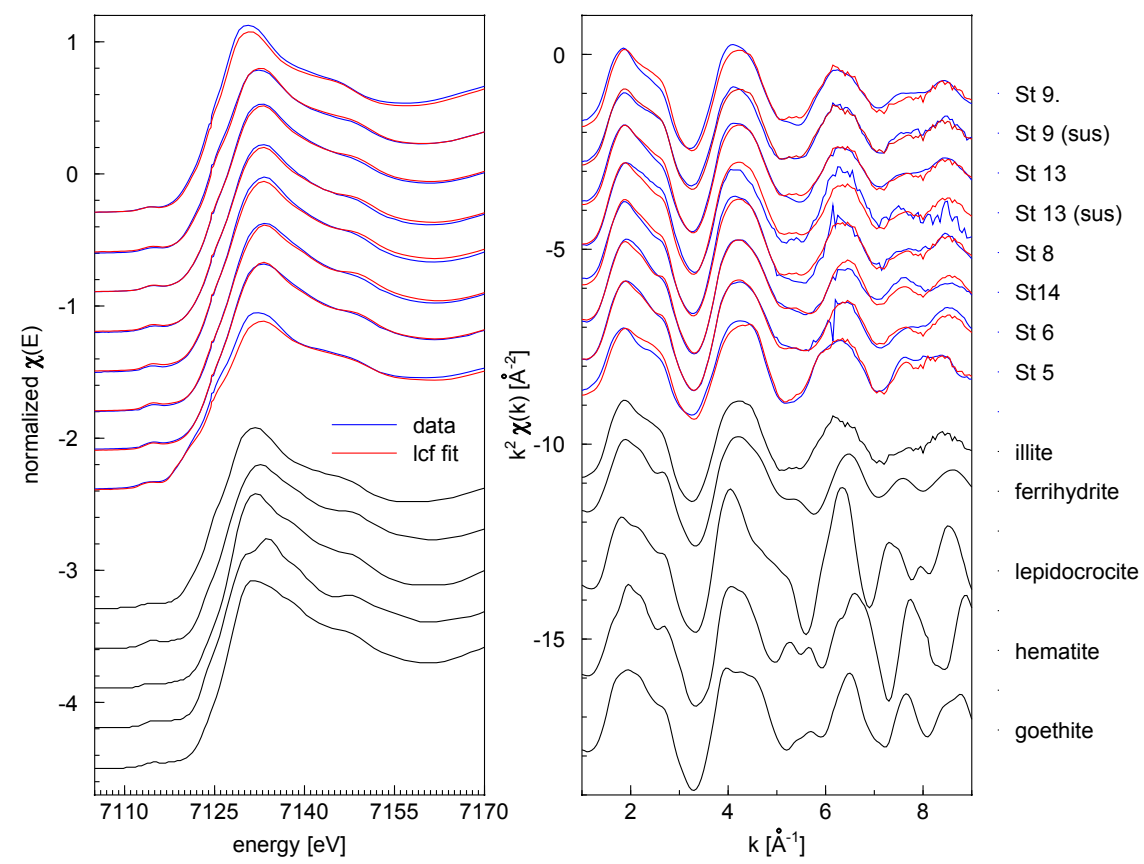

Figure S.5.2 | Fe-XANES and EXAFS spectra of powdered surface sediment samples and suspended matter samples from a range of stations compared to the reference materials illite, ferrihydrite, lepidocrocite, hematite and geothite. 

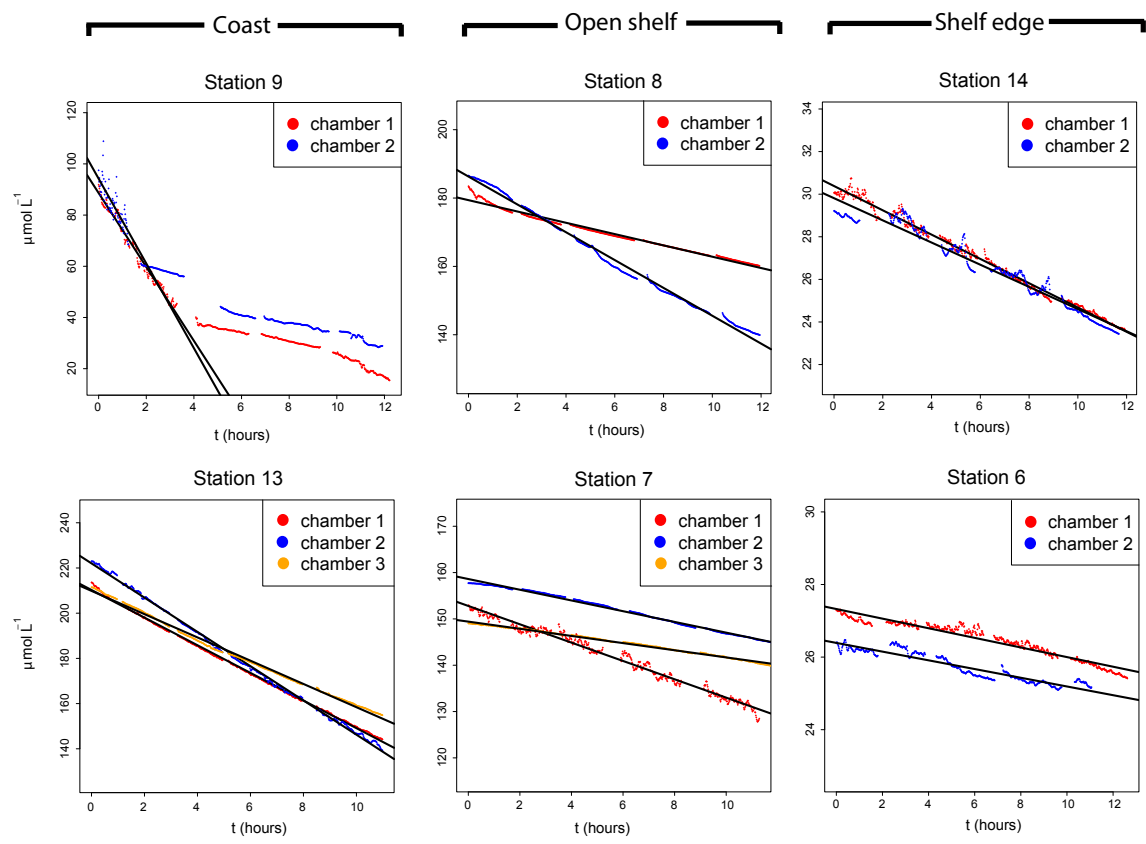

Figure S.5.3 | Oxygen concentrations in chambers of the benthic lander as determined at six stations. Periods without measurements represent time intervals where optode $\mathrm{O}_{2}$ measurements were influenced by sample collection and were therefore discarded. Black lines indicate regression lines used to calculate $\mathrm{O}_{2}$ consumption. 

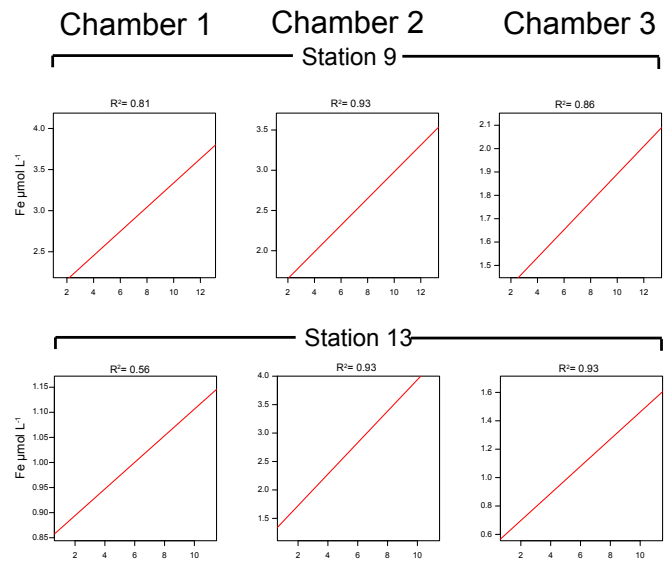

Station 13
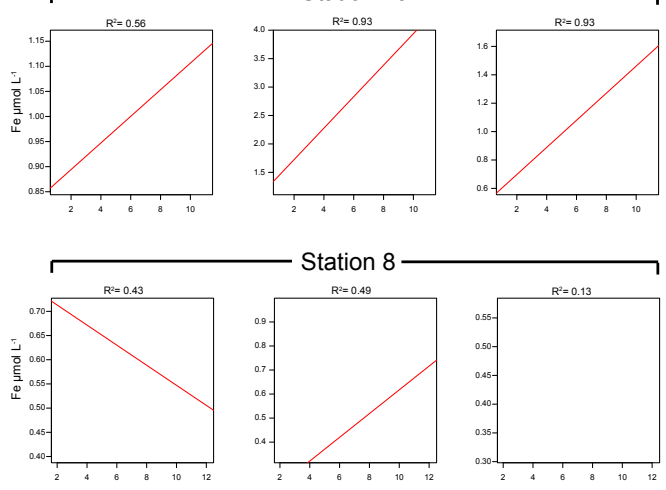

Station 8
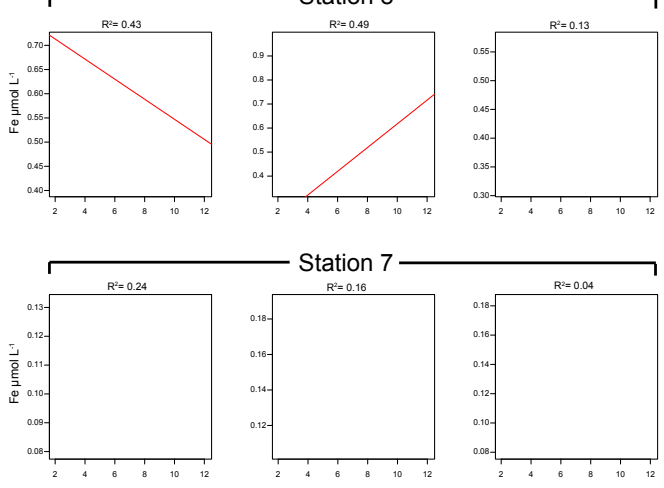

Station 7
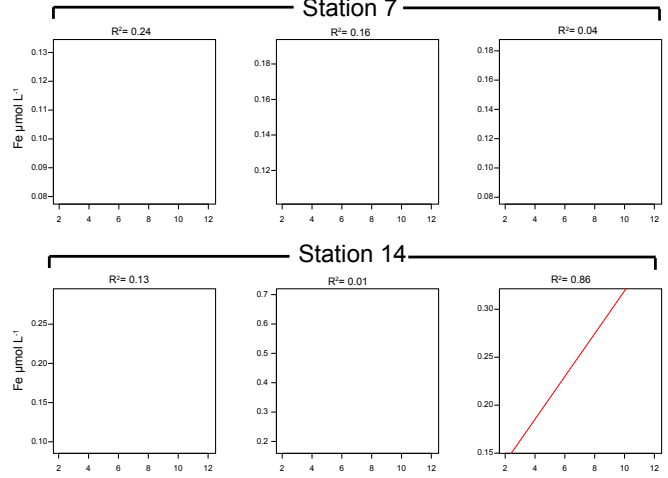

Station 14
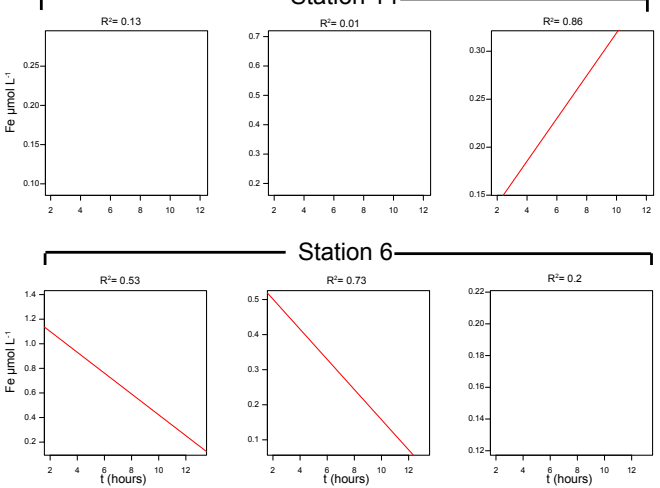

\section{Station 6}
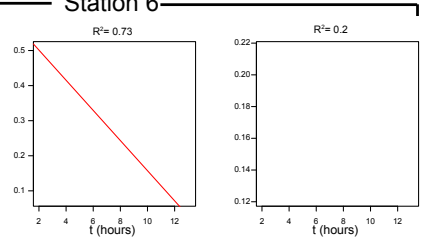

Figure S.5.4 | Total Fe concentration in benthic lander chambers versus time. Fluxes were calculated using linear regression (red line). Only regressions with $\mathrm{R}^{2}>0.3$ were considered following Friedrich et al. (2002). 


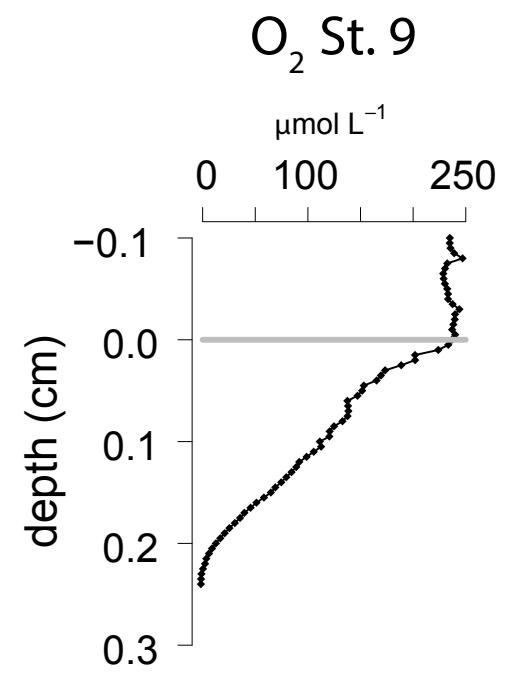

$\mathrm{O}_{2}$ St. 13

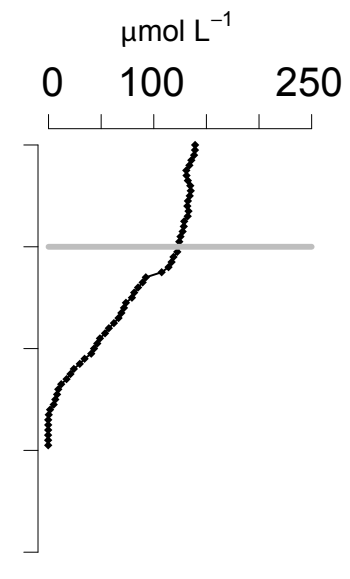

Figure S.5.5 | Pore water depth profiles of $\mathrm{O}_{2}$ at stations 9 and 13 determined using micro-electrodes. Gray line indicates the sediment-water interface. 

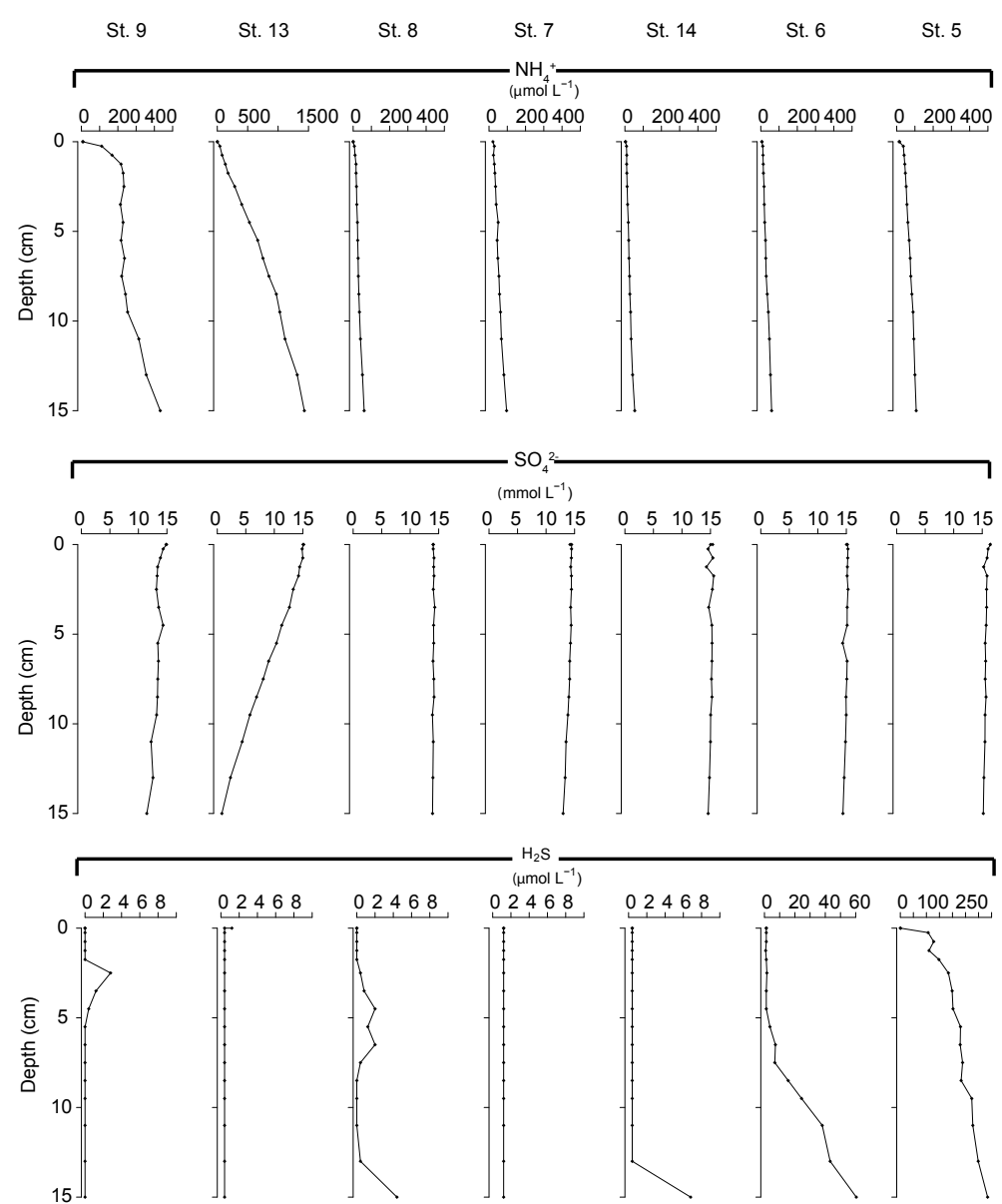

Figure S.5.6 | Pore water depth profiles of $\mathrm{NH}_{4}{ }^{+}, \mathrm{SO}_{4}{ }^{2-}$ and $\mathrm{H}_{2} \mathrm{~S}$ at stations 9, 13, 8, 7, 14, 6 and 5 . 
Station 9

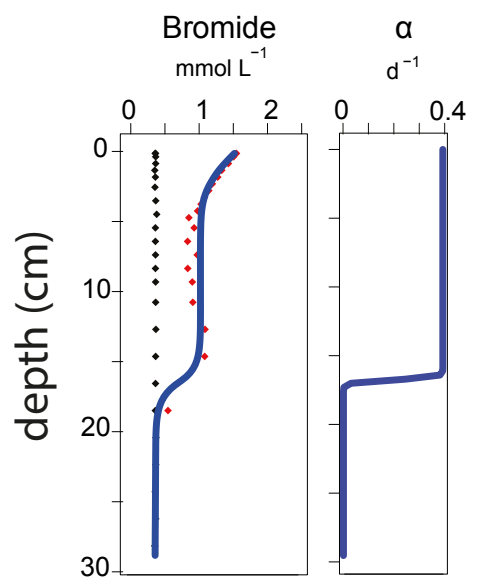

Station 13

Bromide

$\mathrm{mmol} \mathrm{L}^{-1}$

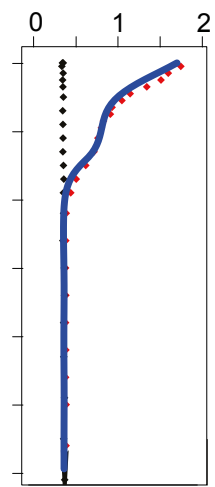

$\alpha$

$d^{-1}$

Figure S.5.7 | Results of bromide tracer incubations at coastal stations 9 and 13. Black diamonds indicate pore water bromide concentrations prior to incubation $(\mathrm{t}=0)$, red diamonds indicate pore water bromide concentrations after incubation. Blue lines indicate modeled pore water bromide concentrations, with bioirrigation. 

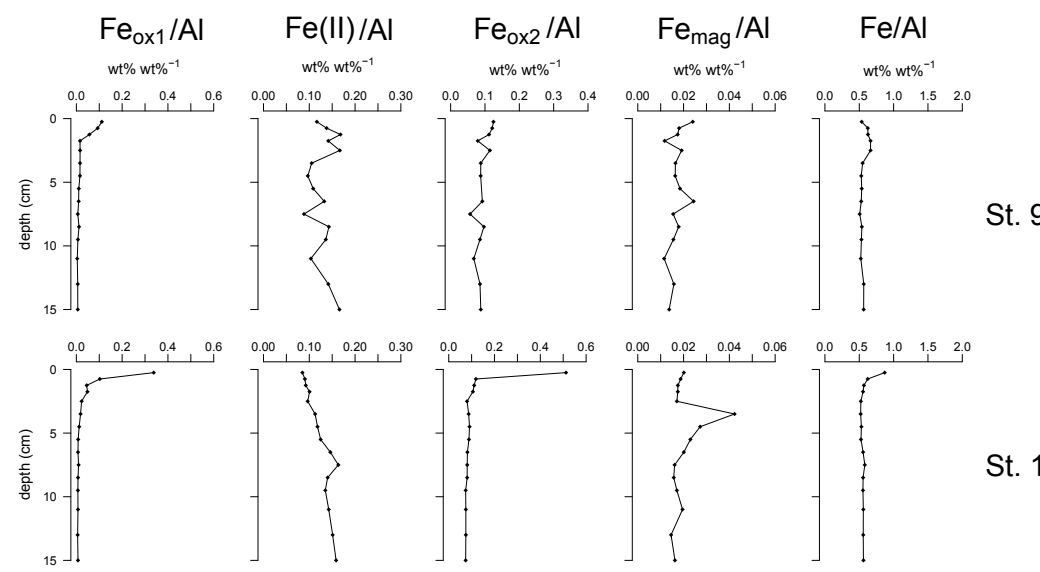

St. 13
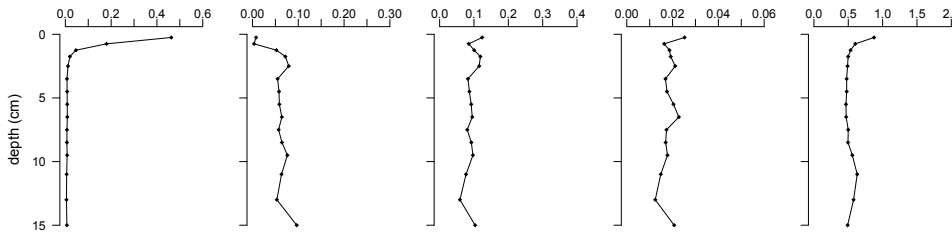

St. 8
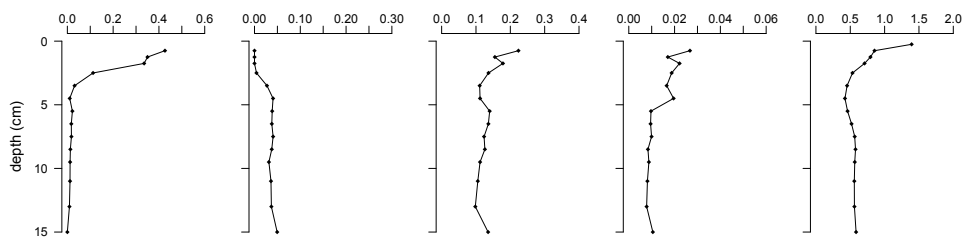

St. 7
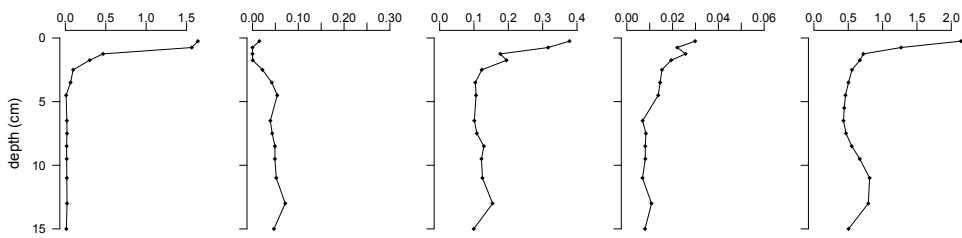

St. 14
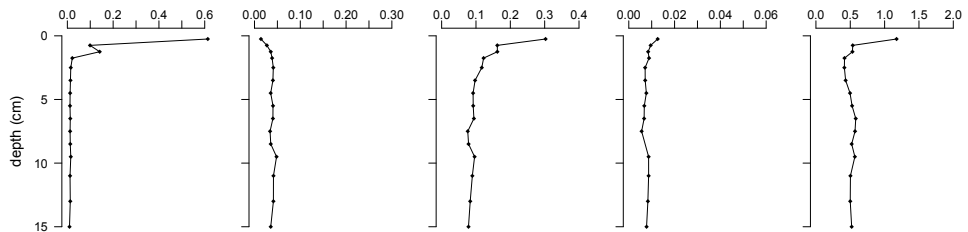

St. 6

Figure S.5.8 | Solid-phase depth profiles of easily reducible $\mathrm{Fe}$ oxides $\left(\mathrm{Fe}_{\text {oxi }}\right)$, $\mathrm{Fe}$ carbonates and $\mathrm{FeS}(\mathrm{Fe}(\mathrm{II}))$, reducible (crystalline) $\mathrm{Fe}$ oxides $\left(\mathrm{Fe}_{\mathrm{ox} 2}\right)$, magnetite $\left(\mathrm{Fe}_{\mathrm{mag}}\right)$, total $\mathrm{Fe}\left(\mathrm{Fe}_{\mathrm{tot}}\right)$ normalized against $\mathrm{Al}$ at six stations on the northwestern Black Sea shelf. 


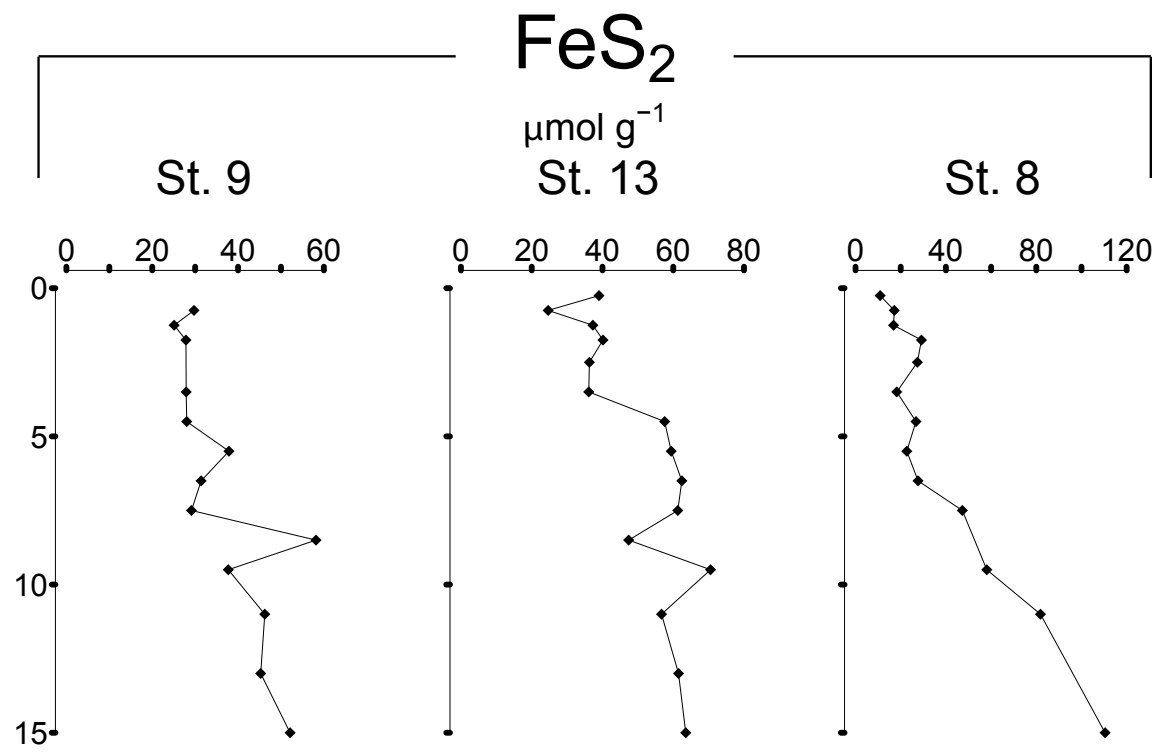

Figure S.5.9 | Solid-phase depth profiles of $\mathrm{FeS}_{2}$ at stations 9, 13 and 8. 

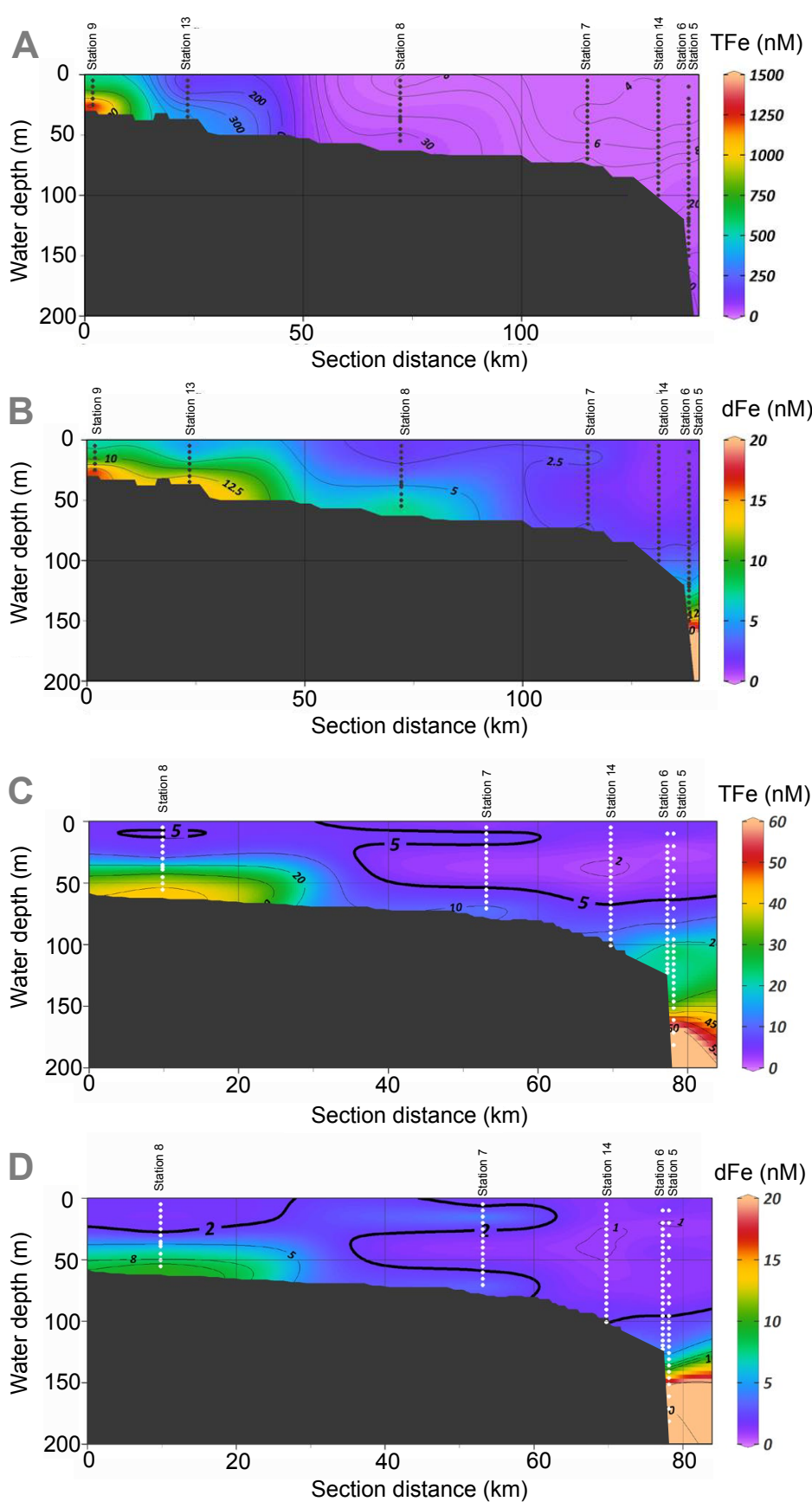

Figure S.5.10 | Interpolated concentrations of total and dissolved $\mathrm{Fe}$ in the water column. A: total Fe for stations 9, 13, 8, 7, 14, 6 and 5; B: dissolved Fe for stations 9, 13, 8, 7, 14, 6 and 5; C: total Fe for stations 8, 7, 14, 6 and 5; D: dissolved Fe for stations 8, 7, 14, 6 and 5. Figure drawn using Ocean Data View (Schlitzer, 2015). 


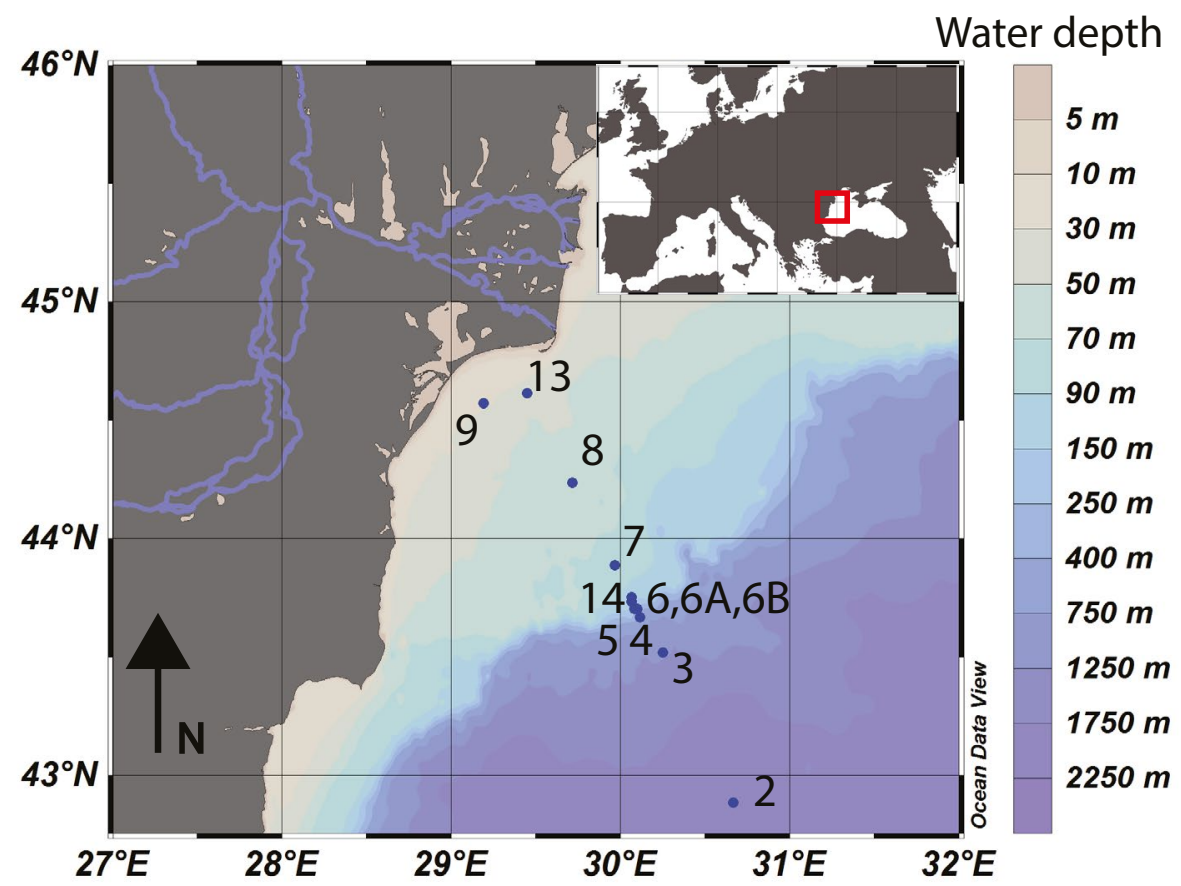

Figure S.5.11 | Locations of the eleven stations sampled on the northwestern Black Sea shelf and deep basin during two fieldwork campaigns, June 2013 and September 2015 (Table S.5.2). Figure drawn using Ocean Data View (Schlitzer, 2015).

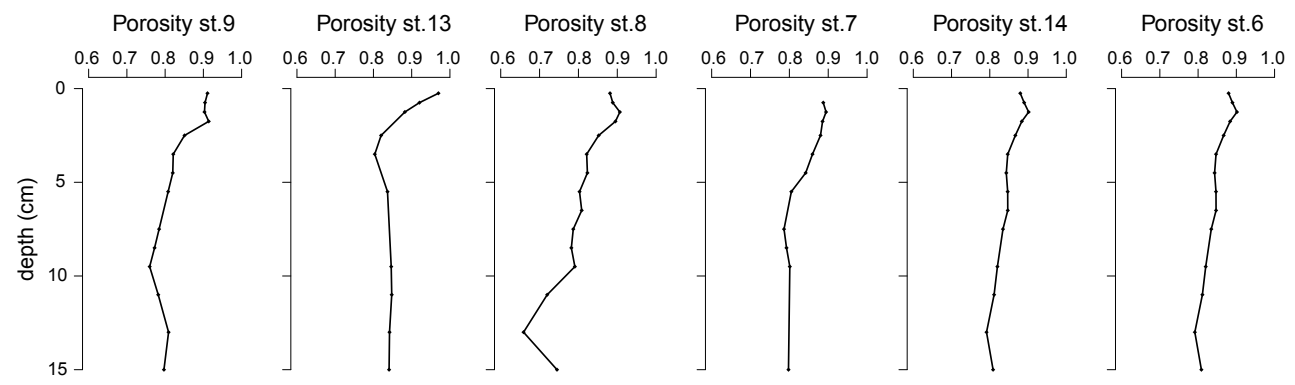

Figure S.5.12 | Depth profiles of porosity at stations 9, 13, 8, 7, 14 and 6. 
Table S.5.1 | Speciation of Fe for suspended matter collected through in-situ filtration at stations 9, 13, 8, 7, 14 and 6. Asc. Fe is ascorbate acid extractable $\mathrm{Fe}, \mathrm{Fe}(\mathrm{II})$ (Fe carbonate and $\mathrm{FeS}$ ), $\mathrm{Fe}_{\mathrm{ox} 1}$ easily reducible $\mathrm{Fe}$ oxides, $\mathrm{Fe}_{\mathrm{ox} 2}$ reducible (crystalline) Fe oxides and Femag magnetite (Table 5.2).

\begin{tabular}{|c|c|c|c|c|c|c|c|}
\hline Station & Depth $\mathrm{m}$ & Volume filtered L & Asc. Fe nmol L-1 & $\mathrm{Fe}(\mathrm{II}) \mathrm{nmol} \mathrm{L}^{-1}$ & $\mathrm{Fe}_{\mathrm{ox1}} \mathrm{nmol} \mathrm{L}^{-1}$ & $\mathrm{Fe}_{\mathrm{ox2}} \mathrm{nmol} \mathrm{L}^{-1}$ & Magnetite $\mathrm{nmol}^{\mathrm{L}^{-1}}$ \\
\hline \multirow[t]{2}{*}{9} & 10 & 36 & 5.9 & 3.7 & 1.3 & 52 & 5.5 \\
\hline & 25 & 25 & 1052.1 & 714.9 & 264.6 & 994.5 & 191.3 \\
\hline \multirow[t]{2}{*}{13} & 10 & 78 & 3.3 & 1.1 & 0.1 & 20.4 & 0.5 \\
\hline & 39 & 91 & 76 & 20.1 & 7.3 & 4.4 & 4 \\
\hline \multirow[t]{4}{*}{8} & 10 & 126 & 1 & 0.2 & 0.1 & 1.8 & 0 \\
\hline & 25 & 42 & 0 & 0.2 & 0 & 4.1 & 0.2 \\
\hline & 35 & 8 & 10.2 & 4.6 & 0.7 & 146 & 2 \\
\hline & 55 & 183 & 26.9 & 3.9 & 1.4 & 9.1 & 1 \\
\hline \multirow[t]{4}{*}{7} & 10 & 220 & 0 & 0.1 & 0 & 4.6 & 0 \\
\hline & 25 & 579 & 0.4 & 0 & 0 & 0.9 & 0.1 \\
\hline & 35 & 328 & 9.5 & 0 & 0 & 2.4 & 0.1 \\
\hline & 70 & 243 & 4.6 & 0.7 & 0.2 & 5.3 & 0.2 \\
\hline \multirow[t]{4}{*}{14} & 20 & 300 & 0 & 0.2 & 0.1 & 5.5 & 0.1 \\
\hline & 40 & 579 & 0.1 & 0.1 & 0 & 0 & 0 \\
\hline & 70 & 328 & 4.1 & 0.5 & 0.3 & 6.5 & 0.1 \\
\hline & 90 & 243 & 4 & 0.7 & 0.2 & 5.3 & 0.2 \\
\hline \multirow[t]{4}{*}{6} & 20 & 120 & 8.6 & 0.1 & 0.2 & 14.5 & 0.1 \\
\hline & 40 & 273 & 0.8 & 0.2 & 0 & 5.4 & 0 \\
\hline & 80 & 379 & 1.4 & 0.4 & 0.1 & 0 & 0.1 \\
\hline & 120 & 216 & 10.1 & 0.9 & 0.3 & 11.5 & 0.1 \\
\hline
\end{tabular}

Table S.5.2 | Coordinates, water depth, bottom water temperature and salinity at the 12 stations sampled on the northwestern Black Sea shelf. Unit mbss is meters below sea surface. N/A: not available.

\begin{tabular}{|c|c|c|c|c|c|c|c|}
\hline Station & Latitude N & Longitude E & Depth mbss & Temperature ${ }^{\circ} \mathrm{C}$ & BW $\mathrm{H}_{2} \mathrm{~S} \mu \mathrm{mol} \mathrm{L}^{-1}$ & Year & $\mathrm{FeS}_{2}$ extraction \\
\hline 9 & $44^{\circ} 34.9^{\prime}$ & $29^{\circ} 11.4^{\prime}$ & 27 & 13.3 & 0 & 2015 & CRS \\
\hline 13 & $44^{\circ} 36.5^{\prime}$ & $29^{\circ} 27.4^{\prime}$ & 44 & 9.2 & 0 & 2015 & CRS \\
\hline 8 & $44^{\circ} 14.7^{\prime}$ & $29^{\circ} 43.4^{\prime}$ & 65 & 8.2 & 0 & 2015 & CRS \\
\hline 7 & $43^{\circ} 53.8^{\prime}$ & $29^{\circ} 58.6^{\prime}$ & 78 & 8.5 & 0 & $2013 / 2015$ & $\mathrm{HNO}_{3}$ \\
\hline 14 & $43^{\circ} 45.9^{\prime}$ & $29^{\circ} 11.3^{\prime}$ & 114 & 8.4 & 0 & 2015 & $\mathrm{~N} / \mathrm{A}$ \\
\hline $6 \mathrm{~A}$ & $43^{\circ} 44.1^{\prime}$ & $30^{\circ} 04.4^{\prime}$ & 120 & 8.5 & 0 & 2013 & $\mathrm{HNO}_{3}$ \\
\hline 6 & $43^{\circ} 42.8^{\prime}$ & $30^{\circ} 05.1^{\prime}$ & 130 & 8.5 & 0 & 2015 & $\mathrm{~N} / \mathrm{A}$ \\
\hline $6 \mathrm{~B}$ & $43^{\circ} 42.8^{\prime}$ & $30^{\circ} 05.1^{\prime}$ & 130 & 8.5 & 0 & 2013 & $\mathrm{HNO}_{3}$ \\
\hline 5 & $43^{\circ} 42.6^{\prime}$ & $30^{\circ} 06.1^{\prime}$ & 180 & 8.6 & 0 & 2015 & $\mathrm{HNO}_{3}$ \\
\hline 4 & $43^{\circ} 40.6^{\prime}$ & $30^{\circ} 07.5^{\prime}$ & 377 & 8.8 & 8.1 & 2013 & $\mathrm{HNO}_{3}$ \\
\hline 3 & $43^{\circ} 31.8^{\prime}$ & $30^{\circ} 15.5^{\prime}$ & 1100 & 9 & 381 & 2013 & $\mathrm{HNO}_{3}$ \\
\hline 2 & $42^{\circ} 4.8^{\prime}$ & $29^{\circ} 40.7^{\prime}$ & 2107 & 9.1 & 418 & 2013 & $\mathrm{HNO}_{3}$ \\
\hline
\end{tabular}

${ }^{1}$ Method used to extract $\mathrm{FeS}_{2}$ from sediment samples as described in Table 5.2. For station 7, the $\mathrm{FeS}_{2}$ extraction was performed on sediment samples collected in 2013. 
Table S.5.3 | Calculated contribution of upward diffusing $\mathrm{Fe}^{2+}$ to the observed enrichment of total Fe at the sedimentwater interface $(0-0.5 \mathrm{~cm})$.

\begin{tabular}{llll}
\hline Station & $\begin{array}{l}\text { Upward diffusing pore water } \\
\text { flux mmol m } \mathbf{~}^{-2} \mathbf{~ r ~}^{-1}\end{array}$ & $\begin{array}{l}\text { Calculated surface enrichment } \\
\mu \mathrm{mol} \mathrm{g}^{-1}\end{array}$ & $\begin{array}{l}\text { Contribution of pore water } \\
\text { Fe \% }\end{array}$ \\
\hline 14 & 5.5 & 20.8 & 383.3 \\
6 & 1.53 & 5.8 & 365 \\
\hline
\end{tabular}

Upward diffusing pore water flux $\left(\mathrm{mmol} \mathrm{m}^{-2} \mathrm{yr}^{-1}\right)$ was calculated using Eq. (5.1). The pore water gradient between $1.75-4.5 \mathrm{~cm}$ and $0.75-2.5 \mathrm{~cm}$ was taken at stations 14 and 6 , respectively. The average porosity over these depth intervals was applied (i.e. 0.87 for both stations; Figure S.5.12). The calculated enrichment is based on the upward diffusing flux and the sedimentation rate at the sediment-water interface. At decreasing sedimentation rates, the role of upward diffusion of $\mathrm{Fe}^{2+}$ increases. Rates of sediment deposition at the shelf edge stations are low (Friedrich et al., 2002). The sedimentation rate at the open shelf is assumed to be $0.1 \mathrm{~cm} \mathrm{yr}^{-1}$ (Wijsman et al., 2002). For this calculation we assumed an even lower rate of sedimentation of $0.01 \mathrm{~cm} \mathrm{yr}^{-1}$. The sediment enrichment $\left(\mu \mathrm{mol} \mathrm{g}{ }^{-1}\right)$ was calculated as follows,

Sed.enrichment $=\frac{\text { upward diffusing flux }}{\left(\text { sedimentation rate } \cdot \text { sediment density } \cdot 10^{4}\right)}$

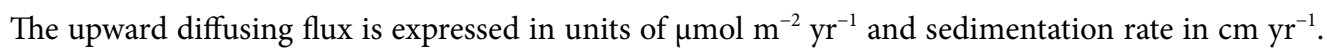
Sediment density was assumed to be $2.65 \mathrm{~g} \mathrm{~cm}^{-3}$ (Burdige, 2006). The contribution of the pore water flux is the percentage of the calculated surface enrichment based on upward diffusing $\mathrm{Fe}^{2+}$ divided by the surface concentration of total $\mathrm{Fe}$ at $0-0.5 \mathrm{~cm}$ depth. 


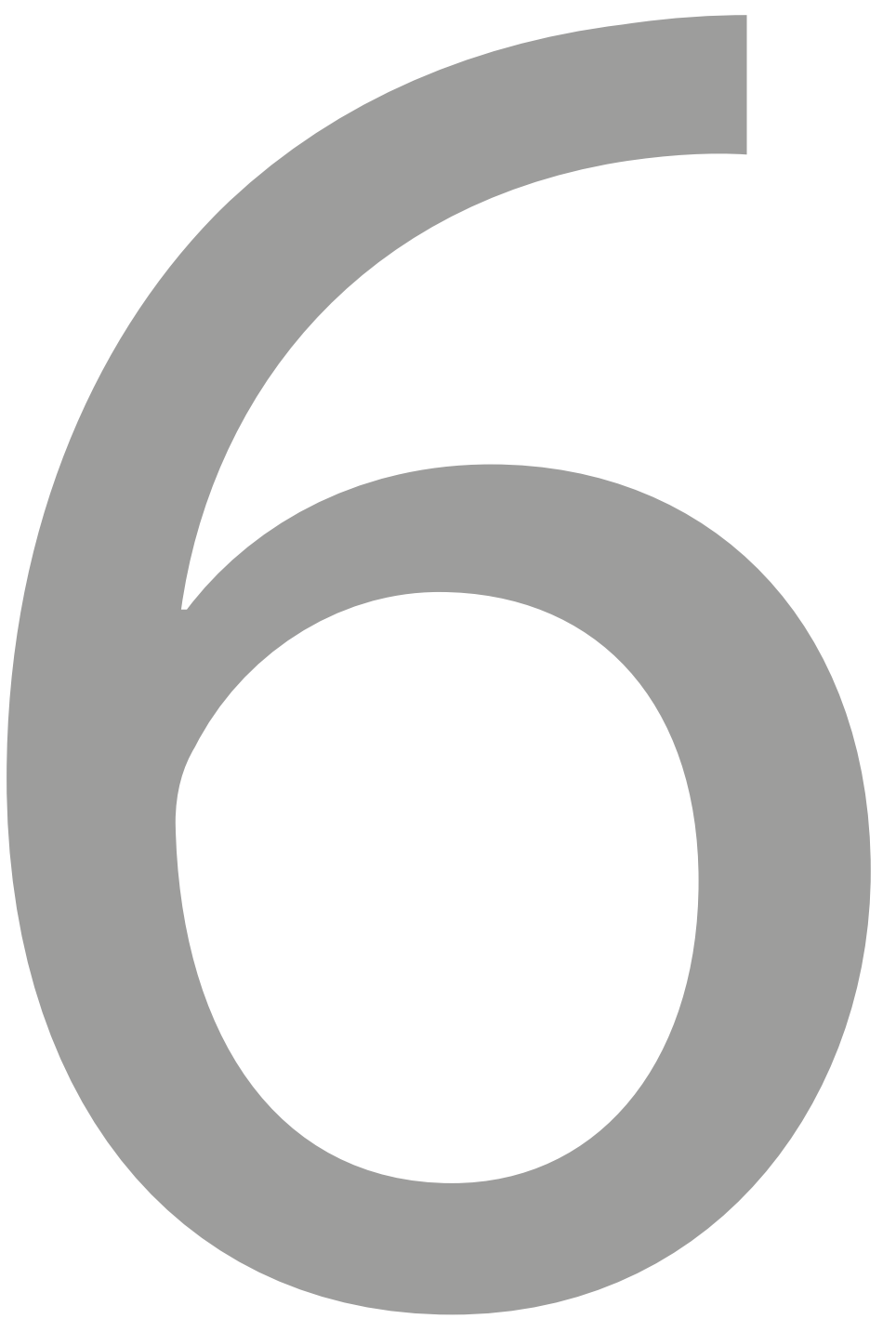




\title{
Chapter 6:
}

\section{Biogeochemical Impact of Cable Bacteria in Coastal Black Sea Sediment}

\author{
Martijn Hermans, Nils Risgaard-Petersen, Filip J.R. Meysman and Caroline P. Slomp
}

\begin{abstract}
Cable bacteria can strongly alter sediment biogeochemistry. Here, we used laboratory incubations to assess whether cable bacteria can establish in iron $(\mathrm{Fe})$ monosulphide-poor coastal Black Sea sediment and the impact of their activity on the cycling of $\mathrm{Fe}$, phosphorus (P) and sulphur (S). Microsensor depth profiles of oxygen, sulphide, $\mathrm{pH}$ and electric potential combined with FISH analyses showed a rapid development ( $<5$ days) of cable bacteria, followed by a long period of activity (at least 200 days). Pore water sulphide was low $(<5 \mu \mathrm{M})$ throughout the experiment. Both $\mathrm{FeS}$ and sulphate reduction acted as sources of sulphide for cable bacteria. Pore water $\mathrm{Fe}^{2+}$ reached levels of up to $1.7 \mathrm{mM}$ during the incubations, due to the dissolution of $\mathrm{FeS}(30 \%)$ and siderite, an $\mathrm{Fe}$ carbonate mineral (70\%). Following upward diffusion of $\mathrm{Fe}^{2+}$, a surface enrichment of $\mathrm{Fe}$ oxides formed. Hence, besides FeS, siderite may act as a major source of Fe for Fe oxides in coastal surface sediments where cable bacteria are active. Using $\mu \mathrm{XRF}$, we show that the enrichments in Fe oxides induced by cable bacteria are located in a thin subsurface layer of $0.3 \mathrm{~mm}$. We show that similar subsurface layers enriched in $\mathrm{Fe}$ and $\mathrm{P}$ are also observed at field sites where cable bacteria were recently active and little bioturbation occurs. This suggests that such subsurface Fe oxide layers, which are not always visible to the eye, could potentially be a marker for recent activity of cable bacteria.
\end{abstract}




\subsection{Introduction}

Depletion of oxygen $\left(\mathrm{O}_{2}\right)$ in bottom waters of coastal areas is increasing worldwide, as a consequence of eutrophication and climate change (Diaz and Rosenberg 2008; Schmidtko et al. 2017; Breitburg et al. 2018). Low $\mathrm{O}_{2}$ can lead to the development of coastal 'dead zones' characterised by mass mortality of marine life (Rabalais et al. 2002; Diaz and Rosenberg 2008). Progressive eutrophication induces a characteristic response of coastal systems with transient and seasonal hypoxia $\left(\mathrm{O}_{2}<63 \mu \mathrm{M}\right)$ transitioning into permanent anoxia $\left(\mathrm{O}_{2}=0 \mu \mathrm{M}\right)$. In this later stage, free sulphide $\left(\mathrm{H}_{2} \mathrm{~S}\right)$ may escape from the sediment and accumulate in the bottom water, a condition referred to as euxinia (Diaz and Rosenberg 2008; Kemp et al. 2009; Rabalais et al. 2014). $\mathrm{As}_{2} \mathrm{~S}$ is highly toxic to higher fauna, the formation of euxinia may aggravate the ecological consequences. However, the presence of iron (Fe) and manganese $(\mathrm{Mn})$ oxides in surface sediments may delay this transition towards euxinia by removing $\mathrm{H}_{2} \mathrm{~S}$ and thus preventing an efflux of $\mathrm{H}_{2} \mathrm{~S}$ to the overlying water (Kristiansen et al. 2002; Kristensen et al. 2003; Diaz and Rosenberg 2008).

Recently, a novel type of filamentous multicellular sulphur (S)-oxidising bacteria was discovered (Pfeffer et al. 2012) that can strongly enhance the formation of Fe and Mn oxides and efficiently remove $\mathrm{H}_{2} \mathrm{~S}$ from surface sediments (Risgaard-Petersen et al. 2012; Seitaj et al. 2015; SuluGambari et al. 2016a). These so-called 'cable bacteria' belong to the Desulfobulbaceae family of the Deltaproteobacteria (Trojan et al. 2016; Kjeldsen et al. 2019). Cable bacteria can spatially link the oxidation of $\mathrm{H}_{2} \mathrm{~S}$ in deeper sediments to the reduction of $\mathrm{O}_{2}$ near the sediment-water interface by transporting electrons over centimetre scale distances (Pfeffer et al. 2012) through a conductive fibre network that is embedded in the cell envelope (Meysman et al. 2019). This spatial coupling provides cable bacteria a competitive advantage over other S-oxidising bacteria in aquatic environments (Meysman 2018).

The metabolic activity of cable bacteria is established as an electrical circuit in the sediment, which involves an electron current through the cable bacteria filaments (Bjerg et al. 2018), and an ionic current through the pore water in the opposite direction (Risgaard-Petersen et al. 2014). As a consequence, an electric potential (EP) is generated in the sediment, which can be used as a reliable indicator for their activity (Damgaard et al. 2014).

Cable bacteria activity additionally generates a distinct biogeochemical signature, that can be assessed by $\mathrm{pH}, \mathrm{O}_{2}$ and $\mathrm{H}_{2} \mathrm{~S}$ depth profiling (Nielsen et al. 2010). Their activity leads to the development of a suboxic zone (i.e. a zone where $\mathrm{O}_{2}$ and $\mathrm{H}_{2} \mathrm{~S}$ are both absent), and also induces a pH profile that strongly changes with depth. Cathodic $\mathrm{O}_{2}$ reduction $\left(\mathrm{O}_{2}+4 \mathrm{H}^{+}+4 \mathrm{e}^{-} \rightarrow 2 \mathrm{H}_{2} \mathrm{O}\right)$ in the oxic zone of the sediment results in a $\mathrm{pH}$ maximum ( $\sim 9)$ due to proton consumption, whereas anodic sulphide oxidation $\left(\mathrm{H}_{2} \mathrm{~S}+4 \mathrm{H}_{2} \mathrm{O} \rightarrow \mathrm{SO}_{4}{ }^{2-}+10 \mathrm{H}^{+}+8 \mathrm{e}^{-}\right)$causes a $\mathrm{pH}$ minimum $(<6.5)$ in the anoxic zone (Figure 6.1A; Nielsen et al. 2010; Meysman et al. 2015).

The presence of cable bacteria in sediments can strongly impact the elemental cycling of $\mathrm{Fe}, \mathrm{Mn}$, Ca and S (Risgaard-Petersen et al. 2012; Seitaj et al. 2015; Sulu-Gambari et al. 2016a; van de Velde et al. 2016). Pore water acidification induced by cable bacteria activity can lead to dissolution of calcium (Ca) carbonates, Fe carbonates (siderite), Mn carbonates and FeS in the zone where the $\mathrm{pH}$ is low, thus generating high concentrations of $\mathrm{Fe}^{2+}$ and $\mathrm{Mn}^{2+}$ in the pore water (Risgaard-Petersen et al. 2012; Rao et al. 2016). When these dissolved species diffuse upward this can lead to strong enrichments of $\mathrm{Fe}$ and $\mathrm{Mn}$ oxides upon contact with $\mathrm{O}_{2}$, or for dissolved $\mathrm{Fe}^{2+}$, also upon contact with Mn oxides (Wang and Van Cappellen 1996; Seitaj et al. 2015; Sulu-Gambari et al. 2016a). These metal oxides are capable of efficiently buffering the benthic release of $\mathrm{H}_{2} \mathrm{~S}$ and phosphate $\left(\mathrm{HPO}_{4}{ }^{2-}\right.$ ) during periods with low bottom water $\mathrm{O}_{2}$. This so-called 'firewall' for $\mathrm{H}_{2} \mathrm{~S}$ and alteration of the 
timing of $\mathrm{HPO}_{4}{ }^{2-}$ release linked to this buffering can play a key role in regulating water quality in seasonally hypoxic coastal systems (Seitaj et al. 2015; Sulu-Gambari et al. 2016b; Hermans et al. 2019a).

In sediments where cable bacteria become active, the $\mathrm{O}_{2}$ penetration is typically temporarily fixed at a depth of several mm's below the sediment-water interface (Meysman et al. 2015). Hence, the oxidation of upward diffusing $\mathrm{Fe}^{2+}$ and $\mathrm{Mn}^{2+}$ is expected to take place below and not at the sediment-water interface. We hypothesise that, as a consequence, most Fe and Mn oxide formation and the retention of upward diffusing $\mathrm{HPO}_{4}{ }^{2-}$ in the initial stages of cable bacteria activity is restricted to a thin subsurface layer of the sediment. However, the sample resolution and timing of the collection of solid phase data in field and laboratory studies published so far do not allow an assessment of this hypothesis.

Cable bacteria are suggested to thrive in coastal sediments characterised by high rates of $\mathrm{H}_{2} \mathrm{~S}$ production due to high rates of organic matter mineralisation (Nielsen et al. 2010; Pfeffer et al. 2012). Laboratory studies have shown that the dissolution of FeS accounts for 40 to $94 \%$ of the $\mathrm{H}_{2} \mathrm{~S}$ consumed by cable bacteria, while the other source is $\mathrm{H}_{2} \mathrm{~S}$ production from the reduction of $\mathrm{SO}_{4}^{2-}$ (Risgaard-Petersen et al. 2012; Meysman et al. 2015). At present, it is not known if cable bacteria activity can establish in sediments that are relatively low in FeS and dissolved $\mathrm{H}_{2} \mathrm{~S}$.

In this study, we assess whether cable bacteria activity can establish in sediments that are relatively poor in $\mathrm{FeS}$ in an incubation experiment using siderite-bearing sediments from a coastal site in the Black Sea. The metabolic activity of cable bacteria is monitored using microsensor profiles of $\mathrm{pH}, \mathrm{O}_{2}, \mathrm{H}_{2} \mathrm{~S}$ and EP. We also use sediment $\mathrm{Fe}$ and $\mathrm{P}$ speciation and $\mu \mathrm{XRF}$ of resin-embedded sediments to test whether we find evidence for subsurface enrichments in Fe oxides and associated P. We find a rapid establishment of cable bacteria ( $<5$ days) and the development of an Fe oxide-rich subsurface layer, with the majority of the $\mathrm{Fe} \sim 70 \%$ supplied through dissolution of siderite induced by cable bacteria activity. The depth of the Fe oxide layer was directly related to the $\mathrm{O}_{2}$ penetration depth and we propose that such subsurface enrichments in Fe, which also can contain $\mathrm{P}$ and $\mathrm{Mn}$, can be used as a marker for recent cable bacteria activity.

\subsection{Methods and Materials}

\subsubsection{Study Area and Experimental Set-up}

In September 2015, 16 sediment cores $(\varnothing 10 \mathrm{~cm})$ were retrieved at a coastal site on the north-western shelf of the Black Sea (27 m water depth; Figure 6.1B; Table 6.1) using a multicorer (Oktopus $\mathrm{GmbH}$, Germany) as described in Lenstra et al. (2019). The overlying water was discarded, and the upper $10 \mathrm{~cm}$ of the sediment was transferred into nitrogen purged aluminium bags that were sealed and stored at $4{ }^{\circ} \mathrm{C}$. Prior to the core incubations, the sediment was passed through a $4 \mathrm{~mm}$ sieve to remove fauna and large debris, and was homogenised. Subsequently, the sediment was transferred to 18 transparent polycarbonate cores ( $\varnothing 6 \mathrm{~cm} ; 20 \mathrm{~cm}$ length).

The bottom $15 \mathrm{~cm}$ of these cores was filled with sediment and the upper $5 \mathrm{~cm}$ with overlying water. The cores were distributed in two continuously aerated aquaria and kept at a constant temperature $\left(\sim 20^{\circ} \mathrm{C}\right)$ in the dark. These aquaria were filled with artificial seawater (Instant Ocean Sea Salt + Ultra High Quality (UHQ) water) with a salinity of 17.9, identical to the bottom water salinity at our study site. The artificial sea water contained negligible concentrations of $\mathrm{NH}_{4}{ }^{+}, \mathrm{NO}_{3}$, $\mathrm{Fe}, \mathrm{Mn}$ and $\mathrm{P}$ as described in Atkinson (1997) and Hovanec and Coshland (2004). Sixteen out of eighteen cores were exposed to oxygenated bottom water, whereas the two remaining cores served 
as the control treatment. For continuous aeration of the sea water, two aquarium pumps were used. The control cores were tightly sealed with rubber stoppers, to prevent the growth of cable bacteria by excluding $\mathrm{O}_{2}$ (Nielsen et al. 2010).

Sampling for pore water and solid phase analyses was performed at eight time points over a total incubation period of 621 days. Each time point involved a three day procedure. On the first day, microsensor depth profiles of $\mathrm{EP}, \mathrm{O}_{2}, \mathrm{pH}$ and $\mathrm{H}_{2} \mathrm{~S}$ were obtained in two randomly selected oxic cores and the two anoxic control cores $\left(\mathrm{O}_{2}\right.$ profiling was not performed in the anoxic cores). On the second day, solute fluxes were measured in the same oxic cores that were used for microsensor depth profiling on the previous day. On the third day, the cores were sectioned, of which only one core was processed further for pore water and solid-phase analyses. Photographs were taken at four time points (day 12; 33; 170 and 621) from one oxic core to follow the visual development of the surface sediment during the experiment.

A

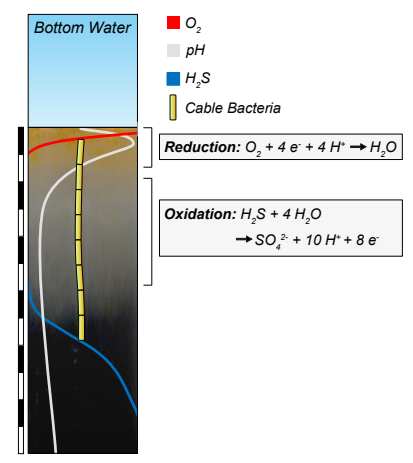

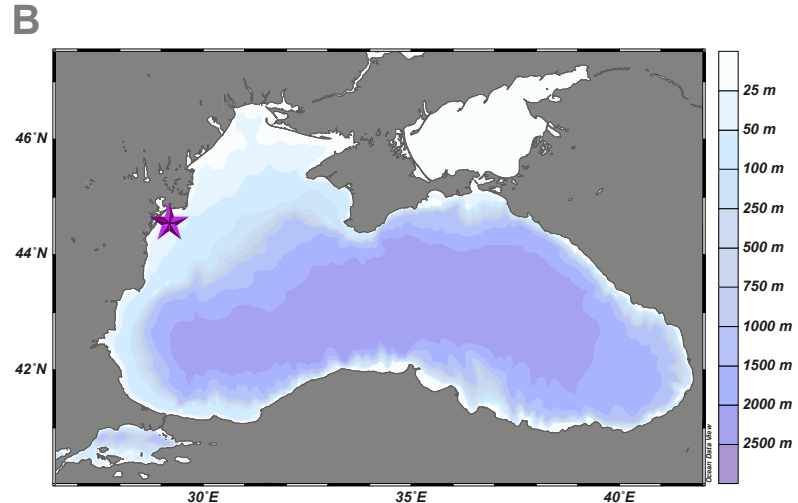

D

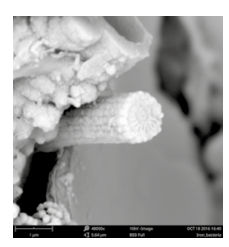

Figure 6.1 | (A) Geochemical pore water fingerprint typical for cable bacteria activity. This fingerprint is defined by a distinct $\mathrm{pH}$ profile (light grey line) and a sub-oxic zone that is devoid of $\mathrm{O}_{2}$ (red line) and $\mathrm{H}_{2} \mathrm{~S}$ (blue line). The cable bacteria filaments are depicted in yellow. On the background, the sediment core photograph, taken 278 days after the start of the experiment, shows a distinct colour zonation where (1) the oxic zone displays an orange colour (2) the suboxic zone has a grey colour and (3) the sulphidic zone has a black colour. The scale bar denotes a distance of $6 \mathrm{~cm}$, with $0.5 \mathrm{~cm}$ intervals. (B) Bathymetric map of the Black Sea. The purple star indicates the location of our study site $\left(44^{\circ} 34.93^{\prime} \mathrm{N}, 29^{\circ} 11.38^{`} \mathrm{E}\right)$, which was sampled with R/V Pelagia in September 2015. Further details are provided in Lenstra et al. (2019). (C) Volumetric density of cable bacteria $\left[\mathrm{m} \mathrm{cm}^{-3}\right]$ in the top $2.5 \mathrm{~cm}$ of the sediment, for in-situ as well as for three time points during the incubation experiment (D) SEM image of a cable bacteria filament that was extracted from the surface sediment after 40 days. 
Table 6.1 | Key site characteristics: latitude, longitude, water depth, bottom water $\mathrm{O}_{2}$ concentration, in-situ $\mathrm{O}_{2}$ uptake, in-situ $\mathrm{O}_{2}$ penetration depth in the sediment, porosity and salinity. These data were retrieved from Lenstra et al. (2019). Our study site is station 9 in Lenstra et al. (2019).

\begin{tabular}{lll}
\hline Black Sea (Station 9) & & Unit \\
\hline Latitude & $44^{\circ} 34.9^{\prime}$ & $\mathrm{N}$ \\
Longitude & $29^{\circ} 11.4^{\prime}$ & $\mathrm{E}$ \\
Water depth & 27 & $\mathrm{~m}$ \\
Bottom water $\mathrm{O}_{2}$ & 92 & $\mu \mathrm{M}$ \\
$\mathrm{O}_{2}$ uptake & $25.8 \pm 1.77$ & $\mathrm{mmol} \mathrm{m}^{-2} \mathrm{~d}^{-1}$ \\
$\mathrm{O}_{2}$ penetration depth & 2.25 & $\mathrm{~mm}$ \\
Porosity & 0.86 & - \\
Salinity & 17.881 & - \\
\hline
\end{tabular}

\subsubsection{High-resolution Microsensor Depth Profiling}

High-resolution depth profiles of $\mathrm{pH}, \mathrm{O}_{2}$ and $\mathrm{H}_{2} \mathrm{~S}$ were obtained $(50-\mu \mathrm{m}$ depth resolution; 3 replicates per oxic core; 2 replicates per anoxic core) using commercial micro electrodes (Unisense A.S., Denmark). For depth profiling of EP (500- $\mu$ m resolution; 3 replicates per core), micro electrodes were used that were custom built at Aarhus University as described in Damgaard et al. (2014). A robust reference electrode (Ref-RM, Unisense, A.S., Denmark) was used during EP and $\mathrm{pH}$ measurements. To exclude turbulence-induced variations in the tip potential of the reference electrode during EP profiling, a silicon tube filled with foam was mounted on the tip of the reference electrode. The background EP signal in the overlying water was subtracted from the EP depth profiles to calculate the EP value relative to that in the overlying water (Damgaard et al. 2014). The $\mathrm{O}_{2}$ sensor was re-calibrated prior to each measurement, using saturated bottom water (100\% $\left.\left[\mathrm{O}_{2}\right]\right)$ and the deeper sediment horizons $\left(0 \%\left[\mathrm{O}_{2}\right]\right)$ as calibration points. Calibrations of the $\mathrm{pH}$ and $\mathrm{H}_{2} \mathrm{~S}$ electrodes were performed as described in Hermans et al. (2019b). pH values are reported on the total scale. Total $\mathrm{H}_{2} \mathrm{~S}\left(\Sigma \mathrm{H}_{2} \mathrm{~S}=\mathrm{H}_{2} \mathrm{~S}+\mathrm{HS}^{-}+\mathrm{S}^{2-}\right)$ was calculated as a function of the recorded $\mathrm{H}_{2} \mathrm{~S}$ and $\mathrm{pH}$ values, as well as temperature and salinity (Millero et al. 1988; Jeroschewski et al. 1996).

\subsubsection{Diffusive $\mathrm{O}_{2}$ Uptake, Electric Field and Current Density}

The diffusive uptake of $\mathrm{O}_{2}$ was determined by modelling of the high-resolution $\mathrm{O}_{2}$ depth profiles using the PROFILE software package (Berg et al. 1998). The electric field in the sediment was calculated from the linear slope of the EP depth profiles (average of triplicates) in the surface sediments (Risgaard-Petersen et al. 2014). The current density was subsequently calculated from the electrical field using Ohm's law:

$J=\sigma_{p w} \cdot E$

where $J$ represents the diffusive flux $\left(\mathrm{mA} \mathrm{m}^{-2}\right), \sigma_{p w}$ is the conductivity of the pore water and $E$ represents the electric field. The conductivity of the pore water was corrected for tortuosity and calculated as a function of the temperature and salinity using the equations provided by Fofonoff and Millard Jr (1983). 


\subsubsection{Solute Flux Measurements}

Solute flux incubations for $\mathrm{NH}_{4}^{+}, \mathrm{Fe}^{2+}, \mathrm{Mn}^{2+}, \mathrm{Ca}^{2+}, \mathrm{HPO}_{4}^{2-}$ and $\mathrm{H}_{4} \mathrm{SiO}_{4}$ were performed. At each time point one core was placed outside the aquarium, and the bottom water was continuously aerated. Parafilm was wrapped on top of the cores to prevent evaporation. Bottom water samples of $3 \mathrm{~mL}$ were retrieved at 7 time points over 24 hours. The same volume of fresh artificial seawater was added to the cores directly after taking each sample. The samples were filtered $(0.45 \mu \mathrm{m})$ and acidified with $10 \mu \mathrm{L}$ Suprapur ${ }^{\circledR} \mathrm{HCl}(35 \%)$ per $\mathrm{mL}$ sample. Concentrations of $\mathrm{NH}_{4}^{+}$in the samples were determined using the phenol hypochlorite method (Koroleff 1969). The total Fe, Mn, Ca, P and $\mathrm{Si}$ concentrations (which are assumed to represent $\mathrm{Fe}^{2+}, \mathrm{Mn}^{2+}, \mathrm{Ca}^{2+}, \mathrm{HPO}_{4}^{2-}$ and $\mathrm{H}_{4} \mathrm{SiO}_{4}$ ) in the samples were determined using Inductively Coupled Plasma-Optical Emission Spectroscopy (ICPOES, Spectro Arcos). The colourimetric detection limit of $\mathrm{NH}_{4}^{+}$is $0.5 \mu \mathrm{M}$. The solute fluxes were calculated as described in Rao et al. (2016).

$J=\frac{d C_{o w}}{d_{t}} \cdot \frac{V_{o w}}{A}$

where $\mathrm{J}$ represents the diffusive flux $\left(\mathrm{mmol} \mathrm{m}^{-2} \mathrm{~d}^{-1}\right), d C_{o w}$ represents the concentration change in the overlying water, $d t$ is the incubation time, $V_{o w}$ is the volume in the overlying water in $\mathrm{m}^{3}$ and A the area of the core in $\mathrm{m}^{2}$. The practical detection limit on the ICP-OES for Fe, Mn and P was $0.00345,0.000531$ and $0.01905 \mathrm{ppm}$, respectively. This translates into a measurable flux of $>0.08$, $>0.012,>0.002$ and $>0.067 \mathrm{mmol} \mathrm{m}^{-2} \mathrm{~d}^{-1}$ for $\mathrm{NH}_{4}^{+}, \mathrm{Fe}, \mathrm{Mn}$ and $\mathrm{P}$, respectively. The concentrations for $\mathrm{NH}_{4}^{+}, \mathrm{Fe}^{2+}, \mathrm{Mn}^{2+}$ and $\mathrm{HPO}_{4}^{2-}$ in our samples were below the detection limit. Hence, only $\mathrm{Ca}^{2+}$ and $\mathrm{H}_{4} \mathrm{SiO}_{4}$ fluxes are presented.

\subsubsection{Sediment and Pore Water Collection}

At each time point, two cores were sectioned at $0.5-1 \mathrm{~cm}$ resolution with an UWITEC push-up pole in a $\mathrm{N}_{2}$-purged glovebag, but only samples for one core were used for sediment and pore water collection and analyses. Bottom water samples were retrieved from the overlying water in the cores. Slices for each depth interval were centrifuged at $3500 \mathrm{rpm}$ for 20 minutes for pore water retrieval. Samples $(1 \mathrm{~mL})$ for pore water S, Fe, Mn, Ca, P and Si were acidified with $10 \mu \mathrm{L}$ Suprapur $\mathrm{HCl}$ (35\%) per $\mathrm{mL}$ sample, and were analysed using ICP-OES. Pore water Fe and $\mathrm{Mn}$ are assumed to be present in the form of $\mathrm{Fe}^{2+}$ and $\mathrm{Mn}^{2+}$, however some $\mathrm{Mn}^{3+}$ (Madison et al. 2013) or colloidal and nanoparticulate Fe and Mn might also be available (Boyd and Ellwood 2010; Raiswell and Canfield 2012). Concentrations of $\mathrm{P}$ and $\mathrm{S}$ are assumed to represent $\mathrm{HPO}_{4}{ }^{2-}$ and $\mathrm{SO}_{4}{ }^{2-}$ respectively. Diffusive downward fluxes of $\mathrm{SO}_{4}{ }^{2-}$ and diffusive upward fluxes of $\mathrm{NH}_{4}^{+}, \mathrm{Fe}^{2+}, \mathrm{Mn}^{2+}$ and $\mathrm{Ca}^{2+}$ were calculated

$J=-\phi D_{s} \cdot \frac{d C}{d z}$

from the linear pore water gradient using Fick's first law (Berner 1980):

The molecular diffusion coefficient was calculated as a function of pressure, salinity and temperature using the R package marelac (Soetaert et al. 2010) and corrected for the ambient tortuosity using the relations listed in Boudreau (1997). Centrifuged sediment samples were freeze- 
dried and ground to a fine powder in a $\mathrm{N}_{2}$-purged glovebox under a strictly anoxic environment to prevent potential oxidation (Kraal et al. 2009; Kraal and Slomp 2014). Only the top $5 \mathrm{~cm}$ of the solid-phase samples were analysed in further detail. The porosity (Supporting Information 6.1.1; Table S.6.1) was calculated from the weight loss upon freeze-drying, using a sediment density of $2.65 \mathrm{~g} \mathrm{~cm}^{-3}$ (Burdige 2006). Salt corrections were performed on the solid-phase data using the gravimetric water content and salinity to determine the amount of salt after freeze-drying.

\subsubsection{Fluorescence In-situ Hybridisation}

Fluorescence in-situ hybridisation (FISH; Pernthaler et al. 2001) was used to microscopically quantify the abundance of cable bacteria filaments, as described in Seitaj et al. (2015). FISH analysis was performed on one intact sediment core retrieved at our sampling site, and the sediment cores from our incubation experiment used for pore water collection at three time points (days 5, 26 and 207). These cores were sectioned at $0.5 \mathrm{~cm}$ depth resolution for the first $2.5 \mathrm{~cm}$. Each sediment slice was homogenised and fixed with $0.5 \mathrm{~mL}$ ethanol ( $\geq 99.8 \%$ purity), and stored in a $2 \mathrm{~mL}$ Eppendorf tube at $-20{ }^{\circ} \mathrm{C}$. For FISH analysis, a volume of $100 \mu \mathrm{L}$ was retrieved from the Eppendorf tubes and mixed with a 1:1 solution of PBS/ethanol $(500 \mu \mathrm{L})$. Then $10 \mu \mathrm{L}$ of this mixture was filtered through a polycarbonate membrane (type GTTP; pore size $0.2 \mu \mathrm{m}$, Millipore, USA). Cable bacteria were classified with a Desulfobulbaceae-specific oligonucleotide probe (DSB706; 5-ACC CGT ATT CCT CCC GAT-3') after counter staining with DAPI $(1 \mu \mathrm{g} / \mathrm{mL})$ under an epifluorescence microscope (Zeiss Axioplan, Germany) at 100x magnification. The abundance of cable bacteria was quantified by determining the length and diameter of all observed filaments in a field $(105 \times 141 \mu \mathrm{m})$ on the filter at 100x magnification (200 fields per sample). Cable bacterial abundances are expressed as filament length per volumetric unit $\left(\mathrm{m} \mathrm{cm}^{-3}\right)$ or depth integrated per unit area of sediment surface ( $\mathrm{m} \mathrm{cm}$-2), consistent with previous studies (Schauer et al. 2014; Malkin et al. 2017).

\subsubsection{Solid-Phase Analysis}

Solid-phase Fe was fractionated into [1] labile ferric $\mathrm{Fe}$ (hydr)oxides and ferrous $\mathrm{Fe}\left(\mathrm{FeS}+\mathrm{FeCO}_{3}\right)$, [2] crystalline Fe minerals, [3] magnetite and [4] pyrite (Supporting Information 1.2; Table S.6.2), using a combination of two operational extraction methods (Poulton and Canfield 2005; Claff et al. 2010) as described by Kraal et al. (2017). Concentrations of Fe in all extracts were determined using the colourimetric phenanthroline method (APHA 2005). Solid-phase S was separated into [1] acid volatile sulphur (AVS; representing FeS) and [2] chromium reducible sulphur (CRS; representing FeS2; Table S.6.1) using the method after Burton et al. $(2006 ; 2008)$ as modified by Kraal et al. (2013). Sulphide released during the S extraction was trapped as $\mathrm{ZnS}$ in alkaline $\mathrm{Zn}$ acetate traps. Concentrations of $S$ were determined by iodometric titration (APHA 2005). Solid-phase siderite $\left(\mathrm{FeCO}_{3}\right)$ was determined by subtracting AVS from the labile ferrous concentrations retrieved from the first step of the Fe extraction. Solid-phase P was fractionated into [1] exchangeable P, [2] citrate-dithionite-bicarbonate (CDB)-P, [3] authigenic P, [4] detrital P and [5] organic P (Table S.6.1) after Ruttenberg (1992) as modified by Slomp et al. (1996). The sum of exchangeable P and CDB-P represents metal bound P, as described in Hermans et al. (2019b). Concentrations of P in all extracts, except CDB, were measured with the molybdenum blue colourimetric method (Murphy and Riley 1958). The P, Mn (assuming to represent Mn oxides; Hermans et al. 2019b) and Si (assuming to represent metal oxide bound Si; Kostka and Luther III 1994; Rao et al. 2016) in CDB extracts was determined using ICP-OES. 


\subsubsection{Elemental Mapping of $\mathrm{Fe}, \mathrm{Mn}, \mathrm{P}$ and $\mathrm{Ca}$}

On day 47, an undisturbed core (first $7 \mathrm{~cm}$ of surface sediment) was sampled for epoxy resin embedding for high-resolution elemental mapping (Jilbert et al. 2008; Jilbert and Slomp 2013). The epoxy-embedded core was split vertically using a rock saw. The surface was smoothed by applying a $0.3 \mu \mathrm{m}$ alumina powder layer. Elemental maps of $\mathrm{Fe}, \mathrm{Mn}, \mathrm{P}$ and $\mathrm{Ca}$ (30 $\mu \mathrm{m}$ resolution) were retrieved using a Desktop EDAX Orbis $\mu \mathrm{XRF}$ analyser (Rh tube set at $30 \mathrm{kV}, 500 \mu \mathrm{A}, 300 \mathrm{~ms}$ dwelltime, equipped with a poly-capillary lens). Similar $\mu$ XRF maps for Fe, $\mathrm{Mn}$ and $\mathrm{P}$ in epoxy embedded surface sediment were obtained for two field sites: (1) the Gulf of Finland, for sediments collected in June 2016 as described by Hermans et al. (Submitted), and Lake Grevelingen, for sediments collected in January and May 2012 as described in Sulu-Gambari et al. (2016a; 2018).

\subsubsection{Scanning electron microscopy}

Cable bacteria filaments were extracted from the oxic zone (upper $2 \mathrm{~mm}$ ) of the surface sediment after 40 days. These filaments were subsequently subjected to scanning electron microscopy (SEM) imaging on a Phenom ProX Desktop SEM (Phenom-World B.V., the Netherlands) to obtain highresolution images, as described in Geerlings et al. (2019). SEM images were generated under 0.1-0.3 mbar vacuum, and a high accelerating voltage (10 or $15 \mathrm{kV})$.

\subsection{Results and Discussion}

\subsubsection{Abundance of Cable Bacteria}

Examination of the top $2.5 \mathrm{~cm}$ of the surface sediments using FISH showed the presence of filamentous cable bacteria (Figures 6.1C and S.6.1). The in-situ cable bacterial abundance in the sediment at our field site was low $\left(14 \mathrm{~m} \mathrm{~cm}^{-2}\right)$. However, after 5 days of incubation in the laboratory, the abundance increased strongly $\left(724 \mathrm{~m} \mathrm{~cm}^{-2}\right)$. At day 26 the abundance of cable bacteria was even higher $\left(1035 \mathrm{~m} \mathrm{~cm}^{-2}\right)$. Such high abundances are similar to those observed in previous experiments in which FeS- and $\mathrm{\Sigma}_{2} \mathrm{~S}$-rich marine sediments from Aarhus Bay and Lake Grevelingen were incubated (Schauer et al. 2014; Burdorf et al. 2018). After 207 days, the cable bacterial abundance in the surface sediment was low again $\left(131 \mathrm{~m} \mathrm{~cm}^{-2}\right)$. SEM imaging confirmed that filaments were indeed cable bacteria (Figure 6.1D), as the external surface of the filament was characterised by a parallel pattern of ridges and grooves along its latitudinal axis, which is a typical feature of cable bacteria (Cornelissen et al. 2018; Geerlings et al. 2019).

\subsubsection{Metabolic Activity of Cable Bacteria}

The development of the high-resolution pore water depth profiles of $\mathrm{pH}, \mathrm{O}_{2}$, and $\mathrm{\Sigma H}_{2} \mathrm{~S}$ during the experiment resemble the distinct biogeochemical fingerprint typical for active cable bacteria (Figure 6.2A), as observed in previous laboratory incubation experiments (Risgaard-Petersen et al. 2012; Malkin et al. 2014; Schauer et al. 2014; Vasquez-Cardenas et al. 2015; Rao et al. 2016; Burdorf et al. 2018). This includes the development of a $\mathrm{pH}$ maximum near the sediment-water interface, and a strong pore water acidification in the deeper sediment (Figure 6.2A). The depth of $\mathrm{O}_{2}$ penetration in the sediment remained constant within the first 40 days of incubation $(\sim 1.1 \mathrm{~mm})$ 
and moved downwards with time to $9.6 \mathrm{~mm}$ (Figures 6.2A, 6.3 and S.6.2). The $\Sigma \mathrm{H}_{2} \mathrm{~S}$ appearance depth was initially equivalent to the $\mathrm{O}_{2}$ penetration depth, and shifted downwards within 5 days, creating a suboxic zone where $\mathrm{O}_{2}$ and $\mathrm{\Sigma}_{2} \mathrm{~S}$ remained below detection (Figures 6.2A and 6.3), as a consequence of the downward expansion of the cable bacteria filament network (Schauer et al. 2014; Vasquez-Cardenas et al. 2015). The width of the suboxic zone remained relatively constant with time ( $25 \mathrm{~mm}$; Figure 6.3). The dissolved $\mathrm{\Sigma H}_{2} \mathrm{~S}$ concentrations remained low $(<5 \mu \mathrm{M})$ throughout the experiment (Figure 6.2A). The consumption of $\mathrm{O}_{2}$ was highest after 5 days and gradually decreased with time from $\sim 30$ to $\sim 3.6 \mathrm{mmol} \mathrm{m}^{-2} \mathrm{~d}^{-1}$ (Figure $6.4 \mathrm{~A}$ ).
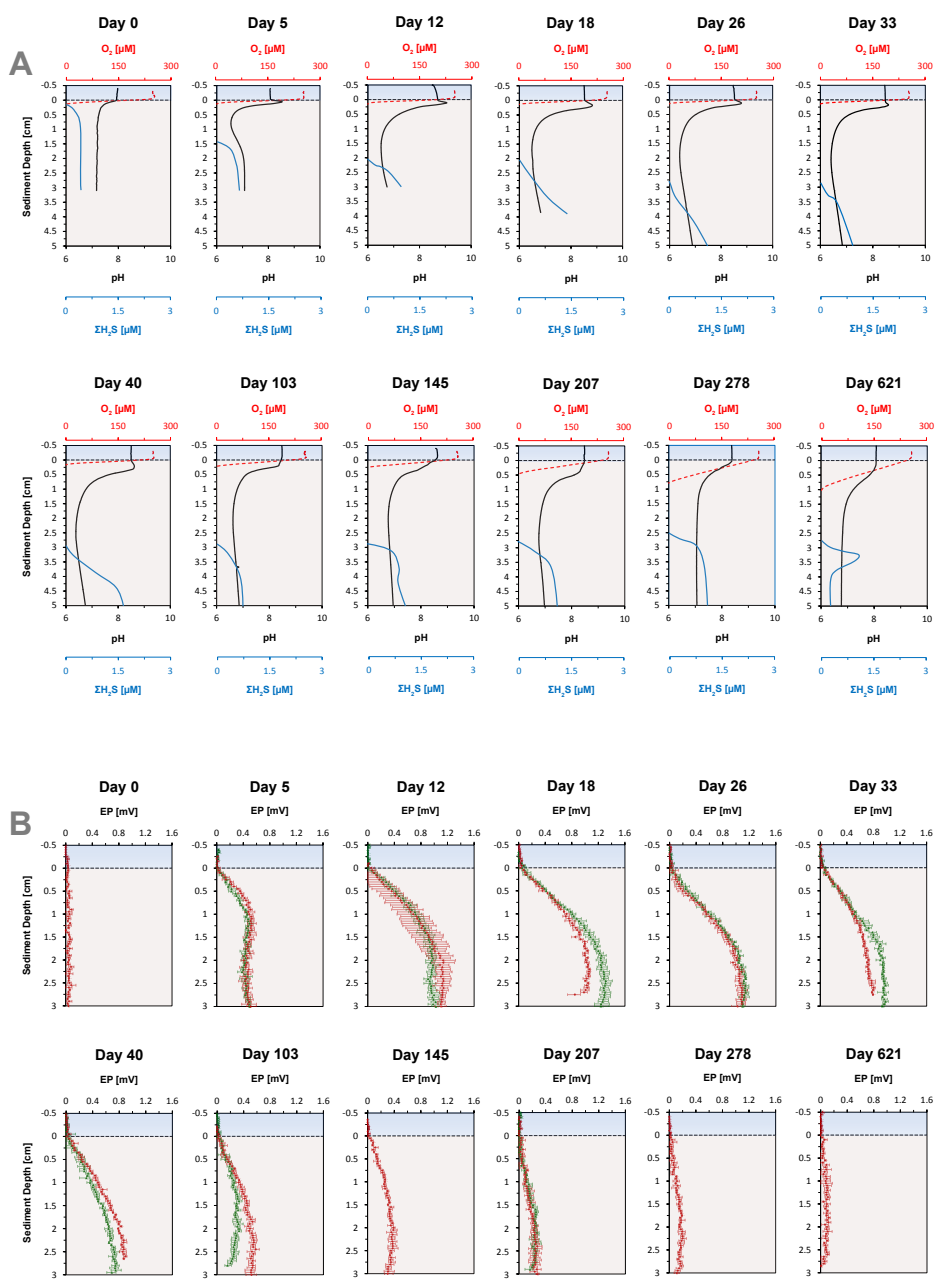

Figure 6.2 (A) Time-series of the pore water $\mathrm{pH}$ (black), $\mathrm{O}_{2}$ (red) and $\Sigma \mathrm{H}_{2} \mathrm{~S}$ (blue) signatures of the incubated sediment. (B) Development of the EP depth profile in the incubated sediment over time. The dashed-line at $0 \mathrm{~mm}$ depth represents the sediment-water interface. The blue boxes indicate the overlying water, whereas the underlying light grey boxes represent the sediment. The EP depth profiles represent an average of 3 replicate measurements. The error bars indicate the minimum and maximum EP values that were observed. The red values represent the measurements obtained from the first cores, whereas the green values were obtained from the duplicate cores. 


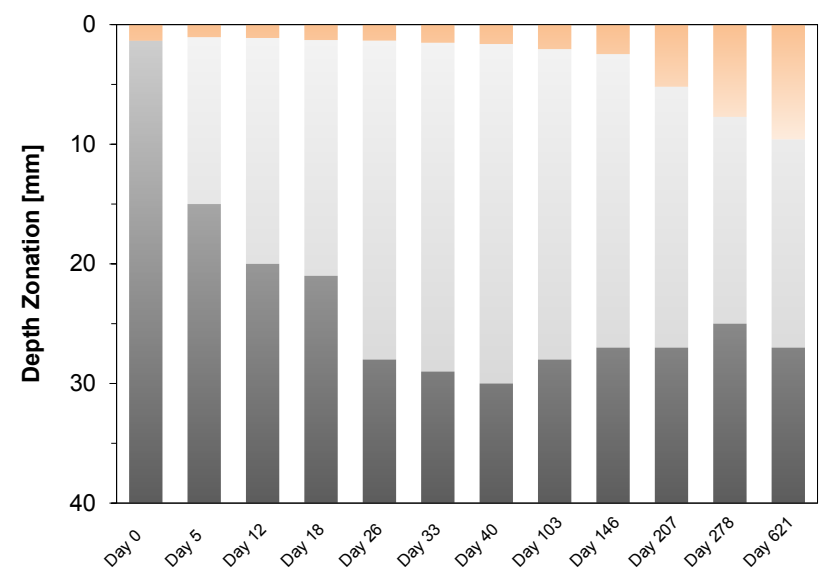

Figure 6.3 | Time-series of the development of the oxic zone (orange), suboxic zone (light grey) and the anoxic/ sulphidic zone (dark grey) in the sediment. These zones were calculated from 3 replicate measurements on two different cores.

\section{A Diffusive $\mathrm{O}_{2}$ Uptake}

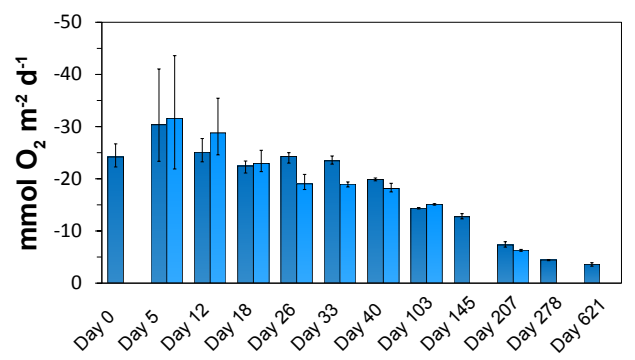

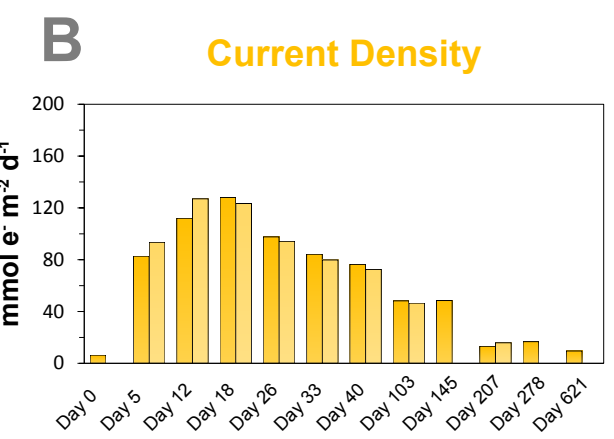

Figure 6.4 Time-series of the (A) diffusive $\mathrm{O}_{2}$ uptake in mmol $\mathrm{O}_{2} \mathrm{~m}^{-2} \mathrm{~d}^{-1}$ and (B) current density as a consequence of long-distance electron transport (e) in $\mathrm{mmol} \mathrm{e}^{-} \mathrm{m}^{-2} \mathrm{~d}^{-1}$ in the sediment incubation.

The EP depth profiles demonstrated that long-distance electron transport by cable bacteria was already active at 5 days after the start of the experiment (as indicated by the increase of EP at depth to $0.4 \mathrm{mV}$ ). With time, the EP signal increased to higher values and also accumulated over a thicker depth horizon (Figure 6.2B), indicating that cable bacteria activity both increased and extended to deeper sediment depth. The EP reached a maximum after 18 days $(1.3 \mathrm{mV}$; Figure $6.2 \mathrm{~B})$ in concert with the highest current density of $\sim 130 \mathrm{mmol} \mathrm{e} \mathrm{m}^{-2} \mathrm{~d}^{-1}$ (Figure 6.4B). This maximum EP value and current density are similar in magnitude as found in a sediment incubation with a similar salinity (Damgaard et al. 2014). From day 18 onwards the EP and current density flux gradually decreased with time to $13 \mathrm{mmol} \mathrm{e} \mathrm{m}^{-2} \mathrm{~d}^{-1}$ after 207 days (Figure 6.4B), which implies a decrease in the metabolic activity of cable bacteria. Remarkably, the suboxic zone persisted long after the current density had decreased (Figure 6.3). Long-distance electron transport was not active in the anoxic control core (Figure S.6.3). 


\subsubsection{Organic Matter Degradation}

Concentrations of $\mathrm{NH}_{4}^{+}$were low near the sediment-water interface and increased with sediment depth reaching levels up to $1.7 \mathrm{mM}$ (Figure 6.5). Calculated diffusive fluxes of $\mathrm{NH}_{4}{ }^{+}$into the oxic zone decreased during the incubation experiment from 4.7 to $1.8 \mathrm{mmol} \mathrm{m}^{-2} \mathrm{~d}^{-1}$ (Figures $6.6 \mathrm{~A}$ and S.6.3; Table S.6.3). These fluxes are assumed to reflect rates of anaerobic degradation of organic matter, and the observed decline during the experiment coincides with the decrease in activity of cable bacteria based on the EP profiles (Figure 6.2). This suggests that the availability of easily degradable organic matter plays a role in sustaining the metabolic activity of cable bacteria, most likely by controlling the rate of $\mathrm{SO}_{4}{ }^{2-}$ reduction (Nielsen and Risgaard-Petersen 2015).

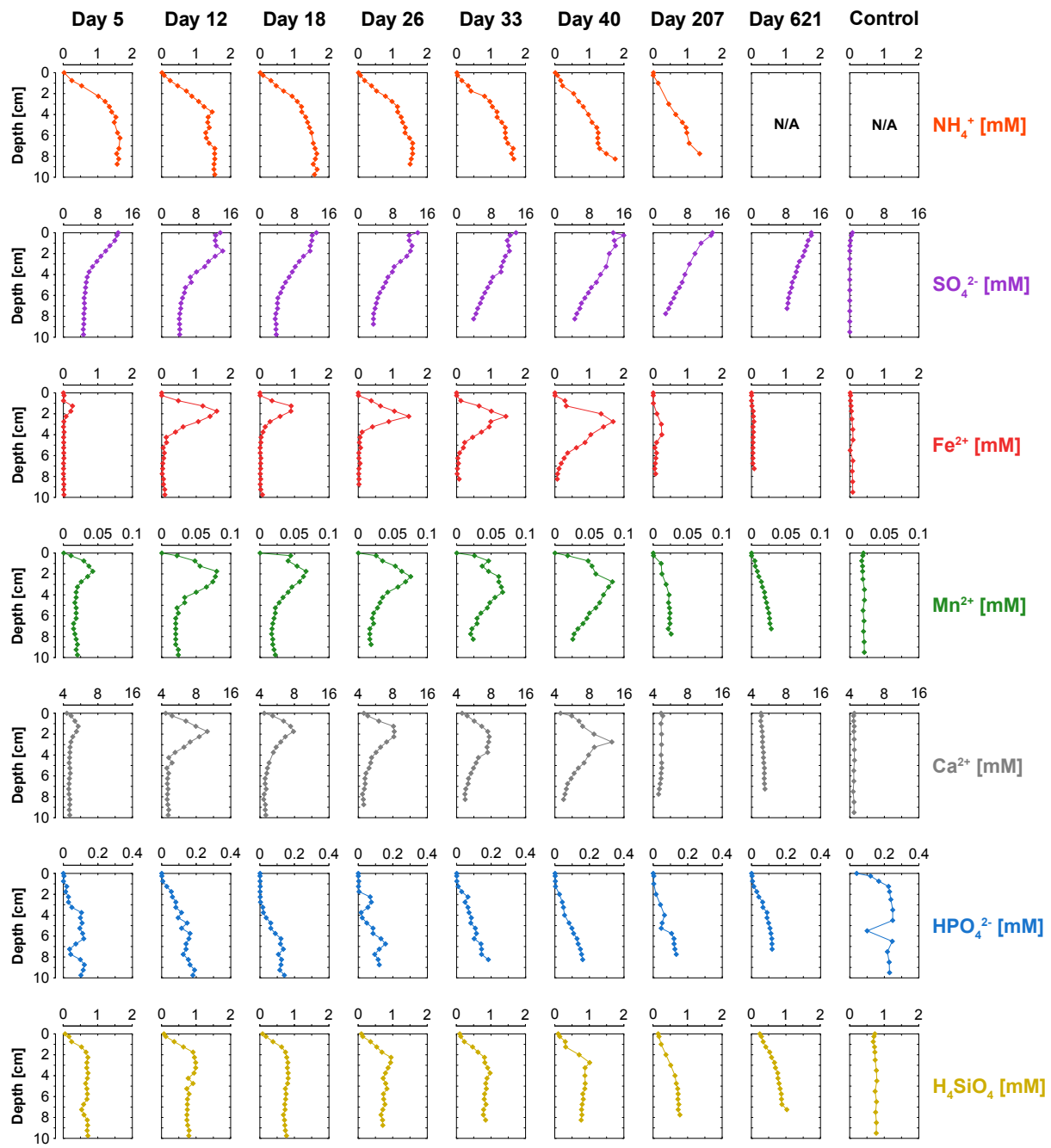

Figure 6.5 Time-series of pore water depth profiles of $\mathrm{NH}_{4}{ }^{+}$(orange), $\mathrm{SO}_{4}^{2-}$ (purple), $\mathrm{Fe}^{2+}$ (red), $\mathrm{Mn}^{2+}$ (green), $\mathrm{Ca}^{2+}$ (grey), $\mathrm{HPO}_{4}^{2-}$ (blue) and $\mathrm{H}_{4} \mathrm{SiO}_{4}$ (yellow). The control core was sampled at day 621 . 
Rates of $\mathrm{SO}_{4}^{2-}$ reduction estimated from the linear gradient of the decrease in pore water $\mathrm{SO}_{4}{ }^{2-}$ in the surface sediment with depth indeed also showed a decline during the experiment (Figures 6.6B and S.6.4; Table S.6.3). We note, however, that a direct measurement of $\mathrm{SO}_{4}^{2-}$ reduction rates (Fossing and Jørgensen 1989; Kallmeyer et al. 2004) would provide a better indicator, since the metabolic activity of cable bacteria can lead to the production of $\mathrm{SO}_{4}{ }^{2-}$ in the suboxic zone via anodic sulphide oxidation (Risgaard-Petersen et al. 2012; Rao et al. 2016). We suspect that this also explains the lack of change in pore water $\mathrm{SO}_{4}{ }^{2-}$ with depth in the upper $2 \mathrm{~cm}$ of the sediment in our experiment between 12 and 40 days (Figure 6.5). Despite relatively high $\mathrm{SO}_{4}^{2-}$ reduction rates ranging from 5.4 to $17.6 \mathrm{mmol} \mathrm{m}^{-2} \mathrm{~d}^{-1}$ (Figure 6.6B; Table S.6.3), pore water concentrations of $\Sigma \mathrm{H}_{2} \mathrm{~S}$ remained very low throughout the experiment (Figure 6.2A). This is likely due to the direct consumption of $\Sigma \mathrm{H}_{2} \mathrm{~S}$ through the activity of cable bacteria, preventing $\Sigma \mathrm{H}_{2} \mathrm{~S}$ from accumulating in the pore water.
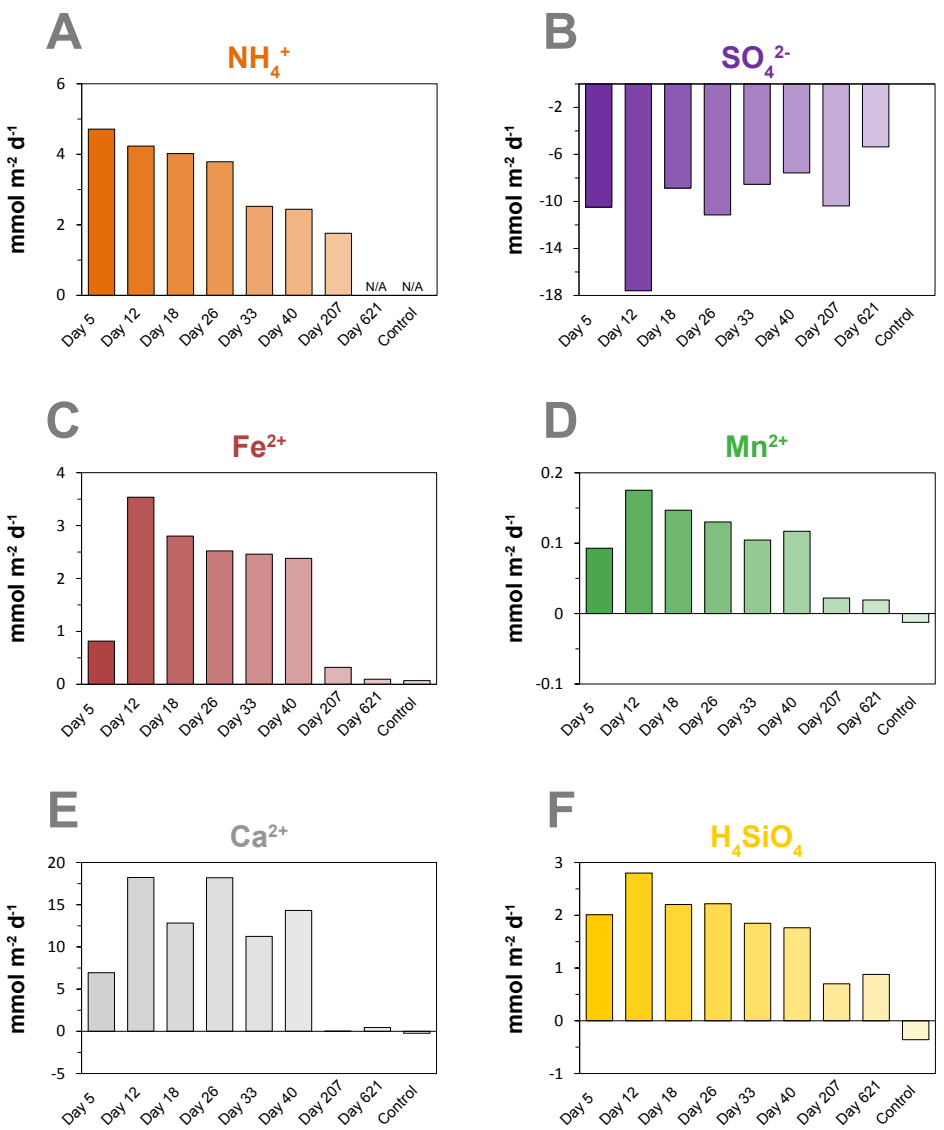

Figure 6.6 $\mid$ Time-series of diffusive fluxes calculated from the linear gradient of the pore water profiles of (A) $\mathrm{NH}_{4}^{+}$, (B) $\mathrm{SO}_{4}^{2-}$, (C) $\mathrm{Fe}^{2+}$, (D) $\mathrm{Mn}^{2+}$, (E) $\mathrm{Ca}^{2+}$ and (F) $\mathrm{H}_{4} \mathrm{SiO}_{4}$ in $\mathrm{mmol} \mathrm{m}^{-2} \mathrm{~d}^{-1}$ towards the oxic zone of the sediment, based on the linear pore water gradients (Section 6.1.6; Fig. S6.3- S6.4). Here, a positive value indicates an upward flux, whereas a negative value represents a downward flux. N/A = not available. The control core was sampled at day 621. 
Laboratory experiments have shown that S-oxidation by cable bacteria can play a dominant role in the $\mathrm{O}_{2}$ uptake of coastal sediments (Nielsen et al. 2010; Schauer et al. 2014), possibly accounting for up to $93 \%$ of the total $\mathrm{O}_{2}$ uptake (Meysman et al. 2015). When we plot the diffusive uptake of $\mathrm{O}_{2}$ against the current density (i.e. upward flux of electrons towards the oxic zone), a linear relationship - with some scatter - emerges for days 12 to 621 (Figure 6.7). However, the data points for day 0 and 5 during the initial stages of our experiment do not follow this linear relationship. We explain these findings as follows: At day 0, the cable bacteria were not active yet and other processes, such as aerobic respiration and oxidation of reduced solutes (predominantly $\mathrm{NH}_{4}^{+}$; Table 6.2) and solids $(\mathrm{FeS})$ dominated the consumption of $\mathrm{O}_{2}$. At day 5 and 12, the activity of cable bacteria and the oxidation of reduced products from anaerobic degradation of organic matter both contributed to consumption of $\mathrm{O}_{2}$. From day 12 onwards, both the $\mathrm{O}_{2}$ consumption and electron flux follow a downward decrease with time (Figure 6.7). If cable bacteria would account for all of the $\mathrm{O}_{2}$ consumption, a ratio between the diffusive uptake of $\mathrm{O}_{2}$ and the current density of 1:4 is expected (Figure 6.1A; Nielsen et al. 2010). We find that from day 12 onwards, most data points plot rather close to the line for this 1:4 relationship (Figure 6.7). This is unexpected because our data indicate complete removal of the $\mathrm{NH}_{4}^{+}$that diffused upward into the oxic zone (Figure 6.6A), and based on the solute fluxes, no escape to the overlying water (see section 6.2.4). This implies substantial $\mathrm{O}_{2}$ consumption due to nitrification (Table 6.2). These findings can be explained, however, if we assume that the $\mathrm{NO}_{3}{ }^{-}$that is being formed near the sediment-water interface is also used for the metabolic activity of cable bacteria. It has been shown that cable bacteria can couple the oxidation of $\mathrm{SH}_{2} \mathrm{~S}$ to $\mathrm{NO}_{3}{ }^{-}$in the absence of $\mathrm{O}_{2}$ (Marzocchi et al. 2014). Our data suggest that this process may also occur in sediments where $\mathrm{O}_{2}$ is present in concert with $\mathrm{NO}_{3}{ }^{-}$near the sediment-water interface.

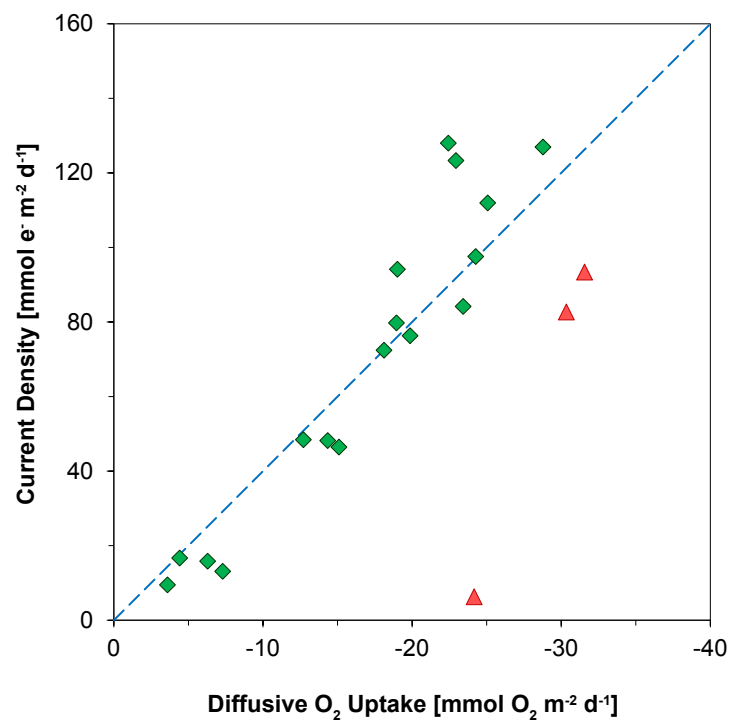

Figure 6.7 The relationship between the diffusive uptake of $\mathrm{O}_{2}\left(\mathrm{mmol} \mathrm{O}_{2} \mathrm{~m}^{-2} \mathrm{~d}^{-1}\right)$ and the current density of longdistance electron transport $\left(\mathrm{mmol} \mathrm{e} \mathrm{m}^{-2} \mathrm{~d}^{-1}\right)$. Red triangles are data for days 0 and 5 . Green diamonds are data for all other time points. The blue line represents the expected correlation between the cathodic $\mathrm{O}_{2}$ consumption rate and the current density assuming a 1:4 ratio (Nielsen et al. 2010). Here, a positive value indicates an upward flux, whereas a negative value represents a downward flux. 
Table 6.2 | Mass balance of $\mathrm{O}_{2}$ consumption. The diffusive uptake of $\mathrm{O}_{2}$ as calculated from the $\mathrm{O}_{2}$ depth profiles (column 1) was compared to the potential $\mathrm{O}_{2}$ demand from the oxidation of $\mathrm{NH}_{4}^{+}, \mathrm{Fe}^{2+}$ and $\mathrm{Mn}^{2+}$ (column 2-4). The $\mathrm{O}_{2}$ consumption of the oxidation of $\mathrm{NH}_{4}^{+}, \mathrm{Fe}^{2+}$ and $\mathrm{Mn}^{2+}$ was determined based on the stoichiometry of $\mathrm{NH}_{4}^{+}$, $\mathrm{Fe}^{2+}$ and $\mathrm{Mn}^{2+}$ oxidation with $\mathrm{O}_{2}$ as described in Reed et al. (2011). The oxidation of dissolved $\mathrm{Fe}^{2+}$ and $\mathrm{Mn}^{2+}$ only played a minor role in the total $\mathrm{O}_{2}$ consumption during the experiment, contributing only 0.9 to $3.8 \%$ and 0.1 to $0.4 \%$, respectively.

\begin{tabular}{ll|lll|l}
\hline & & \multicolumn{3}{|c|}{ Potential $\mathrm{O}_{2}$ Demand } & \\
\hline & $\mathrm{O}_{2}\left[\mathrm{mmol} \mathrm{m}^{-2} \mathrm{~d}^{-1}\right]$ & $\begin{array}{l}\mathrm{NH}_{4}^{+} \\
{\left[\mathrm{mmol} \mathrm{m}^{-2} \mathrm{~d}^{-1}\right]}\end{array}$ & $\begin{array}{l}\mathrm{Fe}^{2+} \\
{\left[\mathrm{mmol} \mathrm{m}^{-2} \mathrm{~d}^{-1}\right]}\end{array}$ & $\begin{array}{l}\mathrm{Mn}^{2+} \\
{\left[\mathrm{mmol} \mathrm{m}^{-2} \mathrm{~d}^{-1}\right]}\end{array}$ & $\begin{array}{l}\mathrm{e}^{-} \\
{\left[\mathrm{mmol} \mathrm{m}^{-2} \mathrm{~d}^{-1}\right]}\end{array}$ \\
\hline Day 5 & -23.35 & 9.42 & 0.21 & 0.05 & 82.68 \\
Day 12 & -23.24 & 8.46 & 0.89 & 0.09 & 111.94 \\
Day 18 & -21.10 & 8.04 & 0.70 & 0.08 & 97.55 \\
Day 26 & -23.00 & 7.58 & 0.63 & 0.07 & 84.16 \\
Day 33 & -22.80 & 5.06 & 0.62 & 0.05 & 76.31 \\
Day 40 & -19.60 & 4.88 & 0.60 & 0.06 & 13.10 \\
Day 207 & -6.90 & 3.52 & 0.08 & 0.01 & 9.47 \\
Day 621 & -3.25 & $\mathrm{~N} / \mathrm{A}$ & 0.03 & 0.01 & \\
\hline
\end{tabular}

\subsubsection{Impact of Cable Bacteria on Fe, Mn and S Cycling}

The activity of cable bacteria had a strong impact on the biogeochemistry of the surface sediment in our experiment (Figure 6.8). The strong acidification of the pore water in the suboxic zone as a consequence of cable bacteria activity (Figure 6.2A) led to the dissolution of Fe and $\mathrm{Mn}$ minerals in deeper sediment layers, as can be inferred from the sharp maxima in dissolved $\mathrm{Fe}^{2+}$ and $\mathrm{Mn}^{2+}$ in the pore water reaching concentrations of up to $\sim 1700$ and $\sim 80 \mu \mathrm{M}$, respectively (Figure 6.5 ). The peaks in dissolved $\mathrm{Fe}^{2+}$ and $\mathrm{Mn}^{2+}$ in the pore water broadened over time spanning a depth of $>5 \mathrm{~cm}$ (Figures 6.5, S.6.5 and 6.6).

The upward diffusive flux of dissolved $\mathrm{Fe}^{2+}$ and $\mathrm{Mn}^{2+}$ was highest after 12 days, reaching values of up to 3.16 and $0.16 \mathrm{mmol} \mathrm{m}^{-2} \mathrm{~d}^{-1}$ respectively. Fluxes subsequently gradually decreased with time (Figure 6.6C and D). The continuous upward diffusion of dissolved $\mathrm{Fe}^{2+}$ and $\mathrm{Mn}^{2+}$ led to enrichments of poorly crystalline Fe and Mn oxides in the surface sediment (Figure 6.8). Despite high upward fluxes of dissolved $\mathrm{Fe}^{2+}$ and $\mathrm{Mn}^{2+}$ towards the sediment-water interface, our solute flux incubations indicate there was little escape of $\mathrm{Fe}^{2+}$ and $\mathrm{Mn}^{2+}$ to the overlying water (see section 6.2.4). This implies that all $\mathrm{Fe}^{2+}$ and $\mathrm{Mn}^{2+}$ that diffused upward was precipitated as $\mathrm{Fe}$ and $\mathrm{Mn}$ oxides upon contact with $\mathrm{O}_{2}$ or $\mathrm{NO}_{3}^{-}$(Buresh and Moraghan 1976; Kuz'minskii et al. 1994; Straub et al. 1996). Little or no escape of dissolved $\mathrm{Fe}^{2+}$ from the sediment into the overlying water, was suggested previously for a field site with active cable bacteria based on diffusive flux calculations (Lake Grevelingen; Sulu-Gambari et al. 2016a) and was determined in flux incubations of cores during a laboratory experiment with cable bacteria (Rao et al. 2016). 


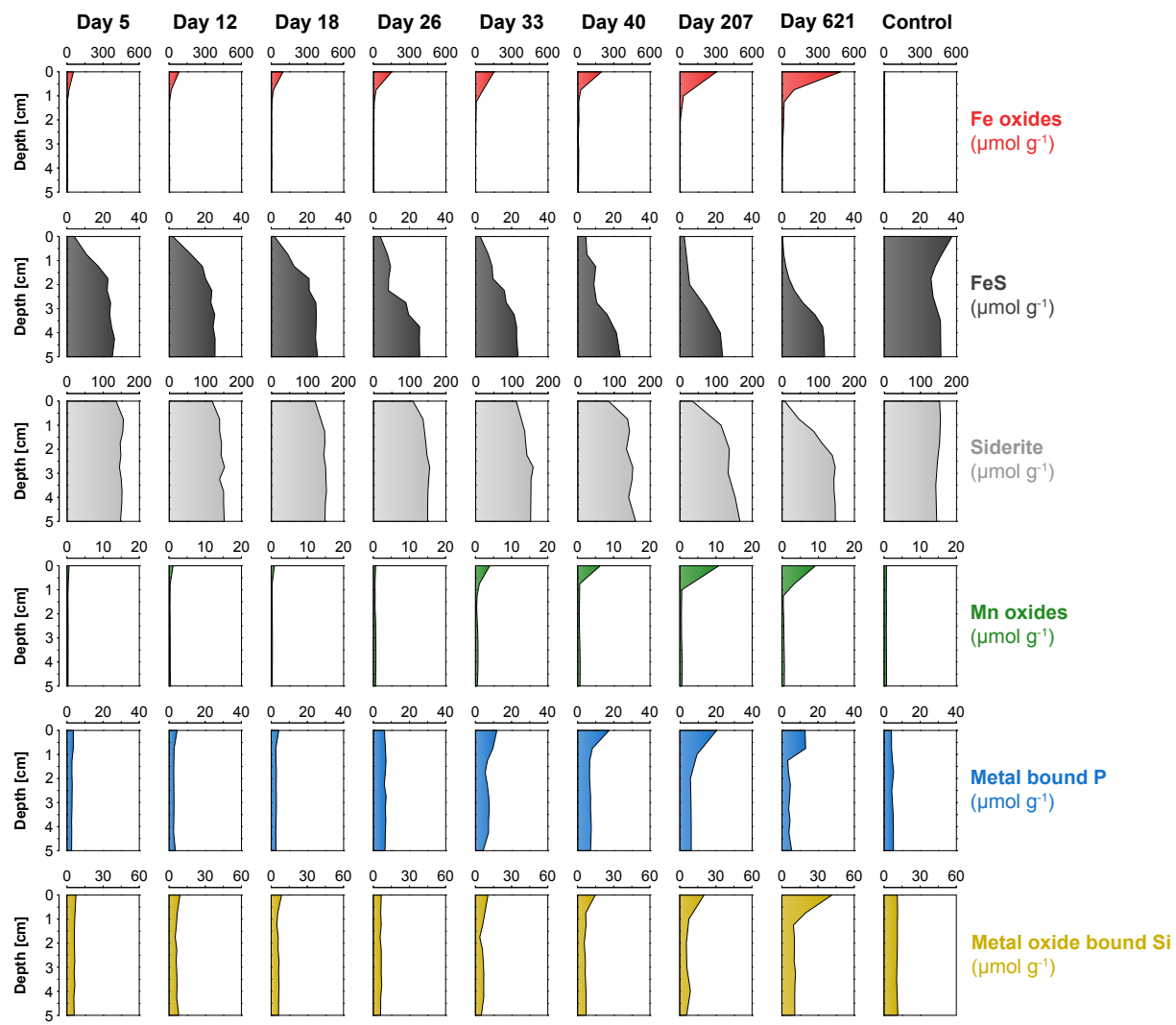

Figure 6.8 | Time-series of solid-phase depth profiles of Fe oxides (red), FeS (black), siderite (grey), Mn oxides (green), metal bound P (blue) and metal oxide bound Si (yellow).

At the start of the experiment, the sedimentary FeS content was $\left(\sim 25 \mu \mathrm{mol} \mathrm{g} \mathrm{g}^{-1}\right)$, which is not unusual for coastal sediments on the north-western Black Sea margin (Wijsman et al. 2001), but is low when compared to sediments in eutrophic coastal systems (e.g. Morgan et al. 2012; Kraal et al. 2013; Hermans et al. 2019a). The solid-phase depth profiles reveal a gradual removal of the FeS in the surface sediment in our experiment over time (Figure 6.8). At the end of our experiment (621 days), there was no longer any FeS within the top $1.5 \mathrm{~cm}$ of the sediment. While approximately $90 \mathrm{mmol} \mathrm{m}^{-2}$ of FeS was removed from the surface sediment within the first 5 days, a total of $\sim 240 \mathrm{mmol} \mathrm{m}^{-2}$ was removed after 621 days (Figure 6.9; Table 6.3). Likely, part of the FeS that was removed from the surface sediment within the first 5 days was removed through oxidation upon contact with $\mathrm{O}_{2}$, rather than the metabolic activity of cable bacteria itself. The pore water acidification associated with cable bacteria activity led to complete loss of siderite from the top $2 \mathrm{~cm}$ of the sediment, with a total removal of $\sim 560 \mathrm{mmol} \mathrm{m}^{-2}$ during the experiment (Figures 6.8 and 6.9; Table 6.3). The depletion of sedimentary FeS and siderite was directly proportional to the formation of Fe oxides near the sediment-water interface (Figure 6.9), and accounted for $30 \%$ and $70 \%$ of the Fe oxides, respectively (Table 6.3). 


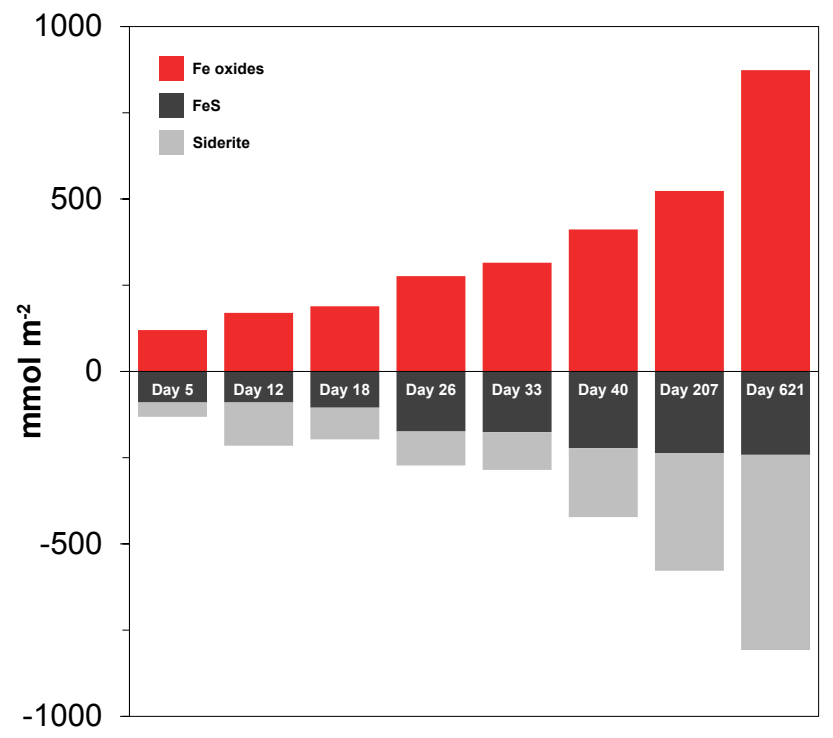

Figure 6.9 | Time-series of solid-phase depth profiles of Fe oxides (red), FeS (black), siderite (grey), Mn oxides (green), metal bound $\mathrm{P}$ (blue) and metal oxide bound Si (yellow).

With these data we cannot accurately determine the role of $\mathrm{FeS}$ versus $\mathrm{SO}_{4}^{2-}$ reduction in supplying the $\mathrm{\Sigma H}_{2} \mathrm{~S}$ sustaining the activity of cable bacteria throughout the experiment. This is primarily related to the variability between cores, and for this type of calculation, the low temporal resolution of sampling. However, our data do indicate that both $\mathrm{FeS}$ and the reduction of $\mathrm{SO}_{4}{ }^{2-}$ provided $\mathrm{\Sigma H}_{2} \mathrm{~S}$ to sustain the activity of the cable bacteria (Figure 6.6B; Table 6.3).

Table 6.3 Mass balance of Fe. Time-series of the depth integrated $(0-5 \mathrm{~cm})$ increase in Fe oxides and the depth integrated $\left(0-5 \mathrm{~cm}\right.$ ) depletion of $\mathrm{FeS}$ and $\mathrm{FeCO}_{3}$ (siderite) in $\mathrm{mmol} \mathrm{m}$. All values are reported in $\mathrm{mmol} \mathrm{Fe} \mathrm{m}^{-2}$. Negative values represent a decrease, whereas positive values indicate an increase in the mineral pools.

\begin{tabular}{llll}
\hline & $\Delta \mathrm{Fe}$ oxides $\left[\mathrm{mmol} \mathrm{m}^{-2}\right]$ & $\Delta \mathrm{FeS}\left[\mathrm{mmol} \mathrm{m}^{-2}\right]$ & $\Delta \mathrm{FeCO}_{3}\left[\mathrm{mmol} \mathrm{m}^{-2}\right]$ \\
\hline Day 5 & 120 & -90 & -42 \\
Day 12 & 170 & -90 & -126 \\
Day 18 & 189 & -105 & -92 \\
Day 26 & 276 & -174 & -99 \\
Day 33 & 315 & -176 & -109 \\
Day 40 & 412 & -223 & -200 \\
Day 207 & 523 & -236 & -341 \\
Day 621 & 874 & -242 & -566 \\
\hline
\end{tabular}




\subsubsection{Impact of Cable Bacteria on Ca, P and Si Cycling}

Cable bacteria activity is known to lead to dissolution of Ca carbonates, because of the strong acidification of the pore water (Risgaard-Petersen et al. 2012; Rao et al. 2016). We indeed find similar maxima in pore water $\mathrm{Ca}^{2+}$ during the experiment (Figure 6.5) and a high upward flux of $\mathrm{Ca}^{2+}$ (up to $\sim 18 \mathrm{mmol} \mathrm{m}^{-2} \mathrm{~d}^{-1}$; Figures 6.6E and S.6.7) of which a substantial fraction (up to $\sim 55 \%$ ) escapes to the overlying water (Figure S.6.9), which is consistent with a previous incubation experiment Rao et al. (2016).

Pore water depth profiles of $\mathrm{HPO}_{4}{ }^{2-}$ reveal a production at depth and removal of all upward diffusing $\mathrm{HPO}_{4}{ }^{2-}$ within the first 1-3 cm of the surface sediment (Figure 6.5). A major proportion of this $\mathrm{HPO}_{4}^{2-}$ is bound to $\mathrm{Fe}$ oxides (Figures 6.8 and 6.9). Given that a large proportion of the $\mathrm{Fe}$ oxides in our sediment cores derive from the dissolution of siderite, this suggests that the buffer mechanism that delays the benthic release of $\mathrm{HPO}_{4}{ }^{2-}$ through retention of $\mathrm{P}$ associated with newly formed Fe oxides (Sulu-Gambari et al. 2016b), might also be active in systems that are relatively poor in sedimentary FeS.

The shape of the pore water $\mathrm{HPO}_{4}{ }^{2-}$ profiles suggests that some of the $\mathrm{HPO}_{4}{ }^{2-}$ is removed below the zone where $\mathrm{Fe}$ and $\mathrm{Mn}$ oxides are present (Figures 6.5 and 6.8). A possible explanation could be the formation of vivianite, an $\mathrm{Fe}$ (II) phosphate mineral. Vivianite formation in sediments typically occurs when pore water levels of $\mathrm{Fe}^{2+}$ and $\mathrm{HPO}_{4}{ }^{2-}$ are high and concentrations of $\Sigma \mathrm{H}_{2} \mathrm{~S}$ are low (Nriagu 1972), as observed in our study. In our experiment, free $\Sigma \mathrm{H}_{2} \mathrm{~S}$ does not accumulate in the pore water, which we attribute to removal through the activity of cable bacteria (Figure 6.2A). Hence, cable bacteria may create a geochemical niche that allows the formation of vivianite in the suboxic zone. Further work with sediments with higher P concentrations would be needed to assess this with direct measurement techniques, such as X-ray spectroscopy (Egger et al. 2015; Kraal et al. 2017; Sulu-Gambari et al. 2018). Other sediment P pools, i.e. organic, authigenic and detrital $P$ remained constant over time, indicating that the $\mathrm{P}$ contents determined for discrete sediment slices using sequential extractions were not affected by pore water acidification as a result of cable bacteria activity (Table S.6.5)

Pore water $\mathrm{H}_{4} \mathrm{SiO}_{4}$ profiles show a typical increase with depth as observed upon dissolution of biogenic silica in marine sediments (Aller 2014). Fluxes of $\mathrm{H}_{4} \mathrm{SiO}_{4}$ towards the sediment-water interface range up to $\sim 2.8 \mathrm{mmol} \mathrm{m}^{-2} \mathrm{~d}^{-1}$ and gradually decreased with time (Figures $6.6 \mathrm{~F}$ and S.6.8). The results of the solute flux incubations indicate that most of this $\mathrm{H}_{4} \mathrm{SiO}_{4}$ escaped to the overlying water (ranging from 28 to 92\%; Table S.6.3; Figure S.6.9). The decline in the benthic release flux of $\mathrm{H}_{4} \mathrm{SiO}_{4}$ contrasts with results of a previous incubation experiment by Rao et al. (2016) with similar pore water concentrations of $\mathrm{H}_{4} \mathrm{SiO}_{4}$ reaching values up to $\sim 1 \mathrm{mM}$. In their study, the flux remained constant over time, possibly because of differences in the amount of biogenic $\mathrm{Si}$ in the sediment. The solid-phase metal oxide bound Si pool in the surface sediment increased directly proportional to the formation of Fe oxides throughout the experiment (Figure 6.8). Silica is known to absorb to Fe oxides (Sigg and Stumm 1981; Davis et al. 2002). Hence, the results suggest that the Fe oxides formed through the activity of cable bacteria captured some of the upward diffusing $\mathrm{H}_{4} \mathrm{SiO}_{4}$.

\subsubsection{Sediment Marker for Cable Bacteria Activity}

Visual observations of core photographs reveal the gradual development of an orange layer (oxic zone) up to $9 \mathrm{~mm}$ thick, overlying a grey layer (suboxic zone) and a black layer (sulphidic zone) during the experiment (Figure S.6.10). This colour zonation is typical for sediments that have 
been geochemically affected by cable bacteria activity (Nielsen and Risgaard-Petersen 2015; SuluGambari et al. 2016a). High-resolution elemental maps of our sediments reveal the development of a $\sim 0.3 \mathrm{~mm}$ thin subsurface layer highly enriched in Fe oxides and associated $\mathrm{P}, 47$ days after the start of the incubation (Figure 6.10A). Below, we describe the formation of this layer in more detail and explain why such subsurface enrichments, detected with $\mu \mathrm{XRF}$, may act as an additional sediment marker for present or recent cable bacteria activity, also in cases where visual observations are not conclusive.
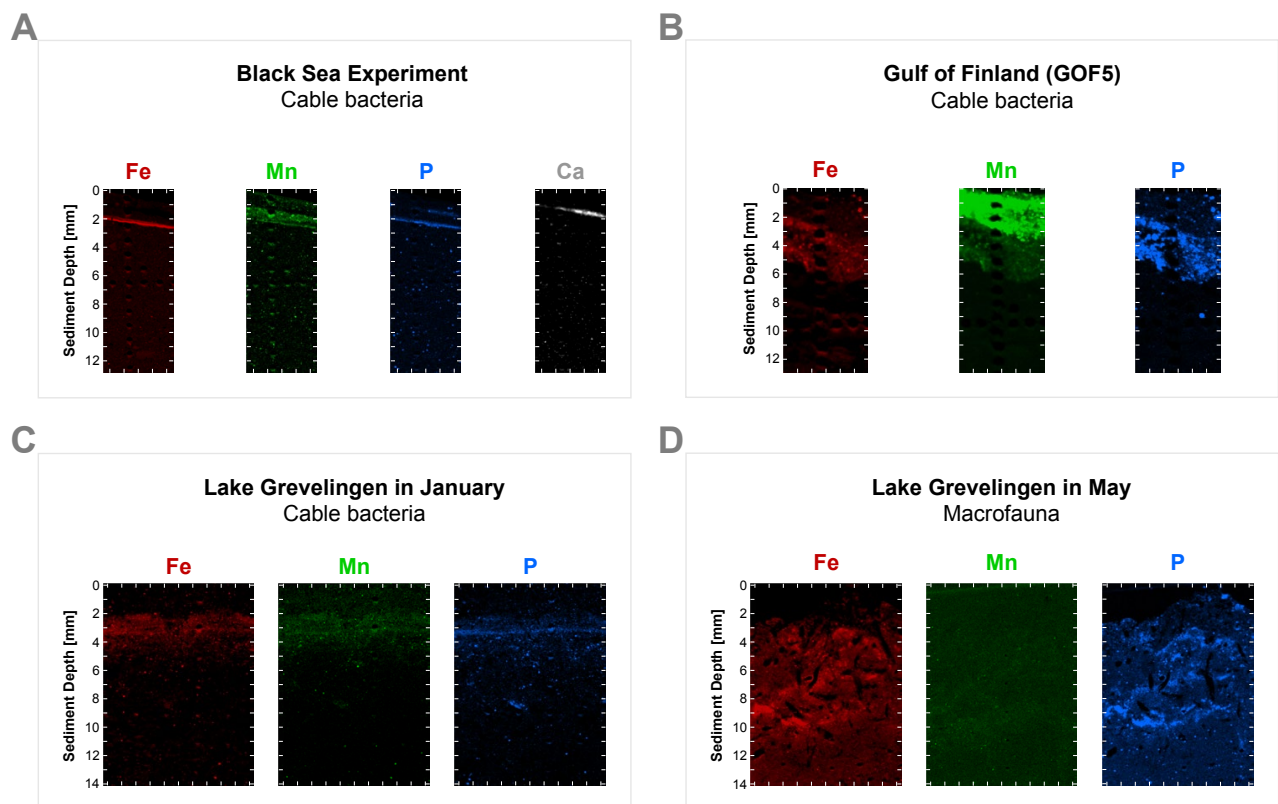

Figure 6.10 | High-resolution elemental maps of Fe (red), Mn (green), P (blue) and Ca (white) of surface sediments. These maps are shown in true vertical orientation and the colours accentuate the relative count intensities adjusted for brightness and contrast to highlight the features in the sediment. The tick marks represent $1 \mathrm{~mm}$ intervals. $\mu$ XRF maps of the surface sediment (A) from the incubation experiment, (B) from the Gulf of Finland at site GOF5 in June (Hermans et al. Submitted), (C) from Lake Grevelingen in January (when cable bacteria become active) and (D) from Lake Grevelingen in May (showing the effects of bioturbation as described in Seitaj et al. (2015)).

During the experiment, $\mathrm{O}_{2}$ penetration varied within a narrow range and was initially fixed between 1 and $2 \mathrm{~mm}$ depth (Figure 6.3A), with the layer highly enriched in Fe forming mostly at a depth of $2 \mathrm{~mm}$ (Figure 6.10A). This can be explained by rapid oxidation of upward diffusing $\mathrm{Fe}^{2+}$ upon contact with $\mathrm{O}_{2}$ (and possibly $\mathrm{NO}_{3}^{-}$; Figure 6.6C). Directly, above the Fe oxide layer a broader $\sim 0.8 \mathrm{~mm}$ thick $\mathrm{Mn}$ oxide layer was observed (Figure 6.10A). This contrast in zonation between $\mathrm{Fe}$ and $\mathrm{Mn}$ is likely due to the slower oxidation kinetics of $\mathrm{Mn}^{2+}$ compared to $\mathrm{Fe}^{2+}$ (Burdige 1993; Luther 2010; Learman et al. 2011).

While the Fe oxide layer is clearly enriched in $\mathrm{P}$, we also observed a second layer enriched in $\mathrm{P}$ close to the sediment-water interface (Figure 6.10A). In this layer, $\mathrm{P}$ is strongly correlated with Ca. This layer likely consists of carbonate fluorapatite (CFA), a Ca-P mineral, which is typically formed in marine sediments (Van Cappellen and Berner 1988; Ruttenberg and Berner 1993). Possibly, the 
high pore water $\mathrm{pH}$ near the sediment-water interface (resulting from cathodic $\mathrm{O}_{z}$ reduction by cable bacteria; Figure 6.2A), which promotes apatite formation (Bellier et al. 2006), and the elevated $\mathrm{Ca}^{2+}$ concentrations (Figure 6.5) created a biogeochemical niche for the formation of CFA.

Such focusing of Fe, Mn, P and associated elements within a thin subsurface layer, as a consequence of cable bacteria activity, also occurs in the field. This was demonstrated by Hermans et al. (Submitted) in a study of a coastal site in the Gulf of Finland where cable bacteria were recently active. Here, $\mu \mathrm{XRF}$ mapping of resin embedded sediments revealed strong focusing of $\mathrm{Fe}$ oxides, $\mathrm{Mn}(\mathrm{II})$ phosphates and Fe bound $\mathrm{P}$ within a $3 \mathrm{~mm}$ thick layer near the sediment-water interface (Figure 6.10B). A re-assessment of the $\mu$ XRF data of Sulu-Gambari et al. (2016a; 2018) of surface sediments with active cable bacteria from seasonally hypoxic marine Lake Grevelingen in January also revealed similar subsurface enrichments in Fe, Mn and P (Figure 6.10C). Importantly, no visual signals for cable bacteria based on the colour pattern of the sediment were observed at the time.

Macrofaunal activity likely counteracts or prevents strong focusing of $\mathrm{Fe}$ oxides and associated $\mathrm{P}$ within such a thin subsurface layer at field sites. Bioturbation, i.e. mixing of the sediment, typically leads to oxidation from the sediment surface downwards (Norkko et al. 2012). Bioirrigation can efficiently pump $\mathrm{O}_{2}$ into the pore water and thereby enhance the oxidation of dissolved $\mathrm{Fe}^{2+}$ (Kristensen et al. 2012; Norkko et al. 2012), but is not expected to lead to such a sharp oxidation front (Norkko et al. 2012; Hermans et al. 2019a). This is also evident from high-resolution elemental maps of the surface sediment from Lake Grevelingen in May, which shows the disappearance of the thin layer highly enriched in Fe and P formed by cable bacteria in January as a consequence of macrofaunal activity in May (Figure 6.10D; Seitaj et al. 2015; Sulu-Gambari et al. 2016b).

We conclude that the focusing of $\mathrm{Fe}, \mathrm{Mn}$ and associated $\mathrm{P}$ within a thin layer below the sediment-water interface is likely a consistent feature in sediments populated by active cable bacteria and may be a marker for their recent activity. When using standard techniques for sediment sampling (i.e. core slicing and chemical analysis of these slices), these layers may be missed due to the relatively coarse depth resolution. Hence, $\mu \mathrm{XRF}$ mapping of epoxy embedded sediment is recommended.

\subsubsection{Cable Bacteria Activity at the Field Site}

We can only speculate about the possible in-situ relevance of cable bacteria at the coastal site in the western Black Sea where the sediment for our incubation was collected. At this site, both bivalves (up to $\sim 7200$ ind. $\mathrm{m}^{-2}$ ) and polychaetes (up to $\sim 1700$ ind. $\mathrm{m}^{-2}$ ) were observed at the time of sampling (Lenstra et al. 2019). Macrofauna can inhibit the activity of cable bacteria through bioturbation by physically cutting and damaging the filaments, rendering them unable to transport electrons (Malkin et al. 2014). Recent work has shown, however, that in some cases, cable bacterial communities can also thrive in sediments with macrofauna (Burdorf et al. 2017; Malkin et al. 2017; Aller et al. 2019). In a study of bivalve reefs, cable bacteria were found to efficiently remove highly toxic $\Sigma \mathrm{H}_{2} \mathrm{~S}$, which is beneficial for bivalves (Malkin et al. 2017). Cable bacteria can also be abundant in bioturbated deposits, when associated with stable subdomains of the bioturbated zone, such as worm tubes (Aller et al. 2019). In such settings, a more complex precipitation pattern, e.g. along tube linings is observed (Aller et al. 2019), than described here for laboratory experiments with defaunated sediments and field sediments with an impoverished macrofaunal population (Figure 6.10A). Further field studies are required to assess the role of cable bacteria at our field site, preferably including an assessment of the burrow structures. 


\subsection{Conclusions}

The results of our laboratory incubation (with a total duration of 621 days) highlight the strong impact of cable bacteria on $\mathrm{Fe}, \mathrm{Mn}, \mathrm{P}$ and $\mathrm{S}$ dynamics in coastal sediments. The strong acidity of the pore water associated with the activity of cable bacteria, which was monitored using microsensor profiling of the EP during the experiment, led to dissolution of FeS and siderite and formation of $\mathrm{Fe}$ and $\mathrm{Mn}$ oxides and $\mathrm{Ca}-\mathrm{P}$ in mineral form near the sediment surface. Both $\mathrm{FeS}$ and $\mathrm{SO}_{4}{ }^{2-}$ reduction provided the $\Sigma \mathrm{H}_{2} \mathrm{~S}$ required by cable bacteria to sustain their activity. Pore water $\Sigma \mathrm{H}_{2} \mathrm{~S}$ was always low $(<5 \mu \mathrm{M})$. Using $\mu \mathrm{XRF}$ mapping of epoxy embedded sediment, we show that the activity of cable bacteria led to the development of a thin subsurface sediment layer $(0.3 \mathrm{~mm})$ that was highly enriched in $\mathrm{Fe}$ and $\mathrm{P}$. The position of this layer in the sediment was directly proportional to the $\mathrm{O}_{2}$ penetration depth during the experiment. We show that a similar layer highly enriched in $\mathrm{Fe}$ and $\mathrm{P}$ was also formed in sediments of field locations populated by cable bacteria (i.e. marine Lake Grevelingen and the brackish Gulf of Finland). We suggest that such layers, which are not necessarily visible by eye, may be used as a marker of cable bacteria activity in sediments with low macrofaunal activity.

\section{Acknowledgements}

We are grateful to the captain and crew of R/V Pelagia for their support during the expedition (64PE411). We thank S. Hidalgo-Martinez for the FISH analysis and N. Geerlings for the SEM image of the cable bacteria filaments. We thank F. Sulu-Gambari for sharing $\mu$ XRF data for sediments from Lake Grevelingen. We also thank Z. Wang, K. Wunsch, T. Hakkert, W.K. Lenstra, N.A.G.M. van Helmond, P. Kraal, M. Egger, A. Tramper, T. Zalm and J.J. Mulder for analytical support. This research was funded by the Netherlands Organisation for Scientific Research (NWO), Vici Grant 865.13.005 to CPS. Further support was provided by Research Foundation Flanders FWO Grant G038819N and NWO Vici Grant 016.VICI.170.072 to FJRM. 


\section{S.6. Supplementary Information}

\section{S6.1. Porosity}

Table S.6.1 | Depth profile of the porosity calculated from the water loss upon freeze-drying and sediment density following Burdige (2006) for one core.

\begin{tabular}{llll}
\hline Depth $[\mathrm{cm}]$ & & Porosity $\left[\mathrm{vol} \mathrm{vol}^{-1}\right]$ \\
\hline 0 & - & 0.5 & 0.90 \\
0.5 & - & 1 & 0.89 \\
1 & - & 1.5 & 0.89 \\
1.5 & - & 2 & 0.90 \\
2 & - & 2.5 & 0.84 \\
2.5 & - & 3 & 0.84 \\
3 & - & 3.5 & 0.81 \\
3.5 & - & 4 & 0.81 \\
4 & - & 4.5 & 0.81 \\
4.5 & - & 5 & 0.81 \\
\hline
\end{tabular}




\section{S6.2. Sequential Extractions}

Table S.6.2 | Sequential extraction scheme for Fe, S and P.

\begin{tabular}{|c|c|c|}
\hline Extracted mineral phase & Solvent & Time \\
\hline \multicolumn{3}{|l|}{ Sequential Fe extraction ${ }^{1,2}$} \\
\hline $\begin{array}{l}1 \text { Labile ferric } \mathrm{Fe} \text { oxides (ferrihydrite, } \\
\text { akaganéite and lepidocrocite) } \\
\text { ferous } \mathrm{Fe}\left(\mathrm{FeS} \text { and } \mathrm{FeCO}_{3}\right)^{1}\end{array}$ & $1 \mathrm{M} \mathrm{HCl}$ & $4 \mathrm{~h}$ \\
\hline 2 Crystalline Fe oxides' & $\begin{array}{l}0.35 \mathrm{M} \text { acetic acid / } 0.2 \mathrm{M} \text { sodium citrate } \\
\text { with } 50 \mathrm{~g} \mathrm{~L}^{-1} \text { sodium dithionite, } \mathrm{pH} 4.8\end{array}$ & $4 \mathrm{~h}$ \\
\hline 3 Magnetite $^{2}$ & $0.2 \mathrm{M}$ ammonium oxalate / $0.14 \mathrm{M}$ oxalic acid, $\mathrm{pH} 3.2$ & $6 \mathrm{~h}$ \\
\hline 4 Pyrite $^{1}$ & $\mathrm{HNO}_{3}(65-70 \%)$ & $2 \mathrm{~h}$ \\
\hline \multicolumn{3}{|l|}{ Sequential S extraction ${ }^{3,4}$} \\
\hline 1 Acid volatile sulphur (AVS) & $6 \mathrm{M} \mathrm{HCl}$ & $24 \mathrm{~h}$ \\
\hline 2 Elemental sulphur $\left(\mathrm{S}_{0}\right)$ & Methanol (99.8\%) & $16 \mathrm{~h}$ \\
\hline 3 Chromium reducible sulfur (CRS) & $500 \mathrm{~g} / \mathrm{L}$ chromous choride in $32 \% \mathrm{HCl}$ & $48 \mathrm{~h}$ \\
\hline \multicolumn{3}{|l|}{ Sequential $\mathrm{P}$ extraction ${ }^{5}$} \\
\hline 1 Exchangeable $P$ & $1 \mathrm{M} \mathrm{MgCl}_{2}$ to $\mathrm{pH} 8$ & $30 \mathrm{~min}$ \\
\hline \multirow[t]{2}{*}{$\begin{array}{l}2 \text { Easily reducible or reactive ferric Fe- } \\
\text { bound P (CDB-P) }\end{array}$} & $\begin{array}{l}\text { Citrate-bicarbonate-CDB buffered to } \mathrm{pH} 7.5 \\
\text { with sodium citrate / sodium bicarbonate }\end{array}$ & $8 \mathrm{~h}$ \\
\hline & $1 \mathrm{M} \mathrm{MgCl}_{2}$ to $\mathrm{pH} 8$ (wash step) & $30 \mathrm{~min}$ \\
\hline \multirow[t]{2}{*}{3 Authigenic $P$} & $\begin{array}{l}1 \mathrm{M} \text { sodium acetate buffered to } \mathrm{pH} 4 \text { with } \\
\text { acetic acid }\end{array}$ & $6 \mathrm{~h}$ \\
\hline & $1 \mathrm{M} \mathrm{MgCl}_{2}$ to $\mathrm{pH} 8$ (wash step) & $30 \mathrm{~min}$ \\
\hline 4 Detrital P & $1 \mathrm{M} \mathrm{HCl}$ & $24 \mathrm{~h}$ \\
\hline 5 Organic $P$ & $1 \mathrm{M} \mathrm{HCl}$, after ashing at $550^{\circ} \mathrm{C}$ & $24 \mathrm{~h}$ \\
\hline
\end{tabular}

${ }^{1}$ Claff et al. (2010)

${ }^{2}$ Poulton and Canfield (2005)

${ }^{3}$ Burton et al. (2006)

${ }^{4}$ Burton et al. (2008)

${ }^{5}$ Ruttenberg (1992) as modified by Slomp et al. (1996) 


\section{S6.3. FISH Image of Filamentous Cable Bacteria}

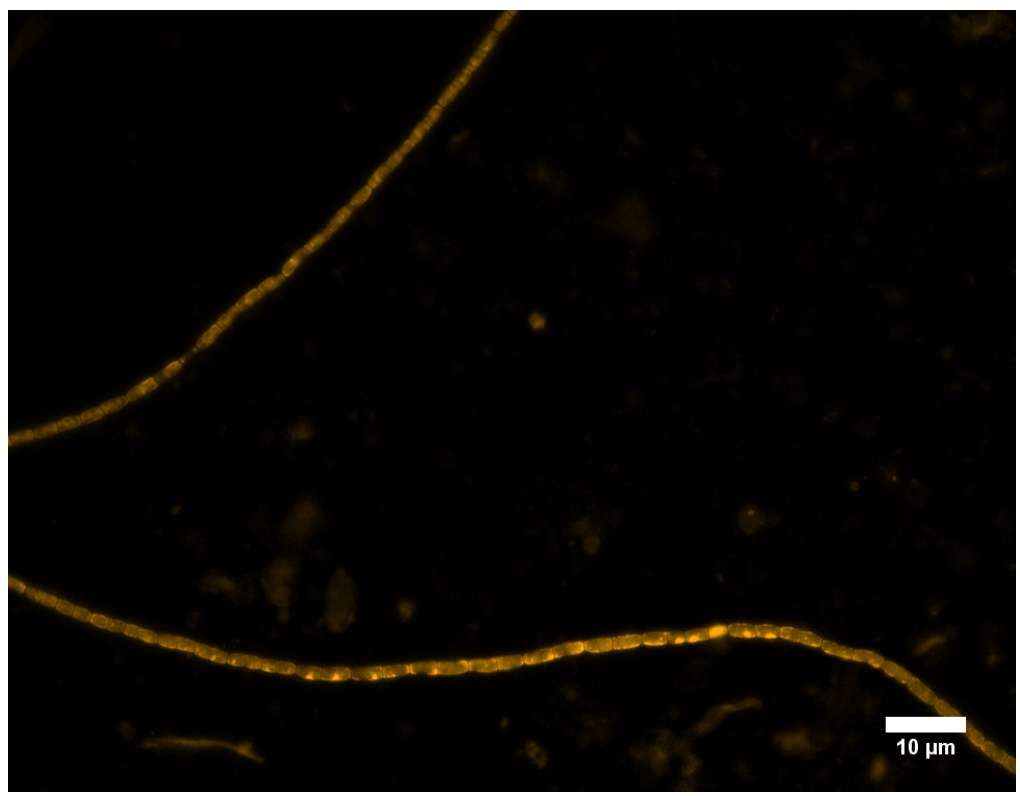

Figure S.6.1 | Microscopic FISH image of two cable bacteria filaments. These filaments were extracted from the surface sediment 207 days after the start of the incubation experiment. The white scale bar denotes a distance of $10 \mu \mathrm{m}$. 
S6.4. Time-series of Oxygen Penetration Depth

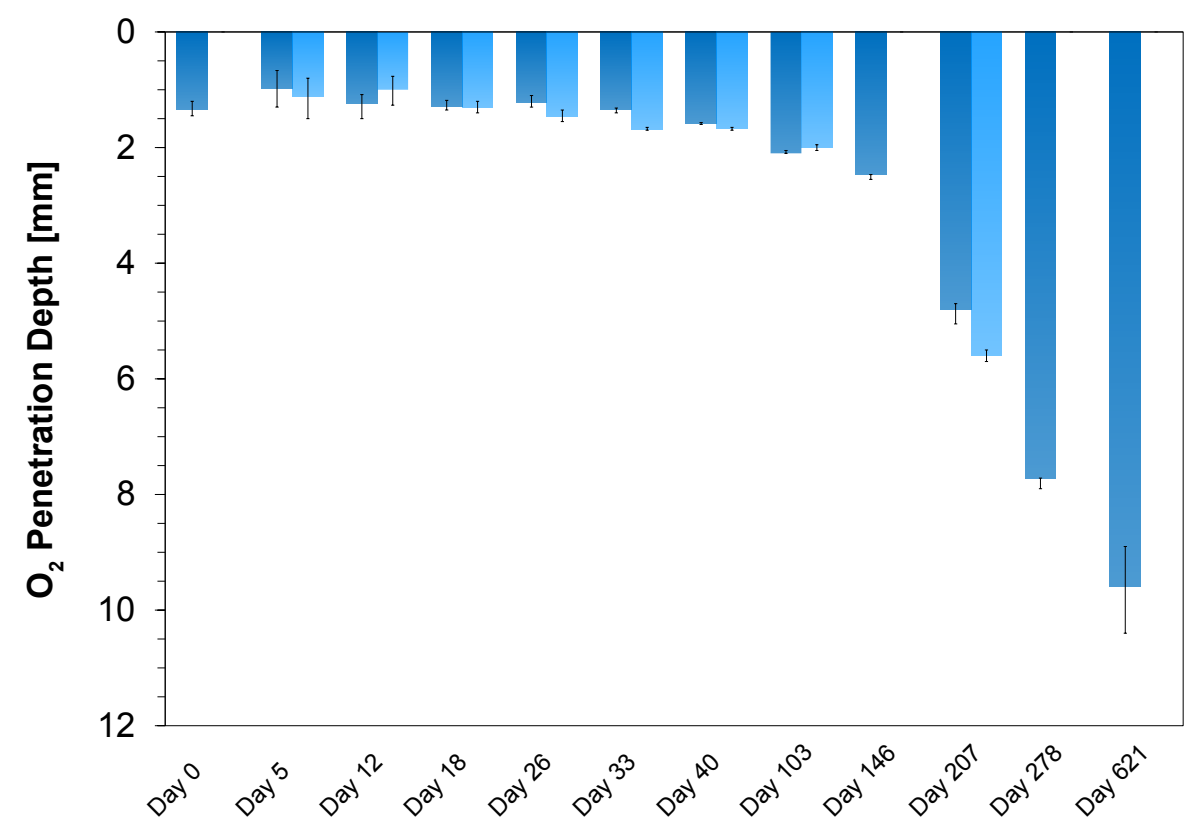

Figure S.6.2 | Time-series of the $\mathrm{O}_{2}$ penetration depth in the surface sediment in $\mathrm{mm}$ in two sediment cores. These $\mathrm{O}_{2}$ penetration depths represent the average value of 3 replicate measurements per core. The error bars represent the minimum and maximum $\mathrm{O}_{2}$ penetration depths. 
Control Day 18

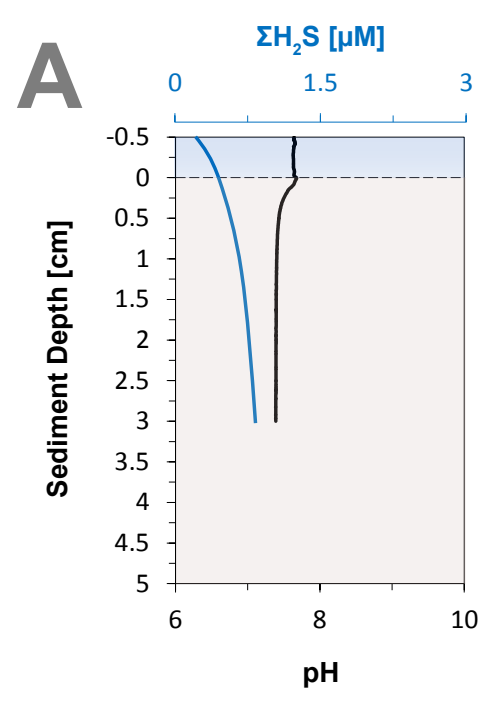

Control Day 18

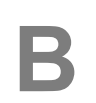

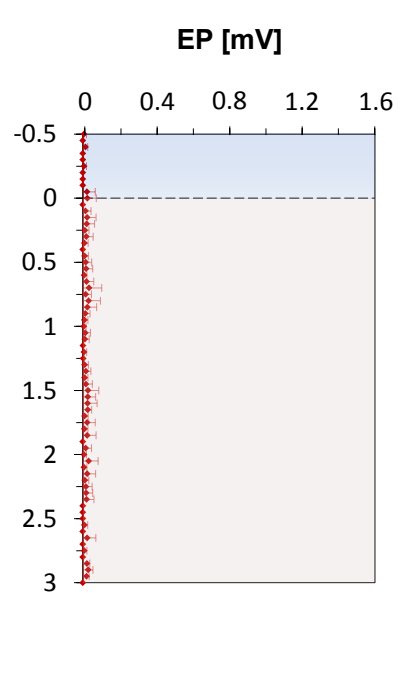

Figure S.6.3 $\mid \mathrm{pH}$ and $\Sigma \mathrm{H}_{2} \mathrm{~S}$ and EP for the anoxic control core at day 18. The pore water depth profiles for the other time points look similar. 
S6.6. Linear Pore Water Gradients of $\mathrm{NH}_{4}{ }^{+}, \mathrm{SO}_{4}{ }^{2-}, \mathrm{Fe}^{2+}, \mathrm{Mn}^{2+}, \mathrm{Ca}^{2+}$ and $\mathrm{H}_{4} \mathrm{SiO}_{4}$ used for Diffusive Fluxes
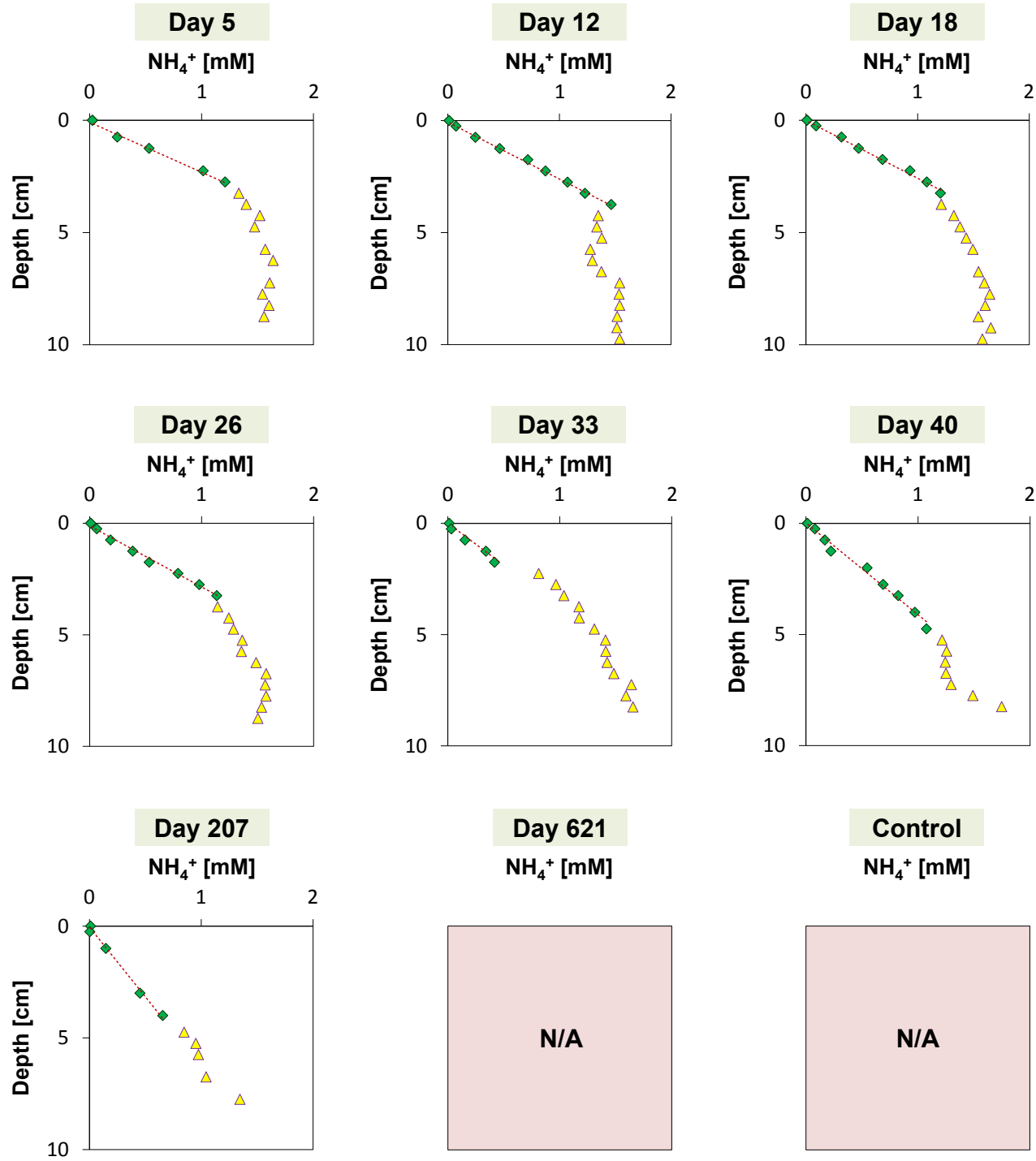

\section{Data points used for flux $\triangle$ Other data points}

Figure S.6.4 | Time-series of pore water depth profiles of $\mathrm{NH}_{4}{ }^{+}$. The linear gradient in the green and cyan diamonds represents data points that were used for the calculation of the upward $\mathrm{NH}_{4}^{+}$flux, whereas the yellow and pink triangles are data points that were not used for this calculation. 

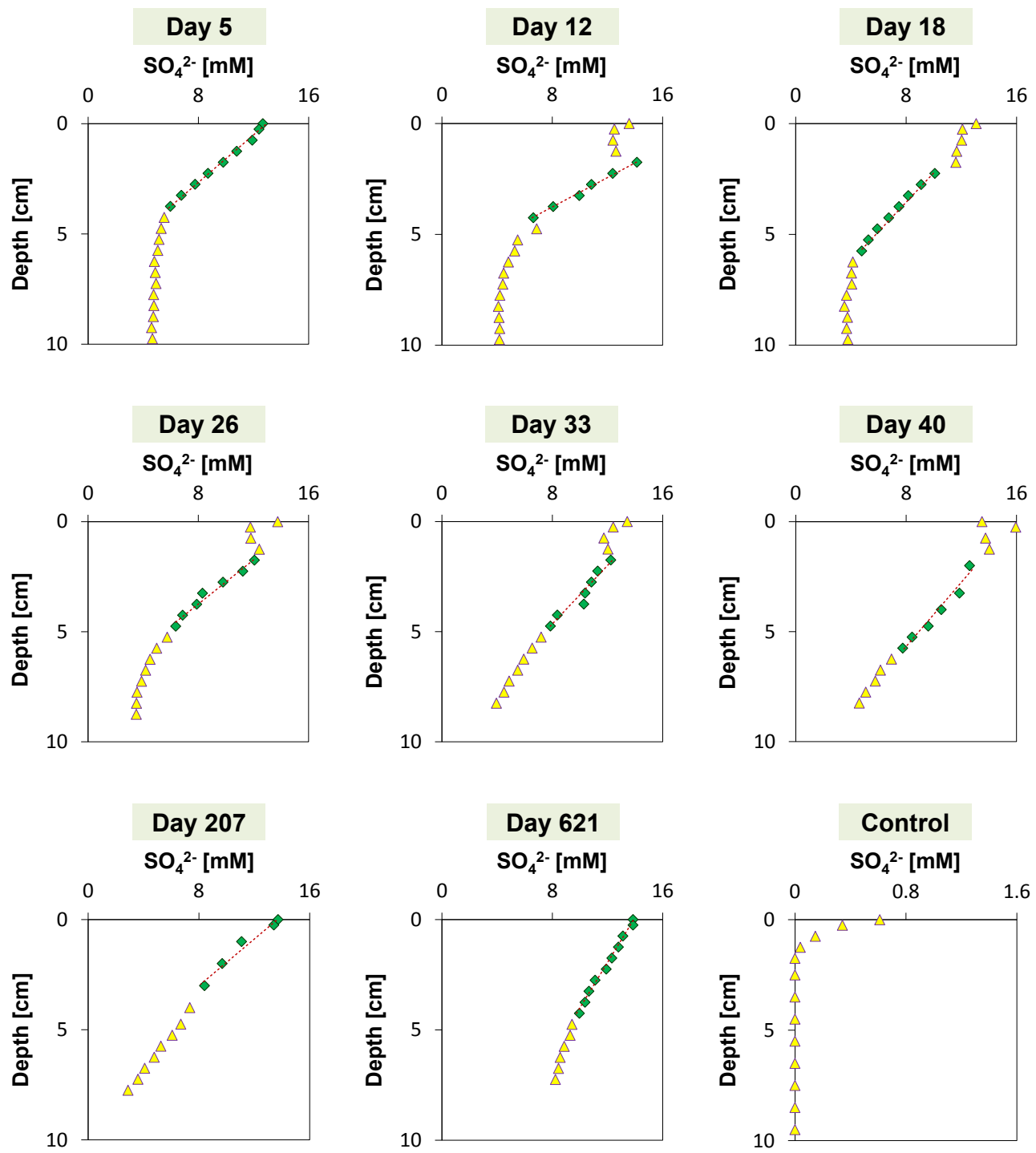

\section{Data points used for flux $\triangle$ Other data points}

Figure S.6.5 | Time-series of pore water depth profiles of $\mathrm{SO}_{4}{ }^{2-}$. The linear gradient in the green diamonds represents data points that were used for the calculation of the downward $\mathrm{SO}_{4}{ }^{2-}$ flux, whereas the yellow triangles are data points that were not used for this calculation. 

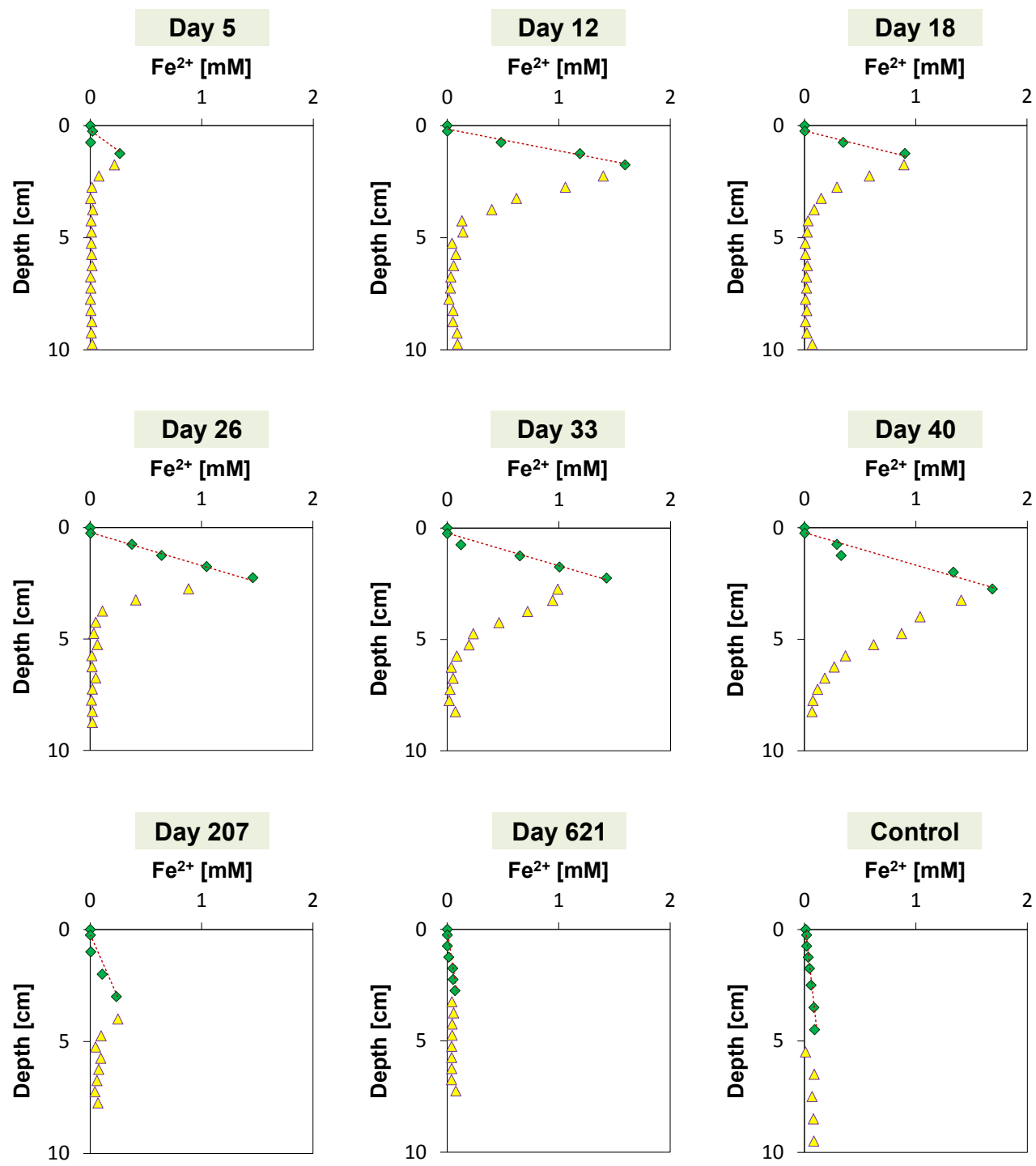

\section{Data points used for flux $\triangle$ Other data points}

Figure S.6.6 | Time-series of pore water depth profiles of dissolved $\mathrm{Fe}^{2+}$. The linear gradient in the green diamonds represents data points that were used for the calculation of the upward $\mathrm{Fe}^{2+}$ flux, whereas the yellow triangles are data points that were not used for this calculation. 

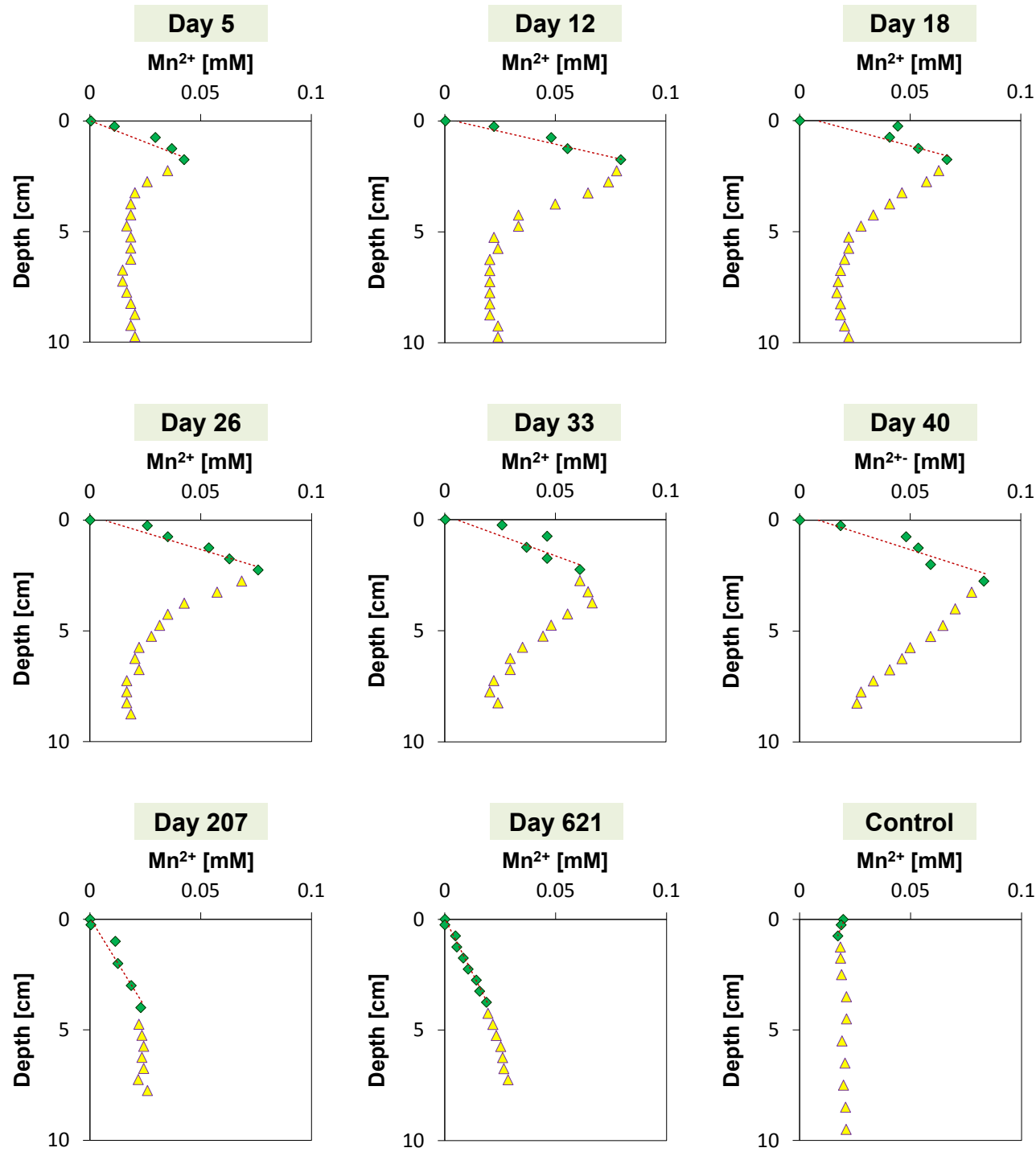

\section{Data points used for flux $\triangle$ Other data points}

Figure S.6.7 | Time-series of pore water depth profiles of dissolved $\mathrm{Mn}^{2+}$. The linear gradient in the green diamonds represents data points that were used for the calculation of the upward $\mathrm{Mn}^{2+}$ flux, whereas the yellow triangles are data points that were not used for this calculation. 

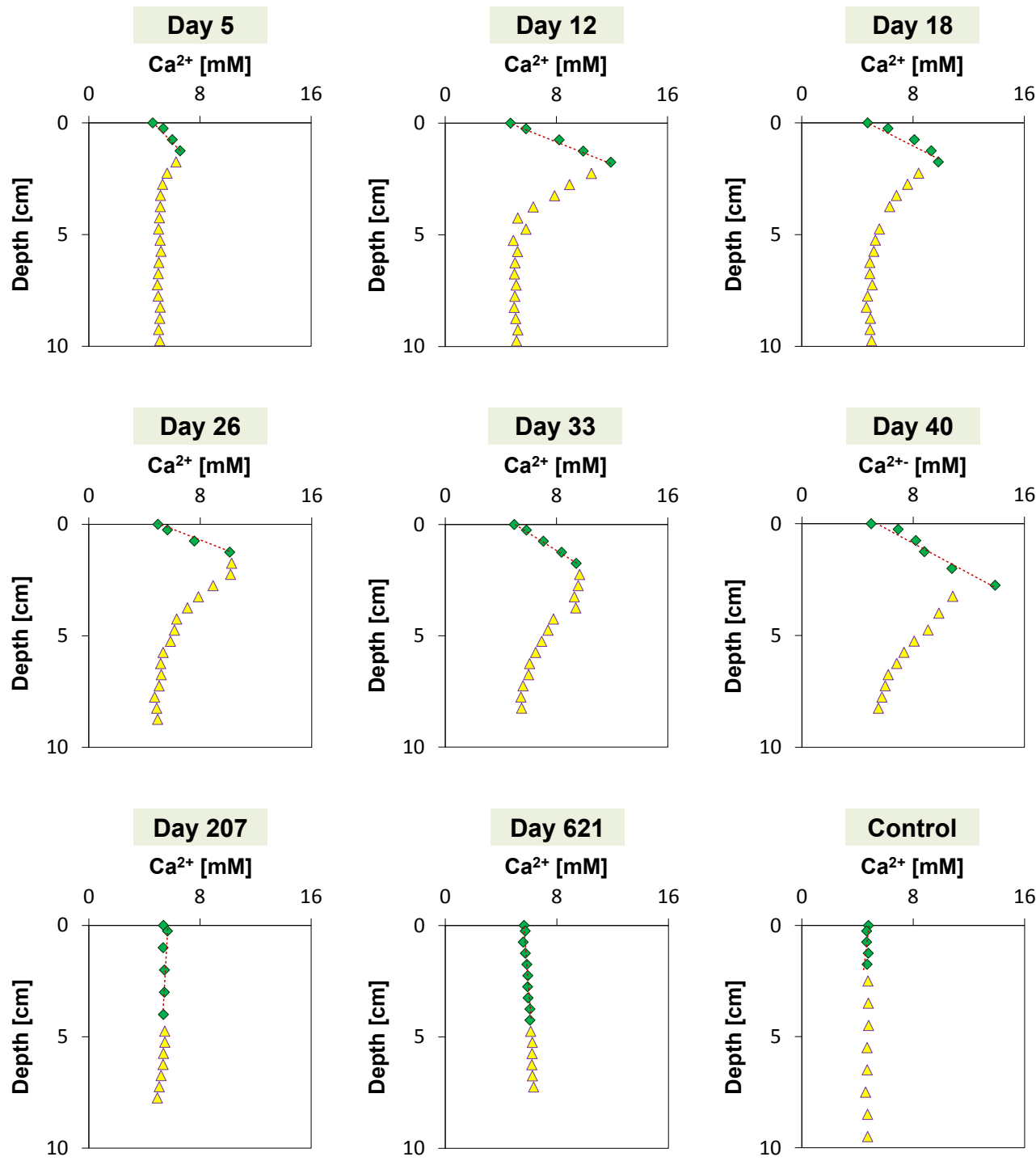

\section{Data points used for flux $\triangle$ Other data points}

Figure S.6.8 | Time-series of pore water depth profiles of dissolved $\mathrm{Ca}^{2+}$. The linear gradient in the green diamonds represents data points that were used for the calculation of the upward $\mathrm{Ca}^{2+}$ flux, whereas the yellow triangles are data points that were not used for this calculation. 

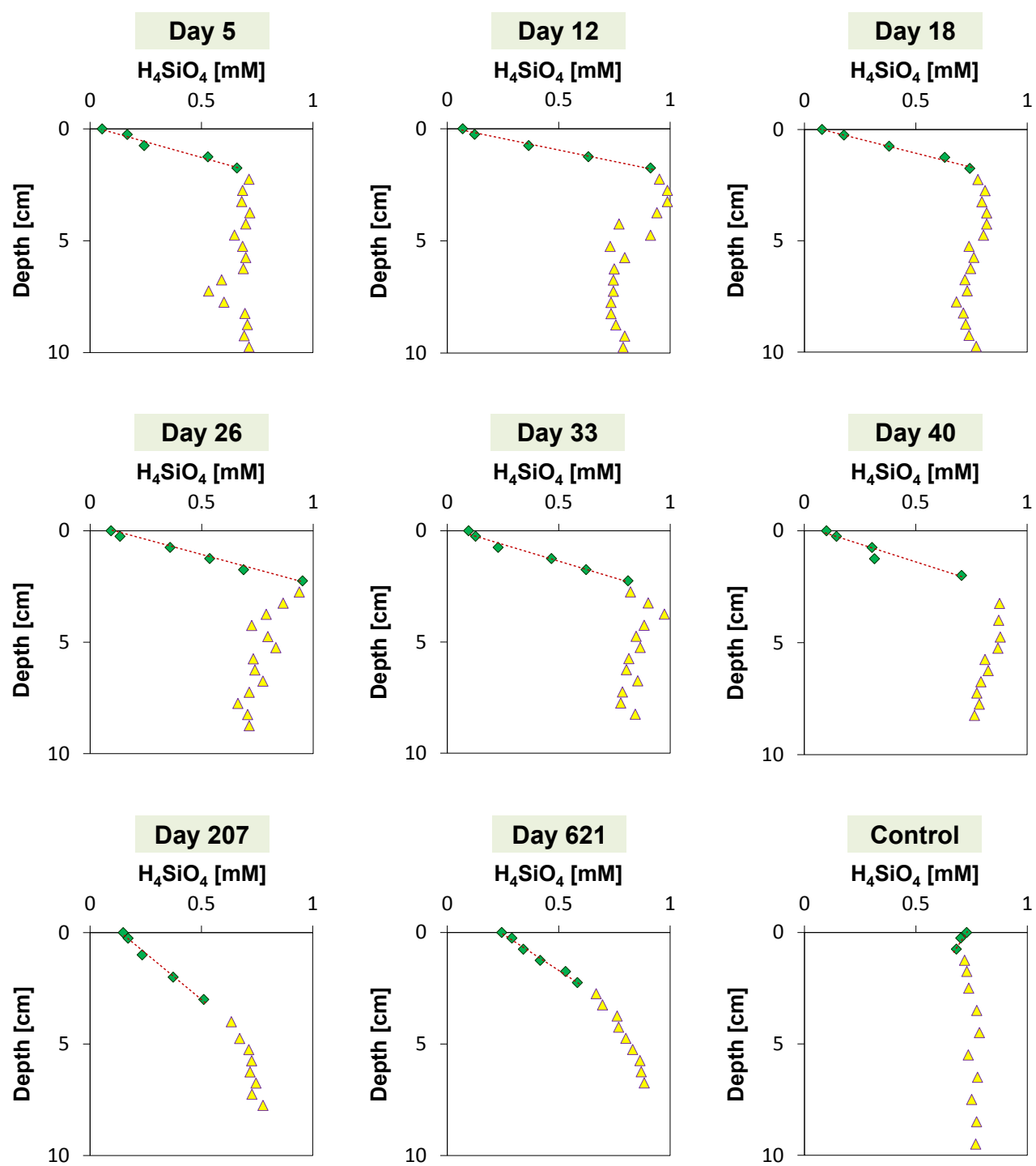

\section{Data points used for flux $\triangle$ Other data points}

Figure S.6.9 | Time-series of pore water depth profiles of dissolved $\mathrm{H}_{4} \mathrm{SiO}_{4}$. The linear gradient in the green diamonds represents data points that were used for the calculation of the upward $\mathrm{H}_{4} \mathrm{SiO}_{4}$ flux, whereas the yellow triangles are data points that were not used for this calculation. 
Table S.6.3 | Diffusive fluxes of $\mathrm{NH}_{4}^{+}, \mathrm{SO}_{4}^{2-}, \mathrm{Fe}^{2+}, \mathrm{Mn}^{2+}, \mathrm{Ca}^{2+}$ and $\mathrm{H}_{4} \mathrm{SiO}_{4}$ in $\mathrm{mmol} \mathrm{m}^{-2} \mathrm{~d}^{-1}$. Positive values indicate an upward flux, whereas negative values represent a downward flux.

\begin{tabular}{|c|c|c|c|c|c|c|}
\hline & $\begin{array}{c}\mathrm{NH}_{4}^{+} \\
\left(\mathrm{mmol} \mathrm{m}^{-2} \mathrm{~d}^{-1}\right)\end{array}$ & $\begin{array}{c}\mathrm{SO}_{4}{ }^{2-} \\
\left(\mathrm{mmol} \mathrm{m}^{-2} \mathrm{~d}^{-1}\right)\end{array}$ & $\begin{array}{c}\mathrm{Fe}^{2+} \\
\left(\mathrm{mmol} \mathrm{m}^{-2} \mathrm{~d}^{-1}\right)\end{array}$ & $\begin{array}{c}\mathrm{Mn}^{2+} \\
\left(\mathrm{mmol} \mathrm{m}^{-2} \mathrm{~d}^{-1}\right)\end{array}$ & $\begin{array}{c}\mathrm{Ca}^{2+} \\
\left(\mathrm{mmol} \mathrm{m}^{-2} \mathrm{~d}^{-1}\right)\end{array}$ & $\begin{array}{c}\mathrm{H}_{4} \mathrm{SiO}_{4} \\
\left(\mathrm{mmol} \mathrm{m}^{-2} \mathrm{~d}^{-1}\right)\end{array}$ \\
\hline Day 5 & 4.71 & -10.49 & 0.82 & 0.09 & 6.95 & 2.01 \\
\hline Day 12 & 4.23 & -17.60 & 3.54 & 0.18 & 18.23 & 2.80 \\
\hline Day 18 & 4.02 & -8.87 & 2.80 & 0.15 & 12.83 & 2.20 \\
\hline Day 26 & 3.79 & -11.15 & 2.52 & 0.13 & 18.20 & 2.22 \\
\hline Day 33 & 2.53 & -8.54 & 2.46 & 0.10 & 11.25 & 1.85 \\
\hline Day 40 & 2.44 & -7.57 & 2.38 & 0.12 & 14.33 & 1.76 \\
\hline Day 207 & 1.76 & -10.38 & 0.32 & 0.02 & 0.00 & 0.70 \\
\hline Day 621 & N/A & -5.36 & 0.10 & 0.02 & 0.45 & 0.88 \\
\hline Control (Day 621) & $\mathrm{N} / \mathrm{A}$ & $\mathrm{N} / \mathrm{A}$ & 0.07 & -0.01 & -0.23 & -0.36 \\
\hline
\end{tabular}




\section{S6.7. Solute Fluxes}
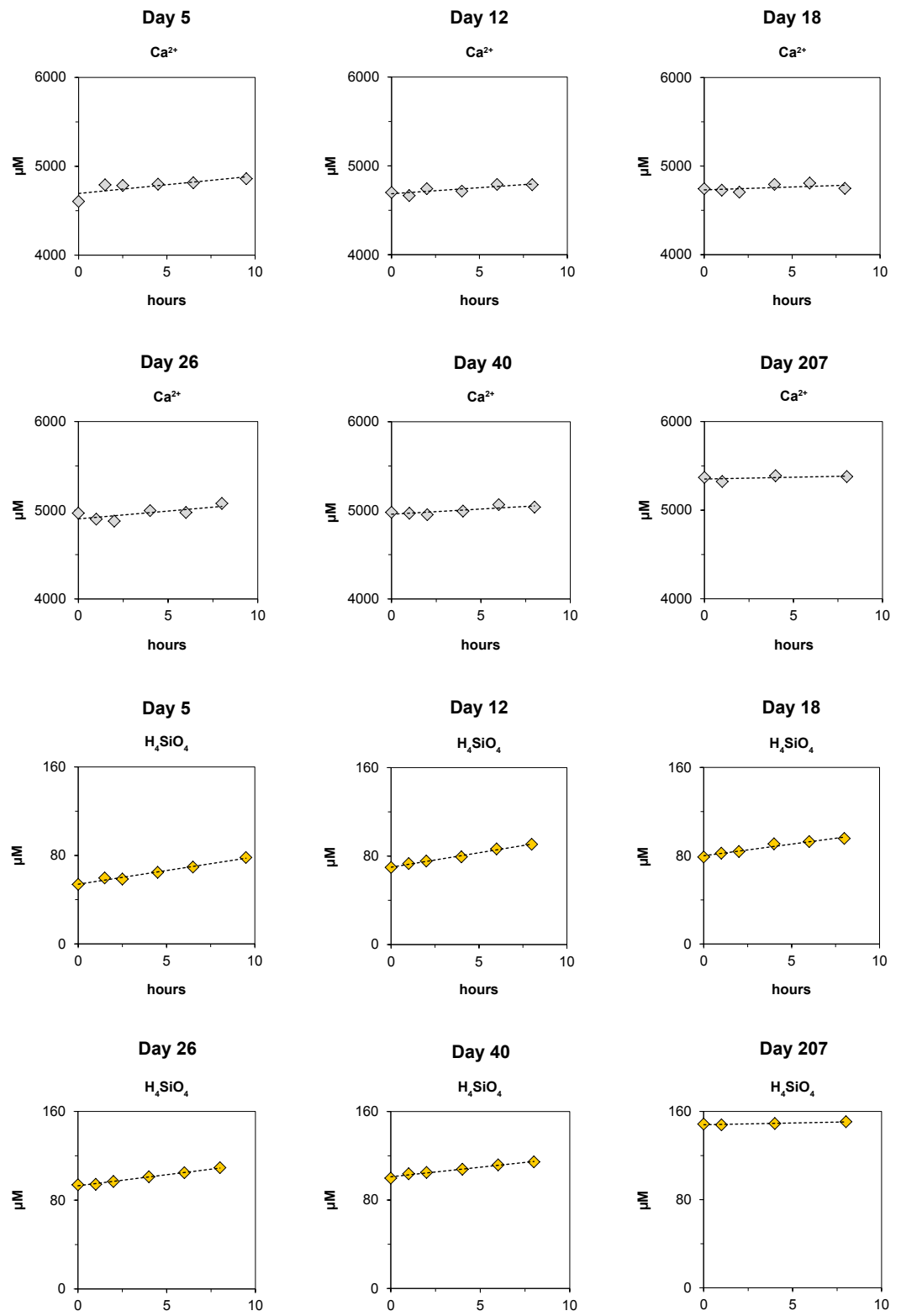

Figure S.6.10 | Concentrations of $\mathrm{Ca}^{2+}$ and $\mathrm{H}_{4} \mathrm{SiO}_{4}$ in the overlying water during solute flux incubations over an 8 hour time period for day 5, $1218,26,40$ and 207. The linear gradient was used for the calculation of the fluxes. 
Table S.6.4 | Solute fluxes of $\mathrm{Ca}^{2+}$ and $\mathrm{H}_{4} \mathrm{SiO}_{4}$ in $\mathrm{mmol} \mathrm{m}^{-2} \mathrm{~d}^{-1}$.

\begin{tabular}{lcc}
\hline & $\begin{array}{c}\mathrm{Ca}^{2+} \\
\left(\mathrm{mmol} \mathrm{m}^{-2} \mathrm{~d}^{-1}\right.\end{array}$ & $\begin{array}{c}\mathrm{H}_{4} \mathrm{SiO}_{4} \\
\left(\mathrm{mmol} \mathrm{m}^{-2} \mathrm{~d}^{-1}\right)\end{array}$ \\
\hline Day 5 & 19.38 & 1.84 \\
Day 12 & 7.88 & 1.89 \\
Day 18 & 0.46 & 1.51 \\
Day 26 & 9.95 & 1.39 \\
Day 40 & 5.27 & 1.33 \\
Day 207 & 0.88 & 0.20 \\
\hline
\end{tabular}

\section{S6.8. Time-series of Core Photographs}

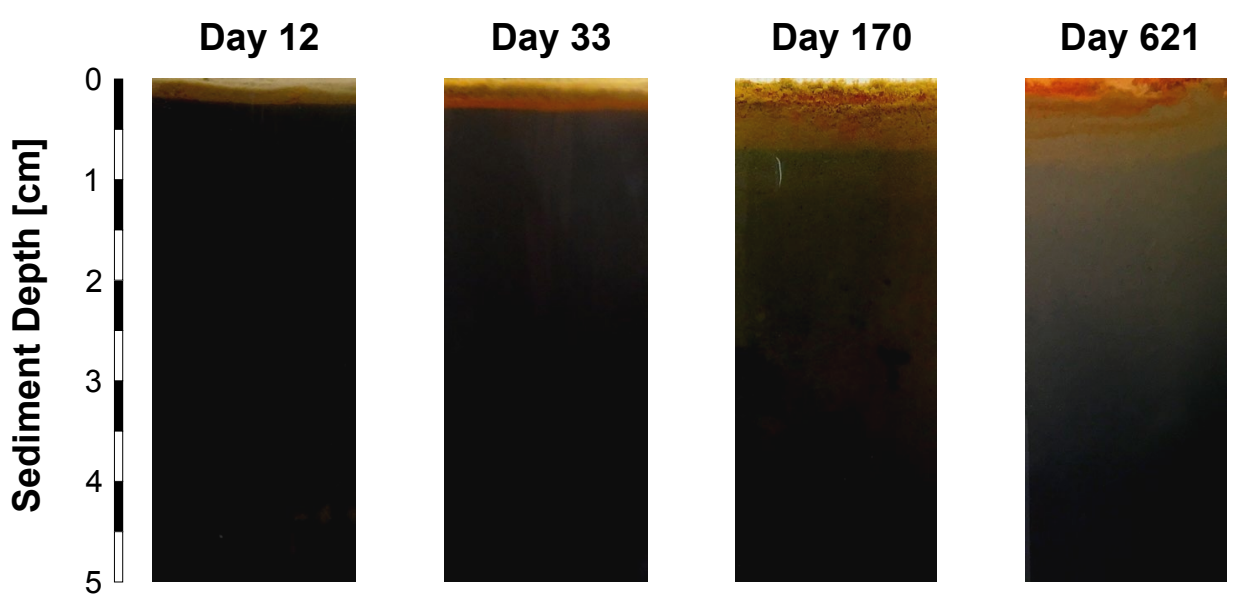

Figure S.6.11 | Time-series of core photographs. The scale bar intervals denote a distance of $0.5 \mathrm{~cm}$. 


\section{S6.9. Time-series of Iron Speciation}

Table S.6.5 | Iron speciation

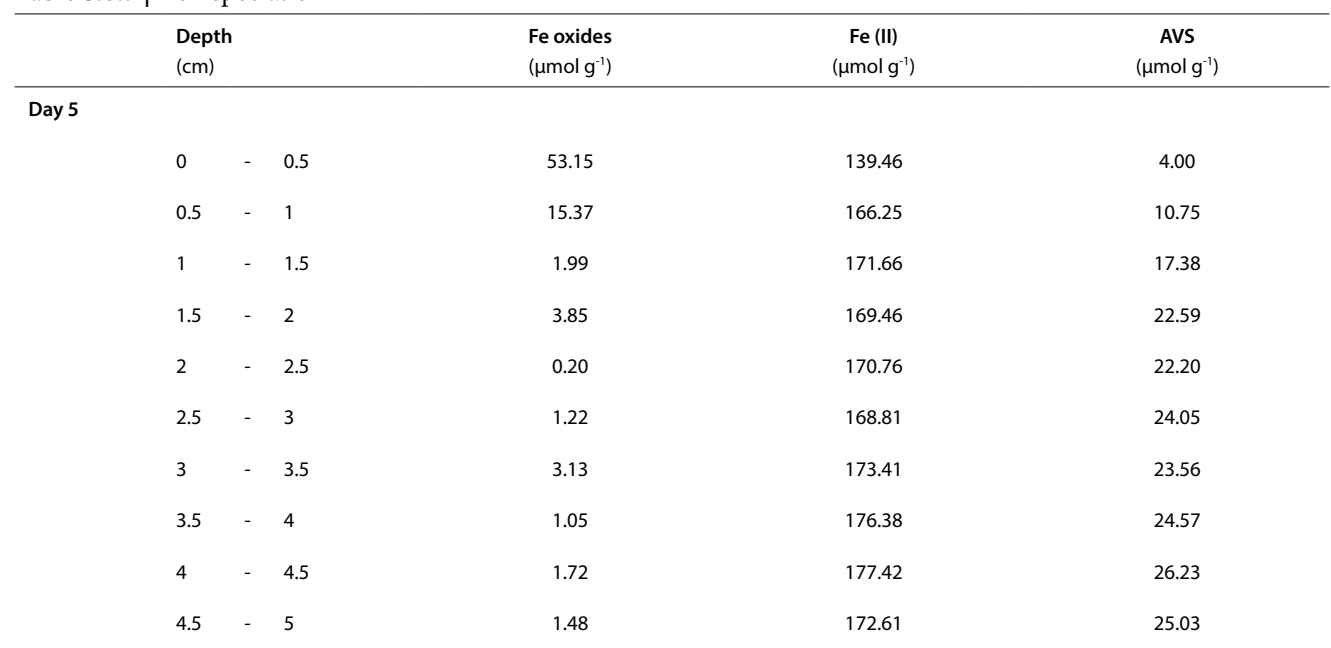

Day 12

$\begin{array}{llllll}0 & - & 0.5 & 81.55 & 120.62 & 1.97 \\ 0.5 & - & 1 & 16.58 & 151.39 & 12.16 \\ 1 & - & 1.5 & 2.87 & 157.71 & 18.41 \\ 1.5 & - & 2 & 2.58 & 164.69 & 20.10 \\ 2 & - & 2.5 & 2.71 & 167.03 & 23.57 \\ 2.5 & - & 3 & 2.71 & 175.84 & 23.04 \\ 3 & - & 3.5 & 1.27 & 164.29 & 25.17 \\ 3.5 & -4 & 1.35 & 174.46 & 24.27 \\ 4 & -4.5 & 3.54 & 175.73 & 25.35 \\ 4.5 & - & 5 & 2.45 & 177.38 & 25.31\end{array}$

Day 18

$\begin{array}{llllll}0 & - & 0.5 & 97.02 & 122.42 & 1.71 \\ 0.5 & - & 1 & 17.45 & 145.63 & 9.16 \\ 1 & - & 1.5 & 4.40 & 159.84 & 12.64 \\ 1.5 & - & 2 & 1.53 & 168.80 & 20.84 \\ 2 & - & 2.5 & 2.47 & 165.99 & 20.93 \\ 2.5 & - & 3 & 1.72 & 174.74 & 24.62 \\ 3 & - & 3.5 & 1.12 & 175.78 & 24.85 \\ 3.5 & - & 4 & 3.60 & 177.05 & 24.72 \\ 4 & -4.5 & 1.41 & 173.60 & 24.42 \\ 4.5 & - & 5 & 2.12 & 173.78 & 25.60\end{array}$


Table S.6.5 | Iron speciation (continued)

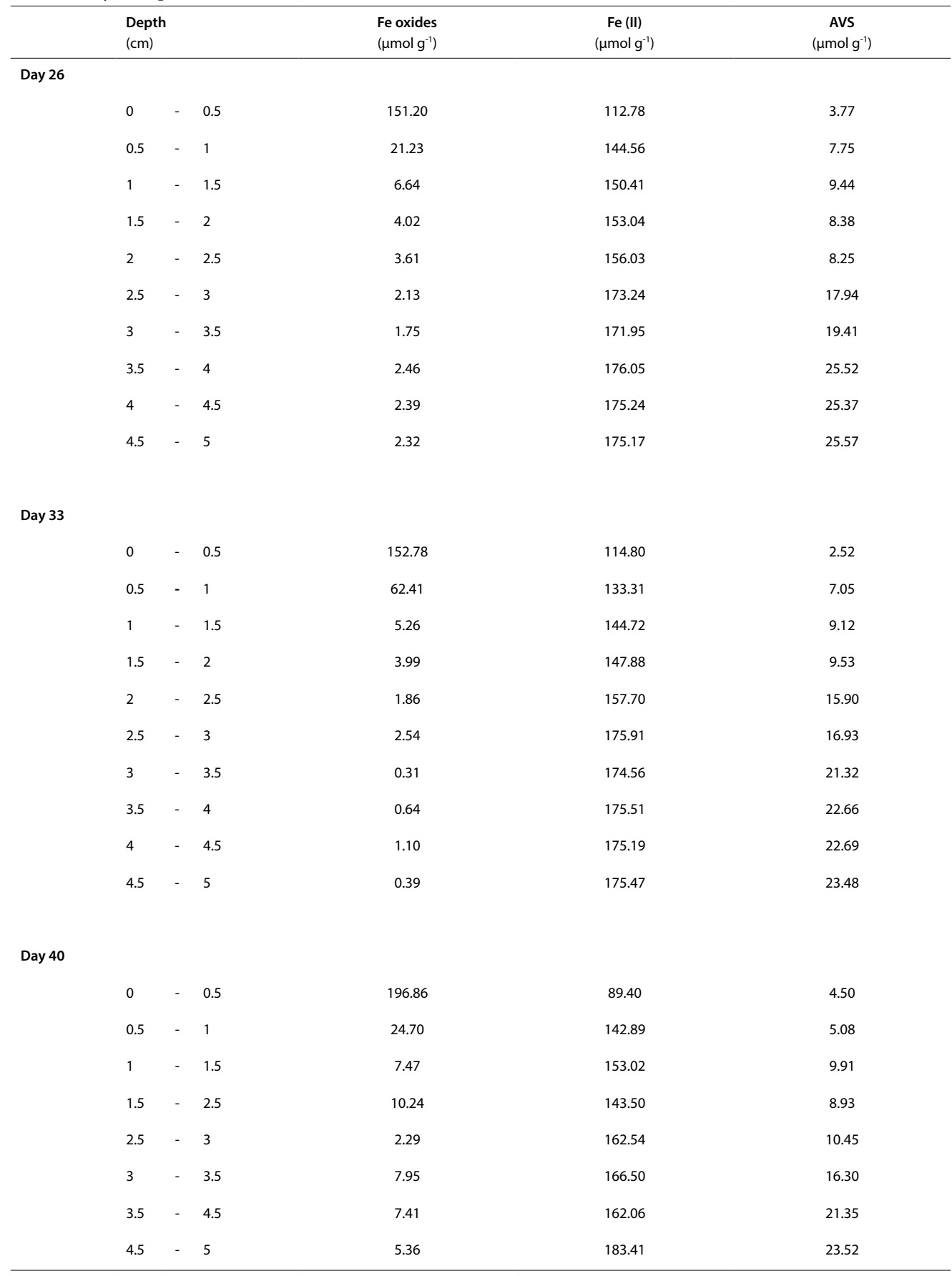


Table S.6.5 | Iron speciation (continued)

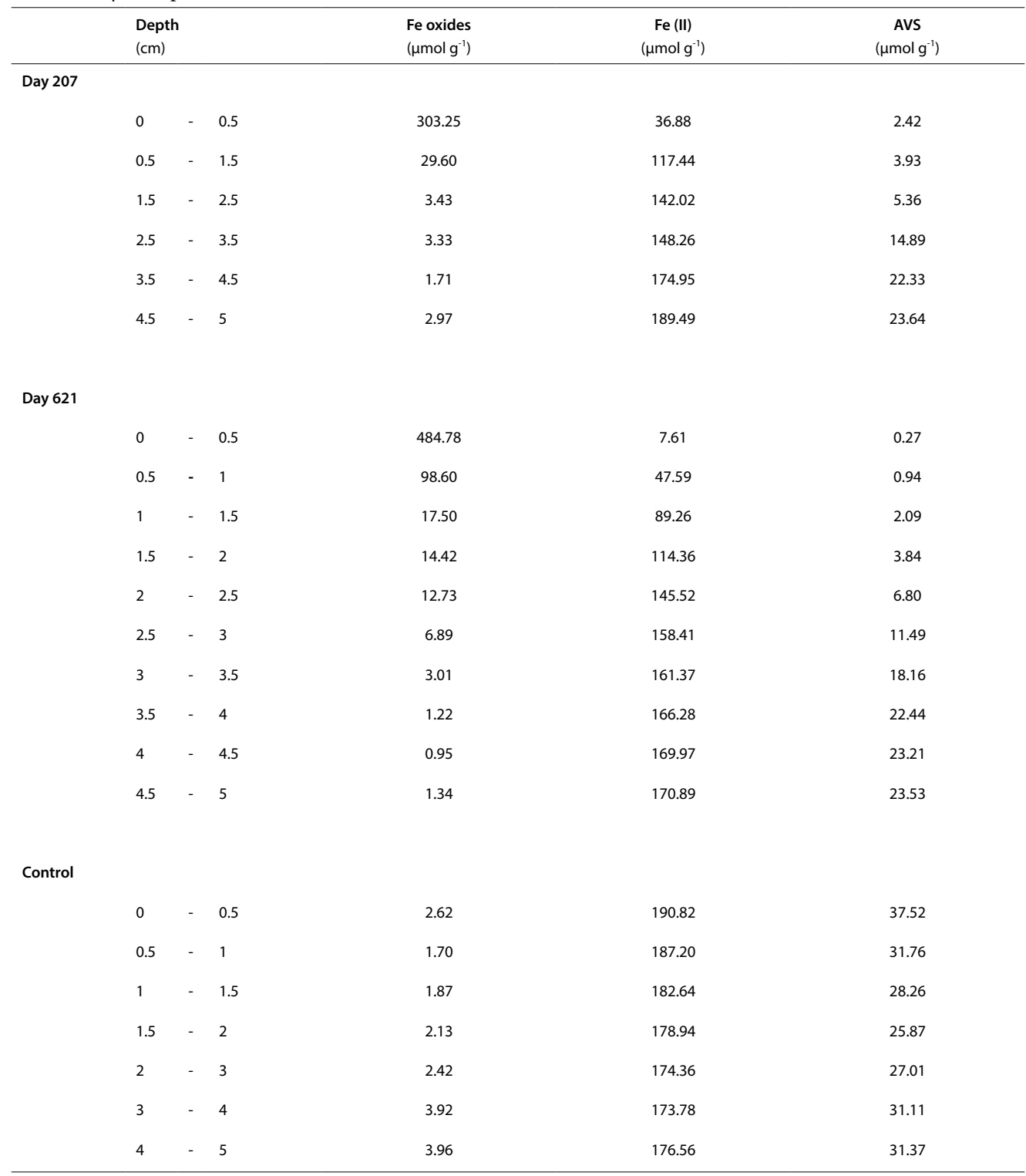




\section{S6.10. Time-series of Phosphorus Speciation}

Table S.6.6| Phosphorus speciation

\begin{tabular}{|c|c|c|c|c|c|c|c|c|}
\hline & $\begin{array}{l}\text { Dept } \\
(\mathrm{cm})\end{array}$ & & & $\begin{array}{c}\text { Exchangeable } P \\
\left(\mu \mathrm{mol} \mathrm{g}^{-1}\right)\end{array}$ & $\begin{array}{c}\text { CDB-P } \\
\left(\mu \mathrm{mol} \mathrm{g} \mathrm{g}^{-1}\right)\end{array}$ & $\begin{array}{c}\text { Authigenic P } \\
\left(\mu \mathrm{mol} \mathrm{g}^{-1}\right)\end{array}$ & $\begin{array}{l}\text { Detrital P } \\
\left.(\mu \mathrm{mol} \mathrm{g})^{-1}\right)\end{array}$ & $\begin{array}{l}\text { Organic P } \\
\left.(\mu \mathrm{mol} \mathrm{g})^{-1}\right)\end{array}$ \\
\hline \multicolumn{9}{|l|}{ Day 5} \\
\hline & 0 & - & 0.5 & 0.88 & 5.73 & 4.82 & 5.22 & $\mathrm{~N} / \mathrm{A}$ \\
\hline & 0.5 & - & 1 & 0.44 & 5.49 & 6.11 & 6.03 & $\mathrm{~N} / \mathrm{A}$ \\
\hline & 1 & - & 1.5 & 0.34 & 4.67 & 5.87 & 6.29 & N/A \\
\hline & 1.5 & - & 2 & 0.39 & 4.76 & 5.86 & 5.81 & N/A \\
\hline & 2 & - & 2.5 & 0.48 & 4.75 & 5.33 & 6.06 & $\mathrm{~N} / \mathrm{A}$ \\
\hline & 2.5 & - & 3 & 0.44 & 4.75 & 5.50 & 5.56 & $\mathrm{~N} / \mathrm{A}$ \\
\hline & 3 & - & 3.5 & 0.47 & 4.60 & 5.39 & 5.55 & N/A \\
\hline & 3.5 & - & 4 & 0.48 & 4.34 & 5.26 & 4.78 & $\mathrm{~N} / \mathrm{A}$ \\
\hline & 4 & - & 4.5 & 0.43 & 4.73 & 5.00 & 5.69 & N/A \\
\hline & 4.5 & - & 5 & 0.50 & 3.71 & 5.00 & 5.85 & $\mathrm{~N} / \mathrm{A}$ \\
\hline
\end{tabular}

Day 12

$\begin{array}{llllllll}0 & - & 0.5 & 0.44 & 6.21 & 6.30 & 4.71 & \mathrm{~N} / \mathrm{A} \\ 0.5 & - & 1 & 0.26 & 4.34 & 5.55 & 4.99 & \mathrm{~N} / \mathrm{A} \\ 1 & - & 1.5 & 0.12 & 3.09 & 4.35 & 4.46 & \mathrm{~N} / \mathrm{A} \\ 1.5 & - & 2 & 0.15 & 3.69 & 4.43 & 4.28 & \mathrm{~N} / \mathrm{A} \\ 2 & - & 2.5 & 0.29 & 4.27 & 5.87 & 5.22 & \mathrm{~N} / \mathrm{A} \\ 2.5 & - & 3 & 0.30 & 4.68 & 5.72 & 5.39 & \mathrm{~N} / \mathrm{A} \\ 3 & - & 3.5 & 0.36 & 4.43 & 6.04 & 5.56 & \mathrm{~N} / \mathrm{A} \\ 3.5 & - & 4 & 0.44 & 4.15 & 5.93 & 5.09 & \mathrm{~N} / \mathrm{A} \\ 4 & - & 4.5 & 0.46 & 4.27 & 4.95 & 5.47 & \mathrm{~N} / \mathrm{A} \\ 4.5 & - & 5 & 0.55 & 4.19 & 4.96 & 5.44 & \mathrm{~N} / \mathrm{A}\end{array}$

Day 18

\begin{tabular}{llllllll}
0 & - & 0.5 & 0.40 & 5.86 & 6.38 & 5.30 & $\mathrm{~N} / \mathrm{A}$ \\
0.5 & - & 1 & 0.16 & 4.20 & 5.41 & 7.01 & $\mathrm{~N} / \mathrm{A}$ \\
1 & - & 1.5 & 0.20 & 4.52 & 5.65 & 6.13 & $\mathrm{~N} / \mathrm{A}$ \\
1.5 & - & 2 & 0.37 & 4.39 & 5.73 & 6.13 & $\mathrm{~N} / \mathrm{A}$ \\
2 & - & 2.5 & 0.20 & 4.24 & 4.57 & 6.58 & $\mathrm{~N} / \mathrm{A}$ \\
2.5 & - & 3 & 0.41 & 4.29 & 4.78 & 5.42 & $\mathrm{~N} / \mathrm{A}$ \\
3 & - & 3.5 & 0.34 & 4.70 & 5.26 & 6.86 & $\mathrm{~N} / \mathrm{A}$ \\
3.5 & - & 4 & 0.48 & 4.07 & 4.41 & 6.32 & $\mathrm{~N} / \mathrm{A}$ \\
4 & - & 4.5 & 0.62 & 3.89 & 4.39 & 5.41 & $\mathrm{~N} / \mathrm{A}$ \\
4.5 & - & 5 & 0.47 & 4.16 & 5.95 & 6.06 & $\mathrm{~N} / \mathrm{A}$ \\
\hline
\end{tabular}


Table S.6.6 | Phosphorus speciation (continued)

\begin{tabular}{|c|c|c|c|c|c|c|c|c|}
\hline & $\begin{array}{l}\text { Deptr } \\
(\mathrm{cm})\end{array}$ & & & $\begin{array}{c}\text { Exchangeable P } \\
\left(\mu \mathrm{mol} \mathrm{g}^{-1}\right)\end{array}$ & $\begin{array}{c}\text { CDB-P } \\
\left(\mu \mathrm{mol} \mathrm{g}^{-1}\right)\end{array}$ & $\begin{array}{l}\text { Authigenic P } \\
\left(\mu \mathrm{mol} \mathrm{g}^{-1}\right)\end{array}$ & $\begin{array}{l}\text { Detrital P } \\
\left(\mu \mathrm{mol} \mathrm{g}^{-1}\right)\end{array}$ & $\begin{array}{l}\text { Organic P } \\
\left.(\mu \mathrm{mol} \mathrm{g})^{-1}\right)\end{array}$ \\
\hline \multicolumn{9}{|l|}{ Day 26} \\
\hline & 0 & - & 0.5 & 1.50 & 6.63 & 5.50 & 6.38 & 5.14 \\
\hline & 0.5 & - & 1 & 0.60 & 6.91 & 5.31 & 6.44 & 5.29 \\
\hline & 1 & - & 1.5 & 0.56 & 7.18 & 5.38 & 6.35 & 5.22 \\
\hline & 1.5 & - & 2 & 0.55 & 6.97 & 4.76 & 5.81 & 4.84 \\
\hline & 2 & - & 2.5 & 0.81 & 6.31 & 4.49 & 5.49 & 4.23 \\
\hline & 2.5 & - & 3 & 0.76 & 7.30 & 5.35 & 6.33 & 5.16 \\
\hline & 3 & - & 3.5 & 0.89 & 6.91 & 5.76 & 6.05 & 4.94 \\
\hline & 3.5 & - & 4 & 1.02 & 7.19 & 5.58 & 5.60 & 4.83 \\
\hline & 4 & - & 4.5 & 0.93 & 7.03 & 5.73 & 5.86 & 4.94 \\
\hline & 4.5 & - & 5 & 1.20 & 6.84 & 5.63 & 6.15 & 5.14 \\
\hline \multicolumn{9}{|l|}{ Day 33} \\
\hline & 0 & - & 0.5 & 0.52 & 12.10 & 5.53 & 6.56 & 5.50 \\
\hline & 0.5 & - & 1 & 0.53 & 9.92 & 5.32 & 6.38 & 5.23 \\
\hline & 1 & - & 1.5 & 0.43 & 6.78 & 5.03 & 6.57 & 5.31 \\
\hline & 1.5 & - & 2 & 0.46 & 5.99 & 5.66 & 6.40 & 5.66 \\
\hline & 2 & - & 2.5 & 0.57 & 6.91 & 5.66 & 5.91 & 5.16 \\
\hline & 2.5 & - & 3 & 0.48 & 7.64 & 5.36 & 6.49 & 4.88 \\
\hline & 3 & - & 3.5 & 0.54 & 7.95 & 5.79 & 5.90 & 5.13 \\
\hline & 3.5 & - & 4 & 0.67 & 7.57 & 6.05 & 6.04 & 5.09 \\
\hline & 4 & - & 4.5 & 0.86 & 7.47 & 5.87 & 6.03 & 5.14 \\
\hline & 4.5 & - & 5 & 0.69 & 3.62 & 5.78 & 6.25 & 5.21 \\
\hline \multicolumn{9}{|l|}{ Day 40} \\
\hline & 0 & - & 0.5 & 0.62 & 18.06 & 5.81 & 6.53 & 5.24 \\
\hline & 0.5 & - & 1 & 0.40 & 8.42 & 5.68 & 5.96 & 5.37 \\
\hline & 1 & - & 1.5 & 0.71 & 7.04 & 5.99 & 5.96 & 5.26 \\
\hline & 1.5 & - & 2.5 & 0.50 & 7.41 & 5.77 & 6.15 & 5.15 \\
\hline & 2.5 & - & 3 & 0.56 & 7.95 & 5.75 & 5.79 & 5.39 \\
\hline & 3 & - & 3.5 & 0.50 & 7.31 & 5.53 & 6.01 & 5.12 \\
\hline & 3.5 & - & 4.5 & 0.51 & 7.69 & 5.55 & 6.21 & 5.26 \\
\hline & 4.5 & - & 5 & 0.73 & 7.69 & 5.66 & 5.86 & 4.95 \\
\hline
\end{tabular}


Table S.6.6 | Phosphorus speciation (continued)

\begin{tabular}{|c|c|c|c|c|c|c|c|c|}
\hline & $\begin{array}{l}\text { Deptr } \\
(\mathrm{cm})\end{array}$ & & & $\begin{array}{c}\text { Exchangeable } P \\
\left(\mu \mathrm{mol} \mathrm{g}^{-1}\right)\end{array}$ & $\begin{array}{c}\text { CDB-P } \\
\left(\mu \mathrm{mol} \mathrm{g}^{-1}\right)\end{array}$ & $\begin{array}{l}\text { Authigenic P } \\
\left(\mu \mathrm{mol} \mathrm{g}^{-1}\right)\end{array}$ & $\begin{array}{l}\text { Detrital P } \\
\left(\mu \mathrm{mol} \mathrm{g}^{-1}\right)\end{array}$ & $\begin{array}{l}\text { Organic P } \\
\left(\mu \mathrm{mol} \mathrm{g}^{-1}\right)\end{array}$ \\
\hline \multicolumn{9}{|l|}{ Day 207} \\
\hline & 0 & - & 0.5 & 0.45 & 21.03 & 5.14 & 5.52 & 5.18 \\
\hline & 0.5 & - & 1.5 & 0.52 & 9.85 & 5.40 & 6.18 & 5.40 \\
\hline & 1.5 & - & 2.5 & 0.51 & 6.32 & 5.69 & 6.29 & 5.03 \\
\hline & 2.5 & - & 3.5 & 0.87 & 6.41 & 5.96 & 6.08 & 5.01 \\
\hline & 3.5 & - & 4.5 & 0.66 & 6.61 & 5.00 & 5.13 & 4.12 \\
\hline & 4.5 & - & 5 & 0.89 & 6.80 & 5.50 & 5.89 & 4.85 \\
\hline \multicolumn{9}{|l|}{ Day 621} \\
\hline & 0 & - & 0.5 & 0.79 & 13.24 & 4.78 & 6.04 & 3.97 \\
\hline & 0.5 & - & 1 & 1.39 & 13.58 & 3.96 & 7.28 & 4.28 \\
\hline & 1 & - & 1.5 & 0.56 & 3.30 & 4.25 & 7.27 & 4.46 \\
\hline & 1.5 & - & 2 & 0.66 & 3.75 & 4.62 & 6.77 & 4.16 \\
\hline & 2 & - & 2.5 & 0.37 & 4.78 & 4.41 & 6.72 & 4.12 \\
\hline & 2.5 & - & 3 & 0.39 & 4.50 & 4.79 & 6.85 & 4.26 \\
\hline & 3 & - & 3.5 & 0.51 & 4.41 & 4.96 & 5.94 & 3.73 \\
\hline & 3.5 & - & 4 & 0.42 & 4.68 & 4.68 & 7.33 & 4.24. \\
\hline & 4 & - & 4.5 & 0.31 & 4.00 & 3.72 & 7.17 & 4.19 \\
\hline & 4.5 & - & 5 & 0.53 & 5.53 & 5.25 & 6.18 & 4.12 \\
\hline \multicolumn{9}{|l|}{ Control } \\
\hline & 0 & - & 0.5 & 0.61 & 4.25 & 4.90 & 6.50 & 3.98 \\
\hline & 0.5 & - & 1 & 0.84 & 4.28 & 4.76 & 6.49 & 4.09 \\
\hline & 1 & - & 1.5 & 0.96 & 4.81 & 5.12 & 6.53 & 3.55 \\
\hline & 1.5 & - & 2 & 0.68 & 5.52 & 4.68 & 6.72 & 4.34 \\
\hline & 2 & - & 3 & 0.84 & 4.41 & 5.88 & 5.25 & 4.17 \\
\hline & 3 & - & 4 & 0.41 & 5.25 & 5.56 & 6.17 & 4.15 \\
\hline & 4 & - & 5 & 0.56 & 5.39 & 4.71 & 6.67 & 4.35 \\
\hline
\end{tabular}




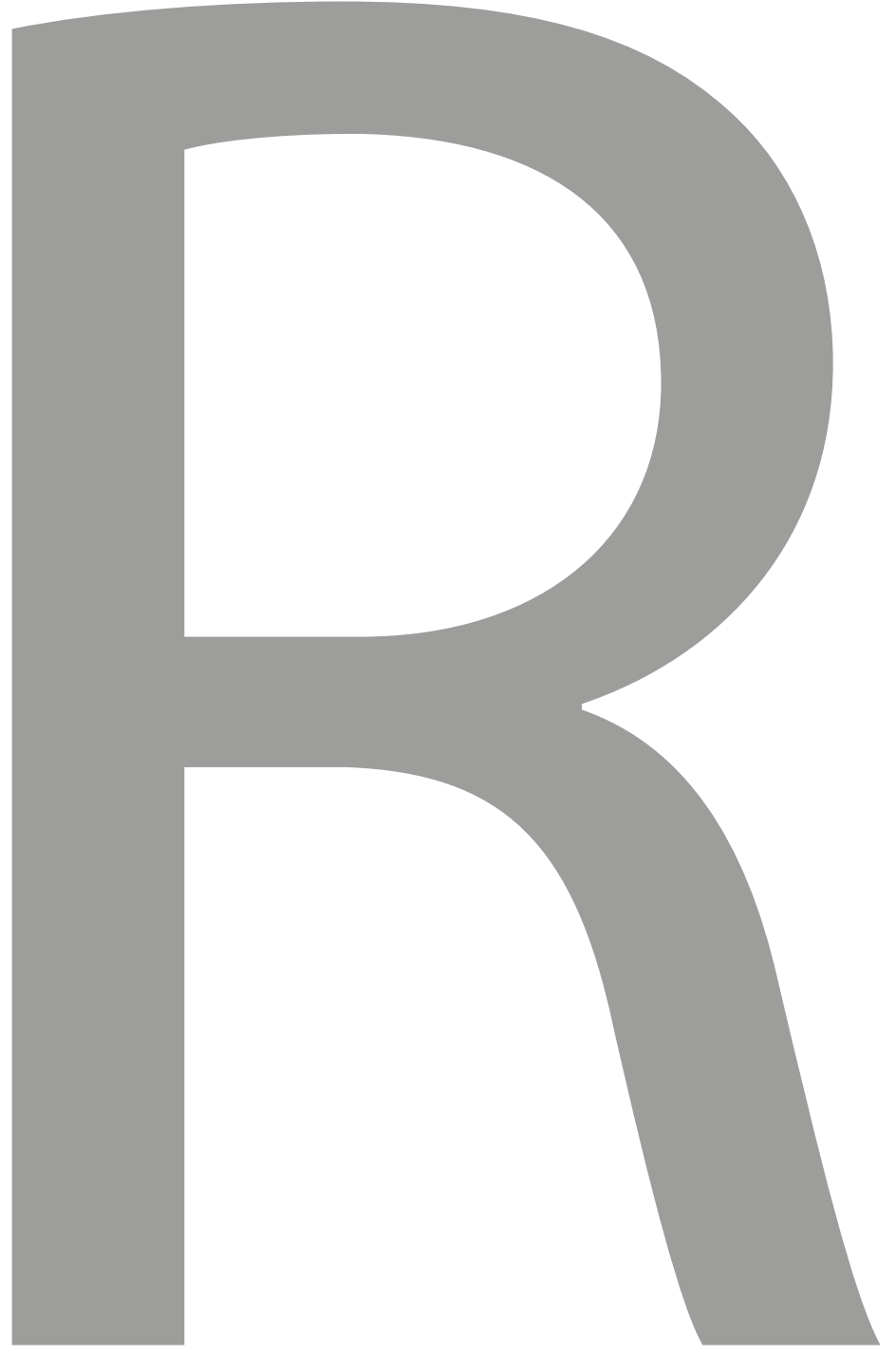




\section{References}

\section{Chapter 1}

Aller, R. C., Aller, J. Y., Zhu, Q., Heilbrun, C., Klingensmith, I., and Kaushik, A. (2019). Worm tubes as conduits for the electrogenic microbial grid in marine sediments. Science Advances 5: eaaw3651.

Anderson, L. A. (1995). On the hydrogen and oxygen content of marine phytoplankton. Deep Sea Research Part I: Oceanographic Research Papers 42: 1675-1680.

Arthur, M. A., and Dean, W. E. (1998). Organic-matter production and preservation and evolution of anoxia in the Holocene Black Sea. Paleoceanography 13: 395-411.

Bjerg, J. T., Damgaard, L. R., Holm, S. A., Schramm, A., and Nielsen, L. P. (2016). Motility of electric cable bacteria. Applied Environmental Microbiology 82: 3816-3821.

Breitburg, D., Levin, L. A., Oschlies, A., Grégoire, M., Chavez, F. P., Conley, D. J., Garçon, V., Gilbert, D., Gutiérrez, D., Isensee, K., Jacinto, G. S., Limburg, K.E., Montes, I., Naqvi, S. W. A., Pitcher, G. C., Rabalais, N. N., Roman, M. R., Rose, K. A., Seibel, B. A., Telszewski, M., Yasuhara, M., and Zhang, J. (2018). Declining oxygen in the global ocean and coastal waters. Science 359: eaam7240.

Burdige, D. J. (1993). The biogeochemistry of manganese and iron reduction in marine sediments. Earth-Science Reviews 35: 249-284.

Burdige, D. J., Dhakar, S. P., and Nealson, K. H. (1992). Effects of manganese oxide mineralogy on microbial and chemical manganese reduction. Geomicrobiology Journal 10: 27-48.

Burdorf, L. D., Hidalgo-Martinez, S., Cook, P. L., and Meysman, F. J. (2016). Long-distance electron transport by cable bacteria in mangrove sediments. Marine Ecology Progress Series 545: 1-8.

Burdorf, L. D., Malkin, S.Y., Bjerg, J.T., Van Rijswijk, P., Criens, F., Tramper, A., and Meysman, F. J. R. (2018). The effect of oxygen availability on long-distance electron transport in marine sediments. Limnology and Oceanography 63 : 1799-1816.

Canfield, D. E., and Thamdrup, B. (2009). Towards a consistent classification scheme for geochemical environments, or, why we wish the term 'suboxic'would go away. Geobiology 7: 385-392.

Carstensen, J., Andersen, J. H., Gustafsson, B. G., and Conley, D. J. (2014a). Deoxygenation of the Baltic Sea during the last century. Proceedings of the National Academy of Sciences 111: 5628-5633.

Carstensen, J., Conley, D. J., Bonsdorff, E., Gustafsson, B. G., Hietanen, S., Janas, U., Jilbert, T., Maximov, A., Norkko, A., Norkko, J., Reed, D. C., Slomp, C. P., Timmermann, K., and Voss., M. (2014b). Hypoxia in the Baltic Sea: Biogeochemical cycles, benthic fauna, and management. Ambio 43: 26-36.

Conley, D. J., Humborg, C., Rahm, L., Savchuk, O. P., and Wulff, F. (2002). Hypoxia in the Baltic Sea and basin-scale changes in phosphorus biogeochemistry. Environmental Science \& Technology 36: 5315-5320.

Coolen, M. J., Saenz, J. P., Giosan, L., Trowbridge, N. Y., Dimitrov, P., Dimitrov, D., and Eglinton, T. I. (2009). DNA and lipid molecular stratigraphic records of haptophyte succession in the Black Sea during the Holocene. Earth and Planetary Science Letters 284: 610-621.

Damgaard, L. R., Risgaard-Petersen, N., and Nielsen, L. P. (2014). Electric potential microelectrode for studies of electrobiogeophysics. Journal of Geophysical Research: Biogeosciences 119: 1906-1917.

Diaz, R. J., and Rosenberg, R. (2008). Spreading dead zones and consequences for marine ecosystems. Science 321: 926-929.

Falkowski, P. G., and Raven, J. A. (2013). Aquatic photosynthesis. Princeton University Press.

Froelich, P. N., Klinkhammer, G. P., Bender, M. L., Luedtke, N. A., Heath, G. R., Cullen, D., Dauphin, P., Hammond, D., Hartman, B., and Maynard V. (1979). Early oxidation of organic matter in pelagic sediments of the eastern equatorial Atlantic: suboxic diagenesis. Geochimica et Cosmochimica Acta 43: 1075-1090. 
Glud, R. N. (2008). Oxygen dynamics of marine sediments. Marine Biology Research 4: 243-289.

Gunnars, A., Blomqvist, S., Johansson, P., and Andersson, C. (2002). Formation of Fe (III) oxyhydroxide colloids in freshwater and brackish seawater, with incorporation of phosphate and calcium. Geochimica et Cosmochimica Acta 66: 745-758.

Gunnerson, C. G., and Ozturgut, E. (1974). The Bosporus: Water.

Gustafsson, B. G., and Andersson, H. C. (2001). Modeling the exchange of the Baltic Sea from the meridional atmospheric pressure difference across the North Sea. Journal of Geophysical Research: Oceans 106: 19731-19744.

Howarth, R., Chan, F., Conley, D. J., Garnier, J., Doney, S. C., Marino, R., and Billen, G. (2011). Coupled biogeochemical cycles: eutrophication and hypoxia in temperate estuaries and coastal marine ecosystems. Frontiers in Ecology and the Environment 9: 18-26.

Ingall, E., and Jahnke, R. (1994). Evidence for enhanced phosphorus regeneration from marine sediments overlain by oxygen depleted waters. Geochimica et Cosmochimica Acta 58: 2571-2575.

Jørgensen, B. (1982). Ecology of the bacteria of the sulphur cycle with special reference to anoxic-oxic interface environments. Philosophical Transactions of the Royal Society of London. B, Biological Sciences 298: 543-561.

Jørgensen, B., and Nelson, D. (2004). Sulfide oxidation in marine sediments: geochemistry meets microbiology. GSA Special Paper 379, 63-81. doi: 10.1130.

Jørgensen, B. B. (1977). The sulfur cycle of a coastal marine sediment (Limfjorden, Denmark) 1. Limnology and Oceanography 22: 814-832.

Kristensen, E., Kristiansen, K. D., and Jensen, M. H. (2003). Temporal behavior of manganese and iron in a sandy coastal sediment exposed to water column anoxia. Estuaries 26: 690-699.

Kristensen, E., Penha-Lopes, G., Delefosse, M., Valdemarsen, T., Quintana, C. O., and Banta, G. T. (2012). What is bioturbation? The need for a precise definition for fauna in aquatic sciences. Marine Ecology Progress Series 446: 285-302.

Kristiansen, K., Kristensen, E., and Jensen, E. (2002). The influence of water column hypoxia on the behaviour of manganese and iron in sandy coastal marine sediment. Estuarine, Coastal and Shelf Science 55: 645-654.

Larsen, S., Nielsen, L. P., and Schramm, A. (2015). Cable bacteria associated with long-distance electron transport in New England salt marsh sediment. Environmental Microbiology Reports 7: 175-179.

Malkin, S. Y., Rao, A. M. F., Seitaj, D., Vasquez-Cardenas, D., Zetsche, E.-M., Hidalgo-Martinez, S., Boschker, T. S., and Meysman F. J. R. (2014). Natural occurrence of microbial sulphur oxidation by long-range electron transport in the seafloor. The ISME Journal 8: 1843-1854.

Malkin, S. Y., Seitaj, D., Burdorf, L. D. W., Nieuwhof, S., Hidalgo-Martinez, S., Tramper, A. Geeraert, N., De Stigter, H., and Meysman, F. J. R. (2017). Electrogenic sulfur oxidation by cable bacteria in bivalve reef sediments. Frontiers in Marine Science 4: 28.

Marzocchi, U., Trojan, D., Larsen, S., Meyer, R. L., Revsbech, N. P., Schramm, A., Nielsen, L. P., and Risgaard-Petersen, N. (2014). Electric coupling between distant nitrate reduction and sulfide oxidation in marine sediment. The ISME Journal 8: 1682-1690.

McQuatters-Gollop, A., Mee, L. D., Raitsos, D. E., and Shapiro, G. I. (2008). Non-linearities, regime shifts and recovery: The recent influence of climate on Black Sea chlorophyll. Journal of Marine Systems 74: 649-658.

Meysman, F. J. (2018). Cable bacteria take a new breath using long-distance electricity. Trends in Microbiology 26: 411422.

Middelburg, J., and Levin, L. (2009). Coastal hypoxia and sediment biogeochemistry. Biogeosciences 6: 1273-1293.

Mohrholz, V., Heene, T., Beier, S., and Naumann, G. N. M. (2016). The impact of the recent series of barotropic inflows on deep water conditions in the Eastern Gotland Basin-time series observations. Multiple Drivers for Earth System Changes in the Baltic Sea Region: 25.

Mohrholz, V., Naumann, M., Nausch, G., Krüger, S., and Gräwe, U. (2015). Fresh oxygen for the Baltic Sea-an exceptional saline inflow after a decade of stagnation. Journal of Marine Systems 148: 152-166. 
Møller, M. M., Nielsen, L. P., and Jørgensen, B. B. (1985). Oxygen responses and mat formation by Beggiatoa spp. Applied Environmental Microbiology 50: 373-382.

Mort, H. P., Slomp, C. P., Gustafsson, B. G., and Andersen, T. J. (2010). Phosphorus recycling and burial in Baltic Sea sediments with contrasting redox conditions. Geochimica et Cosmochimica Acta 74: 1350-1362.

Müller, H., Bosch, J., Griebler, C., Damgaard, L. R., Nielsen, L. P., Lueders, T., and Meckenstock, U. (2016). Longdistance electron transfer by cable bacteria in aquifer sediments. The ISME Journal 10: 2010-2019.

Müller, H., Marozava, S., Probst, A. J., and Meckenstock, R. U. (2019). Groundwater cable bacteria conserve energy by sulfur disproportionation. The ISME Journal 14: 623-634

Neretin, L. N., Volkov, I. I., Böttcher, M. E., and Grinenko, V. A. (2001). A sulfur budget for the Black Sea anoxic zone. Deep Sea Research Part I: Oceanographic Research Papers 48: 2569-2593.

Nielsen, L. P. (2016). Ecology: electrical cable bacteria save marine life. Current Biology 26: R32-R33.

Nielsen, L. P., Risgaard-Petersen, N., Fossing, H., Christensen, P. B., and Sayama, M. (2010). Electric currents couple spatially separated biogeochemical processes in marine sediment. Nature 463: 1071-1074.

Noffke, A., Sommer, S., Dale, A., Hall, P., and Pfannkuche, O. (2016). Benthic nutrient fluxes in the Eastern Gotland Basin (Baltic Sea) with particular focus on microbial mat ecosystems. Journal of Marine Systems 158: 1-12.

Petsch, S. (2003). The global oxygen cycle. Treatise on Geochemistry 8: 682.

Pfeffer, C., Larsen, S., Song, J., Dong, M., Besenbacher, F., Meyer, R. L., Kjeldsen, K. U., Schreiber, L., Gorby, Y. A., El-Naggar, M. Y., Leung, K. M., Schramm, A., Risgaard-Petersen, N., and Nielsen, L. P. (2012). Filamentous bacteria transport electrons over centimetre distances. Nature 491: 218-221.

Pitkänen, H., Kiirikki, M., Savchuk, O. P., Räike, A., Korpinen, P., and Wulff, F. (2007). Searching efficient protection strategies for the eutrophied Gulf of Finland: the combined use of $1 \mathrm{D}$ and 3D modeling in assessing long-term state scenarios with high spatial resolution. AMBIO: A Journal of the Human Environment 36: 272-280.

Preisler, A., De Beer, D., Lichtschlag, A., Lavik, G., Boetius, A., and Jørgensen, B. B. (2007). Biological and chemical sulfide oxidation in a Beggiatoa inhabited marine sediment. The ISME Journal 1: 341.

Rabalais, N., Diaz, R. J., Levin, L., Turner, R., Gilbert, D., and Zhang, J. (2010). Dynamics and distribution of natural and human-caused hypoxia. Biogeosciences 7: 585.

Rabalais, N. N., Turner, R. E., and Wiseman Jr, W. J. (2002). Gulf of Mexico hypoxia, aka "The dead zone". Annual Review of Ecology and Systematics 33: 235-263.

Rao, A. M., Malkin, S. Y., Hidalgo-Martinez, S., and Meysman, F. J. (2016). The impact of electrogenic sulfide oxidation on elemental cycling and solute fluxes in coastal sediment. Geochimica et Cosmochimica Acta 172: 265-286.

Renaud, M. L. (1986). Hypoxia in Louisiana coastal waters during 1983: implications to fisheries. Fishery Bulletin NOAA 84: 19-26.

Risgaard-Petersen, N., Kristiansen, M., Frederiksen, R. B., Dittmer, A. L., Bjerg, J. T., Trojan, D., Schreiber, L., Damgaard, L. R., Schramm, A., and Nielsen, L. P. (2015). Cable bacteria in freshwater sediments. Applied and Environmental Microbiology 81: 6003-6011.

Risgaard-Petersen, N., Revil, A., Meister, P., and Nielsen, L. P. (2012). Sulfur, iron-, and calcium cycling associated with natural electric currents running through marine sediment. Geochimica et Cosmochimica Acta 92: 1-13.

Rosenberg, R. (1980). Effect of oxygen deficiency on benthic macrofauna in fjords, p. 499-514. Fjord oceanography. Springer.

Sayama, M., Risgaard-Petersen, N., Nielsen, L. P., Fossing, H., and Christensen, P. B. (2005). Impact of bacterial NO3transport on sediment biogeochemistry. Applied Environmental Microbiology 71: 7575-7577.

Schlitzer, R. (2015). Ocean Data View.

Schmidtko, S., Stramma, L., and Visbeck, M. (2017). Decline in global oceanic oxygen content during the past five decades. Nature 542: 335-339.

Schulz, H. N., and Jørgensen, B. B. (2001). Big bacteria. Annual Reviews in Microbiology 55: 105-137. 
Seitaj, D., Schauer, R., Sulu-Gambari, F., Hidalgo-Martinez, S., Malkin, S. Y., Burdorf, L. D. W., Slomp, C. P., and Meysman, F. J. R. (2015). Cable bacteria generate a firewall against euxinia in seasonally hypoxic basins. Proceedings of the National Academy of Sciences 112: 13278-13283.

Slomp, C. P., Mort, H. P., Jilbert, T., Reed, D. C., Gustafsson, B. G., and Wolthers, M. (2013). Coupled dynamics of iron and phosphorus in sediments of an oligotrophic coastal basin and the impact of anaerobic oxidation of methane. PloS One 8: e62386.

Steenbergh, A. K., Bodelier, P. L., Slomp, C. P., and Laanbroek, H. J. (2014). Effect of redox conditions on bacterial community structure in Baltic Sea sediments with contrasting phosphorus fluxes. PloS One 9: e92401.

Sulu-Gambari, F., Seitaj, D., Behrends, T., Banerjee, D., Meysman, F. J., and Slomp, C. P. (2016a). Impact of cable bacteria on sedimentary iron and manganese dynamics in a seasonally-hypoxic marine basin. Geochimica et Cosmochimica Acta 192: 49-69.

Sulu-Gambari, F., Seitaj, D., Meysman, F. J., Schauer, R., Polerecky, L., and Slomp, C. P. (2016b). Cable bacteria control iron-phosphorus dynamics in sediments of a coastal hypoxic basin. Environmental Science \& Technology 50: 1227-1233.

Sweerts, J.-P. R., De Beer, D., Nielsen, L. P., Verdouw, H., Van den Heuvel, J. C., Cohen, Y., and Cappenberg, T. E. (1990). Denitrification by sulphur oxidizing Beggiatoa spp. mats on freshwater sediments. Nature 344: 762.

Trojan, D., Schreiber, L., Bjerg, J. T., Bøggild, A., Yang, T., Kjeldsen, K. U., and Schramm, A. (2016). A taxonomic framework for cable bacteria and proposal of the candidate genera Electrothrix and Electronema. Systematic and Applied Microbiology 39: 297-306.

Turnewitsch, R., and Pohl, C. (2010). An estimate of the efficiency of the iron-and manganese-driven dissolved inorganic phosphorus trap at an oxic/euxinic water column redoxcline. Global Biogeochemical Cycles 24.

Vahtera, E., Conley, D. J., Gustafsson, B. G., Kuosa, H., Pitkänen, H., Savchuk, O. P., Tamminen, T., Viitasalo, M., Voss, M., Wasmund, N., and Wulff, F. (2007). Internal ecosystem feedbacks enhance nitrogen-fixing cyanobacteria blooms and complicate management in the Baltic Sea. AMBIO: A Journal of the Human Environment 36: 186-194.

Vaquer-Sunyer, R., and Duarte, C. M. (2008). Thresholds of hypoxia for marine biodiversity. Proceedings of the National Academy of Sciences 105: 15452-15457. 


\section{Chapter 2}

Adelson, J., Helz, G., and Miller, C. (2001). Reconstructing the rise of recent coastal anoxia; molybdenum in Chesapeake Bay sediments. Geochimica et Cosmochimica Acta 65: 237-252.

Almroth-Rosell, E., Eilola, K., Kuznetsov, I., Hall, P. O., and Meier, H. M. (2015). A new approach to model oxygen dependent benthic phosphate fluxes in the Baltic Sea. Journal of Marine Systems 144: 127-141.

Altieri, A. H., Harrison, S. B., Seemann, J., Collin, R., Diaz, R. J., and Knowlton, N. (2017). Tropical dead zones and mass mortalities on coral reefs. Proceedings of the National Academy of Sciences 114: 3660-3665.

Bartlett, J., and Skoog, D. (1954). Colorimetric determination of elemental sulfur in hydrocarbons. Analytical Chemistry 26: 1008-1011.

Berner, R. A. (1980). Early diagenesis: a theoretical approach. Princeton University Press.

Borsboom, M., Bras, W., Cerjak, I., Detollenaere, D., Glastra van Loon, D., Goedtkindt, P., Konijnenburg, M., Lassing, P., Levine, Y.K., Munneke, B. and Oversluizen, M. (1998). The Dutch-Belgian beamline at the ESRF. Journal of Synchrotron Radiation 5: 518-520.

Boudreau, B. P. (1997). Diagenetic models and their implementation.

Boyd, P., and Ellwood, M. (2010). The biogeochemical cycle of iron in the ocean. Nature Geoscience 3: 675.

Brewer, P., and Spencer, D. (1971). Colorimetric determination of manganese in anoxic waters. Limnology and Oceanography 16: 107-110.

Brock, J., and Schulz-Vogt, H. N. (2011). Sulfide induces phosphate release from polyphosphate in cultures of a marine Beggiatoa strain. ISME Journal 5: 497-506.

Burdige, D. J. (1993). The biogeochemistry of manganese and iron reduction in marine sediments. Earth-Science Reviews 35: 249-284.

Burdige, D. J. (2006). Geochemistry of marine sediments. Princeton University Press.

Burdige, D. J., and Nealson, K. H. (1986). Chemical and microbiological studies of sulfide-mediated manganese reduction. Geomicrobiology Journal 4: 361-387.

Burton, E. D., Bush, R. T., and Sullivan, L. A. (2006). Fractionation and extractability of sulfur, iron and trace elements in sulfidic wetland soils. Chemosphere 64: 1421-1428.

Burton, E. D., Sullivan, L. A., Bush, R. T., Johnston, S. G., and Keene, A. F. (2008). A simple and inexpensive chromium-reducible sulfur method for acid-sulfate soils. Applied Geochemistry 23: 2759-2766.

Carstensen, J., Andersen, J. H., Gustafsson, B. G., and Conley, D. J. (2014a). Deoxygenation of the Baltic Sea during the last century. Proceedings of the National Academy of Sciences 111: 5628-5633.

Carstensen, J., Conley, D. J., Bonsdorff, E., Gustafsson, B. G., Hietanen, S., Janas, U., Jilbert, T., Maximov, A., Norkko, A., Norkko, J., Reed, D. C., Slomp, C. P., Timmermann, K., and Voss., M. (2014b). Hypoxia in the Baltic Sea: Biogeochemical cycles, benthic fauna, and management. Ambio 43: 26-36.

Claff, S. R., Sullivan, L. A., Burton, E. D., and Bush, R. T. (2010). A sequential extraction procedure for acid sulfate soils: partitioning of iron. Geoderma 155: 224-230.

Cleceri, L., Greenberg, A., and Eaton, A. (1998). Standard methods for the examination of water and wastewater. APHA.

Conley, D. J. (2012). Ecology: save the baltic sea. Nature 486: 463.

Conley, D. J., Humborg, C., Rahm, L., Savchuk, O. P., and Wulff, F. (2002). Hypoxia in the Baltic Sea and basin-scale changes in phosphorus biogeochemistry. Environmental Science \& Technology 36: 5315-5320.

Crusius, J., Calvert, S., Pedersen, T., and Sage, D. (1996). Rhenium and molybdenum enrichments in sediments as indicators of oxic, suboxic and sulfidic conditions of deposition. Earth and Planetary Science Letters 145: 65-78.

Dale, A. W., Bertics, V. J., Treude, T., Sommer, S., and Wallmann, K. (2013). Modeling benthic-pelagic nutrient exchange processes and porewater distributions in a seasonally hypoxic sediment: evidence for massive phosphate release by Beggiatoa? Biogeosciences 10: 629-651. 
De Baar, H.J.W., Timmermans, K. R., Laan, P., De Porto, H. H., Ober, S., Blom, J. J., Bakker., M. C., Schiling, J., Sarthou, G., Smit, M. G., and Klunder, M. (2008). Titan: a new facility for ultraclean sampling of trace elements and isotopes in the deep oceans in the international Geotraces program. Marine Chemistry 111: 4-21.

De Brabandere, L., Bonaglia, S., Kononets, M. Y., Viktorsson, L., Stigebrandt, A., Thamdrup, B., and Hall, P. O. J. (2015). Oxygenation of an anoxic fjord basin strongly stimulates benthic denitrification and DNRA. Biogeochemistry 126: 131-152.

Dellwig, O., Leipe, T., März, C., Glockzin, M., Pollehne, F., Schnetger, B., Yakushev, E. V., Böttcher, M. E., and Brumsack. H.-J. (2010). A new particulate Mn-Fe-P-shuttle at the redoxcline of anoxic basins. Geochimica et Cosmochimica Acta 74: 7100-7115.

Dellwig, O., Schnetger, B., Meyer, D., Pollehne, F., Häusler, K., and Arz, H. W. (2018). Impact of the Major Baltic Inflow in 2014 on Manganese Cycling in the Gotland Deep (Baltic Sea). Frontiers in Marine Science 5: 248.

Diaz, R. J., and Rosenberg, R. (2008). Spreading dead zones and consequences for marine ecosystems. Science 321: 926-929.

Dickson, A. G. (1990). Standard potential of the reaction: $\mathrm{AgCl}(\mathrm{s})+12 \mathrm{H}_{2}(\mathrm{~g})=\mathrm{Ag}(\mathrm{s})+\mathrm{HCl}(\mathrm{aq})$, and and the standard acidity constant of the ion $\mathrm{HSO}_{4}{ }^{-}$in synthetic sea water from 273.15 to $318.15 \mathrm{~K}$. The Journal of Chemical Thermodynamics 22: 113-127.

Dickson, A. G., Sabine, C. L., and Christian, J. R. (2007). Guide to Best Practices for Ocean $\mathrm{CO}_{2}$ Measurements. North Pacific Marine Science Organization.

Egger, M., Jilbert, T., Behrends, T., Rivard, C., and Slomp, C. P. (2015). Vivianite is a major sink for phosphorus in methanogenic coastal surface sediments. Geochimica et Cosmochimica Acta 169: 217-235.

Eilola, K., Almroth-Rosell, E., and Meier, H. M. (2014). Impact of saltwater inflows on phosphorus cycling and eutrophication in the Baltic Sea: a 3D model study. Tellus A 66: 23985.

Erickson, B. E., and Helz, G. R. (2000). Molybdenum (VI) speciation in sulfidic waters:: stability and lability of thiomolybdates. Geochimica et Cosmochimica Acta 64: 1149-1158.

Goldhammer, T., Brüchert, V., Ferdelman, T. G., and Zabel, M. (2010). Microbial sequestration of phosphorus in anoxic upwelling sediments. Nature Geoscience 3: 557-561.

Grasshoff, K., and Ehrhardt, M. (1983). Automated chemical analysis. Methods of Seawater Analysis. Verlag: 263-289.

Gunnars, A., Blomqvist, S., Johansson, P., and Andersson, C. (2002). Formation of Fe (III) oxyhydroxide colloids in freshwater and brackish seawater, with incorporation of phosphate and calcium. Geochimica et Cosmochimica Acta 66: 745-758.

Gustafsson, B. G., and Andersson, H. C. (2001). Modeling the exchange of the Baltic Sea from the meridional atmospheric pressure difference across the North Sea. Journal of Geophysical Research: Oceans 106: 19731-19744.

Gustafsson, B. G., Schenk, F., Blenckner, T., Eilola, K., Meier, H. E. M., Müller-Karulis, B., Neumann, T., Ruoho-Airola, T., Savchuk, O. P., and Zorita, E. (2012). Reconstructing the development of Baltic Sea eutrophication 1850-2006. Ambio 41: 534-548.

Gustafsson, B. G., and Stigebrandt, A. (2007). Dynamics of nutrients and oxygen/hydrogen sulfide in the Baltic Sea deep water. Journal of Geophysical Research: Biogeosciences: 112.

Hall, P. O., Rosell, E. A., Bonaglia, S., Dale, A. W., Hylén, A., Kononets, M., Nilsson, M., Sommer, S., Van de Velde, and S., Viktorsson, L. (2017). Influence of natural oxygenation of Baltic proper deep water on benthic recycling and removal of phosphorus, nitrogen, silicon and carbon. Frontiers in Marine Science 4: 27.

Häusler, K., Dellwig, O., Schnetger, B., Feldens, P., Leipe, T., Moros, M., Pollehne, F., Schönke, M., Wegwerth, A., and Arz, H. W. (2018). Massive Mn carbonate formation in the Landsort Deep (Baltic Sea): Hydrographic conditions, temporal succession, and Mn budget calculations. Marine Geology 395: 260-270.

Heiser, U., Neumann, T., Scholten, J., and Stüben, D. (2001). Recycling of manganese from anoxic sediments in stagnant basins by seawater inflow: a study of surface sediments from the Gotland Basin, Baltic Sea. Marine Geology 177: 151-166. 
Helz, G., Miller, C. V., Charnock, J. M., Mosselmans, J. F. W., Pattrick, R. A. D., Garner, C. D., and Vaughan, D. J., (1996). Mechanism of molybdenum removal from the sea and its concentration in black shales: EXAFS evidence. Geochimica et Cosmochimica Acta 60: 3631-3642.

Holtermann, P. L., Prien, R., Naumann, M., Mohrholz, V., and Umlauf, L. (2017). Deep-water dynamics and mixing processes during a major inflow event in the central Baltic Sea. Journal of Geophysical Research: Oceans 122: 66486667

Howarth, R., Chan, F., Conley, D. J., Garnier, J., Doney, S. C., Marino, R., and Billen, G. (2011). Coupled biogeochemical cycles: eutrophication and hypoxia in temperate estuaries and coastal marine ecosystems. Frontiers in Ecology and the Environment 9: 18-26.

Huckriede, H., and Meischner, D. (1996). Origin and environment of manganese-rich sediments within black-shale basins. Geochimica et Cosmochimica Acta 60: 1399-1413.

Ingall, E., and Jahnke, R. (1994). Evidence for enhanced phosphorus regeneration from marine sediments overlain by oxygen depleted waters. Geochimica et Cosmochimica Acta 58: 2571-2575.

Jeroschewski, P., Steuckart, C., and Kühl, M. (1996). An amperometric microsensor for the determination of $\mathrm{H}_{2} \mathrm{~S}$ in aquatic environments. Analytical Chemistry 68: 4351-4357.

Jilbert, T., De Lange, G., and Reichart, G. J. (2008). Fluid displacive resin embedding of laminated sediments: preserving trace metals for high-resolution paleoclimate investigations. Limnology and Oceanography: Methods 6 : $16-22$.

Jilbert, T., Slomp, C., Gustafsson, B. G., and Boer, W. (2011). Beyond the Fe-P-redox connection: preferential regeneration of phosphorus from organic matter as a key control on Baltic Sea nutrient cycles. Biogeosciences 8: 1699-1722.

Jilbert, T., and Slomp, C. P. (2013). Iron and manganese shuttles control the formation of authigenic phosphorus minerals in the euxinic basins of the Baltic Sea. Geochimica et Cosmochimica Acta 107: 155-169.

Johnson, K., Elrod, V., Fitzwater, S., Plant, J., Boyle, E., Bergquist, B., Bruland, K., Aguilar-Islas, A., Buck, K., Lohan, M., Smith, G. J., Sohnst, B., Coale, K., Gordon, M., Tanner, S., Measures, C., Moffett, J., Barbeau, K., King, A., Bowie, A., Chase, Z., Cullen, J., Laan, P., Landing, W., Mendez, J., Milne, A., Obata, H., Doi, T., Ossiander, L., Sarthou, G., Sedwick, P., Van den Berg, S., Laglera-Baquer, L., Wu. J.-F., and Cai., Y. (2007). Developing standards for dissolved iron in seawater. Eos, Transactions American Geophysical Union 88: 131-132.

Klunder, M., Laan, P., Middag, R., De Baar, H., and Van Ooijen, J. (2011). Dissolved iron in the Southern Ocean (Atlantic sector). Deep Sea Research Part II: Topical Studies in Oceanography 58: 2678-2694.

Koroleff, F. (1969). Determination of ammonia as indophenol blue. International Council for the Exploration of the Sea (ICES) 9.

Kraal, P., Dijkstra, N., Behrends, T., and Slomp, C. P. (2017). Phosphorus burial in sediments of the sulfidic deep Black Sea: Key roles for adsorption by calcium carbonate and apatite authigenesis. Geochimica et Cosmochimica Acta 204: $140-158$.

Kraal, P., and Slomp, C. P. (2014). Rapid and extensive alteration of phosphorus speciation during oxic storage of wet sediment samples. PloS One 9: e96859.

Kraal, P., Slomp, C. P., Forster, A., Kuypers, M. M., and Sluijs, A. (2009). Pyrite oxidation during sample storage determines phosphorus fractionation in carbonate-poor anoxic sediments. Geochimica et Cosmochimica Acta 73 : 3277-3290.

Kristensen, E., Kristiansen, K. D., and Jensen, M. H. (2003). Temporal behavior of manganese and iron in a sandy coastal sediment exposed to water column anoxia. Estuaries 26: 690-699.

Kristiansen, K., Kristensen, E., and Jensen, E. (2002). The influence of water column hypoxia on the behaviour of manganese and iron in sandy coastal marine sediment. Estuarine, Coastal and Shelf Science 55: 645-654. 
Lagerström, M., Field, M., Séguret, M., Fischer, L., Hann, S., and Sherrell, R. (2013). Automated on-line flow-injection ICP-MS determination of trace metals ( $\mathrm{Mn}, \mathrm{Fe}, \mathrm{Co}, \mathrm{Ni}, \mathrm{Cu}$ and $\mathrm{Zn}$ ) in open ocean seawater: Application to the GEOTRACES program. Marine Chemistry 155: 71-80.

Lenz, C., Behrends, T., Jilbert, T., Silveira, M., and Slomp, C. P. (2014). Redox-dependent changes in manganese speciation in Baltic Sea sediments from the Holocene Thermal Maximum: An EXAFS, XANES and LA-ICP-MS study. Chemical Geology 370: 49-57.

Lenz, C., Jilbert, T., Conley, D., Wolthers, M., and Slomp, C. (2015). Are recent changes in sediment manganese sequestration in the euxinic basins of the Baltic Sea linked to the expansion of hypoxia? Biogeosciences 12: 48754894.

Madison, A. S., Tebo, B. M., Mucci, A., Sundby, B., and Luther, G. W. (2013). Abundant porewater Mn (III) is a major component of the sedimentary redox system. Science 341: 875-878.

Malkin, S. Y., Rao, A. M. F., Seitaj, D., Vasquez-Cardenas, D., Zetsche, E.-M., Hidalgo-Martinez, S., Boschker, T. S., and Meysman F. J. R. (2014). Natural occurrence of microbial sulphur oxidation by long-range electron transport in the seafloor. The ISME Journal 8: 1843-1854.

Manceau, A., Marcus, M. A., and Grangeon, S. (2012). Determination of Mn valence states in mixed-valent manganates by XANES spectroscopy. American Mineralogist 97: 816-827.

Manheim, F. T. (1982). Geochemistry of manganese carbonates in the Baltic Sea. Stockholm Contributions in Geology 37: 145-159.

Martin, W.R., and Banta, G.T. (1992). The measurement of sediment irrigation rates: a comparison of the Br tracer and 222-Rn/ 226-Ra disequilibrium techniques. Journal of Marine Research 50: 125-154.

Millero, F. J., Plese, T., and Fernandez, M. (1988). The dissociation of hydrogen sulfide in seawater. Limnology and Oceanography 33: 269-274.

Mohrholz, V., Heene, T., Beier, S., and Naumann, G. N. M. (2016). The impact of the recent series of barotropic inflows on deep water conditions in the Eastern Gotland Basin-time series observations. Multiple Drivers for Earth System Changes in the Baltic Sea Region: 25.

Mohrholz, V., Naumann, M., Nausch, G., Krüger, S., and Gräwe, U. (2015). Fresh oxygen for the Baltic Sea-an exceptional saline inflow after a decade of stagnation. Journal of Marine Systems 148: 152-166.

Mort, H. P., Slomp, C. P., Gustafsson, B. G., and Andersen, T. J. (2010). Phosphorus recycling and burial in Baltic Sea sediments with contrasting redox conditions. Geochimica et Cosmochimica Acta 74: 1350-1362.

Murphy, J., and Riley, J. P. (1962). A modified single solution method for the determination of phosphate in natural waters. Analytica Chimica Acta 27: 31-36.

Neumann, T., Radtke, H., and Seifert, T. (2017). On the importance of Major Baltic Inflows for oxygenation of the central Baltic Sea. Journal of Geophysical Research: Oceans 122: 1090-1101.

Nielsen, L. P., Risgaard-Petersen, N., Fossing, H., Christensen, P. B., and Sayama, M. (2010). Electric currents couple spatially separated biogeochemical processes in marine sediment. Nature 463: 1071.

Nikitenko, S., Beale, A. M., Van der Eerden, A. M. J., Jacques, S. D. M., Leynaud, O., O’Brien, M. G., Detollennaere, D., Kapitein, R., Weckhuysen, B. M., and Bras, W. (2008). Implementation of a combined SAXS/WAXS/QEXAFS setup for time-resolved in situ experiments. Journal of Synchrotron Radiation 15: 632-640.

Noffke, A., Sommer, S., Dale, A., Hall, P., and Pfannkuche, O. (2016). Benthic nutrient fluxes in the Eastern Gotland Basin (Baltic Sea) with particular focus on microbial mat ecosystems. Journal of Marine Systems 158: 1-12.

Obata, H., Karatani, H., and Nakayama, E. (1993). Automated determination of iron in seawater by chelating resin concentration and chemiluminescence detection. Analytical Chemistry 65: 1524-1528.

Pfeffer, C., Larsen, S., Song, J., Dong, M., Besenbacher, F., Meyer, R. L., Kjeldsen, K. U., Schreiber, L., Gorby, Y. A., El-Naggar, M. Y., Leung, K. M., Schramm, A., Risgaard-Petersen, N., and Nielsen, L. P. (2012). Filamentous bacteria transport electrons over centimetre distances. Nature 491: 218-221. 
Pohl, C., and Fernández-Otero, E. (2012). Iron distribution and speciation in oxic and anoxic waters of the Baltic Sea. Marine Chemistry 145: 1-15.

Poulton, S. W., and Canfield, D. E. (2005). Development of a sequential extraction procedure for iron: implications for iron partitioning in continentally derived particulates. Chemical Geology 214: 209-221.

Raiswell, R., and Canfield, D. E. (2012). The iron biogeochemical cycle past and present. Geochemical Perspectives 1: $1-2$.

Raiswell, R., Vu, H. P., Brinza, L., and Benning, L. G. (2010). The determination of labile Fe in ferrihydrite by ascorbic acid extraction: methodology, dissolution kinetics and loss of solubility with age and de-watering. Chemical Geology 278: 70-79.

Ravel, B., and Newville, M. (2005). ATHENA, ARTEMIS, HEPHAESTUS: data analysis for X-ray absorption spectroscopy using IFEFFIT. Journal of Synchrotron Radiation 12: 537-541.

Reed, D. C., Slomp, C. P., and Gustafsson, B. G. (2011). Sedimentary phosphorus dynamics and the evolution of bottom-water hypoxia: A coupled benthic-pelagic model of a coastal system. Limnology and Oceanography 56: 1075-1092.

Reissmann, J. H., Burchard, H., Feistel, R., Hagen, E., Lass, H. U., Mohrholz, V., Nausch, G., Umlauf, L., and Wieczorek, G. (2009). Vertical mixing in the Baltic Sea and consequences for eutrophication-A review. Progress in Oceanography 82: 47-80.

Rijkenberg, M.J.A., De Baar, H.J.W., Bakker, K., Gerringa, L.J.A., Keijzer, E., Laan, M., Laan, P., Middag, R., Ober, S., Van Ooijen, J., Ossebaar, S., Van Weerlee, E.M., and Smit, M.G. (2015). “PRISTINE”, a new high volume sampler for ultraclean sampling of trace metals and isotopes. Marine Chemistry 177: 501-509.

Rijkenberg, M.J.A., Middag, R., Laan, P., Gerringa, L. J. A., Van Aken, H. M., Schoemann, V., De Jong, J. T. M., and De Baar, H. J. W. (2014). The distribution of dissolved iron in the West Atlantic Ocean. PLoS ONE 9: 1-14.

Rosenberg, R., Magnusson, M., and Stigebrandt, A. (2016). Rapid re-oxygenation of Baltic Sea sediments following a large inflow event. AMBIO 45: 130-132.

Ruttenberg, K. C. (1992). Development of a sequential extraction method for different forms of phosphorus in marine sediments. Limnology and Oceanography 37: 1460-1482.

Salomé, M., Cotte, M., Baker, R., Barett, R., Benseny-Cases, N., Berruyer, G., Bugnazet, D., Castillo-Michel, H., Cornu, C., and Fayard, B. (2013). The ID21 scanning X-ray microscope at ESRF. Journal of Physics: Conference Series 425: 182004.

Schlitzer, R. (2015). Ocean Data View.

Schmidtko, S., Stramma, L., and Visbeck, M. (2017). Decline in global oceanic oxygen content during the past five decades. Nature 542: 335-339.

Schneider, B. (2011). $\mathrm{PO}_{4}$ release at the sediment surface under anoxic conditions: a contribution to the eutrophication of the Baltic Sea? Oceanologia 53: 415-429.

Scott, C., and Lyons, T. W. (2012). Contrasting molybdenum cycling and isotopic properties in euxinic versus noneuxinic sediments and sedimentary rocks: Refining the paleoproxies. Chemical Geology 324: 19-27.

Seitaj, D., Schauer, R., Sulu-Gambari, F., Hidalgo-Martinez, S., Malkin, S. Y., Burdorf, L. D. W., Slomp, C. P., and Meysman, F. J. R. (2015). Cable bacteria generate a firewall against euxinia in seasonally hypoxic basins. Proceedings of the National Academy of Sciences 112: 13278-13283.

Slomp, C. P., Epping, E. H., Helder, W., and Raaphorst, W. V. (1996). A key role for iron-bound phosphorus in authigenic apatite formation in North Atlantic continental platform sediments. Journal of Marine Research 54: 1179-1205.

Soetaert, K., Petzoldt, T., and Meysman, F. (2010). Marelac: Tools for aquatic sciences. R package version.

Solé, V., Papillon, E., Cotte, M., Walter, P., and Susini, J. (2007). A multiplatform code for the analysis of energydispersive X-ray fluorescence spectra. Spectrochimica Acta Part B: Atomic Spectroscopy 62: 63-68. 
Sommer, S., Clemens, D., Yücel, M., Pfannkuche, O., Hall, P. O. J., Almroth-Rosell, E., Schulz-Vogt, H. N., and Dale, A. W. (2017). Major bottom water ventilation events do not significantly reduce basin-wide benthic $\mathrm{N}$ and $\mathrm{P}$ release in the Eastern Gotland Basin (Baltic Sea). Frontiers in Marine Science 4: 1-7.

Steenbergh, A. K., Bodelier, P. L., Slomp, C. P., and Laanbroek, H. J. (2014). Effect of redox conditions on bacterial community structure in Baltic Sea sediments with contrasting phosphorus fluxes. PloS One 9: e92401.

Stigebrandt, A., and Gustafsson, B. G. (2007). Improvement of Baltic proper water quality using large-scale ecological engineering. AMBIO 36: 280-286.

Stigebrandt, A., Liljebladh, B., De Brabandere, L., Forth, M., Granmo, Å, Hall, P., Hammar, J., Hansson, D., Kononets, M., Magnusson, M., Norén, F., Rahm, L., Treusch, A. H., and Viktorsson, L. (2015). An experiment with forced oxygenation of the deepwater of the anoxic By Fjord, western Sweden. AMBIO 44: 42-54.

Stigebrandt, A., Rosenberg, R., Magnusson, M., and Linders, T. (2017). Oxygenated deep bottoms beneath a thick hypoxic layer lack potential of benthic colonization. AMBIO: 47: 106-109.

Strickland, J. D., and Parsons, T. R. (1972). A practical handbook of seawater analysis.

Suess, E. (1979). Mineral phases formed in anoxic sediments by microbial decomposition of organic matter. Geochimica et Cosmochimica Acta 43: 339343-341352.

Sulu-Gambari, F., Roepert, A., Jilbert, T., Hagens, M., Meysman, F. J., and Slomp, C. P. (2017). Molybdenum dynamics in sediments of a seasonally-hypoxic coastal marine basin. Chemical Geology 466: 627-640.

Sulu-Gambari, F., Seitaj, D., Behrends, T., Banerjee, D., Meysman, F. J., and Slomp, C. P. (2016a). Impact of cable bacteria on sedimentary iron and manganese dynamics in a seasonally-hypoxic marine basin. Geochimica et Cosmochimica Acta 192: 49-69.

Sulu-Gambari, F., Seitaj, D., Meysman, F. J., Schauer, R., Polerecky, L., and Slomp, C. P. (2016b). Cable bacteria control iron-phosphorus dynamics in sediments of a coastal hypoxic basin. Environmental Science \& Technology 50: 1227-1233.

Teske, A., and Nelson, D. C. (2006). The genera Beggiatoa and Thioploca. Prokaryotes 6:784-810.

Turner, R. E., Rabalais, N. N., and Justic, D. (2008). Gulf of Mexico hypoxia: Alternate states and a legacy. Environmental Science \& Technology 42: 2323-2327.

Turnewitsch, R., and Pohl, C. (2010). An estimate of the efficiency of the iron-and manganese-driven dissolved inorganic phosphorus trap at an oxic/euxinic water column redoxcline. Global Biogeochemical Cycles 24.

Vahtera, E., Conley, D. J., Gustafsson, B. G., Kuosa, H., Pitkänen, H., Savchuk, O. P., Tamminen, T., Viitasalo, M., Voss, M., Wasmund, N., and Wulff, F. (2007). Internal ecosystem feedbacks enhance nitrogen-fixing cyanobacteria blooms and complicate management in the Baltic Sea. AMBIO: A Journal of the Human Environment 36: 186-194.

Van Santvoort, P., De Lange, G. J., Thomson, J., Cussen, H., Wilson, T. R. S., Krom, M. D., and Ströhle, K. (1996). Active post-depositional oxidation of the most recent sapropel (S1) in sediments of the eastern Mediterranean Sea. Geochimica et Cosmochimica Acta 60: 4007-4024.

Van Santvoort, P.J., De Lange, G.J., Thomson, J., Colley, S., Meysman, F.J., Slomp, C.P. (2002). Oxidation and origin of organic matter in surficial Eastern Mediterranean hemipelagic sediments. Aquatic Geochemistry 8: $153-175$.

Viktorsson, L., Kononets, M., Roos, P., and Hall, P. O. (2013). Recycling and burial of phosphorus in sediments of an anoxic fjord-the By Fjord, western Sweden. Journal of Marine Research 71: 351-374.

Yakushev, E., Kuznetsov, I., Podymov, O., Burchard, H., Neumann, T., and Pollehne, F. (2011). Modeling the influence of oxygenated inflows on the biogeochemical structure of the Gotland Sea, central Baltic Sea: Changes in the distribution of manganese. Computers \& Geosciences 37: 398-409.

Yücel, M., Sommer, S., Dale, A. W., and Pfannkuche, O. (2017). Microbial Sulfide Filter along a Benthic Redox Gradient in the Eastern Gotland Basin, Baltic Sea. Frontiers in Microbiology 8: 169. 


\section{Chapter 3}

APHA(1989). Standard methods for the examination of water and wastewater. American Public Health Association.

Berner, R. A. (1980). Early diagenesis: a theoretical approach. Princeton University Press.

Boudreau, B.P. (1984). On the equivalence of nonlocal and radial-diffusion models for porewater irrigation. Journal of Marine Research 42: 731-735.

Boudreau, B.P. (1996). A method-of-lines code for carbon and nutrient diagenesis in aquatic sediments. Computers \& Geosciences 22: 479-496. 3004(95)00115-8.

Boudreau, B. P. (1997). Diagenetic models and their implementation. Springer Berlin.

Breitburg, D., Levin, L. A., Oschlies, A., Grégoire, M., Chavez, F. P., Conley, D. J., Garçon, V., Gilbert, D., Gutiérrez, D., Isensee, K., Jacinto, G. S., Limburg, K.E., Montes, I., Naqvi, S. W. A., Pitcher, G. C., Rabalais, N. N., Roman, M. R., Rose, K. A., Seibel, B. A., Telszewski, M., Yasuhara, M., and Zhang, J. (2018). Declining oxygen in the global ocean and coastal waters. Science 359: eaam7240

Burdige, D. J. (2006). Geochemistry of marine sediments. Princeton University Press.

Burdorf, L. D., Hidalgo-Martinez, S., Cook, P. L., and Meysman, F. J. (2016). Long-distance electron transport by cable bacteria in mangrove sediments. Marine Ecology Progress Series 545: 1-8.

Burdorf, L. D., Malkin, S.Y., Bjerg, J.T., Van Rijswijk, P., Criens, F., Tramper, A., and Meysman, F. J. R. (2018). The effect of oxygen availability on long-distance electron transport in marine sediments. Limnology and Oceanography 63: 1799-1816.

Burdorf, L. D., Tramper, A., Seitaj, A., Meire, L., Hidalgo-Martinez, S., Zetsche, E.-M., Boschker, H. T. S., and Meysman, F. J. R. (2017). Long-distance electron transport occurs globally in marine sediments. Biogeosciences 14: 683-701.

Burton, E. D., Sullivan, L. A., Bush, R. T., Johnston, S. G., and Keene, A. F. (2008). A simple and inexpensive chromium-reducible sulfur method for acid-sulfate soils. Applied Geochemistry 23: 2759-2766.

Carstensen, J., Andersen, J. H., Gustafsson, B. G., and Conley, D. J. (2014a). Deoxygenation of the Baltic Sea during the last century. Proceedings of the National Academy of Sciences 111: 5628-5633.

Carstensen, J., Conley, D. J., Bonsdorff, E., Gustafsson, B. G., Hietanen, S., Janas, U., Jilbert, T., Maximov, A., Norkko, A., Norkko, J., Reed, D. C., Slomp, C. P., Timmermann, K., and Voss, M. (2014b). Hypoxia in the Baltic Sea: Biogeochemical cycles, benthic fauna, and management. Ambio 43: 26-36.

Claff, S. R., Sullivan, L. A., Burton, E. D., and Bush, R. T. (2010). A sequential extraction procedure for acid sulfate soils: partitioning of iron. Geoderma 155: 224-230.

Conley, D. J., Björck, S., Bonsdorff, E., Carstensen, J., Destouni, G., Gustafsson, B. G., Hietanen, S., Kortekaas, M., Kuosa, H., Meier, H. E. M., Müller-Karulis, B., Nordberg, K., Norkko, A., Nürnberg, G., Pitkänen, H., Rabalais, N. N., Rosenberg, R., Savchuk, O. P., Slomp, C. P., Voss, M., Wulff, F., and Zillén, L. (2009). Hypoxia-related processes in the Baltic Sea. Environmental Science \& Technology 43: 3412-3420.

Dauwe, B., Herman, P., and Heip, C. (1998). Community structure and bioturbation potential of macrofauna at four North Sea stations with contrasting food supply. Marine Ecology Progress Series 173: 67-83.

Diaz, R. J., and Rosenberg, R. (2008). Spreading dead zones and consequences for marine ecosystems. Science 321: 926-929.

Egger, M., Lenstra, W. K., Jong, D., Meysman, F. J. R., Sapart, C. J., Van der Veen, C., Röckmann, T., Gonzalez, S., and Slomp, C. P. (2016). Rapid sediment accumulation results in high methane effluxes from coastal sediments. PloS One 11: e0161609.

Eleftheriou, A. (2013). Methods for the study of marine benthos. John Wiley \& Sons.

Emerson, S., Jahnke, R., and Heggie, D. (1984). Sediment-water exchange in shallow water estuarine sediments. Journal of Marine Research 42: 709-730. 
Fossing, H., and Jørgensen, B. B. (1989). Measurement of bacterial sulfate reduction in sediments: evaluation of a single-step chromium reduction method. Biogeochemistry 8: 205-222.

Friedrich, J., Dinkel, C., Friedl, G., Pimenov, N., Wijsman, J., Gomoiu, M.-T., Cociasu, A., Popa, L., and Wehrli, B.(2002). Benthic nutrient cycling and diagenetic pathways in the north-western Black Sea. Estuarine, Coastal and Shelf Science 54: 369-383.

Grasshoff, K., and Ehrhardt, M. ( 1983). Kremling. Methods of Seawater Analysis. Verlag Chemie. Weinheim, New York.

Hagens, M., Slomp, C. P., Meysman, F. J. R., Seitaj, D., Harlay, J., Borges, A. V., and Middelburg, J. J. (2015). Biogeochemical processes and buffering capacity concurrently affect acidification in a seasonally hypoxic coastal marine basin. Biogeosciences 12: 1561-1583.

Hermans, M., Lenstra, W. K., Van Helmond, N. A. G. M., Behrends, T., Egger, M., Séguret , M. J. M., Gustafsson, E., Gustafsson, B. G., and Slomp. C. P. (2019). Impact of natural re-oxygenation on the sediment dynamics of manganese, iron and phosphorus in a euxinic Baltic Sea basin. Geochimica et Cosmochimica Acta 246: 174-196.

Jeroschewski, P., Steuckart, C., and Kühl, M. (1996). An amperometric microsensor for the determination of $\mathrm{H}_{2} \mathrm{~S}$ in aquatic environments. Analytical Chemistry 68: 4351-4357.

Jilbert, T., and Slomp, C. P. (2013). Iron and manganese shuttles control the formation of authigenic phosphorus minerals in the euxinic basins of the Baltic Sea. Geochimica et Cosmochimica Acta 107: 155-169.

Jørgensen, B., and Fenchel, T. (1974). The sulfur cycle of a marine sediment model system. Marine Biology 24: 189-201.

Josefson, A. B., Norkko, J., and Norkko, A. (2012). Burial and decomposition of plant pigments in surface sediments of the Baltic Sea: role of oxygen and benthic fauna. Marine Ecology Progress Series 455: 33-49.

Kallmeyer, J., Ferdelman, T. G., Weber, A., Fossing, H., and Jørgensen, B. B. (2004). A cold chromium distillation procedure for radiolabeled sulfide applied to sulfate reduction measurements. Limnology and Oceanography: Methods 2: 171-180.

Koroleff, F. (1969). Determination of ammonia as indophenol blue. International Council for the Exploration of the Sea (ICES) 9.

Kraal, P., Burton, E. D., and Bush, R. T. (2013). Iron monosulfide accumulation and pyrite formation in eutrophic estuarine sediments. Geochimica et Cosmochimica Acta 122: 75-88.

Kristensen, E., Kristiansen, K. D., and Jensen, M. H. (2003). Temporal behavior of manganese and iron in a sandy coastal sediment exposed to water column anoxia. Estuaries 26: 690-699.

Kristiansen, K., Kristensen, E., and Jensen, E. (2002). The influence of water column hypoxia on the behaviour of manganese and iron in sandy coastal marine sediment. Estuarine, Coastal and Shelf Science 55: 645-654.

Lenstra, W., Hermans, M., Séguret M. J. M., Witbaard, R., Behends, T., Dijkstra, N., Van Helmond, N. A. G. M., Kraal, P., Laan, P., Rijkenberg, M. J. A., Severmann, S., Teacă, A., and Slomp, C. P. (2019). The shelf-to-basin iron shuttle in the Black Sea revisited. Chemical Geology 511: 314-341.

Malkin, S. Y., Rao, A. M. F., Seitaj, D., Vasquez-Cardenas, D., Zetsche, E.-M., Hidalgo-Martinez, S., Boschker, T. S., and Meysman F. J. R. (2014). Natural occurrence of microbial sulphur oxidation by long-range electron transport in the seafloor. The ISME Journal 8: 1843-1854.

Malkin, S. Y., Seitaj, D., Burdorf, L. D. W., Nieuwhof, S., Hidalgo-Martinez, S., Tramper, A. Geeraert, N., De Stigter, H., and Meysman, F. J. R. (2017). Electrogenic sulfur oxidation by cable bacteria in bivalve reef sediments. Frontiers in Marine Science 4: 28.

Marzocchi, U., Bonaglia, S., Van der Velde, S., Hall, P. O. J., Schramm, A., Risgaard-Petersen, N., and Meysman, F. J. R. (2018). Transient bottom water oxygenation creates a niche for cable bacteria in long-term anoxic sediments of the Eastern Gotland Basin. Environmental Microbiology 20: 3031-3041.

Marzocchi, U., Trojan, D., Larsen, S., Meyer, R. L., Revsbech, N. P., Schramm, A., Nielsen, L. P., and Risgaard-Petersen, N. (2014). Electric coupling between distant nitrate reduction and sulfide oxidation in marine sediment. The ISME Journal 8: 1682. 
Meysman, F. J., Risgaard-Petersen, N., Malkin, S. Y., and Nielsen, L. P. (2015). The geochemical fingerprint of microbial long-distance electron transport in the seafloor. Geochimica et Cosmochimica Acta 152: 122-142.

Mohrholz, V., Heene, T., Beier, S., Naumann, G. N. M., and Nausch, G. (2016). The impact of the recent series of barotropic inflows on deep water conditions in the Eastern Gotland Basin-time series observations. Multiple Drivers for Earth System Changes in the Baltic Sea Region 25.

Mohrholz, V., Naumann, M., Nausch, G., Krüger, S., and Gräwe, U. (2015). Fresh oxygen for the Baltic Sea-An exceptional saline inflow after a decade of stagnation. Journal of Marine Systems 148: 152-166.

Møller, M. M., Nielsen, L. P., and Jørgensen, B. B. (1985). Oxygen responses and mat formation by Beggiatoa spp. Applied and Environmental Microbiology 50: 373-382.

Nelson, D. C., and Jannasch, H. W. (1983). Chemoautotrophic growth of a marine Beggiatoa in sulfide-gradient cultures. Archives of Microbiology 136: 262-269.

Nielsen, L. P., Risgaard-Petersen, N., Fossing, H., Christensen, P. B., and Sayama, M. (2010). Electric currents couple spatially separated biogeochemical processes in marine sediment. Nature 463: 1071.

Norkko, J., Reed, D. C., Timmermann, K. Norkko, A., Gustafsson, B. G., Bonsdorff, E., Slomp, C. P., Carstensen, J., and Conley D. J. (2012). A welcome can of worms? Hypoxia mitigation by an invasive species. Global Change Biology 18: 422-434.

Pfeffer, C., Larsen, S., Song, J., Dong, M., Besenbacher, F., Meyer, R. L., Kjeldsen, K. U., Schreiber, L., Gorby, Y. A., El-Naggar, M. Y., Leung, K. M., Schramm, A., Risgaard-Petersen, N., and Nielsen, L. P. (2012). Filamentous bacteria transport electrons over centimetre distances. Nature 491: 218-221.

Poulton, S. W., and Canfield, D. E. (2005). Development of a sequential extraction procedure for iron: implications for iron partitioning in continentally derived particulates. Chemical Geology 214: 209-221.

Risgaard-Petersen, N., Kristiansen, M., Frederiksen, R. B., Dittmer, A. L., Bjerg, J. T., Trojan, D., Schreiber, L., Damgaard, L. R., Schramm, A., and Nielsen, L. P. (2015). Cable bacteria in freshwater sediments. Applied and Environmental Microbiology 81: 6003-6011.

Risgaard-Petersen, N., Revil, A., Meister, P., and Nielsen, L. P. (2012). Sulfur, iron-, and calcium cycling associated with natural electric currents running through marine sediment. Geochimica et Cosmochimica Acta 92: 1-13.

Seitaj, D., Schauer, R., Sulu-Gambari, F., Hidalgo-Martinez, S., Malkin, S. Y., Burdorf, L. D. W., Slomp, C. P., and Meysman, F. J. R. (2015). Cable bacteria generate a firewall against euxinia in seasonally hypoxic basins. Proceedings of the National Academy of Sciences 112: 13278-13283.

Soetaert, K., Petzoldt, T., and Meysman, F. (2010). Marelac: Tools for aquatic sciences. R package version.

Sulu-Gambari, F., Seitaj, D., Behrends, T., Banerjee, D., Meysman, F. J., and Slomp, C. P. (2016a). Impact of cable bacteria on sedimentary iron and manganese dynamics in a seasonally-hypoxic marine basin. Geochimica et Cosmochimica Acta 192: 49-69.

Sulu-Gambari, F., Seitaj, D., Meysman, F. J., Schauer, R., Polerecky, L., and Slomp, C. P. (2016b). Cable bacteria control iron-phosphorus dynamics in sediments of a coastal hypoxic basin. Environmental Science \& Technology 50: 1227-1233.

Vasquez-Cardenas, D., Van de Vossenberg, J., Polerecky, L., Malkin, S. Y., Schauer, R., Hidalgo-Martinez, S., Confurius, V., Middelburg, J. J., Meysman, F. J. R., and Boschker, H. T. S. (2015). Microbial carbon metabolism associated with electrogenic sulphur oxidation in coastal sediments. ISME Journal 9: 1966.

Witbaard, R., Duineveld, G., Van der Weele, J., Berghuis, E., and Reyss, J. (2000). The benthic response to the seasonal deposition of phytopigments at the Porcupine Abyssal Plain in the North East Atlantic. Journal of Sea Research 43 : 15-31. 


\section{Chapter 4}

Adelson, J., Helz, G., and Miller, C. (2001). Reconstructing the rise of recent coastal anoxia; molybdenum in Chesapeake Bay sediments. Geochimica et Cosmochimica Acta 65: 237-252.

Andrejev, O., Myrberg, K., and Lundberg, P. A. (2004). Age and renewal time of water masses in a semi-enclosed basin-application to the Gulf of Finland. Tellus A 56: 548-558.

Asmala, E., Carstensen, J., Conley, D. J., Slomp, C. P., Stadmark, J., and Voss, M. (2017). Efficiency of the coastal filter: Nitrogen and phosphorus removal in the Baltic Sea. Limnology and Oceanography 62: S222-S238.

Berner, R. A. (1980). Early diagenesis: a theoretical approach. Princeton University Press.

Boudreau, B. P. (1997). Diagenetic models and their implementation. Springer Berlin.

Boyd, P., and Ellwood, M. (2010). The biogeochemical cycle of iron in the ocean. Nature Geoscience 3: 675.

Breitburg, D., Levin, L. A., Oschlies, A., Grégoire, M., Chavez, F. P., Conley, D. J., Garçon, V., Gilbert, D., Gutiérrez, D., Isensee, K., Jacinto, G. S., Limburg, K.E., Montes, I., Naqvi, S. W. A., Pitcher, G. C., Rabalais, N. N., Roman, M. R., Rose, K. A., Seibel, B. A., Telszewski, M., Yasuhara, M., and Zhang, J. (2018). Declining oxygen in the global ocean and coastal waters. Science 359: eaam7240.

Burdige, D. J. (1993). The biogeochemistry of manganese and iron reduction in marine sediments. Earth-Science Reviews 35: 249-284.

Burdige, D.J. (2006). Geochemistry of marine sediments. Princeton University Press.

Burton, E. D., Bush, R. T., and Sullivan, L. A. (2006). Fractionation and extractability of sulfur, iron and trace elements in sulfidic sediments. Chemosphere 64: 1421-1428.

Burton, E. D., Sullivan, L. A., Bush, R. T., Johnston, S. G., and Keene, A. F. (2008). A simple and inexpensive chromium-reducible sulfur method for acid-sulfate soils. Applied Geochemistry 23: 2759-2766.

Carstensen, J., Andersen, J. H., Gustafsson, B. G., and Conley, D. J. (2014). Deoxygenation of the Baltic Sea during the last century. Proceedings of the National Academy of Sciences 111: 5628-5633.

Claff, S. R., Sullivan, L. A., Burton, E. D., and Bush, R. T. (2010). A sequential extraction procedure for acid sulfate soils: partitioning of iron. Geoderma 155: 224-230.

Conley, D. J., Björck, S., Bonsdorff, E., Carstensen, J., Destouni, G., Gustafsson, B. G., Hietanen, S., Kortekaas, M., Kuosa, H., Meier, H. E. M., Müller-Karulis, B., Nordberg, K., Norkko, A., Nürnberg, G., Pitkänen, H., Rabalais, N. N., Rosenberg, R., Savchuk, O. P., Slomp, C. P., Voss, M., Wulff, F., and Zillén, L. (2009). Hypoxia-related processes in the Baltic Sea. Environmental Science \& Technology 43: 3412-3420.

Conley, D. J., Humborg, C., Rahm, L., Savchuk, O. P., and Wulff, F. (2002). Hypoxia in the Baltic Sea and basin-scale changes in phosphorus biogeochemistry. Environmental Science \& Technology 36: 5315-5320.

De Baar, H.J.W., Timmermans, K. R., Laan, P., De Porto, H. H., Ober, S., Blom, J. J., Bakker., M. C., Schiling, J., Sarthou, G., Smit, M. G., and Klunder, M. (2008). Titan: a new facility for ultraclean sampling of trace elements and isotopes in the deep oceans in the international Geotraces program. Marine Chemistry 111: 4-21.

Diaz, R. J., and Rosenberg, R. (2008). Spreading dead zones and consequences for marine ecosystems. Science 321: 926-929.

Edzwald, J. K., Toensing, D. C., and Leung, M. C.-Y. (1976). Phosphate adsorption reactions with clay minerals. Environmental Science \& Technology 10: 485-490.

Elken, J., Raudsepp, U., Laanemets, J., Passenko, J., Maljutenko, I., Pärn, O., and Keevallik, S. (2014). Increased frequency of wintertime stratification collapse events in the Gulf of Finland since the 1990s. Journal of Marine Systems 129: 47-55.

Grasshoff, K., Kremling, K., and Ehrhardt, M. (2009). Methods of seawater analysis. John Wiley \& Sons.

Gunnars, A., Blomqvist, S., Johansson, P., and Andersson, C. (2002). Formation of Fe (III) oxyhydroxide colloids in freshwater and brackish seawater, with incorporation of phosphate and calcium. Geochimica et Cosmochimica Acta 66: 745-758. 
Gustafsson, B. G., Schenk, F., Blenckner, T., Eilola, K., Meier, H. E. M., Müller-Karulis, B., Neumann, T., Ruoho-Airola, T., Savchuk, O. P., and Zorita, E. (2012). Reconstructing the development of Baltic Sea eutrophication 1850-2006. Ambio 41: 534-548.

HELCOM. (2009). Eutrophication in the Baltic Sea: An Integrated Thematic Assessment of the Effects of Nutrient Enrichment in the Baltic Sea Region. Helsinki Commission. Baltic Marine Environment Protection Commission.

Hermans, M. Lenstra, W. K., Hidalgo-Martinez, S., Van Helmond, N. A. G. M., Witbaard, R., Meysman, F. J. R., Gonzalez, S., and Slomp, C. P. (2019a). Abundance and Biogeochemical Impact of Cable Bacteria in Baltic Sea Sediments. Environmental Science \& Technology 53: 7494-7503.

Hermans, M., Lenstra, W. K., Van Helmond, N. A. G. M., Behrends, T., Egger, M., Séguret , M. J. M., Gustafsson, E., Gustafsson, B. G., and Slomp. C. P. (2019b). Impact of natural re-oxygenation on the sediment dynamics of manganese, iron and phosphorus in a euxinic Baltic Sea basin. Geochimica et Cosmochimica Acta 246: 174-196.

Ingall, E., and Jahnke, R. (1994). Evidence for enhanced phosphorus regeneration from marine sediments overlain by oxygen depleted waters. Geochimica et Cosmochimica Acta 58: 2571-2575.

Jilbert, T., De Lange, G., and Reichart, G. J. (2008). Fluid displacive resin embedding of laminated sediments: preserving trace metals for high-resolution paleoclimate investigations. Limnology and Oceanography: Methods 6: 16-22.

Jilbert, T., and Slomp, C. P. (2013). Iron and manganese shuttles control the formation of authigenic phosphorus minerals in the euxinic basins of the Baltic Sea. Geochimica et Cosmochimica Acta 107: 155-169.

Klunder, M., Laan, P., Middag, R., De Baar, H., and Van Ooijen, J. (2011). Dissolved iron in the Southern Ocean (Atlantic sector). Deep Sea Research Part II: Topical Studies in Oceanography 58: 2678-2694.

Koroleff, F. (1969). Determination of ammonia as indophenol blue. International Council for the Exploration of the Sea (ICES) 9.

Kraal, P., Burton, E. D., and Bush, R. T. (2013). Iron monosulfide accumulation and pyrite formation in eutrophic estuarine sediments. Geochimica et Cosmochimica Acta 122: 75-88.

Kraal, P., Dijkstra, N., Behrends, T., and Slomp, C. P. (2017). Phosphorus burial in sediments of the sulfidic deep Black Sea: Key roles for adsorption by calcium carbonate and apatite authigenesis. Geochimica et Cosmochimica Acta 204: 140-158.

Kraal, P., and Slomp, C. P. (2014). Rapid and extensive alteration of phosphorus speciation during oxic storage of wet sediment samples. PloS One 9: e96859.

Kraal, P., Slomp, C. P., Forster, A., Kuypers, M. M., and Sluijs, A. (2009). Pyrite oxidation during sample storage determines phosphorus fractionation in carbonate-poor anoxic sediments. Geochimica et Cosmochimica Acta 73 : 3277-3290.

Lagerström, M., Field, M., Séguret, M., Fischer, L., Hann, S., and Sherrell, R. (2013). Automated on-line flow-injection ICP-MS determination of trace metals ( $\mathrm{Mn}, \mathrm{Fe}, \mathrm{Co}, \mathrm{Ni}, \mathrm{Cu}$ and $\mathrm{Zn}$ ) in open ocean seawater: Application to the GEOTRACES program. Marine Chemistry 155: 71-80.

Learman, D., Voelker, B., Vazquez-Rodriguez, A., and Hansel, C. (2011). Formation of manganese oxides by bacterially generated superoxide. Nature Geoscience 4: 95.

Lehtoranta, J. (2003). Dynamics of sediment phosphorus in the brackish Gulf of Finland. Finnish Environment Institute.

Lehtoranta, J., Savckuk, O. P., Elken, J., Dahlbo, K., Kuosa, H., Raateoja, M., Kauppila, P., Räike, A., and Pitkänen, H. (2017). Atmospheric forcing controlling inter-annual nutrient dynamics in the open Gulf of Finland. Journal of Marine Systems 171: 4-20.

Lenstra, W., Hermans, M., Séguret M. J. M., Witbaard, R., Behends, T., Dijkstra, N., Van Helmond, N. A. G. M., Kraal, P., Laan, P., Rijkenberg, M. J. A., Severmann, S., Teacă, A., and Slomp, C. P. (2019). The shelf-to-basin iron shuttle in the Black Sea revisited. Chemical Geology 511: 314-341. 
Lenstra, W. K., Hermans, M., Séguret, M. J. M., Witbaard, R., Severmann, S., Behrends, T., and Slomp, C. P.

(Submitted). Hypoxia and eutrophication as key controls on benthic release and water column dynamics of iron and manganese in the Baltic Sea.

Lenz, C., Behrends, T., Jilbert, T., Silveira, M., and Slomp, C. P. (2014). Redox-dependent changes in manganese speciation in Baltic Sea sediments from the Holocene Thermal Maximum: An EXAFS, XANES and LA-ICP-MS study. Chemical Geology 370: 49-57.

Lenz, C., Jilbert, T., Conley, D., Wolthers, M., and Slomp, C. (2015). Are recent changes in sediment manganese sequestration in the euxinic basins of the Baltic Sea linked to the expansion of hypoxia? Biogeosciences 12: 48754894.

Liblik, T., Laanemets, J., Raudsepp, U., Elken, J., and Suhhova, I. (2013). Estuarine circulation reversals and related rapid changes in winter near-bottom oxygen conditions in the Gulf of Finland, Baltic Sea. Ocean Science 9: $917-$ 930.

Lukkari, K., Leivuori, M., and Hartikainen, H. (2008). Vertical distribution and chemical character of sediment phosphorus in two shallow estuaries in the Baltic Sea. Biogeochemistry 90: 171-191.

Lukkari, K., Leivuori, M., and Kotilainen, A. (2009a). The chemical character and behaviour of phosphorus in poorly oxygenated sediments from open sea to organic-rich inner bay in the Baltic Sea. Biogeochemistry 96: 25-48.

Lukkari, K., Leivuori, M., Vallius, H., and Kotilainen, A. (2009b). The chemical character and burial of phosphorus in shallow coastal sediments in the northeastern Baltic Sea. Biogeochemistry 94: 141-162.

Luther, G. W. (2010). The role of one-and two-electron transfer reactions in forming thermodynamically unstable intermediates as barriers in multi-electron redox reactions. Aquatic Geochemistry 16: 395-420.

Madison, A. S., Tebo, B. M., Mucci, A., Sundby, B., and Luther, G. W. (2013). Abundant porewater Mn(III) is a major component of the sedimentary redox system. Science 341: 875-878.

Marzocchi, U., Trojan, D., Larsen, S., Meyer, R. L., Revsbech, N. P., Schramm, A., Nielsen, L. P., and Risgaard-Petersen, N. (2014). Electric coupling between distant nitrate reduction and sulfide oxidation in marine sediment. The ISME Journal 8: 1682-1690.

McManus, J., Berelson, W. M., Severmann, S., Johnson, K. S., Hammond, D. E., Roy, M., and Coale, K. H., (2012). Benthic manganese fluxes along the Oregon-California continental shelf and slope. Continental Shelf Research 43 : 71-85.

Murphy, J., and Riley, J. P. (1962). A modified single solution method for the determination of phosphate in natural waters. Analytica Chimica Acta 27: 31-36.

Nielsen, L. P., and Risgaard-Petersen, N. (2015). Rethinking sediment biogeochemistry after the discovery of electric currents. Annual Review of Marine Science 7: 425-442.

Nielsen, L. P., Risgaard-Petersen, N., Fossing, H., Christensen, P. B., and Sayama, M. (2010). Electric currents couple spatially separated biogeochemical processes in marine sediment. Nature 463: 1071.

Norkko, J., Reed, D. C., Timmermann, K. Norkko, A., Gustafsson, B. G., Bonsdorff, E., Slomp, C. P., Carstensen, J., and Conley D. J. (2012). A welcome can of worms? Hypoxia mitigation by an invasive species. Global Change Biology 18: 422-434.

Oldham, V. E., Mucci, A., Tebo, B. M., and Luther III, G. W. (2017). Soluble Mn(III)-L complexes are abundant in oxygenated waters and stabilized by humic ligands. Geochimica et Cosmochimica Acta 199: 238-246.

Pfeffer, C., Larsen, S., Song, J., Dong, M., Besenbacher, F., Meyer, R. L., Kjeldsen, K. U., Schreiber, L., Gorby, Y. A., El-Naggar, M. Y., Leung, K. M., Schramm, A., Risgaard-Petersen, N., and Nielsen, L. P. (2012). Filamentous bacteria transport electrons over centimetre distances. Nature 491: 218-221.

Pitkänen, H. (1994). Eutrophication of the Finnish coastal waters: Origin, fate and effects of riverine nutrient fluxes. National Board of Waters and the Environment. 
Pitkänen, H., Kiirikki, M., Savchuk, O. P., Räike, A., Korpinen, P., and Wulff, F. (2007). Searching efficient protection strategies for the eutrophied Gulf of Finland: the combined use of 1D and 3D modeling in assessing long-term state scenarios with high spatial resolution. AMBIO: A Journal of the Human Environment 36: 272-279.

Pitkänen, H., Lehtoranta, J., and Räike, A. (2001). Internal nutrient fluxes counteract decreases in external load: the case of the estuarial eastern Gulf of Finland, Baltic Sea. AMBIO: A Journal of the Human Environment 30: 195202.

Pohl, C., and Fernández-Otero, E. (2012). Iron distribution and speciation in oxic and anoxic waters of the Baltic Sea. Marine Chemistry 145: 1-15.

Postma, D. (1985). Concentration of Mn and separation from Fe in sediments-I. Kinetics and stoichiometry of the reaction between birnessite and dissolved Fe (II) at 10 C. Geochimica et Cosmochimica Acta 49: 1023-1033.

Poulton, S. W., and Canfield, D. E. (2005). Development of a sequential extraction procedure for iron: implications for iron partitioning in continentally derived particulates. Chemical Geology 214: 209-221.

Rabalais, N. N., Cai, W.-J., Carstensen, J., Conley, D. J., Fry, B., Hu, X., Quiñones-Rivera, Z., Rosenberg, R., Slomp, C. P., Turner, E., Voss, M., Wissel, B., and Zhang, J. (2014). Eutrophication-driven deoxygenation in the coastal ocean. Oceanography 27: 172-183.

Rabalais, N. N., Turner, R. E., and Wiseman Jr, W. J. (2002). Gulf of Mexico hypoxia, aka "The dead zone". Annual Review of Ecology and Systematics 33: 235-263.

Raiswell, R., and Canfield, D. E. (2012). The iron biogeochemical cycle past and present. Geochemical Perspectives 1: $1-2$.

Rao, A. M., Malkin, S. Y., Hidalgo-Martinez, S., and Meysman, F. J. (2016). The impact of electrogenic sulfide oxidation on elemental cycling and solute fluxes in coastal sediment. Geochimica et Cosmochimica Acta 172: 265-286.

Ravel, B., and Newville, M. (2005). ATHENA, ARTEMIS, HEPHAESTUS: data analysis for X-ray absorption spectroscopy using IFEFFIT. Journal of Synchrotron Radiation 12: 537-541.

Rijkenberg, M.J.A., De Baar, H.J.W., Bakker, K., Gerringa, L.J.A., Keijzer, E., Laan, M., Laan, P., Middag, R., Ober, S., Van Ooijen, J., Ossebaar, S., Van Weerlee, E.M., and Smit, M.G. (2015). “PRISTINE”, a new high volume sampler for ultraclean sampling of trace metals and isotopes. Marine Chemistry 177: 501-509.

Rijkenberg, M.J.A., Middag, R., Laan, P., Gerringa, L. J. A., Van Aken, H. M., Schoemann, V., De Jong, J. T. M., and De Baar, H. J. W. (2014). The distribution of dissolved iron in the West Atlantic Ocean. PLoS ONE 9: 1-14.

Risgaard-Petersen, N., Revil, A., Meister, P., and Nielsen, L. P. (2012). Sulfur, iron-, and calcium cycling associated with natural electric currents running through marine sediment. Geochimica et Cosmochimica Acta 92: 1-13.

Rossberg, A., Reich, T., and Bernhard, G. (2003). Complexation of uranium (VI) with protocatechuic acidapplication of iterative transformation factor analysis to EXAFS spectroscopy. Analytical and Bioanalytical Chemistry 376: 631-638.

Ruttenberg, K. C. (1992). Development of a sequential extraction method for different forms of phosphorus in marine sediments. Limnology and Oceanography 37: 1460-1482.

Rydin, E., Malmaeus, J., Karlsson, O., and Jonsson, P. (2011). Phosphorus release from coastal Baltic Sea sediments as estimated from sediment profiles. Estuarine, Coastal and Shelf Science 92: 111-117.

Salomé, M., Cotte, M., Baker, R., Barett, R., Benseny-Cases, N., Berruyer, G., Bugnazet, D., Castillo-Michel, H., Cornu, C., and Fayard, B. (2013). The ID21 scanning X-ray microscope at ESRF. Journal of Physics: Conference Series 425: 182004 .

Savchuk, O. P., Wulff, F., Hille, S., Humborg, C., and Pollehne, F. (2008). The Baltic Sea a century ago-a reconstruction from model simulations, verified by observations. Journal of Marine Systems 74: 485-494.

Seitaj, D., Schauer, R., Sulu-Gambari, F., Hidalgo-Martinez, S., Malkin, S. Y., Burdorf, L. D. W., Slomp, C. P., and Meysman, F. J. R. (2015). Cable bacteria generate a firewall against euxinia in seasonally hypoxic basins. Proceedings of the National Academy of Sciences 112: 13278-13283. 
Sharpley, A., Jarvie, H. P., Buda, A., May, L., Spears, B., and Kleinman, P. (2013). Phosphorus legacy: overcoming the effects of past management practices to mitigate future water quality impairment. Journal of Environmental Quality 42: 1308-1326.

Slomp, C. P., Epping, E. H., Helder, W., and Raaphorst, W. V. (1996). A key role for iron-bound phosphorus in authigenic apatite formation in North Atlantic continental platform sediments. Journal of Marine Research 54: 1179-1205.

Soetaert, K., and Herman, P. M. (2008). A practical guide to ecological modelling: using R as a simulation platform. Springer Science \& Business Media.

Soetaert, K., Petzoldt, T., and Meysman, F.J.R. (2010). Marelac: Tools for Aquatic Sciences v2.1.3. R package.

Solé, V., Papillon, E., Cotte, M., Walter, P., and Susini, J. (2007). A multiplatform code for the analysis of energydispersive X-ray fluorescence spectra. Spectrochimica Acta Part B: Atomic Spectroscopy 62: 63-68.

Suess, E. (1979). Mineral phases formed in anoxic sediments by microbial decomposition of organic matter. Geochimica et Cosmochimica Acta 43: 339-352.

Sulu-Gambari, F., Roepert, A., Jilbert, T., Hagens, M., Meysman, F. J., and Slomp, C. P. (2017). Molybdenum dynamics in sediments of a seasonally-hypoxic coastal marine basin. Chemical Geology 466: 627-640.

Sulu-Gambari, F., Seitaj, D., Behrends, T., Banerjee, D., Meysman, F. J., and Slomp, C. P. (2016a). Impact of cable bacteria on sedimentary iron and manganese dynamics in a seasonally-hypoxic marine basin. Geochimica et Cosmochimica Acta 192: 49-69.

Sulu-Gambari, F., Seitaj, D., Meysman, F. J., Schauer, R., Polerecky, L., and Slomp, C. P. (2016b). Cable bacteria control iron-phosphorus dynamics in sediments of a coastal hypoxic basin. Environmental Science \& Technology 50: 1227-1233.

Sundby, B., Anderson, L. G., Hall, P. O., Iverfeldt, Å., Van der Loeff, M. M. R., and Westerlund, S. F. (1986). The effect of oxygen on release and uptake of cobalt, manganese, iron and phosphate at the sediment-water interface. Geochimica et Cosmochimica Acta 50: 1281-1288.

Turner, R. E., Rabalais, N. N., and Justic, D. (2008). Gulf of Mexico hypoxia: Alternate states and a legacy. Environmental Science \& Technology 42: 2323-2327.

Turnewitsch, R., and Pohl, C. (2010). An estimate of the efficiency of the iron-and manganese-driven dissolved inorganic phosphorus trap at an oxic/euxinic water column redoxcline. Global Biogeochemical Cycles 24.

Van Helmond, N. A., Jilbert, T., and Slomp, C. P. (2018). Hypoxia in the Holocene Baltic Sea: Comparing modern versus past intervals using sedimentary trace metals. Chemical Geology 493: 478-490.

Viktorsson, L., Almroth-Rosell, E., Tengberg, A., Vankevich, R., Neelov, I., Iseaev, A., Kravtsov, V., and Hall, P. O. J. (2012). Benthic phosphorus dynamics in the Gulf of Finland, Baltic Sea. Aquatic Geochemistry 18: 543-564.

Wang, Y., and Van Cappellen, P. (1996). A multicomponent reactive transport model of early diagenesis: Application to redox cycling in coastal marine sediments. Geochimica et Cosmochimica Acta 60: 2993-3014. 


\section{Chapter 5}

Aller, R.C. (1980). Diagenetic processes near the sediment-water interface of Long Island Sound. II. Fe and Mn. Advances in Geophysics 22: 351-415.

Aller, R.C. (1982). The effects of macrobenthos on chemical properties of marine sediment and overlying water. Animal-Sediment Relations. pp. 53-102.

Aller, R.C. (1994). Bioturbation and remineralization of sedimentary organic matter: effects of redox oscillation. Chemical Geology 114: 331-345.

Aller, R.C., and Aller, J.Y. (1998). The effect of biogenic irrigation intensity and solute exchange on diagenetic reaction rates in marine sediments. Journal of Marine Research 56: 905-936.

Anderson, T.F., and Raiswell, R. (2004). Sources and mechanisms for the enrichments of highly reactive iron in euxinic Black Sea sediments. American Journal of Science 304: 203-233.

APHA (2005). Standard methods for the examination of water and wastewater. pp. 1469.

Arthur, M.A., and Dean, W.E. (1998). Organic-matter production and preservation and evolution of anoxia in the Holocene Black Sea. Paleoceanography 13: 395-411.

Berelson, W., McManus, J., Coale, J., Johnson, K., Burdige, K. Kilgore, T., Colodner, D., Chavez, F. Kudela, R. and Boucher, J. (2003). A time series of benthic flux measurements from Monterey Bay, CA. Continental Shelf Research 23: 457-481.

Berner, R.A. (1970). Sedimentary pyrite formation. American Journal Science. 268: 1-23.

Berner, R.A. (1984). Sedimentary pyrite formation: an update. Geochimica et Cosmochimica Acta 48: 605-615.

Bodeanu, N., Moncheva, S., Ruta, G., Popa, L. (1998). Long-term evolution of the algal blooms in Romanian and Bulgarian Black Sea waters. Cercetari Marine $=$ Recherches Marines 31: 37-55.

Borsboom, M., Bras, W., Cerjak, I., Detollenaere, D., Glastra van Loon, D., Goedtkindt, P., Konijnenburg, M., Lassing, P., Levine, Y.K., Munneke, B., and Oversluizen, M. (1998). The Dutch-Belgian beamline at the ESRF. Journal of Synchrotron Radiation 5: 518-520.

Boudreau, B.P. (1984). On the equivalence of nonlocal and radial-diffusion models for porewater irrigation. Journal of Marine Research 42: 731-735.

Boudreau, B.P. (1996). A method-of-lines code for carbon and nutrient diagenesis in aquatic sediments. Computers \& Geosciences 22: 479-496. 3004(95)00115-8.

Boudreau, B.P. (1997). Diagenetic Models and their Implementation. Modelling Transport and Reactions in Aquatic Sediments. vol. 171. pp. 49-66.

Boudreau, B.P. (1998). Mean mixed depth of sediments: the wherefore and the why. Limnology and Oceanography 43: 524-526.

Boyd, P.W., Ellwood, M.J. (2010). The biogeochemical cycle of iron in the ocean. Nature Geoscience 3: 675-682.

Burdige, D.J. (2006). Geochemistry of Marine Sediments. pp. 208-209.

Burton, E.D., Bush, R.T., and Sullivan, L.A. (2006). Fractionation and extractability of sulfur, iron and trace elements in sulfidic sediments. Chemosphere 64: 1421-1428.

Burton, E.D., Sullivan, L.A., Bush, R.T., Johnston, S.G., and Keene, A.F. (2008). A simple and inexpensive chromiumreducible sulfur method for acid-sulfate soils. Applied Geochemistry 23: 2759-2766.

Canfield, D.E., 1989. Reactive iron in marine sediments. Geochimica et Cosmochimica Acta 53: 619-632.

Canfield, D.E., Thamdrup, B., and Hansen, J.W. (1993). The anaerobic degradation of organic matter in Danish coastal sediments: iron reduction, manganese reduction, and sulfate reduction. Geochimica et Cosmochimica Acta 57: 3867-3883.

Canfield, D.E., Lyons, T.W., and Raiswell, R. (1996). A model for iron deposition to euxinic Black Sea sediments. American Journal of Science 296: 818-834. 
Capet, A., Beckers, J.M., and Grégoire, M. (2013). Drivers, mechanisms and long-term variability of seasonal hypoxia on the Black Sea northwestern shelf - is there any recovery after eutrophication? Biogeosciences 10: 3943-3962.

Capet, A., Stanev, E.V., Beckers, J.M., Murray, J.W., and Grégoire, M. (2016). Decline of the Black Sea oxygen inventory. Biogeosciences 13: 1287-1297.

Claff, S.R., Sullivan, L.A., Burton, E.D., and Bush, R.T. (2010). A sequential extraction procedure for acid sulfate soils: partitioning of iron. Geoderma 155: 224-230.

Conway, T.M., and John, S.G. (2014). Quantification of dissolved iron sources to the North Atlantic Ocean. Nature 511: $212-215$.

Coolen, M.J.L., Saenz, J.P., Giosan, L., Trowbridge, N.Y., Dimitrov, P., Dimitrov, D., and Eglinton, T.I. (2009). DNA and lipid molecular stratigraphic records of haptophyte succession in the Black Sea during the Holocene. Earth and Planetary Science Letters 284: 610-621.

Cullen, J.T., Chong, M., and Ianson, D. (2009). GB4012 British Columbian continental shelf as a source of dissolved iron to the subarctic northeast Pacific Ocean. Global Biogeochemical Cycles 23.

Dale, A.W., Nickelsen, L., Scholz, F., Hensen, C., Oschlies, A., and Wallmann, K. (2015). A revised global estimate of dissolved iron fluxes from marine sediments. Glob. Biogeochemical Cycles 29: 691-707.

De Baar, H.J.W., Timmermans, K. R., Laan, P., De Porto, H. H., Ober, S., Blom, J. J., Bakker., M. C., Schiling, J., Sarthou, G., Smit, M. G., and Klunder, M. (2008). Titan: a new facility for ultraclean sampling of trace elements and isotopes in the deep oceans in the international Geotraces program. Marine Chemistry 111: 4-21.

Diaz, R.J., and Rosenberg, R. (1995). Marine benthic hypoxia: a review of its ecological effects and the behavioural responses of benthic macrofauna. Oceanography and Marine Biology. An Annual Review 33: 245-303.

Diaz, R.J., and Rosenberg, R. (2008). Spreading dead zones and consequences for marine ecosystems. Science 321: 926-929.

Eckert, S., Brumsack, H.J., Severmann, S., Schnetger, B., März, C., and Fröllje, H. (2013). Establishment of euxinic conditions in the Holocene Black Sea. Geology 41: 431-434.

Eleftheriou, A., and McIntyre, A. (2007). Methods for the Study of Marine Benthos: Third Edition. pp. 1-418.

Elrod, V.A., Berelson, W.M., Coale, K.H., and Johnson, K.S. (2004). The flux of iron from continental shelf sediments: a missing source for global budgets. Geophysical Research Letters 31: 2-5.

Emerson, S., Jahnke, R., and Heggie, D. (1984). Sediment-water exchange in shallow water estuarine sediments. Journal of Marine Research 42: 709-730.

Friedl, G., Dinkel, C., and Wehrli, B. (1998). Benthic fluxes of nutrients in the northwestern Black Sea. Marine Chemistry 62: 77-88.

Friedrich, J., Dinkel, C., Friedl, G., Pimenov, N., Wijsman, J., Gomoiu, M.-T., Cociasu, A., Popa, L., and Wehrli, B. (2002). Benthic nutrient cycling and diagenetic pathways in the North-western Black Sea. Estuarine, Coastal and Shelf Science 54: 369-383

Gerringa, L.J.A., Rijkenberg, M.J.A., Bown, J., Margolin, A.R., Laan, P., and De Baar, H.J.W. (2016). Fe-binding dissolved organic ligands in the oxic and suboxic waters of the Black Sea. Frontiers in Marine Science 3: 84

Gledhill, M., and Van den Berg, C.M.G. (1994). Determination of complexation of iron(III) with natural organic complexing ligands in seawater using cathodic stripping voltammetry. Marine Chemistry 47: 41-54.

Henkel, S., Kasten, S., Poulton, S.W., and Staubwasser, M. (2016). Determination of the stable iron isotopic composition of sequentially leached iron phases in marine sediments. Chemical Geology 421: 93-102.

Homoky, W.B., Hembury, D.J., Hepburn, L.E., Mills, R.A., Statham, P.J., Fones, G.R., and Palmer, M.R. (2011). Iron and manganese diagenesis in deep sea volcanogenic sediments and the origins of pore water colloids. Geochimica et Cosmochimica Acta 75: 5032-5048.

Hong, H., and Kester, D.R. (1986). Redox state of iron in the offshore waters of Peru. Limnology and Oceanography 3: $612-626$. 
Hoving, A.L., Sander, M., Bruggeman, C., and Behrends, T. (2017). Redox properties of clayrich sediments as assessed by mediated electrochemical analysis: separating pyrite, siderite and structural Fe in clay minerals. Chemical Geology 457: 149-161

Johnson, K., Elrod, V., Fitzwater, S., Plant, J., Boyle, E., Bergquist, B., Bruland, K., Aguilar-Islas, A., Buck, K., Lohan, M., Smith, G. J., Sohnst, B., Coale, K., Gordon, M., Tanner, S., Measures, C., Moffett, J., Barbeau, K., King, A., Bowie, A., Chase, Z., Cullen, J., Laan, P., Landing, W., Mendez, J., Milne, A., Obata, H., Doi, T., Ossiander, L., Sarthou, G., Sedwick, P., Van den Berg, S., Laglera-Baquer, L., Wu. J.-F., and Cai., Y. (2007). Developing standards for dissolved iron in seawater. Eos, Transactions American Geophysical Union 88: 131-132.

Jørgensen, B.B. (1977). The sulfur cycle of a coastal marine sediment (Limfjorden, Denmark). Limnology and Oceanography 22: 814-832.

Kappler, A., Schink, B., and Newman, D.K. (2005). Fe(III) mineral formation and cell encrustation by the nitratedependent Fe(II)-oxidizer strain BoFeN1. Geobiology 3: 235-245.

Klar, J.K., Homoky, W. B., Statham, P. J., Birchill, A. J., Harris, E. L., Woodward, E. M. S., Silburn, B., Cooper, M. J., James, R. H., Conelly, D. P., Chever, F., Lichtschlag, A., and Graves, C. (2017). Stability of dissolved and soluble Fe (II) in shelf sediment pore waters and release to an oxic water column. Biogeochemistry 135: 49-67.

Klunder, M.B., Laan, P., Middag, R., De Baar, H.J.W., and Van Ooijen, J.C. (2011). Dissolved iron in the Southern Ocean (Atlantic sector). Deep Sea Research Part II: Topical Studies in Oceanography 58: 2678-2694.

Kraal, P., Dijkstra, N., Behrends, T., and Slomp, C.P. (2017). Phosphorus burial in sediments of the sulfidic deep Black Sea: key roles for adsorption by calcium carbonate and apatite authigenesis. Geochimica et Cosmochimica Acta 204: 140-158.

Lam, P.J., Ohnemus, D.C., and Marcus, M.A. (2012). The speciation of marine particulate iron adjacent to active and passive continental margins. Geochimica et Cosmochimica Acta 80: 108-124.

Lenz, C., Jilbert, T., Conley, D.J., and Slomp, C.P. (2015). Hypoxia-driven variations in iron and manganese shuttling in the Baltic Sea over the past 8 kyr. Geochemistry, Geophysics, Geosystems 16: 3754-3766.

Levin, L.A., Ekau, W., Gooday, A.J., Jorissen, F., Middelburg, J.J., Naqvi, S.W.A., Neira, C., Rabalais, N.N., and Zhang, J. (2009). Effects of natural and human-induced hypoxia on coastal benthos. Biogeosciences 6: 2063-2098.

Lovley, D.R., and Phillips, E.J. (1987). Rapid assay for microbially reducible ferric iron in aquatic sediments. Applied and Environmental Microbiology 53: 1536-1540.

Lyons, T.W., and Severmann, S. (2006). A critical look at iron paleoredox proxies: new insights from modern euxinic marine basins. Geochimica et Cosmochimica Acta 70: 5698-5722.

Martin, J.H., and Fitzwater, S.E. (1988). Iron Deficiency Limits Phytoplankton Growth in the North-East Pacific Subarctic. Nature 331: 341-343.

Martin, W.R., and Banta, G.T. (1992). The measurement of sediment irrigation rates: a comparison of the Br tracer and 222-Rn/ 226-Ra disequilibrium techniques. Journal of Marine Research 50: 125-154.

Meile, C., Berg, P., Van Cappellen, P., and Tuncay, K. (2005). Solute-specific pore water irrigation: implications for chemical cycling in early diagenesis. Journal of Marine Research 63: 601-621.

Millero, F.J., Sotolongo, S., and Izaguirre, M. (1987). The oxidation kinetics of Fe(II) in seawater. Geochimica et Cosmochimica Acta 51: 793-801.

Moore, C.M., Mills, M. M., Arrigo, K. R., Berman-Frank, I., Bopp, L., Boyd, P. W., Galbraith, E. D., Geider, R. J., Guieu, C., Jaccard, S. L., Jickells, T. D., La Roche, J., Lenton, T. M., Mahowald, N. M., Marañón, E., Marinov, I., Moore, J. K., Nakatsuka, T., Oschlies, A., Saito, M. A., Thingstad, T. F., Tsuda, A., and Ulloa, O. (2013). Processes and patterns of oceanic nutrient limitation. Nature Geoscience 6: 701-710.

Murray, J.W., Jannasch, H.W., Honjo, S., Anderson, R.F., Reeburgh, W.S., Top, Z., Friederich, G.E., Codispoti, L.A., and Izdar, E. (1989). Unexpected changes in the oxic/ anoxic interface in the Black Sea. Nature 338: 411-413.

Nealson, K.H. (1997). Sediment bacteria: who's there, what are they doing, and what's new? Annual Review of Earth and Planetary Sciences 25: 403-434. 
Nikitenko, S., Beale, A. M., Van der Eerden, A. M. J., Jacques, S. D. M., Leynaud, O., O’Brien, M. G., Detollennaere, D., Kapitein, R., Weckhuysen, B. M., and Bras, W. (2008). Implementation of a combined SAXS/WAXS/QEXAFS setup for time-resolved in situ experiments. Journal of Synchrotron Radiation 15: 632-640.

Noble, A.E., Hamborg, C. H., Ohnemus, D. C., Lam, P. J., Goepfert, T. J., Measures, C. I., Frame, C. H., Casciotti, K. L., DiTullio, G. R., Jennings, J., and Saito, M. A. (2012). Basin-scale inputs of cobalt, iron, and manganese from the Benguela-Angola front to the South Atlantic Ocean. Limnology and Oceanography 57: 989-1010.

Noffke, A., Hensen, C., Sommer, S., Scholz, F., Bohlen, L., Mosch, T., Graco, M., and Wallmann, K. (2012). Benthic iron and phosphorus fluxes across the Peruvian oxygen minimum zone. Limnology and Oceanography 57: 851867.

Pakhomova, S.V., Hall, P.O.J., Kononets, M.Y., Rozanov, A.G., Tengberg, A., and Vershinin, A.V. (2007). Fluxes of iron and manganese across the sediment-water interface under various redox conditions. Marine Chemistry 107: $319-331$.

Panin, N., and Jipa, D. (2002). Danube river sediment input and its interaction with the Northwestern Black Sea. Estuarine, Coastal and Shelf Science 54: 551-562.

Pollard, R.T., Salter, I., Sanders, R. J., Lucas, M. I., Moore, C. M., Mills, R. A., Statham, P. J., Allen, J. T., Baker, A. R., Bakker, D. C. E., Charette, M. A., Fielding, S., Fones, G. R., French, M., Hickman, A. E., Holland, R. J., Hughes, J. A., Jickells, T. D., Lampitt, R. S., Morris, P. J., Nédélec, F. H., Nielsdóttir, M., Planquette, H., Popova, E. E., Poulton, A. J., Read, J. F., Seeyave, S., Smith, T., Stinchcombe, M., Taylor, S., Thomalla, S., Venables, H. J., Williamson, R., and Zubkov, M. V. (2009). Southern Ocean deep-water carbon export enhanced by natural iron fertilization. Nature 457: 577-580.

Popa, A. (1993). Liquid and Sediment Inputs of the Danube River into the North-Western Black Sea. Transport of carbon and nutrients in lakes and estuaries, (Part 6). pp. 137-149.

Postma, D. (1985). Concentration of Mn and separation from Fe in sediments-I. Kinetics and stoichiometry of the reaction between birnessite and dissolved Fe(II) at 10 degrees C. Geochimica et Cosmochimica Acta 49: 10231033.

Poulton, S.W., and Canfield, D.E. (2005). Development of a sequential extraction procedure for iron: implications for iron partitioning in continentally derived particulates. Chemical Geology 214: 209-221.

Poulton, S.W., and Raiswell, R. (2002). The low-temperature geochemical cycle of iron: from continental fluxes to marine sediment deposition. American Journal of Science 302: 774-805.

Raiswell, R., and Berner, R.A. (1985). Pyrite formation in euxinic and semi-euxinic sediments. American Journal of Science 285: 710-724.

Raiswell, R., Buckley, F., and Berner, R.A. (1988). Degree of pyritization of iron as a paleoenvironmental indicator of bottom-water oxygenation. SEPM. Journal of Sedimentary Research 58: 812-819

Raiswell, R., and Canfield, D.E. (2012). The iron biogeochemical cycle past and present. Geochemical Perspectives 1: $1-220$.

Raiswell, R., Vu, H.P., Brinza, L., and Benning, L.G. (2010). The determination of labile Fe in ferrihydrite by ascorbic acid extraction: methodology, dissolution kinetics and loss of solubility with age and de-watering. Chemical Geology 278: 70-79.

Ravel, B., and Newville, M. (2005). ATHENA, ARTEMIS, HEPHAESTUS: data analysis for X-ray absorption spectroscopy using IFEFFIT. Journal of Synchrotron Radiation 12: 537-541.

Rijkenberg, M.J.A., De Baar, H.J.W., Bakker, K., Gerringa, L.J.A., Keijzer, E., Laan, M., Laan, P., Middag, R., Ober, S., Van Ooijen, J., Ossebaar, S., Van Weerlee, E.M., and Smit, M.G. (2015). “PRISTINE”, a new high volume sampler for ultraclean sampling of trace metals and isotopes. Marine Chemistry 177: 501-509.

Rijkenberg, M.J.A., Middag, R., Laan, P., Gerringa, L. J. A., Van Aken, H. M., Schoemann, V., De Jong, J. T. M., and De Baar, H. J. W. (2014). The distribution of dissolved iron in the West Atlantic Ocean. PLoS ONE 9: 1-14. 
Robertson, E.K., Roberts, K.L., Burdorf, L.D.W., Cook, P., and Thamdrup, B. (2016). Dissimilatory nitrate reduction to ammonium coupled to $\mathrm{Fe}(\mathrm{II})$ oxidation in sediments of a periodically hypoxic estuary. Limnology and Oceanography 61: 365-381.

Rue, E.L., and Bruland, K.W. (1995). Complexation of iron(III) by natural organic ligands in the Central North Pacific as determined by a new competitive ligand equilibration/adsorptive cathodic stripping voltammetric method. Marine Chemistry 50: 117-138.

Salomé, M., Cotte, M., Baker, R., Barett, R., Benseny-Cases, N., Berruyer, G., Bugnazet, D., Castillo-Michel, H., Cornu, C., and Fayard, B. (2013). The ID21 scanning X-ray microscope at ESRF. Journal of Physics: Conference Series 425 : 182004.

Schlitzer, R., 2015. Ocean Data View. (2012).

Schlüter, M., Sauter, E., Hansen, H.P., and Suess, E. (2000). Seasonal variations of bioirrigation in coastal sediments: modelling of field data. Geochimica et Cosmochimica Acta 64: 821-834.

Scholz, F., Loscher, C.R., Fiskal, A., Sommer, S., Hensen, C., Lomnitz, U., Wuttig, K., Gottlicher, J., Kossel, E., Steininger, R., and Canfield, D.E. (2016). Nitrate-dependent iron oxidation limits iron transport in anoxic ocean regions. Earth and Planetary Science Letters 454: 272-281.

Scholz, F., McManus, J., Mix, A.C., Hensen, C., and Schneider, R.R. (2014a). The impact of ocean deoxygenation on iron release from continental margin sediments. Nature Geoscience 7: 433-437.

Scholz, F., Severmann, S., McManus, J., and Hensen, C. (2014b). Beyond the Black Sea paradigm: the sedimentary fingerprint of an open-marine iron shuttle. Geochimica et Cosmochimica Acta 127: 368-380.

Schwertmann, U., and Cornell, R.M. (2007). Frontmatter. In: Iron Oxides in the Laboratory.

Severmann, S., McManus, J., Berelson, W.M., and Hammond, D.E. (2010). The continentalshelf benthic iron flux and its isotope composition. Geochimica et Cosmochimica Acta 74: 3984-4004.

Sinninghe Damsté, J.S., Wakeham, S.G., Kohnen, M.E.L., Hayes, J.M., and De Leeuw, J.W. (1993). A 6000 year sedimentary molecular record of chemocline excursions in the Black Sea. Nature 362: 827-829.

Slomp, C.P., Malschaert, J.F.P., Lohse, L., and Van Raaphorst, W. (1997). Iron and manganese cycling in different sedimentary environments on the North Sea continental margin. Continental Shelf Research 17:1083-1117.

Slomp, C.P., Mort, H.P., Jilbert, T., Reed, D.C., Gustafsson, B.G., and Wolthers, M. (2013). Coupled dynamics of iron and phosphorus in sediments of an oligotrophic coastal basin and the impact of anaerobic oxidation of methane. PLOS ONE 8.

Soetaert, K., Petzoldt, T., and Meysman, F.J.R. (2010). Marelac: Tools for Aquatic Sciences v2.1.3. R package.

Tagliabue, A., Bowie, A. R., Boyd, P. W., Buck, K. N., Johnson, K. S., and Saito, M. A. (2017). The integral role of iron in ocean biogeochemistry. Nature 543: 51-59

Tankéré, S.P.C., Muller, F.L.L., Burton, J.D., Statham, P.J., Guieu, C., and Martin, J.M. (2001). Trace metal distributions in shelf waters of the northwestern Black Sea. Continental Shelf Research 21: 1501-1532.

Van Santvoort, P.J., De Lange, G.J., Thomson, J., Colley, S., Meysman, F.J., and Slomp, C.P. (2002). Oxidation and origin of organic matter in surficial Eastern Mediterranean hemipelagic sediments. Aquatic Geochemistry 8: 153-175.

Vink, S. (2001). Dissolved Fe in the upper waters of the Pacific sector of the Southern Ocean. Deep Sea Research Part II: Topical Studies in Oceanograph 48: 3913-3941.

Weber, A., Riess, W., Wenzhoefer, F., and Jørgensen, B.B. (2001). Sulfate reduction in Black Sea sediments: in situ and laboratory radiotracer measurements from the shelf to 2000m depth. Deep Sea Research Part I: Oceanographic Research Papers 48: 2073-2096.

Wijsman, J.W.M., Herman, P.M.J., and Gomoiu, M.T. (1999). Spatial distribution in sediment characteristics and benthic activity on the northwestern Black Sea shelf. Marine Ecology Progress Series 181: 25-39.

Wijsman, J.W.M., Herman, P.M.J., Middelburg, J.J., and Soetaert, K. (2002). A model for early diagenetic processes in sediments of the continental shelf of the Black Sea. Estuarine, Coastal and Shelf Science 54: 403-421. 
Wijsman, J.W.M., Middelburg, J.J., and Heip, C.H.R. (2001a). Reactive iron in Black Sea sediments: implications for iron cycling. Marine Geology 172: 167-180.

Wijsman, J.W.M., Middelburg, J.J., Herman, P.M.J., Böttcher, M.E., and Heip, C.H.R. (2001b). Sulfur and iron speciation in surface sediments along the northwestern margin of the Black Sea. Marine Chemistry 74: 261-278.

Witbaard, R., Duineveld, G.C.A., Van der Weele, J.A., Berghuis, E.M., and Reyss, J.P. (2000). The benthic response to the seasonal deposition of phytopigments at the Porcupine Abyssal Plain in the North East Atlantic. Journal of Sea Research 43: 15-31.

Wu, J., Boyle, E., Sunda, W., and Wen, L.S. (2001). Soluble and colloidal iron in the oligotrophic North Atlantic and North Pacific. Science 293: 847-849. 


\section{Chapter 6}

Aller, R. (2014). Sedimentary diagenesis, depositional environments, and benthic fluxes.

Aller, R. C., Aller, J. Y., Zhu, Q., Heilbrun, C., Klingensmith, I., and Kaushik, A. (2019). Worm tubes as conduits for the electrogenic microbial grid in marine sediments. Science Advances 5: eaaw3651.

APHA. (2005). Standard methods for the examination of water and wastewater. American Public Health Association (APHA): Washington, DC, USA.

Atkinson, M. (1997). Elemental composition of commercial seasalts. Journal of Aquariculture and Aquatic Sciences 8 : 39-43.

Bellier, N., Chazarenc, F., and Comeau, Y. (2006). Phosphorus removal from wastewater by mineral apatite. Water Research 40: 2965-2971.

Berg, P., Risgaard-Petersen, N., and Rysgaard, S. (1998). Interpretation of measured concentration profiles in sediment pore water. Limnology and Oceanography 43: 1500-1510.

Berner, R. A. (1980). Early diagenesis: a theoretical approach. Princeton University Press.

Bjerg, J. T., Boschker, H. T. S., Larsen, S., Berry, D., Schmid, M., Millo, D., Tataru, P., Meysman, F. J. R., Wagner, M., Nielsen, L. P., and Schramm, A. (2018). Long-distance electron transport in individual, living cable bacteria. Proceedings of the National Academy of Sciences 115: 5786-5791.

Boudreau, B. P. (1997). Diagenetic models and their implementation. Springer Berlin.

Boyd, P., and Ellwood, M. (2010). The biogeochemical cycle of iron in the ocean. Nature Geoscience 3: 675.

Breitburg, D., Levin, L. A., Oschlies, A., Grégoire, M., Chavez, F. P., Conley, D. J., Garçon, V., Gilbert, D., Gutiérrez, D., Isensee, K., Jacinto, G. S., Limburg, K.E., Montes, I., Naqvi, S. W. A., Pitcher, G. C., Rabalais, N. N., Roman, M. R., Rose, K. A., Seibel, B. A., Telszewski, M., Yasuhara, M., and Zhang, J. (2018). Declining oxygen in the global ocean and coastal waters. Science 359: eaam7240.

Burdige, D. J. (1993). The biogeochemistry of manganese and iron reduction in marine sediments. Earth-Science Reviews 35: 249-284.

Burdige, D. J. (2006). Geochemistry of marine sediments. Princeton University Press.

Burdorf, L. D., Malkin, S.Y., Bjerg, J.T., Van Rijswijk, P., Criens, F., Tramper, A., and Meysman, F. J. R. (2018). The effect of oxygen availability on long-distance electron transport in marine sediments. Limnology and Oceanography 63: 1799-1816.

Burdorf, L. D., Tramper, A., Seitaj, A., Meire, L., Hidalgo-Martinez, S., Zetsche, E.-M., Boschker, H. T. S., and Meysman, F. J. R. (2017). Long-distance electron transport occurs globally in marine sediments. Biogeosciences 14: 683-701.

Buresh, R. J., and Moraghan, J. (1976). Chemical Reduction of Nitrate by Ferrous Iron 1. Journal of Environmental Quality 5: 320-325.

Burton, E. D., Bush, R. T., and Sullivan, L. A. (2006). Fractionation and extractability of sulfur, iron and trace elements in sulfidic sediments. Chemosphere 64: 1421-1428.

Burton, E. D., Sullivan, L. A., Bush, R. T., Johnston, S. G., and Keene, A. F. (2008). A simple and inexpensive chromium-reducible sulfur method for acid-sulfate soils. Applied Geochemistry 23: 2759-2766.

Claff, S. R., Sullivan, L. A., Burton, E. D., and Bush, R. T. (2010). A sequential extraction procedure for acid sulfate soils: partitioning of iron. Geoderma 155: 224-230.

Cornelissen, R., Bøggild, A., Eachambadi, R. T., Koning, R. I., Kremer, A., Hidalgo-Martinez, S., Zetsche, E.-M., Damgaard, L. R., Bonné, R., Drijkoningen, J., Geelhoed, J. S., Boesen, T., Boschker, H. T. S., Valcke, R., Nielsen, L. P., D'Haen, J., Manca, J. V., and Meysman, F. J. R. (2018). The cell envelope structure of cable bacteria. Frontiers in Microbiology 9: 3044 .

Damgaard, L. R., Risgaard-Petersen, N., and Nielsen, L. P. (2014). Electric potential microelectrode for studies of electrobiogeophysics. Journal of Geophysical Research: Biogeosciences 119: 1906-1917. 
Davis, C. C., Chen, H.-W., and Edwards, M. (2002). Modeling silica sorption to iron hydroxide. Environmental Science \& Technology 36: 582-587.

Diaz, R. J., and Rosenberg, R. (2008). Spreading dead zones and consequences for marine ecosystems. Science 321: 926-929.

Egger, M., Jilbert, T., Behrends, T., Rivard, C., and Slomp, C. P. (2015). Vivianite is a major sink for phosphorus in methanogenic coastal surface sediments. Geochimica et Cosmochimica Acta 169: 217-235.

Fofonoff, N. P., and Millard Jr, R. (1983). Algorithms for the computation of fundamental properties of seawater.

Fossing, H., and Jørgensen, B. B. (1989). Measurement of bacterial sulfate reduction in sediments: evaluation of a single-step chromium reduction method. Biogeochemistry 8: 205-222.

Geerlings, N., Zetsche, E.-M., Hidalgo-Martinez, S., Middelburg, J. J., and Meysman, F. J. (2019). Mineral formation induced by cable bacteria performing long-distance electron transport in marine sediments. Biogeosciences 16: 811-829.

Hermans, M., Astudillo Pascual, M., Behrends, T., Lenstra, W. K., Conley, D. J., and Slomp, C. P. (Submitted). Coupled dynamics of iron, manganese and phosphorus in brackish coastal sediments populated by cable bacteria.

Hermans, M. Lenstra, W. K., Hidalgo-Martinez, S., Van Helmond, N. A. G. M., Witbaard, R., Meysman, F. J. R., Gonzalez, S., and Slomp, C. P. (2019a). Abundance and Biogeochemical Impact of Cable Bacteria in Baltic Sea Sediments. Environmental Science \& Technology 53: 7494-7503.

Hermans, M., Lenstra, W. K., Van Helmond, N. A. G. M., Behrends, T., Egger, M., Séguret , M. J. M., Gustafsson, E., Gustafsson, B. G., and Slomp. C. P. (2019b). Impact of natural re-oxygenation on the sediment dynamics of manganese, iron and phosphorus in a euxinic Baltic Sea basin. Geochimica et Cosmochimica Acta 246: 174-196.

Hovanec, T. A., and Coshland, J. L. (2004). A chemical analysis of select trace elements in synthetic sea salts and natural seawater. Sea Scope, Aquarium Systems 21.

Jeroschewski, P., Steuckart, C., and Kühl, M. (1996). An amperometric microsensor for the determination of $\mathrm{H}_{2} \mathrm{~S}$ in aquatic environments. Analytical Chemistry 68: 4351-4357.

Jilbert, T., De Lange, G., and Reichart, G. J. (2008). Fluid displacive resin embedding of laminated sediments: preserving trace metals for high-resolution paleoclimate investigations. Limnology and Oceanography: Methods 6: $16-22$.

Jilbert, T., and Slomp, C. P. (2013). Iron and manganese shuttles control the formation of authigenic phosphorus minerals in the euxinic basins of the Baltic Sea. Geochimica et Cosmochimica Acta 107: 155-169.

Kallmeyer, J., Ferdelman, T. G., Weber, A., Fossing, H., and Jørgensen, B. B. (2004). A cold chromium distillation procedure for radiolabeled sulfide applied to sulfate reduction measurements. Limnology and Oceanography: Methods 2: 171-180.

Kemp, W., Testa, J., Conley, D., Gilbert, D., and Hagy, J. (2009). Temporal responses of coastal hypoxia to nutrient loading and physical controls. Biogeosciences 6: 2985-3008.

Kjeldsen, K. U., Schreiber, L., Thorup, C. A., Boesen, T., Bjerg, J. T., Yang, T., Dueholm, M. S., Larsen, S., RisgaardPetersen, N., Nierychlo, M., Schmid, M., Bøggild, A., Van de Vossenberg, J., Geelhoed, J. S., Meysman, F. J. R., Wagner, M., Nielsen, P. H., Nielsen, L. P., and Schramm, A. (2019). On the evolution and physiology of cable bacteria. Proceedings of the National Academy of Sciences 116: 19116-19125.

Koroleff, F. (1969). Determination of ammonia as indophenol blue. International Council for the Exploration of the Sea (ICES) 9.

Kraal, P., Burton, E. D., and Bush, R. T. (2013). Iron monosulfide accumulation and pyrite formation in eutrophic estuarine sediments. Geochimica et Cosmochimica Acta 122: 75-88.

Kraal, P., Dijkstra, N., Behrends, T., and Slomp, C. P. (2017). Phosphorus burial in sediments of the sulfidic deep Black Sea: Key roles for adsorption by calcium carbonate and apatite authigenesis. Geochimica et Cosmochimica Acta 204: $140-158$. 
Kraal, P., and Slomp, C. P. (2014). Rapid and extensive alteration of phosphorus speciation during oxic storage of wet sediment samples. PloS One 9: e96859.

Kraal, P., Slomp, C. P., Forster, A., Kuypers, M. M., and Sluijs, A. (2009). Pyrite oxidation during sample storage determines phosphorus fractionation in carbonate-poor anoxic sediments. Geochimica et Cosmochimica Acta 73 : 3277-3290.

Kristensen, E., Kristiansen, K. D., and Jensen, M. H. (2003). Temporal behavior of manganese and iron in a sandy coastal sediment exposed to water column anoxia. Estuaries 26: 690-699.

Kristensen, E., Penha-Lopes, G., Delefosse, M., Valdemarsen, T., Quintana, C. O., and Banta, G. T. (2012). What is bioturbation? The need for a precise definition for fauna in aquatic sciences. Marine Ecology Progress Series 446: 285-302.

Kristiansen, K., Kristensen, E., and Jensen, E. (2002). The influence of water column hypoxia on the behaviour of manganese and iron in sandy coastal marine sediment. Estuarine, Coastal and Shelf Science 55: 645-654.

Kuz'minskii, Y. V., Andriiko, A., and Nyrkova, L. (1994). Chemical and phase composition of manganese oxides obtained by Mn (II) oxidation in nitrate solutions. Journal of Power Sources 52: 49-53.

Learman, D., Voelker, B., Vazquez-Rodriguez, A., and Hansel, C. (2011). Formation of manganese oxides by bacterially generated superoxide. Nature Geoscience 4: 95.

Lenstra, W., Hermans, M., Séguret M. J. M., Witbaard, R., Behends, T., Dijkstra, N., Van Helmond, N. A. G. M., Kraal, P., Laan, P., Rijkenberg, M. J. A., Severmann, S., Teacă, A., and Slomp, C. P. (2019). The shelf-to-basin iron shuttle in the Black Sea revisited. Chemical Geology 511: 314-341.

Luther, G. W. (2010). The role of one-and two-electron transfer reactions in forming thermodynamically unstable intermediates as barriers in multi-electron redox reactions. Aquatic Geochemistry 16: 395-420.

Madison, A. S., Tebo, B. M., Mucci, A., Sundby, B., and Luther, G. W. (2013). Abundant porewater Mn(III) is a major component of the sedimentary redox system. Science 341: 875-878.

Malkin, S. Y., Rao, A. M. F., Seitaj, D., Vasquez-Cardenas, D., Zetsche, E.-M., Hidalgo-Martinez, S., Boschker, T. S., and Meysman F. J. R. (2014). Natural occurrence of microbial sulphur oxidation by long-range electron transport in the seafloor. The ISME Journal 8: 1843-1854.

Malkin, S. Y., Seitaj, D., Burdorf, L. D. W., Nieuwhof, S., Hidalgo-Martinez, S., Tramper, A. Geeraert, N., De Stigter, H., and Meysman, F. J. R. (2017). Electrogenic sulfur oxidation by cable bacteria in bivalve reef sediments. Frontiers in Marine Science 4: 28.

Marzocchi, U., Trojan, D., Larsen, S., Meyer, R. L., Revsbech, N. P., Schramm, A., Nielsen, L. P., and Risgaard-Petersen, N. (2014). Electric coupling between distant nitrate reduction and sulfide oxidation in marine sediment. The ISME Journal 8: 1682-1690.

Meysman, F. J. (2018). Cable bacteria take a new breath using long-distance electricity. Trends in Microbiology 26: 411422.

Meysman, F. J., Cornelissen, R., Trashin, S., Bonné, R., Hidalgo-Martinez, S., Van der Veen, J., Blom, C. J., Karman, C., Hou, J.-L., Eachambadi, R. T., Geelhoed, J. S. De Wael, K., Beaumont, J. E., Cleuren, B., Valcke, R., Van der Zant, H. S. J., Boschker, H. T. S., and Manca, J. V. (2019). A highly conductive fibre network enables centimetre-scale electron transport in multicellular cable bacteria. Nature Communications 10: 1-8.

Meysman, F. J., Risgaard-Petersen, N., Malkin, S. Y., and Nielsen, L. P. (2015). The geochemical fingerprint of microbial long-distance electron transport in the seafloor. Geochimica et Cosmochimica Acta 152: 122-142.

Millero, F. J., Plese, T., and Fernandez, M. (1988). The dissociation of hydrogen sulfide in seawater 1. Limnology and Oceanography 33: 269-274.

Morgan, B., Burton, E. D., and Rate, A. W. (2012). Iron monosulfide enrichment and the presence of organosulfur in eutrophic estuarine sediments. Chemical Geology 296: 119-130.

Murphy, J., and Riley, J. (1958). A single-solution method for the determination of soluble phosphate in sea water. Journal of the Marine Biological Association of the United Kingdom 37: 9-14. 
Nielsen, L. P., and Risgaard-Petersen, N. (2015). Rethinking sediment biogeochemistry after the discovery of electric currents. Annual Review of Marine Science 7: 425-442.

Nielsen, L. P., Risgaard-Petersen, N., Fossing, H., Christensen, P. B., and Sayama, M. (2010). Electric currents couple spatially separated biogeochemical processes in marine sediment. Nature 463: 1071.

Norkko, J., Reed, D. C., Timmermann, K. Norkko, A., Gustafsson, B. G., Bonsdorff, E., Slomp, C. P., Carstensen, J., and Conley D. J. (2012). A welcome can of worms? Hypoxia mitigation by an invasive species. Global Change Biology 18: $422-434$.

Nriagu, J. O. (1972). Stability of vivianite and ion-pair formation in the system fe3 $\left(\mathrm{PO}_{4}\right) 2-\mathrm{H}_{3} \mathrm{PO}_{4} \mathrm{H}_{3} \mathrm{PO}_{4}-\mathrm{H}_{2} \mathrm{O}$. Geochimica et Cosmochimica Acta 36: 459-470.

Pernthaler, J., Glöckner, F.-O., Schönhuber, W., and Amann, R. (2001). Fluorescence in situ hybridization (FISH) with rRNA-targeted oligonucleotide probes. Methods in Microbiology 30: 207-226.

Pfeffer, C., Larsen, S., Song, J., Dong, M., Besenbacher, F., Meyer, R. L., Kjeldsen, K. U., Schreiber, L., Gorby, Y. A., El-Naggar, M. Y., Leung, K. M., Schramm, A., Risgaard-Petersen, N., and Nielsen, L. P. (2012). Filamentous bacteria transport electrons over centimetre distances. Nature 491: 218-221.

Poulton, S. W., and Canfield, D. E. (2005). Development of a sequential extraction procedure for iron: implications for iron partitioning in continentally derived particulates. Chemical Geology 214: 209-221.

Rabalais, N. N., Cai, W.-J., Carstensen, J., Conley, D. J., Fry, B., Hu, X., Quiñones-Rivera, Z., Rosenberg, R., Slomp, C. P., Turner, E., Voss, M., Wissel, B., and Zhang, J. (2014). Eutrophication-driven deoxygenation in the coastal ocean. Oceanography 27: 172-183.

Rabalais, N. N., Turner, R. E., and Wiseman Jr, W. J. (2002). Gulf of Mexico hypoxia, aka “The dead zone”. Annual Review of Ecology and Systematics 33: 235-263.

Raiswell, R., and Canfield, D. E. (2012). The iron biogeochemical cycle past and present. Geochemical Perspectives 1: $1-2$.

Rao, A. M., Malkin, S. Y., Hidalgo-Martinez, S., and Meysman, F. J. (2016). The impact of electrogenic sulfide oxidation on elemental cycling and solute fluxes in coastal sediment. Geochimica et Cosmochimica Acta 172: 265-286.

Reed, D. C., Slomp, C. P., and Gustafsson, B. G. (2011). Sedimentary phosphorus dynamics and the evolution of bottom-water hypoxia: A coupled benthic-pelagic model of a coastal system. Limnology and Oceanography 56: 1075-1092.

Risgaard-Petersen, N., Revil, A., Meister, P., and Nielsen, L. P. (2012). Sulfur, iron-, and calcium cycling associated with natural electric currents running through marine sediment. Geochimica et Cosmochimica Acta 92: 1-13.

Risgaard-Petersen, N., Damgaard, L. R., Revil, A., and Nielsen, L. P. (2014). Mapping electron sources and sinks in a marine biogeobattery. Journal of Geophysical Research: Biogeosciences 119: 1475-1486.

Ruttenberg, K. C. (1992). Development of a sequential extraction method for different forms of phosphorus in marine sediments. Limnology and Oceanography 37: 1460-1482.

Ruttenberg, K. C., and Berner, R. A. (1993). Authigenic apatite formation and burial in sediments from non-upwelling, continental margin environments. Geochimica et Cosmochimica Acta 57: 991-1007.

Schauer, R., Risgaard-Petersen, N., Kjeldsen, K. U., Bjerg, J. T., Jørgensen, B. B., Schramm, A., and Nielsen, L. P. (2014). Succession of cable bacteria and electric currents in marine sediment. The ISME Journal 8: 1314-1322.

Schmidtko, S., Stramma, L., and Visbeck, M. (2017). Decline in global oceanic oxygen content during the past five decades. Nature 542: 335.

Seitaj, D., Schauer, R., Sulu-Gambari, F., Hidalgo-Martinez, S., Malkin, S. Y., Burdorf, L. D. W., Slomp, C. P., and Meysman, F. J. R. (2015). Cable bacteria generate a firewall against euxinia in seasonally hypoxic basins. Proceedings of the National Academy of Sciences 112: 13278-13283.

Sigg, L., and Stumm, W. (1981). The interaction of anions and weak acids with the hydrous goethite $(\alpha-\mathrm{FeOOH})$ surface. Colloids and Surfaces 2: 101-117. 
Slomp, C. P., Epping, E. H., Helder, W., and Raaphorst, W. V. (1996). A key role for iron-bound phosphorus in authigenic apatite formation in North Atlantic continental platform sediments. Journal of Marine Research 54: 1179-1205.

Soetaert, K., Petzoldt, T., and Meysman, F. (2010). Marelac: Tools for aquatic sciences. R package version.

Straub, K. L., Benz, M., Schink, B., and Widdel, F. (1996). Anaerobic, nitrate-dependent microbial oxidation of ferrous iron. Applied and Environmental Microbiology 62: 1458-1460.

Sulu-Gambari, F., Hagens, M., Behrends, T., Seitaj, D., Meysman, F. J. R., Middelburg, J., and Slomp. C. P. (2018). Phosphorus cycling and burial in sediments of a seasonally hypoxic Marine Basin. Estuaries and Coasts 41: 921 939.

Sulu-Gambari, F., Seitaj, D., Behrends, T., Banerjee, D., Meysman, F. J., and Slomp, C. P. (2016a). Impact of cable bacteria on sedimentary iron and manganese dynamics in a seasonally-hypoxic marine basin. Geochimica et Cosmochimica Acta 192: 49-69.

Sulu-Gambari, F., Seitaj, D., Meysman, F. J., Schauer, R., Polerecky, L., and Slomp, C. P. (2016b). Cable bacteria control iron-phosphorus dynamics in sediments of a coastal hypoxic basin. Environmental Science \& Technology 50: 1227-1233.

Trojan, D., Schreiber, L., Bjerg, J. T., Bøggild, A., Yang, T., Kjeldsen, K. U., Schramm, A. (2016). A taxonomic framework for cable bacteria and proposal of the candidate genera Electrothrix and Electronema. Systematic and Applied Microbiology 39: 297-306.

Van Cappellen, P., and Berner, R. A. (1988). A mathematical model for the early diagenesis of phosphorus and fluorine in marine sediments; apatite precipitation. American Journal of Science 288: 289-333.

Van de Velde, S., Lesven, L., Burdorf, L. D. W., Hidalgo-Martinez, S., Geelhoed, J. S., Van Rijswijk, P., Gao, Y., and Meysman F. J. R. (2016). The impact of electrogenic sulfur oxidation on the biogeochemistry of coastal sediments: A field study. Geochimica et Cosmochimica Acta 194: 211-232.

Vasquez-Cardenas, D., Van de Vossenberg, J., Polerecky, L., Malkin, S. Y., Schauer, R., Hidalgo-Martinez, S., Confurius, V., Middelburg, J. J., Meysman, F. J. R., Boschker, H. T. S. (2015). Microbial carbon metabolism associated with electrogenic sulphur oxidation in coastal sediments. ISME Journal 9: 1966.

Wang, Y., and Van Cappellen, P. (1996). A multicomponent reactive transport model of early diagenesis: Application to redox cycling in coastal marine sediments. Geochimica et Cosmochimica Acta 60: 2993-3014.

Wijsman, J. W., Middelburg, J. J., Herman, P. M., Böttcher, M. E., and Heip, C. H. (2001). Sulfur and iron speciation in surface sediments along the northwestern margin of the Black Sea. Marine Chemistry 74: 261-278. 


$$
S
$$




\section{Nederlandse Samenvatting (Summary in Dutch)}

\section{Zuurstofloosheid in de oceanen}

Zuurstof is van cruciaal belang voor het leven in de oceanen, die $~ 70 \%$ van het aardoppervlak bedekken. Zuurstof wordt door de oceanen opgenomen uit de atmosfeer en het wordt geproduceerd door fotosynthese in de fotische zone, d.w.z. het bovenste gedeelte van de waterkolom, waar zonlicht doordringt. Fotosynthese wordt verricht door planten, algen en bacteriën die in staat zijn om koolstofdioxide en water, onder invloed van energie uit zonlicht, om te zetten in organisch materiaal en zuurstof. Opgelost zuurstof is van belang voor mariene flora en fauna, aangezien het essentieel is voor hun metabolisme. Wanneer in de zee de zuurstofvraag hoger is dan de toevoer kan dit leiden tot hypoxie (zuurstofschaarste; $<63 \mu \mathrm{M}$ ) of zelfs tot anoxie (totale afwezigheid van zuurstof; $0 \mu \mathrm{M}$ ).

Hypoxie en anoxie kan van nature voorkomen in de zee als de uitwisseling met andere wateren en circulatie van het water gering zijn. De Zwarte Zee is een klassiek voorbeeld van een dergelijk systeem, aangezien de sterke stratificatie, d.w.z. gelaagdheid door waterlagen die onderling slecht met elkaar mengen, in de waterkolom de beluchting van het diepere water beperkt. Zuurstofschaarste kan ook veroorzaakt worden door menselijke activiteiten. In kustgebieden, is dit vaak het gevolg van een hoge aanvoer van stikstof en fosfor afkomstig van de agrarische sector en afvalwater en een toename in de mondiale temperatuur. Een hogere temperatuur als gevolg van klimaatverandering leidt tot een afname van de hoeveelheid zuurstof die kan oplossen in het oppervlaktewater en vermindert daarnaast ook de beluchting van het bodemwater door een toename in de temperatuur-gedreven stratificatie. In de meeste kustgebieden is eutrofiëring momenteel de hoofdoorzaak van zuurstofschaarste.

Hogere organismen, zoals vissen, kreeftachtigen en schelpen zijn gevoelig voor zuurstofconcentraties onder een grenswaarde van $63 \mu \mathrm{M}$. Wanneer het zuurstofgehalte in het bodemwater afneemt en meer depositie van organisch materiaal ten gevolge van eutrofiëring plaatsvindt, leidt dit tot een hogere snelheid van sulfaatreductie in het sediment. De reductie van sulfaat is gekoppeld aan de afbraak van organisch materiaal in kustsedimenten, en leidt tot hoge concentraties van opgelost sulfide in poriewaters. Dit kan leiden tot het ontsnappen van sulfide uit het sediment en vervolgens tot een accumulatie van sulfide in het bodemwater, wat bekend staat als 'bodemwater euxinie'.

In kustsystemen die op seizoens-basis hypoxisch zijn, kan zuurstofschaarste en/of het vrijkomen van het zeer giftige sulfide in bodemwaters leiden tot de ontwikkeling van 'dode zones' (Figuur 1). Deze dode zones worden gekarakteriseerd door massale sterfte van het leven in de zee. De afname van zuurstof in het bodemwater kan uiteindelijk leiden tot een sterke afname in biodiversiteit en kan een negatief effect hebben op de overlevende organismen door een tal van factoren, zoals een afname in groei en reproductie en gedwongen migratie. Zuurstofschaarste in kustsystemen kan ook leiden tot een afname van vissen, garnalen en krabben. Behalve deze negatieve consequenties van zuurstofschaarste voor het leven in de zee, kunnen lage zuurstofconcentraties ook een invloed hebben op de kringloop van nutriënten wat kan leiden tot een verslechtering van de waterkwaliteit. 


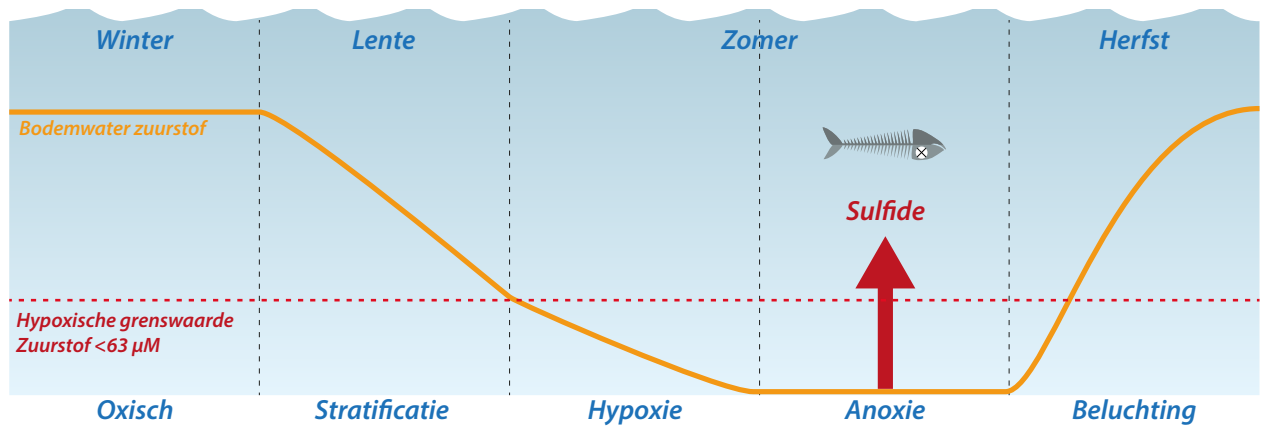

Figuur 1 | Schematisch overzicht van hypoxie in kustsystemen: de concentratie van zuurstof in bodemwater vertoont een sterk seizoenspatroon. De oranje lijn representeert de bodemwater zuurstofconcentratie door het jaar heen en de rode lijn is de grenswaarde tussen hypoxie en oxisch water. Tijdens de winter is de concentratie van zuurstof in het bodemwater hoog. In het voorjaar neemt de concentratie van zuurstof in het bodemwater langzaam af als gevolg van de temperatuur-gedreven stratificatie in de waterkolom. Tijdens het piekmoment van anoxie in de zomer, kan het zeer toxische sulfide ontsnappen uit het sediment in het overliggend water, wat potentieel kan leiden tot het verlies van het leven in de zee. In de herfst verdwijnt de waterkolom stratificatie, wat kan leiden tot beluchting van het bodemwater.

\section{Invloed van lage zuurstofconcentraties op de biogeochemie van sedimenten}

De biogeochemische kringlopen van elementen, zoals ijzer, mangaan, fosfor en stikstof worden sterk beïnvloed door de bodemwater zuurstofconcentraties in zee. Zuurstof is energetisch gezien de meest geprefereerde elektronacceptor voor de microbiële respiratie in mariene sedimenten. Wanneer zuurstof niet meer beschikbaar is, kan een reeks van andere elektronacceptoren worden gebruikt voor de anaerobe respiratie. Alternatieve elektronacceptoren in volgorde van hun energetische opbrengst zijn: nitraat, mangaan(IV), ijzer(III) en sulfaat. Deze serie aan reacties is terug te zien in de verticale verdeling van deze elektronacceptoren in het sediment. Met andere woorden, wanneer een elektronacceptor is verbruikt, wordt de volgende met de meeste voorkeur geconsumeerd, waarbij overlap tussen de verschillende consumptieroutes kan plaatsvinden. In kustsedimenten is sulfaatreductie het meest belangrijke anaerobe mineralisatieproces, als gevolg van een hoge toevoer van organisch materiaal. Dit leidt tot de productie van sulfide in het sediment en wanneer zuurstof niet beschikbaar is dan kan dit leiden tot het vrijkomen van sulfide en een accumulatie van sulfide in het bodemwater.

Veranderingen in bodemwater zuurstofconcentraties kunnen een grote invloed hebben op de bacteriële gemeenschappen. Bovendien kan de uitputting van zuurstof ook een schadelijk effect hebben op de macrofauna-gemeenschappen, zodra de concentraties beneden de hypoxische grenswaarde komen te liggen. Wanneer voldoende zuurstof beschikbaar is, kan de activiteit van macrofauna sterk de biogeochemie van het sediment beïnvloeden door fysieke verplaatsing van deeltjes en opgeloste stoffen, wat bekend staat als 'bioturbatie'. Macrofauna activiteit kan ook leiden tot de uitwisseling van opgeloste stoffen tussen het poriewater in het sediment en het overliggend water door ventilatie door gangen die gegraven zijn door macrofauna, wat bekend staat als 'bioirrigatie'. In de afwezigheid van bodemwater zuurstof vinden deze twee processen niet plaats, wat betekent dat de geochemie van het sediment alleen wordt beïnvloed door microbiële en abiotische processen. 
Samengevat heeft de beschikbaarheid van zuurstof in het bodemwater een grote invloed op de biogeochemie van het sediment, aangezien het een belangrijke rol speelt in de prevalente redox reacties en de samenstelling en activiteit van bacteriële- en macrofauna-gemeenschappen.

\section{Sulfide oxidatie door bacteriën}

De productie van sulfide in sedimenten bevordert de activiteit van zwavel-oxiderende bacteriën, die sulfide als een elektronacceptor kunnen gebruiken voor hun groei. Zwavel-oxiderende bacteriën bestaan uit een grote verscheidenheid aan micro-organismen, variërend van eencellige tot meercellige. De grote zwavel-oxiderende bacteriën die bekend staan als Beggiatoaceae, zijn normaal gesproken aanwezig als witte microbiële matten aan het sedimentoppervlak. Beggiatoaceae zijn beweeglijk en kunnen zich tussen sedimentzones met zuurstof en sulfide verplaatsen. Doordat ze efficiënt sulfide kunnen oxideren, zijn ze in staat om een dunne suboxische zone te creëren, waar geen zuurstof en sulfide aanwezig is. Sommige leden van de Beggiatoaceae familie zijn in staat om nitraat op te slaan in hun interne vacuolen (vochtblaasjes) dat vervolgens gebruikt kan worden om sulfide te oxideren.

Onlangs is een nieuw type meercellige filamentachtige zwavel-oxiderende bacteriën ontdekt, die behoren tot de Deltaproteobacteriën binnen de familie van de Desulfobulbaceae. Deze zogenoemde 'kabelbacteriën' kunnen een paar centimeter lang worden. Kabelbacteriën werden ontdekt in incubatie-experimenten van mariene sedimenten in het laboratorium. Meer recent onderzoek heeft aangetoond dat ze ook van nature voorkomen in diverse typen marien sediment uit verschillende milieus, zoals die van het continentale plat, het op seizoens-basis hypoxische Grevelingenmeer, zoutmoerassen en mangroven. Daarnaast kunnen kabelbacteriën voorkomen rond wormgaten waarin bioirrigatie plaatsvindt. Kabelbacteriën zijn ook aangetroffen in zoetwatersystemen, zoals sedimenten van rivieroevers, en in incubatie-experimenten in het laboratorium waarbij gebruik is gemaakt van aquifer sedimenten. In natuurlijke omgevingen kunnen kabelbacteriën netwerken vormen met een hoge dichtheid in het oppervlaktesediment, oplopend tot honderden meters kabelbacterie-filament per vierkante centimeter sediment.

Filamentachtige kabelbacteriën zijn in staat om ruimtelijk de oxidatie van opgelost sulfide in het diepere sediment te koppelen aan de reductie van zuurstof (of in sommige gevallen nitraat) dichtbij het sediment-water oppervlak, door elektronen over afstanden van centimeters te geleiden. Dit geeft ze een competitief voordeel boven andere zwavel-oxiderende bacteriën in het aquatische milieu. De activiteit van kabelbacteriën leidt meestal tot het ontstaan van een suboxische zone die een paar centimeter breed kan worden en een karakteristiek pH profiel (Figuur 2). Dit pH profiel is gedefinieerd door een relatief hoge $\mathrm{pH}(\sim 9)$ vlakbij het sediment-wateroppervlak en een lage $\mathrm{pH}$ ( 6.5) in de suboxische zone. Het transport van elektronen van cel tot cel door de kabelbacterie filamenten genereert ook een elektrisch veld van een paar $\mathrm{mV}$, dat kan worden gebruikt als indicatie voor hun activiteit. Beggiatoaceae concurreren om dezelfde ecologische niche als kabelbacteriën. Maar Beggiatoaceae komen meestal in sedimenten voor waar de beschikbaarheid van zuurstof in het bodemwater lager is dan in sedimenten met kabelbacteriën. 


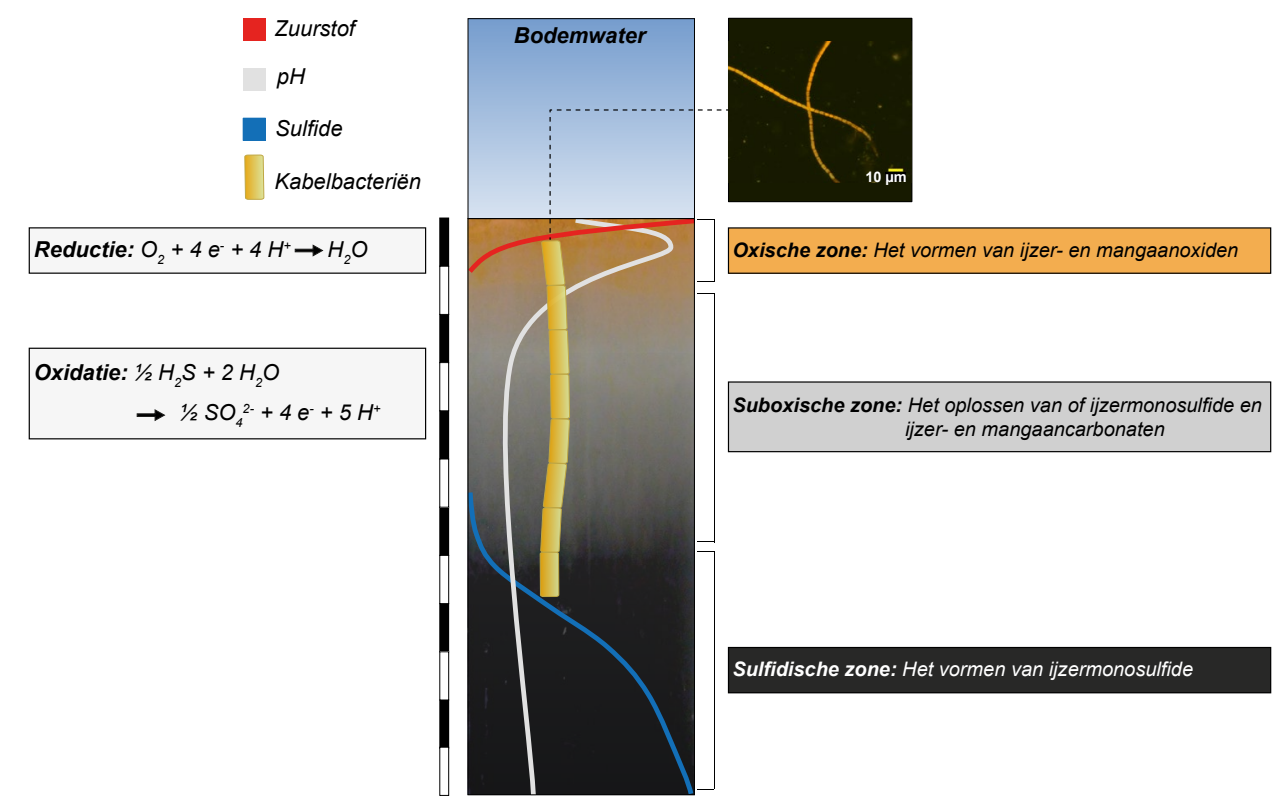

Figuur 2 | Invloed van filamentachtige kabelbacteriën op de geochemie van het sediment. De verticale schaal geeft een afstand aan van $6 \mathrm{~cm}$, met $0.5 \mathrm{~cm}$ diepte intervallen. De diepteprofielen in het sediment representeren stoffen in het poriewater $(\mathrm{pH}=$ wit, opgelost zuurstof $=$ rood en sulfide $=$ blauw). De gele ketting van rechthoeken representeert een kabelbacterie en het paneel rechtsboven laat een microscopische FISH afbeelding zien van twee kabelbacteriefilamenten. De activiteit van kabelbacteriën leidt tot een unieke kleurzonering in het oppervlaktesediment wat gekarakteriseerd is door (1) een oxische zone (oranje kleur), waar ijzer- en mangaanoxiden vormen, (2) een suboxische zone (grijze kleur) waar ijzermonosulfide, ijzer- en mangaancarbonaten oplossen en (3) een sulfidische zone (zwarte kleur) waar ijzermonosulfide vormt.

\section{Kabelbacteriën zijn ecosysteem-ingenieurs}

De activiteit van kabelbacteriën heeft een sterke invloed op de geochemie van het sediment, aangezien dit leidt tot de verwijdering van sulfide en de vorming van ijzer- en mangaanoxiden in oppervlaktesedimenten bevordert. De sterke verzuring van het poriewater in de suboxische zone stimuleert het oplossen van diverse mineralen: naast ijzermonosulfide ook ijzer-, mangaan- en calciumcarbonaten. Wanneer de opgeloste ijzer- en mangaan-ionen die vrij zijn gekomen bij het oplossen van deze mineralen naar boven diffunderen, kunnen deze dichtbij het sedimentwateroppervlak met zuurstof of bijvoorbeeld mangaanoxiden reageren en precipiteren als ijzer- en mangaanoxiden.

Beggiatoaceae kunnen ook bijdragen aan de preservatie van ijzer- en mangaanoxiden in het oppervlaktesediment door de vorming van een suboxische zone. Beggiatoaceae zijn niet staat om ijzermonosulfide op te lossen, wat impliceert dan hun enige bron van sulfide afkomstig is van sulfaatreductie. In het algemeen hebben kabelbacteriën een sterkere invloed op de biogeochemie van het sediment dan Beggiatoaceae. 
De vorming van ijzer- en mangaanoxiden vlakbij het sediment-wateroppervlak kan voorkomen dat sulfide ontsnapt uit het sediment. Mangaanoxiden hebben een sterkere neiging om gereduceerd en opgelost te worden in de aanwezigheid van sulfide vergeleken met ijzeroxiden, en reduceren dus eerst. IJzer- en mangaanoxiden in het oppervlaktesediment kunnen beide efficiënt fosfaat vastleggen. IJzeroxiden kunnen verhoudingsgewijs $\sim 20$ keer meer fosfaat opnemen vergeleken met mangaanoxiden.

Kabelbacteriën stimuleren de vorming van ijzer- en mangaanoxiden en kunnen daarmee fungeren als ecosysteem-ingenieurs en van ecologisch belang zijn in mariene systemen die op seizoens-basis hypoxisch zijn. De ijzer- en mangaanoxiden kunnen het vrijkomen van sulfide en fosfaat uit het sediment naar het bodemwater bufferen tijdens het piekmoment van hypoxie, wat aangetoond is in het Grevelingenmeer. Er is nog maar weinig bekend over de aanwezigheid en de effecten van kabelbacteriën in andere mariene systemen waar op seizoens-basis hypoxie plaatsvindt, zoals de brakke Oostzee. Ook is weinig bekend over de minerale vormen waarin fosfor in het sediment wordt vastgelegd als gevolg van kabelbacterie-activiteit.

\section{Overzicht van dit proefschrift}

Dit proefschrift richt zich op de invloed van kabelbacteriën op de gekoppelde kringlopen van ijzer, mangaan, fosfor en zwavel in het sediment van kustgebieden op plekken waar veranderingen in bodemwater zuurstofconcentraties plaatsvinden. Voor het bestuderen van de complexe interacties van deze elementen, is een breed scala aan monstername technieken gebruikt tijdens onderzoeksexpedities op de Oostzee en Zwarte Zee. Dit zijn (1) het bemonsteren van de waterkolom, (2) het verzamelen van zwevende deeltjes door middel van in-situ pompen, (3) in-situ bentische lander incubaties, (4) het verzamelen van sediment voor poriewater en vaste fase analyses door kernen (multicores) te nemen. Op deze sedimentmonsters is vervolgens een breed assortiment aan analysetechnieken toegepast, zoals sequentiële extracties van ijzer, fosfor en zwavel, gecombineerd met hoge-resolutie microscopische en spectroscopische technieken, zoals micro $\mathrm{X}$-ray fluorescentie en X-ray spectroscopie om de mineralogie en kwantiteit van ijzer, mangaan, fosfor en zwavel te bepalen in deze monsters.

\section{De Oostzee}

Drie hoofdstukken van dit proefschrift beschrijven de invloed van veranderingen in bodemwater zuurstofconcentraties en de aanwezigheid en activiteit van kabelbacteriën op de biogeochemie van de zeebodem in de Oostzee. De monsters voor dit onderzoek zijn verzameld tijdens een expeditie met het onderzoeksschip de Pelagia in mei en juni 2016. De brakke Oostzee (Figuur 3.A) is ongunstig beïnvloed door antropogene toevoer van nutriënten en is momenteel 's werelds grootste zuurstofloze watermassa ten gevolge van menselijke invloeden. De Finse Golf is, van de verschillende delen van de Oostzee, het meest geëutrofieerd. De omvang van het gebied met hypoxie in de Oostzee is in de afgelopen eeuw drastisch toegenomen. Hypoxie was voor 1950 beperkt tot een oppervlakte van $<10.000 \mathrm{~km}^{2}$ en is daarna in een relatief korte tijd toegenomen tot $50.000 \mathrm{~km}^{2}$ rond 1970. De Oostzee is van nature gevoelig voor hypoxie, omdat sills (drempels) op de zeebodem de horizontale wateruitwisseling beperken en sterke verticale stratificatie in de waterkolom verder de toevoer van zuurstof naar het diepere water limiteert. De natuurlijke beluchting van bodemwater in de Oostzee hangt af van de grootschalige periodieke instroom van zeewater uit de aangrenzende Noordzee. Dit soort instromen worden aangeduid als 'Major Baltic inflow' en worden veroorzaakt 
door wind en luchtdruk gedreven variaties in het zeeniveau. Typerend voor een 'Major Baltic inflow' is dat het resulteert in substantiële toevoer van zout- en zuurstofrijk water naar het diepere water van de Oostzee. Op korte termijn beluchten deze instromen het diepere water. Echter over langere tijdsperioden, van jaren tot decennia, leidt de instroom van zoutwater tot een versterking van de stratificatie, wat resulteert in een afname in de verticale menging van zuurstof. Recentelijk hebben twee 'Major Baltic inflows' plaatsgevonden die de diepere bekkens van de Oostzee hebben belucht.

Hoofdstuk 2 beschrijft de invloed van deze twee recente 'Major Baltic inflows' op de biogeochemie van de waterkolom en het sediment in het Gotland Diep, een euxinisch bekken in de Oostzee. De resultaten laten zien dat de beluchting van het bodemwater de activiteit van de zwavel-oxiderende bacteriën Beggiatoaceae heeft geïnduceerd. Dit leidde tot de verwijdering van sulfide en de ontwikkeling van een suboxische zone in het sediment. Kabelbacteriën waren ook aanwezig, maar de biogeochemische vingerafdruk van hun activiteit, gebaseerd op $\mathrm{pH}$, zuurstof en sulfide profielen in het poriewater, is niet geobserveerd. De beperkte hoeveelheid kabelbacteriën wijst er op dat ze waarschijnlijk geen invloed hebben gehad op de geochemie van het sediment. Met behulp van synchrotron X-ray spectroscopie is aangetoond dat de mineralen rhodochrosiet en mangaan(II)fosfaat in grote hoeveelheid aanwezig waren in het sediment. Er was slechts een beperkte vastlegging van fosfaat in het sediment door ijzeroxiden. Deze resultaten suggereren dat kunstmatige beluchtingsprojecten met als doel om fosfaat in de waterkolom te verwijderen door middel van vastlegging van fosfaat aan ijzeroxiden in het sediment, waarschijnlijk niet het gewenste effect zullen opleveren. Dit hoofdstuk laat verder zien dat de zuurstofvraag die ontstaan is door de ophoping van organisch rijk sediment over meerdere decennia, ook wel de 'legacy of hypoxia' genoemd, significante implicaties heeft voor de biogeochemische respons van euxinische bekkens op beluchting.

Hoofdstuk 3 beschrijft het voorkomen, de activiteit en de biogeochemische invloed van kabelbacteriën in Oostzee sedimenten uit contrasterende afzettingsmilieus, waaronder bodemwater redox-condities. De bevindingen laten zien dat drie factoren essentieel zijn voor de aanwezigheid en hoeveelheid kabelbacteriën: (1) de beschikbaarheid van zuurstof in het bodemwater, (2) de toevoer van sulfide en (3) de mate van bioturbatie. De geochemische data suggereren dat kabelbacteriën de conversie van ijzermonosulfide naar ijzeroxiden bevorderen in de Finse Golf in het voorjaar, wat waarschijnlijk verklaart waarom het bodemwater in deze extreem geëutrofieerde omgeving zelden euxinisch wordt in het piekmoment van hypoxie tijdens de zomer.

Hoofdstuk 4 beschrijft de invloed van kabelbacteriën op de gekoppelde dynamiek van ijzer, fosfor en mangaan in sedimenten van de Finse Golf. De bevindingen laten zien dat kabelbacteriën mogelijk de vorming van ijzeroxiden met een zwakke kristallijne structuur en mangaan(II)fosfaten induceren, en de preservatie van mangaanoxiden in het oppervlaktesediment bevorderen. De ijzeroxiden met een zwakke kristallijne structuur en de mangaan(II)fosfaten zijn vermoedelijk gevormd in de zeebodem, maar de mangaanoxiden zijn waarschijnlijk grotendeels afkomstig uit de waterkolom, als gevolg van een herhalende cyclus, waarbij depositie en remobilisatie plaatsvindt, ook wel 'refluxing' genoemd. Kabelbacteriën hebben weinig invloed op de permanente begraving van ijzer, mangaan en fosfor in de sedimenten van de Finse Golf, maar hun activiteit versterkt wel de seizoenscyclus van de ijzer, mangaan en fosfor kringlopen in het sediment. 


\section{De Zwarte Zee}

De laatste twee hoofdstukken gaan over de Zwarte Zee. De monsters voor dit onderzoek zijn verzameld tijdens een expeditie met het onderzoekschip de Pelagia in september 2015 in het noordwestelijke gedeelte van de Zwarte Zee (Figuur 3.B). De Zwarte Zee is een relatief afgesloten bekken, omdat het alleen via de Straat van Bosporus, de Zee van Marmara en hierop volgend de Straat der Dardanellen verbonden is met de oceaan. De Bosporus sill bevindt zich op 35 meter waterdiepte en beperkt de toevoer van relatief warm en zout oppervlaktewater uit de Middellandse Zee naar de Zwarte Zee. De waterkolom van de Zwarte Zee is gestratificeerd, als gevolg van een gradiënt in de saliniteit en het zuurstofrijke oppervlaktewater is gescheiden van het euxinische diepere bekken door middel van een suboxische chemocline die zich op 150 meter waterdiepte bevindt. Als gevolg hiervan is de Zwarte Zee 's werelds grootste natuurlijk gevormd euxinisch bekken. In het diepere water, onder de redoxcline, bereikt sulfide concentraties oplopend tot $\sim 370$ $\mu \mathrm{M}$.

Hoofdstuk 5 beschrijft de mechanismen die de mobilisatie en het lateraal transport van ijzer, het zgn. 'shuttling' van ijzer, over het continentale plat (het gedeelte van een continent dat onder water staat) in het noordwestelijke gedeelte van de Zwarte Zee reguleren. Dit hoofdstuk laat zien dat ijzer vrijkomt uit organische rijk biogeïrrigeerd sediment met overliggend zuurstofrijk bodemwater en dat het vervolgens lateraal wordt getransporteerd naar het diepere bekken in de vorm van het mineraal ferrihydriet (ijzer(III)oxide) en ijzer gebonden aan klei. De uitkomst van dit onderzoek benadrukt dat de toevoer van organisch materiaal, de biologische activiteit en de ijzer toevoer afkomstig van rivieren een belangrijke rol spelen in de ijzer 'shuttling' op continentale platten. Dit hoofdstuk laat ook zien dat het fysische transport uiteindelijk de grootste rol speelt in de ijzer 'shuttling' over een continentale plat als de aanvoer van organisch materiaal naar het sediment laag is.

Hoofdstuk 6 beschrijft de potentiële invloed van kabelbacteriën op de biogeochemie van ijzer, zwavel, mangaan en fosfor door middel van incubatie-experimenten in het laboratorium, waarin ijzermonosulfide-arm kustsediment van de Zwarte Zee is gebruikt. De resultaten laten zien dat het oplossen van het mineraal sideriet door de activiteit van kabelbacteriën kan leiden tot het vrijkomen van een grote hoeveelheid opgelost ijzer in het poriewater. Als gevolg van de oxidatie van dit opgelost ijzer met zuurstof wordt een laag gevormd die sterk verrijkt is in ijzeroxiden. Door middel van X-ray fluorescentie laten we zien dat de aanrijking in ijzeroxiden die is gevormd door de activiteit van kabelbacteriën zich beperkt tot een dunne laag van een paar millimeter direct onder het sediment-wateroppervlak. Verder laten we zien dat de vorming van dit soort lagen ook op veldlocaties plaatsvindt, waar kabelbacteriën recentelijk actief zijn geweest en waar relatief weinig bioturbatie voorkomt. Dit suggereert dat deze dunne, sterk in ijzeroxiden verrijkte lagen een consistent kenmerk zijn van sedimenten waarin kabelbacteriën voorkomen en dat een dergelijke laag potentieel een marker is voor hun huidige of recente activiteit. 


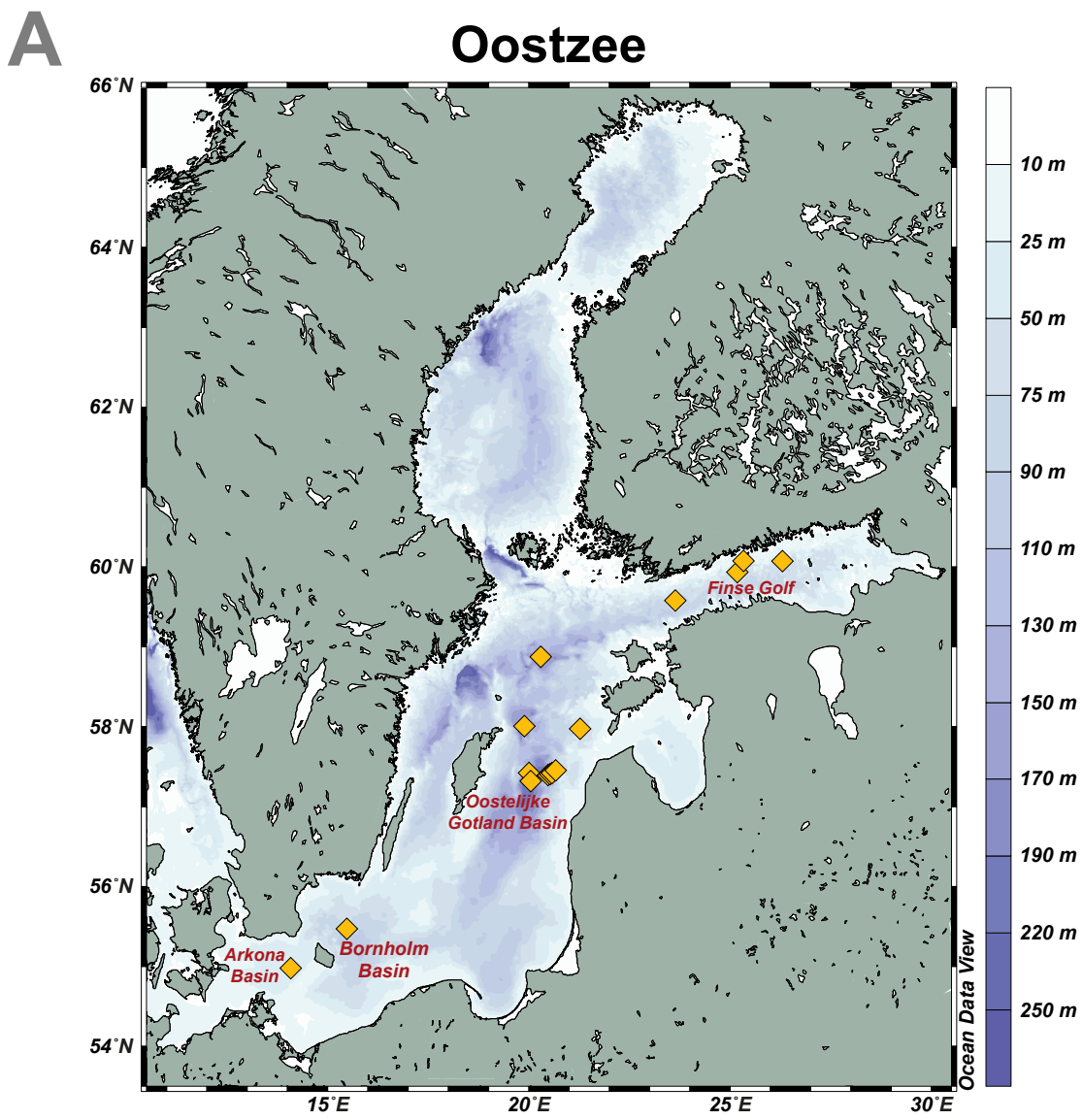

\section{Zwarte Zee}

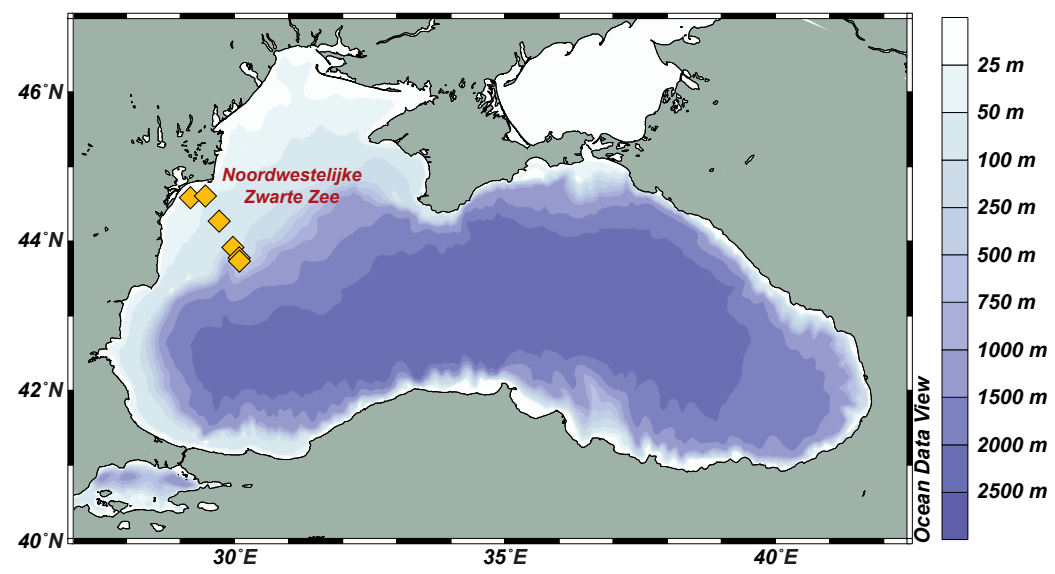

Figuur 3 | Onderzoekslocaties in de Oostzee en Zwarte Zee. 
We all like to take this four lane highway, but we always step over the shovel. All I did was pick up that shovel and made my own path.

\section{- David Goggins}




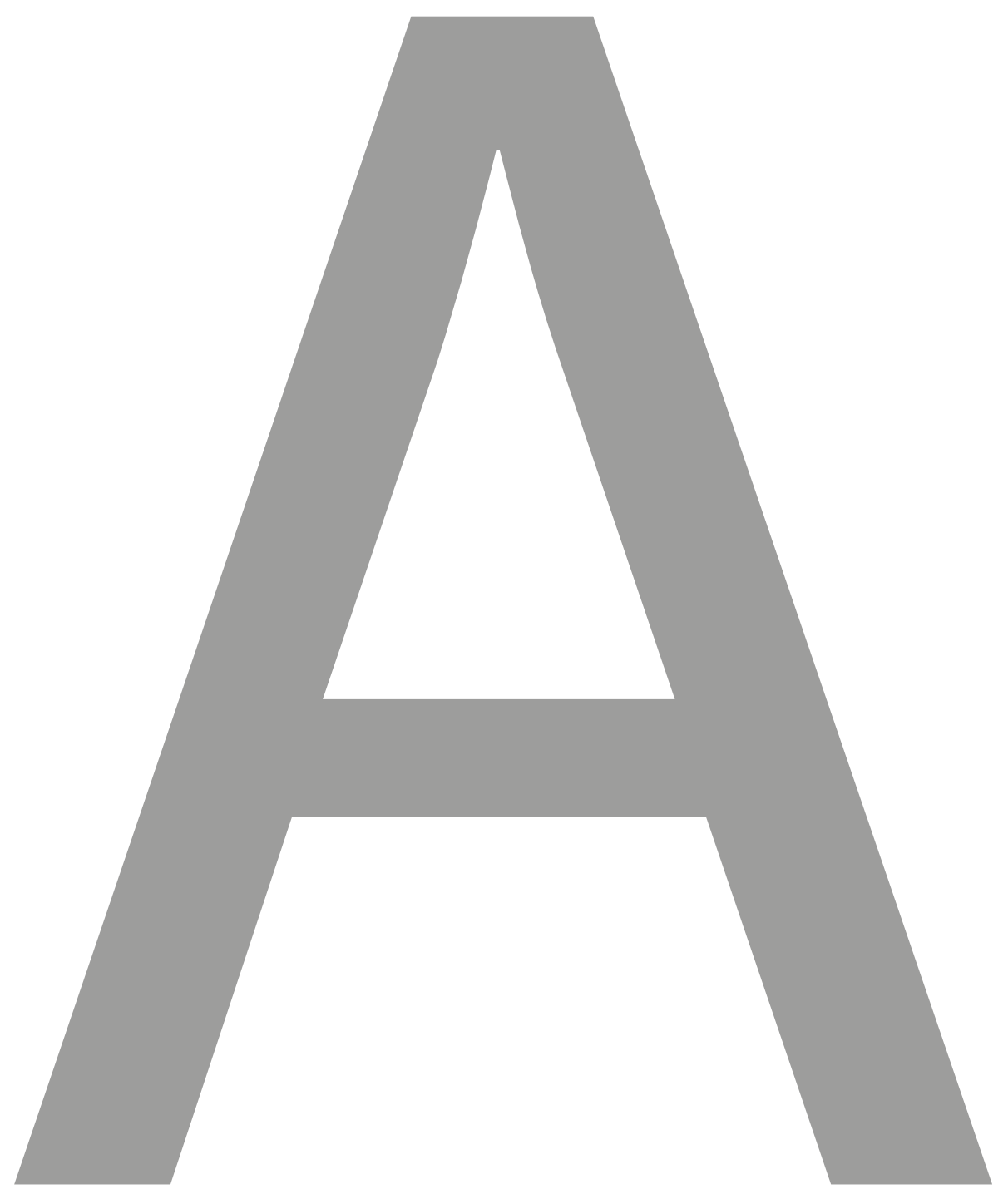




\section{Acknowlegdments}

Caroline Slomp, thank you for giving me the opportunity to do a $\mathrm{PhD}$ and for enthusiastically introducing me to the wonders of marine biogeochemistry. You taught me a lot over the years! This $\mathrm{PhD}$ position allowed me to further develop my scientific skills in terms of practical and theoretical biogeochemistry. I greatly appreciate your invaluable comments on my manuscript drafts in various stages, which ultimately led to this $\mathrm{PhD}$ thesis. Daniel Conley, thank you for funding my postdoc, which allowed me to continue working in the marine biogeochemistry group at Utrecht University for a bit longer.

Robert Aller, Jack Middelburg, Lars Peter Nielsen, Karline Soetaert and Bo Thamdrup, thank you for taking the time to read my thesis, and your critical and insightful feedback. I would further like to express my gratitude to all the co-authors: Marina Astudillo Pascual, Thilo Behrends, Daniel Conley, Nikki Dijkstra, Matthias Egger, Reinier Groeneveld, Santiago Gonzalez, Bo Gustafsson, Erik Gustafsson, Christoph Humborg, Niels van Helmond, Silvia Hidalgo-Martinez, Filip Meysman, Peter Kraal, Joëlle Kubeneck, Patrick Laan, Wytze Lenstra, Micha Rijkenberg, Elizabeth Robertson, Nils Risgaard-Petersen, Marie Séguret, Silke Severmann, Caroline Slomp, Adrian Teacă and Rob Witbaard. This PhD thesis would not have existed without your assistance and teamwork!

Anton Tramper, Lars Riis Damgaard and Niels Risgaard-Petersen, thank you for welcoming me to the world of microelectrodes, which allowed me to explore the uncharted depths of the surface sediment. Dipanjan Banerjee, Ana Elena Pradas Del Real and Wout de Nolf, thank you for your technical support during my visits to the European Synchrotron Radiation Facility (ESRF). Thilo Behrends, thanks for the intriguing and humorous discussions, and your assistance with the analyses of the data that we collected at the ESRF. Filip Meysman, thanks for your enthusiastic anecdotes and stories about the fascinating cable bacteria!

Coen Mulder, Helen de Waard and Ton Zalm, thank you for analysing my countless pore water samples and other solutions. The data you guys provided are of great relevance for this thesis. Arnold van Dijk, thanks for determining the carbon and nitrogen contents in my samples. Natasja Welters, thanks for being accommodating with the freeze-dryer. Thony van der Gon Netscher, thanks for providing custom-made materials, which have been put to good use in my incubation experiments. Thom Claessen, Dineke van de Meent and John Visser, thank you for your analytical assistance. Thom Claessen much obliged for being a jester.

Jan-Willem de Blok, Annuska Exel, Marjolein Mullen and Tjitske Vos, thanks for the administrative support! Amalia Filippidi, thanks for relocating all my samples to the new storage facility. Jan van Tongeren and Sven Edelstein, thank you for supporting me with the storage of samples and materials. Margot Stoete, thank you for helping me out with the front cover for my thesis. Peter Wientjes, thank you for printing my thesis.

Nikki Dijkstra, thanks for sharing the office with me! Matthias Egger, I would also like to thank you for being my office comrade, and for the workouts and boxing matches! Peter Kraal, thank you for enthusiastically introducing me to an arsenal of analytical techniques! Wytze Lenstra, it was nice to share the office with you. You are like a laboratory brother to me, after spending countless hours of doing sequential extractions together! Mathilde Hagens, thanks for helping me out with coding in R. Niels van Helmond, bedankt voor de totaal destructies en je Brabantse gebabbel, of nie dan? Lilia Orozco, thanks for the nice coffee breaks and so much more, you are a good friend! Nina Papadomanolaki, it was nice to have you as an office mate as well! Itzel Ruvalcaba Baroni and Marie Séguret, thanks for your company. Fatima Sulu-Gambari, thanks for answering my cable bacteria related questions. 
I would also like to thank the following persons in our department: Shaun Akse, Karel As, Remco Bos, Regina Flores, Joost Frieling, Nicole Geerlings, Wim Joost van Hoek, Alwina Hoving, Suning Hou, Tom Jilbert, Helen King, Matthias Kuderer, Joep Langeveld, Mingkai Ma, Jack Middelburg, Melanie Münch, Mareike Paul, Francien Peterse, Robin van der Ploeg, Lubos Polerecky, Martin Schobben, Olivier Sulpis, Lauriane Vilmin, Mădălina Vița, Mariette Wolthers and Olga Żygadłowska.

I would like to thank the following people for their company during the expeditions: Miguel Angel Huerta-Diaz, Laurine Burdorf, Paula Dalcin Martins, Nikki Dijkstra, Matthias Egger, Loes Gerringa, Santiago Gonzalez, Mathilde Hagens, Hans van Haren, Niels van Helmond, Silvia Hidalgo-Martinez, Jeras de Jonge, Peter Kraal, Amy Kuzminov, Martin Laan, Wytze Lenstra, James McManus, Lilia Orozco, Sharyn Ossebaar, Elizabeth Robertson, Rasmus Rodineliussen, Marie Séguret, Silke Severmann, Caroline Slomp, Adrian Teacă, Katharina Theopold, Kristin Ungerhofer, Rob Witbaard, Yvo Witte, Roosmarijn van Zummeren and many others.

I would like to express my gratitude to the following BSc and MSc students for their help with laboratory analysis and their company: Tom Bastiaan, Sterre de Haas, Tim Hakkert, Ocea van Loenen, Matteo Mikos, Francesca Sahit, Floor Wille, Ella Wesdorp and Katrin Wunsch. Marina Astudillo Pascual, muchas gracias por los buenos y divertidos momentos en el laboratorio, fue una maravilla trabajar contigo. ¡Nunca olvidaré nuestra aventura con la pizza voladora! ¡Que la Fuerza te acompañe! Zongyi Wang, thank you very much for helping me out with acquiring data for the final chapter of my thesis. I would also like to thank you for our walks and challenging workouts!

The honorary Radboud group: Anniek de Jong, Paula Dalcin Martins and Michiel in 't Zandt, much obliged for the nice beach sessions and the amazing dinners! Bektur Abdilla, rahmat moy brat! I appreciate your company during my stay in Boston and Barcelona.

Olga T. and Jan- Willem, thank you very much for welcoming me into your home! Luiz, thanks for your company, support and conversations! I hope you will finish your $\mathrm{PhD}$ soon, with success! Keep the good work up! Olga Ż., thanks for being my roomie, introducing me to Polish food and sharing hilarious memes! Saskia and Moline, thanks for your company and chit-chats! Hessel, my furry friend, thank you for accompanying me during our walks, your loyalty and unconditional friendship!

Special thanks to the Brawl Boys, Appie, Mahid, Reinier, Remco and Suning, for the superheropacked movie nights and brawls!

Anna, Спасибо большое! We have been friends for a long time. I really enjoyed hanging out with you in Wageningen. I cherish all those moments!

Anupol, you have always been a good friend of mine! I am indebted to you, for our friendship, the numerous cycling trips and forest walks, and all the spicy dinners 555+ You are one of the most generous people I know. The best of luck with finishing your PhD! You are almost there!

Eric, meda wo ase! Masa, I appreciate our fruitful conversations and discussions. Your dark humour and unprecedented trolling is next level, but really makes me laugh. Wabodam! You have been away for a quite a while. Nevertheless, we always stayed in touch. I hope to see you again in the near future!

Jeras, it was nice to meet you, and to get to know you better during my expedition on the Atlantic Ocean. Thanks for all the conversations! I really enjoyed our cycling trip on Texel!

Joëlle, it was always nice talking to you, and to have you around. You are missed! Thanks for all the delicious and amazing cakes! 
Kristin, thanks for your company during our epic adventure on the Pacific Ocean. We travelled quite a distance together, from Oregon all the way down to Mexico! I will never forget the notorious 'labimals' that we built out of laboratory consumables! Thanks for the pleasant conversations, joyful hang-outs and laughs! I appreciate that you welcomed me at Texel. Finally, I managed to explore the island for the first time, after all countless visits to NIOZ!

Lilia, we have become very close friends in a short time! You are technically my third paranymph. My sincere gratitude for our daily conversations, adventurous walks, cosy lunches, delicious Mexican dinners and epic movie nights. Lilia, I truly enjoy hanging out with you, and I value our friendship very much. Thank you very much for all the fun and laughter we share. Eres una de las personas más humilde que he conocido en la vida. Estoy muy agradecido por el ánimo recibido en mis últimos meses de doctorado. Eres muy buena horneando pasteles y galletas, me dio alegría comerlos. Gracias a ti este año fue agradable. Fue un placer compartir contigo esta experiencia inolvidable. Hogar no es un lugar, lo hace la gente. ¡Sin ti no habría sido lo mismo! ¡Súper Lilia! ¡Tú eres la mejor! ¡Un abrazo muy fuerte para ti!

Mădălina, îţi mulţumesc pentru toate momentele petrecute cu tine! You have the honour to be my paranymph! I enjoyed our delightful tea breaks and lunches. It was a nice distraction from work. Thanks for your kind support and help. My apologies for the other day when I scared the hell out of you with that fierce wasp! I will never do such a thing again, or maybe I will...

Mahid, salam mere dost! Thank you very much for the amusing conversations, our Marvel and DC related discussions, chess games, twisted jokes and for always listening! Bruv, I am looking forward to the release of your grime album! Keep working the bag bro, soon Darkseid and Thanos will be no match for you!

Mareike, thanks for all the nice lunch breaks, conversations and laughs. It was nice to have you around. I really appreciate your kindness and support during the last months of my PhD!

Paula, we quickly became friends during our adventure in Sweden! You also have the honour to be my paranymph! Foi um muito bom ter a sua companhia e conhecer você melhor! Explorar Estocolmo e Umeå com você foi um grande prazer! Obrigado por todas as caminhadas, jantares deliciosos, seu carinho e seu suporte! Ainda, obrigado por me receber em sua casa! Give Francielo, Bitzy and Ozzy a hug from me!

Roos, thanks for your cheerful company during our short holiday in Gran Canaria. I will never forget that rocky ride in the mountains! I enjoyed our cruise from the Canary Islands to Texel. It was nice to get to know you better. Thanks for your assistance during the expedition, and I am grateful for the epic table football and video game challenges onboard ship!

Willem, we have been friends for over a decade! We went to the same high school, and did our BSc and MSc programmes together! We have shared a lot of memories and laughter over the years! Thanks for accommodating me and your support! I enjoyed going to the movies with you, and our various walks in nature! I was always welcomed by you during my weekends in Brabant!

Graag wil ik mijn familie bedanken voor alle steun. Jan, bedankt dat je contact opnam tijdens mijn expedities. Miek, bedankt dat je altijd zeer geïnteresseerd bent geweest in mijn onderzoek. Tot slot, wil ik graag mijn ouders bedanken voor de steun die ze mij hebben gegeven tijdens mijn promotie-onderzoek. Pap en Mam heel erg bedankt dat jullie altijd voor mij klaar staan! 


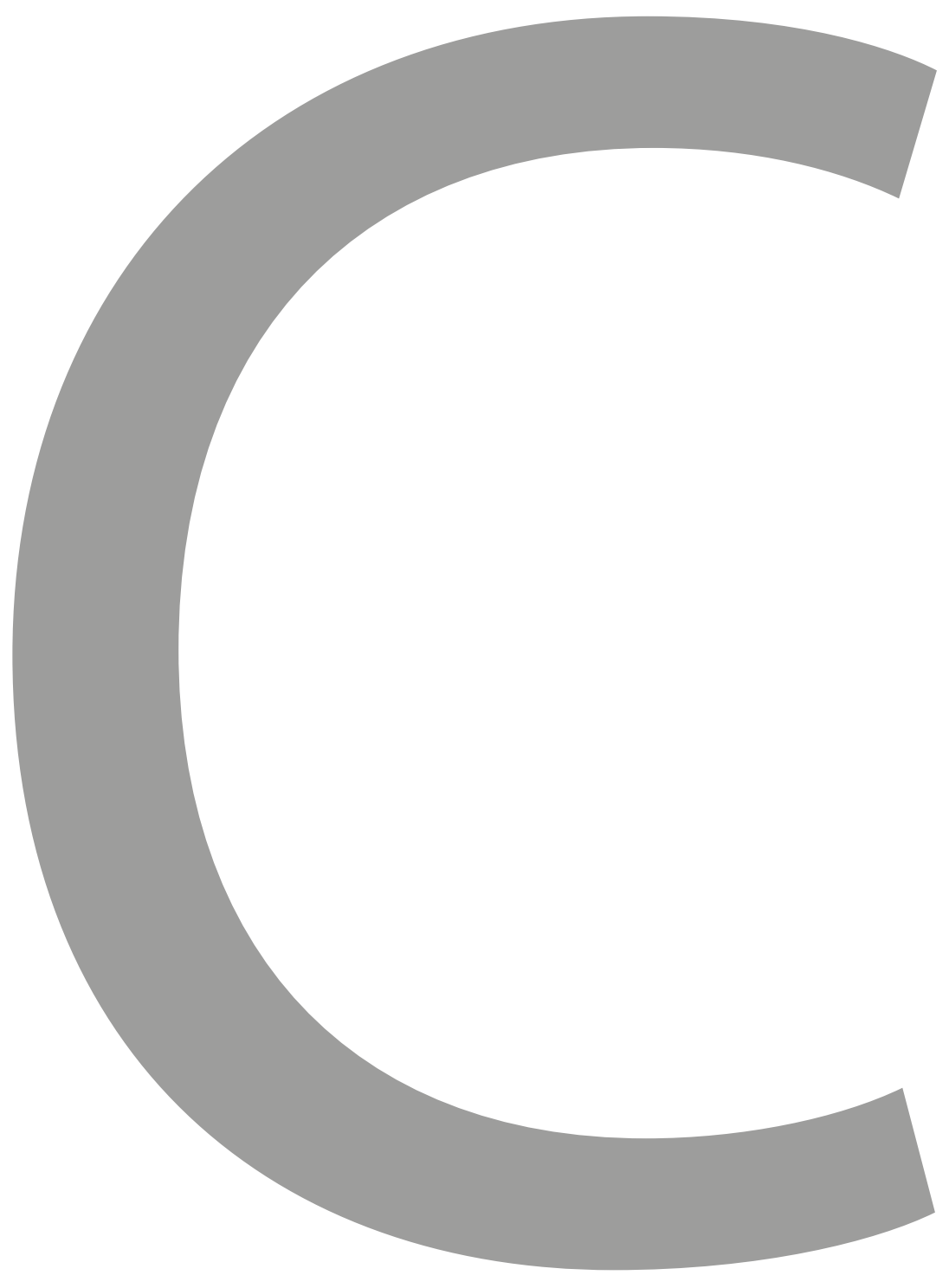




\section{Curriculum Vitae}

Martijn Hermans was born on the 24th of July 1991 in Veghel, the Netherlands. He attended the University of Applied Sciences HAS Den Bosch, where he obtained his BSc degree in Environmental Science in 2012. During his BSc he developed a strong affinity with water quality and ecosystems, after which he decided to continue, with a MSc programme at Wageningen University and Research (WUR). At WUR he obtained major in Environmental Systems Analysis and a minor in Earth System Science. After completing his MSc degree in 2014, he briefly worked as a teaching assistant in the Earth System Science at WUR.

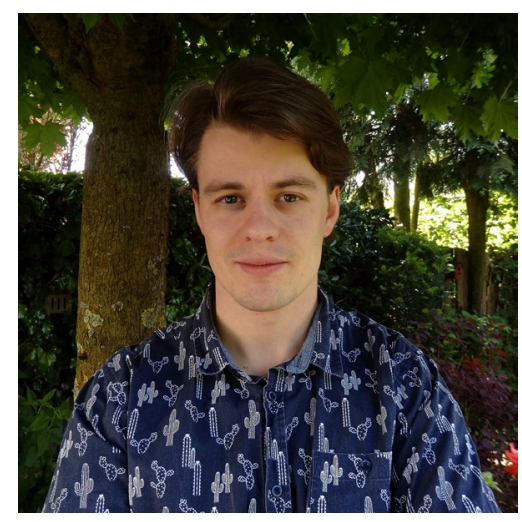

In 2015 he started his $\mathrm{PhD}$ in the Marine Biogeochemistry group at Utrecht University, where he participated in nine research expeditions to the Baltic Sea, Bothnian Sea, Black Sea, Eastern Central Atlantic Ocean, Northeast Pacific Ocean and Lake Grevelingen. He will start working for Deltares in September 2020 as a medior consultant/researcher in the hydrogeochemistry group. 


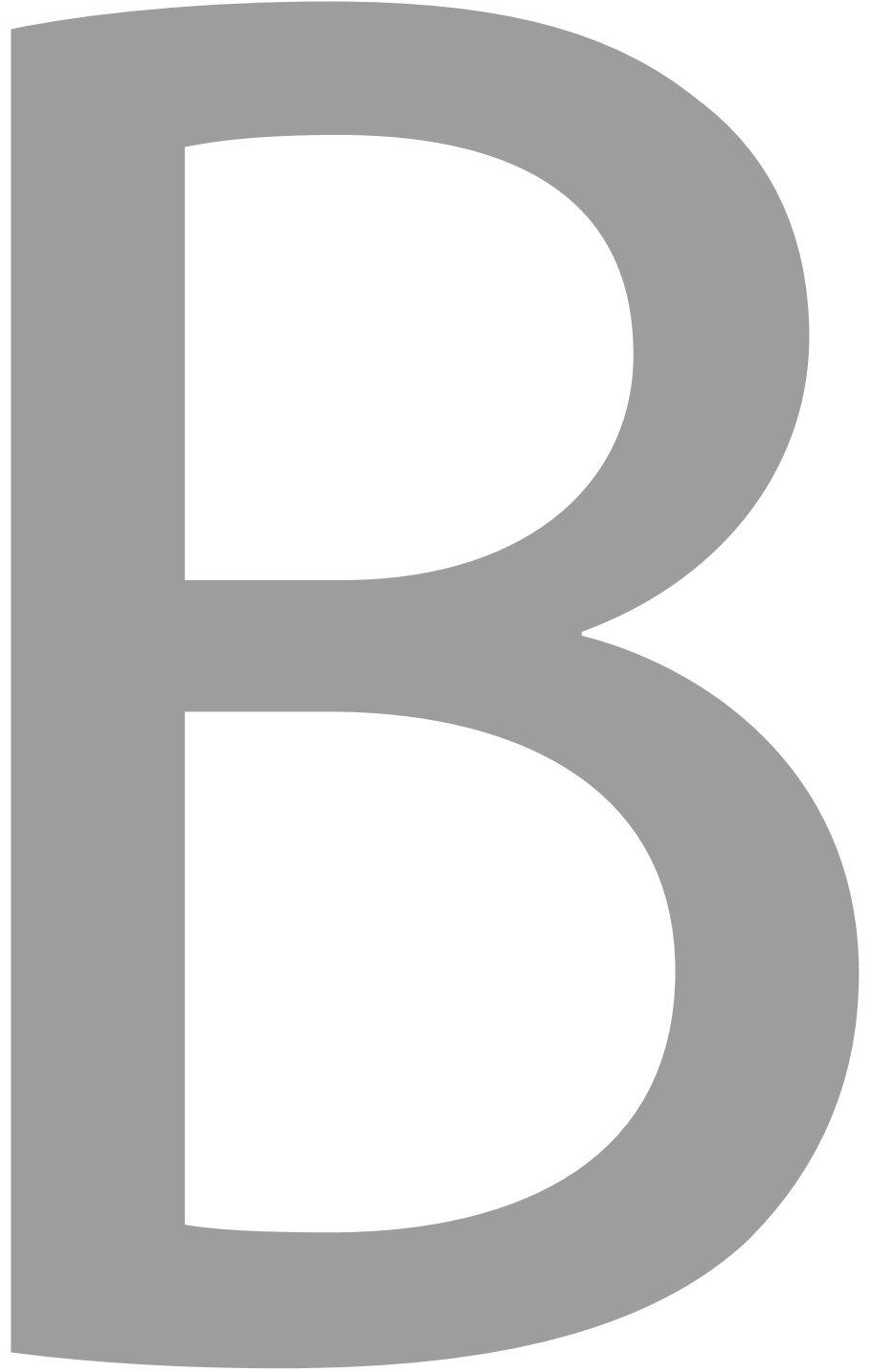




\section{Bibliography}

van Helmond, N.A.G.M., Robertson, E.K., Conley, D.J., Hermans, M., Humborg, C., Kubeneck, L.J., Lenstra, W.K. and Slomp C.P. (2019). Efficient removal of phosphorus and nitrogen in sediments of the eutrophic Stockholm Archipelago, Baltic Sea. Biogeosciences

Lenstra, W.K., Séguret, M. J. M., Behrends, T., Groeneveld, R.K., Hermans, M., Witbaard, R. and Slomp C.P. (2020) Controls on the shuttling of manganese over the northwestern Black Sea shelf and its fate in the euxinic deep basin. Geochimica et Cosmochimica Acta

Hermans, M., Lenstra, W.K., Hidalgo-Martinez, S., van Helmond, N.A.G.M., Witbaard, R., Meysman, F.J.R., Gonzalez, S. and Slomp, C.P. (2019). Abundance and Biogeochemical Impact of Cable Bacteria in Baltic Sea Sediments. Environmental Science \& Technology

Hermans, M., Lenstra, W. K., van Helmond, N. A., Behrends, T., Egger, M., Séguret, M.J.M., Gustafsson, E., Gustafsson, Bo. G. and Slomp, C. P. (2019). Impact of natural re-oxygenation on the sediment dynamics of manganese, iron and phosphorus in a euxinic Baltic Sea basin. Geochimica et Cosmochimica Acta

Lenstra, W. K., Hermans, M., Séguret, M. J. M., Witbaard, R., Behrends, T., Dijkstra, N., van Helmond, N.A.G.M., Kraal, P., Laan, P., Rijkenberg, M.J.A., Severmann, S., Teaca, A. and Slomp, C.P. (2018). The shelf-to-basin iron shuttle in the Black Sea revisited. Chemical Geology 
